MARCIO RODRIGUES DA CUNHA

DESENVOLVIMENTO DE MICRORREATORES EM TECNOLOGIA LTCC PARA PRODUÇÃO DE BIODIESEL

SÃO PAULO

2012 
MARCIO RODRIGUES DA CUNHA

DESENVOLVIMENTO DE MICRORREATORES EM TECNOLOGIA LTCC PARA PRODUÇÃO DE BIODIESEL

SÃO PAULO

2012 
MARCIO RODRIGUES DA CUNHA

\section{DESENVOLVIMENTO DE MICRORREATORES EM TECNOLOGIA LTCC PARA PRODUÇÃO DE BIODIESEL}

Tese apresentada à Escola Politécnica da Universidade de São Paulo para obtenção do título de Doutor em Engenharia

Área de concentração: Microeletrônica

Orientador: prof. Dr. Antonio Carlos Seabra

\section{SÃO PAULO}

2012 
Este exemplar foi revisado e alterado em relação à versão original, sob responsabilidade única do autor e com a anuência do seu orientador.

São Paulo, 30 de julho de 2012

Assinatura do autor:

Assinatura do orientador:

FICHA CATALOGRÁFICA

\section{Cunha, Marcio Rodrigues da}

Desenvolvimento de microrreatores em tecnologia Itcc para produção de biodiesel / M.R. da Cunha. - ed. rev. - São Paulo, 2012.

$246 \mathrm{p}$.

Tese (Doutorado) - Escola Politécnica da Universidade de São Paulo. Departamento de Engenharia de Sistemas Eletrônicos.

1. Microtecnologia 2. Reatores 3. Biodiesel 4. Microssistema I. Universidade de São Paulo. Escola Politécnica. Departamento de Engenharia de Sistemas Eletrônicos II. t. 


\section{DEDICATÓRIA}

Dedico este trabalho a minha esposa Dayana e aos meus pais, Tereza e Idelino. 


\section{AGRADECIMENTOS}

A Deus, por ter iluminado e abençoado meus caminhos ao longo destes cinco anos.

Ao prof. Dr. Antonio Carlos Seabra, pela orientação, apoio, incentivo e pela amizade.

Ao prof. Dr. Mário Ricardo Gongora Rubio, pela orientação, apoio, incentivo e pela amizade.

A Dra. Maria Filomena de Andrade Rodrigues, Diretora do CTPP - IPT, por disponibilizar as instalações do CTPP - IPT, para realização deste trabalho.

Ao Dr. Wagner Aldeia, chefe do LPP / CTPP - IPT, por disponibilizar as instalações do LPP, pelo apoio, incentivo e amizade.

A profa. Dra. Maria Inês Ré, pelo apoio e incentivo no início deste trabalho, e pela amizade.

Ao Dr. Adriano Marim de Oliveira, por ter auxiliado nos ensaios de produção de biodiesel e outras contribuição, pelo apoio, incentivo e amizade.

Ao David Freitas, técnico de laboratório do LPP / CTPP - IPT, por ter auxilio diversas vezes nos ensaios e outras contribuições, pelo apoio, incentivo e amizade.

A minha esposa Dayana, pelo carinho, amor e dedicação, e pelo apoio, incentivo e revisão do trabalho.

Aos amigos do LPP / CTPP - IPT, que continuam ou não no laboratório durante esses cinco anos: Juliana, Houari, Thomas, Kleber, Pierre, Shirley, Izabela, Bento, David, Mariana, Renata, Fernanda, Fernanda, Ariane, Maria Helena, João Guilherme e Silas, pelas idéias e momentos de descontração.

Ao $\mathrm{CNPq}$, pelo apoio financeiro por meio da bolsa de doutorado.

A todos que direta ou indireta, colaboraram com a realização deste trabalho. 
To mix or not to mix

Patrick Tabeling 


\section{RESUMO}

O escopo deste trabalho foi o desenvolvimento de microrreatores em tecnologia LTCC para produção de biodiesel, com foco na otimização de uma geometria de micromisturador. Esta proposta é resultado das oportunidades identificadas em três áreas do conhecimento: Microtecnologia, Intensificação de processos e Biocombustíveis. A principal ferramenta de desenvolvimento desta proposta é a fluidodinâmica computacional.

Os microcanais baseados em geometrias com sucessivos cotovelos foram os escolhidos, para a investigação computacional e experimental.

A metodologia computacional desenvolvida para alcançar os objetivos propostos envolve as etapas de: definição de um padrão de comparação, projeto das distâncias entre cotovelos, escolha de uma geometria com base na comparação entre diversas geometrias baseadas em sucessivos cotovelos e a otimização da geometria em função dos parâmetros fluidodinâmicos.

Paralelamente, ensaios para a produção de biodiesel foram realizados, bem como, a investigação da produção de emulsões para avaliar como uma etapa do processo de produção do biodiesel.

A geometria escolhida e otimizada foi a serpentina 3D, o que permitiu a otimização do módulo de tempo de residência e o projeto do microrreator.

Finalizando, um microrreator foi projetado com parâmetros ótimos, obtendo assim a intensificação de processo por meio de conceitos de microtecnologia, para aplicação na produção de biocombustíveis.

Palavras-chave: microtecnologia, intensificação de processo, biodiesel, microrreatores, microssistemas, fluidodinâmica computacional. 
The scope of this work was the development of microreactors in LTCC technology for biodiesel production, with a focus on the optimization of a micromixer geometry. This proposal is resulted from the opportunities identified in three areas of knowledge: Microtechnology, processes intensification and Biofuels. The main tool for development of this proposal is the computational fluid dynamics (CFD).

The microchannels geometry with successive elbows were chosen for computational and experimental research.

The computational methodology developed to achieve the proposed goals involves the following steps: defining a standard of comparison, a project of the distances between elbows, a choice of geometry based on the comparison between different geometries based on successive elbows and geometry optimization for the parameters hydrodynamic.

In addition, tests for the production of biodiesel were being made and the investigations of production of emulsions to evaluate a step in the producing of biodiesel process.

The geometry was chosen and optimized serpentine 3D, allowing the optimization of residence time module and the design of the microreactor.

Finally, a microreactor was designed with optimal parameters, thus obtaining the intensification process through microtechnology concepts for application in the biofuels production.

Keywords: microtechnology, process intensification, biodiesel, microreactors, microsystems, computational fluid dynamics. 


\section{LISTA DE ILUSTRAÇÕES}

Figura 1. Impacto da intensificação de processos nos métodos de mistura para produção industrial (Stankiewicz, 2004).

Figura 2. Consumo mundial de energia por tipo de fonte: histórico e projeção (CNI, 2007).. 29

Figura 3. Rotas de produção de biocombustíveis (BCSD Portugal, 2008). .29

Figura 4. Produção de etanol (BCSD Portugal, 2008; CNI, 2007). .30

Figura 5. Projeção de consumo de biocombustíveis (BCSD Portugal, 2008). .31

Figura 6. Triglicerídeo formado por ácidos graxos oléicos. 39

Figura 7. Fluidos Supercríticos: (a) diagrama pressão em função da temperatura do $\mathrm{CH}_{3} \mathrm{OH}$ e (b) características e aplicações destes fluidos (Lee, 2005). 40

Figura 8. Reação química de produção do biodiesel pelo processo de transesterificação. ...42

Figura 9. Diagrama de blocos do processo de produção de biodiesel com catálise (a) básica e (b) ácida. Adaptada de Helwani (2009).

Figura 10. Microcanal reto e aparato experimental para produção de biodiesel (Carlisle, 2005).

Figura 11. Descrição do escoamento nos microcanais retos e resultados de Sun (2008).....48

Figura 12. Desenho esquemático dos dispositivos estudados por Wen (2009). .49

Figura 13 Resultados das emulsões geradas em Wen (2009). .50

Figura 14 Comparação do método convencional com a rota microtecnológica de produção de biodiesel (Wen, 2009).

Figura 15. Produção de biodiesel em Sun (2010): (I) desenho esquemático do aparato experimental e (II) micromisturadores testados, a - misturador T, b - misturador $\mathrm{J}, \mathrm{c}-$ misturador RIMM e d - SIMM-V2. .

Figura 16. Resultados obtidos por Sun (2010): (I) conversão em função do tipo de micromisturador, (II) conversão em função da vazão para um módulo de tempo de residência específico e (III) visualização do escoamento.

Figura 17. Desenho esquemático de um sistema para realizar a produção de biodiesel com a delimitação (linha tracejada) do escopo deste trabalho.

Figura 18. Dispositivos usados por (a) Haverkamp et al. (1999), Freitas et al. (2003) e Wischke et al.(2005) e (b) Mae et al. (2004).

Figura 19. Interface entre dois líquidos em um canal reto.

Figura 20. Micromisturadores ativos e passivos encontrados na literatura.

Figura 21. Dispositivos ativos: (a) Oddy, 2001, (b) Oddy, 2001, (c) Bau, 2001, e (d) Yang, 2001. 
Figura 22. Dispositivos passivos: (a) Mengeaud, 2002, (b) Liu, 2000, (c) Stroock, 2002, e (d) Böhm, 2001

Figura 23. Número de Reynolds por Fator de atrito para vários microcanais em comparação a equações clássicas (MALA; LI, 1999).

Figura 24. Diagrama de Moody (Fox, 1985).

Figura 25. Mapas de Poincaré.

Figura 26. Desenho esquemático de misturadores microfluídicos que operam em (a) baixo, (b) intermediário e (c) alto número de Reynolds (NGUYEN e WU, 2005). .............................73

Figura 27. Mapas de Velocidade para o canal reto de $D_{h}=1 \mathrm{~mm} \mathrm{e} \mathrm{L}=20 \mathrm{~mm} \ldots \ldots \ldots \ldots \ldots \ldots \ldots . . . .79$

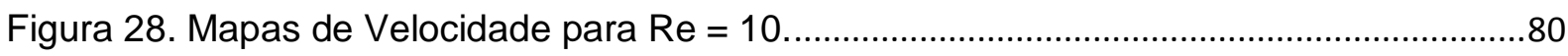

Figura 29. Mapas de Pressão.

Figura 30. Visualização dos mapas do campo de velocidades para estrutura 1, em função do número de Reynolds.

Figura 31. Detalhe do escoamento na região dos cotovelos para as estruturas 1, 2 e 3, para $\operatorname{Re}=100$

Figura 32. Mapas de velocidade da serpentina 3D 1. 106

Figura 33. Mapas de velocidade das 08 geometrias restantes para $\mathrm{Re}=10$ (coluna esquerda) e $R e=100$ (coluna direita). 109

Figura 34. Mapa de pressão da geometria serpentina 3D 1 para $R e=100$. 110

Figura 35. Mapas de concentração: comparação do microcanal reto com a serpentina 3D 1.

Figura 36. Mapas de concentração das geometrias baseadas em sucessivos cotovelos....122

Figura 37. Mapas de concentração: saída das geometrias. 125

Figura 38. Mapas de concentração: cortes no plano xy. 126

Figura 39. Mapas de concentração: cortes no plano yz. 128

Figura 40. Mapas de concentração: cortes no plano xz. 128

Figura 41. Mapas de velocidade em função do número de seções para $R e=100$ 138

Figura 42. Mapas de velocidade em função do número de seções para $R e=100$ : cortes no plano $x y$. 140

Figura 43. Mapa de pressão para zigzag com 10 seções para $R e=100$. 141

Figura 44. Mapas de concentração: saídas em função do número de seções. 149

Figura 45. Mapas de velocidade e pressão para a geometria serpentina 3D de $600 \mu \mathrm{m}$ e 16 seções em $\operatorname{Re}=100$. 155

Figura 46. Mapas de concentração da saída em função do número de seções, para $R e=$ 100 e $D_{h}=600 \mu m$. 
Figura 47. Mapas de velocidade em função do número de Reynolds e mapa de pressão para $\mathrm{Re}=10$.

Figura 48. Mapas de concentração em função do número de Reynolds. ..............................176

Figura 49. Geometria dos micromisturadores aplicados a produção de biodiesel.................181

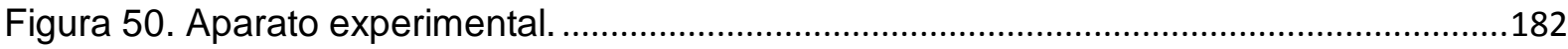

Figura 51. Amostras geradas nos ensaios de produção do biodiesel. ....................................182

Figura 52. Projeto em CAD e dispositivos fabricados 184

Figura 53. Desenho esquemático do processo iterativo para resolução do problema de

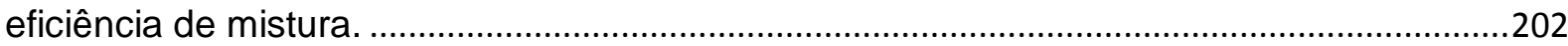

Figura 54. Evolução dos mapas de concentração em função do número de iterações. .......206

Figura 55. Variação da viscosidade ao longo do tempo no processo de produção do

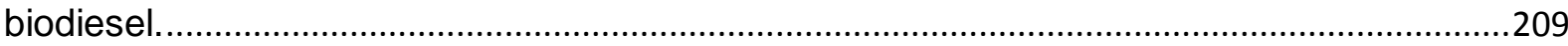

Figura 56. Perfis de concentração em função do tempo Sharma (2008)...............................215

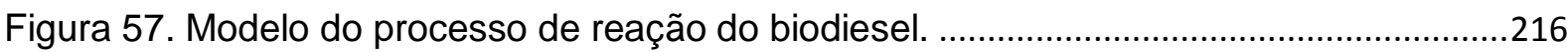

Figura 58. Aproximação do modelo de processo de produção. ..............................................216

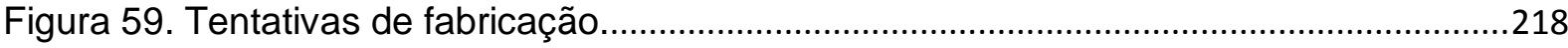

Figura 60. Camadas cerâmicas usinadas e microrreator pronto.............................................219

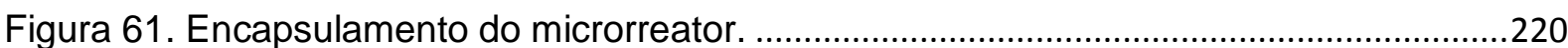

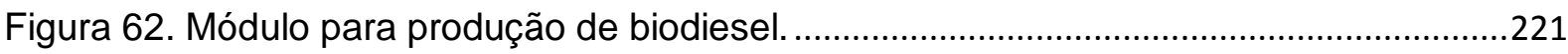

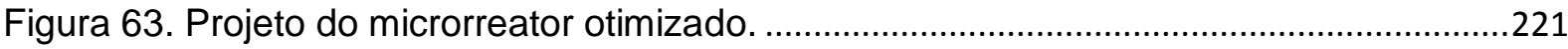




\section{LISTA DE GRÁFICOS}

Gráfico 1. Fator de atrito (f) e coeficiente de perda de carga (K) em função do número de Reynolds.

Gráfico 2. Vorticidade em função do número de Reynolds.

Gráfico 3. Diferença de pressão e resistência hidráulica em função da vazão. .84

Gráfico 4. Tempo de residência e potência volumétrica em função da vazão. .85

Gráfico 5. Tempo de residência em função da diferença de pressão. .86

Gráfico 6. Tempo de residência em função da potência volumétrica. .86

Gráfico 7. Estrutura 1: $\mathrm{K}$ relativo em função do número de Reynolds, para as diversas distâncias entre cotovelos.

Gráfico 8. Estrutura 1: Vorticidade relativa em função do número de Reynolds, para as diversas distâncias entre cotovelos.

Gráfico 9. Vorticidade e $\mathrm{K}$ relativos em função da distância entre os cotovelos, para estrutura 1 e $\operatorname{Re}=100$.

Gráfico 10. Vorticidade relativa em função da distância entre cotovelos, para as três estruturas e $\operatorname{Re}=100$.

Gráfico 11. Velocidade máxima relativa $\left(\mathrm{vm}_{\mathrm{r}}\right)$ em função da distância entre cotovelos, para as três estruturas e $\mathrm{Re}=100$.

Gráfico 12. Coeficiente de perda de carga em função do número de Reynolds: (a) valor absoluto e (b) valor relativo.

Gráfico 13. Vorticidade em função do número de Reynolds: (a) valor absoluto e (b) valor relativo.

Gráfico 14. Diferença de pressão (a) e a resistência hidráulica (b) em função da vazão.....114

Gráfico 15. Tempo de residência e potência volumétrica em função da vazão.

Gráfico 16. Tempo de residência em função da (a) diferença de pressão e da (b) potência volumétrica.

Gráfico 17. Eficiência de mistura em função do número de Reynolds. 130

Gráfico 18. Eficiência de mistura em função do tempo de residência.

Gráfico 19. Eficiência de mistura em função da potência volumétrica.

Gráfico 20. Coeficiente de perda de carga em função do número de Reynolds: (a) valores absolutos e (b) valores relativos.

Gráfico 21. Vorticidade em função do número de Reynolds: (a) valores absolutos e (b) valores relativos. 
Gráfico 23. Tempo de residência e potência volumétrica em função da vazão.

Gráfico 24. Eficiência de mistura em função do número de seções.

Gráfico 25. K em função de Re para variação do (a) número de seções e do (b) $D_{h}$ 156

Gráfico 26. Parâmetros numéricos: (a) vorticidade em função do número de seções e do $D_{h}$ e (b) diferença de pressão em função do número de seções e do $D_{h}$ 157

Gráfico 27. Eficiência de mistura em função do (a) número de seções e do (b) do $D_{h}$ 162

Gráfico 28. Eficiência de mistura em função do (a) número de seções e do Dh, e em função do (b) tempo de residência.

Gráfico 29. Comportamento da geometria serpentina 3D 1 em função do número de seções.

Gráfico 30. Comportamento da geometria serpentina 3D em função do número de seções.

Gráfico 31. Parâmetros fluidodinâmicos: (a) K e vorticidade em função de Re e (b) diferença de pressão e resistência hidráulica em função da vazão. 172

Gráfico 32. Tempo de residência e potência volumétrica em função da vazão. .173

Gráfico 33. Eficiência de mistura em função do (a) número de Reynolds e (b) do tempo de residência.

Gráfico 34, medidas de perda de carga: (a) BIODIESEL_01, 02 e 03, (b) BIODIESEL_04, 05 e 06, (c) BIODIESEL_07, 08 e 09 e (d) BIODIESEL_10, 11 e 12.

Gráfico 35. Distribuição de tamanho de partícula: (a) BIODIESEL_03 e (b) BIODIESEL_09.

Gráfico 36. Estabilidade da emulsão produzida com BIODIESEL_03 para 5 horas e 30 min.

Gráfico 37. Comportamento da geometria serpentina 3D em função do número de seções.

Gráfico 38. Eficiência de mistura em função do número de seções. 206

Gráfico 39. Comportamento da geometria serpentina 3D em função do número de seções. 


\section{LISTA DE TABELAS}

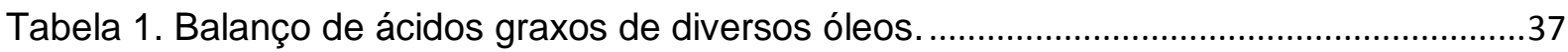

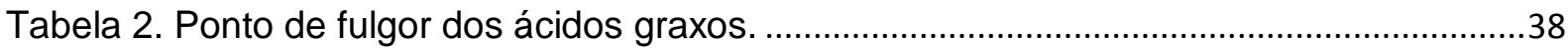

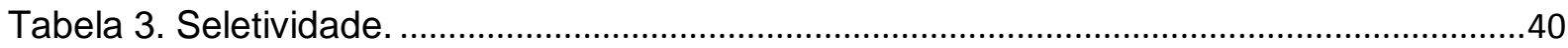

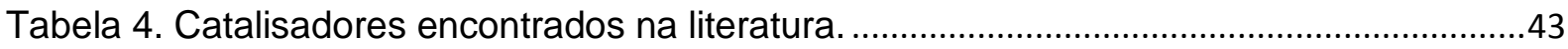

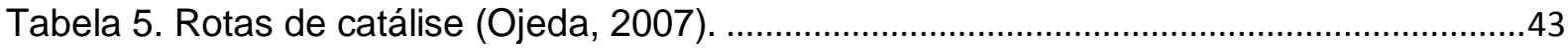

Tabela 6. Rotas de produção do biodiesel (Sharma, 2008) .....................................................46

Tabela 7. Parâmetros geométricos e desempenho dos dispositivos estudados (Wen, 2009).

Tabela 8. Produção de biodiesel por via microtecnológica. ..........................................................54

Tabela 9. Cálculo da superfície de contato. ...........................................................................64

Tabela 10. Escalamento das dimensões. ................................................................................66

Tabela 11. Investigações sobre o estudo do escoamento em micro-escala versus macro-

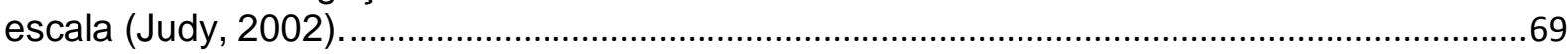

Tabela 12. Resultados dos testes de sensibilidade. .............................................................. 75

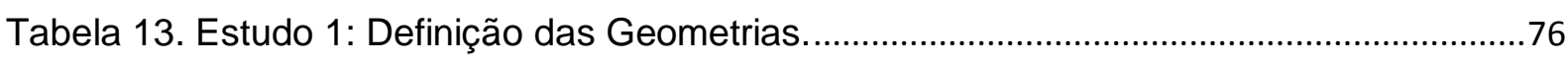

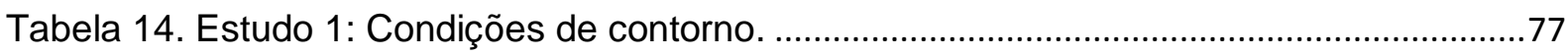

Tabela 15. Estudo 1: Discretização da geometria. ……............................................................78

Tabela 16. Estudo 2: Definição das geometrias. ..........................................................................90

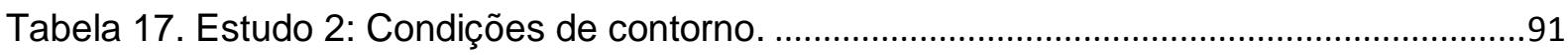

Tabela 18. Estudo 2: Discretização da geometria. ………….................................................92

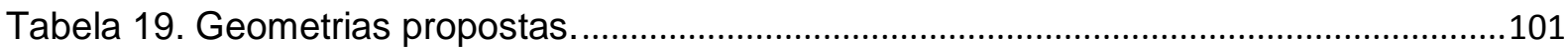

Tabela 20. Estudo 3: Definição das geometrias. ...................................................................102

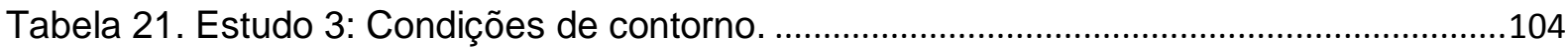

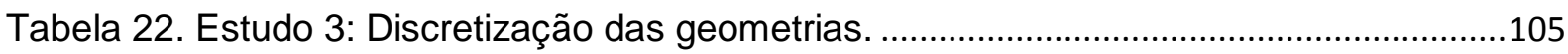

Tabela 23. Estudo 3.1: Condições de contorno. .....................................................................118

Tabela 24. Estudo 3.1: Discretização das geometrias. ........................................................119

Tabela 25. Índice de comparação do desempenho das geometrias estudadas para $R e=100$.

Tabela 26. Índice de comparação do desempenho das geometrias estudadas para $\operatorname{Re}=100$.

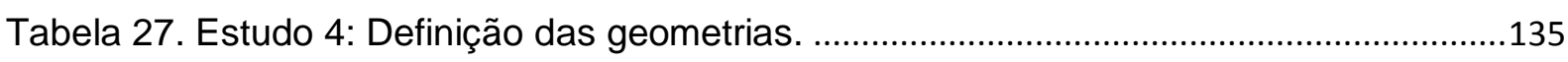

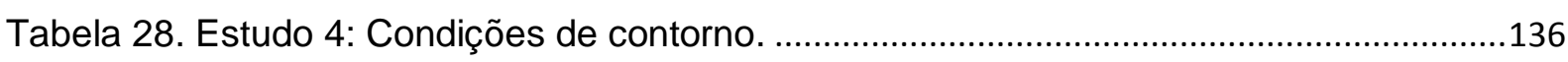

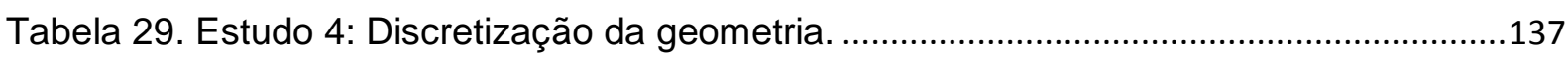

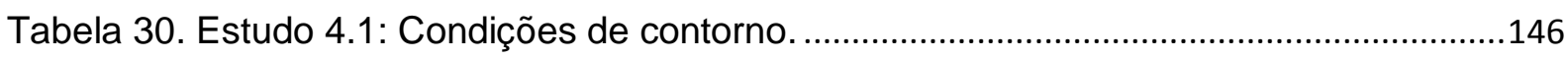


Tabela 31. Estudo 4.1: Discretização das geometrias.

Tabela 32. Comparação da eficiência de mistura relativamente a uma seção ......................151

Tabela 33. Estudo 5: Definição das geometrias. ......................................................................152

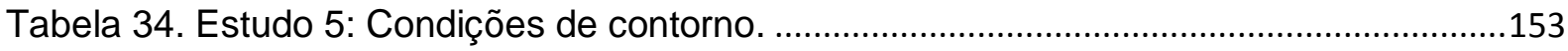

Tabela 35. Estudo 5: Discretização da geometria..................................................................154

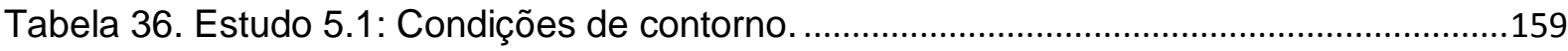

Tabela 37. Estudo 5.1: Discretização das geometrias.............................................................160

Tabela 38. Índice comparativo em função do número de seções. ............................................163

Tabela 39. Índice comparativo em função do número de seções. ............................................167

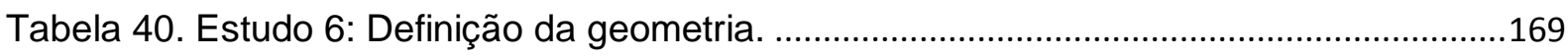

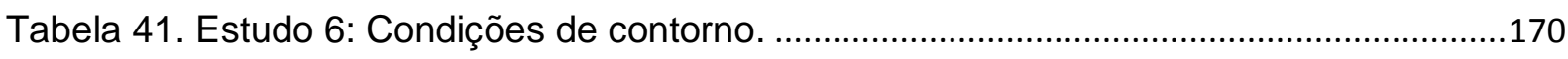

Tabela 42. Estudo 6: Discretização da geometria. ...................................................................171

Tabela 43. Estudo 6.1: Condições de contorno...................................................................174

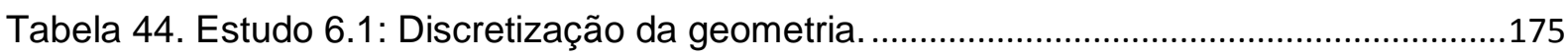

Tabela 45. Parâmetros dos ensaios de produção do biodiesel. ..............................................182

Tabela 46. Resultados obtidos por cromatografia gasosa. ....................................................183

Tabela 47. Índice de comparação do desempenho das geometrias estudadas para $R e=100$.

Tabela 48. Comparação da eficiência de mistura relativamente a uma seção .......................191

Tabela 49. Índice comparativo em função do número de seções. .........................................191

Tabela 50. Produção de biodiesel por via microtecnológica...................................................199

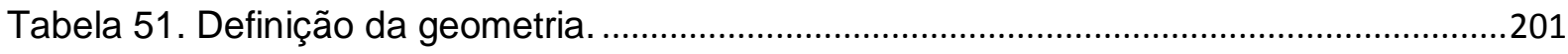

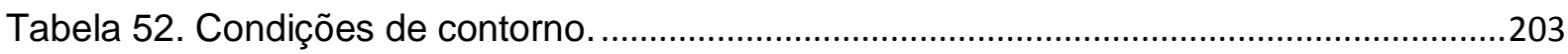

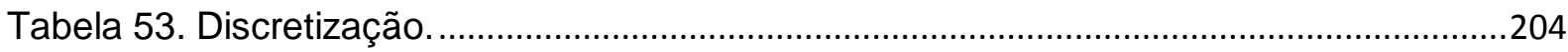

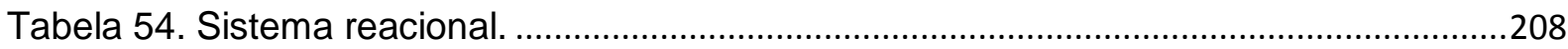

Tabela 55. Comparação do modelo teórico com a prática experimental encontrada na

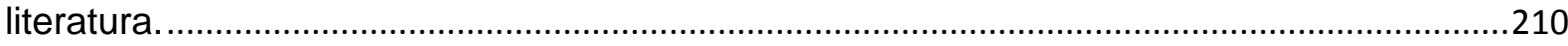

Tabela 56. Investigação das constantes de velocidade de reação (Fonseca, 2010). ...........214

Tabela 57. Produção de biodiesel por via microtecnológica...................................................215

Tabela 58. Índice de comparação do desempenho das geometrias estudadas para $R e=100$.

Tabela 59. Comparação da eficiência de mistura relativamente a uma seção .......................228

Tabela 60. Índice comparativo em função do número de seções. ............................................228 


\section{LISTA DE ABREVIATURAS E SIGLAS}

\begin{tabular}{|c|c|c|}
\hline LTCC & - & Cerâmica com baixa temperatura de sinterização. \\
\hline DNA & - & Ácido desoxirribonucléico. \\
\hline ONU & - & Organização da Nações Unidas. \\
\hline CDE & - & Conta de Desenvolvimento Energético. \\
\hline RGR & - & Reserva Global de Reversão. \\
\hline PZT & - & Titanato zirconato de chumbo. \\
\hline PDMS & - & Poli-dimetilsiloxano. \\
\hline FS & - & Sílica fundida. \\
\hline SS & - & Aço inox. \\
\hline EDO & - & Equação diferencial ordinária. \\
\hline RF & - & Rádio freqüência. \\
\hline MEMS & - & Sistemas Micro-Eletromecânicos. \\
\hline MTR & - & Módulo de tempo de residência. \\
\hline LPP & - & Laboratório de Processos Químicos e Tecnologia de Partículas. \\
\hline CTPP & - & Centro de Tecnologia de Processos e Produtos. \\
\hline IPT & - & Instituto de Pesquisas Tecnológicas do Estado de São Paulo \\
\hline $\mathrm{CNPq}$ & - & Conselho Nacional de Pesquisa e Desenvolvimento. \\
\hline HPLC & - & Cromatografia líquida de alta pressão. \\
\hline TG & - & Triglicerídeo. \\
\hline
\end{tabular}




$\begin{array}{lll}\text { DG } & - & \text { Diglicerídeo. } \\ \text { MG } & - & \text { Monoglicerídeo. } \\ \text { E } & - & \text { éster. } \\ \text { G } & - & \text { glicerina. } \\ \text { A } & - & \text { álcool. } \\ \text { CFD } & - & \text { Fluidodinâmica Computacional. }\end{array}$




\section{LISTA DE SÍMBOLOS}

\begin{tabular}{|c|c|c|}
\hline$\rho$ & - & densidade. \\
\hline$\sigma$ & - & variância relativa. \\
\hline$\sigma_{\mathrm{e}}$ & - & variância relativa na entrada. \\
\hline$\sigma_{\mathrm{s}}$ & - & variância relativa na saída. \\
\hline$\tau$ & - & tempo de residência teórico. \\
\hline$\varepsilon$ & - & eficiência de mistura. \\
\hline$\omega$ & - & vorticidade. \\
\hline$\omega_{r}$ & - & vorticidade relativa. \\
\hline$\Delta \mathrm{P}$ & - & diferença de pressão. \\
\hline$\eta$ & - & viscosidade dinâmica. \\
\hline$V_{\text {in }}$ & - & velocidade na entrada. \\
\hline $\mathrm{vm}_{\mathrm{r}}$ & - & velocidade máxima relativa. \\
\hline$D_{h}$ & - & diâmetro hidráulico. \\
\hline $\mathrm{Re}$ & - & número de Reynolds. \\
\hline $\mathrm{L}$ & - & comprimento. \\
\hline $\mathrm{L}$ & - & dimensão. \\
\hline$f$ & - & fator de atrito. \\
\hline K & - & coeficiente de perda de carga. \\
\hline $\mathrm{K}_{\mathrm{r}}$ & - & coeficiente de perda de carga relativa. \\
\hline C & - & constante característica de uma seção transversal. \\
\hline
\end{tabular}


concentração.

$\mathrm{C}_{0}$

concentração inicial.

$\mathrm{L}_{\mathrm{e}}$

comprimento equivalente.

Q

vazão.

$\mathrm{R}_{\mathrm{h}} \quad-\quad$ resistência hidráulica.

t

tempo de residência.

$\Delta \mathrm{V} \quad$ - $\quad$ volume.

V $\quad$ - volume.

$\mathrm{P}_{\mathrm{v}} \quad-\quad$ potência volumétrica.

$\mathrm{D}_{\mathrm{e}} \quad-\quad$ distância de entrada.

Ds $\quad$ - $\quad$ distância de saída.

dec - distância entre cotovelos (relativa).

$D_{\mathrm{ec}} \quad$ - distância entre cotovelos (m).

d $\quad$ - dimensão característica de um sistema.

D $\quad$ - $\quad$ coeficiente de difusão.

R $\quad$ - $\quad$ taxa de reação.

$\mathrm{N} \quad-\quad$ fluxo. 


\section{SUMÁRIO}

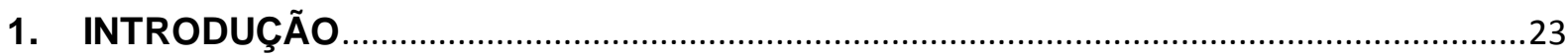

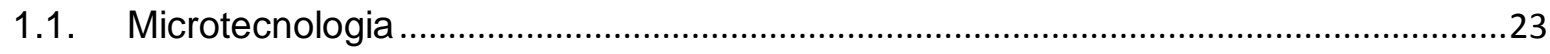

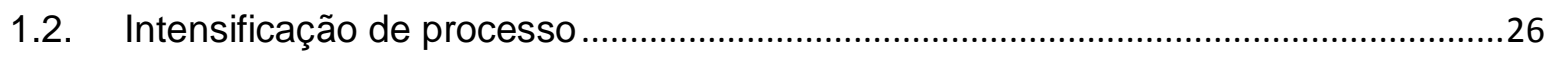

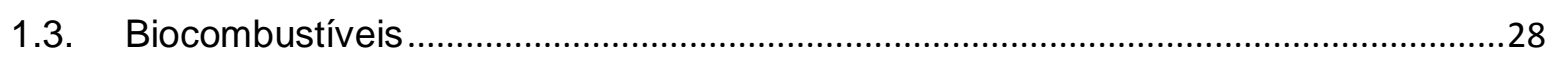

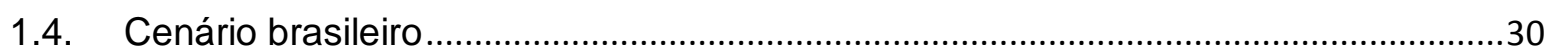

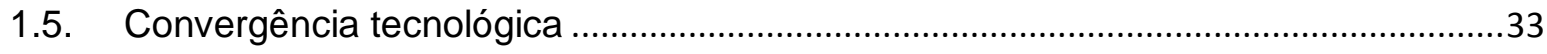

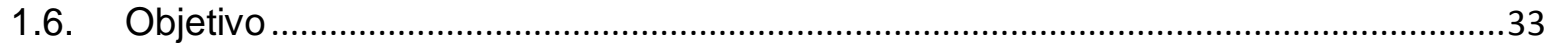

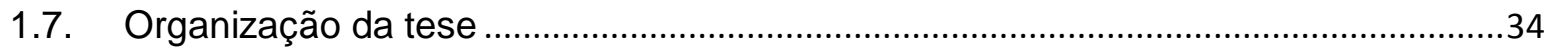

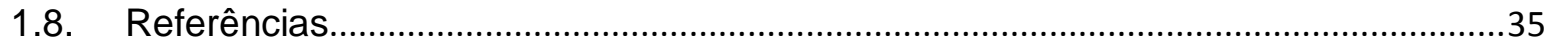

2. ESTADO DA ARTE

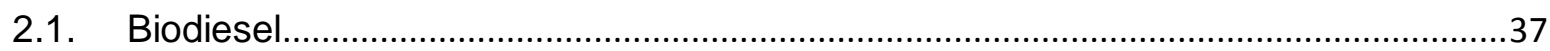

2.2. Biodiesel, Intensificação de Processo e Microtecnologia...........................................47

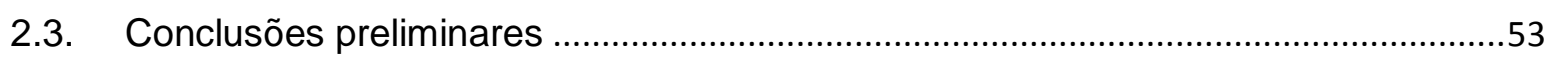

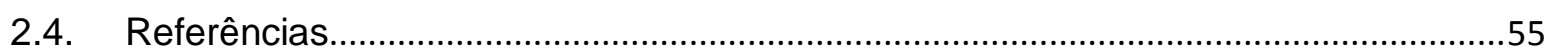

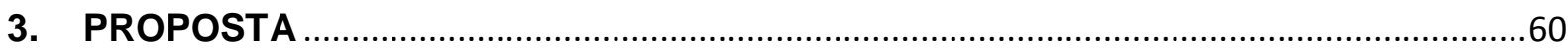

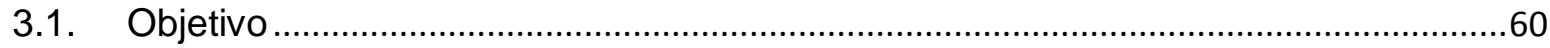

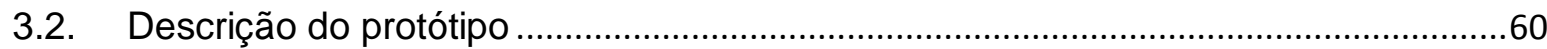

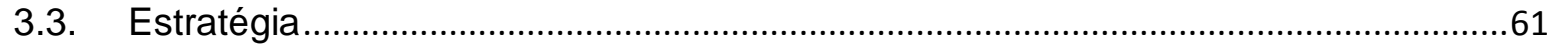

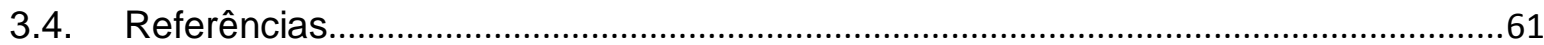

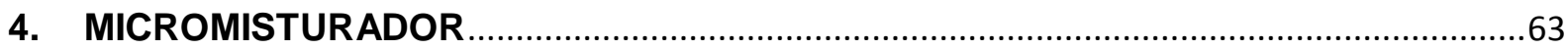

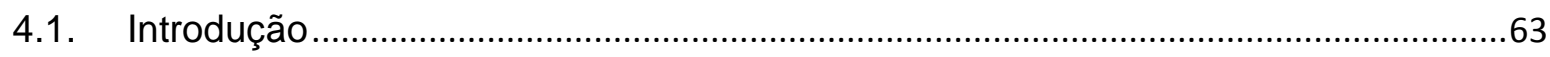

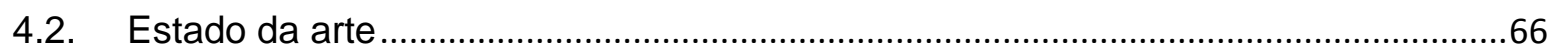

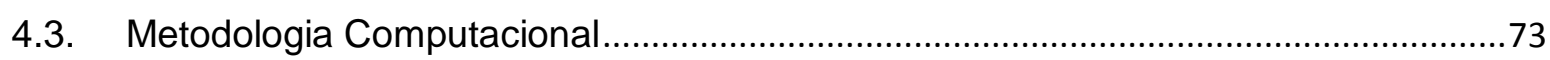

4.4. Estudo 1: Descrição do escoamento em microcanais retos .......................................76

4.5. Estudo 2: Influência da distância entre dois cotovelos sucessivos.............................89

4.6. Estudo 3: Comparação de diversas geometrias ......................................................101

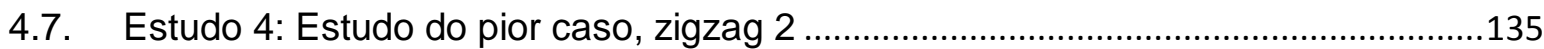

4.8. Estudo 5: Estudo do melhor caso, serpentina 3D 1 ...............................................152

4.9. Estudo 6: Serpentina 3D 1, nas condições de processo .............................................169

4.10. Otimização de micromisturadores baseados em sucessivos cotovelos ..............180 


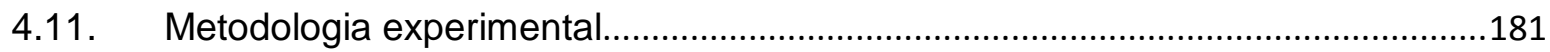

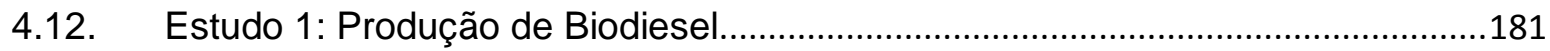

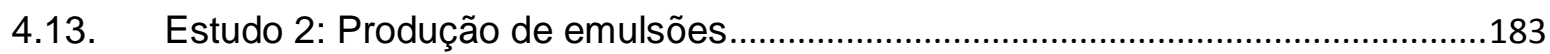

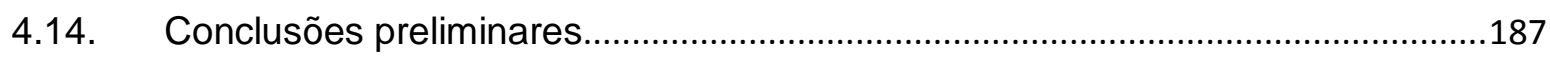

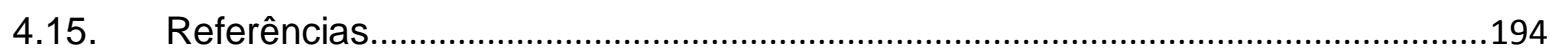

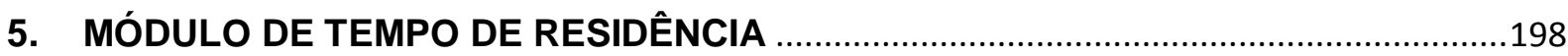

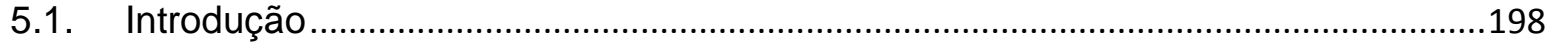

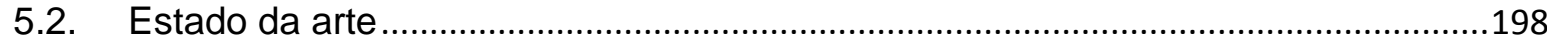

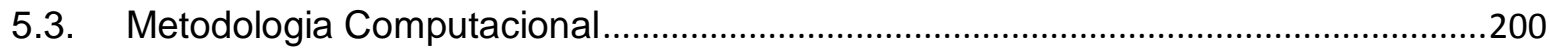

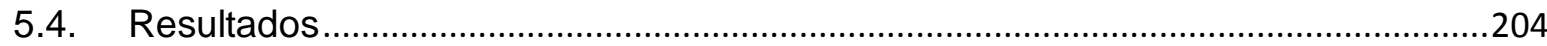

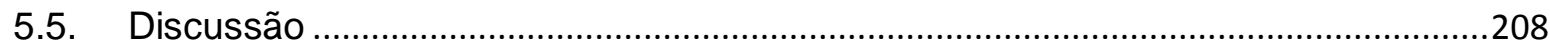

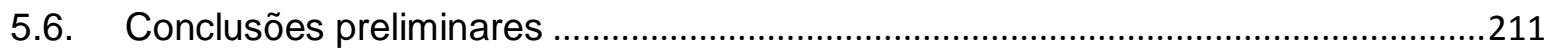

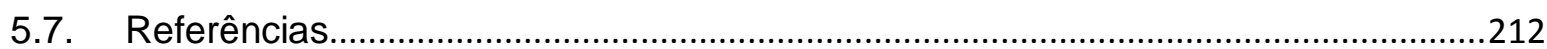

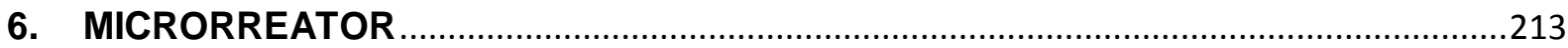

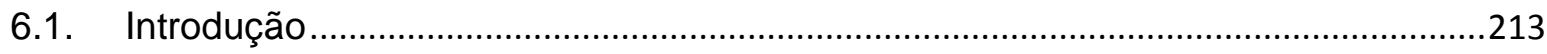

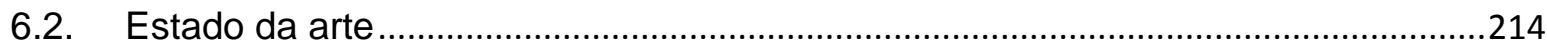

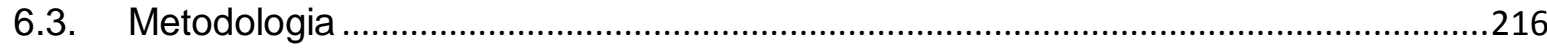

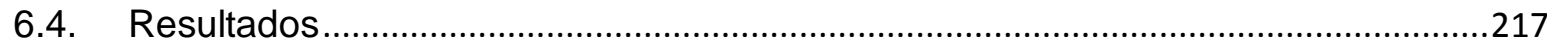

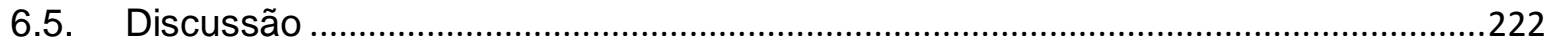

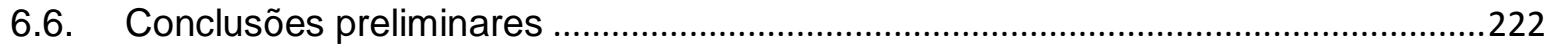

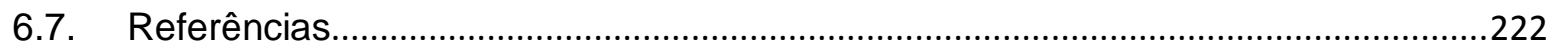

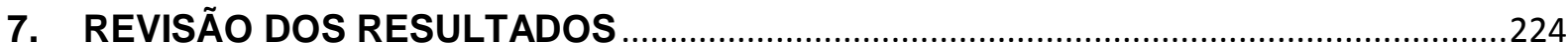

8. CONCLUSÃO

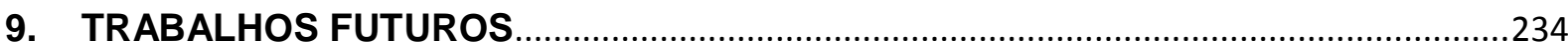

APÊNDICE A - SISTEMA DE MEDIÇÃO E CONTROLE DE VAZÃO ...................................235

APÊNDICE B - SISTEMA DE MEDIÇÃO E CONTROLE DE TEMPERATURA ....................238

APÊNDICE C - FABRICAÇÃO EM TECNOLOGIA LTCC …...........................................242 


\section{INTRODUÇÃO}

O tema proposto para este trabalho decorre dos conceitos e oportunidades percebidos em três áreas do conhecimento

- microtecnologia,

- intensificação de processo e

- biocombustíveis.

\subsection{Microtecnologia}

A microtecnologia é uma área do conhecimento que utiliza diversas técnicas de microfabricação para integrar e miniaturizar dispositivos, componentes e sistemas para uma larga gama de aplicações, apresentando ramificações como

- a microeletrônica,

- a micro-óptica,

- a micromecânica, e

- a microfluídica.

A microeletrônica sem dúvida foi a mais significante tecnologia do último século, que com a integração de circuitos e o progresso no processamento de informação, mudou a forma de trabalhar, descobrir e inventar (Nguyen, 2002).

Em particular, a microfluídica nas últimas três décadas firmou-se como uma tecnologia emergente, servindo de ferramenta para diversas áreas tanto na ciência como na indústria. Essa nova área do conhecimento promete revolucionar a manipulação e gestão de fluidos assim como a microeletrônica revolucionou a computação e a eletrônica.

Usando tecnologias de fabricação estabelecidas, como as baseadas em silício para fabricação em microeletrônica, na microfluídica desenvolveram-se:

- microssensores de fluxo,

- microbombas e

- microválvulas, 
que dominaram num primeiro estágio essa nova disciplina. Posteriormente, tecnologias de fabricação com base em cerâmicas e polímeros, foram introduzidas para fabricação de dispositivos e sistemas microfluídicos. Sendo que atualmente, técnicas como micro-usinagem a laser, permitem que uma maior gama de materiais seja usada para fabricação em microfluídica (Nguyen, 2002).

A microfluídica apresenta-se também como uma importante ferramenta para aplicações em química e ciências da vida. Apresentando vantagens como

- portabilidade,

- capacidade de integração,

- controle e medição precisos, e

- implementação do processo contínuo.

Portanto, a microfluídica mostra-se de vital importância para intensificação de processos e gerenciamento de fluidos em áreas como farmácia, química, medicina e biologia. Com o recente desenvolvimento em biotecnologia, tendo como exemplo os trabalhos de mapeamento do genoma humano, novas aplicações estão surgindo requerendo novos dispositivos e sistemas microfluídicos. Basicamente, a microfluídica atua em química e ciências da vida com os seguintes dispositivos:

- micro-agulha (Lin, 1999),

- microdispensador (Koide, 2000),

- microfiltro (Yang, 1999),

- microsseparador,

- micromisturador (Nguyen, 2005) e

- microrreator.

Micromisturadores estão presentes nas mais variadas aplicações na indústria e na ciência. A rápida e eficiente mistura de fluidos se faz necessária em situações como síntese de ácidos nucléicos, análise de DNA, ativação celular e reações envolvendo enzimas e proteínas (Stroock, 2002; Liu, 2000). Nas indústrias, cosmética e alimentícia, a mistura também representa uma fase crítica da linha de produção.

Em particular, microrreatores são largamente utilizados em produção química e análises químicas. Com 0 advento da microfluídica e tecnologias de microfabricação é possível conceber microrreatores que excedem as funções de reatores convencionais, com vantagens como 
- alto rendimento $\mathrm{e}$

- baixo custo para produção em massa.

Parâmetros de interesse como pequena inércia térmica, altos gradientes de propriedades físicas, temperatura uniforme, curto tempo de residência e alta razão superfície-volume são alcançados devido às dimensões microscópicas e pelo maior controle sobre pequenas quantidades de fluidos. A possibilidade de integração de dispositivos de segurança nos reatores, utilizados em processos que envolvem reações com grande liberação de calor com perigo de chamas e explosões, também é de fundamental importância nesse ramo industrial e científico, tornando-se uma grande vantagem gerada pelas tecnologias de microfabricação.

Geralmente, um sistema de reação são constituídos dos seguintes elementos (operações unitárias):

- elementos funcionais para gerenciamento térmico (aquecedores, sensores de temperatura e dissipadores de calor),

- estruturas de catálise (superfícies porosas, membranas de catálise e camadas de catálise),

- elementos de mistura (micromisturadores),

- elementos de separação (microsseparadores) e

- elementos de sensoriamento (sensores químicos).

Dentro deste contexto, a microfluídica apresenta-se com um grande potencial comercial. Além dos tradicionais dispositivos microfluídicos, tais como cabeça de impressão por jato de tinta e sensores de pressão, que movimentam um mercado de milhões de dólares, áreas como

- diagnósticos médicos,

- descoberta e desenvolvimento de drogas,

- biotecnologia e

- produção química

são de interesse, já que dispositivos microfluídicos podem apresentar-se como novas ferramentas a serem utilizadas em novas aplicações, visando proporcionar um maior desempenho e eficiência. 


\subsection{Intensificação de processo}

Os métodos de processamento químicos não mudaram muito desde os seus primórdios, a intensificação de processos e sua miniaturização poderão mudar essa situação, como mostrado na figura 1. A intensificação de processos se refere a processos com alto rendimento e seletividade, mais rápidos, mais seguros e ambientalmente benignos (redução de impurezas e resíduos) e mais produtivos (menos custos de investimento e menos custos operacionais), o que quer dizer, aumentar a quantidade de produto produzido por unidade de tempo e por unidade de volume.

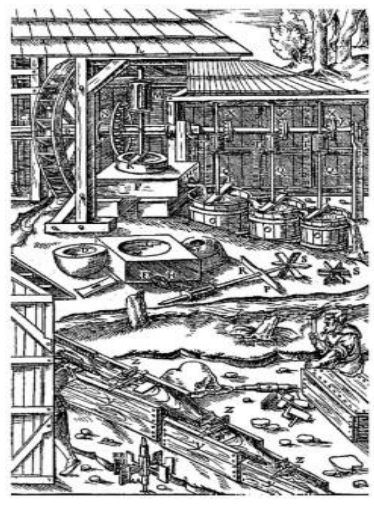

Ontem

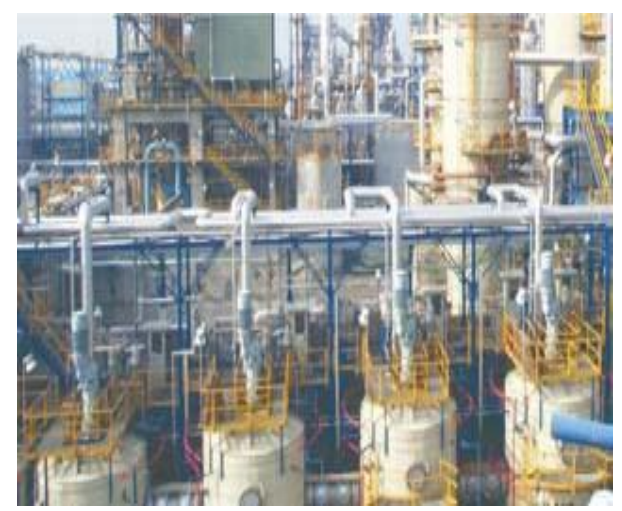

Hoje

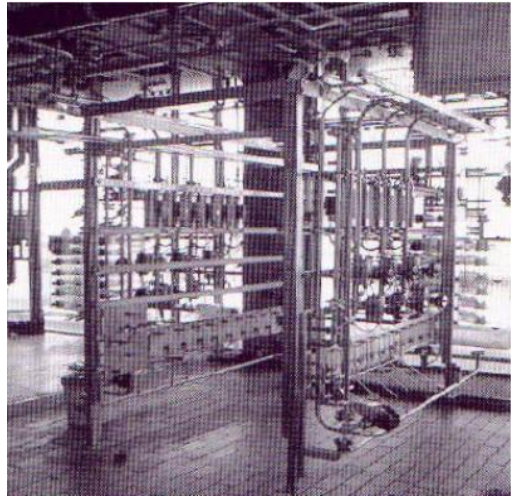

Amanhã

Figura 1. Impacto da intensificação de processos nos métodos de mistura para produção industrial (Stankiewicz, 2004).

Neste sentido, a intensificação de processos engloba o projeto de novos equipamentos e técnicas que são implementadas para melhorar o processo de produção, resultando em tecnologias mais seguras, baratas, compactas, ambientalmente corretas e energeticamente eficientes.

Portanto, a intensificação de processos está sendo adotada como um novo paradigma na engenharia de processos químicos junto com os paradigmas tradicionais: operações unitárias e fenômenos de transporte.

Dentre as características de processos que usam intensificação de processos pode-se destacar:

- mudança de processamento em batelada para processamento contínuo;

- volume de reação diminuído;

- mudança para processamento com microrreatores com altas taxas de mistura e transferência de calor; 
- aumento da razão superfície/volume;

- tempos de residência menores e

- aumento da portabilidade e diminuição do volume do equipamento.

A miniaturização, dos diversos componentes do sistema, usando técnicas de Microtecnologia, permite a Intensificação de Processos em diversos setores industriais, especialmente em processos que apresentam meios complexos ou material particulado. Por exemplo, fluidos não-newtonianos, géis, polímeros, colóides, dispersões, emulsões e suspensões em que a reologia e fenômenos interfaciais são importantes.

Existem diversas vantagens na utilização desta nova tecnologia em relação à tecnologia atual. Algumas destas estão descritas a seguir:

- obtenção de altas taxas de transferência de calor e massa no sistema de microfluídica;

- possibilidade de efetuar reações com maior grau de controle e de eficiência do que o obtido em reatores convencionais;

- maior segurança na produção, pois caso haja vazamento de produtos tóxicos ou explosões, será em uma escala tal, que as conseqüências serão restritas a uma área extremamente pequena;

- possibilidade de produzir compostos especialmente perigosos como cianetos e peróxidos sob demanda, isto é, sem a necessidade de armazenamento ou transporte;

- possibilidade de escalonamento do processo é muito mais fácil que nos processos convencionais, pois basta adicionar novos microrreatores em paralelo ao invés de reprojetar a escala industrial com base nos dados obtidos em escala piloto;

- testes de avaliação de desempenho através de um planejamento de experimentos (screening), por exemplo, com um catalisador é muito mais rápido e menos custoso, pois o tempo de residência é muito menor e é possível efetuar diversos testes em paralelo e

- possibilidade de implementar sistemas portáveis para fabricação sob demanda. 


\subsection{Biocombustíveis}

A questão energética é um ponto crítico no mundo moderno e industrializado. Os mais variados tipos de consumo de energia, doméstico, comercial, industrial, agro-industrial e tecnológico, criam uma demanda considerável por energia. O impacto ambiental causado pela produção de energia e matériasprimas para atender as demandas de desenvolvimento, está evidenciado pela quantidade crescente de

- reportagens veiculadas pelos meios de comunicação,

- pesquisas científicas,

- discussões em conferências internacionais e em organismos ligados a ONU (Organização das Nações Unidas)

sobre os temas:

- poluição urbana,

- efeito estufa,

- aquecimento global,

- regulação da emissão de carbono, entre outros.

As principais fontes de energia consumida no mundo são petróleo, gás natural e carvão (CNI, 2007), conforme mostrado na figura 2. Esses combustíveis são derivados de fontes fósseis, não renováveis e energeticamente sujas. Além disso, instabilidades geopolíticas e incertezas energéticas, como suprimento, são geradas, devido

- $85 \%$ das reservas mundiais de petróleo estão concentradas em 10 países: Arábia Saudita, Canadá, Irã, Iraque, Kuwait, Venezuela, Rússia, Líbia, Nigéria e Emirados Árabes Unidos (CNI, 2007),

- $58 \%$ das reservas mundiais de gás natural estão concentradas em 03 países: Rússia, Catar e Irã (CNI, 2007) e

- $66 \%$ das reservas mundiais de carvão estão concentradas em 04 países: Rússia, Estados Unidos, China e Índia (CNI, 2007). 


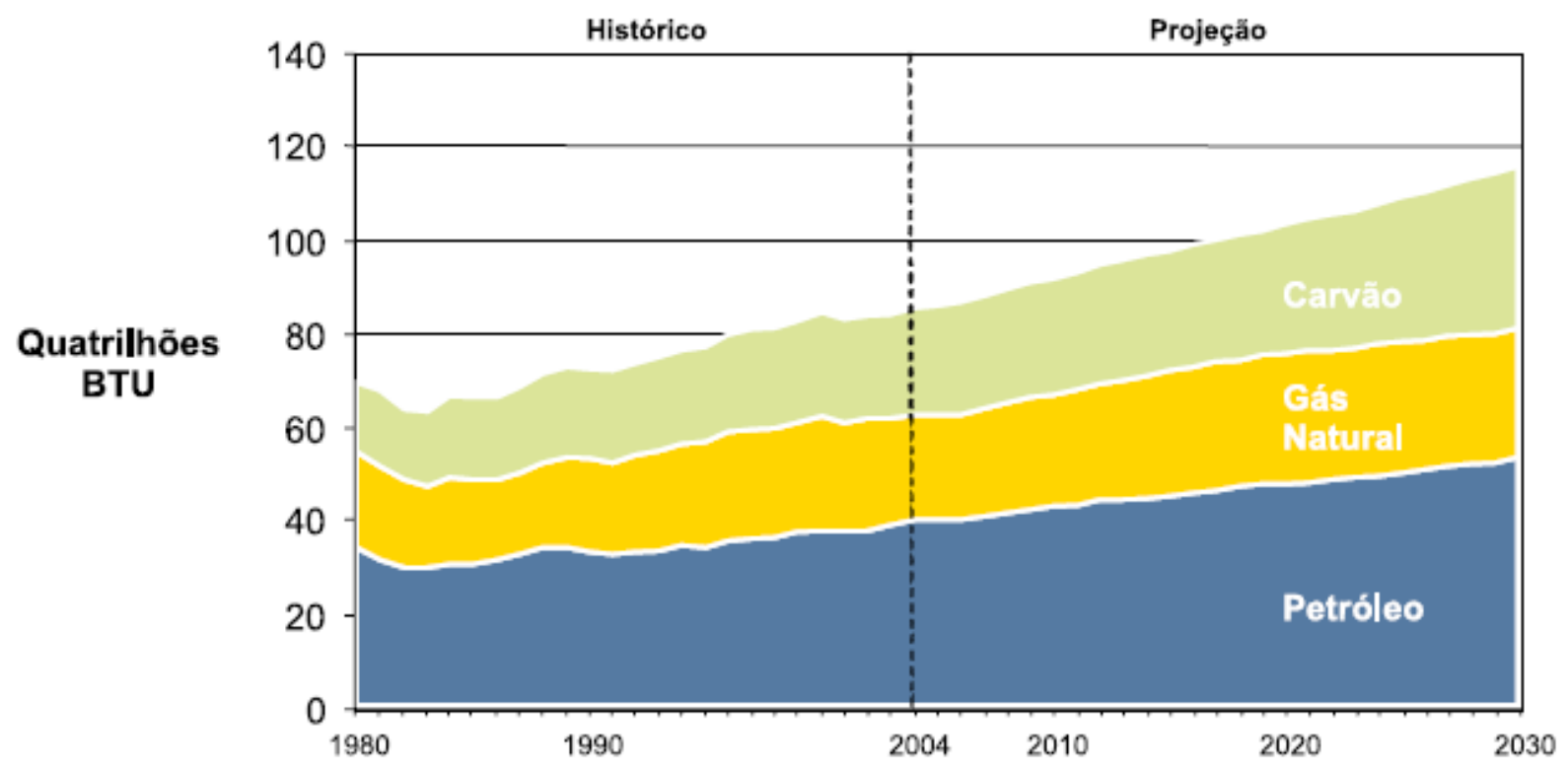

Figura 2. Consumo mundial de energia por tipo de fonte: histórico e projeção (CNI, 2007).

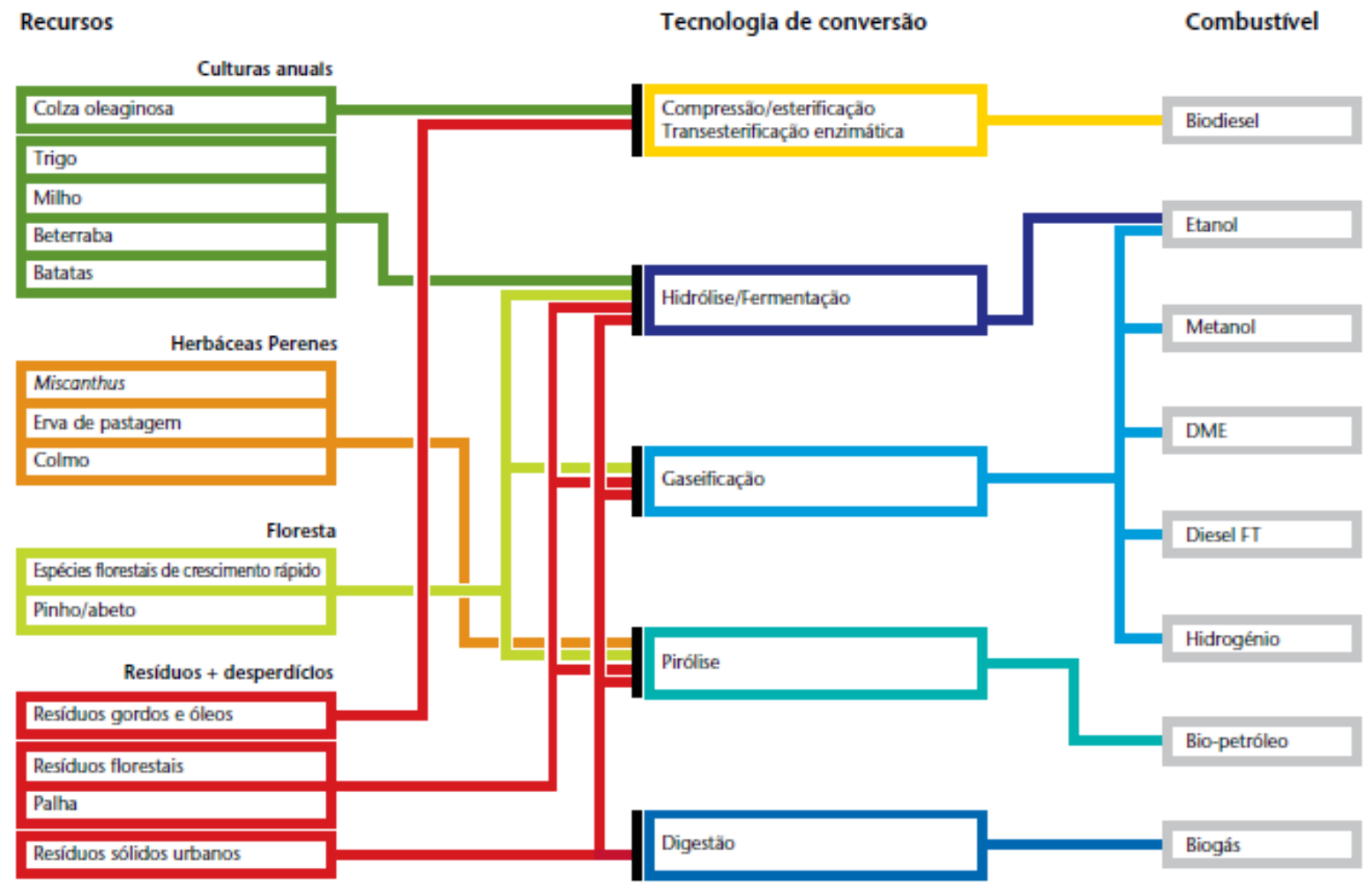

Figura 3. Rotas de produção de biocombustíveis (BCSD Portugal, 2008).

Logo, a pesquisa, o desenvolvimento e a inovação em energias limpas e/ou renováveis estão sendo exploradas, tais como: energia solar, energia eólica, 
energia hidráulica e biocombustíveis. A figura 3 mostra as principais rotas de produção de biocombustíveis, entre eles, o biodiesel.

\subsection{Cenário brasileiro}

Recentemente, no Brasil, descobriram-se enormes reservas de petróleo, no que ficou conhecido como “Pré-Sal”. Estas reservas, futuramente, podem levar o Brasil a uma posição de menor dependência ou supressão da dependência energética com relação ao petróleo.

No entanto, a matriz energética do Brasil é diferenciada em relação ao que é praticado no mundo, enquanto, no Brasil 45\% da matriz constitui-se de energias renováveis, a média mundial é de 14\% (CNI, 2007). Este cenário é devido a dois personagens: hidrelétricas e etanol, onde o Brasil é um dos pioneiros na produção (BCSD Portugal, 2008), respondendo por $\mathbf{4 0 \%}$ da produção mundial (CNI, 2007), conforme mostrado na figura 4.

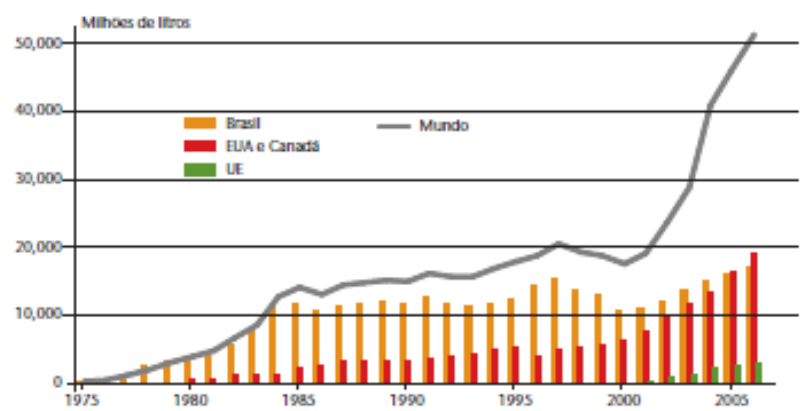

(a)

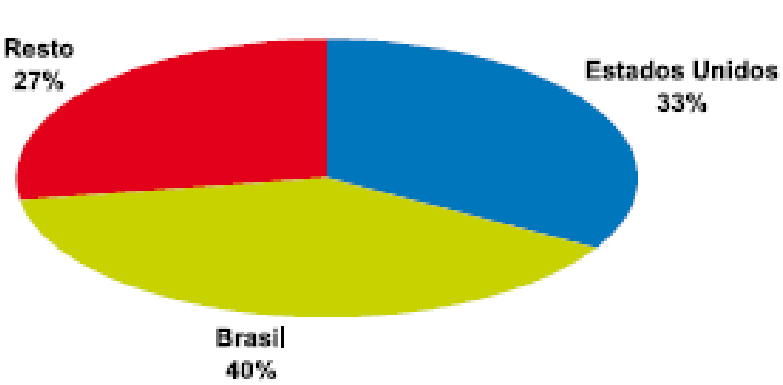

(b)

Figura 4. Produção de etanol (BCSD Portugal, 2008; CNI, 2007).

A tendência de substituição de combustíveis fósseis por energias renováveis, como biocombustíveis, é uma realidade mundial, acompanhada pelo Brasil, devido aos impactos ambientais, instabilidades geopolíticas e segurança do suprimento. A figura 5 mostra a projeção mundial onde o Brasil é um personagem em destaque (BCSD Portugal, 2008). 


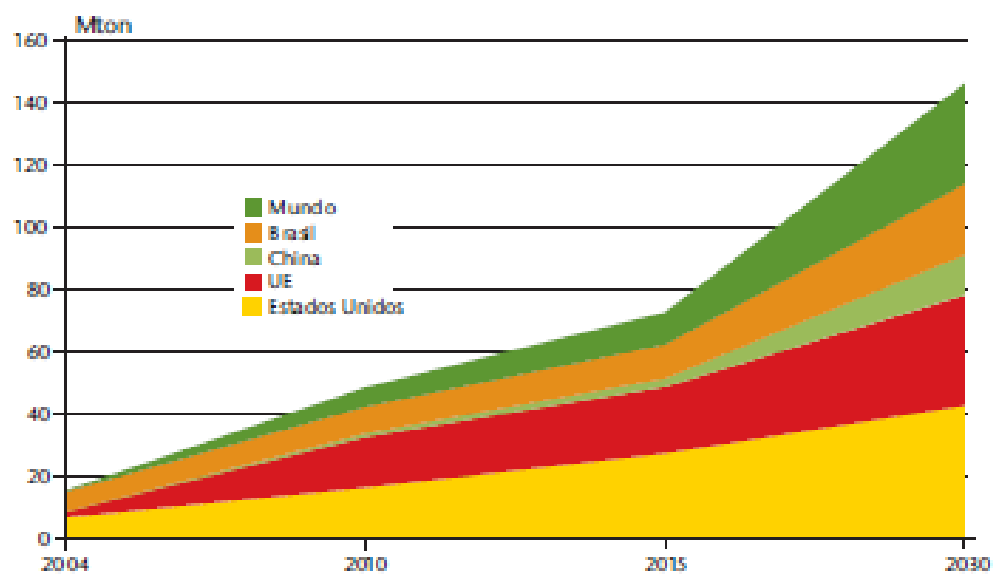

Figura 5. Projeção de consumo de biocombustíveis (BCSD Portugal, 2008).

Essa tendência brasileira de desenvolvimento energético, principalmente em biocombustíveis, foi primeiramente catalisada pelas políticas públicas pró-etanol, e mais recentemente por duas políticas públicas.

A primeira política pública é o "Programa Luz para todos", que o Governo Brasileiro lançou em novembro de 2003 com o desafio de acabar com a exclusão elétrica no país, tendo a meta de levar energia elétrica para mais de 10 milhões de pessoas do meio rural até o ano de 2008 (Programa Luz para Todos, 2011).

O Programa é coordenado pelo Ministério de Minas e Energia, operacionalizado pela Eletrobrás e executado pelas concessionárias de energia elétrica, e cooperativas de eletrificação rural (Programa Luz para Todos, 2011).

Para 0 atendimento da meta inicial, foram investidos $R \$ 12,7$ bilhões. $O$ Governo Federal destinará $R \$ 9,1$ bilhões e o restante será partilhado entre governos estaduais e as empresas de energia elétrica. Os recursos federais são provenientes de fundos setoriais de energia - a Conta de Desenvolvimento Energético (CDE) e a Reserva Global de Reversão (RGR) (Programa Luz para Todos, 2011).

O mapa da exclusão elétrica no país revela que as famílias sem acesso à energia estão majoritariamente nas localidades de menor Índice de Desenvolvimento Humano e nas famílias de baixa renda. Cerca de $90 \%$ destas famílias têm renda inferior a três salários-mínimos e $80 \%$ estão no meio rural (Programa Luz para Todos, 2011).

Por isso, o objetivo do governo é utilizar a energia como vetor de desenvolvimento social e econômico destas comunidades, contribuindo para a 
redução da pobreza e aumento da renda familiar. A chegada da energia elétrica facilitará a integração dos programas sociais do governo federal, além do acesso a serviços de saúde, educação, abastecimento de água e saneamento (Programa Luz para Todos, 2011).

Durante a execução do Programa, novas famílias sem energia elétrica em casa foram localizadas e, em função do surgimento de um grande número de demandas, o "LUZ PARA TODOS" foi prorrogado para ser concluído no ano de 2010 (Programa Luz para Todos, 2011).

Ressalta-se também que grande parte da energia elétrica no país advém de hidroelétricas, que é um sistema robusto, mas que apresenta fragilidades como as expostas nos "apagões" em 1999 e 2009. Neste contexto a diversificação da matriz energética brasileira é pertinente. $\mathrm{O}$ uso de um biocombustível derivado de fontes renováveis para cumprir tal objetivo é estrategicamente interessante.

A segunda política pública é o "Programa Nacional de Produção e Uso do Biodiesel', que é um programa interministerial do Governo Federal que objetiva a implementação de forma sustentável, tanto técnica, como economicamente, a produção e uso do Biodiesel, com enfoque na inclusão social e no desenvolvimento regional, via geração de emprego e renda (Programa Nacional de Produção e Uso do Biodiesel, 2011).

As principais diretrizes do Programa Nacional de Produção e Uso do Biodiesel:

- implantar um programa sustentável, promovendo inclusão social,

- garantir preços competitivos, qualidade e suprimento, e

- produzir o biodiesel a partir de diferentes fontes oleaginosas e em regiões diversas.

A Lei $n^{\circ}$ 11.097, de 13 de janeiro de 2005, estabelece a obrigatoriedade da adição de um percentual mínimo de biodiesel ao óleo diesel comercializado ao consumidor, em qualquer parte do território nacional. Esse percentual obrigatório será de $5 \%$ oito anos após a publicação da referida lei, havendo um percentual obrigatório intermediário de $2 \%$ três anos após a publicação da mesma (Programa Nacional de Produção e Uso do Biodiesel, 2011).

Neste contexto, visando usar a produção de energia como vetor de desenvolvimento e inclusão social, bem como atingir um modelo de produção descentralizada que atinja sítios distantes do território nacional, é importante e 
motivador propor outros paradigmas de desenvolvimento e inovação tecnológica na área energética.

Portanto, viabilizar a geração de biodiesel em pequenas quantidades, para gerar eletricidade e calor em sítios remotos através de células ou geradores de eletricidade alimentados por combustível, é possível com o advento da microtecnologia. Por exemplo, um gerador de eletricidade a diesel tem autonomia de 7 horas para um tanque de 12 litros, para uma potência de 3600 watts (Nardini, 2009). Uma produção de biodiesel de $12 \mathrm{l} / \mathrm{dia}$ ou $0,5 \mathrm{l} / \mathrm{h}$ ou ainda $8,3 \mathrm{ml} / \mathrm{min}$ fornecerá 7 horas de energia elétrica pelo gerador.

Logo, o histórico brasileiro e as políticas públicas mencionadas (Pousa, 2007) catalisam oportunidades para pesquisa, desenvolvimento e inovação no setor energético brasileiro, destacando o biodiesel que é a motivação deste trabalho.

\subsection{Convergência tecnológica}

O foco do trabalho será o desenvolvimento de um protótipo usando os conceitos da microtecnologia, aproveitando as vantagens já citadas dessa área do conhecimento para a intensificação do processo de produção de biodiesel (biocombustível).

Neste contexto, o tema proposto foi contextualizado dentro destas três áreas do conhecimento: Microtecnologia, Intensificação de Processos e Biocombustíveis. Observa-se uma clara convergência tecnológica entre essas áreas, permitindo propor um trabalho de inovação tecnológica na área energética brasileira, compatível com a contribuição esperada para o programa de doutorado.

\subsection{Objetivo}

O escopo deste trabalho é desenvolver um microrreator em tecnologia LTCC (Low Temperature Co-fired Ceramics - Cerâmica com baixa temperatura de sinterização) dedicado à produção de biodiesel. Tal dispositivo será composto por

- 01 micromisturador, e

- 01 módulo de tempo de residência. 
Esses dispositivos serão integrados num substrato implementado em tecnologia LTCC (Gongora-Rubio, 2001).

A principal ferramenta de desenvolvimento que será utilizada neste trabalho é a fluidodinâmica computacional (CFD), com foco na otimização da geometria do micromisturador, que é o principal componente do protótipo proposto.

\subsection{Organização da tese}

Esta tese esta organizada em 8 capítulos:

- Capítulo 1. Introdução: este capítulo tem por objetivo contextualizar o trabalho dentro da(s) grandes áreas de conhecimento ao qual ele pertence;

- Capítulo 2. Estado da arte: este capítulo tem por objetivo elencar as contribuições ao processo de produção de biodiesel, inclusive por via microtecnológica;

- Capítulo 3. Proposta: este capítulo tem por objetivo definir a proposta de tese, contribuindo com o estado da arte analisado no capítulo anterior;

- Capítulo 4. Micromisturador: este capítulo tem por objetivo definir e otimizar uma geometria para intensificação do processo de transferência de massa através de simulações numéricas;

- Capítulo 5. Módulo de tempo de residência: este capítulo tem por objetivo verificar a necessidade de um dispositivo para modular o tempo de residência e especificá-lo caso necessário;

- Capítulo 6. Microrreator: este capítulo tem por objetivo apresentar o projeto do microrreator.

- Capítulo 7. Revisão dos resultados: este capítulo tem por objetivo elencar os resultados obtidos ao longo do desenvolvimento da tese;

- Capítulo 8. Conclusões: este capítulo tem por objetivo identificar a contribuições geradas por este trabalho para o estado da arte já estabelecido.

- Capítulo 9. Trabalhos futuros: este capítulo tem por objetivo elencar os trabalhos futuros decorrentes deste desenvolvimento. 


\subsection{Referências}

\section{BCSD Portugal, Conselho Empresarial para o Desenvolvimento Sustentável.}

Biocombustíveis. 2008. Site: http://www.bcsdportugal.org. Acesso: 28/03/2011.

CNI, Confederação Nacional da Indústria. Matriz energética: cenários, oportunidades e desafios. Brasília, 2007. Site: http://www.cni.org.br/. Acesso: 28/03/2011.

Gongora-Rubio, Mario Ricardo, Santiago-Avilles, J. J., Sola-Laguna, L., EspinosaVallejos, P., "Overview of low temperature co-fired ceramics tape technology for mesosystem technology," Sensor and Actuators A, 2001, Vol. 89, p. 222-241.

Koide, A., Sasaki, Y., Yoshimura, Y., Miyake, R. and Terayama, T., "Micromachined Dispenser with High Flow Rate and High Resolution," Proceedings of MEMS'00, 13th IEEE International Workshop Micro Electromechanical System, Miyazaci, Japan, Jan. 23-27, 2000, pp. 424-428.

Lin, L., and Pisano, A. P., "Silicon-Processed Microneedles," IEEE Journal of Microelectromechanical Systems, Vol. 8, No. 1, 1999, pp. 78-84.

Liu, R. H., Stremler, M. A., Sharp, K. V., Olsen, M. G., Santiago, J. G., Adrian, R. J., Aref, H. and Beebe, D. J., "Passive Mixing in a Three-Dimensional Serpentine Microchannel," Journal of Microelectromechanical Systems, Vol. 9, No. 2, 2000, pp. 190-197.

Nardini

Elétrica.

Site:

http://www.nardinieletrica.com.br/detalhesProduto.php?prodld=446.

Acesso: 07/12/2009.

Nguyen, N.-T. and Wu, Z., "Micromixers-a review," Journal of Micromechanics and Microengineering, Vol. 15, No. 2, 2005, R1-R16.

Nguyen, N.-T., and Wereley, S. T., "Fundamentals and Applications of Microfluidics," Artech House, 2002, p. 1-10.

Pousa, Gabriella P.A.G., Santos, Andre' L.F., Suarez, Paulo A.Z., "History and policy of biodiesel in Brazil", Energy Policy, Vol. 35, 2007, pp. 5393-5398. 
Programa

Luz

Para

Todos.

Site:

http://luzparatodos.mme.gov.br/luzparatodos/Asp/o programa.asp.

Acesso:

28/03/2011.

Programa Nacional de Produção e Uso do Biodiesel. Site: http://www.biodiesel.gov.br/. Acesso: 28/03/2011

Stankiewicz, A., Moulijn, J. A., Re-Engineering the Chemical Processing Plant: Process Intensification. Marcel Dekker, Inc. 2004. Chapter 1.

Stroock, A. D., Dertinger, S. K. W., Ajdari, A., Mezic, I., Stone, H. A. and Whitesides, G. M., "Chaotic Mixer for Microchannels," Science, Vol. 295, 2002, pp. 647-651.

Yang, X., Yang, J. M., Tai, Y. C. and Ho, C. M., "Micromachined Membrane Particle Filters," Sensors and Actuators A, Vol. 73, 1999, pp. 184-191. 


\section{ESTADO DA ARTE}

2.1. Biodiesel

Biodiesel é um combustível biodegradável derivado de fontes renováveis, que pode ser produzido a partir de gorduras animais ou de óleos vegetais, existindo dezenas de espécies vegetais no Brasil que podem ser utilizadas, tais como mamona, dendê (palma), girassol, babaçu, amendoim, pinhão manso e soja, dentre outras (PNPB, 2004).

Os óleos vegetais e gorduras animais são compostos por um balanço de ácidos graxos (Karmakar, 2010), que por sua vez compõe a molécula chamada triglicerídeo. A tabela 1 mostra o balanço de ácidos graxos de diversos óleos, onde se observa que cada ácido graxo é composto por uma cadeia de carbonos ( $\boldsymbol{C}: \boldsymbol{Y}$ ). $\mathrm{O}$ valor $\boldsymbol{X}$ determina o número de carbonos da cadeia e o valor $\boldsymbol{Y}$ determina 0 número de duplas ligações $\boldsymbol{C}=\boldsymbol{C}$. Quando $Y$ é nulo (zero) o ácido graxo é saturado, ou seja, a cadeia de carbonos realiza o máximo de ligações com hidrogênios. Quando $Y>0$ (zero) o ácido graxo é insaturado.

Tabela 1. Balanço de ácidos graxos de diversos óleos.

\begin{tabular}{|l|c|c|c|c|c|}
\hline \multicolumn{1}{|c|}{ Ácidos Graxos } & Soja & Girassol & Palma & Amendoim & Oliva \\
\hline Butírico (C 4:0) & - & - & - & - & - \\
\hline Capróico (C 6:0) & - & - & - & - & - \\
\hline Caprílico (C 8:0) & - & - & - & - & - \\
\hline Cáprico (C 10:0) & - & - & - & - & - \\
\hline Láurico (C 12:0) & - & - & - & - & - \\
\hline Mirístico (C 14:0) & $<0,5$ & $<1,0$ & $0,5-2,0$ & - & $0,1-1,2$ \\
\hline Palmitico (C 16:0) & $7,0-11,0$ & $3,0-6,0$ & $32,0-45,0$ & $6,0-9,0$ & $7,0-16,0$ \\
\hline Esteárico (C 18:0) & $2,0-6.0$ & $1,0-3,0$ & $2,0-7,0$ & $3,0-6,0$ & $1,0-3,0$ \\
\hline Araquídico (C 20:0) & $<1,0$ & $0,6-4,0$ & - & $2,0-4,0$ & $0,1-1,3$ \\
\hline Lignocérico (C 24:0) & - & - & - & - & - \\
\hline Palmitoléico (C 16:1) & - & - & - & - & - \\
\hline Oléico (C 18:1) & $19,0-34,0$ & $14,0-35,0$ & $38,0-52,0$ & $52,0-60,0$ & $65,0-80,0$ \\
\hline Vacênico (C 18:1) & - & - & - & - & - \\
\hline Elaídico (C 18:1) & - & - & - & - & - \\
\hline Linoléico (C 18:2) & $43,0-56,0$ & $44,0-75,0$ & - & $13,0-27,0$ & $4,0-10,0$ \\
\hline Linolênico (C 18:3) & $5,0-11,0$ & $<1,5$ & $5,0-11,0$ & - & - \\
\hline Araquidônico (C 20:4) & - & - & - & - & - \\
\hline
\end{tabular}

Adaptada de Karmakar, 2010. 
O balanço de ácidos graxos presente em óleos vegetais e gorduras animais influencia diretamente na qualidade do combustível, pois cada cadeia carbônica tem o seu ponto de fulgor, ou seja, temperatura a partir da qual ocorre combustão. A tabela 2 apresenta o ponto de fulgor das diversas cadeias carbônicas presentes nos óleos vegetais e gorduras animais.

Tabela 2. Ponto de fulgor dos ácidos graxos.

\begin{tabular}{|l|c|}
\hline \multicolumn{1}{|c|}{ Ácidos Graxos } & Ponto de Fulgor $\left({ }^{\circ} \mathbf{C}\right)$ \\
\hline Butírico (C 4:0) & $-5,3$ \\
\hline Capróico (C 6:0) & $-3,2$ \\
\hline Caprílico (C 8:0) & 6,5 \\
\hline Cáprico (C 10:0) & 31,6 \\
\hline Láurico (C 12:0) & 44,8 \\
\hline Mirístico (C 14:0) & 54,4 \\
\hline Palmitico (C 16:0) & 62,9 \\
\hline Esteárico (C 18:0) & 70,1 \\
\hline Araquídico (C 20:0) & 76,1 \\
\hline Lignocérico (C 24:0) & 84,2 \\
\hline Palmitoléico (C 16:1) & 0,0 \\
\hline Oléico (C 18:1) & 16,3 \\
\hline Vacênico (C 18:1) & 39,5 \\
\hline Elaídico (C 18:1) & 44,0 \\
\hline Linoléico (C 18:2) & $-5,0$ \\
\hline Linolênico (C 18:3) & $-11,0$ \\
\hline Araquidônico (C 20:4) & $-49,5$ \\
\hline Adappada de Barerarelano
\end{tabular}

Adaptada de Barrera-Arellano, 2005.

O triglicerídeo é uma molécula de alto peso molecular composta pelos ácidos graxos (como já citado) e pelo glicerol. A figura 6 mostra um triglicerídeo formado por três ácidos graxos oléicos (cor azul) e o glicerol (cor vermelha). O triglicerídeo mostrado é formado por 60 carbonos, 110 hidrogênios e 6 oxigênios, $C_{60} H_{110} O_{6}$, ou seja, uma massa molar de $\mathbf{9 2 6} \mathbf{g}$. Além do triglicerídeo, existe uma porcentagem de ácidos graxos livres nos óleos vegetais e gorduras animais, ou seja, cadeias carbônicas livres do glicerol, formando diglicerídeos e monoglicerídeos. 


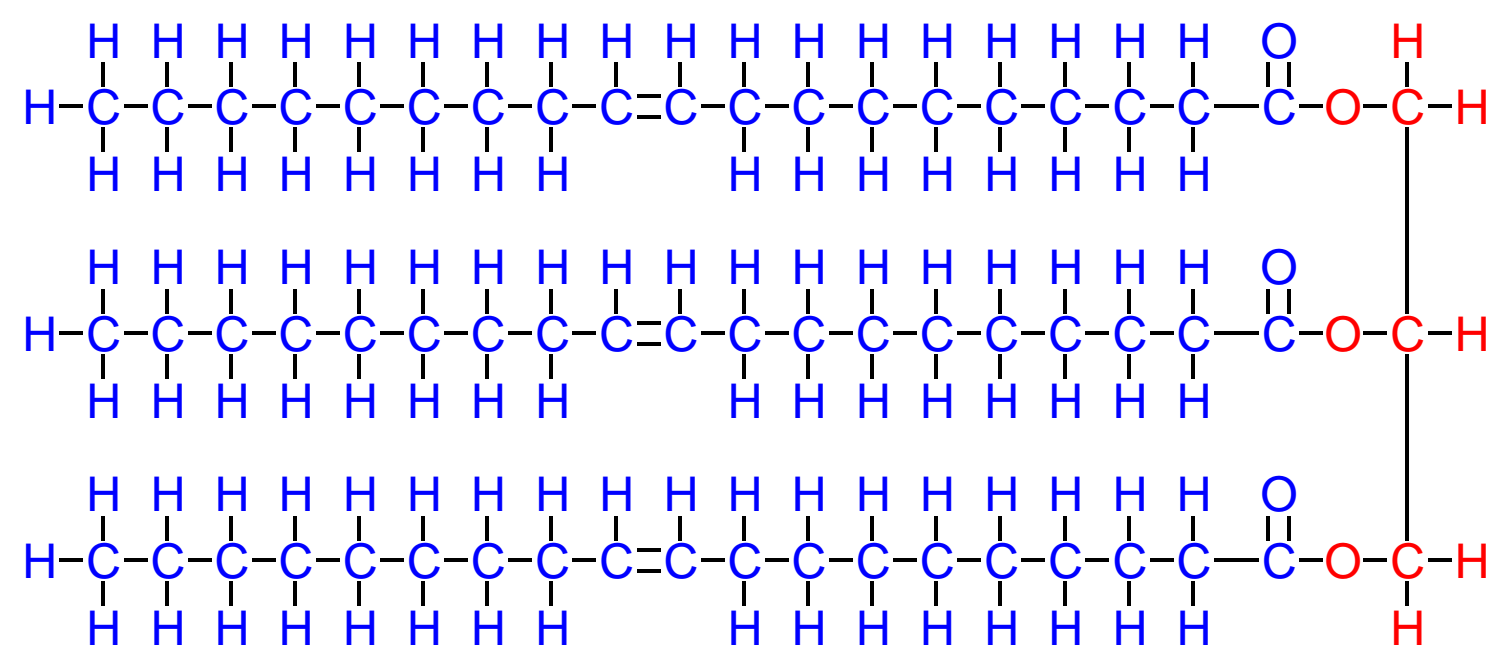

Figura 6. Triglicerídeo formado por ácidos graxos oléicos.

A produção de biodiesel consiste exatamente na quebra da ligação dos ácidos graxos separando-os do glicerol para formação dos ésteres. Existem diversas estratégias para a quebra dessa ligação, conduzindo a diversos processos tecnológicos.

Portanto, o biodiesel pode ser obtido por diferentes processos (Andrade, 2011), tais como

- o processo supercrítico (Tan, 2011),

- o craqueamento (Ma, 1999),

- a esterificação (Sharma, 2008), ou

- a transesterificação (Balat, 2010).

\subsubsection{Processo Supercrítico}

O processo envolvendo fluidos supercríticos, que vem sendo estudado por diversos autores (Madras, 2004; Wang, 2007; Lee, 2005, Balat, 2008; Demirbas, 2005; Demirbas, 2006; He, 2007; Vieitez, 2008, Demirbas, 2007), consiste em reagir álcool (metanol ou etanol) em condições supercríticas (figura 7(a)) com uma gordura animal ou óleo vegetal. Nestas condições, o álcool assume propriedades inerentes a líquidos e gases, por exemplo, densidade semelhante à de um líquido e mobilidade semelhante à de um gás, tornando este fluido mais reativo (figura $7(b)$ ) do que em condições não críticas. 


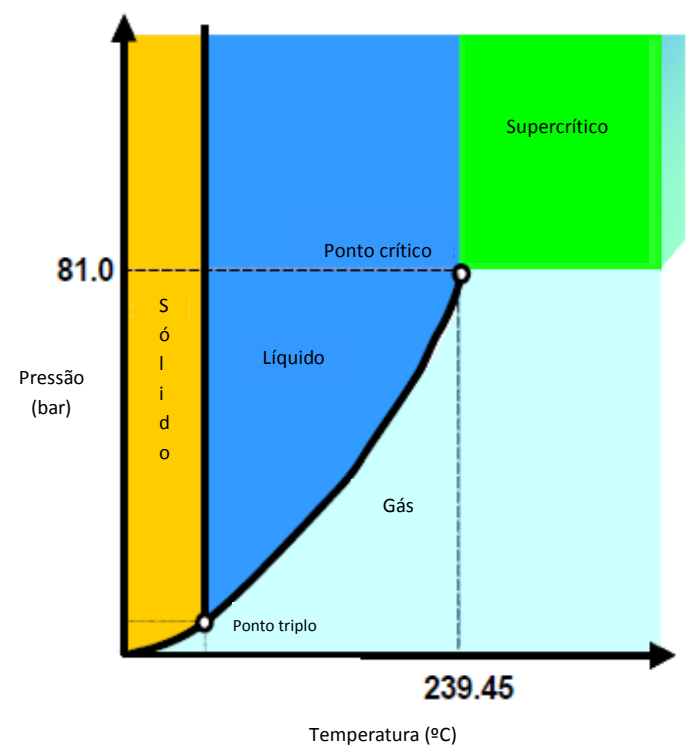

(a)

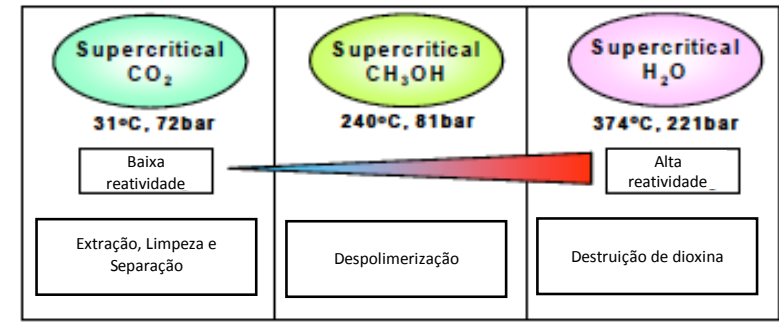

(b)

Figura 7. Fluidos Supercríticos: (a) diagrama pressão em função da temperatura do $\mathrm{CH}_{3} \mathrm{OH}$ e (b) características e aplicações destes fluidos (Lee, 2005).

\subsubsection{Craqueamento}

O craqueamento ou pirólise consiste na conversão do óleo vegetal em combustível através da decomposição térmica da molécula chamada triglicerídeo (Ma, 1999; Yusuf, 2011). Uma grande dificuldade deste processo está na grande variedade de produtos gerados termicamente, além das altas temperaturas usadas no processo. A tabela 3 mostra a seletividade dos produtos em função das temperaturas de craqueamento ou pirólise.

Tabela 3. Seletividade.

\begin{tabular}{|c|c|c|c|c|c|c|c|}
\hline & \multicolumn{7}{|c|}{ Seletividade (\% molar de átomos de carbono craqueados) } \\
\hline & $550^{\circ} \mathrm{C}$ & $600^{\circ} \mathrm{C}$ & $650^{\circ} \mathrm{C}$ & $700 \stackrel{\circ}{C}$ & $750^{\circ} \mathrm{C}$ & $800^{\circ} \mathrm{C}$ & $850^{\circ} \mathrm{C}$ \\
\hline $\mathrm{C}_{1}-\mathrm{C}_{4}$ & 10,0 & 18,6 & 28,2 & 38,7 & 35,1 & 45,1 & 66,1 \\
\hline $\mathrm{C}_{5}-\mathrm{C}_{9}$ & 36,0 & 19,6 & 17,6 & 13,2 & 17,5 & 12,6 & 3,6 \\
\hline aromáticos & 5,2 & 2,0 & 2,7 & 3,9 & 7,2 & 11,6 & 8,9 \\
\hline$C_{3: 1}-C_{8: 1}$ & 8,5 & 16,6 & 10,3 & 7,2 & 5,9 & 4,1 & 0,9 \\
\hline $\mathrm{C}_{9: 1}-\mathrm{C}_{16: 1}$ & 2,3 & 3,2 & 3,4 & 2,3 & 0,9 & 0,5 & 0,3 \\
\hline éster saturado & 2,0 & 1,2 & 1,6 & 2,4 & 3,7 & 3,1 & 2,6 \\
\hline $\mathrm{CO}$ & 0,5 & 1,2 & 1,3 & 2,3 & 2,7 & 3,8 & 5,3 \\
\hline outros produtos & 25,2 & 29,0 & 25,3 & 20,4 & 21,3 & 13,3 & 5,1 \\
\hline \multicolumn{8}{|c|}{ Seletividade (\% molar de átomos de hidrogênio craqueado) } \\
\hline $\mathrm{H}_{2}$ & 0,3 & 0,9 & 1,7 & 2,7 & 3,6 & 4,6 & 5,9 \\
\hline
\end{tabular}

Adaptada de Ma (1999). 


\subsubsection{Esterificação}

A esterificação (Kusdiana, 2001) consiste na reação química entre óleos vegetais ou gorduras animais com álcool (metanol) produzindo éster e água, conforme mostrado na equação 1

$$
\mathrm{R}-\mathrm{COOH}+\mathrm{CH}_{3} \mathrm{OH} \rightarrow \mathrm{R}-\mathrm{COOCH}_{3}+\mathrm{H}_{2} \mathrm{O}
$$

eq. 1.

A principal desvantagem desta reação é a presença de água, gerando a saponificação e também a retenção de água no combustível.

\subsubsection{Transesterificação}

A transesterificação, em particular, (Bournay, 2005; Zabeti, 2009; Helwani, 2009; Helwani, 2009; Ferella, 2010; Semwal, 2011; Cerro-Alarcón, 2010; Ellis, 2008; Silva, 2008; Patil, 2009; Mendow, 2011; Marchetti, 2007; Sharma, 2009; Dubé, 2007; Fukuda, 2001) é o processo mais explorado atualmente para a produção de biodiesel.

O processo consiste numa reação química dos óleos vegetais ou gorduras animais com o álcool (metanol ou etanol), estimulada por temperatura e por um catalisador. Com o objetivo de remover moléculas de glicerina, subproduto com aplicações diversas na indústria química, e, promover a formação de ésteres de baixa viscosidade, o biodiesel.

$\mathrm{Na}$ cadeia produtiva do biodiesel gera-se uma série de outros co-produtos (torta, farelo, etc.) que podem agregar valor e se constituir em outras fontes de renda importantes para os produtores (PNPB, 2004). A figura 8 mostra a reação química de obtenção do biodiesel.

Observa-se que a reação é realizada com uma molécula de triglicerídeo $\left(\mathrm{C}_{60} \mathrm{H}_{110} \mathrm{O}_{6}-926 \mathrm{~g}\right)$ para três moléculas de metanol $\left(\mathrm{CH}_{4} \mathrm{O}-32 \mathrm{~g}\right)$ gerando três ésteres metílicos $\left(\mathrm{C}_{20} \mathrm{H}_{38} \mathrm{O}_{2}-310 \mathrm{~g}\right)$ e uma glicerina $\left(\mathrm{C}_{3} \mathrm{H}_{8} \mathrm{O}_{6}-92 \mathrm{~g}\right)$. 


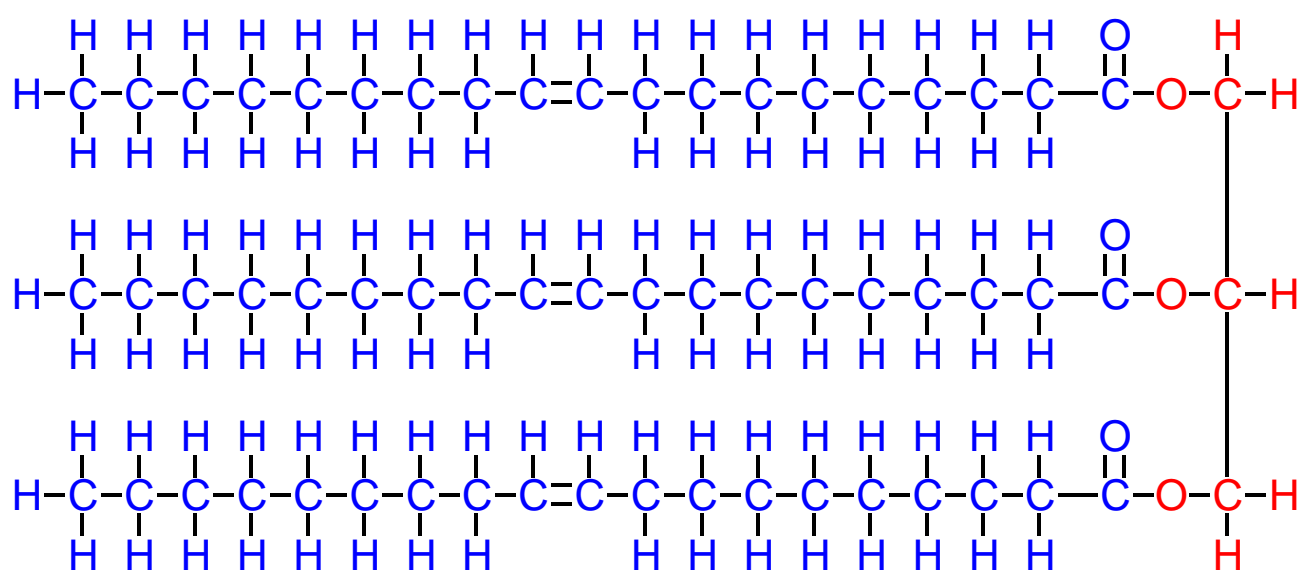<smiles>CO</smiles><smiles>CO</smiles><smiles>CO</smiles>

$<=>$

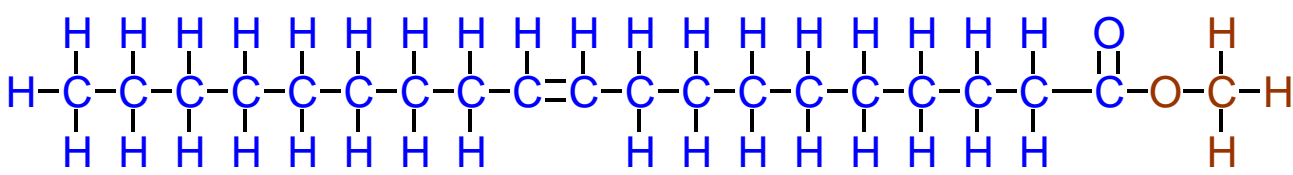
$\mathrm{H} \mathrm{H} \mathrm{H} \mathrm{H} \mathrm{H} \mathrm{H} \mathrm{H} \mathrm{H} \mathrm{H} \mathrm{H} \mathrm{H} \mathrm{H} \mathrm{H} \mathrm{H} \mathrm{O} \mathrm{H} \mathrm{H}$

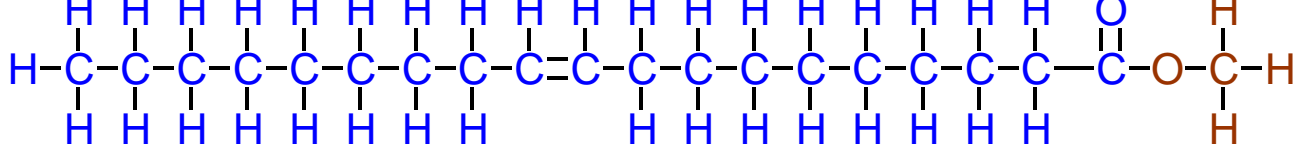
$\mathrm{H} \mathrm{H} \mathrm{H} \mathrm{H} \mathrm{H} \mathrm{H} \mathrm{H} \mathrm{H} \mathrm{H} \mathrm{H} \mathrm{H} \mathrm{H} \mathrm{H} \mathrm{H} \mathrm{O} \mathrm{H} \mathrm{H}$

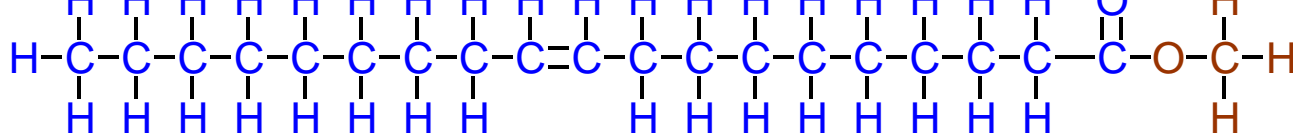<smiles>OCCO</smiles>

Figura 8. Reação química de produção do biodiesel pelo processo de transesterificação. 
A catálise básica na reação química de formação do biodiesel é realizada por um catalisador homogêneo usando hidróxidos ou alcóxidos de metais alcalinos, gerando os ésteres metílicos ou etílicos. A catálise também pode ser heterogênea usando elementos de mistura com compartimentos contendo o material catalisador ou com a superfície interna do elemento de mistura impregnada com o catalisador. A tabela 4 mostra os principais catalisadores usados nos trabalhos encontrados na literatura.

Tabela 4. Catalisadores encontrados na literatura.

\begin{tabular}{|c|c|c|}
\hline Trabalho & Catálise homogênea & Catálise heterogênea \\
\hline Bournay, 2005 & 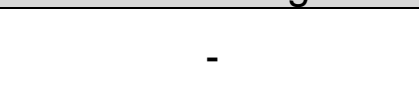 & $\begin{array}{c}\text { mistura de óxido de zinco } \\
\text { e alumínio }\end{array}$ \\
\hline Zabeti, 2009 & - & $\begin{array}{c}\text { óxido de cálcio } \\
\text { óxido de zinco } \\
\text { alumina }\end{array}$ \\
\hline Helwani, 2009 & - & óxido de cálcio \\
\hline Helwani, 2009 & $\begin{array}{l}\text { hidróxido de potássio } \\
\text { hidróxido de sódio }\end{array}$ & $\begin{array}{l}\text { sulfato de zorcônio } \\
\text { óxido de magnésio }\end{array}$ \\
\hline Ferella, 2010 & hidróxido de potássio & \\
\hline Semwal, 2011 & 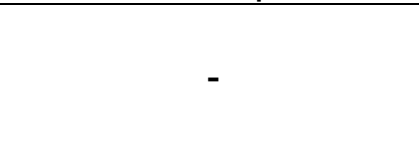 & $\begin{array}{c}\text { fosfato de vanádio } \\
\text { óxido de cálcio } \\
\text { alumina }\end{array}$ \\
\hline Ellis, 2008 & hidróxido de potássio & \\
\hline
\end{tabular}

Portanto, um enorme esforço é realizado no estudo de catalisadores para intensificar o processo de produção de biodiesel. Ojeda (2007) identificou as principais rotas de catálise, identificando as vantagens e desvantagens de cada processo, como mostrado na tabela 5.

Tabela 5. Rotas de catálise (Ojeda, 2007).

\begin{tabular}{|c|c|c|c|}
\hline Tecnologias & Vantagens & Desvantagens & $\begin{array}{c}\text { Características da } \\
\text { Tecnologia }\end{array}$ \\
\hline Catálise alcalina & $\begin{array}{l}\text { - Tecnologia mais } \\
\text { usada } \\
\text { comercialmente } \\
\text { - Condições } \\
\text { moderadas de } \\
\text { pressão e } \\
\text { temperatura } \\
\text { - Conversões com } \\
\text { tempos de reação } \\
\text { de } \\
\text { aproximadamente } \\
60 \text { minutos }\end{array}$ & $\begin{array}{l}\text { - Requer que o } \\
\text { álcool e óleo sejam } \\
\text { anidros para evitar } \\
\text { a saponificação }\end{array}$ & $\begin{array}{l}\text { - Quantidade } \\
\text { apreciável de } \\
\text { operações unitárias } \\
\text { para separação } \\
\text { dos produtos } \\
\text { - A reação realiza-se } \\
\text { em condições } \\
\text { atmosféricas } \\
\text { - Requer o uso de } \\
\text { catalisador alcalino }\end{array}$ \\
\hline
\end{tabular}




\begin{tabular}{|c|c|c|c|}
\hline Catálise ácida & $\begin{array}{l}\text { - Utiliza-se no ajuste } \\
\text { do óleo } \\
\text { (esterificação de } \\
\text { ácidos graxos livres } \\
\text { com metanol). } \\
\text { Capacidade de } \\
\text { processamento de } \\
\text { matérias primas } \\
\text { com altos níveis de } \\
\text { ácidos graxos livres } \\
\text { (gorduras animais } \\
\text { e óleos usados) }\end{array}$ & $\begin{array}{l}\text { - Os tempos de } \\
\text { reação são muito } \\
\text { mais lentos em } \\
\text { relação a catálise } \\
\text { alcalina }\end{array}$ & $\begin{array}{l}\text { - Utilizado como } \\
\text { processo de pré- } \\
\text { esterificação antes } \\
\text { de se realizar o } \\
\text { processo via } \\
\text { catálise alcalina } \\
\text { - Requer o uso de } \\
\text { catalisador ácido }\end{array}$ \\
\hline Catálise enzimática & $\begin{array}{l}\text { - A reação não é } \\
\text { afetada pela } \\
\text { presença de água } \\
\text { e ácidos graxos } \\
\text { livres nas matérias } \\
\text { primas }\end{array}$ & $\begin{array}{l}\text { - Os tempos de } \\
\text { reação são } \\
\text { elevados, por que } \\
\text { os processos de } \\
\text { obtenção do } \\
\text { biodiesel não } \\
\text { podem ser } \\
\text { contínuos }\end{array}$ & $\begin{array}{l}\text { - Utilizam-se } \\
\text { solventes } \\
\text { orgânicos como } \\
\text { meio de reação }\end{array}$ \\
\hline Álcool supercrítico & $\begin{array}{l}\text { - Baixos tempos de } \\
\text { reação } \\
\text { - Processamento de } \\
\text { matérias primas } \\
\text { com altos graus de } \\
\text { ácidos graxos livres } \\
\text { e água } \\
\text { - Não é necessária a } \\
\text { utilização de } \\
\text { catalisador }\end{array}$ & $\begin{array}{l}\text { - Altos custos devido } \\
\text { as condições de } \\
\text { trabalho da reação: } \\
\text { altas temperaturas } \\
\text { e altas pressões }\end{array}$ & $\begin{array}{l}\text { - Usam-se } \\
\text { temperaturas e } \\
\text { pressões elevadas }\end{array}$ \\
\hline
\end{tabular}

É interessante observar que na via supercrítica não é utilizado um catalisador. A reação é intensificada por um projeto específico da planta de produção que permite o trabalho com os fluidos em condição supercrítica. Em função, muitos trabalhos têm explorado o processo de transesterificação em condições supercríticas.

Nos processos com uso de catalisador o projeto da planta de produção também é importante. Dependendo do tipo de catálise um projeto específico de planta é concebido. A figura 9 (Helwani, 2009) mostra duas plantas em função do tipo de catálise: (a) catálise básica e (b) catálise ácida. 


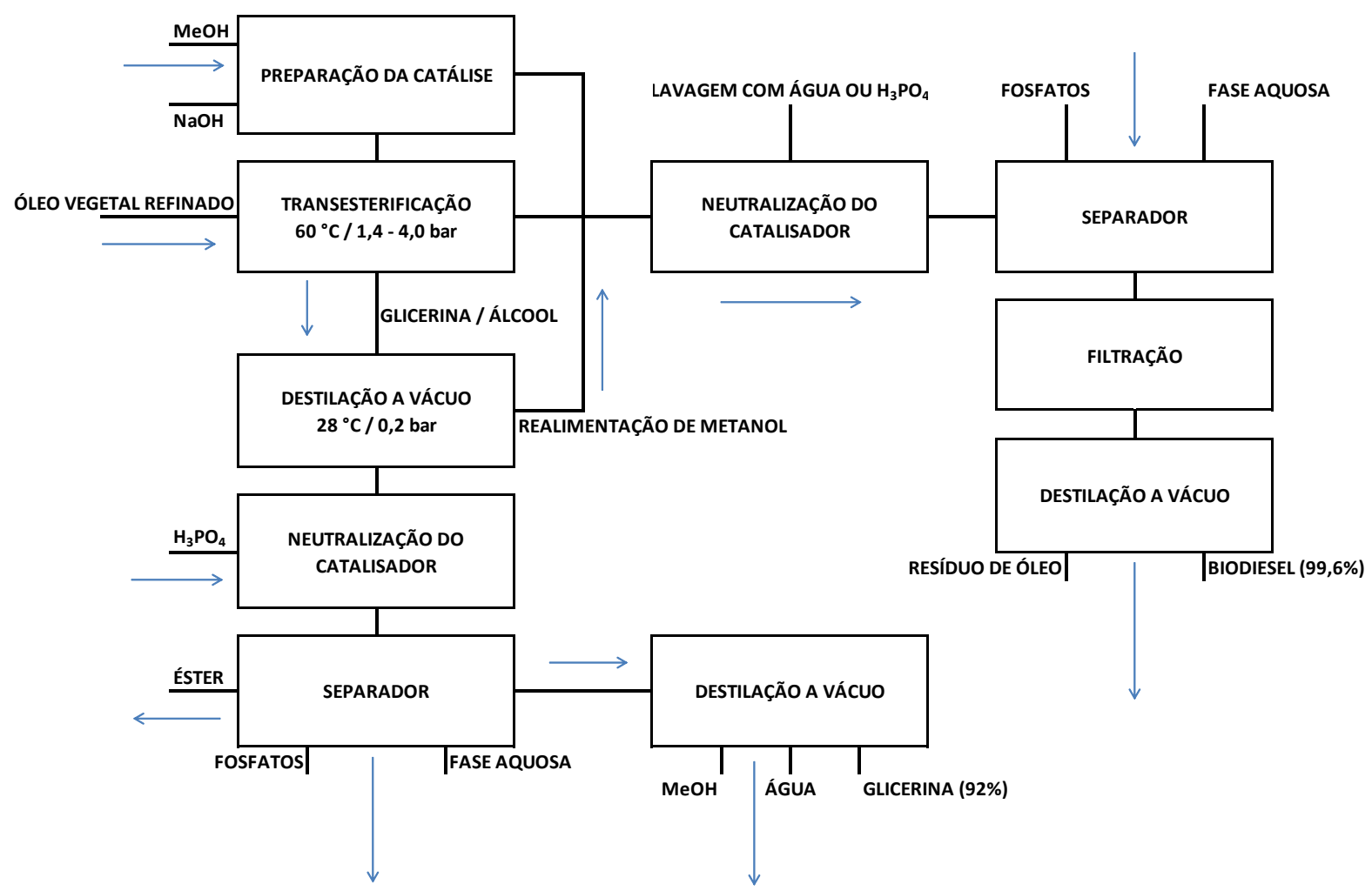

(a)

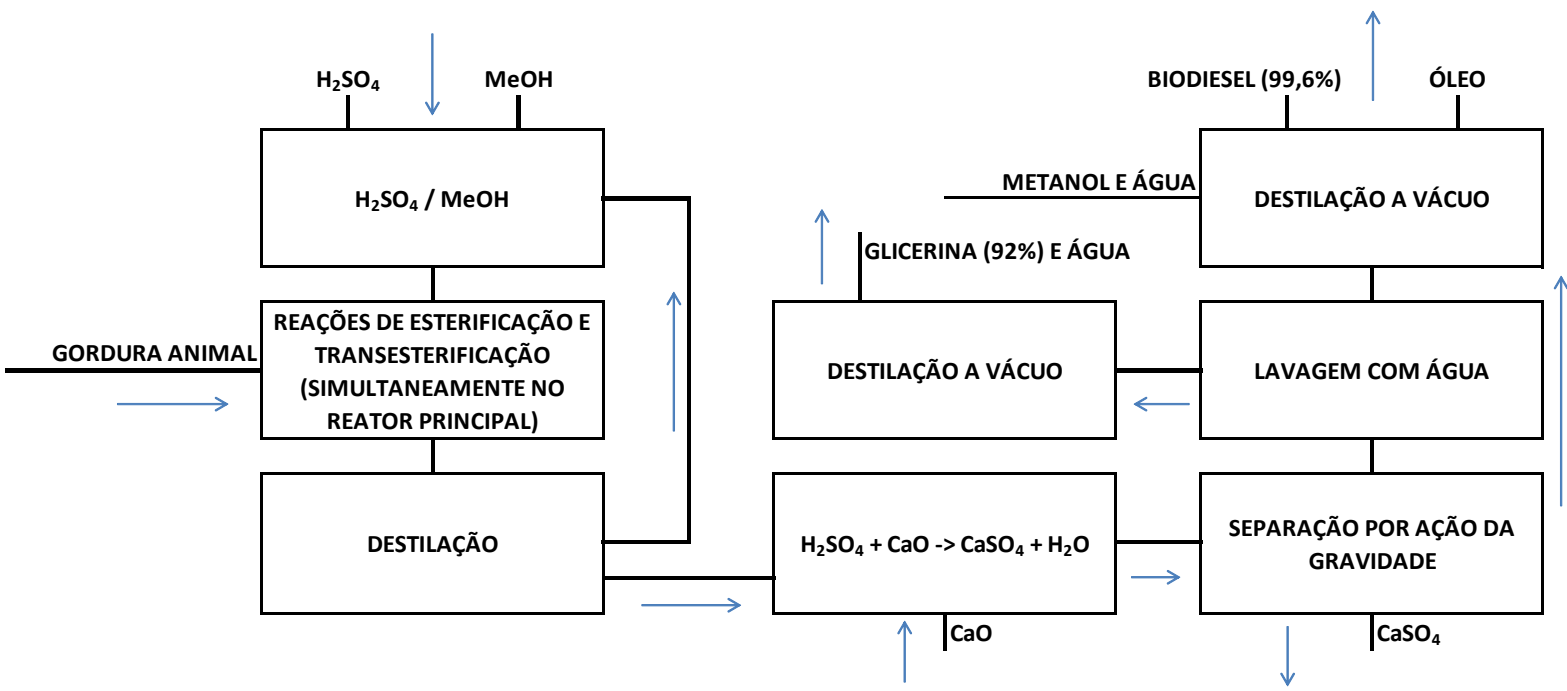

(b)

Figura 9. Diagrama de blocos do processo de produção de biodiesel com catálise (a) básica e (b) ácida. Adaptada de Helwani (2009).

Neste contexto, a uma melhor eficiência no processo de produção de biodiesel pode ser explorada por duas rotas. A primeira contempla o desenvolvimento de reatores inovadores e a segunda contempla o processo reacional com o ajuste de: melhor de temperatura de processo, melhor razão molar entre as fases e catalisadores eficientes. 


\subsubsection{Limitações}

Os processos mostrados (supercrítico, craqueamento, esterificação e transesterificação) têm explorado estas duas alternativas. No entanto, algumas limitações têm sido encontradas:

- $\quad$ p processo supercrítico opera em pressões e temperaturas elevadas;

- O processo de craqueamento gera uma série de outros produtos além dos ésteres;

- O processo de esterificação gera água, causando problemas de saponificação e de separação da água do biocombustível;

- $\quad$ O processo de transesterificação é o mais explorado na literatura, no entanto, apresenta longos tempos de processamento.

Tabela 6. Rotas de produção do biodiesel (Sharma, 2008).

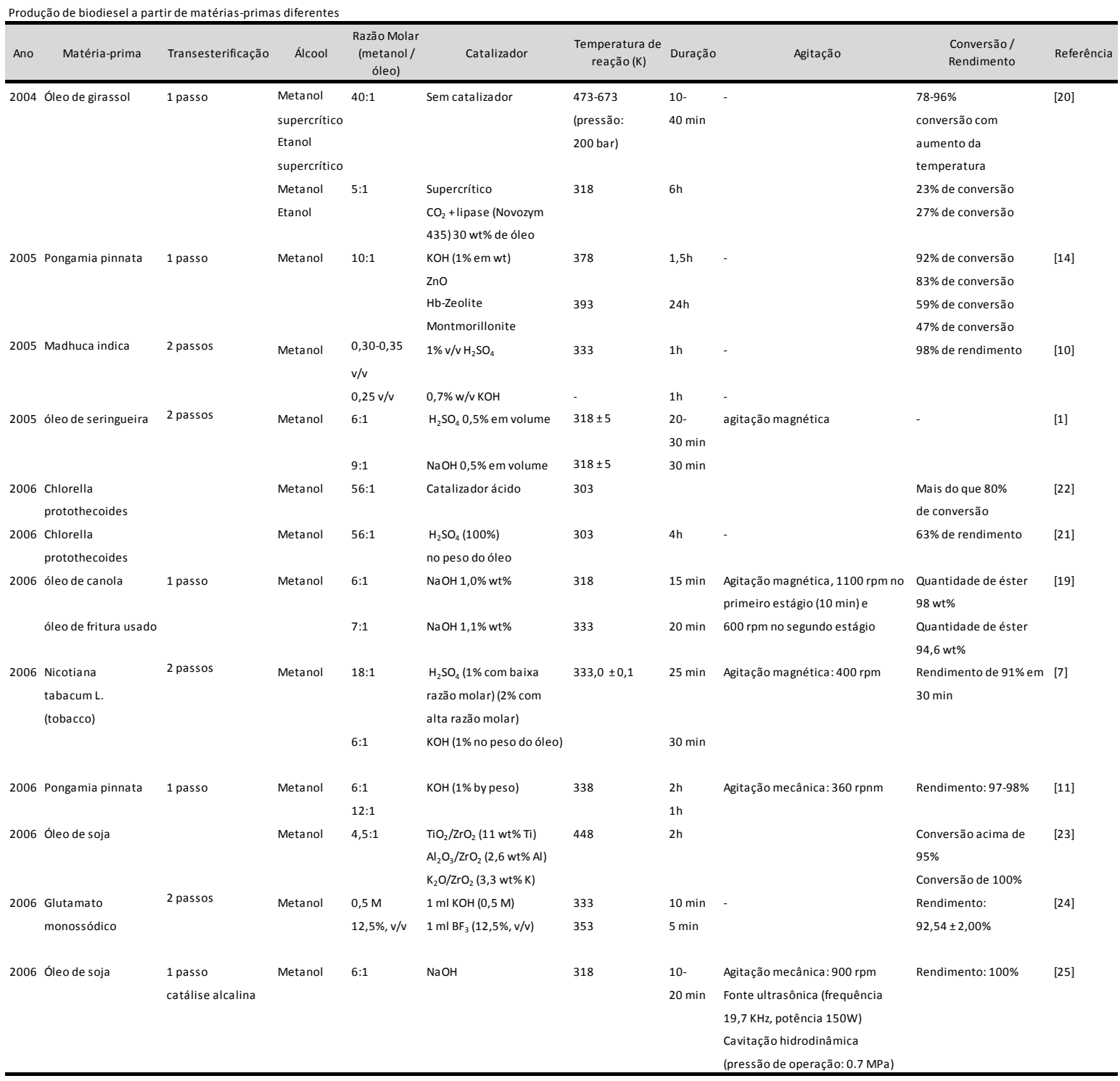


A tabela 6 mostra diversos trabalhos usando o processo de transesterificação, em função do tipo de óleo, tipo de álcool, razão molar, catálise, temperatura de reação e tempo de conversão.

\subsection{Biodiesel, Intensificação de Processo e Microtecnologia}

Recentemente, uma nova rota de produção de biocombustíveis (Shin, 2003) tem sido explorada com o advento da microtecnologia, gerando microssistemas ou módulos para diversos processos.
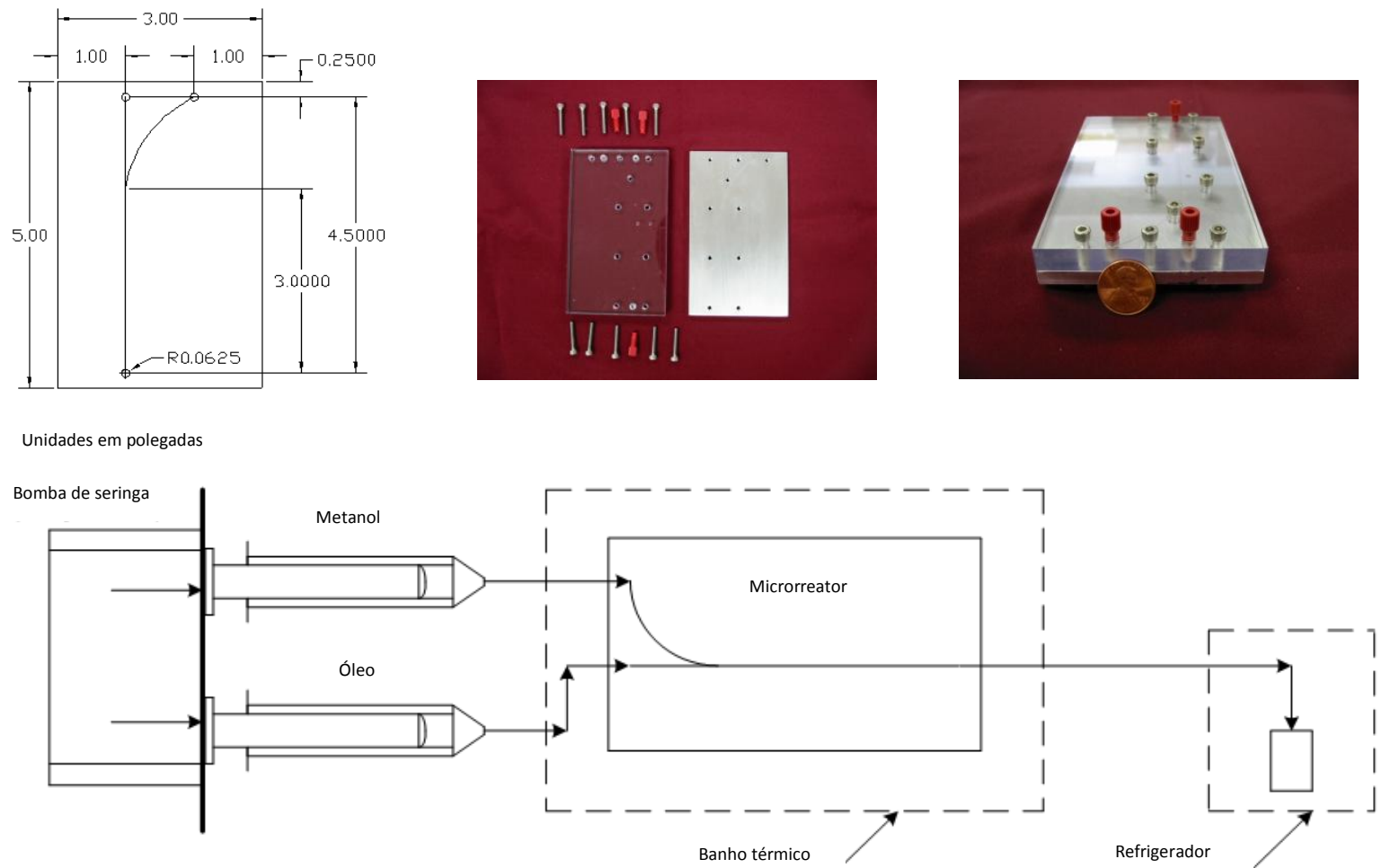

Figura 10. Microcanal reto e aparato experimental para produção de biodiesel (Carlisle, 2005).

Carlisle (2005) explorou a produção de Biodiesel usando um microcanal reto com seção transversal quadrada de $100 \mu \mathrm{m} \times 100 \mu \mathrm{m}$ e $7 \mathrm{~cm}$ de comprimento. A figura 10 mostra o microcanal e o aparato experimental utilizado nos ensaios. Os ensaios indicaram de 90 a $98 \%$ de conversão. No entanto, apresenta uma desvantagem que é a baixa produção devido à vazão do ensaio de $0,03 \mathrm{ml} / \mathrm{h}$ para cada reagente, ou seja, $0,06 \mathrm{ml} / \mathrm{h}$. O tempo de residência do ensaio foi de $45 \mathrm{~s}$. 
Sun (2008) também explorou microcanais retos para produção de biodiesel. Os canais utilizados foram de diâmetro hidráulico de $530 \mu \mathrm{m}$ e $250 \mu \mathrm{m}$ e comprimento de $30 \mathrm{~m}$. Os ensaios foram realizados com tempos de residência entre 3 e $20 \mathrm{~min}$, com vazões sempre menores que $1,1 \mathrm{ml} / \mathrm{min}$. A figura 11 mostra um dos resultados obtidos e a descrição do escoamento nos microcanais. O tempo de residência foi de $\sim 5,8$ min para uma conversão $>99 \%$.
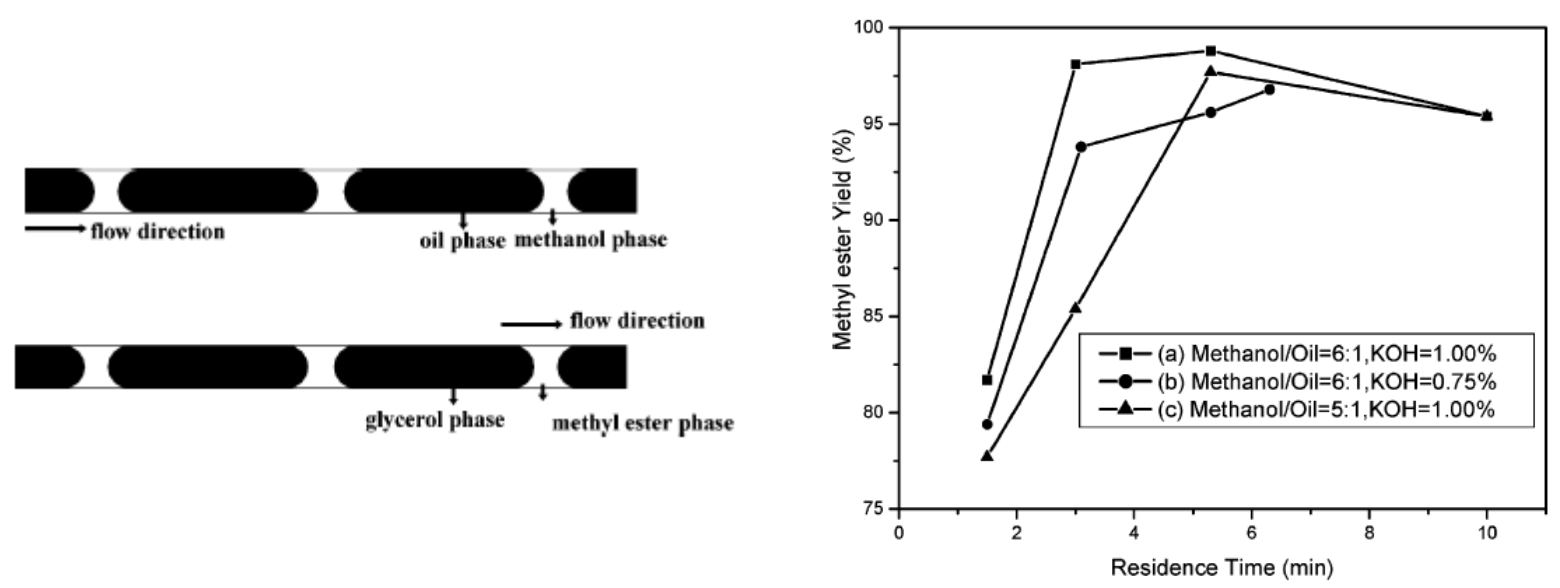

Figura 11. Descrição do escoamento nos microcanais retos e resultados de Sun (2008).

Wen (2009) explora em seu trabalho um microcanal com geometria ZigZag. A tabela 7 mostra os parâmetros geométricos utilizados na concepção dos dispositivos e o rendimento alcançado pelos vários dispositivos.

Todos os dispositivos apresentam comprimento de $1,07 \mathrm{~m}$, com diâmetro hidráulico variando entre $240 \mu \mathrm{m}$ e $900 \mu \mathrm{m}$. Considerando esse comprimento e um diâmetro hidráulico de $900 \mu \mathrm{m}$, tem-se um volume de $107 \mathrm{~cm} \times 0,09 \mathrm{~cm} \times 0,09 \mathrm{~cm}=$ $0,867 \mathrm{~cm}^{3}$. Com um tempo de residência de $28 \mathrm{~s}$, tem-se uma vazão de trabalho $0,031 \mathrm{~cm}^{3} / \mathrm{s}$ ou $1,86 \mathrm{ml} / \mathrm{min}$. 
Tabela 7. Parâmetros geométricos e desempenho dos dispositivos estudados (Wen, 2009).

\begin{tabular}{ccccc}
\hline Dispositivo & Seção $(\mu \mathrm{m} \times \mu \mathrm{m})$ & Dh $(\mu \mathrm{m})$ & Seções & Conversão $(\%)$ \\
\hline Zigzag-1 & $200 \times 300$ & 240 & 350 & 97,3 \\
Zigzag-2 & $300 \times 500$ & 375 & 350 & 91,3 \\
Zigzag-3 & $500 \times 500$ & 500 & 350 & 81,1 \\
Zigzag-4 & $500 \times 900$ & 643 & 350 & 80,9 \\
Zigzag-5 & $900 \times 900$ & 900 & 350 & 77,8 \\
Zigzag-6 & $500 \times 500$ & 500 & 10 & 60,0 \\
Zigzag-7 & $500 \times 500$ & 500 & 50 & 63,2 \\
Zigzag-8 & $500 \times 500$ & 500 & 100 & 70,2 \\
Zigzag-9 & $500 \times 500$ & 500 & 200 & 79,8 \\
\hline
\end{tabular}

Condições de reação: razão molar de óleo/metanol - 1:6, concentração de catalisador $-1 \%$, temperatura $60^{\circ} \mathrm{C}$ e tempo de residência $-28 \mathrm{~s}$.
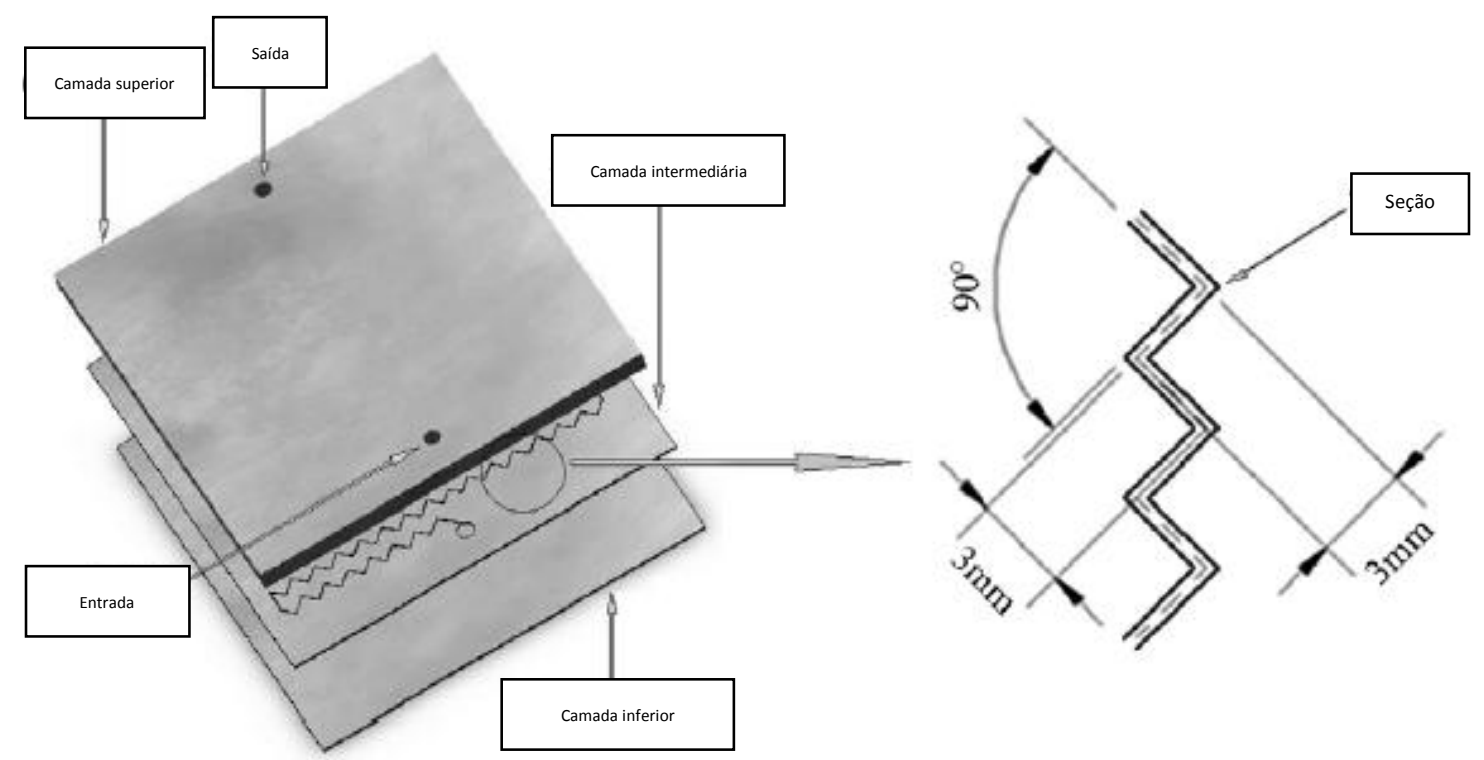

Figura 12. Desenho esquemático dos dispositivos estudados por Wen (2009).

Wen (2009) compara o rendimento da produção de biodiesel com a capacidade destes dispositivos gerarem emulsões, chegando à conclusão que quanto menor o 
diâmetro médio de gota melhor será a taxa de conversão alcançada. A figura 13 mostra as medida das emulsões geradas no trabalho de Wen (2009).
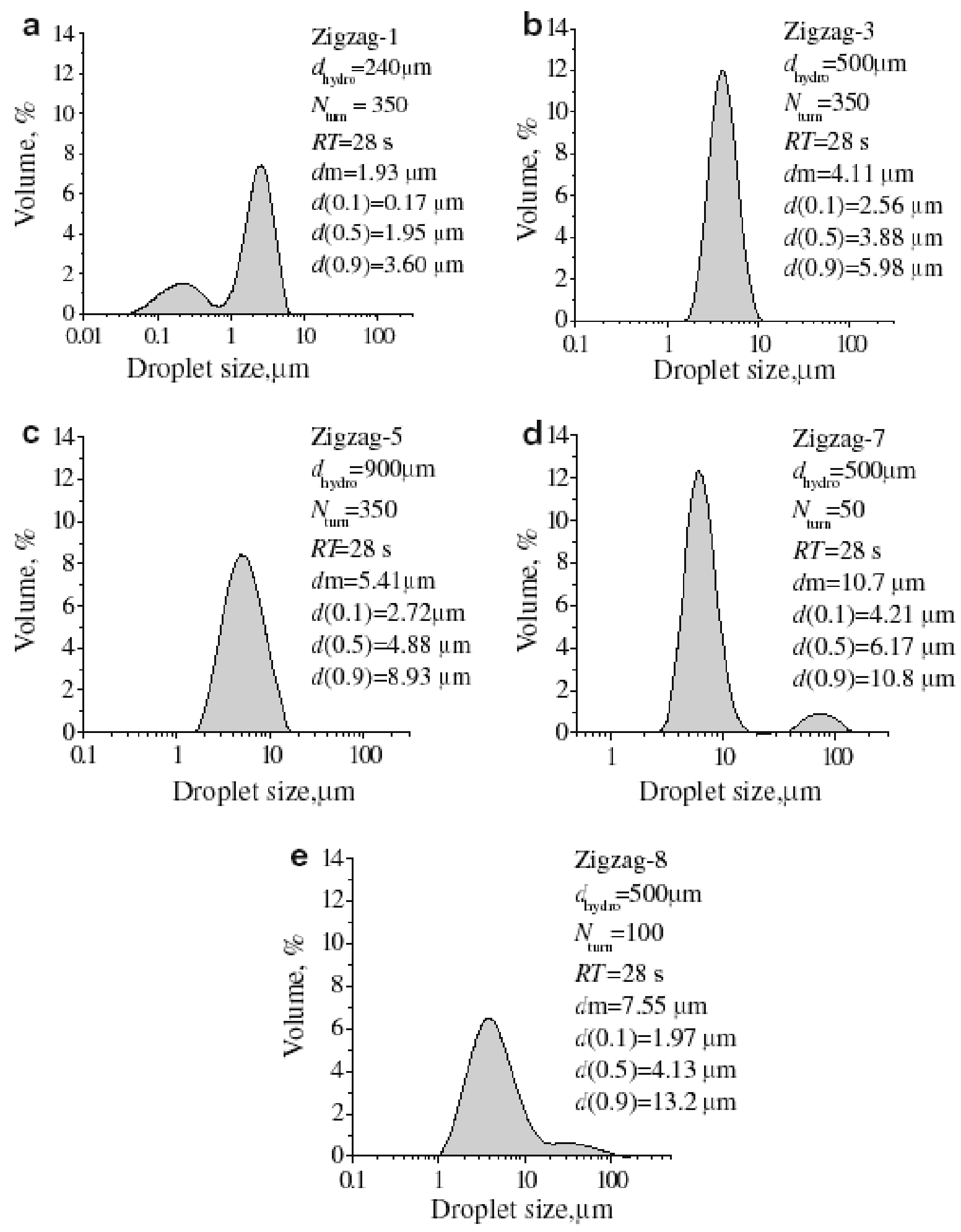

Figura 13 Resultados das emulsões geradas em Wen (2009).

Wen (2009) também compara a produção de biodiesel com dispositivos microtecnológicos com um método convencional. A figura 14 mostra que a rota 
microtecnológica apresenta vantagens em relação ao processo batelada, considerando os parâmetros: conversão, tempo de residência e energia consumida.

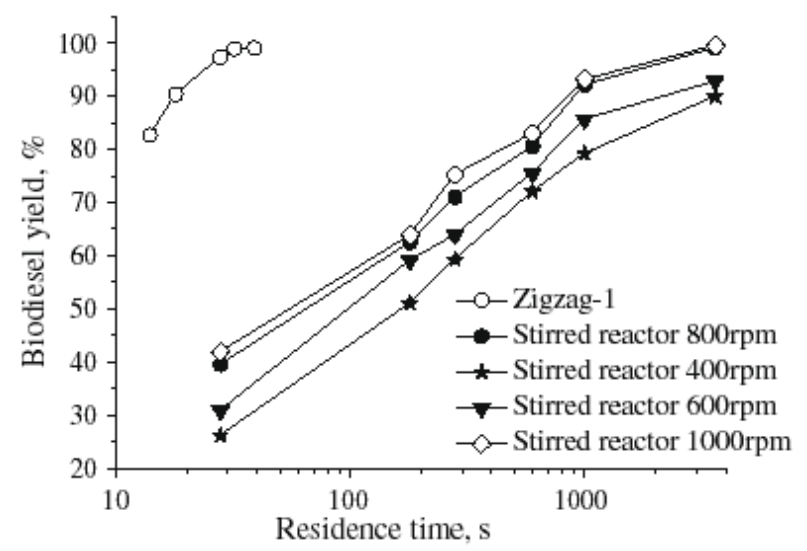

\begin{tabular}{|c|c|c|c|c|}
\hline Nome & Modo de Reação & Rendimento $^{a}(\%)$ & $P^{b}(W)$ & $\mathrm{Wg}^{\mathrm{c}}(\mathrm{J} / \mathrm{g})$ \\
\hline Zigzag- $1^{\text {d }}$ & contínuo & 97,3 & 0,175 & 54,5 \\
\hline reator batelada agitado ${ }^{\mathrm{e}}$ & batelada & 97,2 & 3,70 & 133,2 \\
\hline \multicolumn{5}{|c|}{${ }^{2}$ Condições de reação: razão molar de metanol/óleo 6 , catalizador $1 \%$ wt, temperatura $60^{\circ} \mathrm{C}$} \\
\hline \multicolumn{5}{|c|}{$\begin{array}{l}\text { ' P: potência consumida (W) medida usando sensor de pressão para o Zigzag-1 e sensor de torque } \\
\text { para o reator batelada agitado }\end{array}$} \\
\hline \multicolumn{5}{|c|}{$\begin{array}{l}\text { ' } W g \text { : energia consumida por grama de biodiesel em } 1 \mathrm{~h} \text { calculado por } \mathrm{Wg}=\mathrm{P} \times 3600 / \mathrm{m}, \mathrm{P} \text { : a potência } \\
\text { consumida (W), } \mathrm{m} \text { : a massa total de biodiesel produzido em } 1 \mathrm{~h}(\mathrm{~g})\end{array}$} \\
\hline \multicolumn{5}{|c|}{ d Vazão da mistura de óleo soja e metanol: $16,1 \mathrm{ml} / \mathrm{h}$, massa total de biodiesel obtido em $1 \mathrm{~h}: 11,6 \mathrm{~g}$} \\
\hline \multicolumn{5}{|c|}{ eVelocidade de agitação: $800 \mathrm{rpm}$, massa total de biodiesel obtido em $1 \mathrm{~h}: 100 \mathrm{~g}$} \\
\hline
\end{tabular}

Figura 14 Comparação do método convencional com a rota microtecnológica de produção de biodiesel (Wen, 2009).

Sun (2010) explorou diversos tipos de micromisturadores com um módulo de tempo de residência acoplado. A figura 15 mostra o esquema do aparato experimental bem como as geometrias dos micromisturadores comerciais testados.
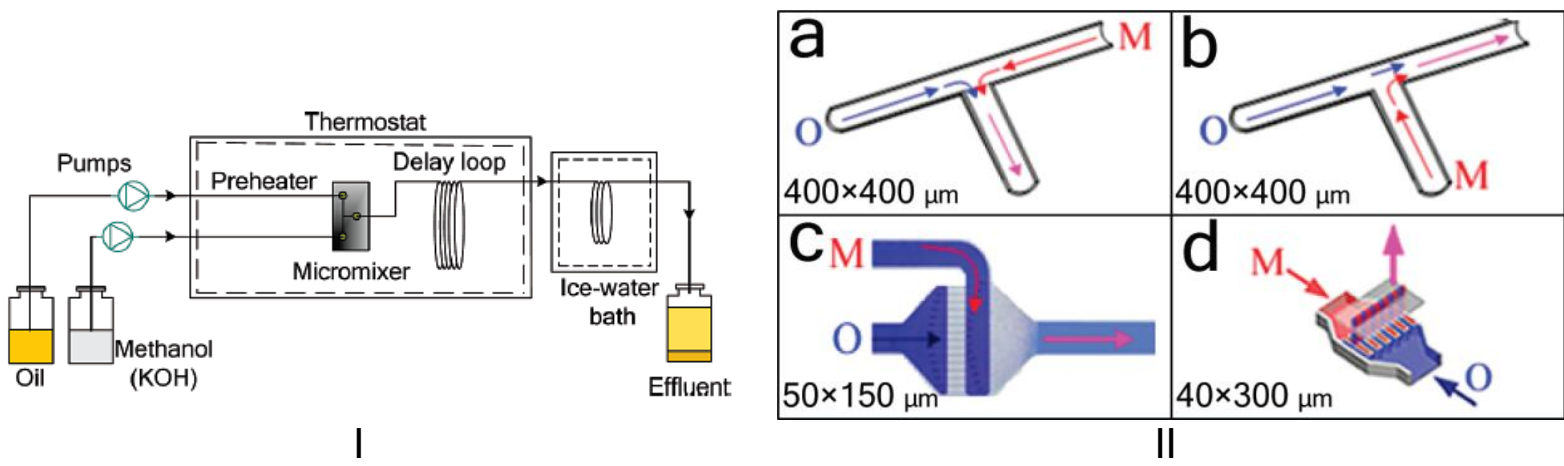

Figura 15. Produção de biodiesel em Sun (2010): (I) desenho esquemático do aparato experimental e (II) micromisturadores testados, a - misturador $\mathbf{T}, \mathbf{b}-$ misturador J, c - misturador RIMM e d - SIMM-V2.

A figura 16 mostra os resultados obtidos por Sun (2010): (I) conversão em função do tipo de micromisturador, (II) conversão em função da vazão para um módulo de tempo de residência específico e (III) visualização do escoamento.

Em I, os ensaios foram realizados com um módulo de tempo de residência de 2,5 $\mathrm{m}$ de canal reto, com tempo de residência ajustado para $44 \mathrm{~s}$. Observa-se claramente, que a conversão foi influenciada pelo tipo de micromisturador. 
Em II, o dispositivo RIMM foi escolhido para compor o sistema reacional junto com um módulo de tempo de residência comercial baseado em anéis de Dixon. $O$ tempo de residência foi variado em função da vazão. Para $t=17 \mathrm{~s}$, obteve-se uma conversão de 99,6\%, com uma diferença de pressão de 0,8 MPa.

Em III, é possível visualizar o escoamento para os 04 tipos de micromisturadores testados. Observa-se claramente, a formação de emulsões nestes microcanais, como também foi observado em Wen (2009).
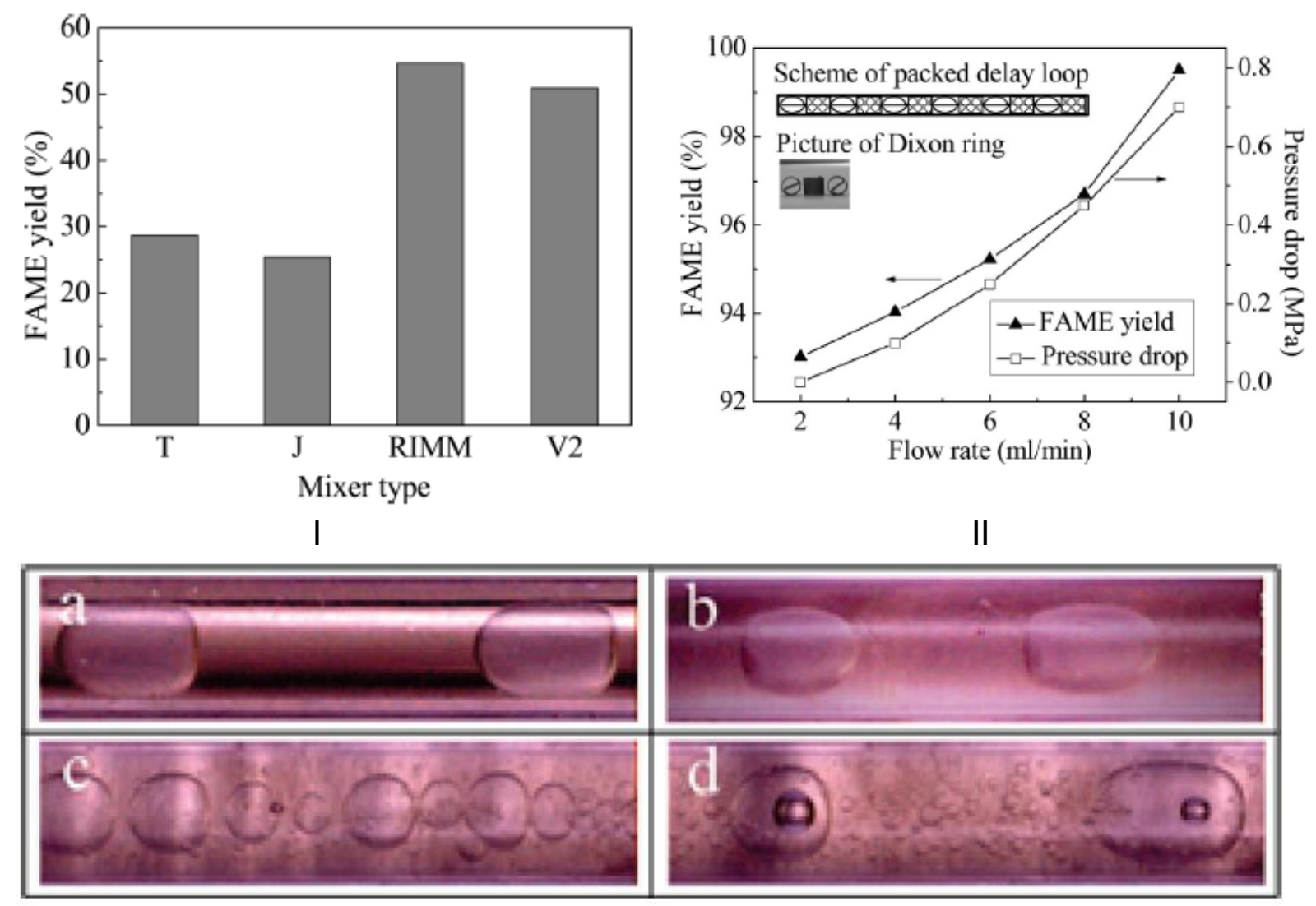

III

Figura 16. Resultados obtidos por Sun (2010): (I) conversão em função do tipo de micromisturador, (II) conversão em função da vazão para um módulo de tempo de residência específico e (III) visualização do escoamento.

As referências apresentadas para produção de biodiesel usando a rota microtecnológica (Carlisle, 2005; Sun, 2008; Wen, 2009; Sun, 2010), tiveram uma abordagem parecida em relação ao aparato experimental e parâmetros estudados.

Quanto ao aparato, usaram um banho térmico para controle de temperatura, e bombas de seringa para o controle da vazão. Não é mencionada nos trabalhos a 
integração de quaisquer tipos de outros microdispositivos para conceber um módulo que realize a reação com controle de temperatura e vazão.

Quanto aos parâmetros estudados, com exceção de Carlisle (2005), todos abordaram a temperatura de processo, a razão molar entre as fases, o tipo de misturador e os parâmetros dimensionais desses dispositivos, para obtenção de uma conversão ótima. No entanto, pouco se discutiu sobre a descrição do escoamento para obter parâmetros ótimos dos microdispositivos, faltando estabelecer assim uma regra de projeto ou uma metodologia de otimização desses microdispositivos.

\subsection{Conclusões preliminares}

Foram analisadas diversas referências contemplando processos convencionais e processos microtecnológicos.

Nos processos convencionais, a transesterificação é o mais abordado. O foco da discussão em muitas referências é em relação à eficiência do catalisador. Em função disto, uma alternativa também muito explorada é a via supercrítica, que suprime o uso do catalisador melhorando bastante o tempo de processamento para $\sim 5$ min, enquanto que, com o uso de catalisador encontra-se nos diversos trabalhos tempos desde 10 min até algumas horas.

Em geral, foram detectadas algumas limitações nos processos convencionais, tais como: geração de produtos indesejáveis; alto consumo de energia; longos tempos de processamento; saponificação e separação da água do biocombustível.

Para superar as limitações dos processos convencionais, alguns autores têm explorado a via microtecnológica. A produção de biodiesel usando micromisturadores é viável e tem sido explorada com sucesso, conforme visto em Carlisle (2005), Sun (2008), Wen (2009) e Sun (2010).

A tabela 8 mostra os trabalhos de produção de biodiesel usando a via microtecnológica em comparação com processo batelada. Observa-se que a escala de tempo de residência nesses trabalhos varia de $17 \mathrm{~s}$ a 5,8 min. Por outro lado, no 
processo batelada o tempo de residência é de $\sim 90 \mathrm{~min}$. A escala de comprimento varia de $40 \mathrm{~cm}$ a $30 \mathrm{~m}$.

Apesar do sucesso na produção do biodiesel, com a exploração de parâmetros de interesse como temperatura de processo, razão molar entre as fases reagentes, concentração do catalisador, ainda não se tem uma metodologia de otimização de micromisturadores para este tipo de reação.

Tabela 8. Produção de biodiesel por via microtecnológica.

\begin{tabular}{|c|c|c|c|c|c|c|}
\hline Trabalhos & $\begin{array}{c}\text { Tipo de } \\
\text { misturador }\end{array}$ & $\mathrm{D}_{\mathrm{h}}$ & Seções & Comprimento & $\begin{array}{c}\text { Módulo de } \\
\text { tempo de } \\
\text { residência }\end{array}$ & $\begin{array}{c}\text { Tempo de } \\
\text { residência }\end{array}$ \\
\hline $\begin{array}{c}\text { *Nouredini } \\
(1997)\end{array}$ & $\begin{array}{c}\text { Reator } \\
\text { batelada }\end{array}$ & - & - & - & - & $\sim 90 \mathrm{~min}$ \\
\hline $\begin{array}{c}\text { Carlisle } \\
(2005)\end{array}$ & $\begin{array}{c}\text { Microcanal } \\
\text { reto }\end{array}$ & $\begin{array}{c}100 \\
\mu \mathrm{m}\end{array}$ & - & $7 \mathrm{~cm}$ & - & $45 \mathrm{~s}$ \\
\hline $\begin{array}{c}\text { Sun } \\
(2008)\end{array}$ & $\begin{array}{c}\text { Microcanal } \\
\text { reto }\end{array}$ & $\begin{array}{c}250 \\
\mu \mathrm{m}\end{array}$ & - & $30 \mathrm{~m}$ & - & $5,8 \mathrm{~min}$ \\
\hline $\begin{array}{c}\text { Wen } \\
(2009)\end{array}$ & $\begin{array}{c}\text { Microcanal } \\
\text { zigzag }\end{array}$ & $\begin{array}{c}240 \\
\mu \mathrm{m}\end{array}$ & 350 & $\sim 1 \mathrm{~m}$ & - & $28 \mathrm{~s}$ \\
\hline $\begin{array}{c}\text { Sun } \\
(2010)\end{array}$ & Diversos & $\begin{array}{c}250 \\
\mu \mathrm{m}\end{array}$ & - & - & $40 \mathrm{~cm}$ & $17 \mathrm{~s}$ \\
\hline
\end{tabular}

*processo convencional

Nos trabalhos pode-se visualizar a formação de emulsões nos microcanais. Este processo sugere que a reação está sendo controlada pela interface de contato da distribuição de gotas de álcool e o meio oleoso. A variação na escala de tempo em função do micromisturador (tabela 8), sugere que há espaço para a escolha e a otimização de uma geometria de micromisturadores mais adequada para o processo buscando otimizar o contato entre as fases.

A análise do estado da arte indica que o desenvolvimento de um módulo integrado para produção de biodiesel com suas funções, mistura, tempo de residência, controle de temperatura, controle de vazão, bem como a otimização de uma geometria para intensificar a superfície de contato entre as fases, é uma lacuna encontrada na literatura.

Portanto, o objetivo e a estratégia do trabalho serão alinhados com essa lacuna existente para propor uma contribuição ao estado da arte. Sendo assim uma proposta adequada para o programa de doutorado. 


\subsection{Referências}

Andrade, J.E., Pérez, A., Sebastian, P.J., e Eapen, D., "A review of bio-diesel production processes", Biomass and bioenergy, Vol. 35, 2011, pp. 1008 e 1020.

Balat, M., "Biodiesel Fuel Production from Vegetable Oils via Supercritical Ethanol Transesterification", Energy Sources, Part A: Recovery, Utilization, and Environmental Effects, Vol. 30:5, 2008, pp. $429-440$.

Balat, Mustafa e Balat, Havva, "Progress in biodiesel processing", Applied Energy, Vol. 87, 2010, pp. 1815-1835.

Barrera-Arellano, Daniel. "Química de Óleos e Gorduras", Short Course on Edible Oil Processing, Campinas, Brasil, 2005.

Bournay, L.; Casanave, D.; Delfort, B.; Hillion, G. e Chodorge, J.A. "New heterogeneous process for biodiesel production: A way to improve the quality and the value of the crude glycerin produced by biodiesel plants", Catalysis Today, 2005, Vol. 106, pp. 190-192.

Carlisle, Trevor, Kurt Spies, Sara York. Production of Biodiesel using a Microreactor. Technical Notes, Oregon University, 2005.

Cerro-Alarcón, Miriam; Corma, Avelino; Iborra, Sara; Martínez, Cristina; Sabater, María José. "Methanolysis of sunflower oil using gem-diamines as active organocatalysts for biodiesel production", Applied Catalysis A: General, 2010, Vol. 382, pp. $36-42$.

Demirbas, Ayhan, "Biodiesel from sunflower oil in supercritical methanol with calcium oxide", Energy Conversion and Management, Vol. 48, 2007, pp. 937-941.

Demirbas, Ayhan, "Biodiesel production from vegetable oils via catalytic and noncatalytic supercritical methanol transesterification methods", Progress in Energy and Combustion Science, Vol. 31, 2005, pp. 466-487. 
Demirbas, Ayhan, "Biodiesel production via non-catalytic SCF method and biodiesel fuel characteristics", Energy Conversion and Management, Vol. 47, 2006, pp. $2271-$ 2282.

Dubé, M.A.; Tremblay, A.Y.; Liu, J. "Biodiesel production using a membrane reactor", Bioresource Technology, 2007, Vol. 98, pp. $639-647$.

Ellis, Naoko; Guan, Feng; Chen, Tim; Poon, Conrad. "Monitoring biodiesel production (transesterification) using in situ viscometer", Chemical Engineering Journal, 2008, Vol. 138, pp. $200-206$.

Ferella, F.; Di Celso, G. Mazziotti; De Michelis, I.; Stanisci, V. e Vegliò, F. "Optimization of the transesterification reaction in biodiesel production", Fuel, 2010, Vol. 89, pp. $36-42$.

Fukuda, Hideki; Kondo, Akihiko; Noda, Hideo. "Biodiesel Fuel Production by Transesterification of Oils", Journal of Bioscience and Bioengineering, 2001, Vol. 92, no 5 , pp. $405-416$.

He, Huayang; Wang, Tao e Zhu, Shenlin, "Continuous production of biodiesel fuel from vegetable oil using supercritical methanol process", Fuel, Vol. 86, 2007, pp. 442-447.

Helwani, Z.; Othman, M.R.; Aziz, N.; Fernando, W.J.N. e Kim, J. "Technologies for production of biodiesel focusing on green catalytic techniques: A review", Fuel Processing Technology, 2009, Vol. 90, pp. $1502-1514$.

Helwani, Z.; Othman, M.R.; Aziz, N.; Kim, J. e Fernando, W.J.N. "Solid heterogeneous catalysts for transesterification of triglycerides with methanol: $A$ review", Applied Catalysis A: General, 2009, Vol. 363, pp. 1 - 10.

Karmakar, Aninidita; Karmakar, Subrata e Mukherjee, Souti. "Properties of various plants and animals feedstocks for biodiesel production", Bioresource Technology, 2010, Vol. 101, pp. $7201-7210$. 
Kusdiana, Dadan e Saka, Shiro. "Methyl Esterification of free fatty acids of Rapeseed Oil as Treated in Supercritical Methanol", Journal of Chemical Engeneering of Japan, 2001, Vol. 34, № 3, pp. $383-387$.

Lee, Youn-Woo; Song, Eun-Seok, e Kim, Hwayong, "Synthesis of Biodiesel Using Supercritical Fluid”, CLEAN TECHNOLOGY, December 2005, Vol. 11(4), pp. 171179.

Ma, Fangrui e Hanna, Milford A., "Biodiesel production: a review", Bioresource Technology, Vol. 70, 1999, pp. 1-15.

Madras, Giridhar, Kolluru, Chandana, e Kumar, Rajnish, "Synthesis of biodiesel in supercritical fluids", Fuel, Vol. 83, 2004, pp. 2029-2033.

Marchetti, J.M.; Miguel, V.U.; Errazu, A.F. "Possible methods for biodiesel production", Renewable and Sustainable Energy Reviews, 2007, Vol. 11, pp. 1300 1311.

Mendow, G.; Monella, F.C.; Pisarello, M.L.; Querini, C.A. "Biodiesel production from non-degummed vegetable oils: Phosphorus balance throughout the process", Fuel Processing Technology, 2011, Vol. 92, pp. $864-870$.

Noureddini, H., D. Zhu. Kinetics of Transesterification of Soybean Oil. JAOCS, Vol. 74, n. 11, 1997.

Ojeda, Yesid. Panorama de las Tecnologías para la produccíon de biodiesel. Seminario Taller, Biocombustibles, Biodiesel - Bioetanol, 2007, Colciencias, Colombia.

Patil, Prafulla D.; Deng, Shuguang. "Optimization of biodiesel production from edible and non-edible vegetable oils", Fuel, 2009, Vol. 88, pp. 1302 - 1306.

Programa Nacional de Produção e Uso do Biodiesel (PNPB). "Biodiesel. O Novo Combustível do Brasil“. 2004. Site: http://www.biodiesel.gov.br/docs/cartilha.pdf. Acesso: 01/05/2011. 
Semwal, Surbhi; Arora, Ajay K.; Badoni, Rajendra P. e Tuli, Deepak K. "Biodiesel production using heterogeneous catalysts", Bioresource Technology, 2011, Vol. 102, pp. $2151-2161$.

Sharma, Y.C., Singh, B., Upadhyay, S.N., "Advancements in development and characterization of biodiesel: A review", Fuel, Vol. 87, 2008, pp. 2355-2373.

Sharma, Y.C.; Singh, B. "Development of biodiesel: Current scenario", Renewable and Sustainable Energy Reviews, 2009, Vol. 13, pp. 1646 - 1651.

Shin, Y., Kim, O., Hong, J. C., Oh, J. H., Kim, W. J., Haam, S. and Chung, C. H., "The development of micro-fuel processor using low temperature co-fired ceramic (LTCC)," International Journal of Hydrogen Energy, 2006,Vol. 31, № 13, pg. 1925 1933.

Silva, Nívea de Lima da; Rivera, Elmer Ccopa; Batistella, César Benedito; Lima, Danilo Ribeiro de; Maciel Filho, Rubens; Maciel, Maria Regina Wolf. "Biodiesel production from vegetable oils: Operational strategies for large scale systems", 2008, 18th European Symposium on Computer Aided Process Engineering - ESCAPE 18, pp. $1101-1106$.

Sun, Juan, Jingxi Ju, Lei Ji, Lixiong Zhang, Nanping Xu. Synthesis of Biodiesel in Capillary Microreactors. Ind. Eng. Chem. Res. 2008, 47, 1398-1403.

Sun, Peiyong, Bin Wang, Jianfeng Yao, Lixiong Zhang, and Nanping Xu. Fast Synthesis of Biodiesel at High Throughput in Microstructured Reactors. Ind. Eng. Chem. Res. 2010, 49, 1259-1264.

Tan, Kok Tat e Lee, Keat Teong, "A review on supercritical fluids (SCF) technology in sustainable biodiesel production: Potential and challenges", Renewable and Sustainable Energy Reviews, Vol. 15, 2011, pp. 2452-2456.

Vieitez, Ignacio; Silva, Camila da; Borges, Gustavo R., Corazza, Fernanda C., Oliveira, J. Vladimir; Grompone, Maria A., e Jachmanián, Iván, "Continuous Production of Soybean Biodiesel in Supercritical Ethanol-Water Mixtures", Energy \& Fuels, Vol. 22, 2008, pp. 2805-2809. 
Wang, Lianyuan; He, Huayang; Xie, Zifeng; Yang, Jichu, e Zhu, Shenlin, "Transesterification of the crude oil of rapeseed with $\mathrm{NaOH}$ in supercritical and subcritical methanol”, Fuel Processing Technology, Vol. 88, 2007, pp. 477-481.

Wen, Zhenzhong, Xinhai Yu, Shan-Tung Tu, Jinyue Yan, Erik Dahlquist. Intensification of biodiesel synthesis using zigzag micro-channel reactors. Bioresource Technology, Vol. 100, 2009, 3054-3060.

Yusuf, N.N.A.N.; Kamarudin, S.K., e Yaakub, Z. "Overview on the current trends in biodiesel production", Energy Conversion and Management, 2011, Vol. 52, pp. 2741-2751.

Zabeti, Masoud; Daud, Wan Mohd Ashri Wan; Aroua, Mohamed Kheireddine. "Activity of solid catalysts for biodiesel production: A review", Fuel Processing Technology, 2009, Vol. 90, pp. 770-777. 


\section{PROPOSTA}

\subsection{Objetivo}

O objetivo deste trabalho é desenvolver um microrreator em tecnologia LTCC para produção de biodiesel, com foco na otimização de uma geometria de micromisturador para intensificar a superfície de contato entre as fases.

\subsection{Descrição do protótipo}

Uma aproximação de um sistema para realizar a reação química de produção do biodiesel é mostrada na figura 17, com a seguinte composição: duas bombas comerciais responsáveis pela alimentação dos reagentes (óleo e álcool) na entrada do micromisturador. O micromisturador é responsável pela mistura dos reagentes, entregando-a ao módulo de tempo de residência, que é responsável por efetivar a reação química entre óleo e álcool, gerando os produtos, os ésteres e a glicerina.

Neste sistema tem-se ainda o controle de temperatura e o controle de vazão. O controle de temperatura é composto de um aquecedor, um sensor de temperatura e um circuito de controle de temperatura. O controle de vazão é composto por dois sensores de vazão, as bombas de alimentação e um circuito de controle.

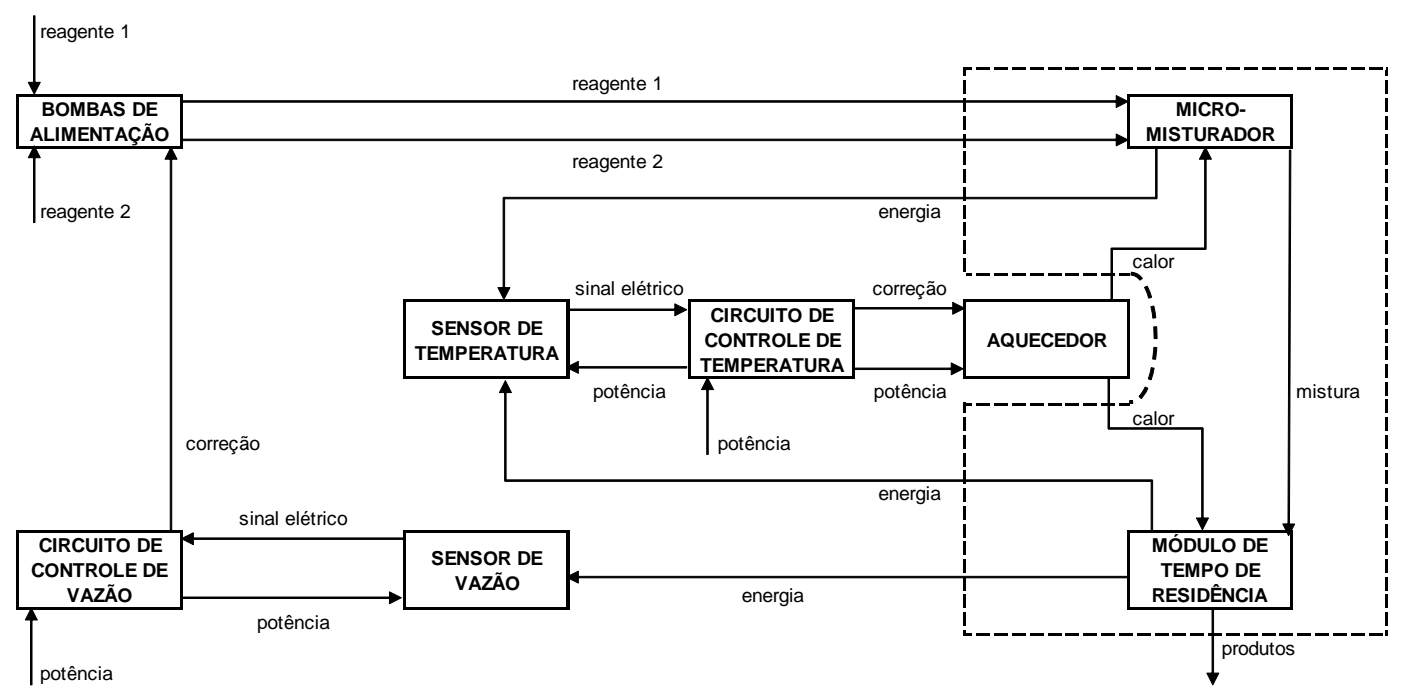

Figura 17. Desenho esquemático de um sistema para realizar a produção de biodiesel com a delimitação (linha tracejada) do escopo deste trabalho. 
A proposta do trabalho é atuar no campo limitado pela linha tracejada (conforme figura 17) com o projeto e a fabricação do micromisturador e do módulo de tempo de residência integrados num substrato em LTCC.

\subsection{Estratégia}

A reação química do processo de produção de biodiesel é realizada em temperaturas em torno de $50{ }^{\circ} \mathrm{C}$ a $80{ }^{\circ} \mathrm{C}$, e catalisada homogênea ou heterogeneamente, com hidróxidos, alcóxidos e óxidos. Com a aplicação da microfluídica, a intensificação deste processo será buscada através da otimização da transferência de massa e do tempo de residência.

Portanto, a estratégia é privilegiar elementos de mistura que provoquem aumento da superfície de contato entre as duas fases líquidas envolvidas na reação química, como os dispositivos geradores de emulsões encontrados na literatura (Haverkamp et al., 1999; Freitas et al., 2003; Wischke et al., 2005; Mae et al.; 2004; Cunha, 2007).

O tempo de residência será otimizado por um dispositivo miniaturizado, que privilegie a manutenção da emulsão gerada pelo micromisturador e a modulação do tempo adequado para efetivação da reação (Sun, 2010).

\subsection{Referências}

Cunha, Marcio Rodrigues da. Desenvolvimento de misturadores microfluídicos para fabricação de micro-esferas poliméricas. Dissertação de Mestrado. Orientador: Mario Ricardo Gongora-Rubio. EPUSP, 2007.

Freitas, S., Walz, A., Merkle, H. P. and Gander, B., "Solvent extraction employing a static micromixer: a simple, robust and versatile technology for the microencapsulation of proteins," Journal of microencapsulation, 2003, Vol. 20, No. 1 , pp. 67-85. 
Haverkamp, V., Ehrfeld, W., Gebauer, K., Hessel, V., Löwe, H., Richter, T., and Wille, C., "The potential of micromixers for contacting of disperse liquid phases", Fresenius' Journal of Analytical Chemistry, Vol. 364, 1999, pp. 617-624.

Mae, K., Maki, T., Hasegawa, I., Eto, U., Mizutani, Y. and Honda, N., "Development of a new micromixer based on split/recombination for mass production and its application to soap free emulsifier," Chemical Engineering Journal, 2004, Vol. 101, pp. 31-38.

Sun, Peiyong, Bin Wang, Jianfeng Yao, Lixiong Zhang, and Nanping Xu. Fast Synthesis of Biodiesel at High Throughput in Microstructured Reactors. Ind. Eng. Chem. Res. 2010, 49, 1259-1264.

Wischke, C., Lorenzen, D., Zimmermann, J., and Borchert, H. H., "Preparation of protein loaded poly $(\mathrm{D}, \mathrm{L}$-lactide-co-glycolide) microparticles for the antigen delivery to dendritic cells using a static micromixer", European Journal of Pharmaceutics and Biopharmaceutics, Vol. 62, No. 3, 2006, pp. 247-253. 


\section{MICROMISTURADOR}

\subsection{Introdução}

A mistura de fluidos é uma etapa fundamental em muitos processos químicos. Considerando a mistura de líquidos, dois processos (entre outros) podem ocorrer dependendo dos líquidos envolvidos: o processo de emulsificação ou o processo de reação química.

No processo de emulsificação é gerada uma distribuição de gotas de um líquido 01 em um líquido 02, formando assim uma emulsão. Os líquidos envolvidos são imiscíveis e a distribuição apresenta um tempo de estabilidade. Após esse tempo de estabilidade ocorre a separação de fases entre os líquidos envolvidos.

Diversos autores têm explorado o processo de emulsificação usando a rota microtecnológica. A figura 18 mostra os microdispositivos usados por Haverkamp et al. (1999), Freitas et al. (2003), Wischke et al.(2005) e Mae et al. (2004), para produção de emulsões.

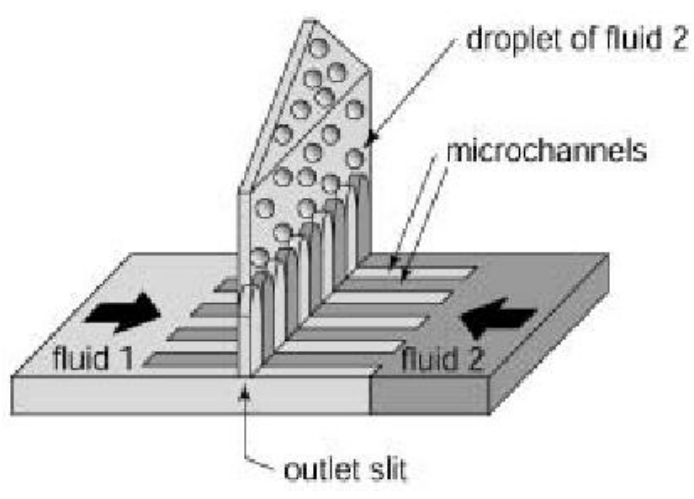

(a)

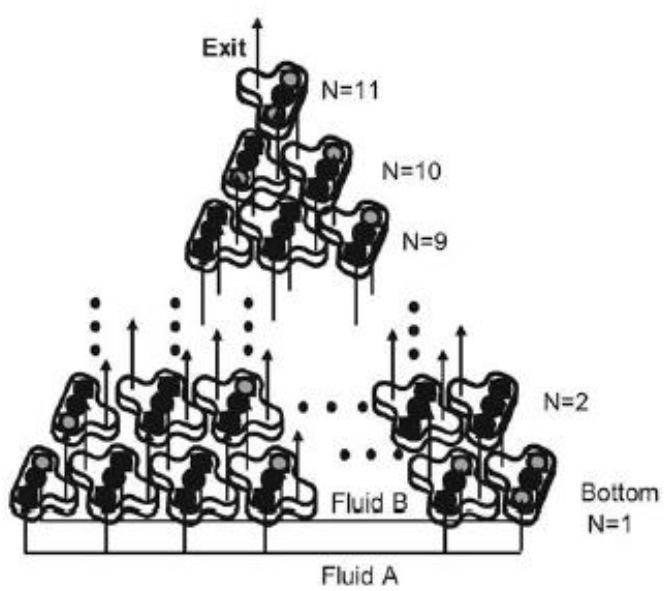

(b)

Figura 18. Dispositivos usados por (a) Haverkamp et al. (1999), Freitas et al. (2003) e Wischke et al.(2005) e (b) Mae et al. (2004).

O processo de emulsificação resulta na intensificação da superfície de contato entre dois líquidos. Considerando um microcanal reto com seção transversal quadrada de $400 \mu \mathrm{m} \times 400 \mu \mathrm{m}$ e com comprimento de $4 \mathrm{~mm}$, a superfície de contato 
entre os dois líquidos é de 1,6 mm². A figura 19 mostra a interface entre dois fluidos em um microcanal reto.

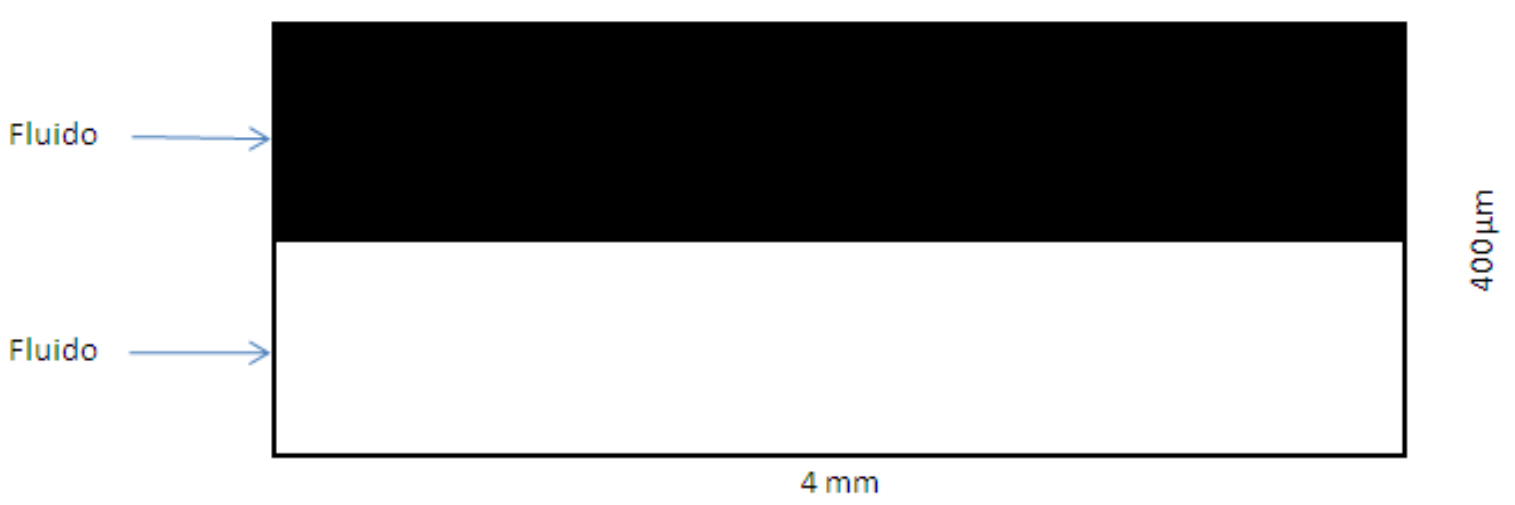

Figura 19. Interface entre dois líquidos em um canal reto.

Considerando que no canal da figura 19 os líquidos estejam dividindo pela metade o volume do canal, o volume de cada líquido é de $0,32 \mathrm{~mm}^{3}$.

Agora, considere gotas desse líquido com diâmetro médio de $100 \mu \mathrm{m}$. Cada gota tem um volume de $5,24 \cdot 10^{-4} \mathrm{~mm}^{3}$. Dividindo-se o volume total do líquido pelo volume de cada gota têm-se 610 gotas. Calculando-se a superfície de cada gota tem-se uma área de $0,03 \mathrm{~mm}^{2}$. Portanto, multiplicando-se a superfície de uma gota por 610, a superfície total de contato é de $19 \mathrm{~mm}^{2}$.

Tabela 9. Cálculo da superfície de contato.

\begin{tabular}{|c|c|}
\hline Situação & Superfície de contato $\left(\mathrm{mm}^{2}\right)$ \\
\hline Sem geração da emulsão & 1,6 \\
\hline Com geração da emulsão & 19 \\
\hline
\end{tabular}

Neste contexto, comparando-se a superfície de contato entre os dois líquidos para os casos: (1) sem e (2) com geração da emulsão, o segundo caso apresenta uma superfície de contato uma ordem de grandeza superior ao primeiro caso. Ou seja, a superfície de contato entre os líquidos é aumentada. Logo, quanto menor o diâmetro médio das gotas de uma emulsão, mais a superfície de contato entre duas fases líquidas será otimizada.

No processo de reação química ocorre a transformação de reagentes em produtos segundo uma equação química:

$$
A B+C D<=>A D+B C
$$


Basicamente, as reações químicas acontecem porque os íons das espécies reagentes $\left(A^{+}, B^{-}, C^{+}\right.$e $\left.D^{-}\right)$colidem com energia adequada para formação dos produtos ( $A D$ e $B C$ ). Vários parâmetros são ajustados para favorecer a colisão dos íons reagentes e conseqüentemente a reação química: método de mistura, temperatura de processo, tipo de catálise, proporção dos reagentes, etc.

Um fator importante para intensificar uma reação química é a superfície de contato entre os líquidos reagentes, pois, quanto maior for a superfície de contato entre os líquidos maior é a freqüência de colisões entre as espécies reagentes. Portanto, a escolha do método de mistura é de fundamental importância para intensificação da superfície de contato entre os líquidos.

Considerando o processo de produção do biodiesel, as considerações sobre os processos de emulsificação e de reação química são importantes, pois os líquidos envolvidos, óleo vegetal (soja, girassol, etc) e álcool (metanol ou etanol), geram um processo onde estão presentes, emulsificação e reação química.

A mistura de óleo e álcool na temperatura ambiente $\left(25^{\circ} \mathrm{C}\right)$ gera uma emulsão, que tem como característica a superfície de contato intensificada. Após a mistura, a emulsão gerada rapidamente separa fase. Nestas condições, não se observa reação química.

Realizando-se essa mistura numa temperatura adequada e na presença de um catalisador, verifica-se simultaneamente a formação de uma emulsão e a ocorrência de reação química. Neste contexto, a superfície de contato intensificada entre líquidos (característica da emulsão) acelera o processo de reação química entre óleo e álcool.

Somando-se a isso, a escolha de uma rota microtecnológica incrementa a intensificação do processo, pois o escalamento das dimensões apresenta condições favoráveis para o transporte de massa. A tabela 10 mostra o escalamento da superfície e do volume, bem como, a comparação entre eles. Observando a tabela 10 verifica-se que reduzindo a escala o volume diminui mais acentuadamente do que a superfície, pois o volume depende de um fator elevado ao cubo enquanto a superfície depende de um fator elevado ao quadrado. Comparando-se a razão volume/superfície, verifica-se a dependência de um fator elevado à primeira 
potência. Portanto, com a redução da escala observa-se um aumento de superfície por unidade de volume.

Tabela 10. Escalamento das dimensões.

\begin{tabular}{|l|c|c|c|c|}
\hline \multicolumn{1}{|c|}{ Parâmetros } & $\mathrm{nm}$ & $\mu \mathrm{m}$ & $\mathrm{mm}$ & $\mathrm{m}$ \\
\hline Área de uma superfície $\left(\mathrm{L}^{2}\right)$ & $10^{-18}$ & $10^{-12}$ & $10^{-6}$ & 1 \\
\hline Volume $\left(\mathrm{L}^{3}\right)$ & $10^{-27}$ & $10^{-18}$ & $10^{-9}$ & 1 \\
\hline Área de uma superfície / Volume $\left(\mathrm{L}^{-1}\right)$ & $10^{9}$ & $10^{6}$ & $10^{3}$ & 1 \\
\hline
\end{tabular}

Neste contexto, o trabalho será focalizado na escolha e estudo do micromisturador para se obter características otimizadas para efetivação da reação química de produção do biodiesel.

\subsection{Estado da arte}

Diversos autores têm explorado a mistura de fluidos usando micromisturadores. $\mathrm{Na}$ literatura encontram-se dispositivos com os mais diversos princípios de funcionamento, como mostrado na figura 20. Basicamente, os dispositivos estão classificados pelo método de mistura passivo ou ativo.

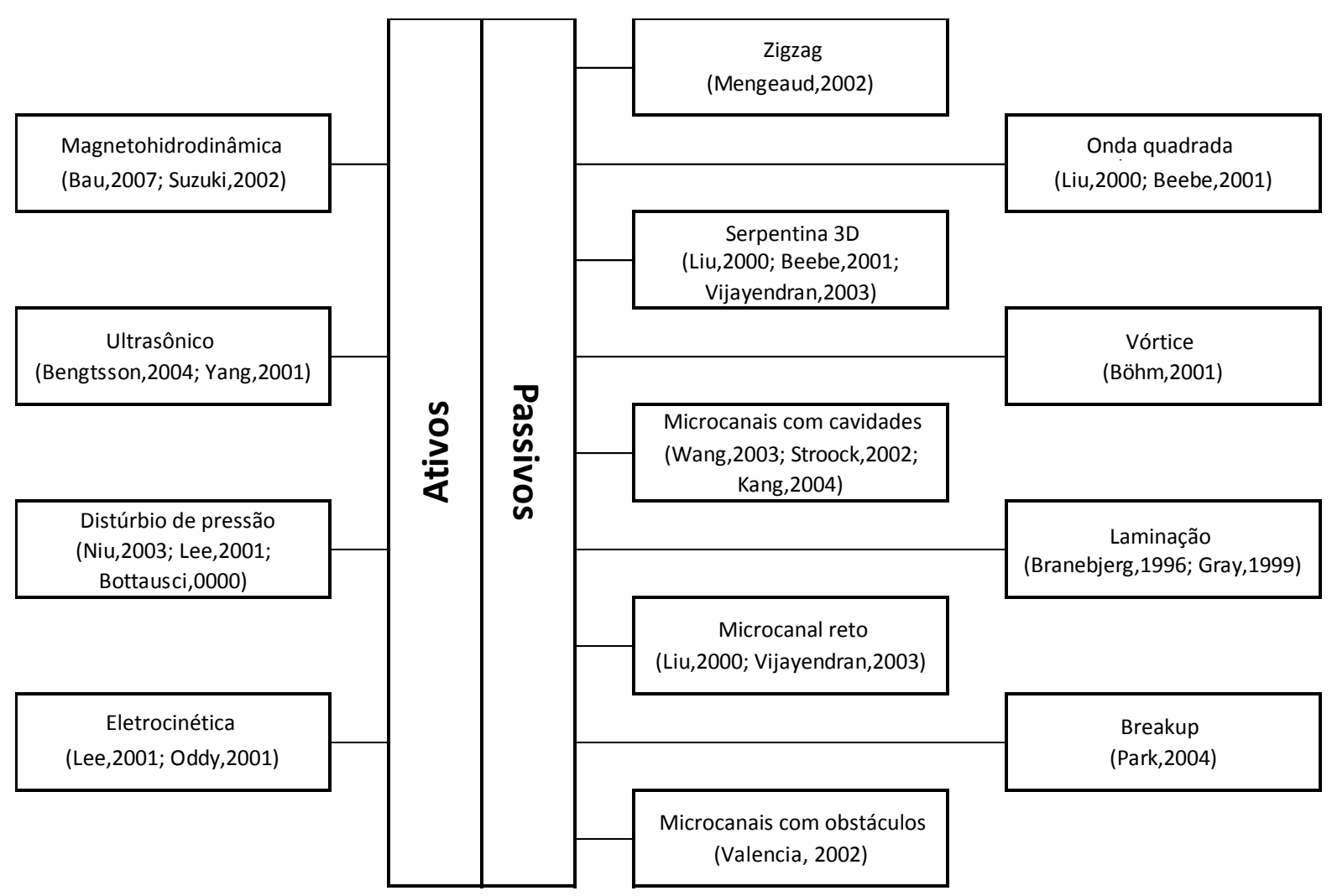

Figura 20. Micromisturadores ativos e passivos encontrados na literatura. 
No método ativo a mistura é realizada com a interferência no escoamento dos fluidos através de distúrbios gerados por uma fonte de energia externa. A figura 21 mostra algumas configurações de dispositivos ativos, usando campos elétricos, campos magnéticos e onda ultrassônicas. Na figura 21(a), um campo elétrico é gerado no mesmo sentido do eixo do escoamento. Por outro lado, na figura 21(b), um campo elétrico é gerado no sentido ortogonal do eixo do escoamento. Na figura 21(c), são mostradas as partes construtivas de uma cavidade (1, 2 e 3), onde um imã (4) é acoplado à parte inferior da cavidade para geração de um campo magnético. Na figura 21(d), uma cerâmica PZT é acoplada na parte inferior de uma câmara de mistura. Quando a PZT é excitada, propaga no ambiente as chamadas ondas ultrassônicas.

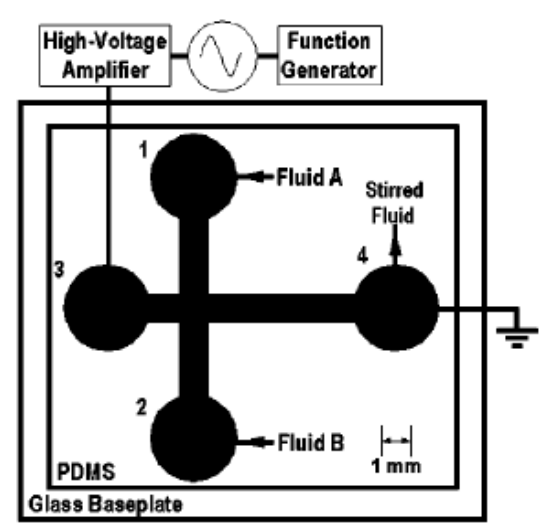

(a)

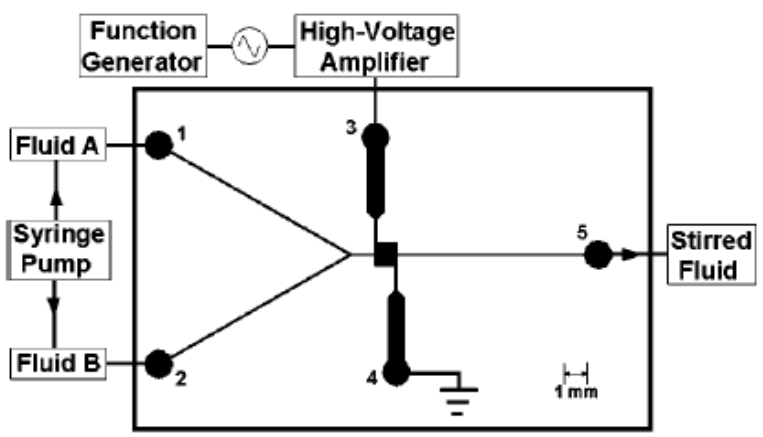

(b)

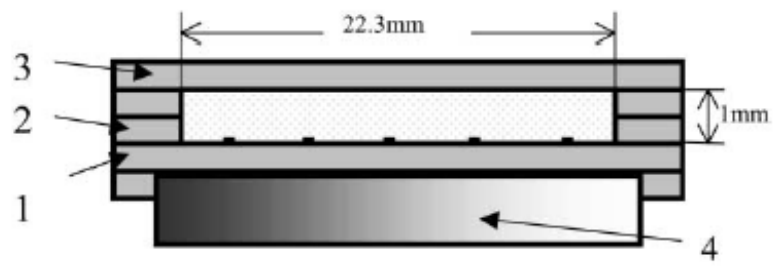

(c)

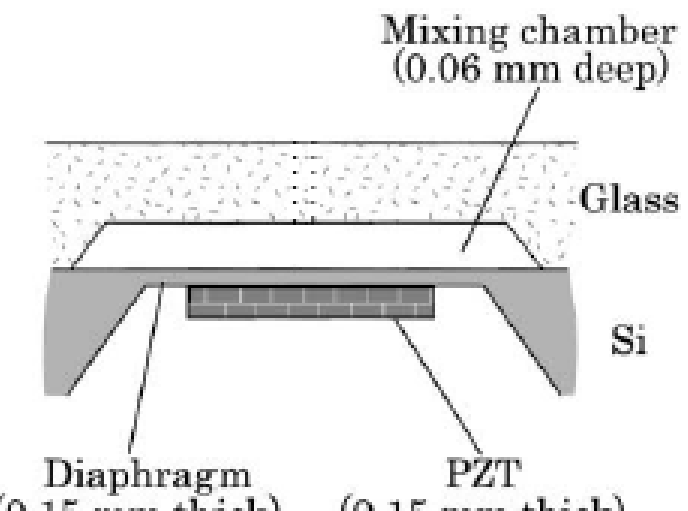

$(0.15 \mathrm{~mm}$ thick $) \quad(0.15 \mathrm{~mm}$ thick $)$

(d)

Figura 21. Dispositivos ativos: (a) Oddy, 2001, (b) Oddy, 2001, (c) Bau, 2001, e (d) Yang, 2001.

No método passivo a mistura é realizada com a interferência no escoamento dos fluidos através de distúrbios gerados pela forma geométrica do microcanal. A figura 22 mostra algumas configurações de dispositivos passivos, usando microcanais com cotovelos (a e c), microcanais com cavidades (b) e estrutura vortex (d). 


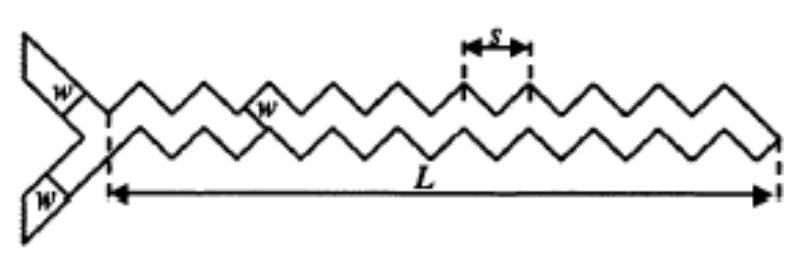

(a)

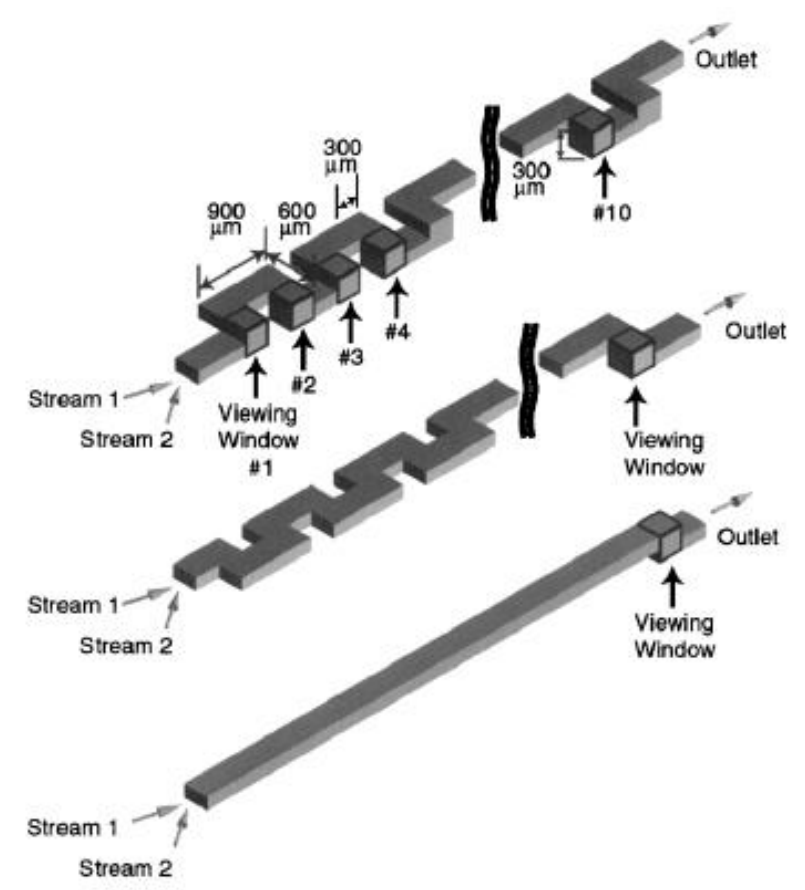

(c)

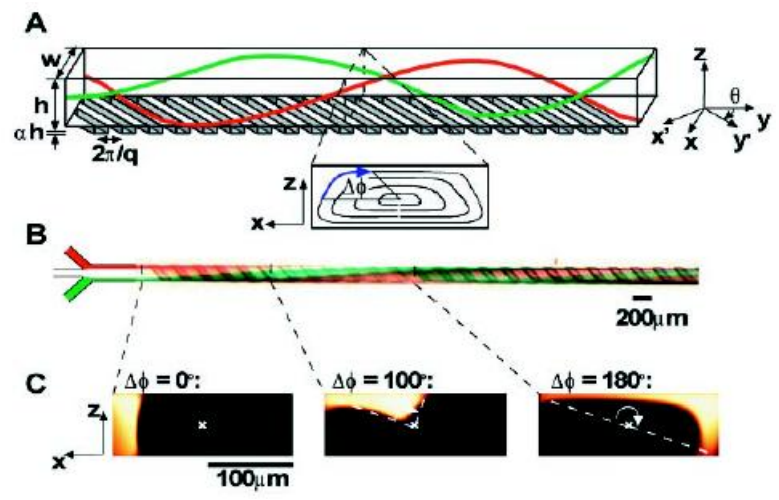

(b)

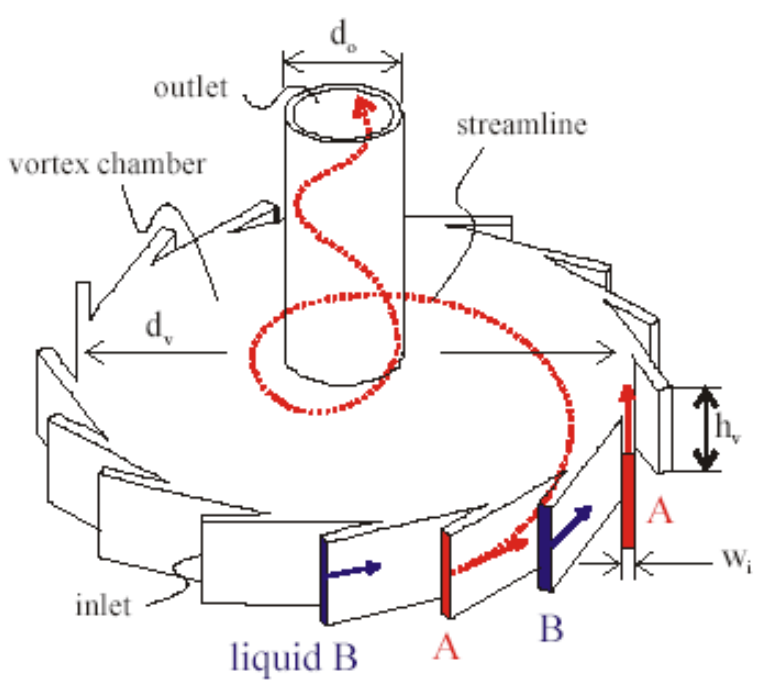

(d)

Figura 22. Dispositivos passivos: (a) Mengeaud, 2002, (b) Liu, 2000, (c) Stroock, 2002, e (d) Böhm, 2001.

Neste contexto, no método de mistura ativo necessita-se de mais insumos para integrar ou acoplar uma fonte de energia no dispositivo, e uma maior instrumentação para o controle do processo onde esses dispositivos passam ser aplicados. Por outro lado, no método passivo as geometrias dos microcanais são mais complexas, aumentando assim a complexidade de fabricação dos dispositivos.

Quanto à operação dos microdispositivos, no método ativo existem interações entre o fluido e a energia externa aplicada, por exemplo, fluido-campo elétrico. Enquanto que, no método passivo somente o escoamento é estudado. O que não 
representa um desafio menor, pois ainda existem divergências na literatura sobre a dinâmica dos fluidos em escoamentos nos microcanais.

Portanto, este trabalho contribuirá com o estudo de um método passivo aplicado ao processo de produção de biodiesel. Dentre vários dispositivos, os microcanais baseados em sucessivos cotovelos têm sido largamente explorados na literatura, inclusive, com aplicações no processo de produção de biodiesel. Logo, propõe-se estudar diversas geometrias de microcanais baseados em sucessivos cotovelos usando como base de comparação um microcanal reto, para obter a geometria mais adequada para o processo de produção do biodiesel.

Seguindo essa linha de trabalho será avaliada a eficiência de mistura dos microdispositivos, que dependerá fundamentalmente do tipo de escoamento encontrado nos microcanais. Diversos autores têm estudado o escoamento em micro-escala e comparado com a teoria clássica ou em macro-escala. A tabela 11 mostra um levantamento de várias investigações sobre o comportamento distinto do escoamento entre canais em macro-escala e micro-escala, mostrando diversos comportamentos distintos.

\section{Tabela 11. Investigações sobre o estudo do escoamento em micro-escala versus macro-escala (Judy, 2002).}

\begin{tabular}{|c|c|c|c|c|c|}
\hline Estudo & material do microcanal & $\mathrm{D}(\mu \mathrm{m})$ & Fluido & $\operatorname{Re}$ & Desvios observados da teoria de Stokes \\
\hline Urbanek et al. [8] & canal de silício & 12,25 & $\begin{array}{l}\text { 1-2 Propanol } \\
\text { 1-3 Pentanol }\end{array}$ & NA & $\begin{array}{l}5 \text { a } 30 \% \text { de aumento em } f \operatorname{Re} \text {; dependendo da } \\
\text { temperatura do fluido }\end{array}$ \\
\hline Papautsky et al. [9, 19] & canal metálico & 44,57 & Água & $0,001-120$ & 10 a $20 \%$ de aumento em $f \operatorname{Re}$ \\
\hline Mala et al. [10] & canal de silício & $51-169$ & Água & $0-1500$ & 0 a $40 \%$ de aumento em $f \operatorname{Re}$ \\
\hline Pfahler et al. [11] & canal de silício & $0,5-40$ & $\begin{array}{l}\text { Isopropanol, } \\
\text { óleo de silício }\end{array}$ & $<100$ & $\begin{array}{l}0 \text { a } 30 \% \text { de diminuição em } f \operatorname{Re} \text { com o tipo de fluido, } \\
\text { diâmetro; observação depende de } \operatorname{Re}\end{array}$ \\
\hline Yu et al. [12] & tubo circular de siica fundida & 52 & Água & $300-2000$ & $19 \%$ de diminuição em $f \operatorname{Re}$ \\
\hline Jiang et al. [13] & canal de silício & $35-120$ & Água & $1-30$ & 50 a $100 \%$ de diminuição em $f \operatorname{Re}$ \\
\hline Harms et al. [14] & canal de silício & 403 & Água & $125-1500$ & Boa concordância com a teoria de Stokes \\
\hline Pfund et al. [15] & canal de silício & $200-900$ & Água & $40-1300$ & Boa concordância com a teoria de Stokes \\
\hline Webb and Zhang [16] & canal de silício & 133 & $\mathrm{R}-134 \mathrm{a}$ & Turbulent & $\begin{array}{l}\text { Boa concordância com dados empíricos de } \\
\text { escoamento turbulento em macroescala }\end{array}$ \\
\hline Peng and Peterson [17] & canal de aço inox & $133-143$ & Água & $100-3000$ & $\begin{array}{l}\text { aumento de } f \text { Re para alguns diâmetros, } \\
\text { diminuição para outros; dependendo de Re }\end{array}$ \\
\hline Peng et al. [18] & canal de aço inox & $133-367$ & Água & $100-800$ & $\begin{array}{l}\text { aumento de } f \text { Re para alguns diâmetros, } \\
\text { diminuição para outros; dependendo de Re }\end{array}$ \\
\hline
\end{tabular}

Li e Olsen (2006) mostram em seu trabalho a caracterização do escoamento em microcanais retos fabricados em PDMS com seção transversal retangular e com diâmetros hidráulicos entre 200 e 640 m, no intervalo do número de Reynolds entre 200 e 3971. O fluido de trabalho foi água deionizada. Verificou-se que não há evidência de uma transição prematura para regime turbulento, observando a zona 
de transição em números de Reynolds entre 1718 e 1885, para vários microcanais com diferentes tamanhos.

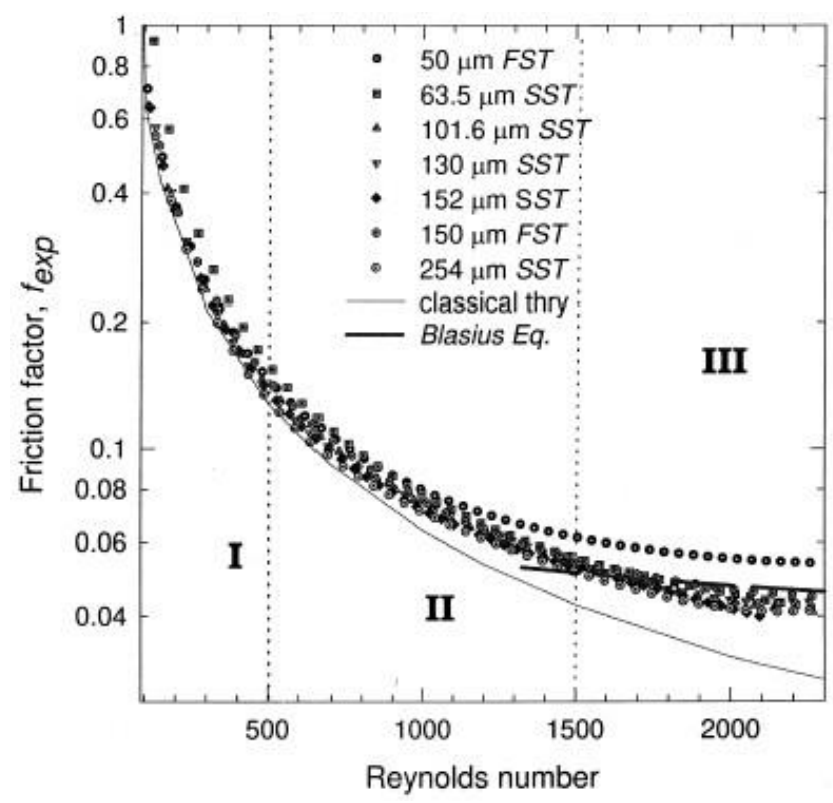

Figura 23. Número de Reynolds por Fator de atrito para vários microcanais em comparação a equações clássicas (MALA; LI, 1999).

Por outro lado, Mala e Li (1999) mostram em seu trabalho a caracterização de microcanais retos com seções transversais circulares fabricados em sílica fundida (FS) e aço inox (SS) com diversos diâmetros hidráulicos de 50 a $254 \mu \mathrm{m}$. A figura 23 mostra o gráfico do fator de atrito experimental em função do número de Reynolds para vários microcanais comparados com as equações: $f_{\exp }=64 / \operatorname{Re}$ (classical thry) e $\mathrm{f}_{\text {Blasius }}=0,3164 . \mathrm{Re}^{-0,25}$ (Blasius Eq.). Verificando que nas regiões II e III as medidas experimentais apresentam comportamento distinto da teoria clássica.

Com análises complementares dos dados mostrados na figura 23, Mala e Li (1999) confirmaram um comportamento distinto entre os dados experimentais e a teoria clássica e concluíram que tal comportamento pode ser devido a uma prematura região transição de regime laminar para o turbulento ou a efeitos de rugosidade das paredes.

Neste contexto, o entendimento do escoamento, tanto para microcanais retos quanto para microcanais baseados em sucessivos cotovelos, é fundamental para aplicação na mistura de fluidos. A determinação do regime de escoamento será realizada em função da metodologia estabelecida pelo diagrama de Moody, onde é verificado o comportamento do fator de atrito em função do número de Reynolds. 


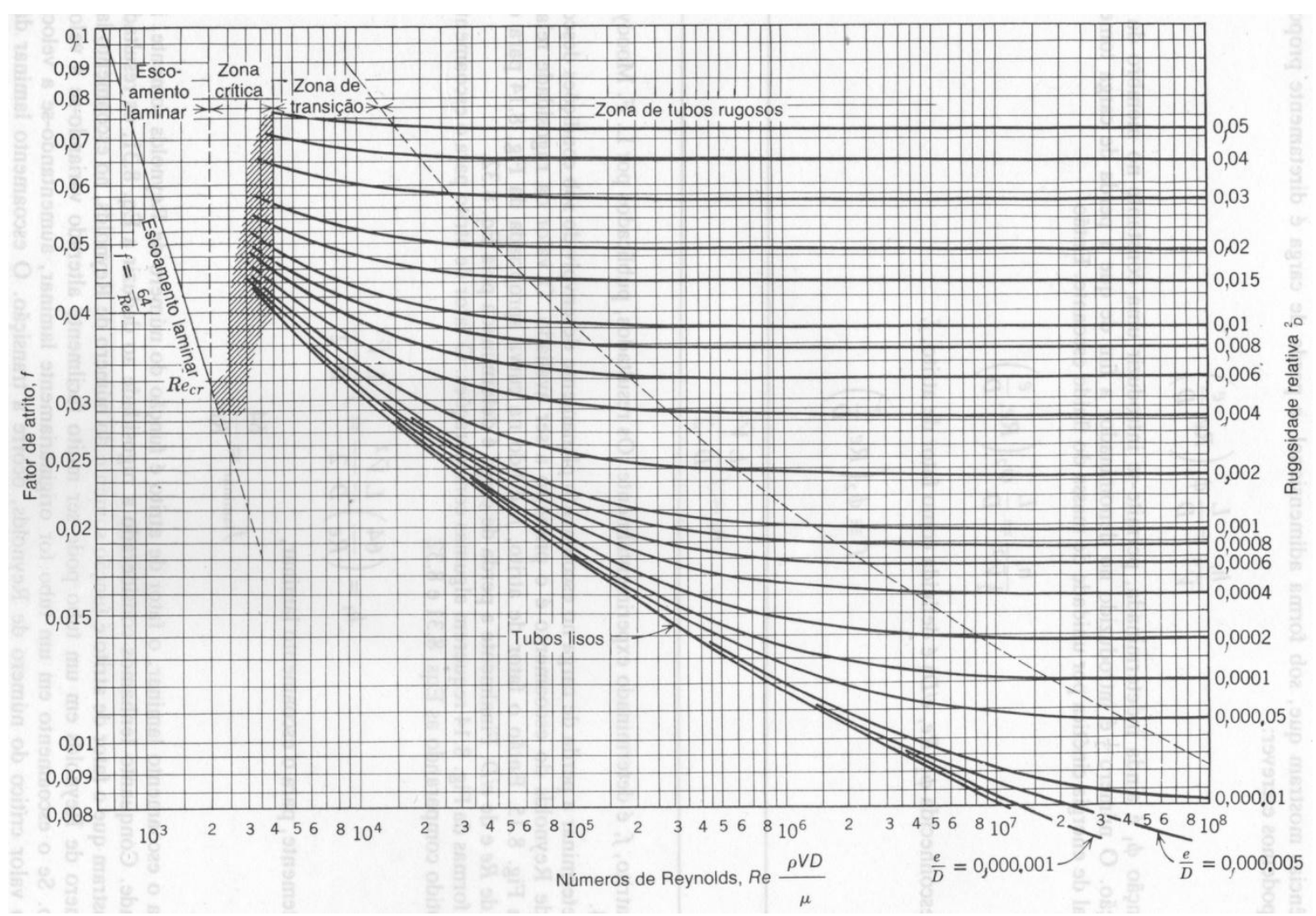

Figura 24. Diagrama de Moody (Fox, 1985).

Outro fator importante na descrição do escoamento em microcanais a ser discutido neste trabalho é o fenômeno chamado advecção caótica, mostrado em diversos trabalhos (Niu, 2003; Lee, 2001; Liu, 2000; Suzuki, 2002; Vijayendran, 2003) em contraponto à advecção passiva encontrada classicamente. Segundo Aref (2002), advecção passiva refere-se ao movimento das partículas fluidas que estão inertes no fluxo e podem somente seguir $O$ escoamento respondendo instantaneamente a algum ajuste de velocidade ou instabilidade. A equação geral que descreve a advecção passiva é dada por

$$
\vec{V}_{\text {particula }}=\vec{V}_{\text {fluido }}
$$

A velocidade da partícula pode ser expressa em termos da taxa de variação de suas coordenadas espaciais $(x, y, z)$.

$$
\vec{V}_{\text {particula }}=\left(\frac{d x}{d t}, \frac{d y}{d t}, \frac{d z}{d t}\right)
$$

A velocidade do fluido é geralmente expressa por um conjunto de equações diferenciais parciais como equações de Euler ou Navier-Stokes. Sendo expressa em termos de suas componentes de velocidade, tem-se 


$$
\vec{V}_{\text {fluido }}=(u(x, y, z, t), v(x, y, z, t), w(x, y, z, t))
$$

eq. 5.

Da equação 3 compõe-se o seguinte conjunto de equações diferenciais ordinárias (EDO) chamadas equações de advecção

$$
\left(\begin{array}{l}
\frac{d x}{d t}=u(x, y, z, t) \\
\frac{d y}{d t}=v(x, y, z, t) \\
\frac{d z}{d t}=w(x, y, z, t)
\end{array}\right)
$$

eq. 6 .

Assim as equações de advecção descrevem o modelo cinemático do escoamento em termos da descrição lagrangeana das partículas e descrição euleriana do campo de velocidades. A integrabilidade destas equações conduz a advecção passiva. Da teoria de sistemas dinâmicos sabe-se que três EDOs como na equação 6 podem produzir dinâmica não integrável. A não integrabilidade é o princípio matemático fundamental da advecção caótica. Assim, escoamentos 3D permanentes ou não permanentes e escoamentos $2 \mathrm{D}$ não permanentes produzem movimento caótico.

No estudo da advecção caótica em microdispositivos baseados em cotovelos sucessivos, vários autores têm apresentado os mapas de Poincaré (Suzuki, 2002; $\mathrm{Niu}, 2003)$, que mostram o padrão dos campos de velocidade e a interface entre fluidos nestes dispositivos. Esses mapas é uma das formas de se visualizar os distúrbios gerados em uma seção de escoamento em um microcanal operando com a presença de advecção caótica. A figura 25 mostra os mapas de Poincaré.
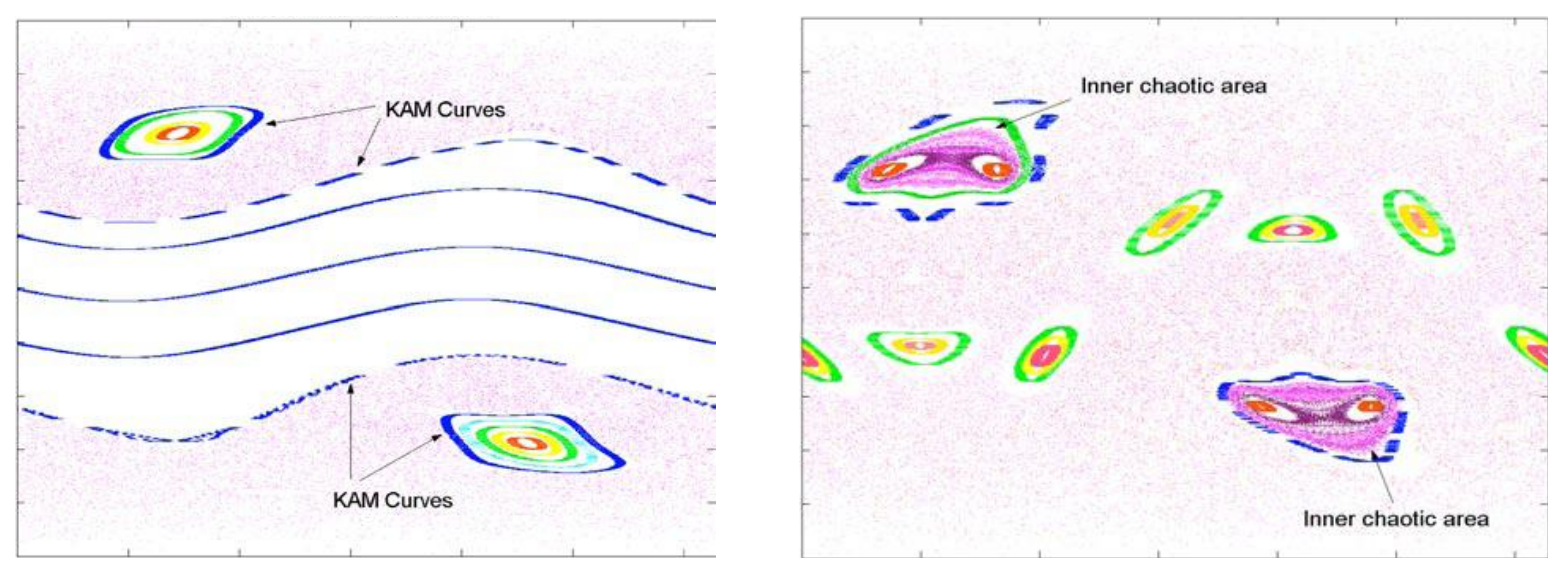

Figura 25. Mapas de Poincaré.

Outro fator importante encontrado na literatura, que será apreciado neste trabalho, é a faixa de operação dos microdispositivos baseados em advecção 
caótica. Nguyen e Wu (2005) classificam misturadores microfluídicos baseados em advecção caótica em três faixas de operação, conforme a figura 26 :

- Baixa - Re $<10$;

- Intermediária - $10<\operatorname{Re}<100$, e

- Alta - Re > 100 .
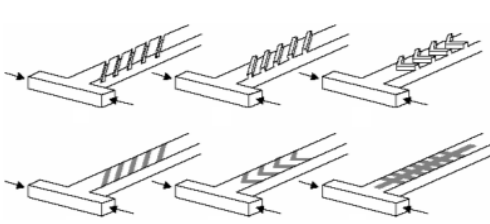

(a)

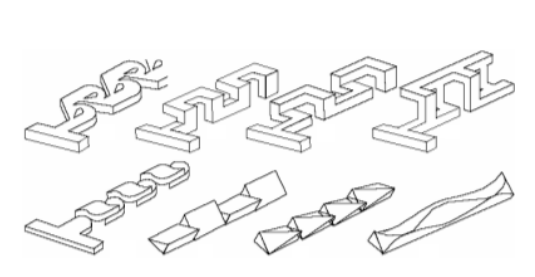

(b)

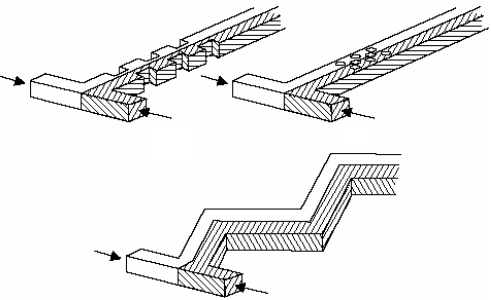

(c)

Figura 26. Desenho esquemático de misturadores microfluídicos que operam em (a) baixo, (b) intermediário e (c) alto número de Reynolds (NGUYEN e WU, 2005).

\subsection{Metodologia Computacional}

Desenvolveu-se uma metodologia baseada em simulação numérica para escolha e otimização de uma geometria para um micromisturador, com o objetivo de intensificar a interface de contato entre dois líquidos.

Esta metodologia está organizada em 06 estudos, com os seguintes objetivos:

- Estudo 1:Descrição do escoamento em microcanais retos, este estudo tem por objetivo definir um padrão de comparação usando um microcanal reto, e também definir uma faixa de investigação baseada no número de Reynolds;

- Estudo 2: Influência da distância entre dois cotovelos sucessivos, este estudo tem por objetivo investigar a distância ótima entre dois cotovelos sucessivos, bem como identificar possíveis arranjos de cotovelos no espaço;

- Estudo 3: Comparação de diversas geometrias, este estudo tem por objetivo estabelecer uma metodologia de comparação entre diversas estruturas baseadas em sucessivos cotovelos com o padrão microcanal reto; 
- Estudo 4: Estudo do pior caso, zigzag 2, este estudo tem por objetivo investigar as características desta geometria, que já foi aplicada no processo de produção do biodiesel (Wen, 2009);

- Estudo 5: Estudo do melhor caso, serpentina 3D 1, este estudo tem por objetivo investigar as características desta geometria, mostrando sua melhor eficiência de mistura;

- Estudo 6: Serpentina 3D nas condições de processo, este estudo tem por objetivo extrair as características fluidodinâmicas desta geometria, aplicando algumas características do processo de produção do biodiesel.

O software utilizado neste estudo computacional foi o COMSOL 3.4. Este aplicativo é baseado no método numérico dos elementos finitos. É composto por módulos de diversas áreas do conhecimento, tais como:

- Mecânica estrutural;

- RF;

- MEMS;

- Transferência de calor;

- Ciências da terra;

- Acústica;

- Engenharia química, dentre outros.

As simulações foram realizadas usando duas estações de trabalho com as seguintes configurações:

- Dell Precision T7400 (CNPq, 140628/2007-0): 1 processador Intel Pentium Xeon Quad-Core (2 GHz), 8 Gb de memória, e

- Dell Precision T7400 (LPP/CTPP - IPT): 2 processadores Intel Pentium Xeon Quad-Core (2.54 GHz), 16 Gb de memória.

A metodologia para realizar a modelagem numérica utilizando o ambiente descrito, envolve três etapas:

- Pré-processamento: nesta etapa define-se a geometria a ser modelada, as condições de contorno do problema e a discretização da geometria por uma malha baseada em elementos e nós; 
- Processamento: nesta etapa as estações de trabalho realizam o processo de cálculo numérico até que os critérios de convergência sejam satisfeitos;

- Pós-processamento: nesta etapa são extraídos os mapas de propriedades (físicas, químicas, etc) e os parâmetros de interesse, para serem analisados.

As simulações numéricas concebidas e apresentadas neste trabalho sofreram testes de sensibilidade para verificar flutuações nos resultados. Essas flutuações ocorrem em função da discretização realizada nas geometrias. Em simulações estáticas, como as apresentadas neste trabalho, quanto menor o elemento utilizado na discretização da geometria melhor a precisão do modelo. Por se tratar de escoamento de fluidos, essa precisão tende a diminuir em função do aumento do número de Reynolds.

O padrão utilizado para o teste de sensibilidade e determinação de uma discretização inicial foi um microcanal reto com diâmetro hidráulico de $1 \mathrm{~mm}$ e comprimento de $20 \mathrm{~mm}$, para número de Reynolds $R e=2000$. Diversas condições de malha foram utilizadas, com discretizações globais e locais.

Deste estudo inicial de sensibilidade identificou-se a necessidade de uma discretização mais fina na entrada dos microcanais. Os resultados de flutuação são mostrados na tabela 12. Todos os resultados apresentados neste trabalho em função das malhas ajustadas estão dentro das flutuações apresentadas na tabela.

Tabela 12. Resultados dos testes de sensibilidade.

\begin{tabular}{|l|c|}
\hline \multicolumn{1}{|c|}{ Parâmetros } & Flutuação \\
\hline Diferença de Pressão & $\pm 3,13 \%$ \\
\hline Número de Reynolds na entrada & $\pm 1,84 \%$ \\
\hline Número de Reynolds na saída & $\pm 1,83 \%$ \\
\hline
\end{tabular}

Todas as simulações apresentadas nos estudos a seguir as unidades estão nos SI. 
4.4. Estudo 1: Descrição do escoamento em microcanais retos

O objetivo deste estudo é mostrar a descrição do(s) escoamento(s) em microcanais retos para servir de comparação com outros microcanais baseados em geometrias com cotovelos. Essa descrição será realizada em função de dados computacionais obtidos através de simulações numéricas.

A metodologia computacional deste estudo envolve cinco passos: definição da geometria, condições de contorno, discretização, visualização de mapas das propriedades do(s) escoamento(s) e obtenção de parâmetros.

Tabela 13. Estudo 1: Definição das Geometrias.

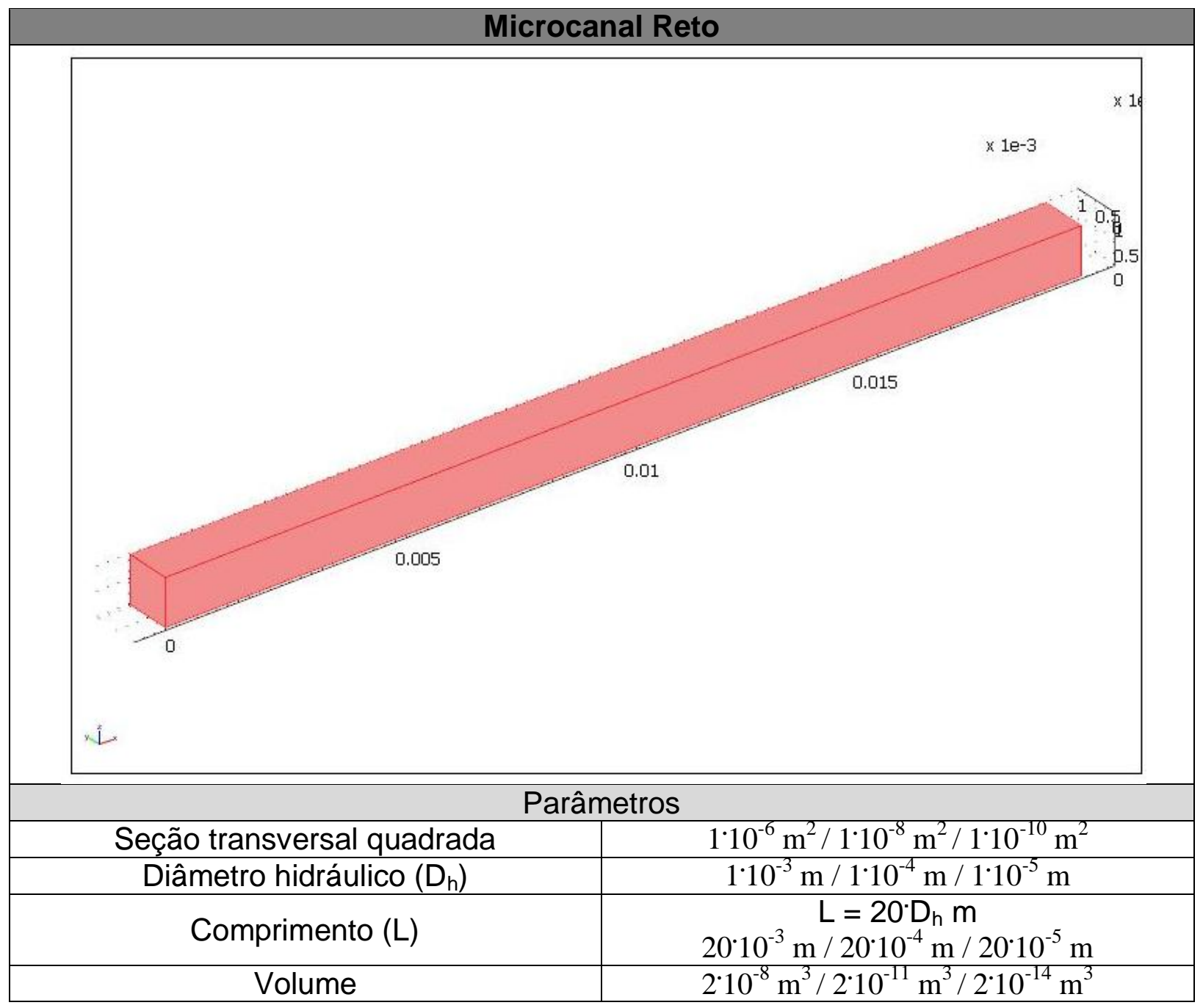

A geometria definida para este estudo é um microcanal reto com seção transversal quadrada. Foram escolhidos três diâmetros hidráulicos $(1 \mathrm{~mm}, 100 \mu \mathrm{m}$ e $10 \mu \mathrm{m})$ para serem estudados e os comprimentos dos canais foram parametrizados 
em função dos diâmetros hidráulicos $\left(20 \cdot D_{h}\right)$. Portanto, serão estudados três microcanais retos com diâmetros hidráulicos e comprimentos diferentes. A tabela 13 mostra a geometria estudada com suas respectivas características.

Tabela 14. Estudo 1: Condições de contorno.

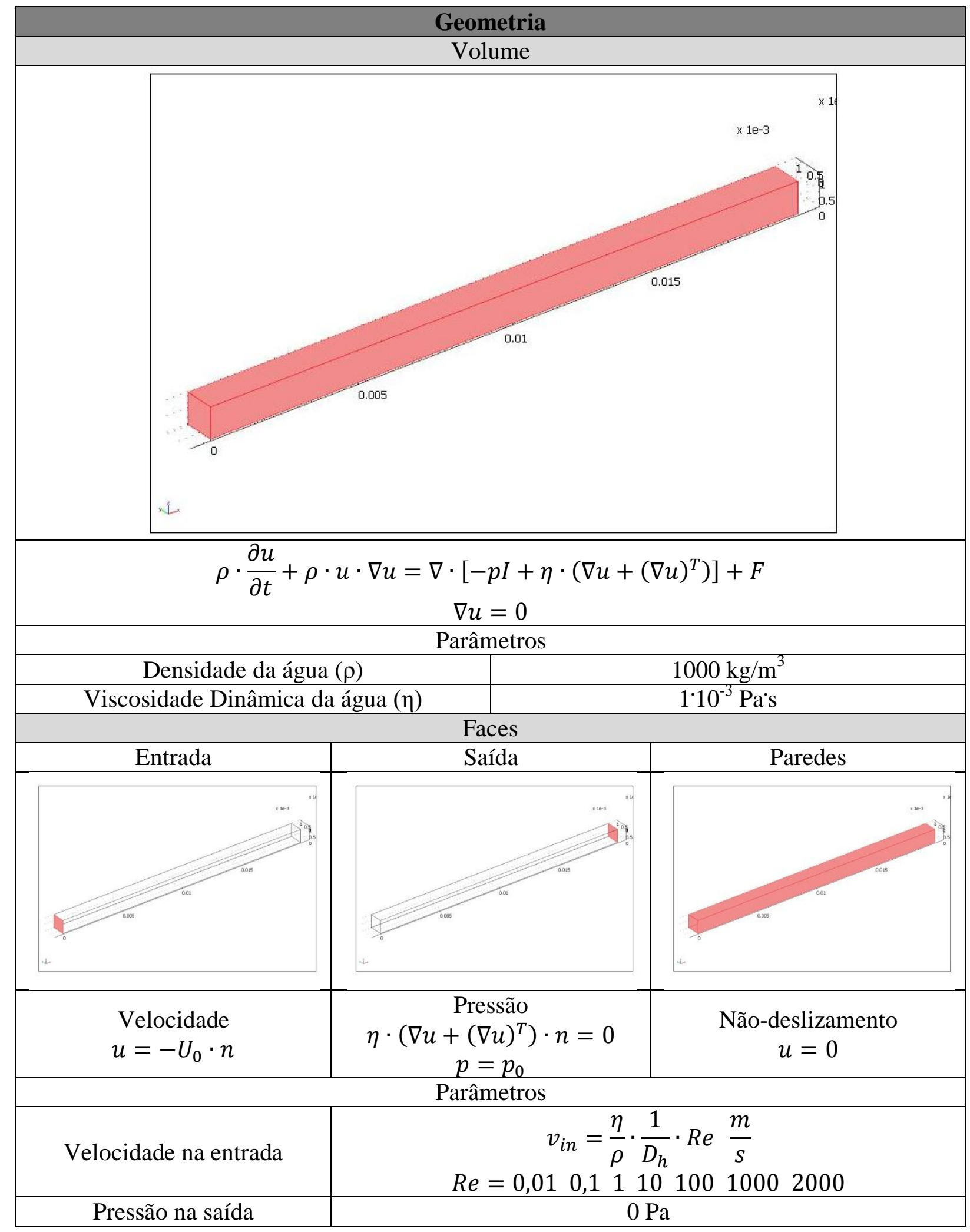


Em função da geometria escolhida, são definidas condições de contorno no volume e nas faces da geometria. A tabela 14 mostra as condições de contorno definidas no volume e nas faces da geometria. No volume ou domínio da geometria definiu-se a equação de governo a ser resolvida numericamente: equação de Navier-Stokes na forma diferencial. Os parâmetros apresentados nessa equação: $u$ é a velocidade, $p$ é a pressão, $\rho$ é a densidade e $\eta$ é a viscosidade dinâmica.

Nas faces são definidas três diferentes tipos de condições de contorno: (1) perfil de velocidade uniforme na entrada, (2) pressão nula na saída e (3) velocidade nula nas paredes. O perfil de velocidades na entrada foi definido em função do diâmetro hidráulico do canal, das propriedades físicas do fluido, água, e parametrizado em função do Re. A equação é mostrada na tabela 14.

Para cada canal foram simulados 07 pontos no intervalo de Re entre $0,01 \mathrm{a}$ 2000. Portanto, como são três canais estudados, totalizando 21 simulações.

A discretização da geometria é a etapa de divisão do domínio em elementos, gerando uma malha. Em cada elemento são calculadas numericamente as propriedades físicas do escoamento ou problema em questão. $O$ elemento utilizado foi o tetraedro, com tamanho global e local, mostrados na tabela 15.

Tabela 15. Estudo 1: Discretização da geometria.

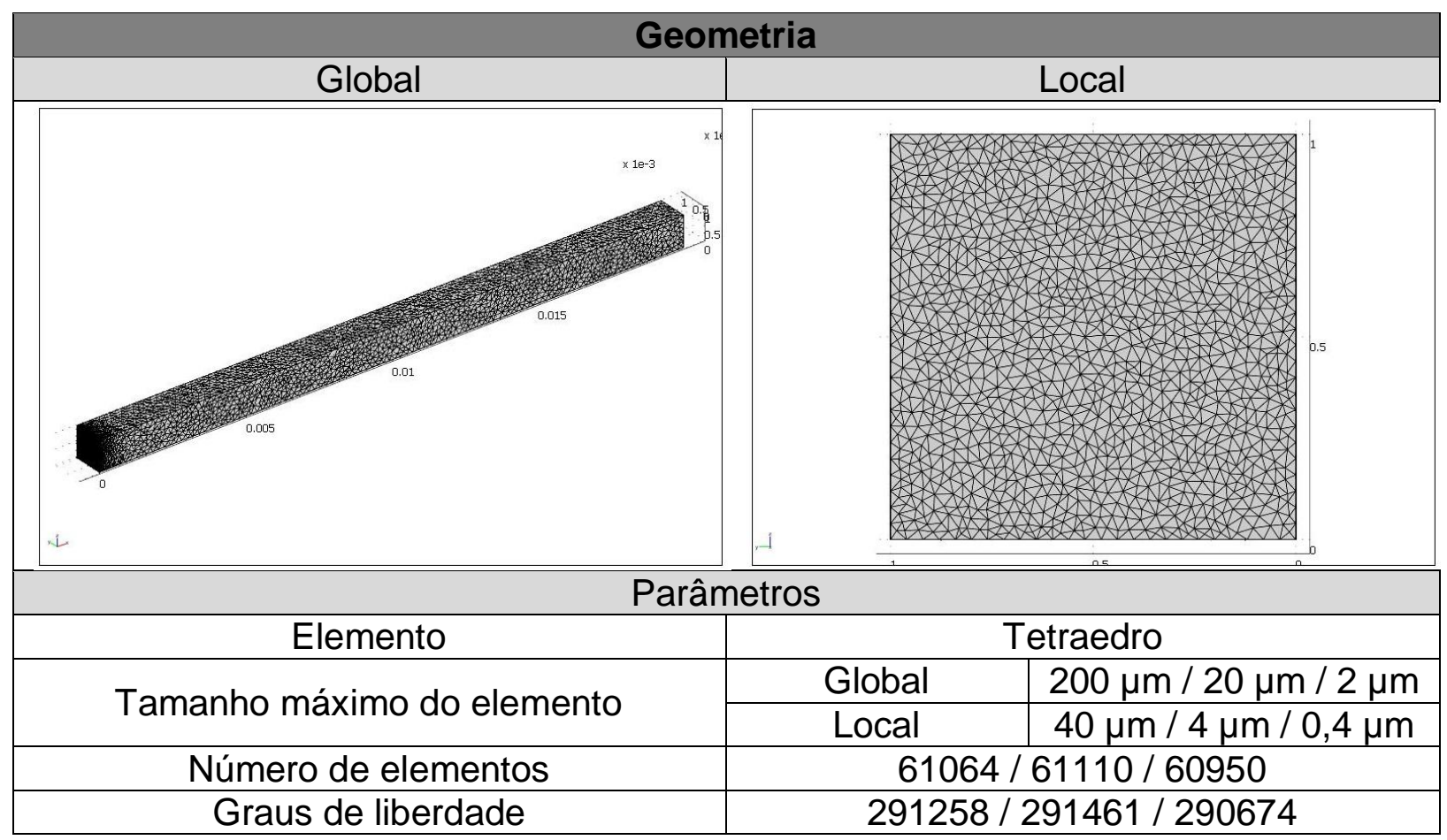


A escolha do tamanho do elemento é um compromisso entre o esforço computacional e a precisão nos cálculos. Considerando uma geometria fixa, quanto menor o tamanho do elemento, maior será o tempo de processamento e em geral melhor será a precisão.

Após a preparação do modelo (definição da geometria, condições de contorno e discretização) e o processamento do mesmo usando o solver UMFPACK, realizase 0 pós-processamento (visualização de mapas das propriedades do(s) escoamento(s) e obtenção de parâmetros).

Para a visualização das propriedades de interesse foram extraídos os mapas do campo de velocidades e do campo de pressões.

A figura 27 mostra os mapas de velocidade para o microcanal reto de $D_{h}=1$ $\mathrm{mm}$ e $\mathrm{L}=20 \mathrm{~mm}$. As cores frias e quentes representam baixas e altas velocidades, respectivamente. Observa-se que conforme o número de Reynolds aumenta o comportamento (descrição) do escoamento é modificado.

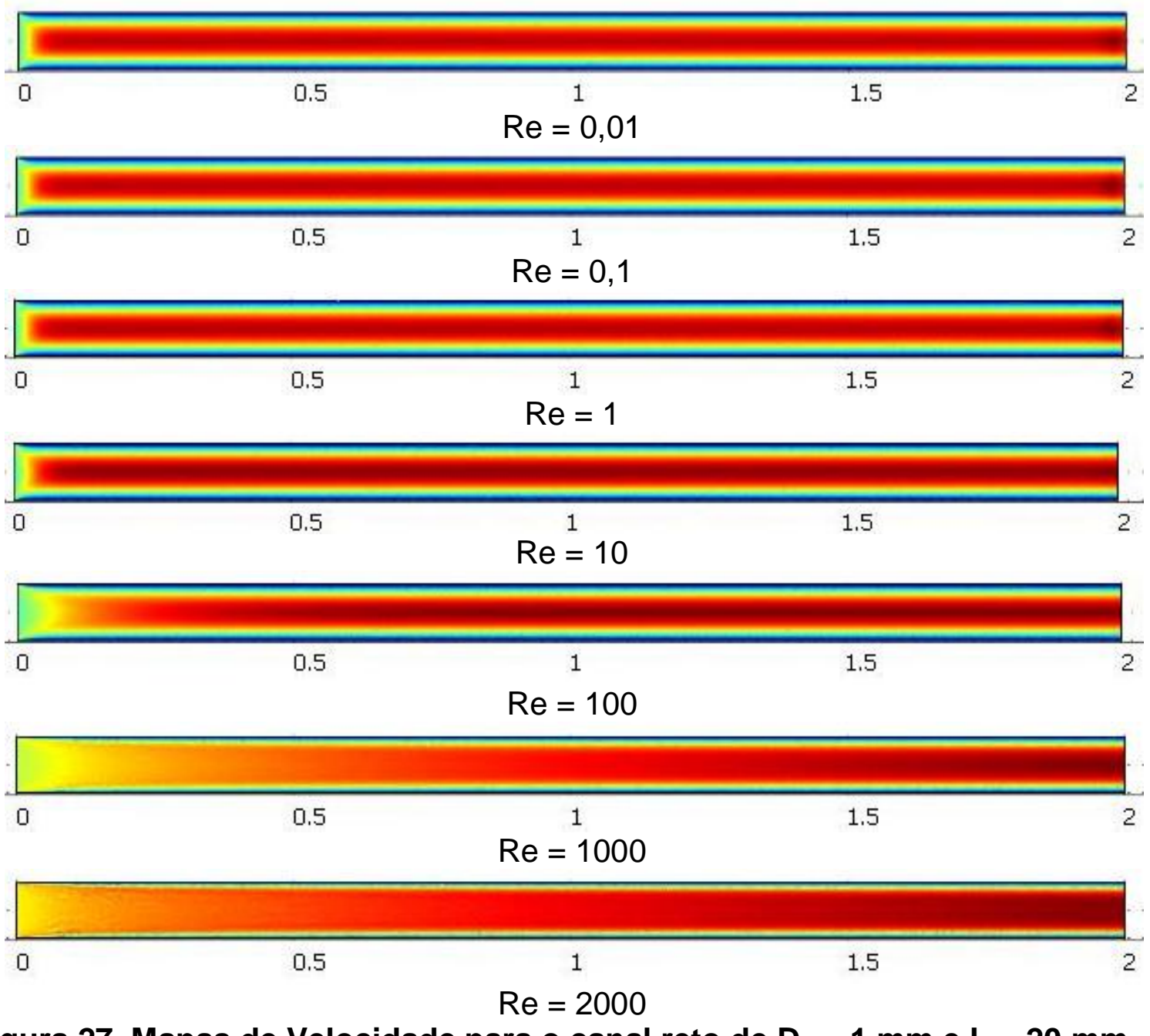

Figura 27. Mapas de Velocidade para o canal reto de $D_{h}=1 \mathrm{~mm}$ e $L=20 \mathrm{~mm}$. 
Essa mudança indica a transição de regime de escoamento, de escoamento laminar para escoamento intermediário. Com a obtenção dos parâmetros característicos do escoamento será possível discutir melhor o tipo de escoamento e transição entre escoamentos.

A figura 28 mostra os mapas de velocidade para o canal reto de $D_{h}=1 \mathrm{~mm}$ e $L$ $=20 \mathrm{~mm}$ em número de Reynolds igual a 10. As velocidades características deste escoamento varia entre 0 e $0,2 \mathrm{~m} / \mathrm{s}$. A comparação entre o perfil uniforme na entrada e o perfil parabólico na saída mostra uma velocidade média em torno de $0,1 \mathrm{~m} / \mathrm{s}$ e uma velocidade máxima de $0,2 \mathrm{~m} / \mathrm{s}$, respectivamente. Ou seja, a velocidade máxima é duas vezes a velocidade média do escoamento.

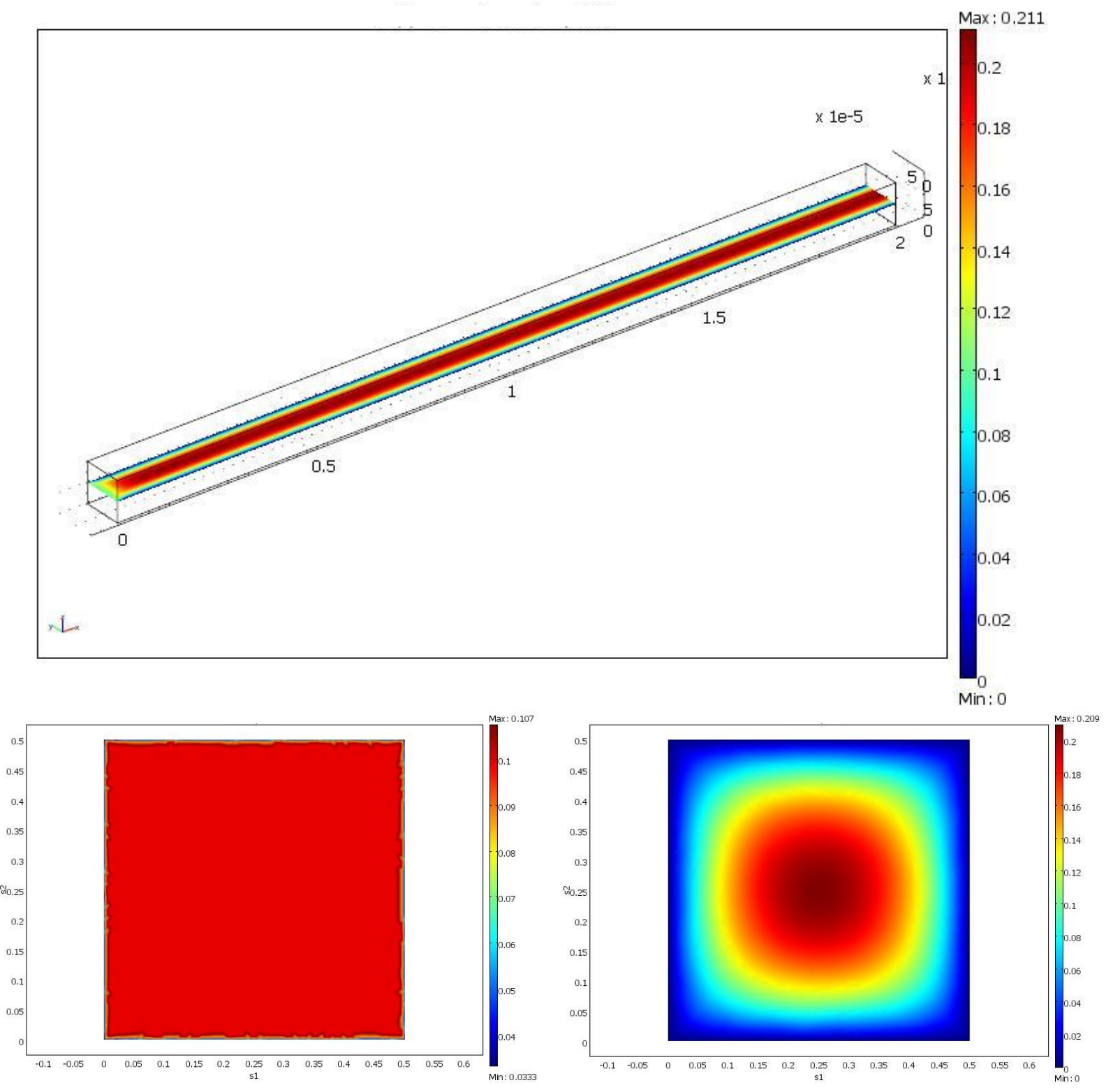

Figura 28. Mapas de Velocidade para $\mathbf{R e}=10$. 
A figura 29 mostra o mapa de pressão para o canal reto de $D_{h}=1 \mathrm{~mm} \mathrm{e} L=20$ mm em número de Reynolds igual a 10. A diferença de pressão característica para esta geometria e condição é igual a $600 \mathrm{~Pa}$. A diferença de pressão é importante para o dimensionamento do sistema de bombeamento e para a descrição do escoamento.

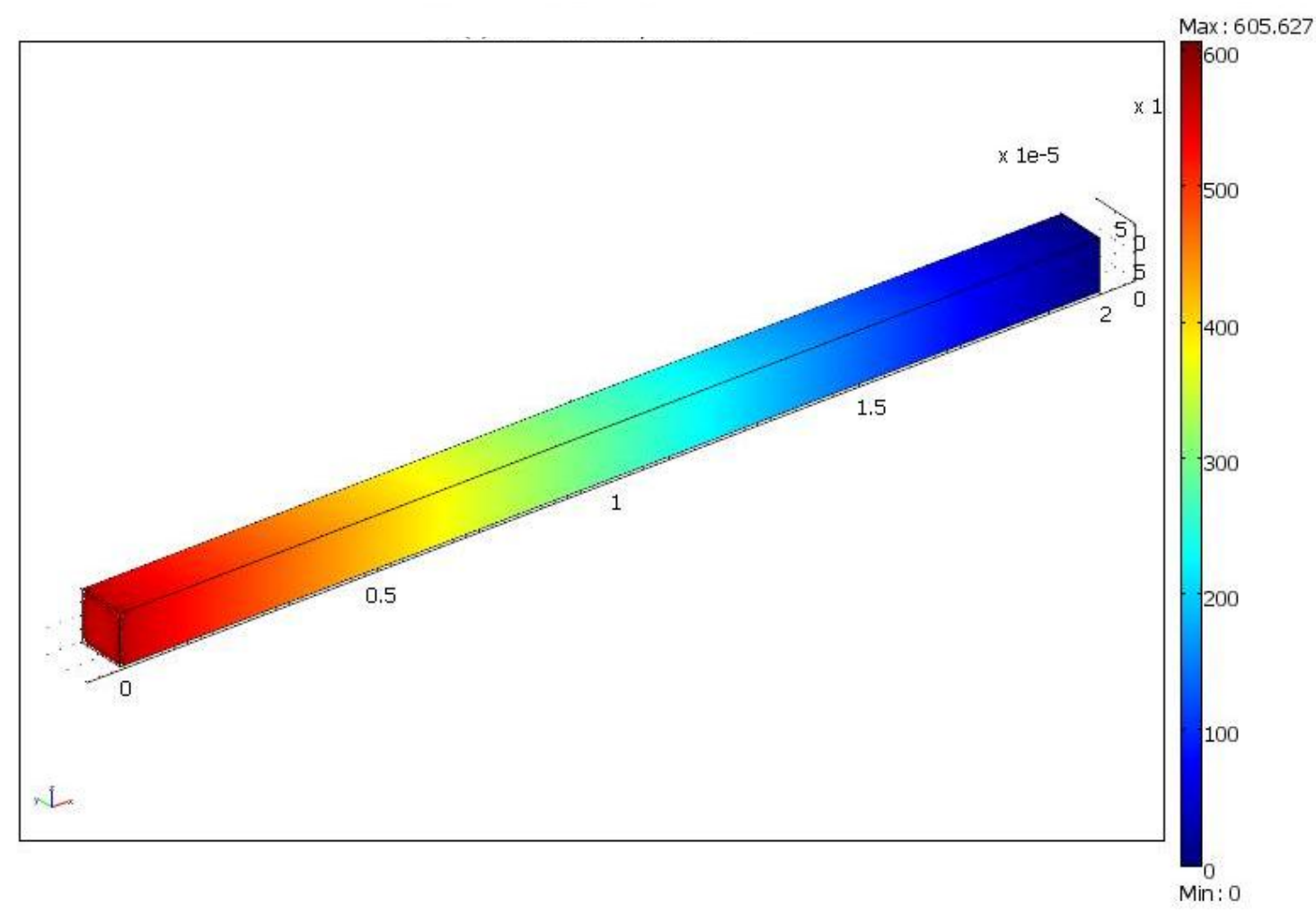

Figura 29. Mapas de Pressão.

Após a visualização dos mapas foram extraídos os parâmetros de interesse das simulações: fator de atrito, coeficiente de perda de carga, vorticidade, diferença de pressão, resistência hidráulica, tempo de residência e potência volumétrica.

$\mathrm{O}$ fator de atrito (f) em regime laminar é inversamente proporcional ao número de Reynolds $(R e)$, dado pela equação

$$
f=\frac{c}{R e} \text { (Fox, 1985) }
$$

eq. 7 ,

onde c é uma constante que depende da geometria da seção transversal do canal. Sendo $c=64$ e $c=56,9083$, para seção transversal circular e quadrada, respectivamente.

O coeficiente de perda de carga em regime laminar é dado pela equação

$$
K=f \cdot \frac{L_{e}}{D_{h}}(\text { Fox, 1985) }
$$

eq. 8 , 
onde f é o fator de atrito e $D_{\mathrm{h}}$ é o diâmetro hidráulico. Esse parâmetro é utilizado quando existem perdas de locais num canal. Essas perdas locais referem-se a cotovelos, restrições e outros acessórios que podem ser acoplados num canal. Com esses acessórios, o comprimento do canal reto (L) não é mais usado, sendo substituído por comprimento equivalente de canal reto, chamado $\mathrm{L}_{\mathrm{e}}$.

O gráfico 1 mostra o fator de atrito e o coeficiente de perda de carga em função do número de Reynolds, para microcanais com três diâmetros hidráulicos, $1 \mathrm{~mm}$, $100 \mu \mathrm{m}$ e $10 \mu \mathrm{m}$. As curvas em preto (sólida e tracejada) mostram o fator de atrito e o coeficiente de perda de carga calculados analiticamente pelas equações 7 e 8 , respectivamente. As outras curvas referem-se a dados simulados numericamente. Observando o gráfico 1, verifica-se que a partir de $R e=100$ ocorre a transição de regime. Para $R e<100$, o regime de escoamento é puramente laminar. Para $R e>$ 100 , o regime de escoamento é intermediário entre laminar e turbulento.

Os dados numéricos apresentados no gráfico 1 confirmam as observações visuais da figura 27 , onde o mapa de velocidade para $R e=100$, começa a apresentar comportamento distinto dos mapas para números de Reynolds menores.

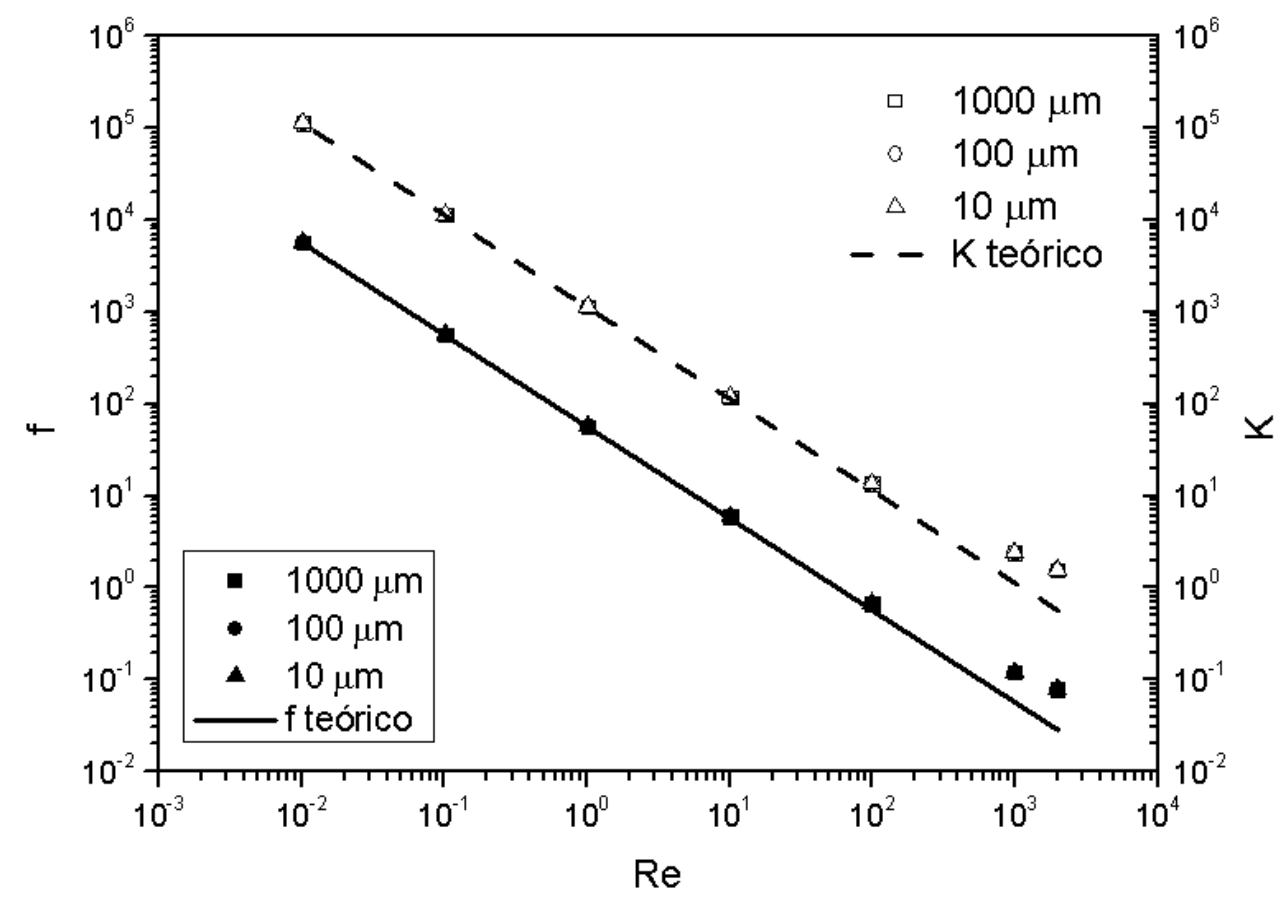

Gráfico 1. Fator de atrito (f) e coeficiente de perda de carga (K) em função do número de Reynolds.

A vorticidade $(\omega)$ quantifica a frequência de rotação de um fluido e é dada pela equação 
O gráfico 2 mostra a vorticidade em função do número de Reynolds, para canais com três diâmetros hidráulicos, $1 \mathrm{~mm}, 100 \mu \mathrm{m}$ e $10 \mu \mathrm{m}$. Em todos os gráficos contendo dados sobre vorticidade, inclusive o gráfico 2, o cálculo dessa grandeza é a média sobre todo o microcanal. Observa-se que a vorticidade apresenta um comportamento linear em função do número de Reynolds no intervalo estudado (0,01 e 2000), para os três diâmetros hidráulicos.

O canal de $1 \mathrm{~mm}$ apresenta vorticidade no intervalo estudado variando de 0,05 e 9184 1/s. Enquanto o canal com $10 \mu \mathrm{m}$, observa-se uma variação entre $497 \mathrm{e}$ $920371401 / \mathrm{s}$.

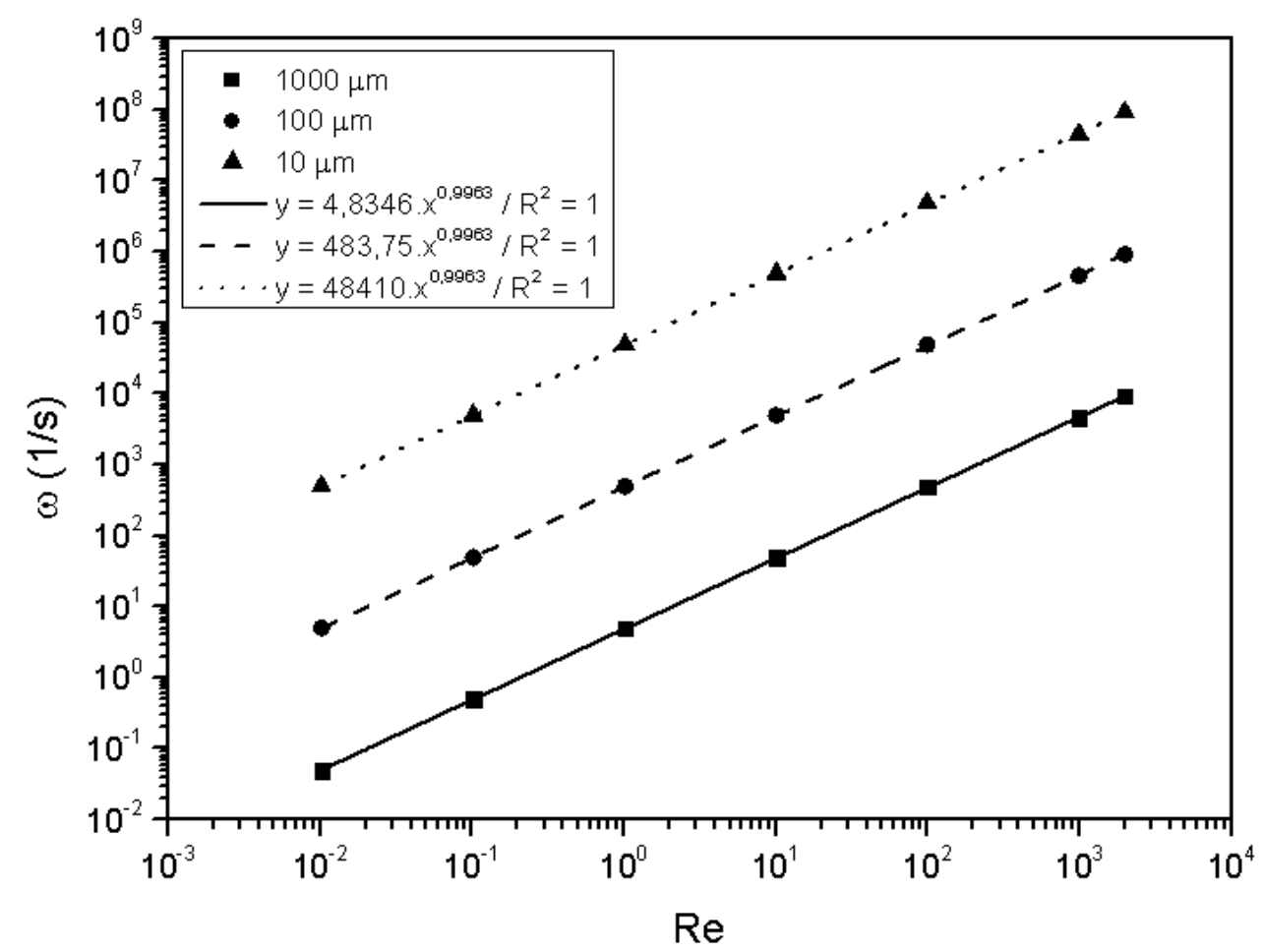

Gráfico 2. Vorticidade em função do número de Reynolds.

A diferença de pressão em regime laminar é diretamente proporcional a vazão no canal, dada pela equação

$$
\Delta P=R_{h} \cdot Q \text { (Bruus, 2000) }
$$

eq. 10 ,

onde $R_{h}$ é uma constante em regime laminar chamada resistência hidráulica. $O$ gráfico 3 apresenta as curvas de diferença de pressão (linhas sólidas) e resistência hidráulica (linhas tracejadas) em função da vazão.

Observa-se que tanto as curvas de diferença de pressão e resistência hidráulica apresentam duas regiões. Considerando a diferença de pressão para o canal com $1 \mathrm{~mm}$ de diâmetro hidráulico, observa-se as regiões A e B. 
$\mathrm{Na}$ região $\mathrm{A}$, observa-se um comportamento linear da diferença de pressão $(0,006$ e 67,093 Pa) em função do intervalo de vazão estudado $(0,0006$ e 5,9863 $\mathrm{ml} / \mathrm{min}$ ), ou seja, essa região obedece a equação 10 , diferença de pressão em função da vazão em regime laminar.

Na região $\mathrm{B}$, observa-se um comportamento distinto do encontrado na região A. A diferença de pressão (67,093 e 3111,651 Pa) apresenta um comportamento não-linear em função do intervalo de vazão estudado (5,9863 e 119,1851 ml/min). Essa diferença de comportamento deve-se a descrições de regime de escoamento diferentes nas regiões $A$ e $B$.

Se projetarmos as regiões $A$ e B, na curva de resistência hidráulica em função vazão, observa-se uma região de resistência hidráulica constante, característica da descrição de regime laminar. E uma região onde a resistência hidráulica é nãoconstante, obedecendo outra descrição de escoamento.

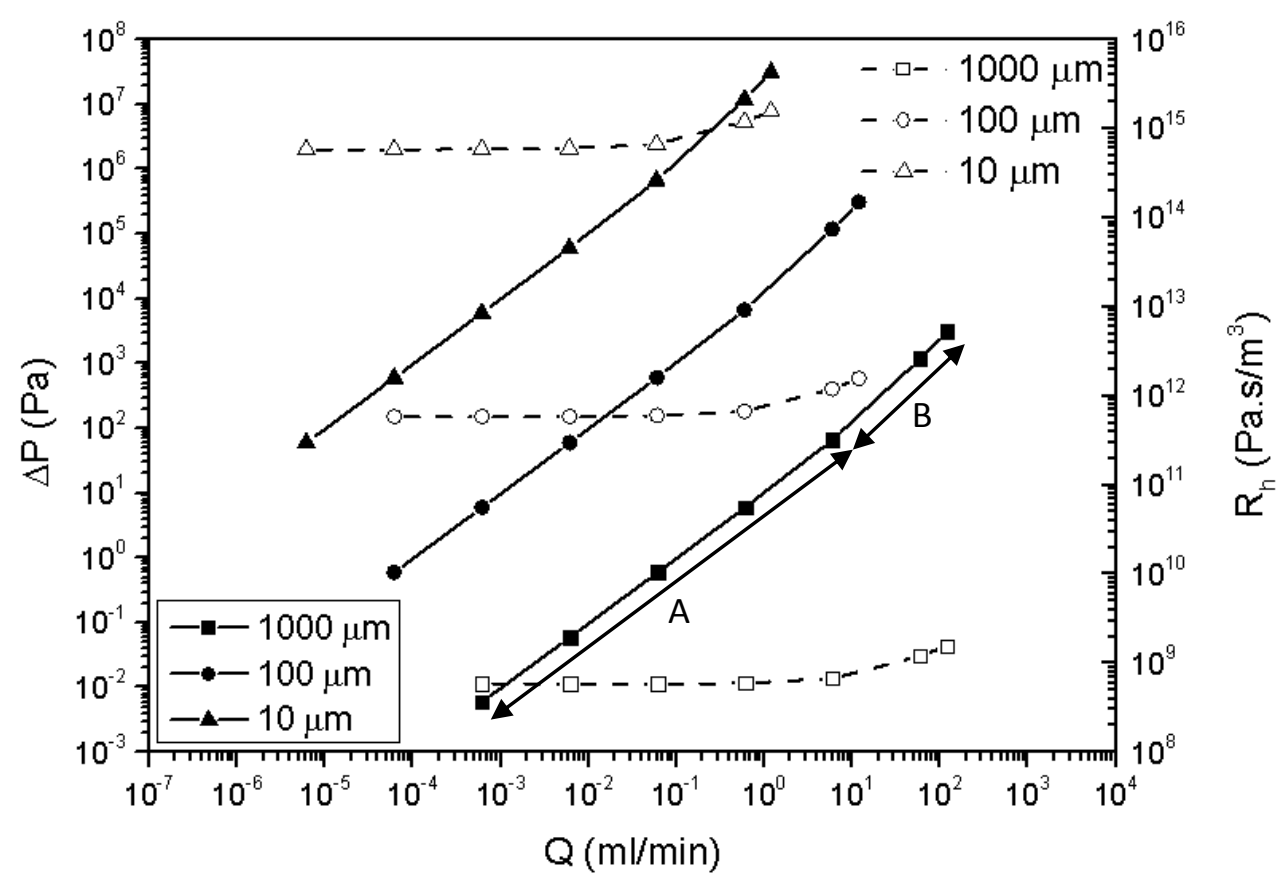

Gráfico 3. Diferença de pressão e resistência hidráulica em função da vazão.

O tempo de residência é o tempo gasto por um volume infinitesimal entre a entrada e a saída de um microcanal. O valor médio do tempo de residência é dado pela equação

$$
t=\frac{\Delta V}{Q}(\text { Bruss, 2000) }
$$

eq. 11,

onde $\Delta V$ é o volume do canal e $Q$ é a vazão. 
A potência volumétrica $\left(\mathrm{W} / \mathrm{m}^{3}\right)$ é a potência gasta na produção por unidade de volume e é dada pela equação

$$
P_{v}=\frac{\Delta P \cdot Q}{\Delta V}
$$

onde $\Delta \mathrm{P}$ é a diferença de pressão, $\mathrm{Q}$ é a vazão e $\Delta \mathrm{V}$ é o volume do dispositivo.

O gráfico 4 mostra as curvas de tempo de residência (linhas sólidas) e de potência volumétrica (linhas tracejadas) em função da vazão, para três diâmetros hidráulicos, $1 \mathrm{~mm}, 100 \mu \mathrm{m}$ e $10 \mu \mathrm{m}$. Observa-se que o tempo de residência é inversamente proporcional a vazão, enquanto a potência volumétrica é diretamente proporcional a vazão.

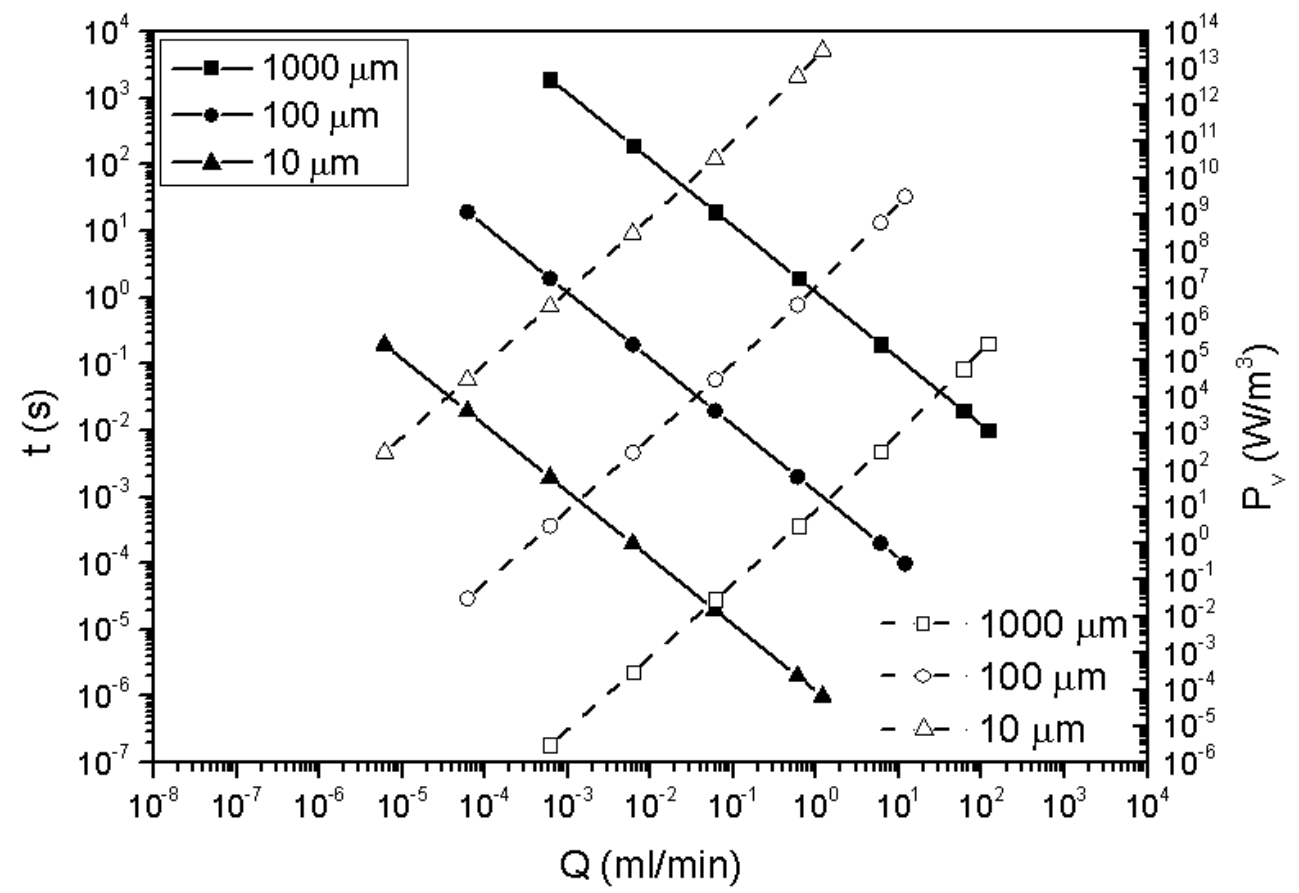

\section{Gráfico 4. Tempo de residência e potência volumétrica em função da vazão.}

O tempo de residência também pode ser escrito em função da diferença de pressão ou da potência volumétrica. Em função da diferença de pressão é dado pela equação

$$
t=\frac{\Delta V \cdot R_{h}}{\Delta P}
$$

e em função da potência volumétrica é dado pela equação

$$
t=R_{h} \cdot \frac{Q}{P_{v}}
$$

O gráfico 5 mostra o tempo de residência em função da diferença de pressão, para canais com três diâmetros hidráulicos diferentes, 1 mm, $100 \mu \mathrm{m}$ e $10 \mu \mathrm{m}$. Observa-se que o tempo de residência é inversamente proporcional a diferença de pressão. As curvas também são influenciadas pelos regimes de escoamento 
encontrados nos dados anteriores. Portanto, as curvas apresentam duas regiões: uma referente à descrição de escoamento do regime laminar e outra referente ao regime intermediário.

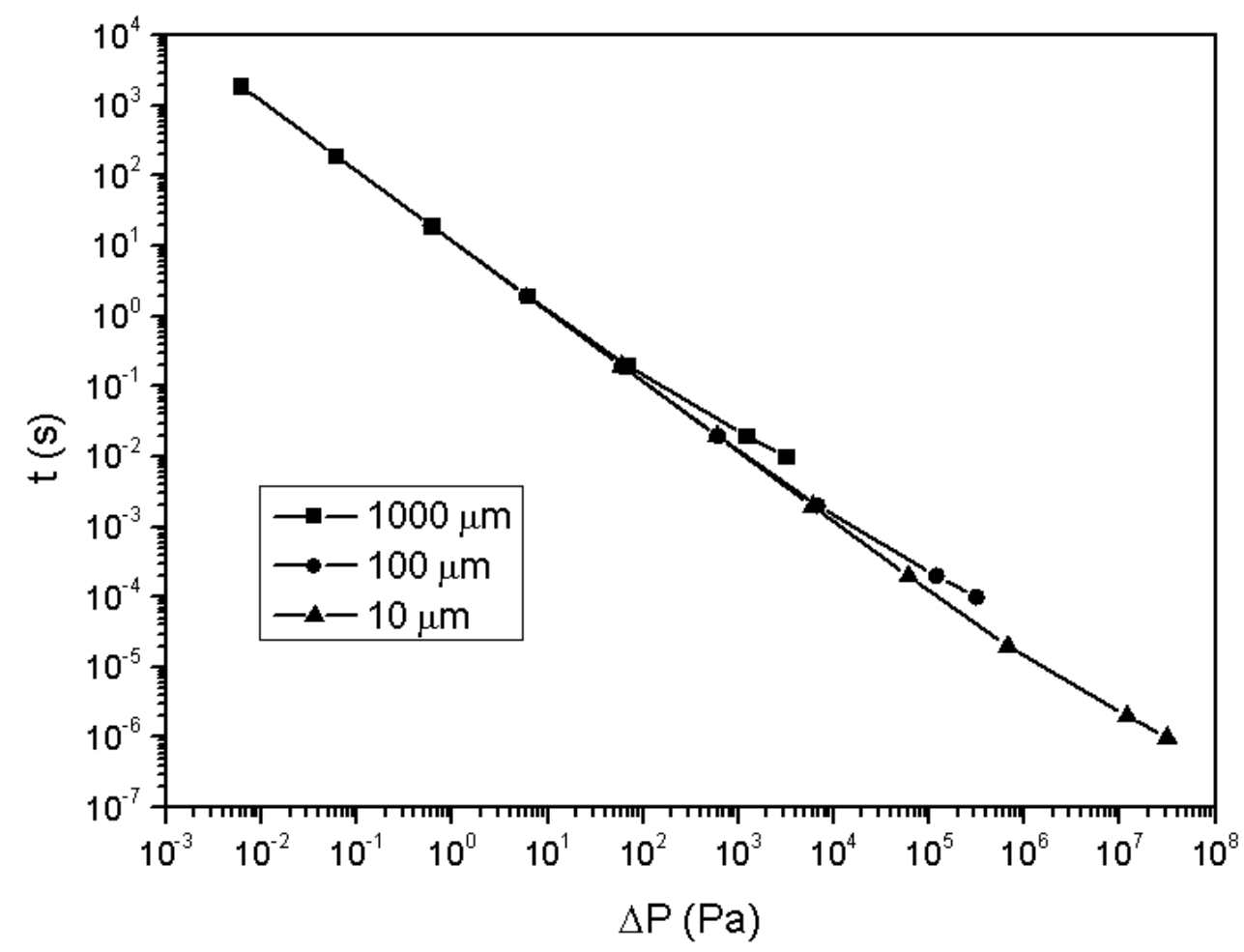

Gráfico 5. Tempo de residência em função da diferença de pressão.

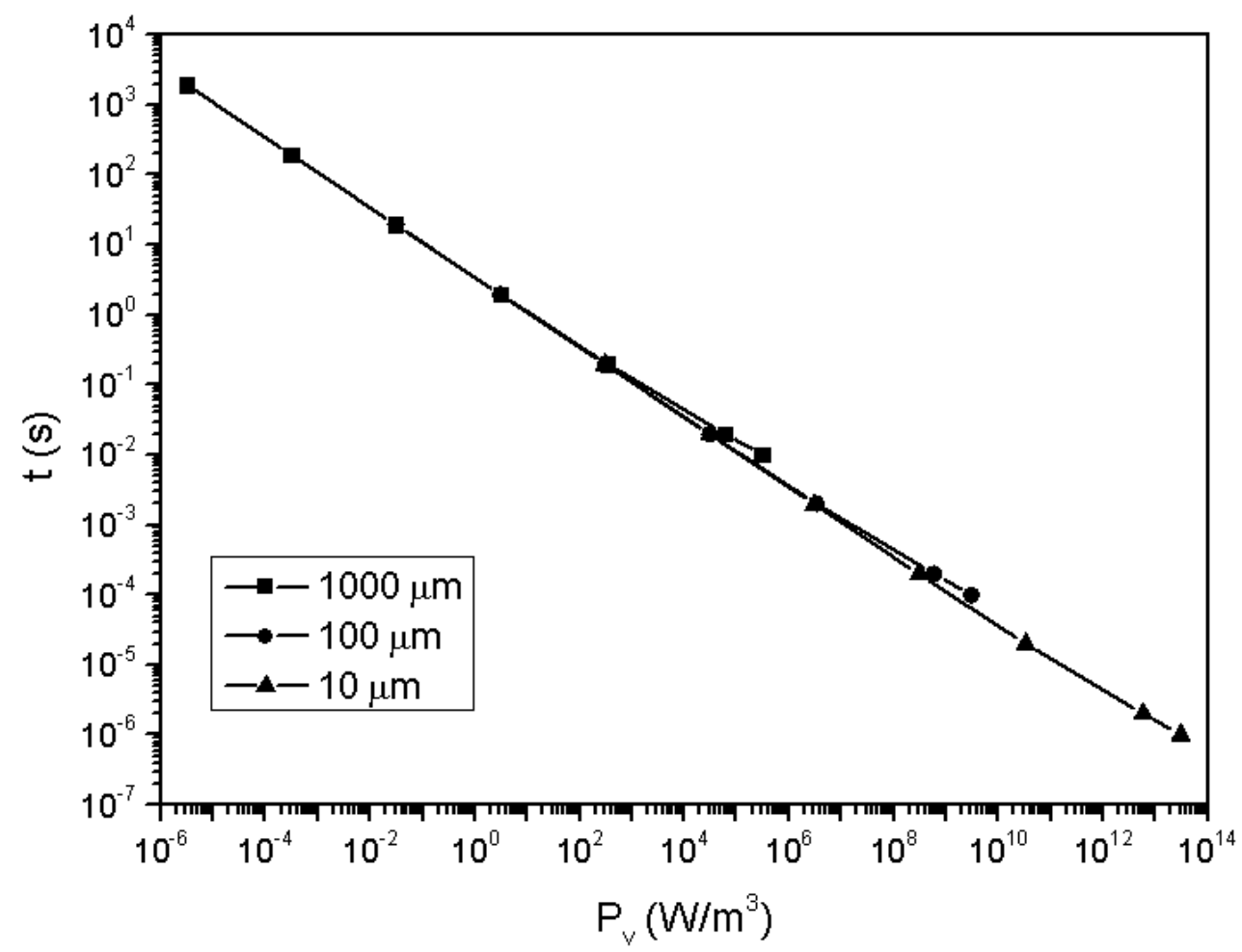

Gráfico 6. Tempo de residência em função da potência volumétrica. 
O gráfico 6 mostra o tempo de residência em função da potência volumétrica, para canais com três diâmetros hidráulicos diferentes, $1 \mathrm{~mm}, 100 \mu \mathrm{m}$ e $10 \mu \mathrm{m}$. Observa-se que o tempo de residência é inversamente proporcional a potência volumétrica.

Os gráficos 4, 5 e 6 são importantes para o mapeamento das características do processo químico em questão. As reações químicas ocorrem em função do tempo de residência. Para um dado tempo de residência, com as curvas traçadas é possível saber qual a vazão necessária para o processo. Bem como, obter a diferença de pressão e a potência volumétrica resultantes do processo.

\subsubsection{Resumo}

O estudo computacional foi realizado com três microcanais retos com diâmetros hidráulicos diferentes ( $1 \mathrm{~mm}, 100 \mu \mathrm{m}$ e $10 \mu \mathrm{m}$ ), no intervalo do número de Reynolds entre 0,01 e 2000.

A visualização dos mapas de velocidade permitiu identificar dois regimes de escoamento. Com a obtenção dos parâmetros numéricos foi possível identificar o regime de escoamento laminar no intervalo do número de Reynolds entre 0,01 e 100. No intervalo do número de Reynolds entre 100 e 2000, o regime de escoamento é intermediário entre o laminar e o turbulento. Essa transição de regime para canais em macro-escala é registrada na literatura para número de Reynolds entre 1000 e 2000.

A obtenção dos parâmetros numéricos permitiu investigar alguns comportamentos no intervalo do regime laminar:

- O fator de atrito é inversamente proporcional ao número de Reynolds,

- O coeficiente de perda de carga é inversamente proporcional ao número de Reynolds,

- A vorticidade é diretamente proporcional ao número de Reynolds,

- A diferença de pressão é diretamente proporcional a vazão e relacionados por uma constante de proporcionalidade chamada resistência hidráulica,

- O tempo de residência é inversamente proporcional a vazão,

- O tempo de residência é inversamente proporcional a diferença de pressão, 
- O tempo de residência é inversamente proporcional a potência volumétrica, e

- A potência volumétrica é diretamente proporcional a vazão.

Os próximos estudos serão conduzidos no intervalo do número de Reynolds entre 0,01 e 100, que é o intervalo conhecido de regime laminar em microcanais retos. Esse procedimento será adotado para comparação com os microcanais baseados em sucessivos cotovelos neste mesmo intervalo. 
4.5. Estudo 2: Influência da distância entre dois cotovelos sucessivos

O objetivo deste estudo é verificar como dois cotovelos sucessivos influenciam na descrição do regime de escoamento. A partir desta constatação será possível obter parâmetros de interesse como a distância entre dois cotovelos sucessivos (dec) e a disposição espacial destes cotovelos.

A tabela 16 mostra a definição das geometrias estudadas, onde três disposições espaciais entre dois cotovelos sucessivos foram identificadas como:

- estrutura 1,

- estrutura 2, e

- estrutura 3.

Para cada estrutura os comprimentos de entrada (A) e saída (B) foram mantidos constantes, $D_{e}=8 \mathrm{~mm}$ e $D_{s}=8 \mathrm{~mm}$, respectivamente, para isolar as variações na descrição do escoamento entre os cotovelos.

A parte intermediária (C) do microcanal foi variada para obtenção das distâncias entre os cotovelos (dec), como mostrado na tabela 16 para estrutura 1. Para as estruturas 2 e 3, as distâncias entre os cotovelos foram $\operatorname{dec}=1,2,3,4,5$ e 10. Logo, a distância entre cotovelos parametrizada em função do diâmetro hidráulico do microcanal é dada por $D_{\mathrm{ec}}=\operatorname{dec} \cdot \mathrm{D}_{\mathrm{h}}$. Ao total, 17 geometrias serão avaliadas neste estudo. 
Tabela 16. Estudo 2: Definição das geometrias.

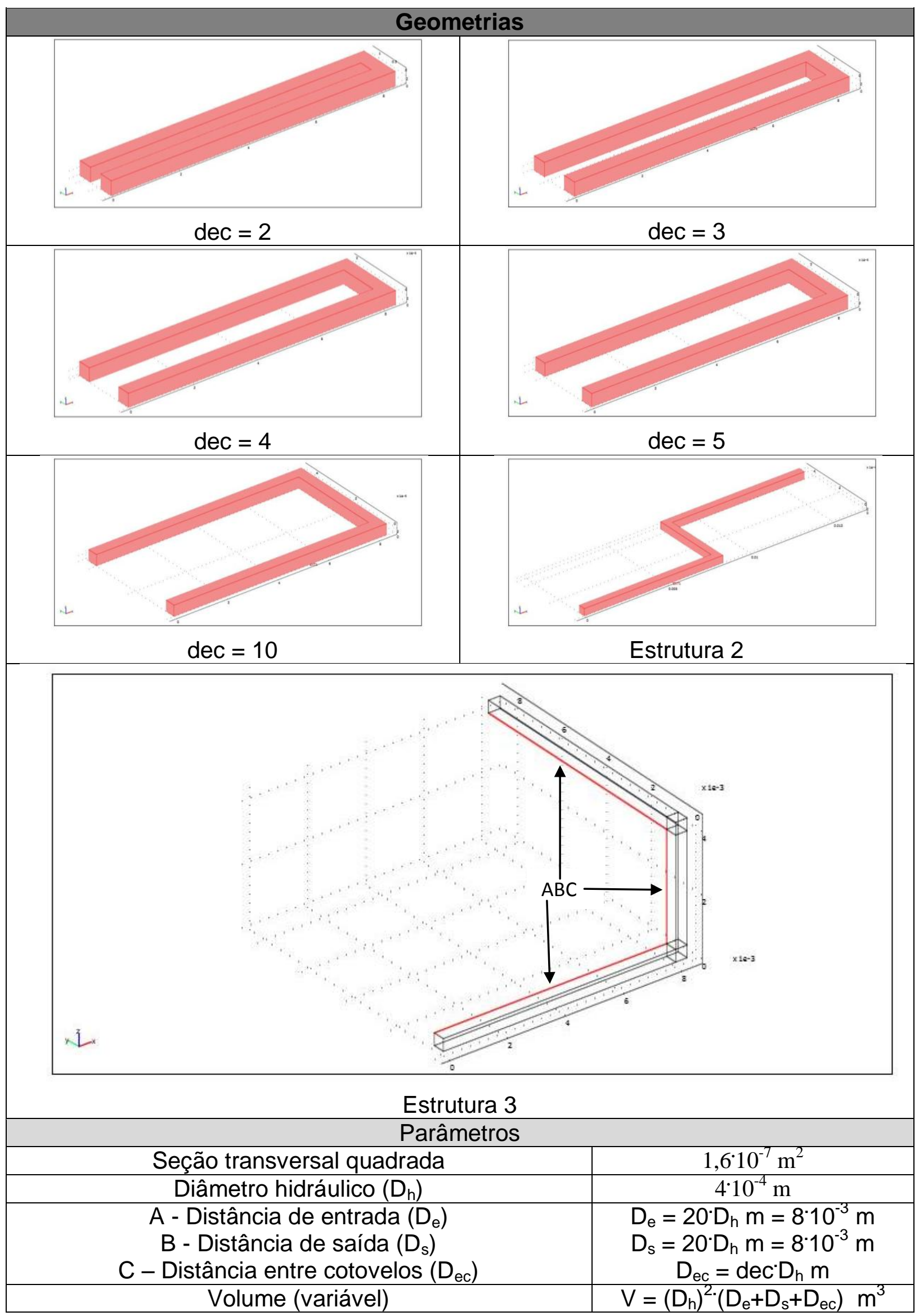


Tabela 17. Estudo 2: Condições de contorno.

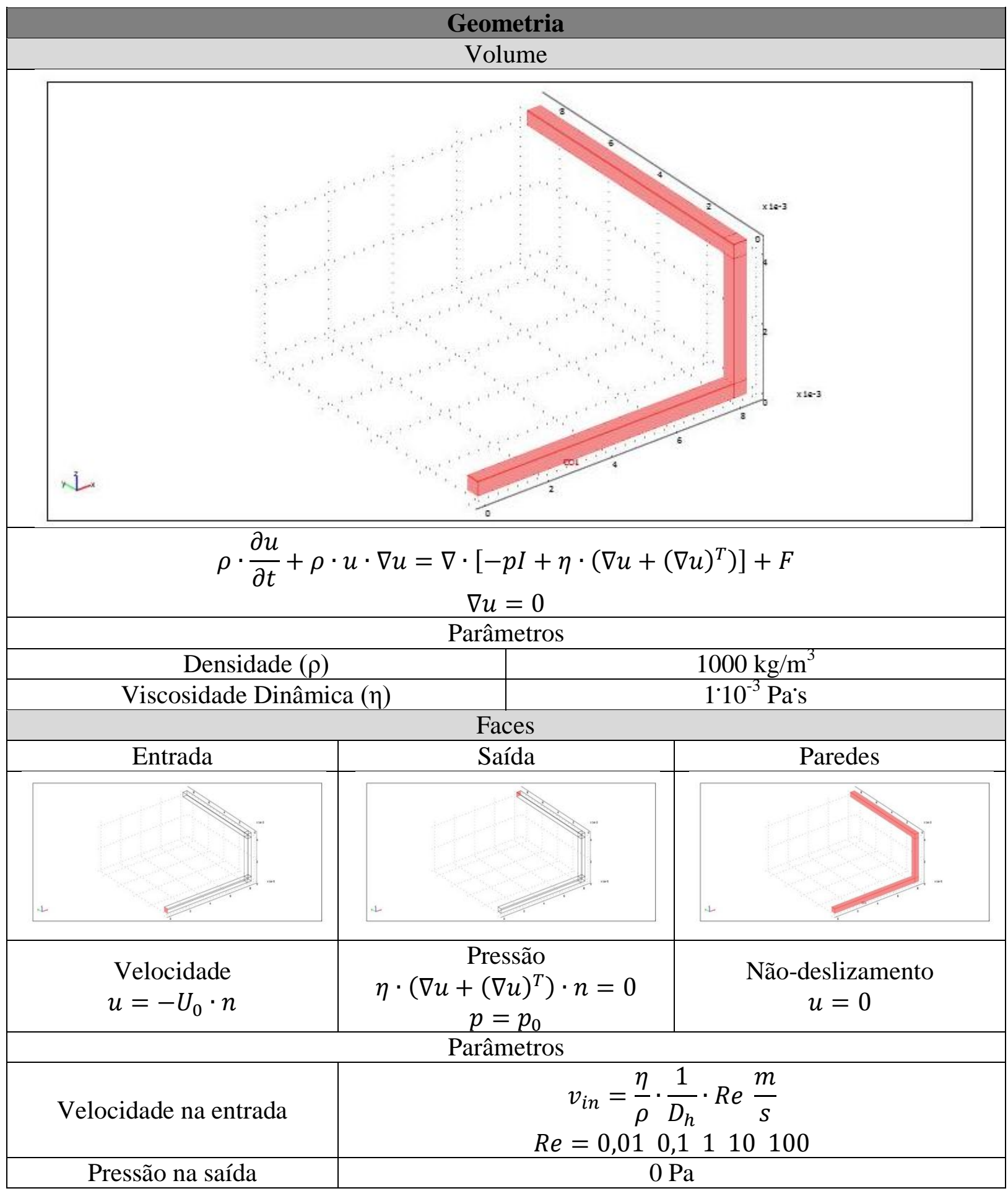

As condições de contorno estão definidas na tabela 17. No volume, a equação de Navier-Stokes na forma diferencial é resolvida numericamente, com difusão artificial Streamline diffusion - Galerkin Least-Squares (GLS). Nas faces, perfil de velocidade uniforme na entrada, pressão nula na saída e condição de nãodeslizamento (velocidade nula) nas paredes. Cada uma das 17 geometrias será 
analisada no intervalo de cinco décadas do número de Reynolds (0,01 0,1110 100), totalizando 85 simulações.

Tabela 18. Estudo 2: Discretização da geometria.

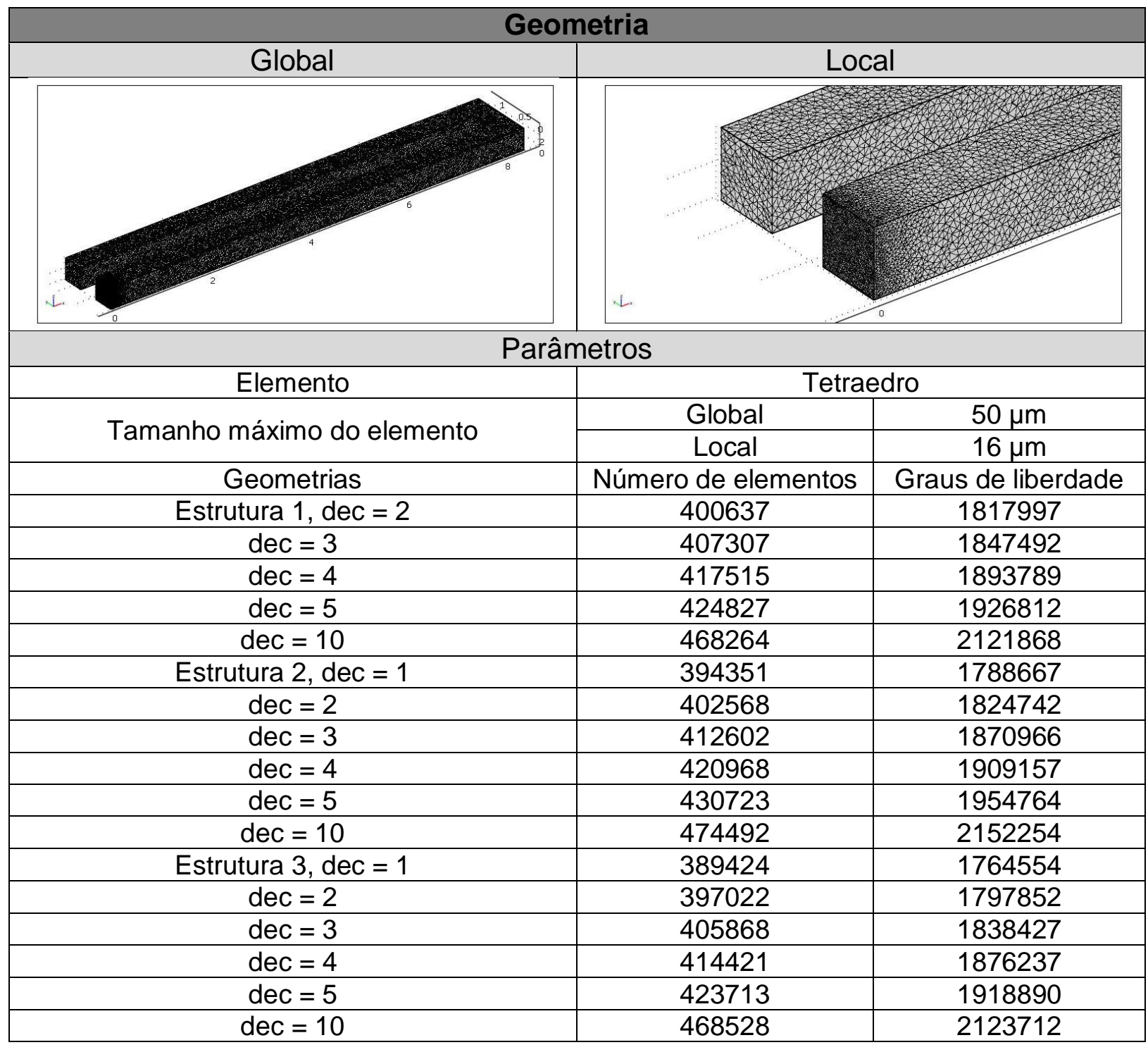

A tabela 18 mostra a discretização da geometria. O elemento utilizado foi 0 tetraedro (04 faces e 04 nós) com tamanho global no volume e tamanho local na face de entrada. Finalizado o pré-processamento, o modelo está pronto para ser processado.

Após o processamento com solver GMRES e pré-condicionador Geometric multigrid foram obtidos os mapas das propriedades de interesse. A figura 30 mostra os mapas do campo de velocidades para o intervalo do número de Reynolds estudado, para estrutura 1. Verifica-se que o comportamento do escoamento para $\operatorname{Re}=0,010,1110$, não apresentou nenhuma alteração significativa visualizando-se 
os mapas dos campos de velocidades. Essa mesma constatação é válida para as outras distâncias entre cotovelos para estrutura 1, bem como, para estrutura 2 e 3 , no mesmo intervalo do número de Reynolds.

Para $R e=100$, observa-se um diferente comportamento do regime de escoamento. Perto dos cotovelos, verifica-se que as linhas do campo de velocidades apresentam um padrão distinto do observado para número de Reynolds menores. Essa constatação é válida para as outras distâncias entre cotovelos para estrutura 1, bem como, para estrutura 2 e $3, R e=100$.

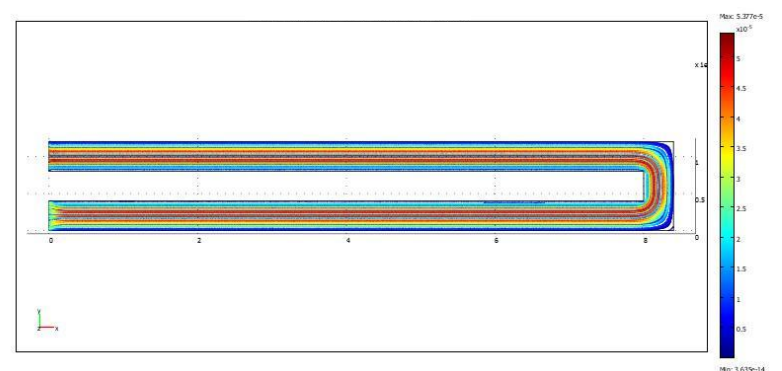

$\mathrm{Re}=0,01$

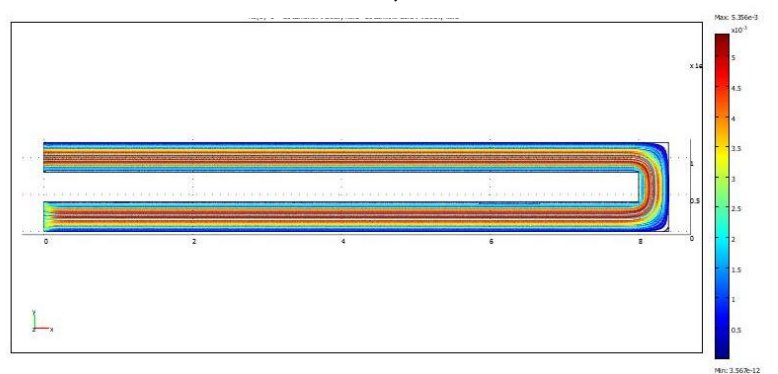

$\operatorname{Re}=1$

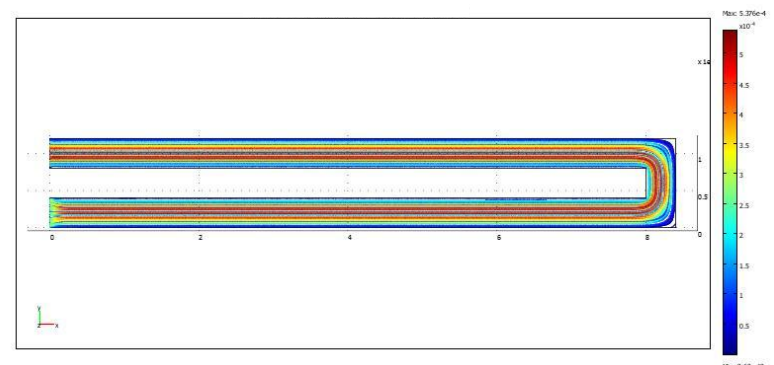

$\mathrm{Re}=0,1$

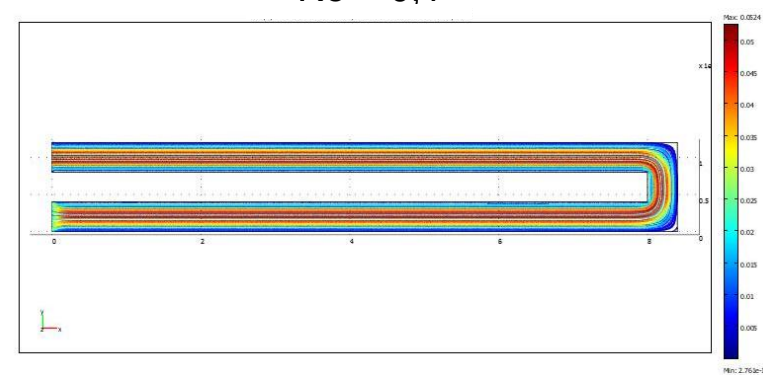

$\mathrm{Re}=10$

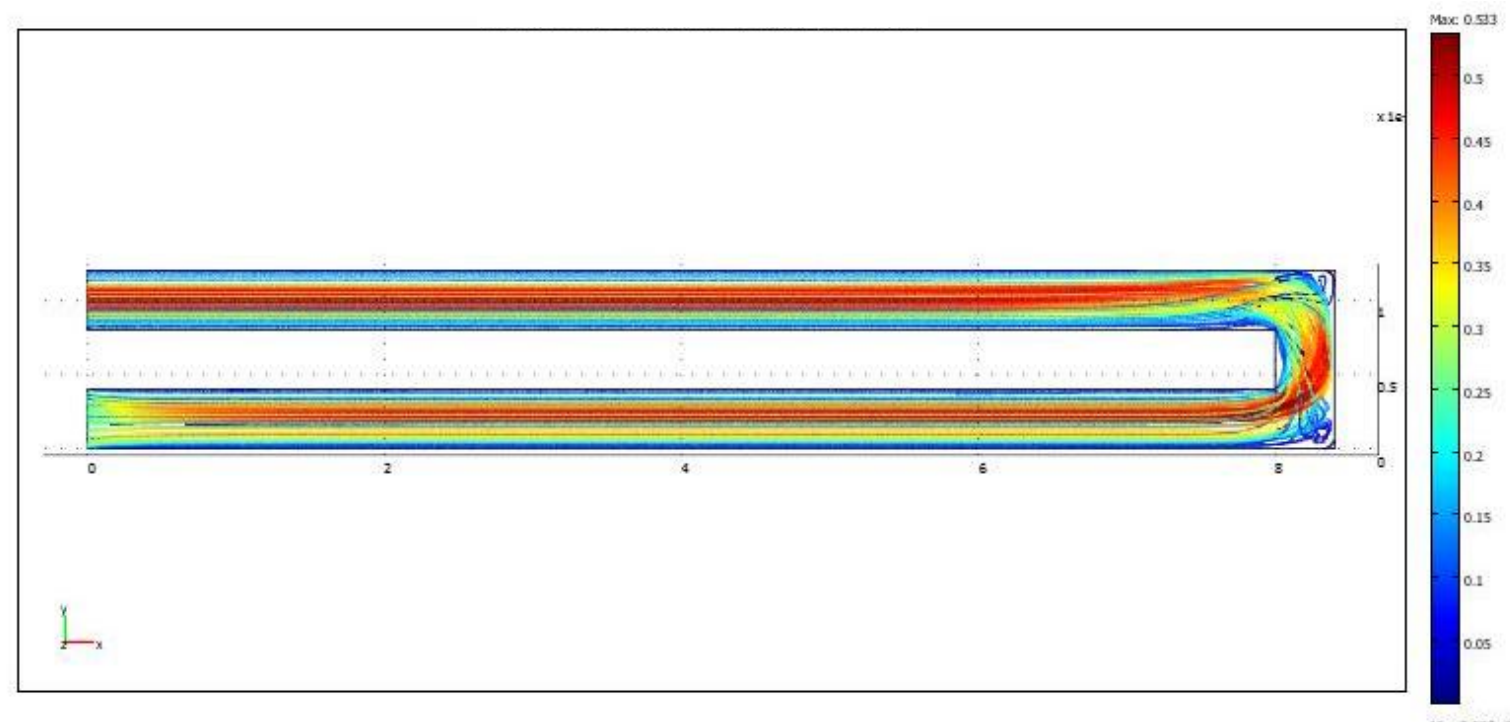

$\operatorname{Re}=100$

Figura 30. Visualização dos mapas do campo de velocidades para estrutura 1, em função do número de Reynolds. 
A figura 31 mostra o detalhe das linhas de campo de velocidades na região dos cotovelos para as estruturas 1,2 e 3 , para $R e=100$. Verifica-se que na região dos cotovelos as linhas de campo ficam instáveis, apresentando torção e cruzamento das linhas de campo. Portanto, será dada atenção no seguimento deste estudo para a obtenção dos parâmetros em $\mathrm{Re}=100$.

Após a visualização dos mapas das propriedades de interesse, foram obtidos os seguintes parâmetros numéricos: coeficiente de perda de carga, vorticidade e velocidade máxima relativa, todos em função do número de Reynolds e da distância entre cotovelos.

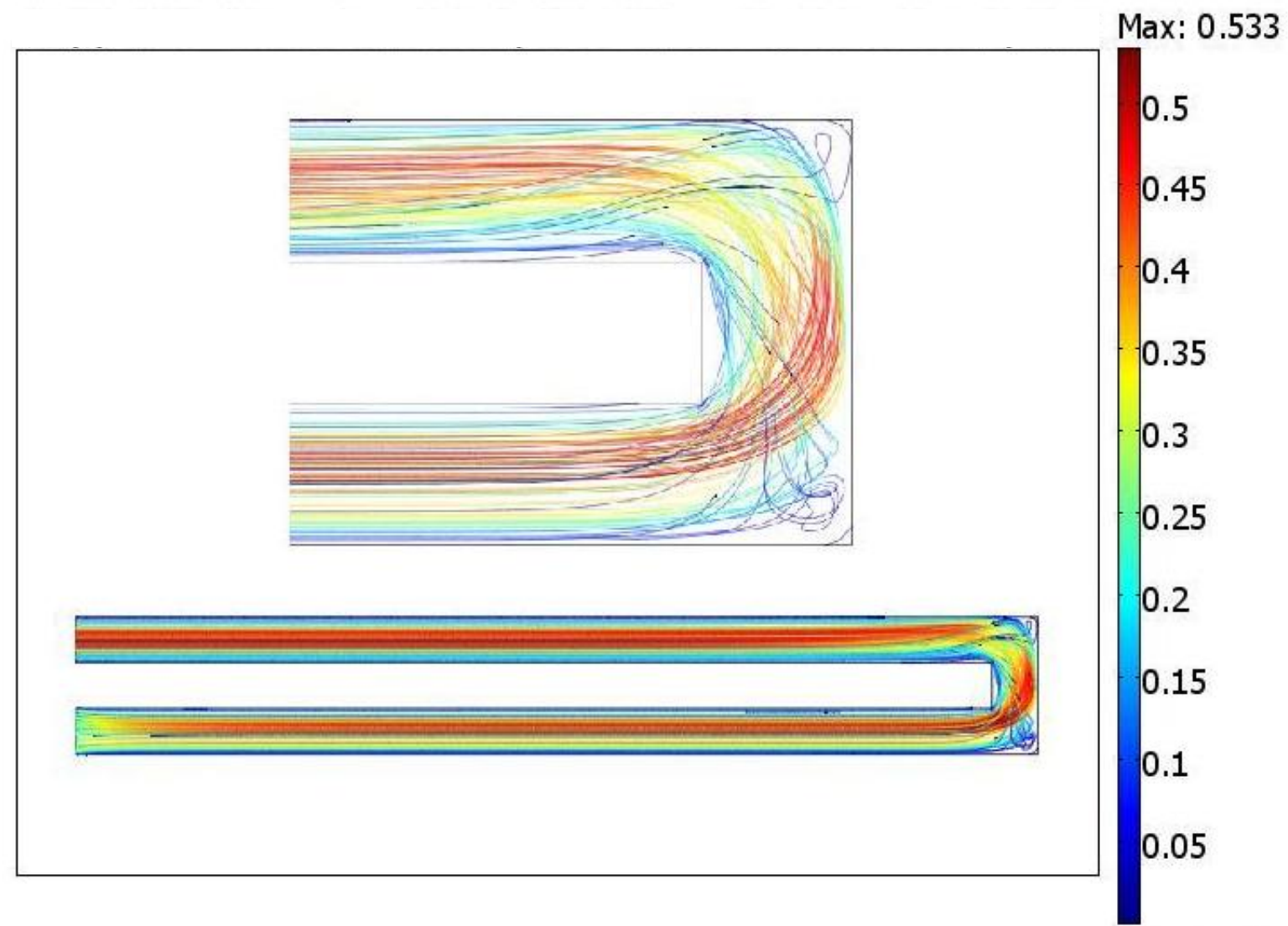

Min: $3.593 e-9$ 
Max: 0.631

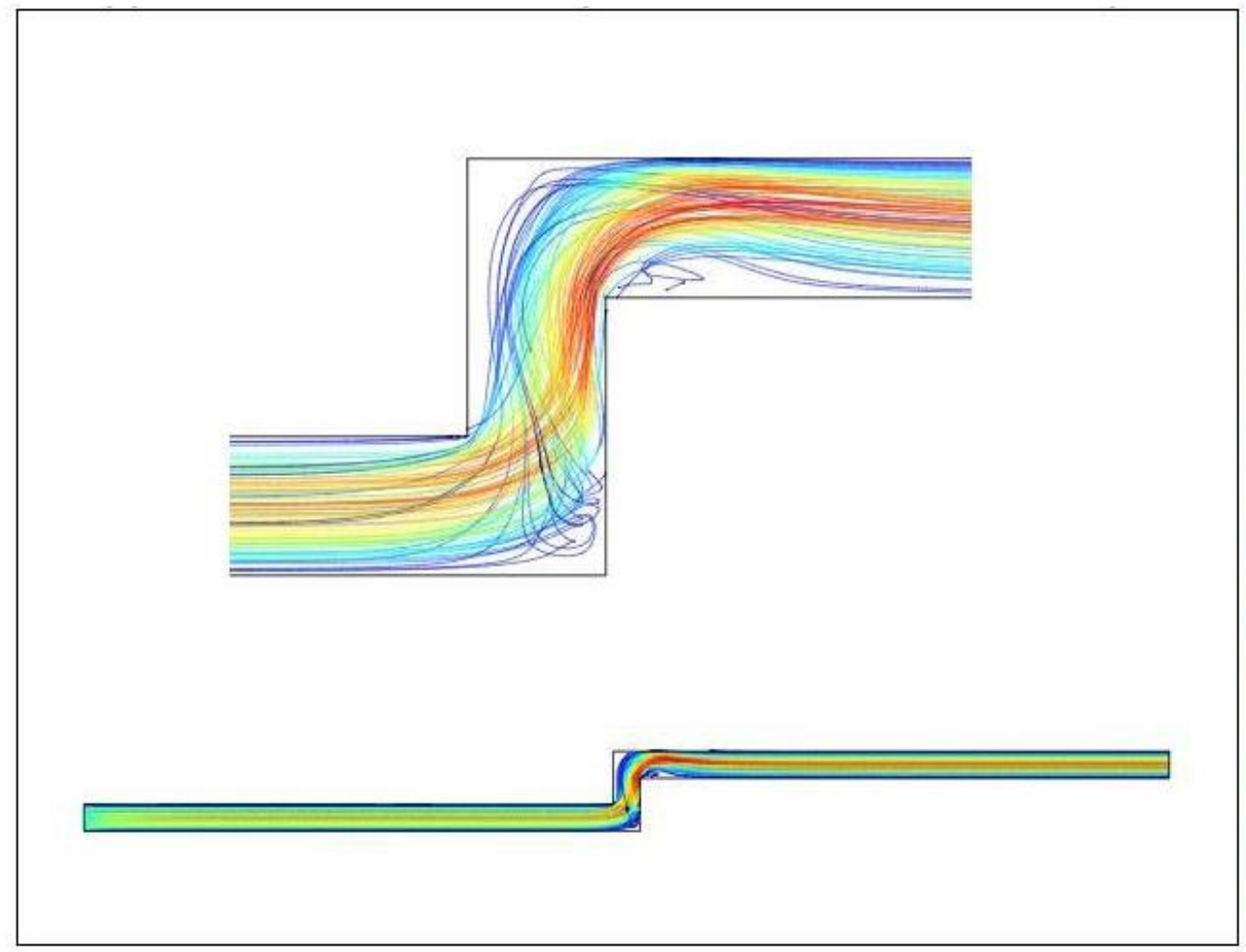

0.6

0.5

0.4

0.3

0.2

0.1

Min: $1.841 \mathrm{e}-9$

Max: 0.581

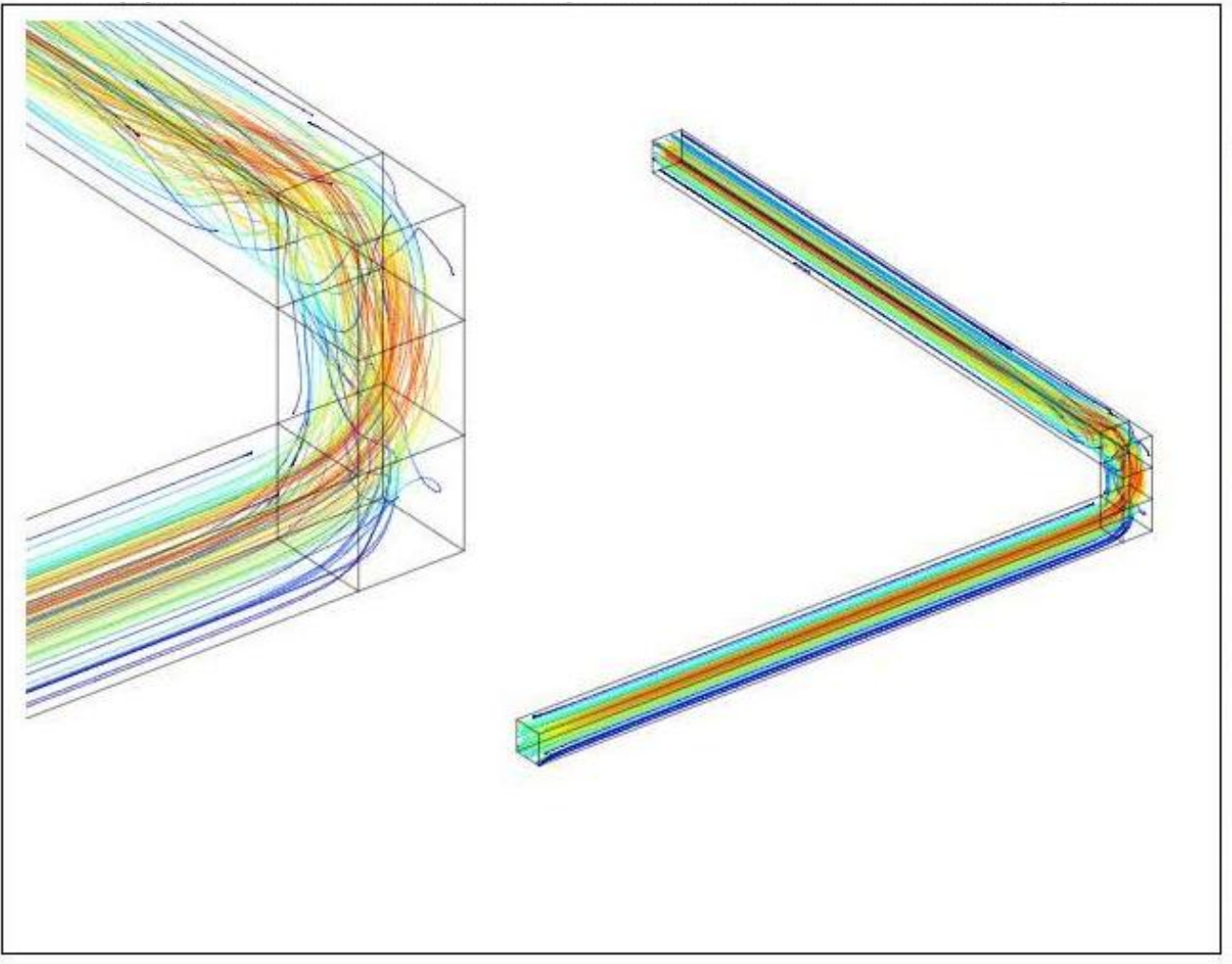

0.5

0.4

0.3

0.2

0.1

Min: $6.904 \mathrm{e}-9$

Figura 31. Detalhe do escoamento na região dos cotovelos para as estruturas 1,2 e 3, para $\operatorname{Re}=100$. 


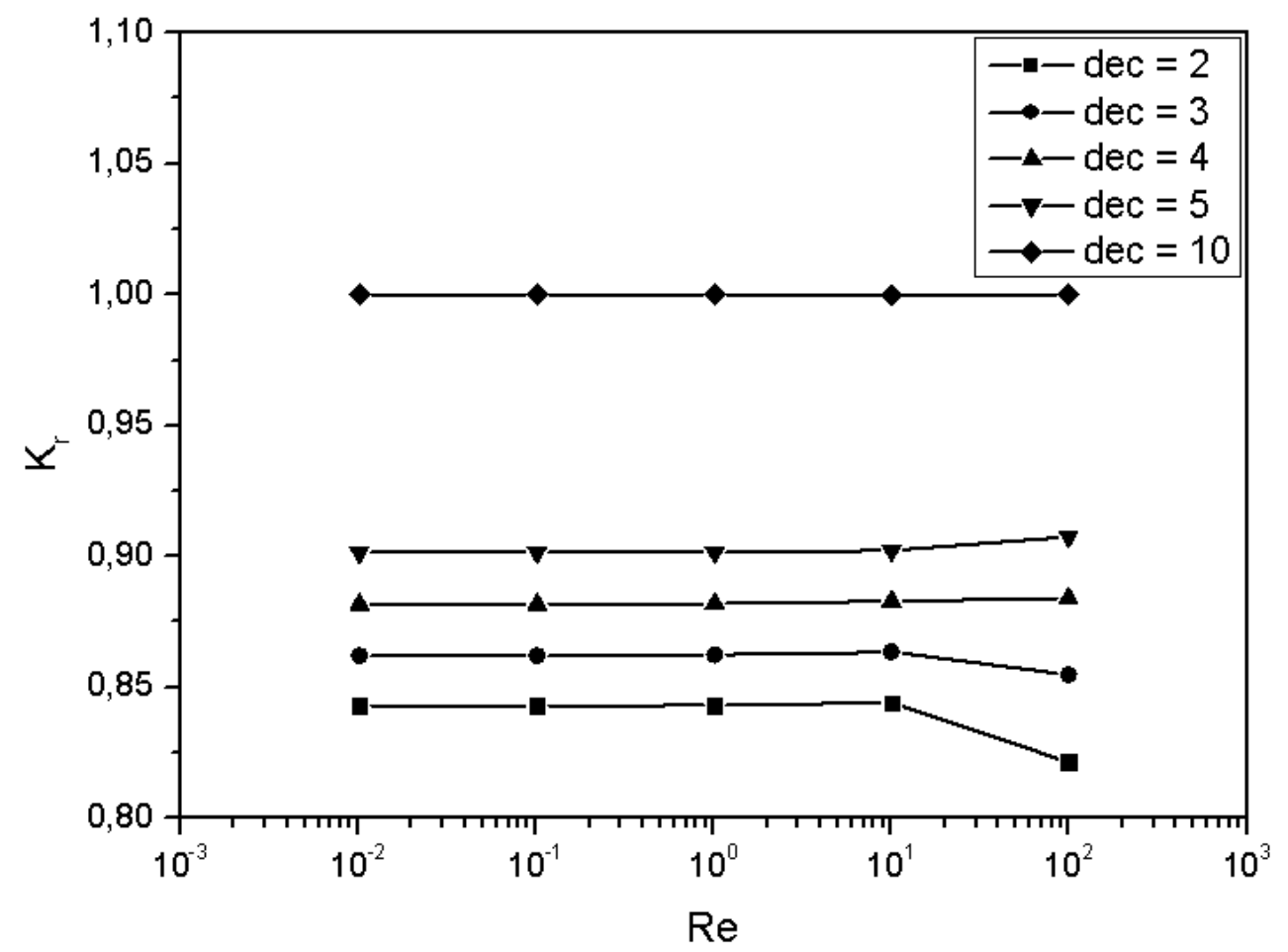

Gráfico 7. Estrutura 1: K relativo em função do número de Reynolds, para as diversas distâncias entre cotovelos.

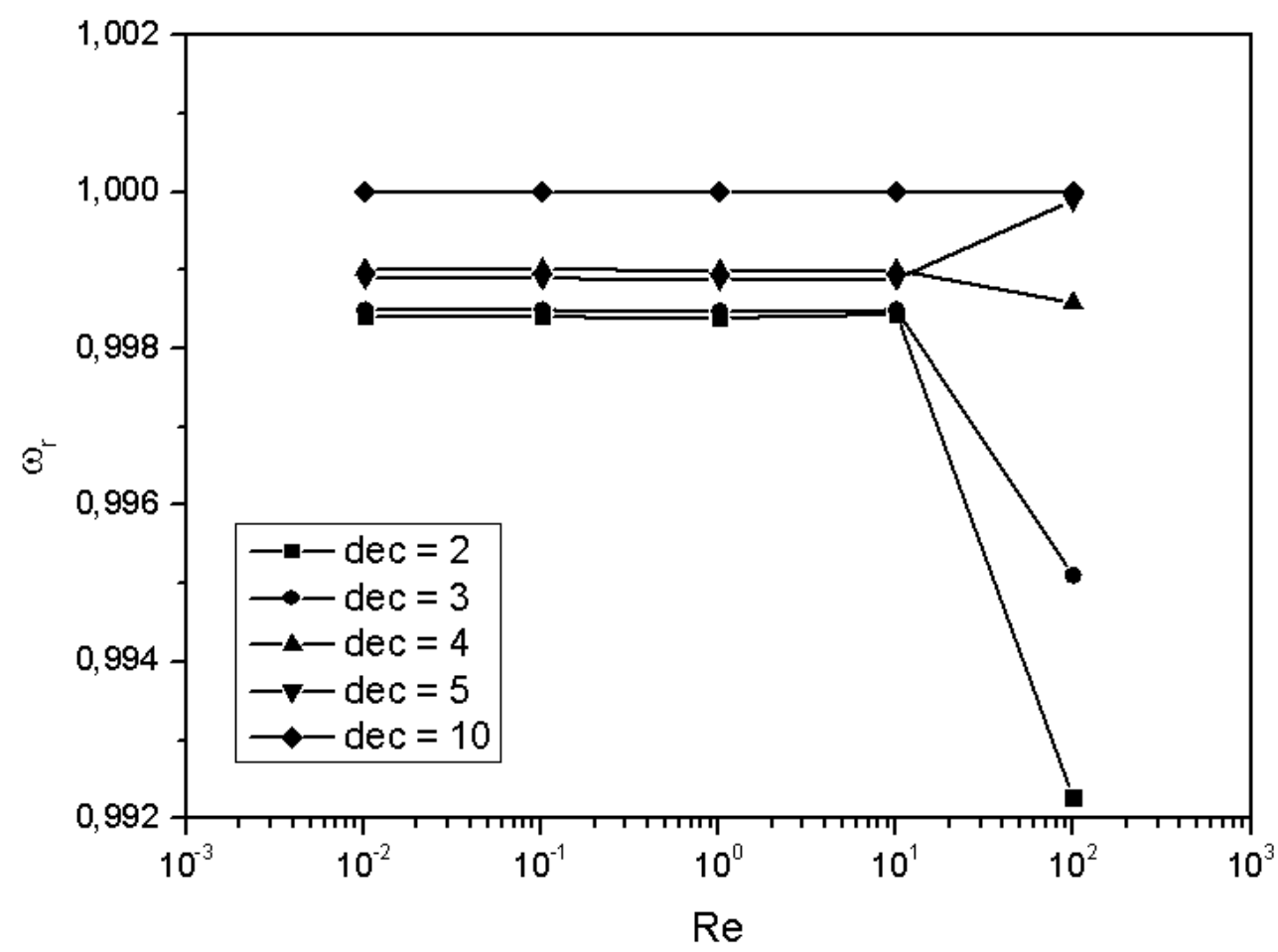

Gráfico 8. Estrutura 1: Vorticidade relativa em função do número de Reynolds, para as diversas distâncias entre cotovelos.

O gráfico 7 mostra o $\mathrm{K}$ relativo $\left(\mathrm{K}_{\mathrm{r}}\right)$ em função do número de Reynolds para as diversas distâncias entre cotovelos. $\mathrm{O} \mathrm{K}_{\mathrm{r}}$ é calculado dividindo-se todas as curvas de 
$\mathrm{K}$ pela curva de $\mathrm{K}$ para dec $=\mathbf{1 0}$. Observa-se nas curvas um leve desvio para $\mathrm{Re}=$ 100 , no entanto, verifica-se que na escala do eixo $K$ que esse desvio é não significativo numericamente. $O$ gráfico 8 mostra a vorticidade relativa em função do número de Reynolds para as diversas distâncias entre cotovelos. A $\omega_{\mathrm{r}}$ é calculada dividindo-se todas as curvas de $\omega$ pela curva de $\omega$ para $\operatorname{dec}=10$. Observa-se um mesmo desvio não significativo numericamente.

Restringindo a análise para $\operatorname{Re}=100$, o gráfico 9 mostra as curvas de vorticidade e $\mathrm{K}$ relativos em função da distância entre cotovelos. Observa-se que a vorticidade aproxima-se para uma constante em função da distância entre cotovelos. A alta vorticidade está sempre relacionada a fluxos convectivos em comparação a fluxos difusivos. Portanto, é importante para a mistura de fluidos que a vorticidade não tenha perdas significativas em função da distância entre os cotovelos.

Por outro lado, observa-se que $\circ \mathrm{K}$ relativo tem uma perda significativa em função da distância entre os cotovelos. Um $\mathrm{K}$ menor significa uma perda de carga menor. Portanto, o sistema de bombeamento é menos exigido e a energia gasta no processo é menor.

Logo, a combinação de uma vorticidade constante e um $\mathrm{K}$ reduzido, em função de menores distâncias entre cotovelos é o ideal para o projeto de dispositivos para mistura de fluidos.

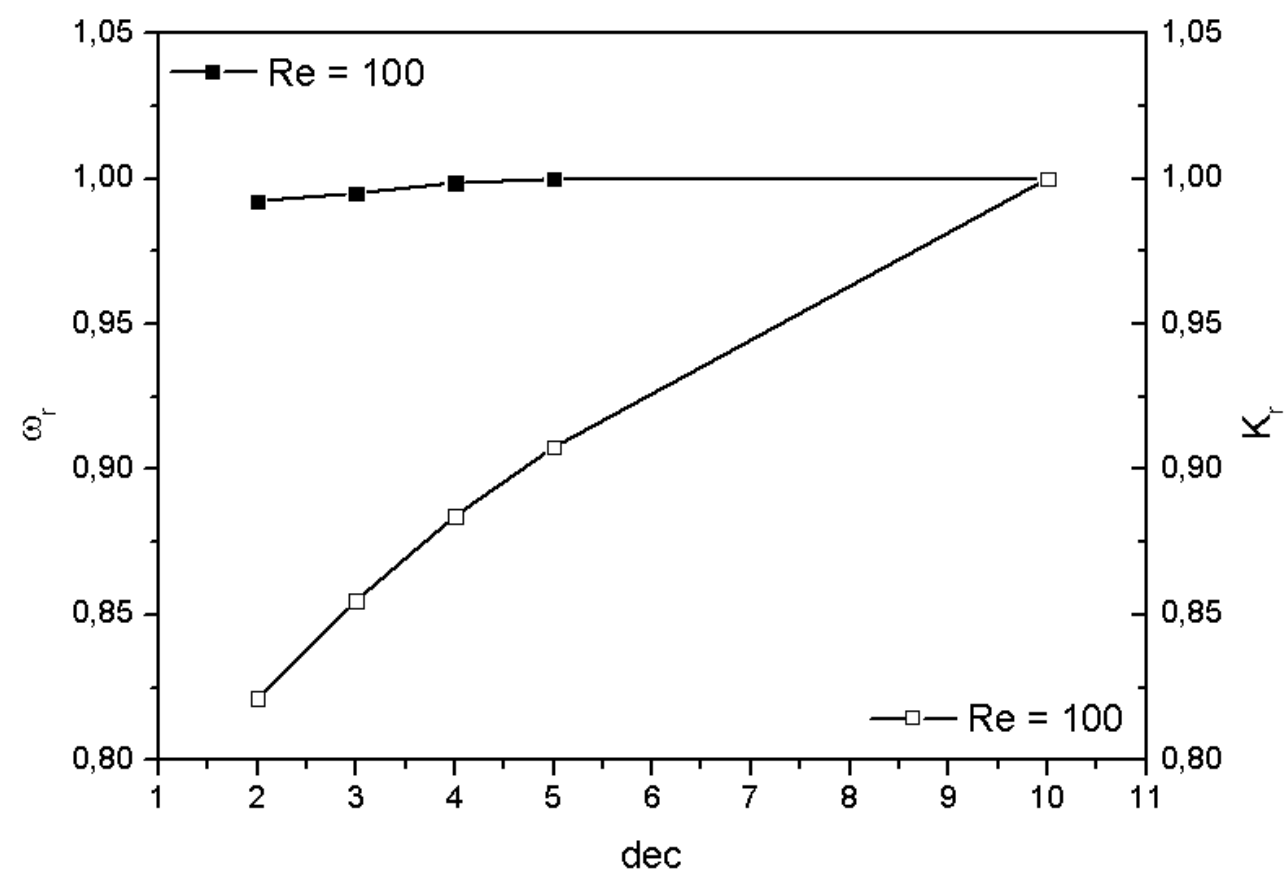

Gráfico 9. Vorticidade e $\mathrm{K}$ relativos em função da distância entre os cotovelos, para estrutura 1 e $\operatorname{Re}=100$. 
O gráfico 10 mostra o comportamento da vorticidade relativa das três estruturas em função da distância entre cotovelos, para $R e=100$. Verifica-se para as três estruturas que a redução da distância entre os cotovelos provocam desvios não significativos numericamente. Portanto, a vorticidade relativa é constante em função da distância entre os cotovelos, para $\mathrm{Re}=100$.

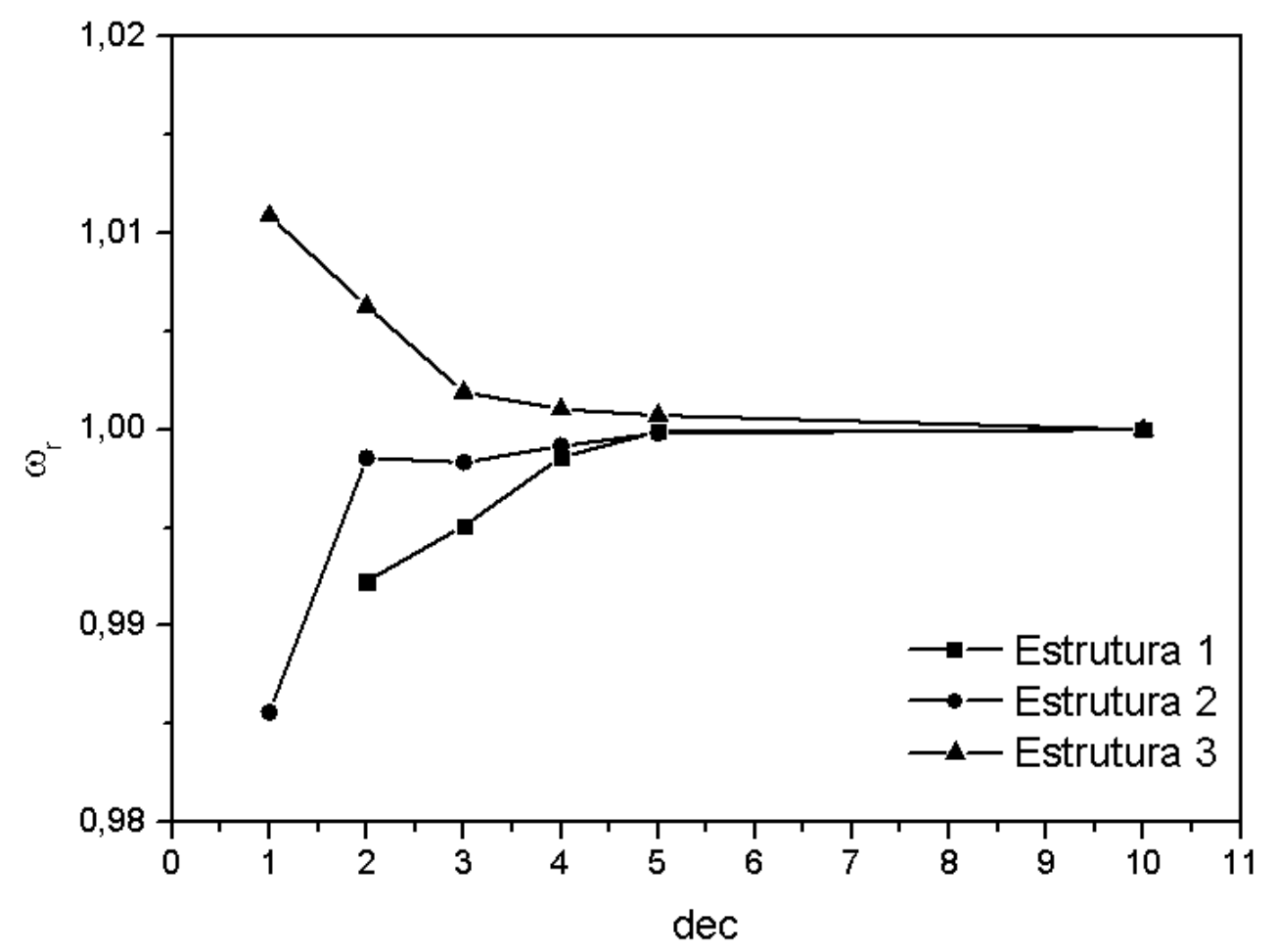

Gráfico 10. Vorticidade relativa em função da distância entre cotovelos, para as três estruturas e $\mathbf{R e}=100$.

O gráfico 11 mostra a velocidade máxima relativa em função da distância entre os cotovelos, para as três estruturas estudadas e $R e=100$. Para estrutura 1, verifica-se que a velocidade máxima relativa é uma constante em função da distância entre os cotovelos.

Para a estrutura 2, verifica-se um aumento da velocidade máxima relativa em função da redução da distância entre os cotovelos.

Para a estrutura 3, verifica-se o aumento da velocidade máxima relativa em função da redução da distância entre os cotovelos, atingindo um pico em dec $=2$. $\mathrm{Em} \mathrm{dec}=1$, observa-se uma redução da velocidade máxima relativa. 


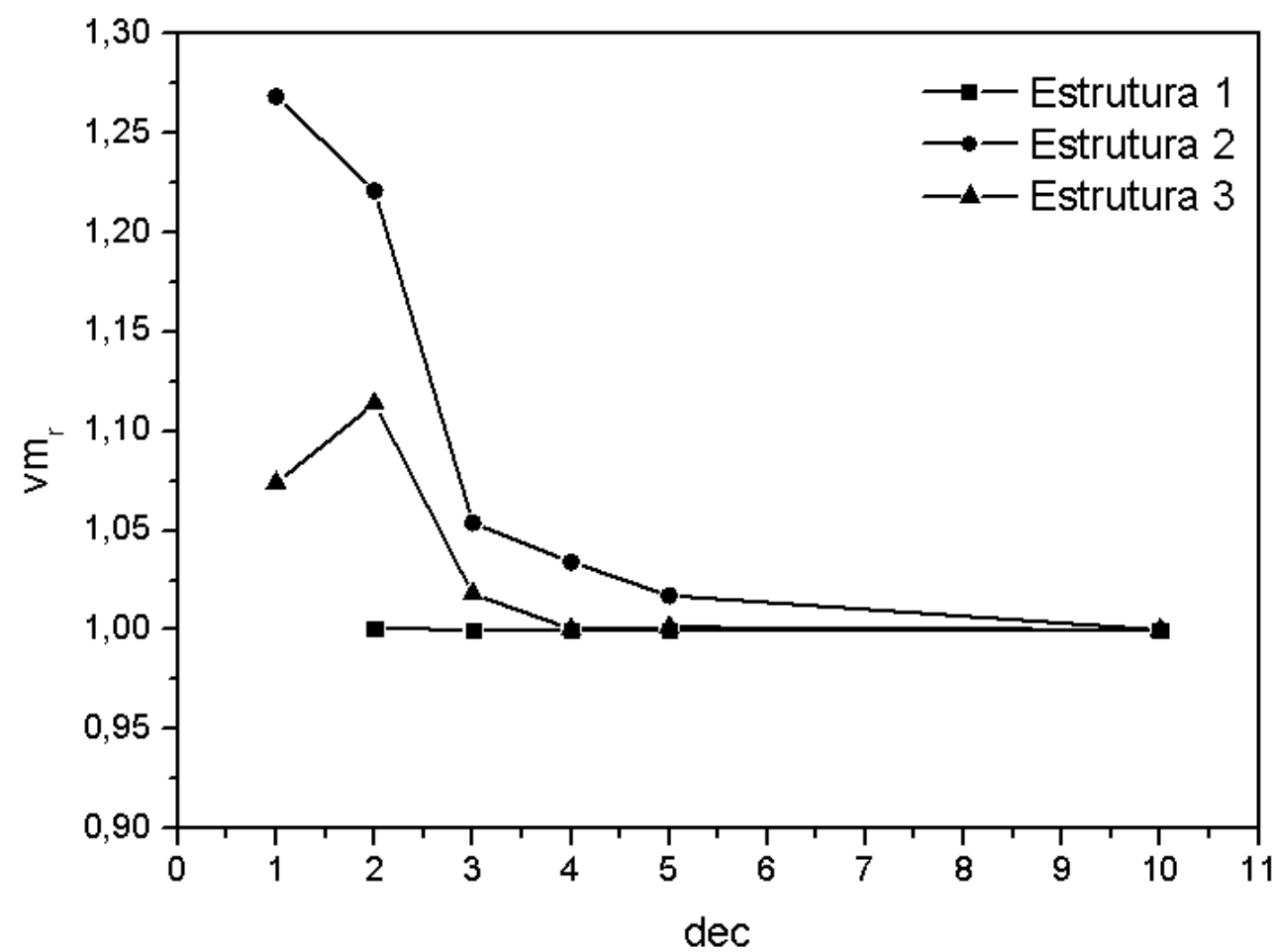

Gráfico 11. Velocidade máxima relativa $\left(\mathrm{vm}_{\mathrm{r}}\right)$ em função da distância entre cotovelos, para as três estruturas e $\mathrm{Re}=100$.

Pontos com velocidade máxima altos são desejáveis, pois esses pontos induzem a geração de vórtices e regiões de recirculação, que proporcionam uma maior instabilidade no escoamento. Como se pretende projetar microcanais com diversos cotovelos sucessivos, ou seja, um somatório de diversos pontos com aumento de velocidade, esse é um resultado importante para conduzir o próximo estudo.

Portanto, em função da discussão dos resultados mostrados pelos gráficos $9 \mathrm{e}$ 11 , principalmente, as seguintes distâncias entre os cotovelos serão escolhidas para o projeto de dispositivos baseados em microcanais com sucessivos cotovelos:

- Estrutura 1-dec $=2$,

- Estrutura 2- dec $=1$ e 2, e

- Estrura 3- dec $=1$ e 2. 


\subsubsection{Resumo}

O estudo computacional foi realizado com três estruturas com diferentes configurações espaciais entre dois cotovelos sucessivos, no intervalo do número de Reynolds entre 0,01 e 100.

A visualização dos mapas do campo de velocidades permitiu identificar uma distinta descrição das linhas de campo, para $R e=100$, quando comparada com a descrição encontrada em outros valores de Re, no intervalo estudado.

Com a obtenção dos parâmetros numéricos foi possível identificar a combinação de uma vorticidade constante e uma perda de carga reduzida em função da diminuição da distância entre cotovelos.

Além disso, a redução da distância entre os cotovelos induz a geração de pontos com alta velocidade no escoamento, permitindo a escolha de distâncias entre os cotovelos para serem investigadas no próximo estudo:

- Estrutura $1-\mathrm{dec}=2$,

- Estrutura $2-$ dec $=1$ e 2, e

- Estrura 3-dec = 1 e 2. 
4.6. Estudo 3: Comparação de diversas geometrias

O objetivo deste estudo é comparar as diversas geometrias baseadas em sucessivos cotovelos usando como base de comparação o microcanal reto. Os microcanais baseados em sucessivos cotovelos propostos neste estudo são resultado das distâncias entre os cotovelos encontradas no estudo anterior. A tabela 19 mostra 8 geometrias propostas para este estudo, as seis primeiras baseadas na literatura com a contribuição do estudo que definiu distâncias entre os cotovelos otimizadas. As duas últimas geometrias são duas contribuições originais deste trabalho, Zigzag 3D 1 e 2.

As geometrias onda quadrada 1 e 2 são baseadas na intercalação das estruturas 1 e 2 . A onda quadrada 1 usa $\operatorname{dec}=1$ (estrutura 2), enquanto a onda quadrada 2 usa dec $=2$ (estrutura 2).

As geometrias zigzag 1 e 2 são baseadas na estrutura 2, com dec $=1$ para zigzag 1 e dec $=2$ para zigzag 2 .

As geometrias serpentina 3D 1 e 2 são baseadas na estrutura 3, sendo a serpentina 3D 1 intercalando duas distâncias entre os cotovelos (dec = 1 e 2) e a serpentina 3D 2 usando apenas $\mathrm{dec}=2$.

As geometrias zigzag 3D 1 e 2 são baseadas na intercalação das estruturas 1 e 3. A zigzag 3D 1 intercala dec $=2$ (estrutura 1 ) e dec $=1$ (estrutura 3 ), enquanto a zigzag 3D 1 intercala dec $=2$ (estrutura 1$)$ e dec $=2$ (estrutura 3 ).

Tabela 19. Geometrias propostas.

\begin{tabular}{|l|c|c|c|}
\hline \multicolumn{1}{|c|}{ Geometrias } & Estrutura 1 & Estrutura 2 & Estrutura 3 \\
\hline Onda Quadrada 1 & $\mathrm{dec}=2$ & $\mathrm{dec}=1$ & - \\
\hline Onda Quadrada 2 & $\mathrm{dec}=2$ & $\mathrm{dec}=2$ & - \\
\hline Zigzag 1 & - & $\mathrm{dec}=1$ & - \\
\hline Zigzag 2 & - & $\mathrm{dec}=2$ & - \\
\hline Serpentina 3D 1 & - & - & $\mathrm{dec}=1 \mathrm{e}$ dec $=2$ \\
\hline Serpentina 3D 2 & - & - & $\mathrm{dec}=2$ \\
\hline Zigzag 3D 1 & $\mathrm{dec}=2$ & - & $\mathrm{dec}=1$ \\
\hline Zigzag 3D 2 & $\mathrm{dec}=2$ & $\mathrm{dec}=2$ \\
\hline
\end{tabular}

A tabela 20 mostra as 09 geometrias propostas para este estudo. A seção transversal é quadrada com $400 \mu \mathrm{m}$ de diâmetro hidráulico. $\mathrm{O}$ comprimento dos 
canais foi parametrizado em função do $D_{h}, L=20 . D_{h}$. Ressaltando que 0 comprimento usado para os microcanais baseados em sucessivos cotovelos é o traçado da linha que começa no ponto central da face de entrada e termina no ponto central da face de saída, ou seja, é o eixo central do canal.

Em função da adoção do mesmo comprimento para todos os microcanais é possível realizar a comparação entre eles, resultando num mesmo volume interno para todas as geometrias.

Tabela 20. Estudo 3: Definição das geometrias.

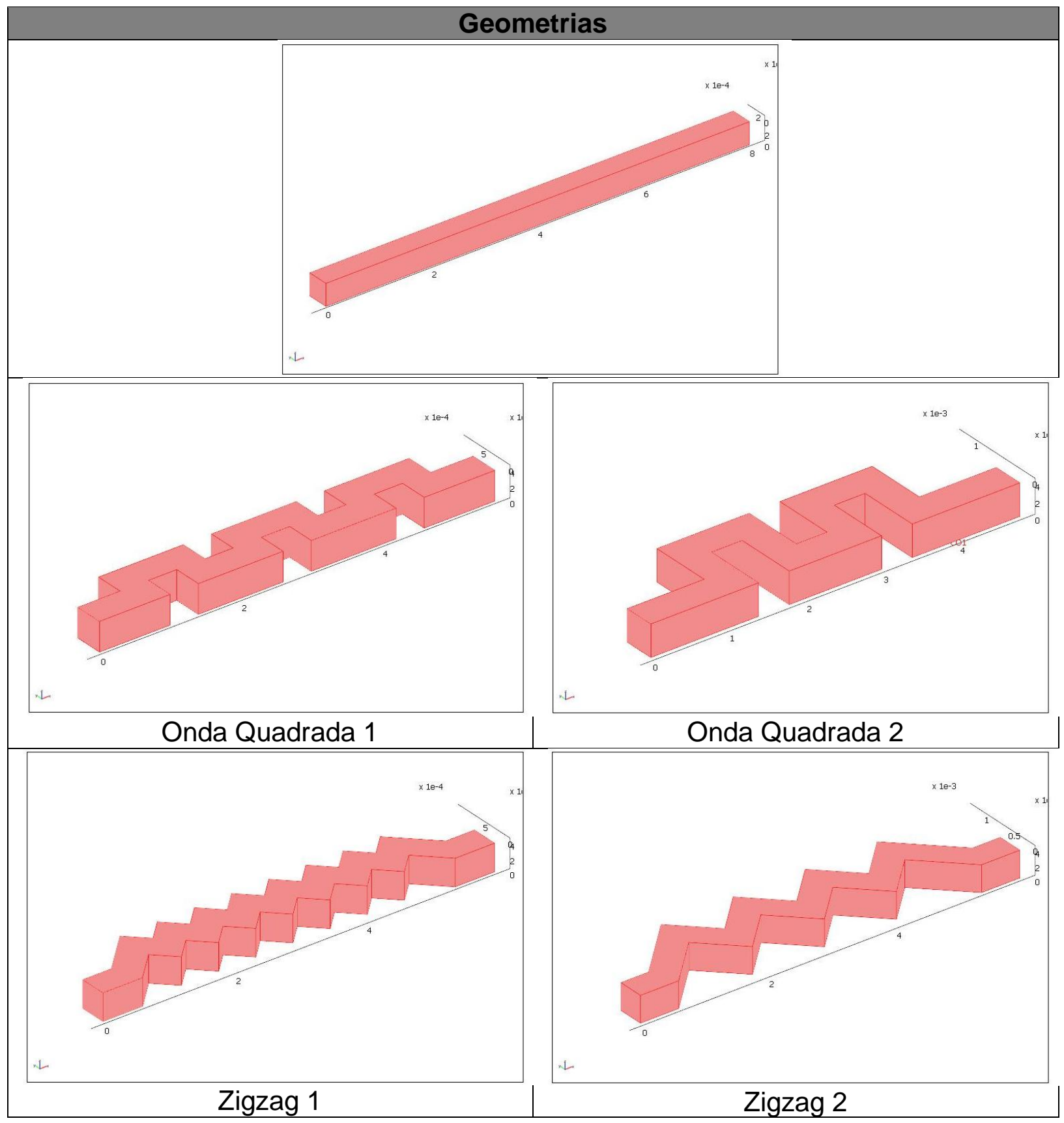




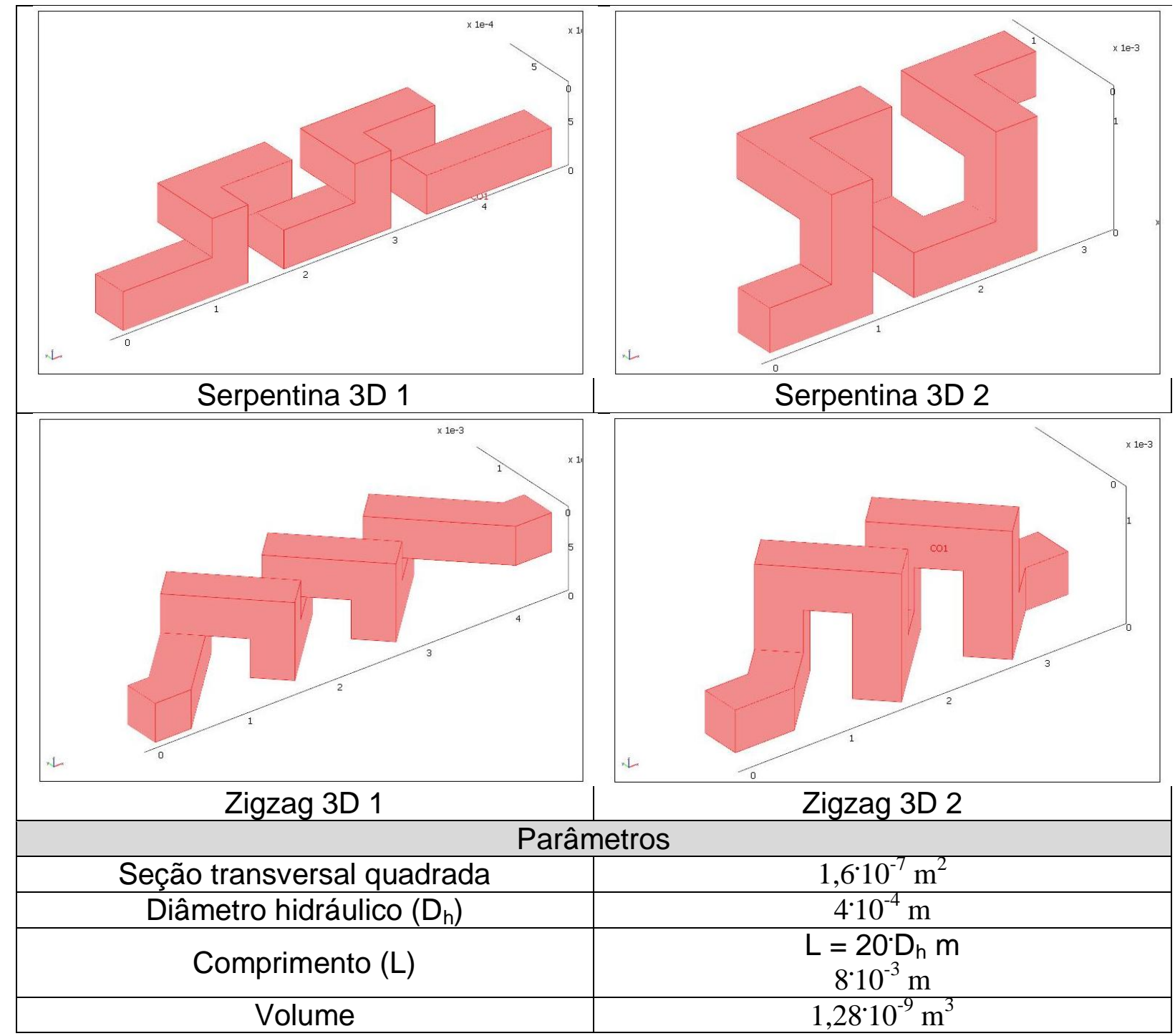

A tabela 21 mostra as condições de contorno utilizadas neste estudo. No domínio (volume) é resolvida numericamente a equação de Navier-Stokes na forma diferencial com difusão artificial Streamline diffusion - Galerkin Least-Squares (GLS). Os parâmetros do fluido de trabalho, água, são definidos no volume, densidade e viscosidade dinâmica.

Nas faces são aplicadas as seguintes condições de contorno: (a) na face de entrada é aplicado um perfil uniforme de velocidade, parametrizado em função do número de Reynolds no intervalo de 0,01 a 100; (b) na face de saída é aplicada uma pressão nula e (c) nas paredes é aplicada a condição de não-deslizamento, velocidade nula.

Portanto, são nove geometrias propostas em cinco pontos no intervalo de 0,01 a 100 do número de Reynolds, totalizando 45 simulações. 
Tabela 21. Estudo 3: Condições de contorno.

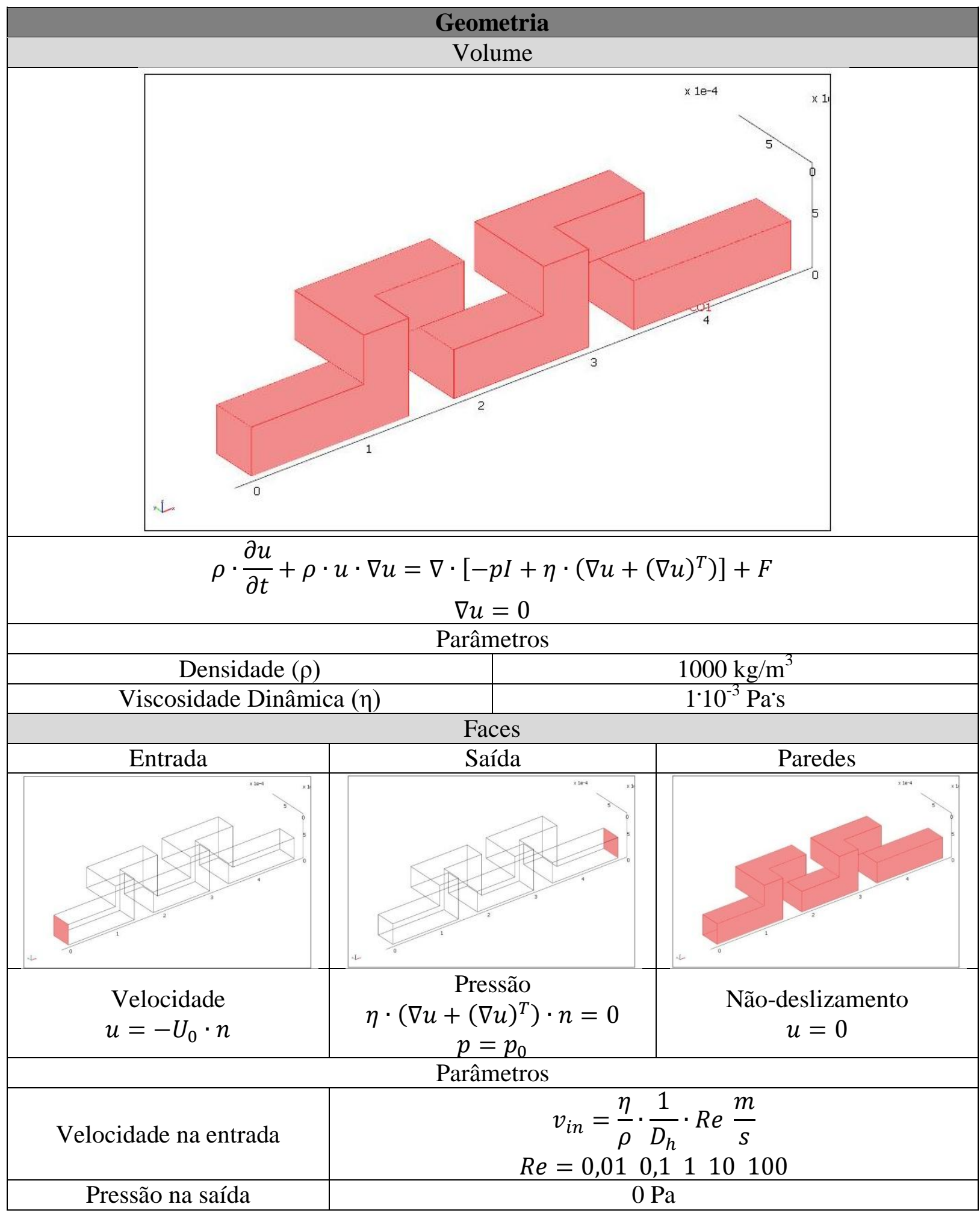

A tabela 22 mostra a discretização das geometrias estudadas. O elemento utilizado é o tetraedro com tamanho global de $40 \mu \mathrm{m}$, com exceção do microcanal reto que foi utilizada malha global com tamanho de $80 \mu \mathrm{m}$. A malha também teve uma discretização local com tamanho de $16 \mu \mathrm{m}$. 
Tabela 22. Estudo 3: Discretização das geometrias.

\begin{tabular}{|c|c|c|}
\hline \multicolumn{3}{|c|}{ Geometria } \\
\hline Global & \multicolumn{2}{|c|}{ Local } \\
\hline$\perp$ & & 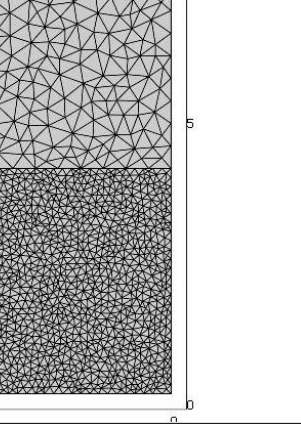 \\
\hline \multicolumn{3}{|c|}{ Parâmetros } \\
\hline Elemento & \multicolumn{2}{|c|}{ Tetraedro } \\
\hline Tamanho máximo do elemento & Global & ${ }^{*} 80 \mu \mathrm{m} / 40 \mu \mathrm{m}$ \\
\hline Tamarmio maxinto do elementio & Local & $16 \mu \mathrm{m}$ \\
\hline Geometrias & $\begin{array}{l}\text { Número de } \\
\text { elementos }\end{array}$ & $\begin{array}{l}\text { Graus de } \\
\text { liberdade }\end{array}$ \\
\hline Canal reto & 61110 & 291461 \\
\hline Onda quadrada 1 & 361246 & 1615109 \\
\hline Onda quadrada 2 & 359590 & 1608062 \\
\hline Zigzag 1 & 360445 & 1612072 \\
\hline Zigzag 2 & 360365 & 1610938 \\
\hline Serpentina 3D 1 & 358520 & 1602103 \\
\hline Serpentina 3D 2 & 358435 & 1601655 \\
\hline Zigzag 3D 1 & 359937 & 1609853 \\
\hline Zigzag 3D 2 & 359249 & 1606474 \\
\hline
\end{tabular}

${ }^{*}$ canal reto

Após o processamento dos modelos com o solver GMRES e pré-condicionador Geometric multigrid foram obtidos os mapas das propriedades físicas de interesse: mapas do campo de velocidade para as diversas geometrias e condições de $R e$, e mapa do campo de pressões para uma geometria escolhida.

A figura 32 mostra os mapas do campo de velocidades para geometria serpentina 3D 1 para cinco condições do número de Reynolds, no intervalo de 0,01 a 100. Observando a figura é possível identificar dois comportamentos distintos de escoamento.

Para as condições, $R e=0,01 ; 0,1 ; 1$ e 10 , verifica-se um escoamento tipicamente laminar, com as linhas de campo paralelas. Para condição $R e=100$, verifica-se uma descrição do comportamento do escoamento distinta do regime 
laminar. Observa-se a torção e o cruzamento das linhas de campo, bem como a geração de regiões de recirculação, indicando um comportamento diferente do laminar.

Este resultado conduz a conclusão de que houve uma transição de regime entre os números de Reynolds 10 e 100 . Para $R e<10$, em função da observação visual do escoamento encontra-se um regime puramente laminar.

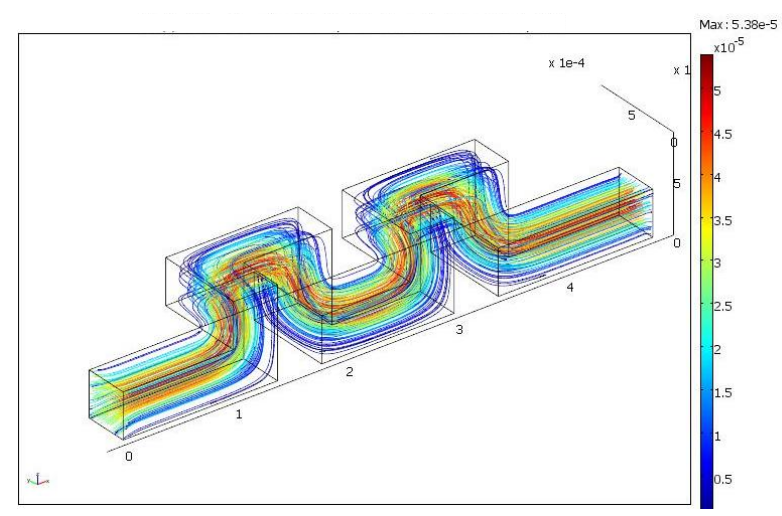

$\operatorname{Re}=0,01$

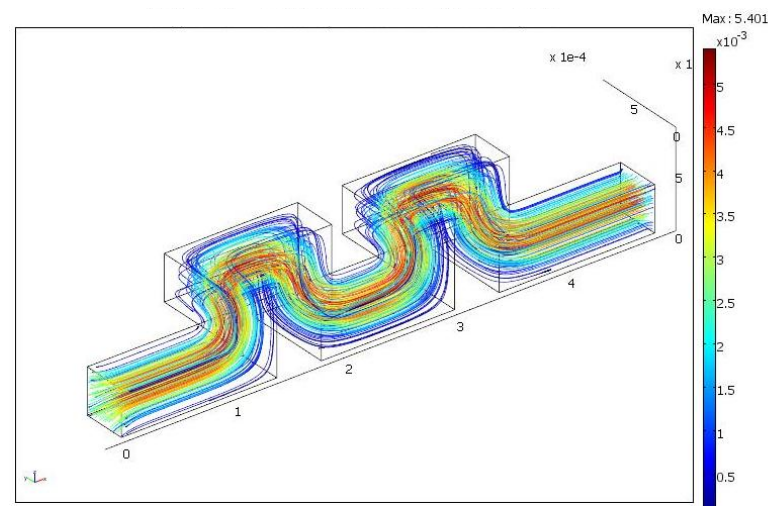

$\mathrm{Re}=1$

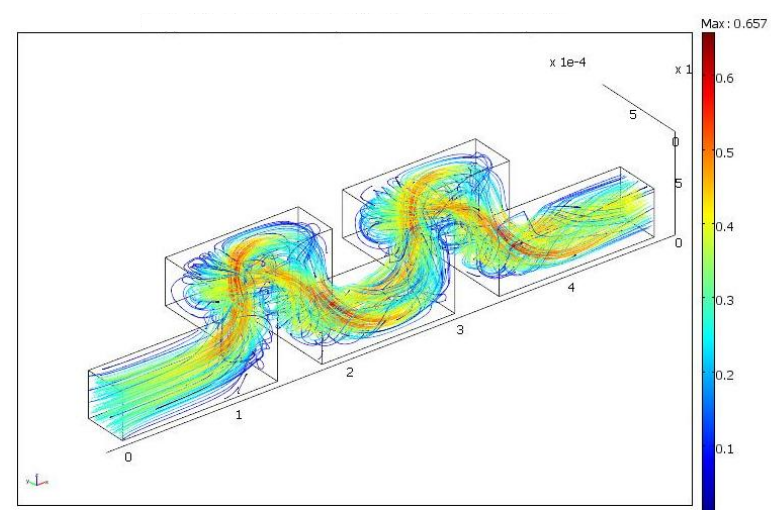

$\mathrm{Re}=100$

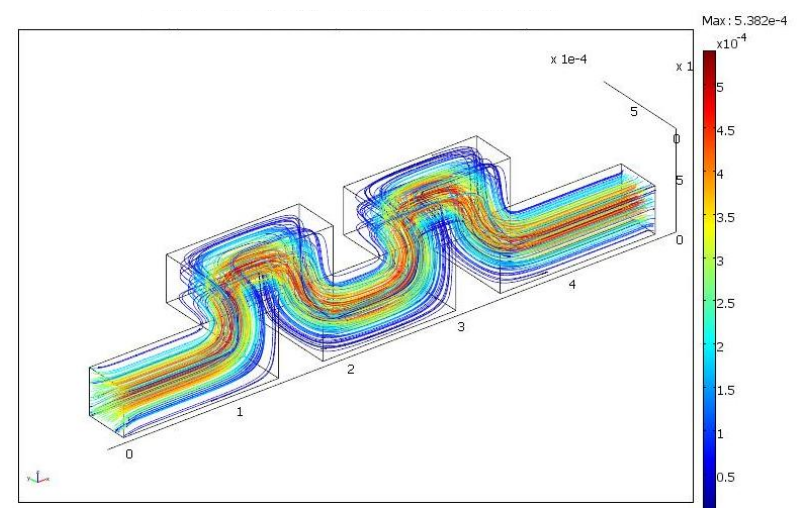

$\mathrm{Re}=0,1$

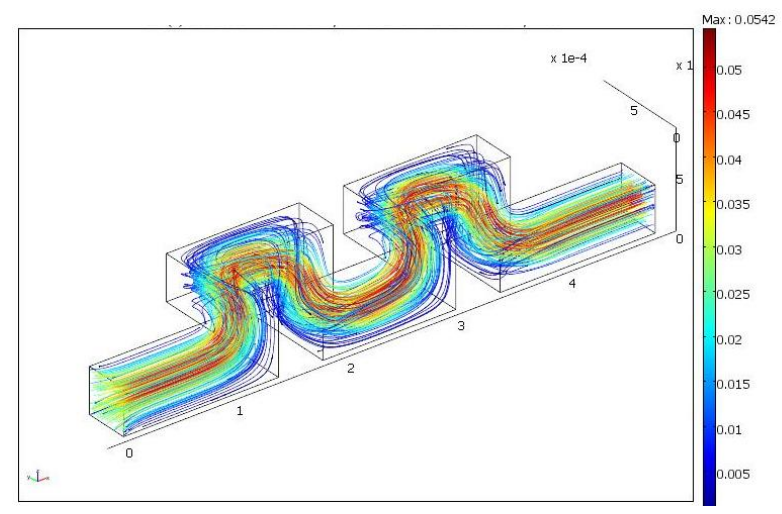

$\mathrm{Re}=10$

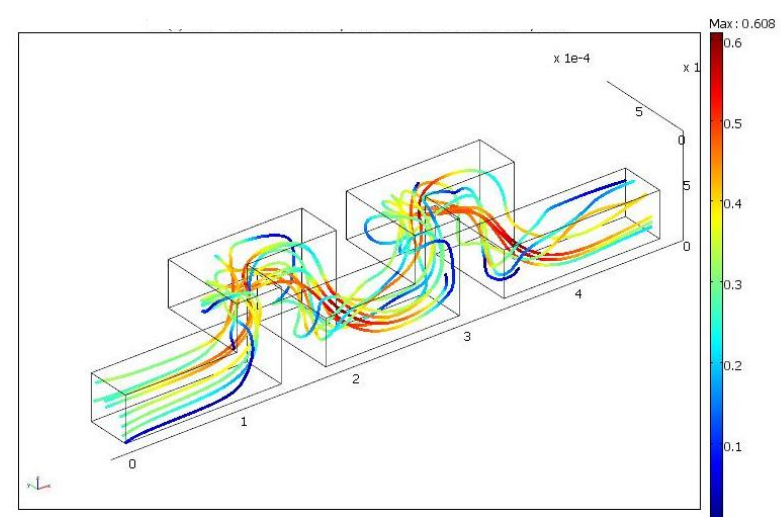

$\operatorname{Re}=100$

Figura 32. Mapas de velocidade da serpentina 3D 1. 
A determinação da transição de regime, laminar para intermediário, é de fundamental importância para a mistura de fluidos. O tipo de escoamento determinará as características do processo de mistura.

$\mathrm{Na}$ literatura, a descrição do escoamento é focalizada no fenômeno de advecção caótica, que apresenta um comportamento similar ao mostrado na figura 32, para $\operatorname{Re}=100$. Só encontram-se estudos de transição de regime para microcanais retos. Caso a análise dos parâmetros numéricos (realizada após a visualização dos mapas) confirme a transição de regime, nas condições estabelecidas neste estudo, esse resultado é uma contribuição original para o estado da arte:

- A advecção caótica não ocorre em regime laminar, e

- A advecção caótica ocorre após a transição de regime, ou seja, sua ocorrência é observável a partir do regime intermediário.

A figura 33 mostra as outras geometrias estudadas para as condições $R e=10$ (coluna esquerda) e $\mathrm{Re}=100$ (coluna direita). Observa-se para o microcanal reto que não ocorre mudanças no comportamento do escoamento para as duas condições visualizadas.

Para todas as outras geometrias observa-se um escoamento comportado para $R e=10$, tipicamente laminar. Enquanto, observa-se para todas as outras geometrias em $R e=100$, um escoamento com formação de regiões de recirculação, com torção e cruzamento das linhas de campo, distinto do comportamento encontrado em regime laminar. 

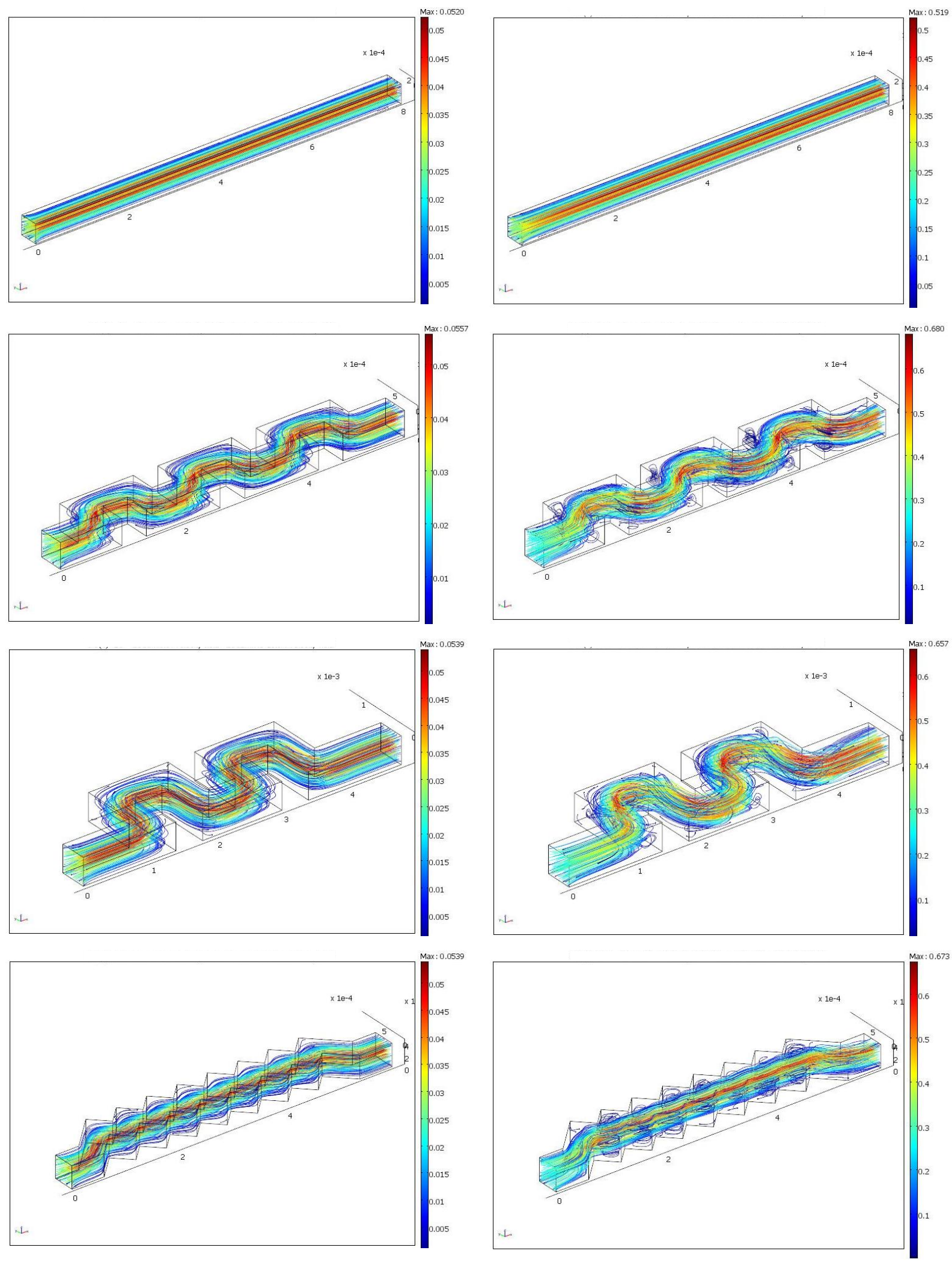

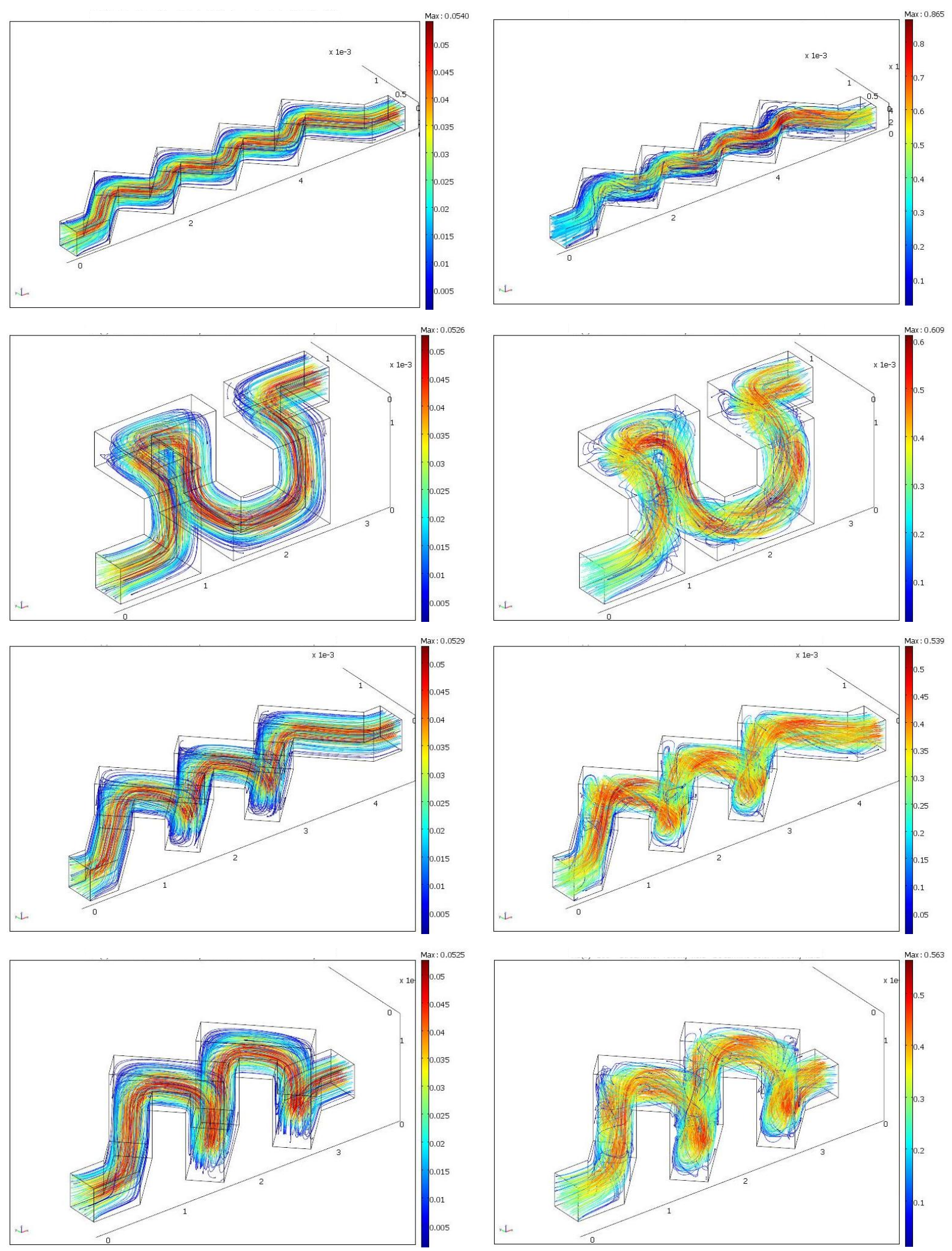

Figura 33. Mapas de velocidade das 08 geometrias restantes para $\mathrm{Re}=10$ (coluna esquerda) e $\mathbf{R e}=\mathbf{1 0 0}$ (coluna direita).

A figura 34 mostra o mapa de pressão para geometria serpentina 3D 1 para condição $\mathrm{Re}=100$. Observa-se que a $\Delta \mathrm{P}$ é aproximadamente $900 \mathrm{~Pa}$. 


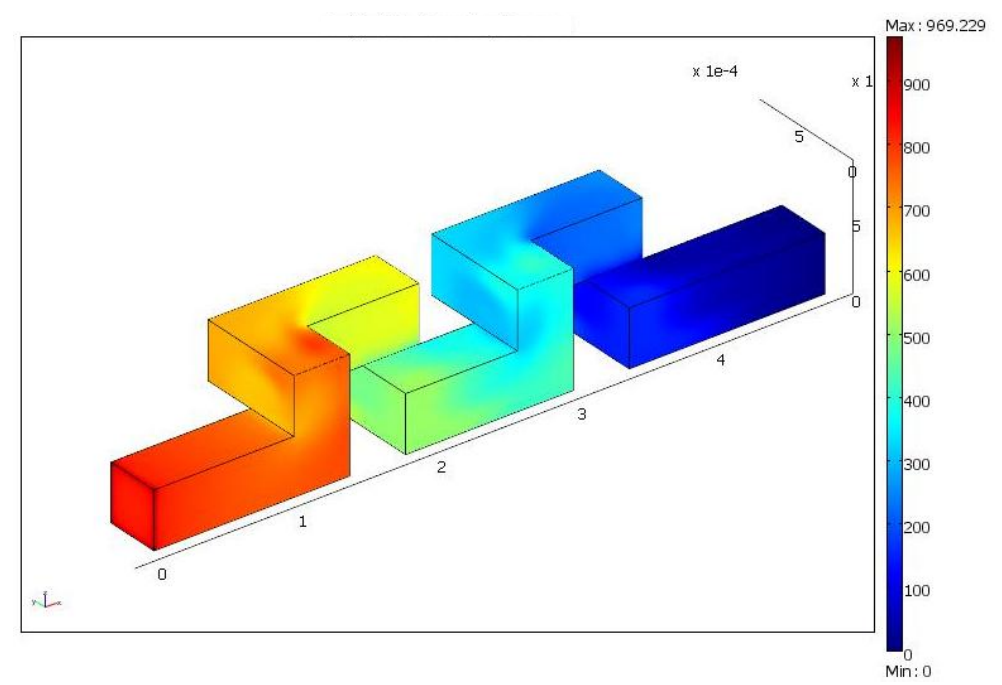

Figura 34. Mapa de pressão da geometria serpentina 3D 1 para $R e=100$.

Após a visualização e análise dos mapas, foram obtidos os parâmetros números: coeficiente de perda de carga, vorticidade, diferença de pressão, resistência hidráulica, tempo de residência e potência volumétrica.

O gráfico 12 mostra o coeficiente de perda de carga em função do número de Reynolds em dois pontos de vista: (a) com valores absolutos e (b) com valores relativos. Analisando a parte (a) com valores absolutos, verifica-se que o microcanal reto apresenta um comportamento inversamente proporcional do $\mathrm{K}$ em função do intervalo estudado do Re de 0,01 a 100, típico do regime de escoamento laminar.

Para as geometrias baseadas em sucessivos cotovelos, verifica-se um comportamento idêntico ao verificado para o microcanal reto no intervalo do número de Reynolds entre 0,01 e 10. Para o intervalo entre $R e=10$ e $R e=100$, observa-se um comportamento distinto do encontrado para o microcanal reto. Os mapas do campo de velocidades das figuras 32 e 33 indicavam uma descrição de escoamento diferenciada e os parâmetros numéricos estão confirmando a transição de regime no intervalo entre 10 e 100, de laminar para intermediário.

Analisando os valores relativos, fica evidente a mudança de comportamento do coeficiente K para o intervalo de Re entre 10 e 100 . Ressalta-se que cada geometria baseada em cotovelos sucessivos apresenta um valor de $\mathrm{K}$ diferente para $\mathrm{Re}=100$, indicando que a transição ocorre em valores diferentes de Re para cada geometria estudada. 


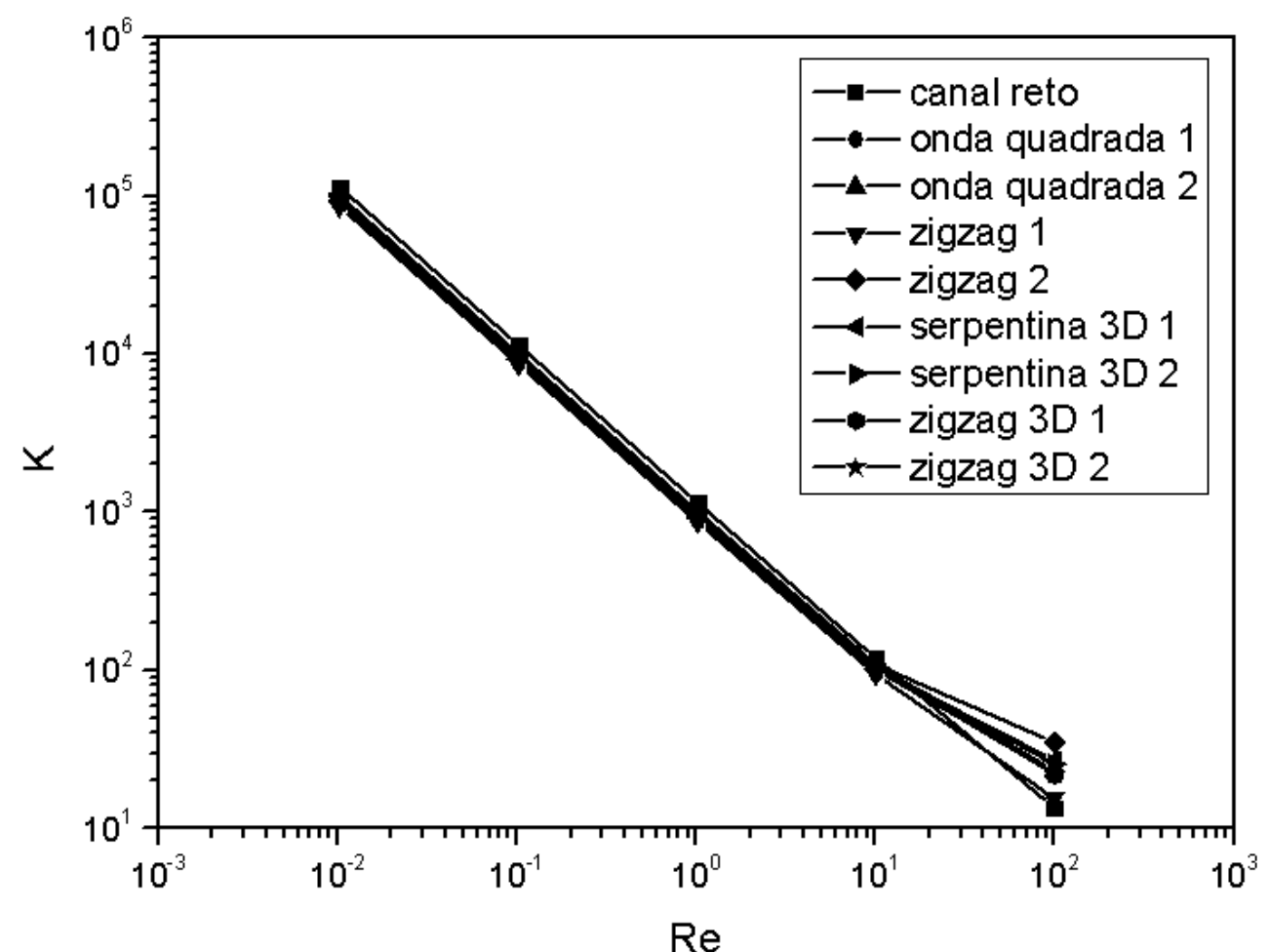

(a)

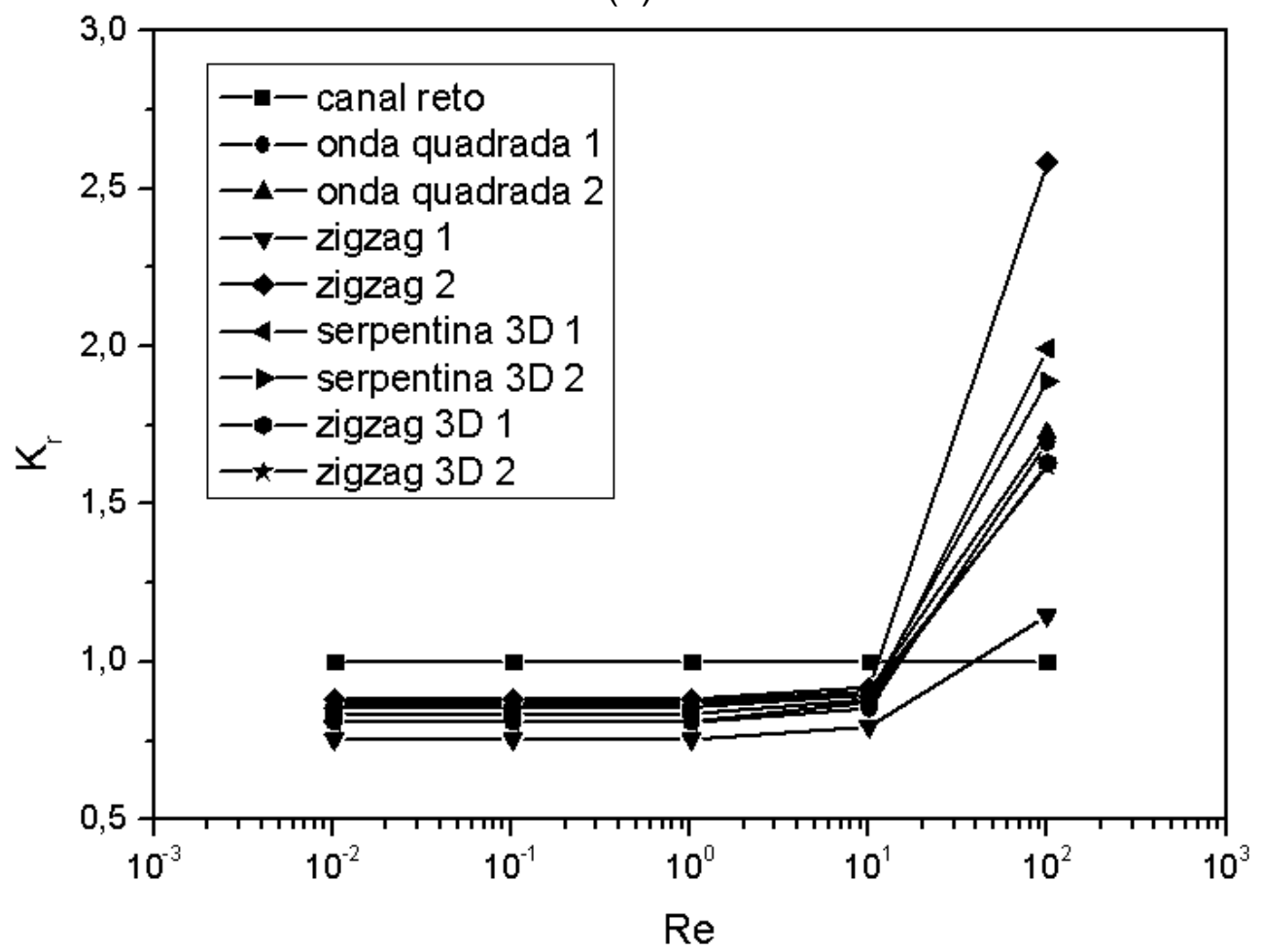

(b)

Gráfico 12. Coeficiente de perda de carga em função do número de Reynolds: (a) valor absoluto e (b) valor relativo. 


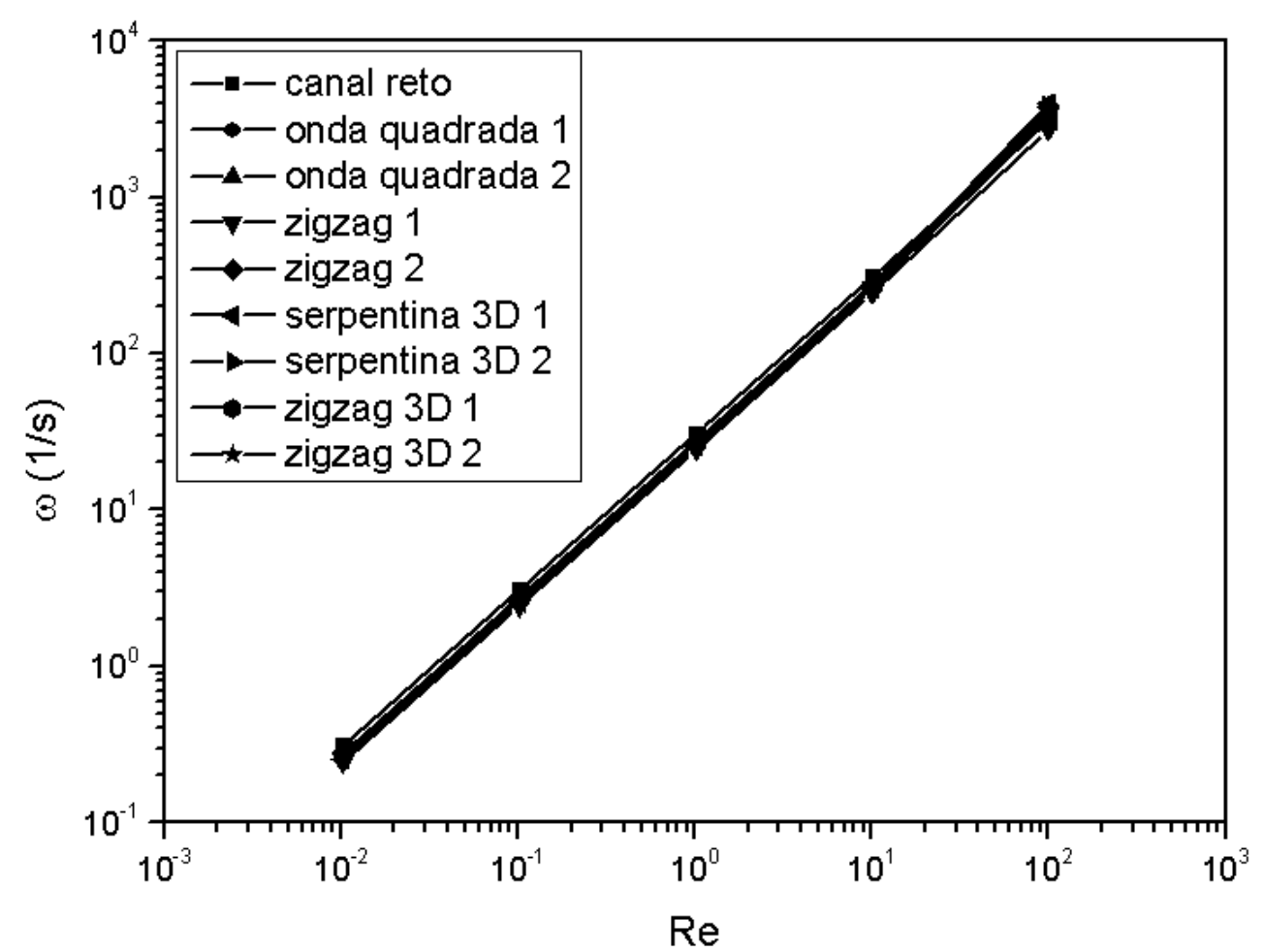

(a)

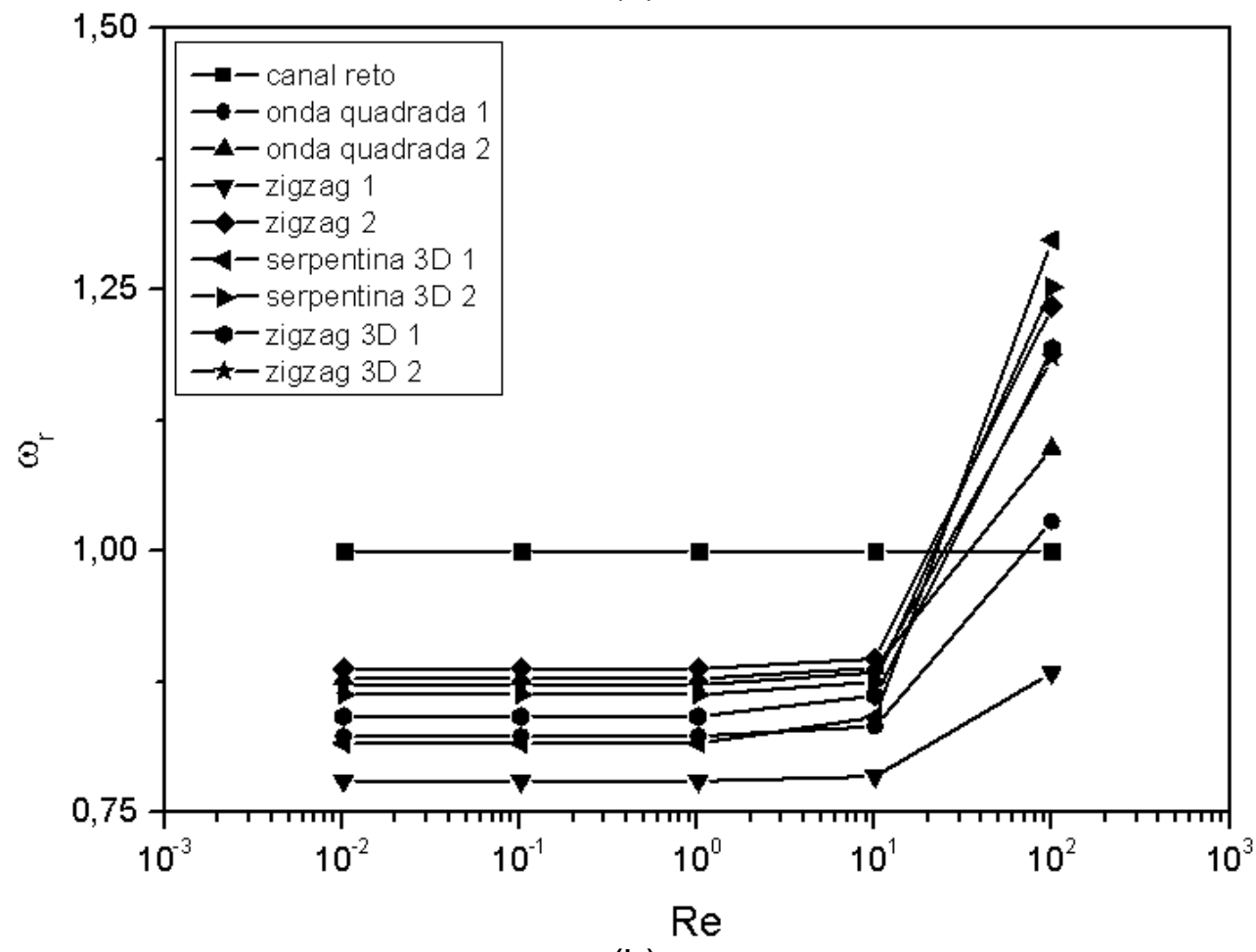

(b)

Gráfico 13. Vorticidade em função do número de Reynolds: (a) valor absoluto e (b) valor relativo.

O gráfico 13 mostra a vorticidade em função do número de Reynolds para (a) valores absolutos e (b) valores relativos. Observando os valores absolutos, verificase que a vorticidade é diretamente proporcional ao número de Reynolds. 
Considerando o microcanal reto encontra-se uma variação de 0,31 a 3059,35 1/s no intervalo de Re entre 0,01 a 100.

Observando os valores relativos, verifica-se que as geometrias baseadas em sucessivos cotovelos apresentam valores entre 0,7 a 0,9 em relação ao valor do microcanal reto. Isto se deve ao fato das geometrias com sucessivos cotovelos terem um volume morto (regiões com baixa velocidade) no intervalo do Re entre 0,01 e 10, ou seja, em regime laminar. Quando ocorre a transição de regime em $\mathrm{Re}$ entre 10 e 100, observa-se nos valores relativos a mudança de comportamento da vorticidade, confirmando uma descrição de escoamento distinta da encontrada em regime laminar.

Portanto, dentre as geometrias estudadas o microcanal reto é o ideal para o trabalho em regime laminar $(\mathrm{Re}<10)$, sendo o processo dominado por difusão. Após a transição de regime (Re entre 10 e 100), o ideal é o uso de uma geometria baseada em sucessivos cotovelos, pois a vorticidade é incrementada, sendo então o processo dominado por convecção.

O gráfico 14 mostra a diferença de pressão (a) e a resistência hidráulica (b) em função da vazão. Observa-se nas curvas de diferença de pressão duas regiões, uma com comportamento linear em função da vazão, típica do regime laminar, e outra região não-linear correspondente ao regime intermediário.

O mesmo é observado nas curvas de resistência hidráulica, uma região onde a resistência é uma constante, confirmando o regime laminar, e outra região nãoconstante, correspondente ao regime intermediário. 


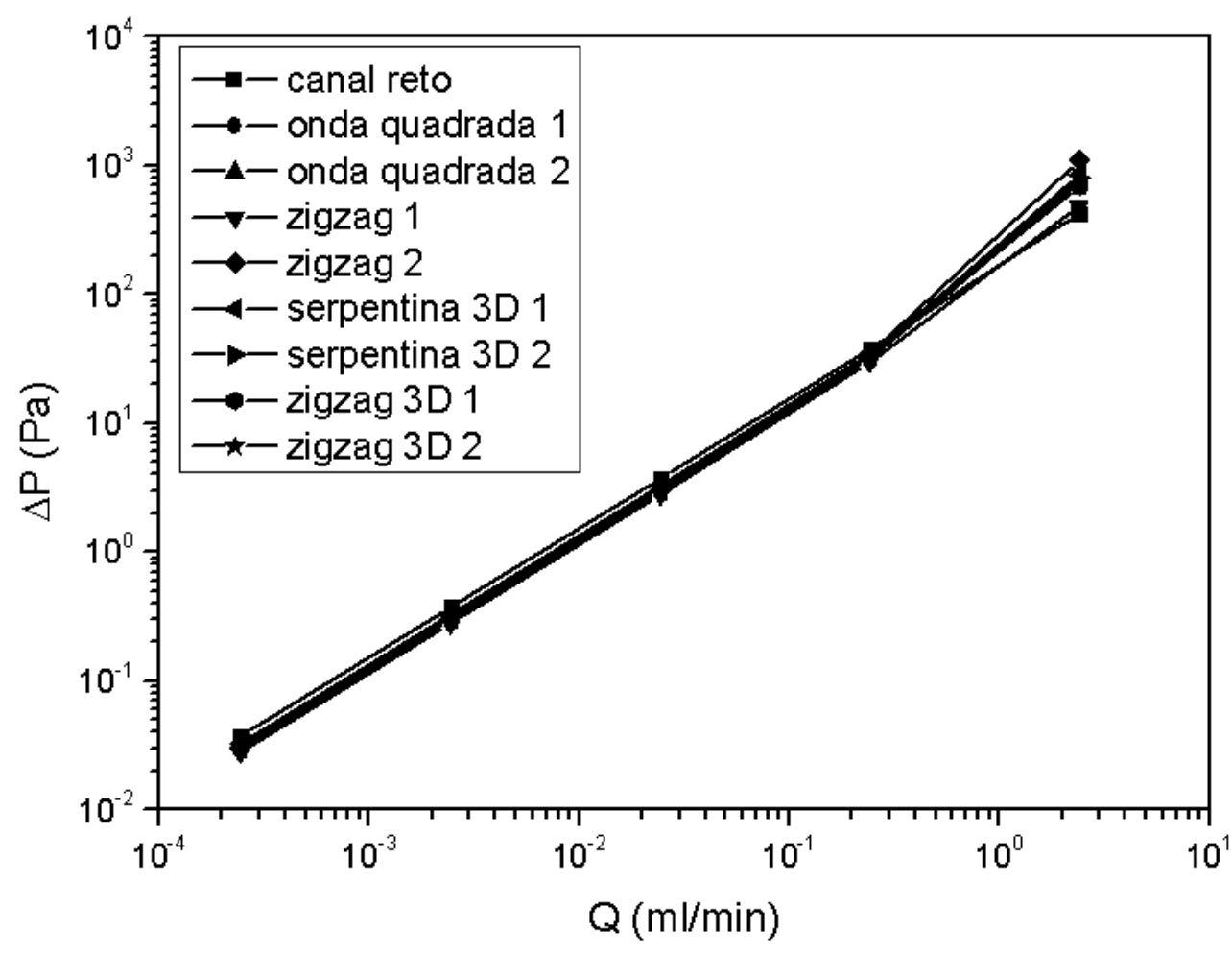

(a)

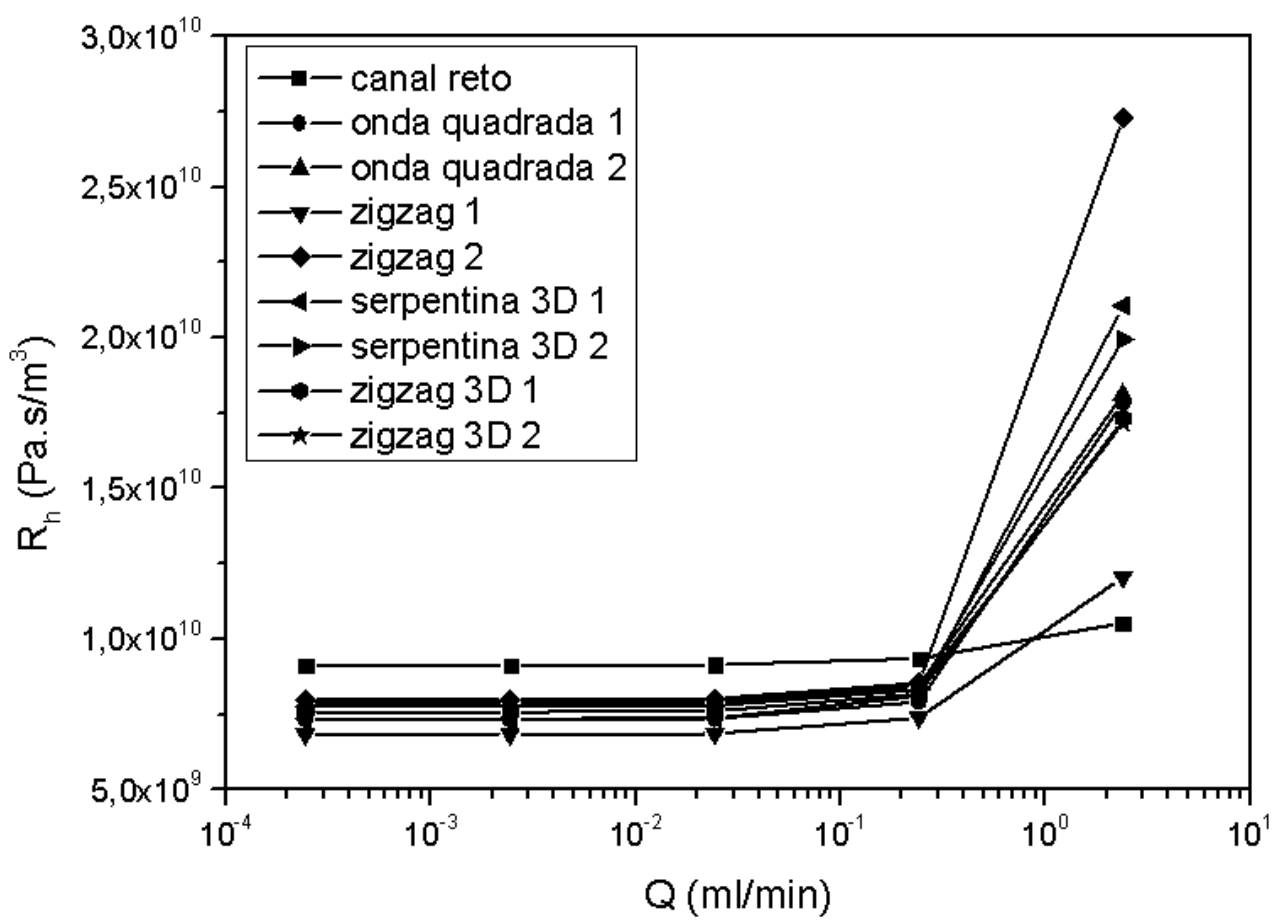

(b)

Gráfico 14. Diferença de pressão (a) e a resistência hidráulica (b) em função da vazão. 
O gráfico 15 mostra o tempo de residência e a potência volumétrica em função da vazão. As curvas de tempo de residência apresentam valores idênticos para as nove geometrias estudadas, pois para estabelecer a base de comparação, a área da seção transversal e volume dos microcanais, foram definidas iguais para todas as geometrias.

Considerando o intervalo do regime de escoamento laminar $\left(2,46 \cdot 10^{-4}\right.$ a $2,43 \cdot 10^{-1} \mathrm{ml} / \mathrm{min}$ ) observa-se a variação do tempo de residência entre 312 a 0,316 s. No regime intermediário $\left(2,43.10^{-1}\right.$ a $\left.2,39 \mathrm{ml} / \mathrm{min}\right)$, observa-se uma variação do tempo de residência entre 0,316 a $0,032 \mathrm{~s}$. Portanto, em regime laminar os processos são lentos e dominados por difusão, enquanto que em regime intermediário os processos são mais rápidos dominados por convecção.

Outro fator importante é a relação tempo de residência-potência volumétrica. Por um lado, o tempo de residência é inversamente proporcional a vazão, enquanto por outro lado, a potência volumétrica é diretamente proporcional a vazão. Ou seja, considerando as extremidades, encontra-se numa extremidade processos com baixo consumo de energia $(+)$, mas lentos (-), e na outra extremidade processos rápidos $(+)$, mas com alto consumo de energia (-).

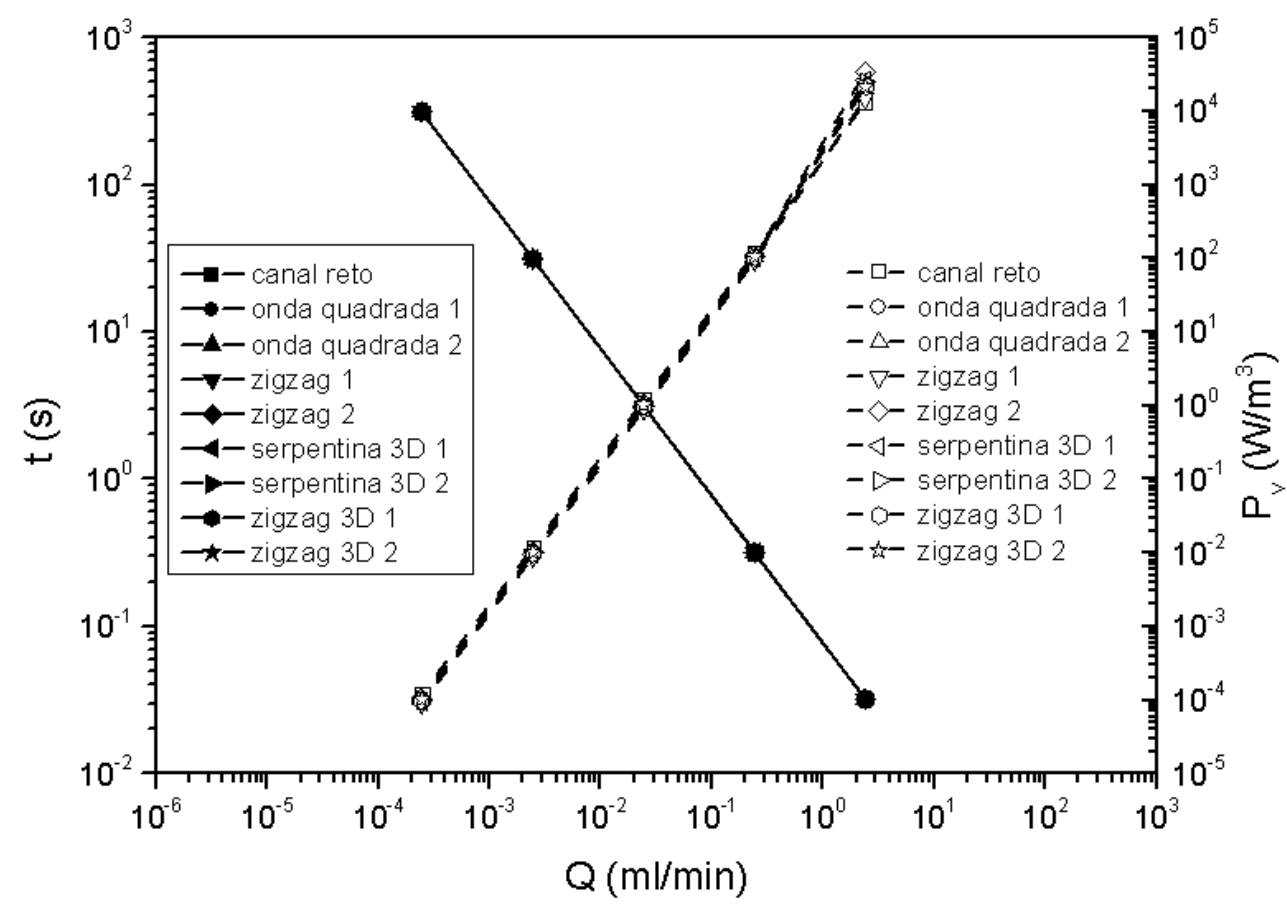

Gráfico 15. Tempo de residência e potência volumétrica em função da vazão. 


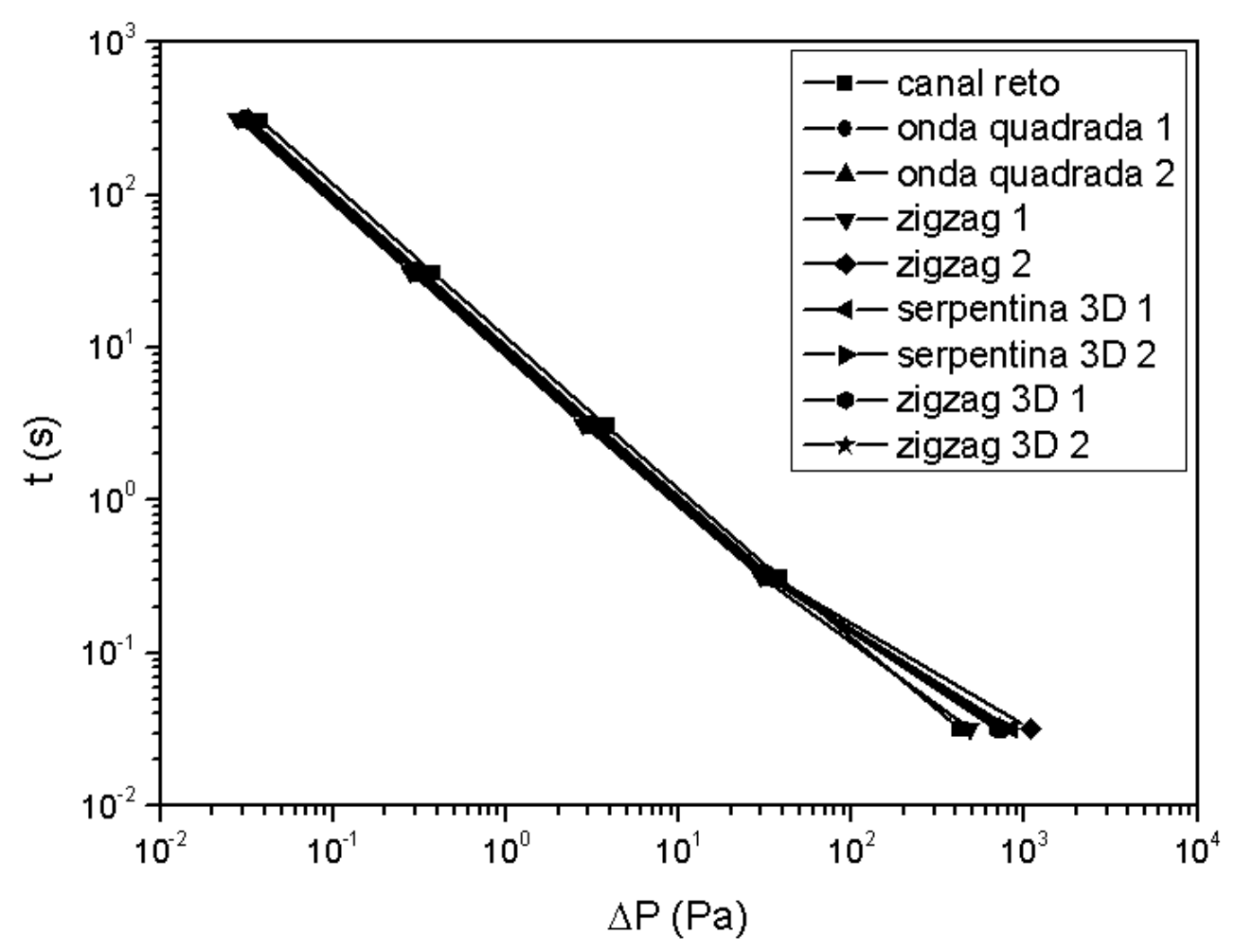

(a)

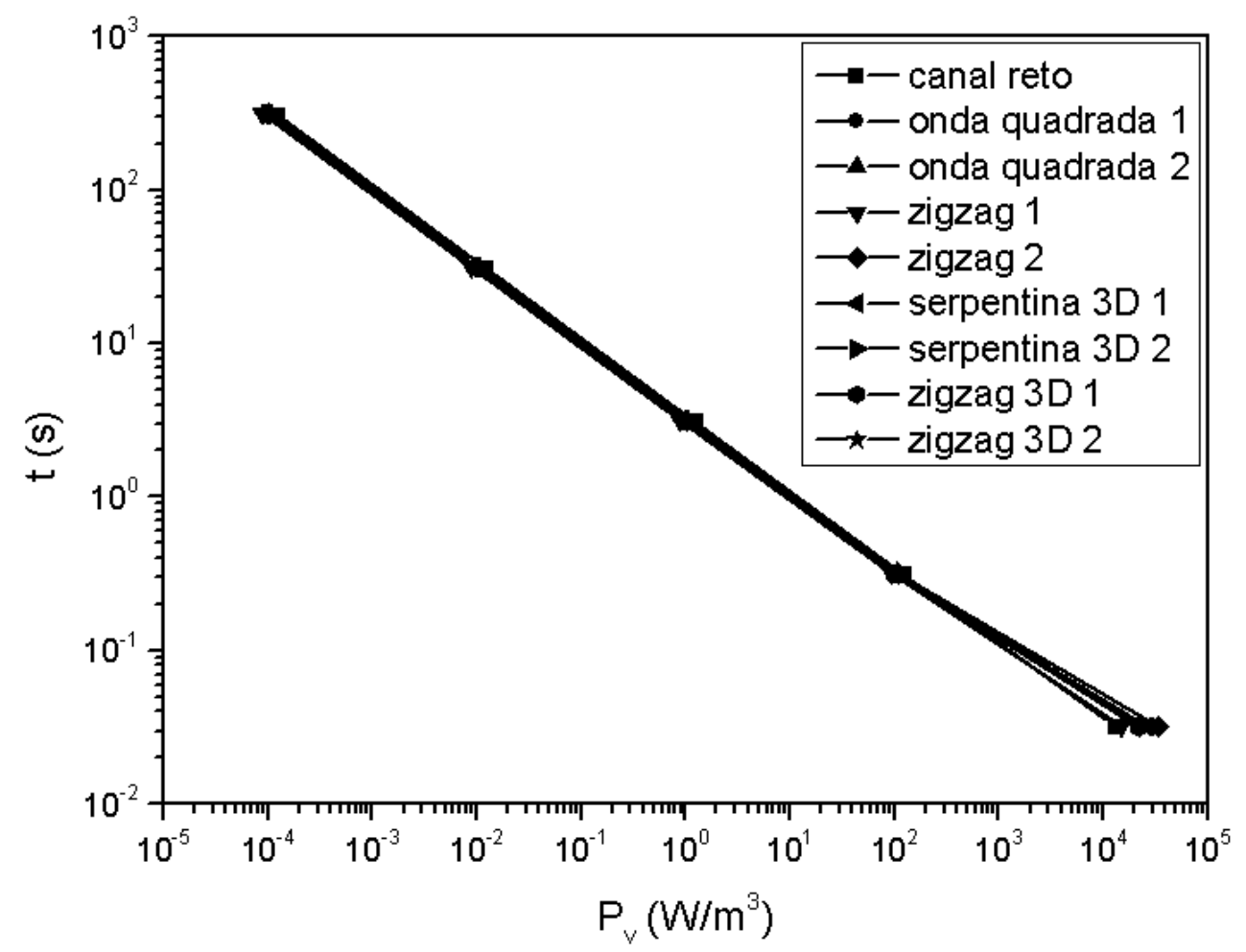

(b)

Gráfico 16. Tempo de residência em função da (a) diferença de pressão e da (b) potência volumétrica. 
Para verificar o esforço do sistema de bombeamento e a potência gasta no processo, o gráfico 16 mostra as curvas características das geometrias estudadas, onde o tempo de residência é mostrado em função da diferença de pressão e da potência volumétrica. Observa-se que o tempo de residência é inversamente proporcional a diferença de pressão e a potência volumétrica.

\subsubsection{Estudo 3.1: Eficiência de mistura}

O último parâmetro de interesse neste estudo é a eficiência de mistura. Para obter esse parâmetro o modelo de Equação de Convecção e Difusão é acoplado ao modelo de Equações de Navier-Stokes. As geometrias são as mesmas definidas nas tabelas 19 e 20.

As condições de contorno são mostradas na tabela 23. No volume é resolvida numericamente a equação de difusão-convecção com difusão artificial Streamline diffusion - Petrov-Galerkin / Compensated, em função dos campos de velocidades obtidos anteriormente, para o intervalo de Re estudado. Foi utilizado um fluido fictício com coeficiente de difusão (D) na água de $1 \cdot 10^{-8} \mathrm{~m}^{2} / \mathrm{s}$. O tempo de residência é dado em função do coeficiente de difusão, pela equação

$$
\tau=\frac{d^{2}}{2 \cdot D} \text { (Nguyen, 2002) }
$$

eq. 15 ,

onde d é uma dimensão característica do sistema de mistura e $D$ é o coeficiente de difusão. Considerando o diâmetro hidráulico adotado neste estudo para os microcanais $(400 \mu \mathrm{m})$ e coeficiente de difusão adotado, tem-se um tempo de residência de $8 \mathrm{~s}$. Esse tempo servirá de base de comparação para analisar as geometrias propostas.

Nas faces foram utilizadas as seguintes condições de contorno: (a) na entrada um perfil de concentração dado pela equação mostrada na tabela 23 , (b) na saída foi aplicada a condição de fluxo convectivo e (c) nas paredes a condição de isolação/simetria.

Foram utilizadas nove geometrias e para cada uma delas calculada a eficiência de mistura em cinco pontos no intervalo do número de Reynolds entre 0,01 e 100, totalizando 45 simulações. 
Tabela 23. Estudo 3.1: Condições de contorno.

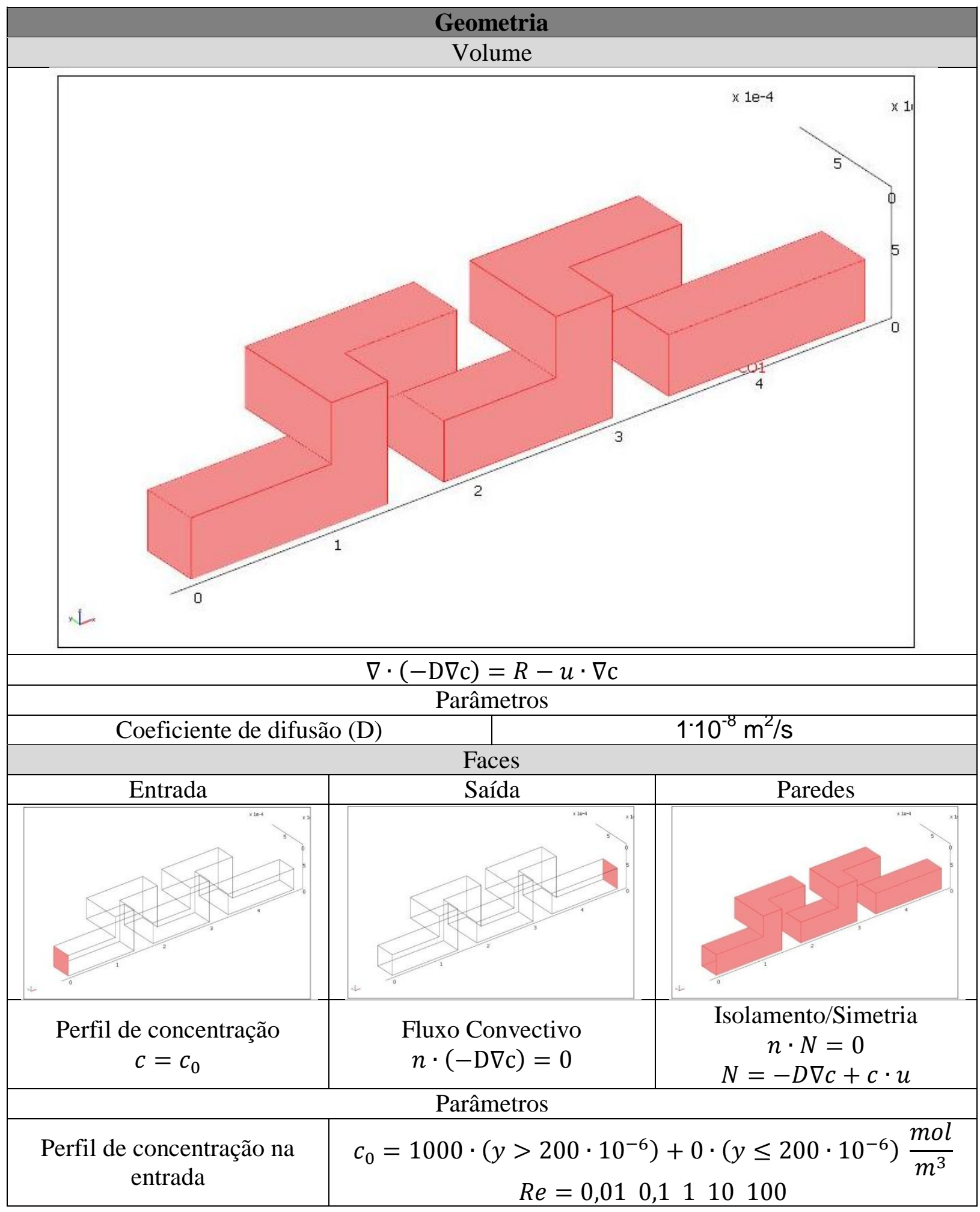

A discretização da malha é mostrada na tabela 24 , com mudanças em relação a malha anterior, pois nesse modelo computacional está envolvida a interface entre dois fluidos o que requer uma malha mais fina. O elemento utilizado é o tetraedro com tamanho global de $20 \mu \mathrm{m}$ e tamanho local de $16 \mu \mathrm{m}$. 
Tabela 24. Estudo 3.1: Discretização das geometrias.

\begin{tabular}{|c|c|c|}
\hline \multicolumn{3}{|c|}{ Geometria } \\
\hline
\end{tabular}

Após o processamento do modelo com o solver GMRES e o pré-condicionador Geometric multigrid foram obtidos os mapas de concentração em diversas condições para a análise das geometrias.

A figura 35 mostra os mapas de concentração de duas geometrias: (a) microcanal reto e (b) serpentina 3D 1, para diversas condições de Re. Observa-se que para as condições de $\operatorname{Re}=0,01$ e $R e=0,1$; a mistura dos fluidos é processada de forma idêntica para ambas as geometrias, microcanal reto e serpentina 3D 1.

Para $R e=1$, observa-se que a qualidade da mistura diminui em relação às condições anteriores, verificando ainda uma distribuição de concentração na saída de ambas as geometrias analisadas. Esse fato se deve a diminuição do tempo de residência das espécies dentro do microcanal que para $R e=1$ é igual 3,1 s. Este tempo é insuficiente para efetivar a mistura dos fluidos, pois o valor teórico calculado é de $8 \mathrm{~s}$. 
Para as condições $R e=10$ e $R e=100$, observa-se para o microcanal reto que a qualidade da mistura só diminui, ocorrendo apenas uma difusão não significativa na interface entre os fluidos.

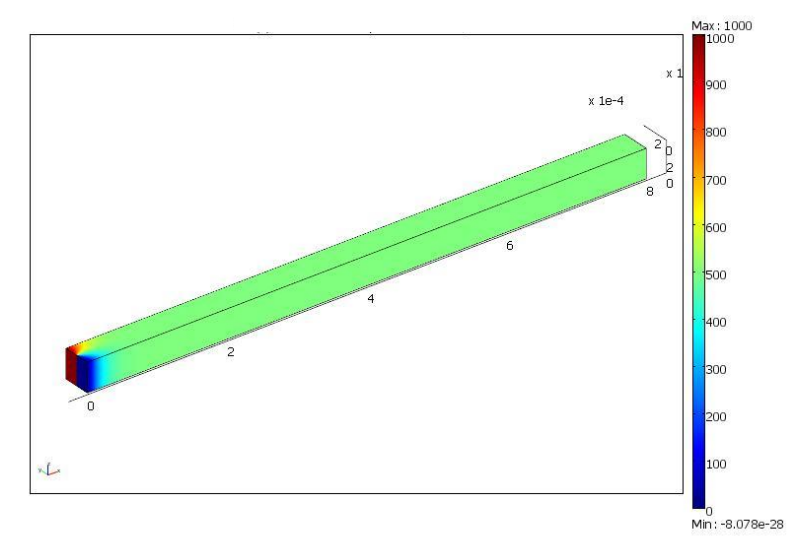

$$
\operatorname{Re}=0,01
$$

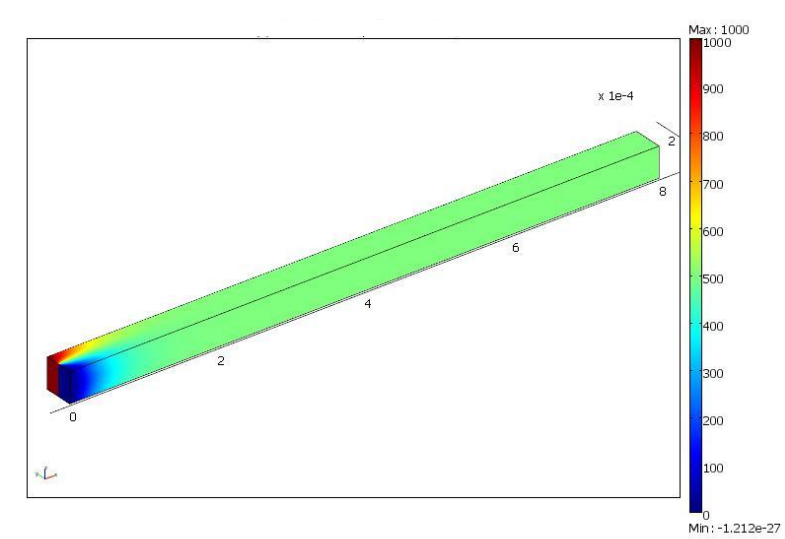

$$
\mathrm{Re}=0,1
$$

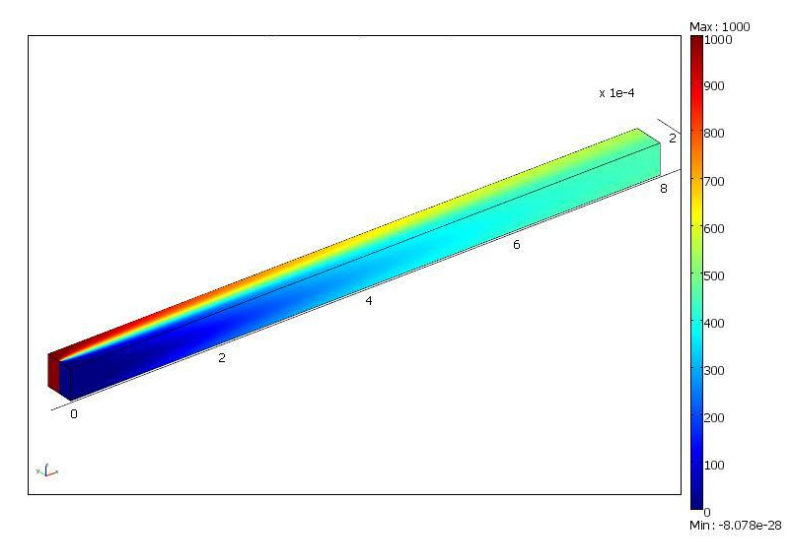

$\mathrm{Re}=1$

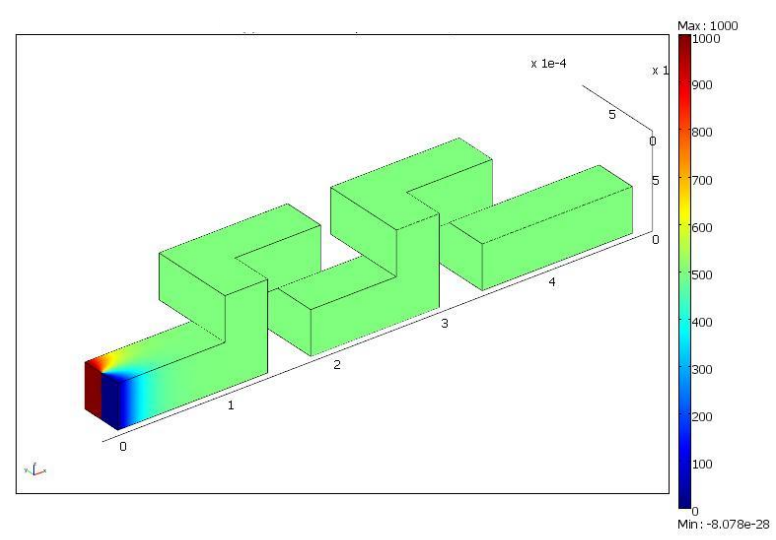

$\operatorname{Re}=0,01$

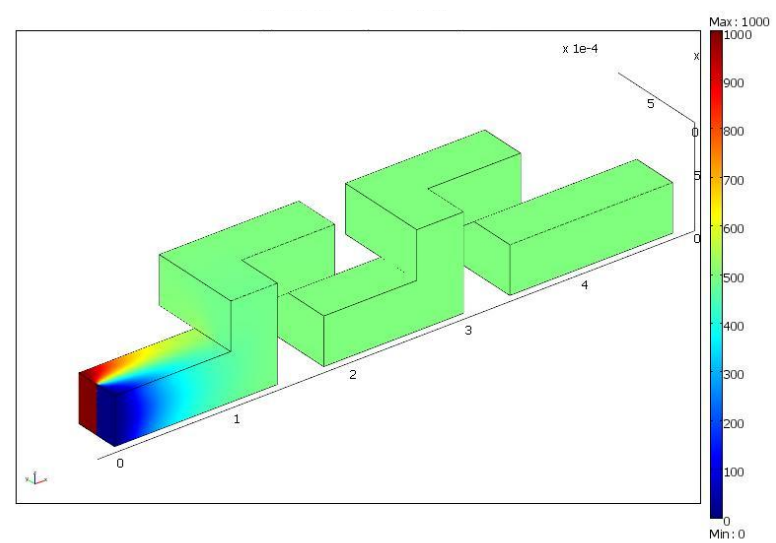

$\operatorname{Re}=0,1$

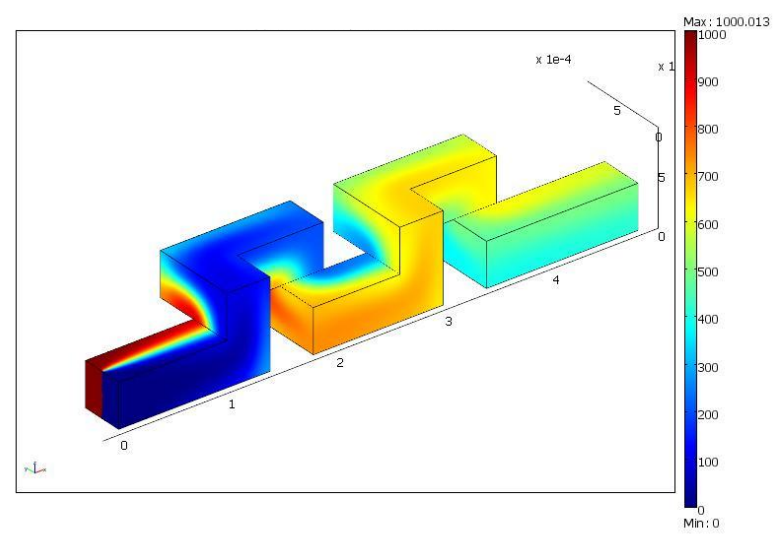

$\operatorname{Re}=1$ 

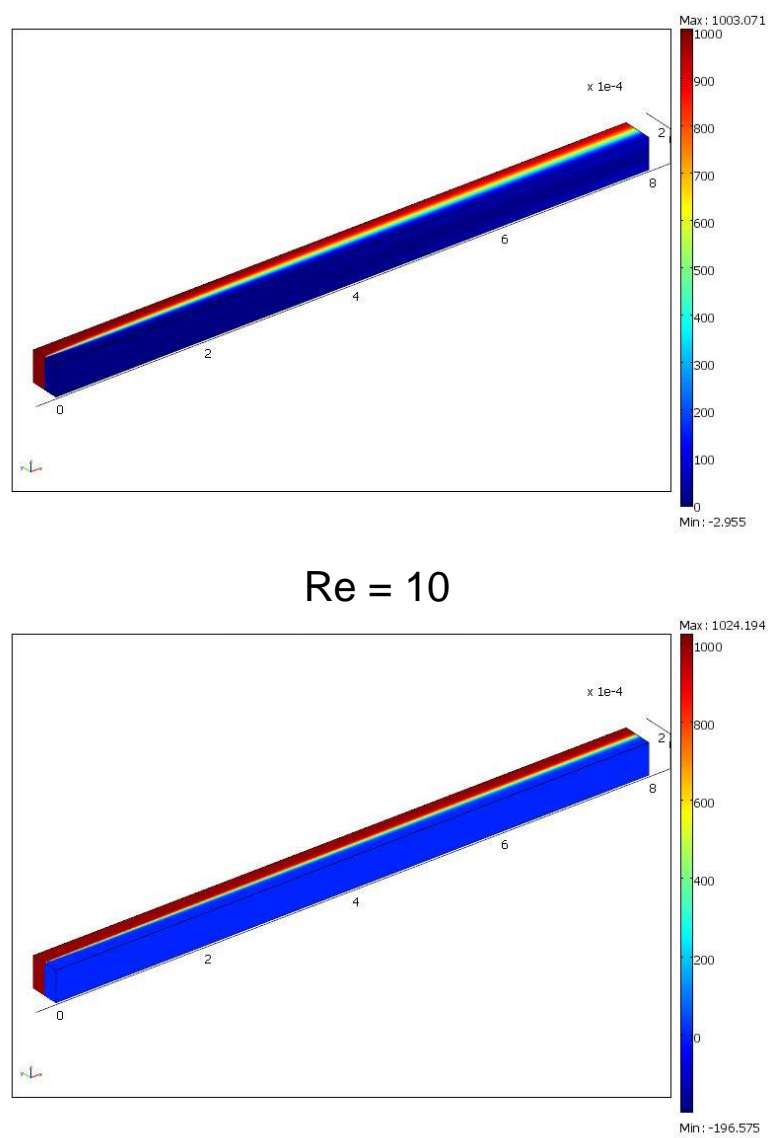

$\mathrm{Re}=100$

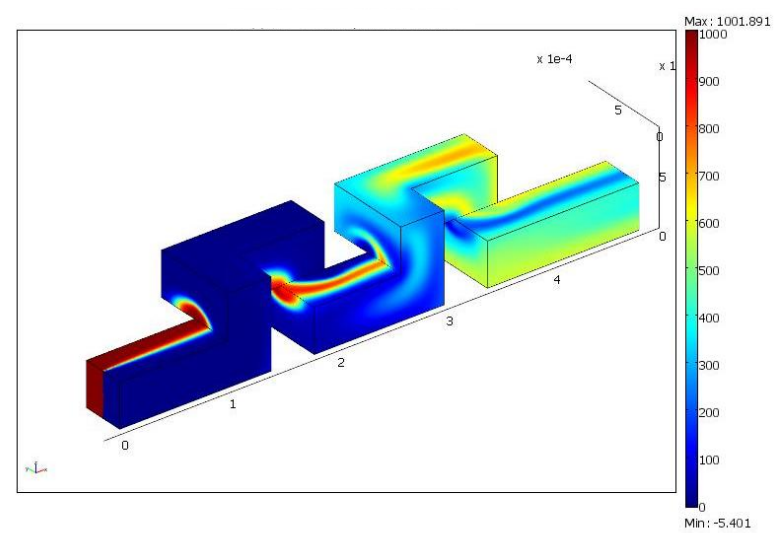

$\mathrm{Re}=10$

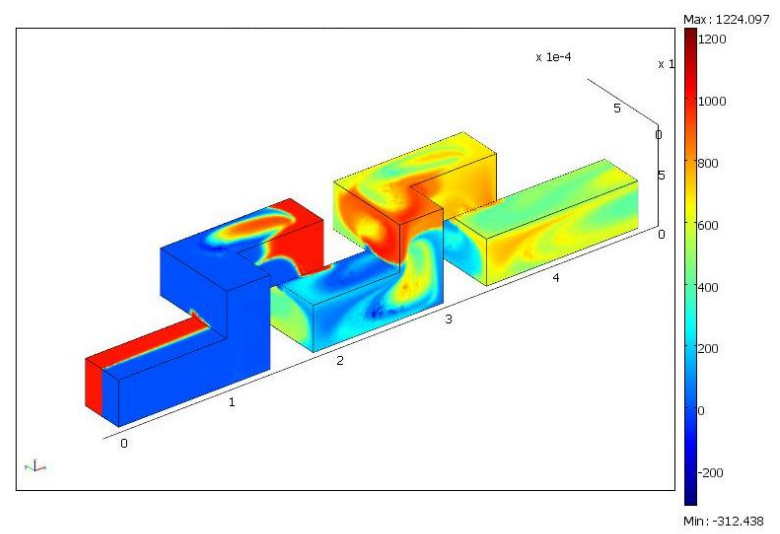

$\mathrm{Re}=100$

Figura 35. Mapas de concentração: comparação do microcanal reto com a serpentina 3D 1.

Já para a geometria serpentina 3D 1, em $R e=10$ e $R e=100$, observa-se uma melhora na qualidade da mistura em relação ao microcanal reto nas mesmas condições. Esse intervalo de Re entre 10 e 100, foi identificado como a região onde ocorre a transição de regime de escoamento para as geometrias baseadas em sucessivos cotovelos, de regime laminar para intermediário. Enquanto que para o mesmo intervalo não ocorre transição de regime para o microcanal reto. Portanto, explica-se a melhor qualidade de mistura da serpentina 3D 1 comparando com 0 microcanal reto, em função da descrição de escoamento diferenciada.

Além disso, comparando a geometria serpentina 3D 1 para Re entre 10 e 100, observa-se que a qualidade da mistura para $\mathrm{Re}=100$ é melhor que para $\mathrm{Re}=10 \mathrm{~A}$ análise dos mapas de velocidade e dos dados de vorticidade, realizados no início deste estudo, permite concluir que a descrição de escoamento visualizada no mapa de velocidade e o aumento de vorticidade para $\mathrm{Re}=100$ foi determinante para a melhora da qualidade de mistura para Re entre 10 e 100. 


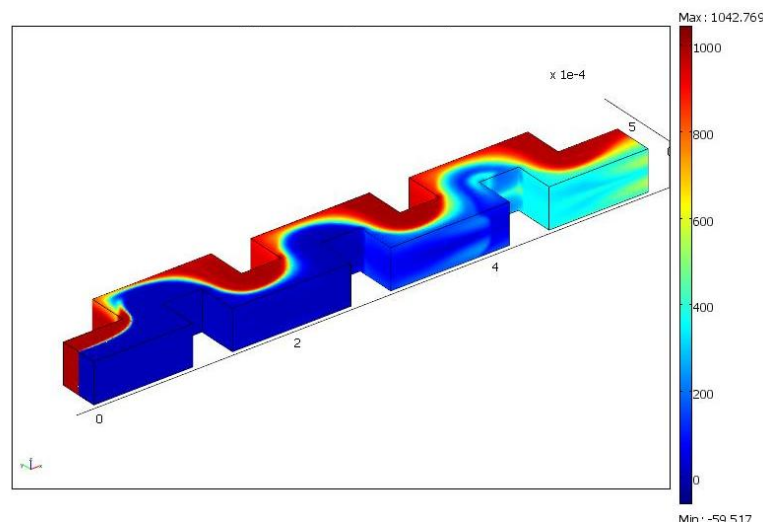

Onda quadrada 1

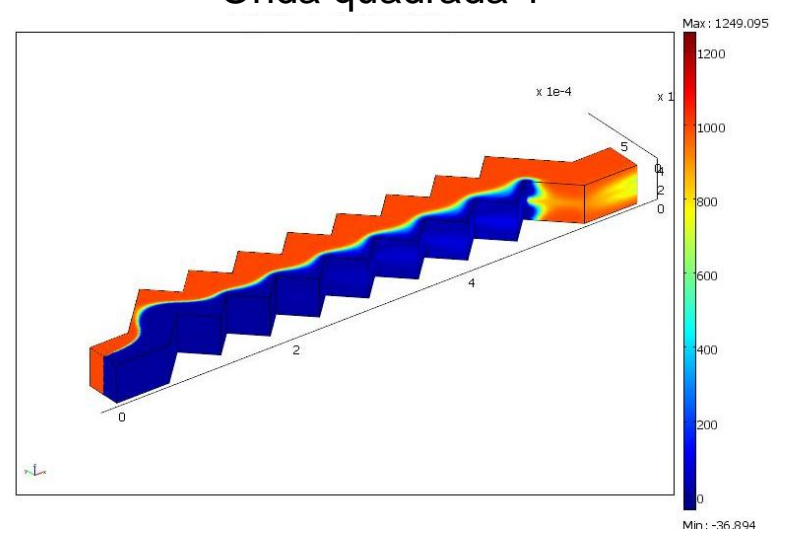

Zigzag 1

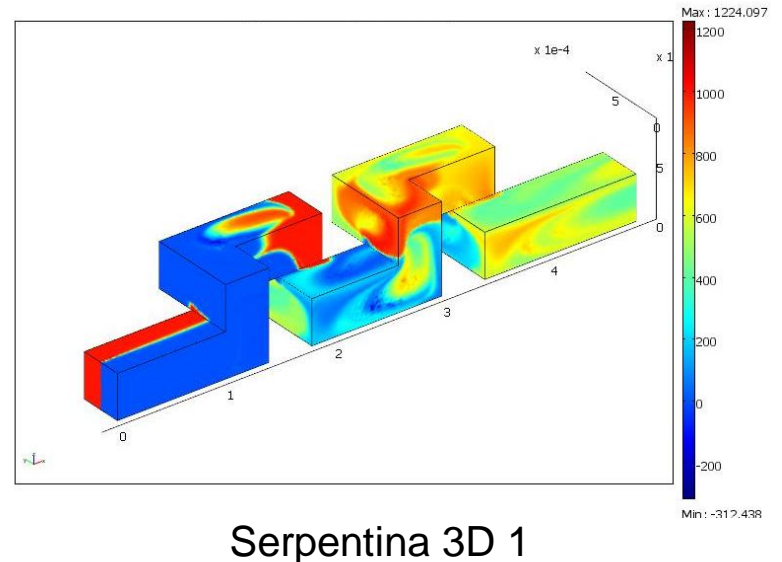

Serpentina 3D 1

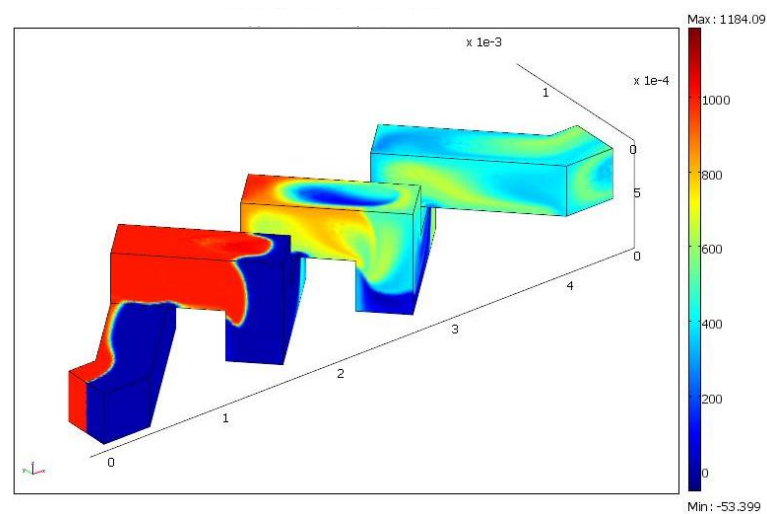

Zigzag 3D 1

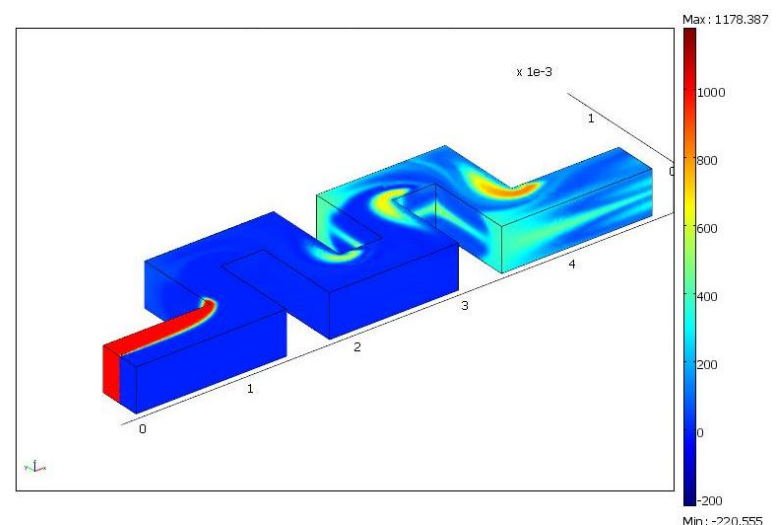

Onda quadrada 2

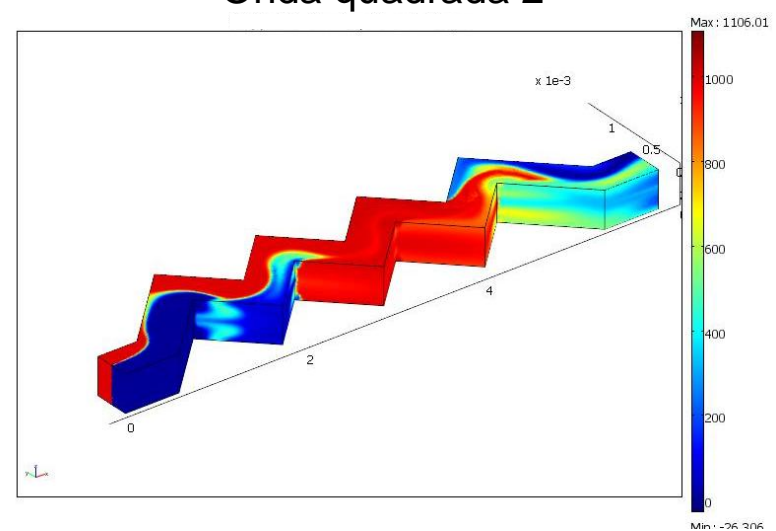

Zigzag 2

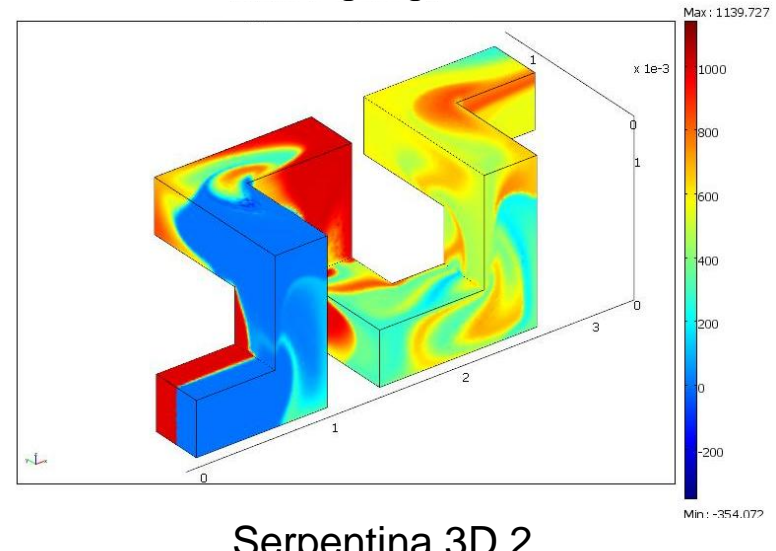

Serpentina 3D 2

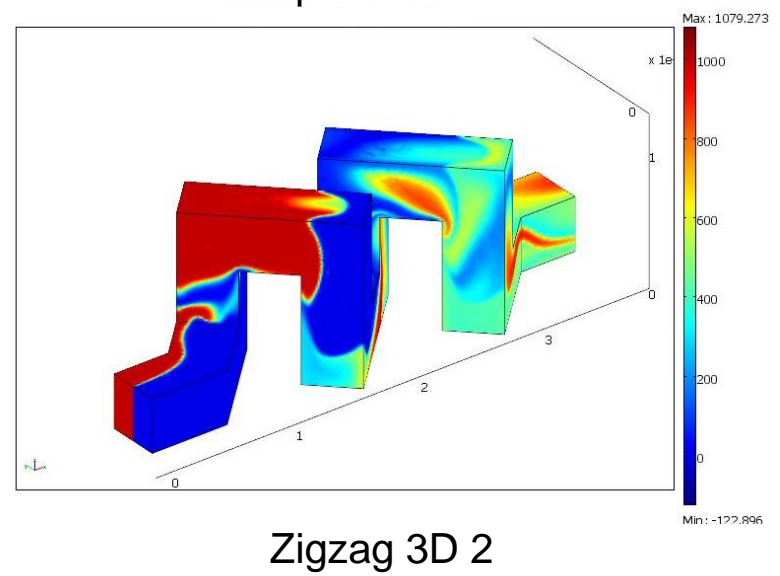

Figura 36. Mapas de concentração das geometrias baseadas em sucessivos cotovelos. 
A figura 36 mostra os mapas de concentração das geometrias baseadas em sucessivos cotovelos para $R e=100$. Esta figura permite analisar visualmente quais distâncias entre cotovelos foram mais efetivas no projeto dos microcanais.

Visualmente, comparando as geometrias pares, chegam-se as seguintes melhores qualidades de misturas:

- Onda quadrada 2 melhor que onda quadrada 1 ,

- Zigzag 2 melhor que zigzag 1,

- Serpentina 3D 1 melhor que serpentina 3D 2, e

- Zigzag 3D 1 melhor que zigzag 3D 2.

Portanto, as distâncias entre os cotovelos que foram mais efetivas no projeto dos microcanais são as seguintes em função do tipo de estrutura:

- Estrutura 1: $\mathrm{dec}=2$,

- Estrutura 2: $\operatorname{dec}=2$,

- Estrutura 3: $\operatorname{dec}=1$.

Além disso, a percepção geral com a visualização dos mapas de concentração é que as geometrias 3D apresentam melhor eficiência de mistura que as geometrias 2D.

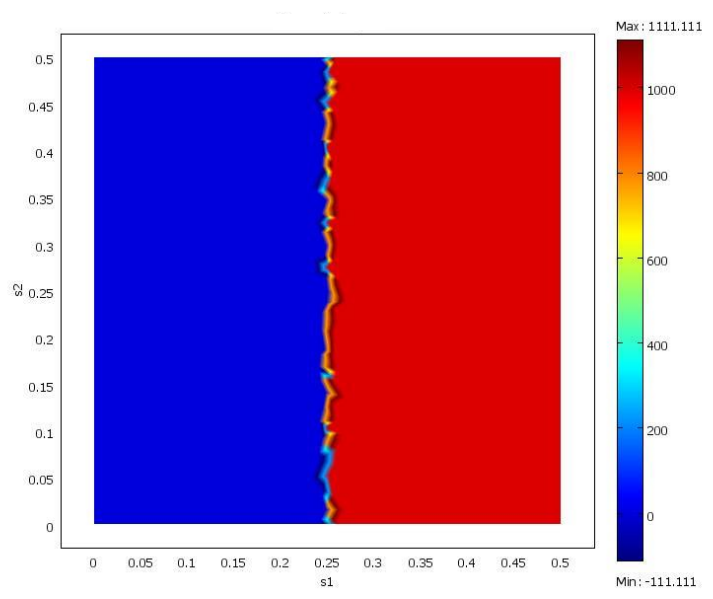

Perfil de concentração nas entradas

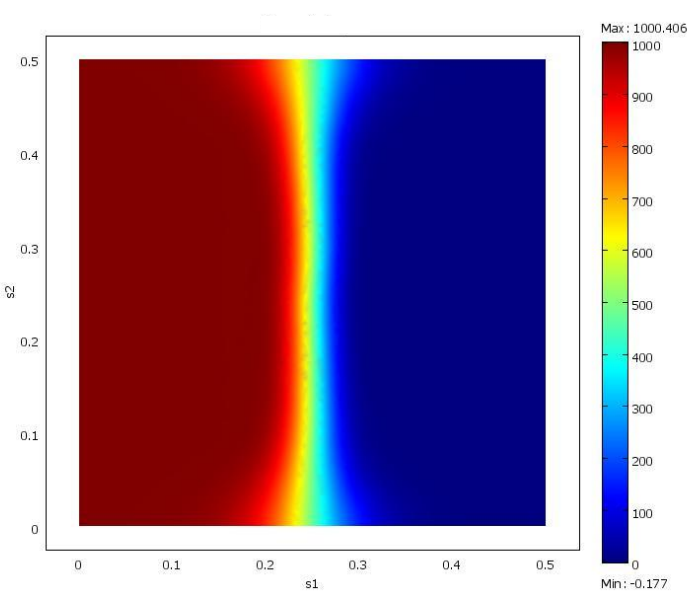

Microcanal reto/Saída: 0 a 1000 


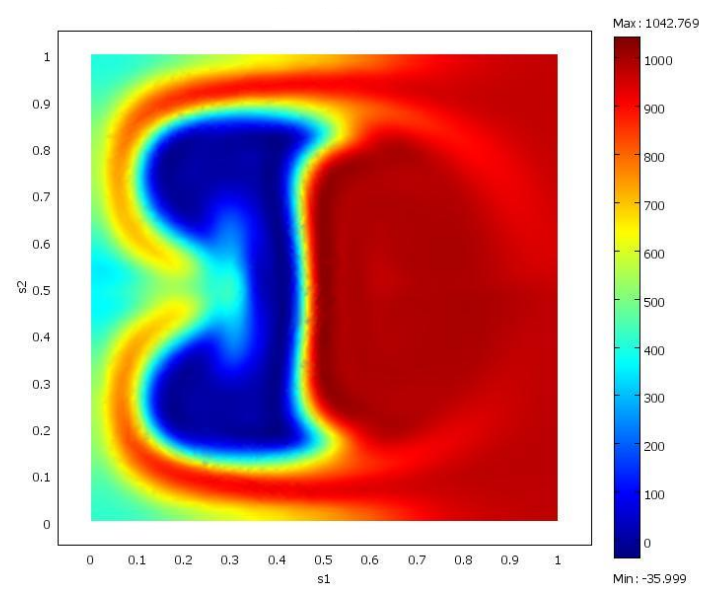

Onda quadrada 1/Saída: 0 a 1000

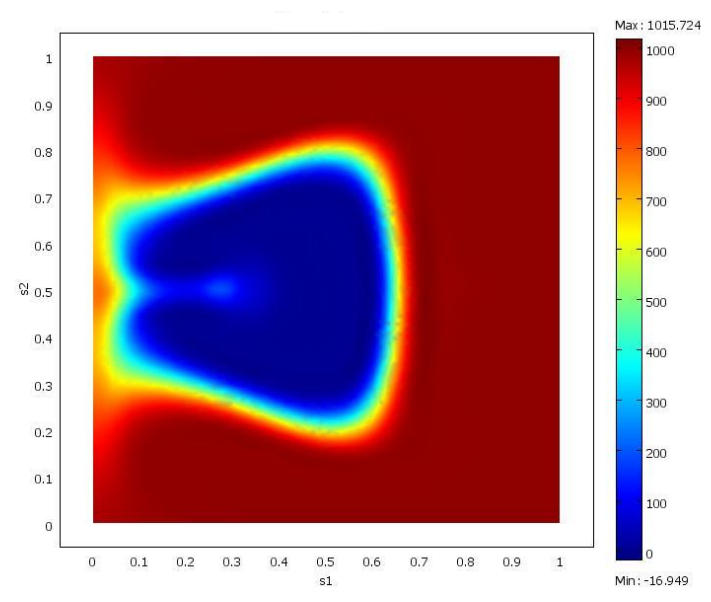

Zigzag 1/Saída: 0 a 1000

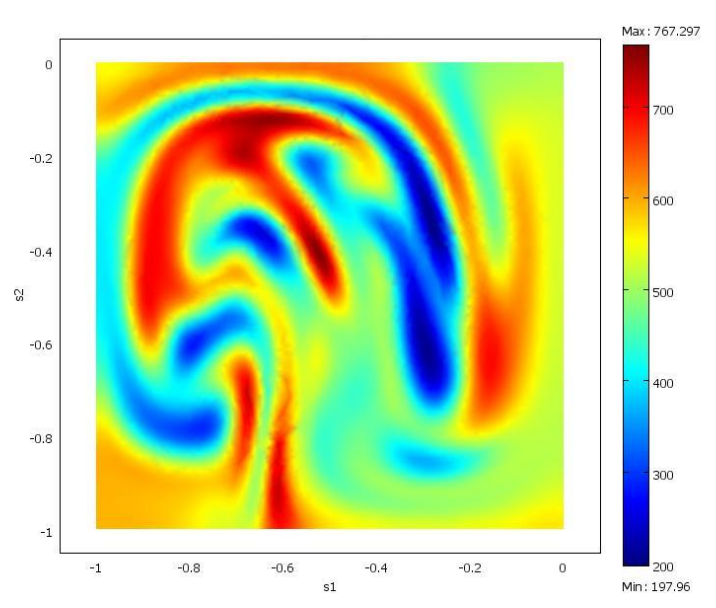

Serpentina 3D 1/Saída: 197 a 767

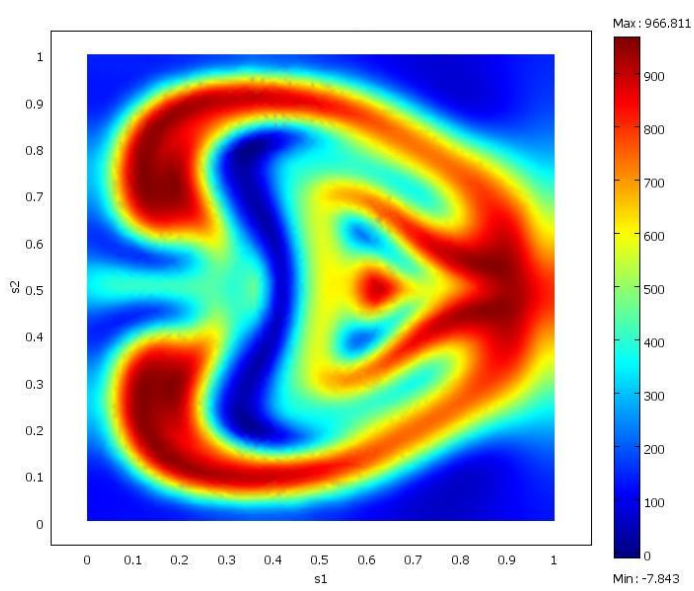

Onda quadrada 2/Saída: 0 a 966

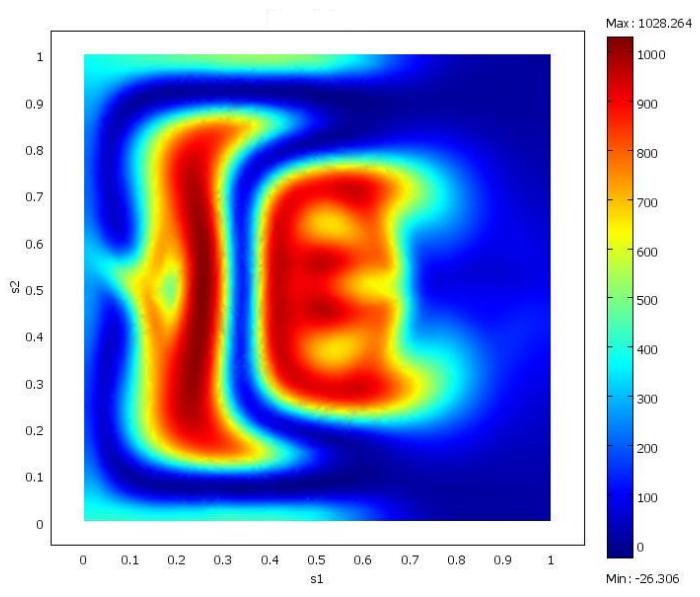

Zigzag 2/Saída: 0 a 1000

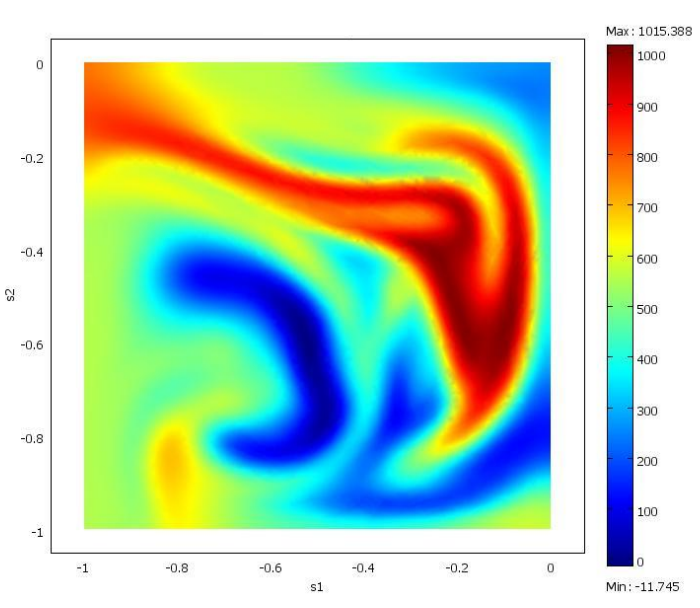

Serpentina 3D 2/Saída: 0 a 1000 


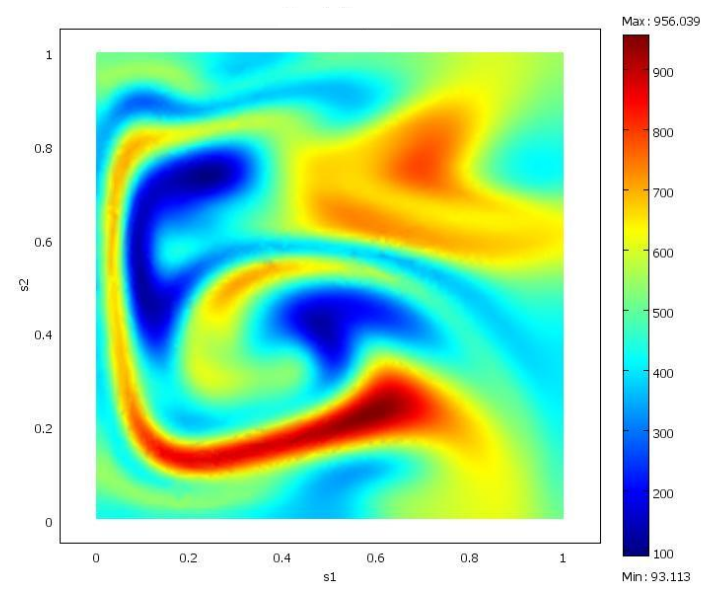

Zigzag 3D 1/Saída: 93 a 956

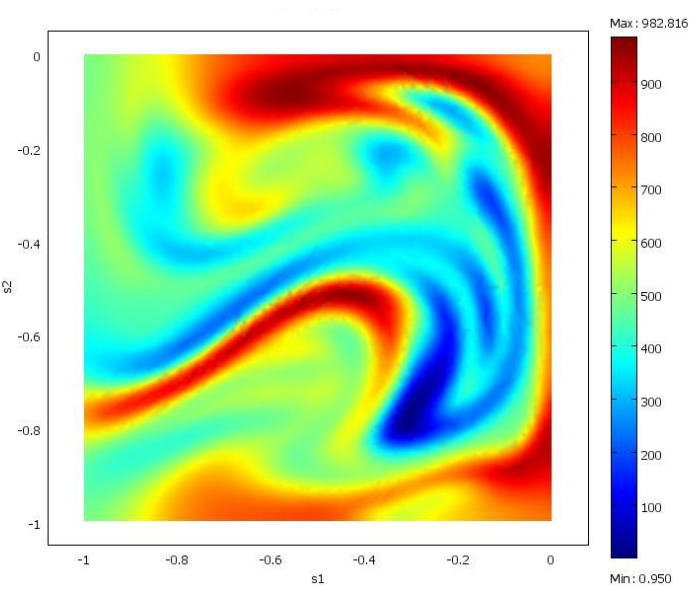

Zigzag 3D 2/Saída: 0 a 982

Figura 37. Mapas de concentração: saída das geometrias.

A figura 37 mostra os mapas de concentração da face de saída das geometrias estudas, para $R e=100$. O primeiro mapa mostra o perfil de concentração que é comum a entrada de todos os dispositivos. Esta figura confirma as observações discutidas da figura 36 .

Os dispositivos onda quadrada 2, zigzag 2, serpentina 3D 1 e zigzag 3D 1 apresentam melhor eficiência de mistura que seus dispositivos pares, respectivamente, confirmando as distâncias entre os cotovelos utilizadas para o projeto dessas geometrias. Além disso, confirma-se que as geometrias $3 D$ apresentam melhor desempenho que as $2 \mathrm{D}$. No geral, observa-se que a serpentina 3D 1 e a zigzag 3D 1 são as que apresentam melhor resultado.

Uma importante observação ainda a fazer sobre a figura 37 é em relação a interface entre as concentrações observadas nos mapas. Tomando como base de comparação o microcanal reto, onde é observada uma interface bem definida e a difusão ocorrendo nela. Nas geometrias baseadas em sucessivos cotovelos a interface é visualmente muito maior e totalmente distorcida.

Portanto, a observação visual dos mapas de concentração é que as geometrias 3D tem a interface entre os fluidos intensificada em relação as geometrias 2D, que por sua vez tem a interface intensificada em relação ao microcanal reto. 


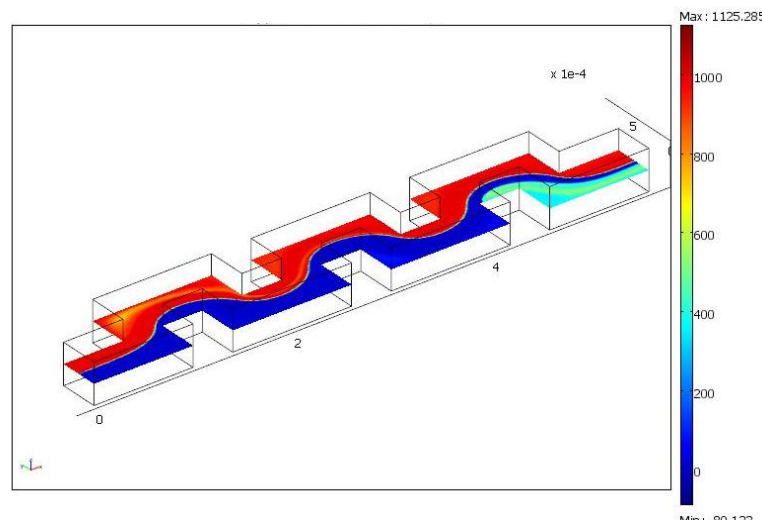

Onda quadrada 1

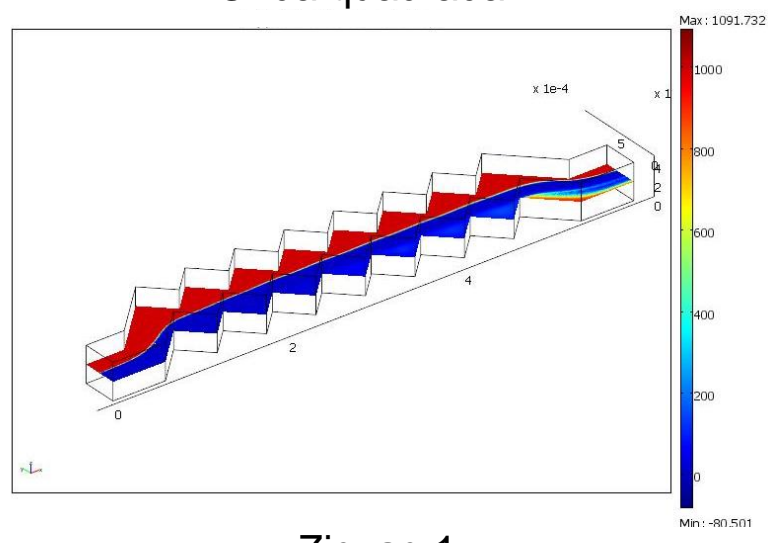

Zigzag 1

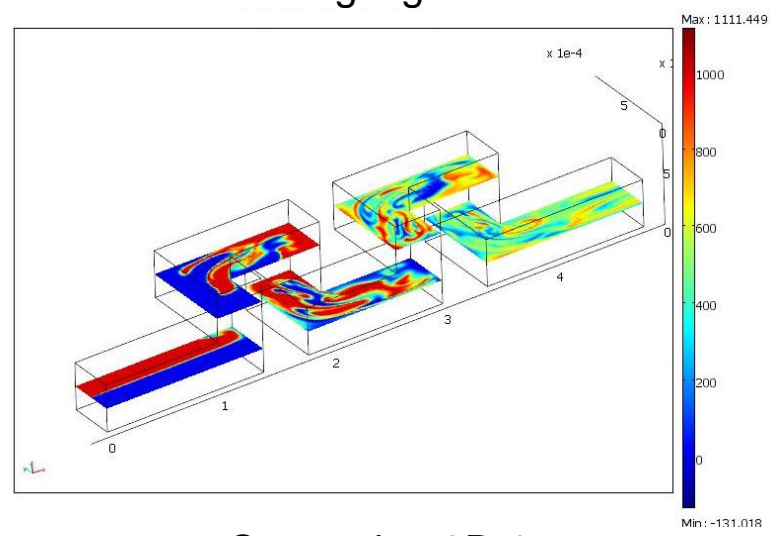

Serpentina 3D 1

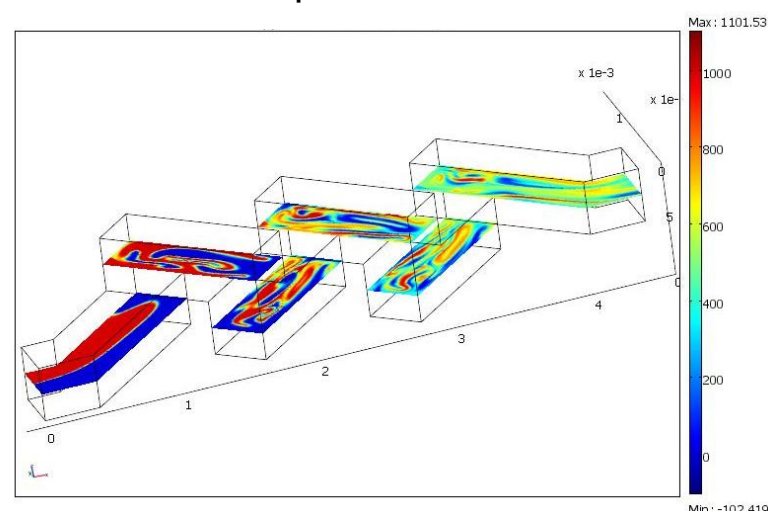

Zigzag 3D 1

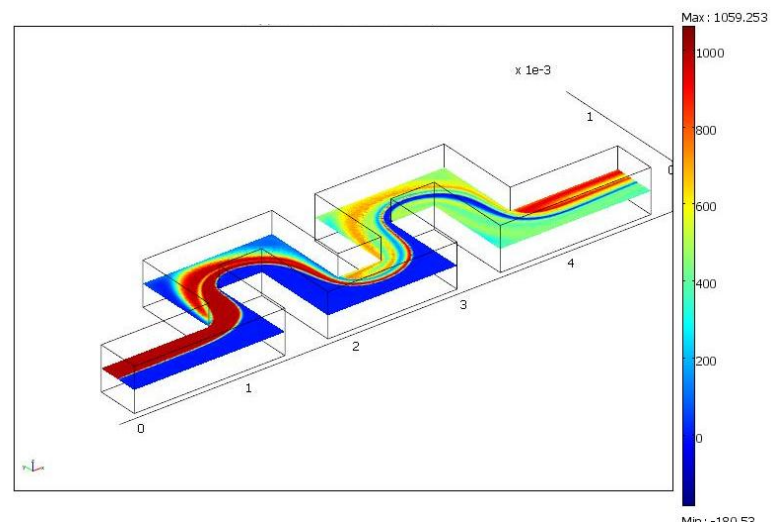

Onda quadrada 2

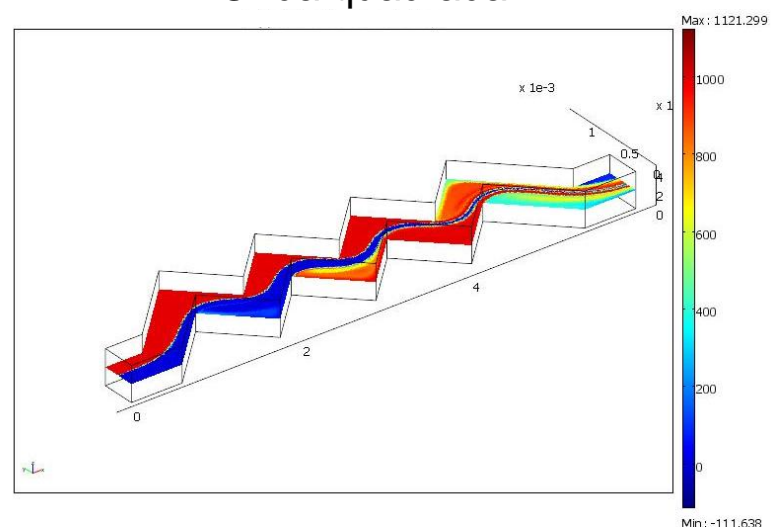

Zigzag 2

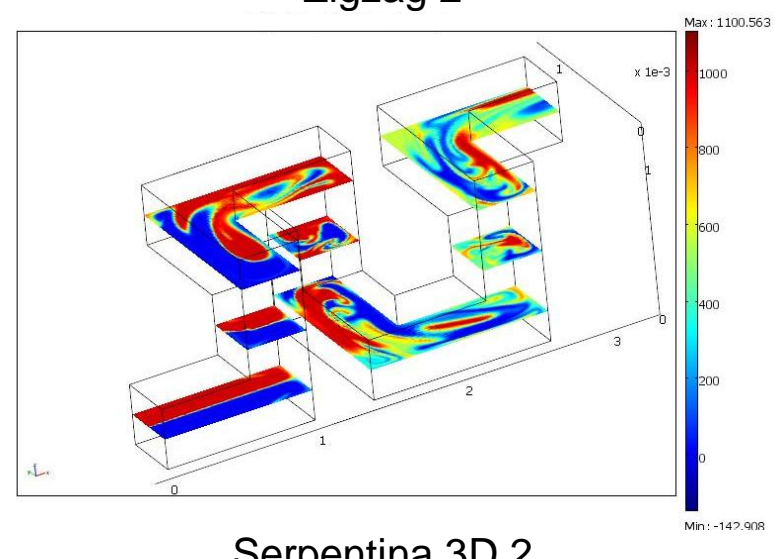

Serpentina 3D 2

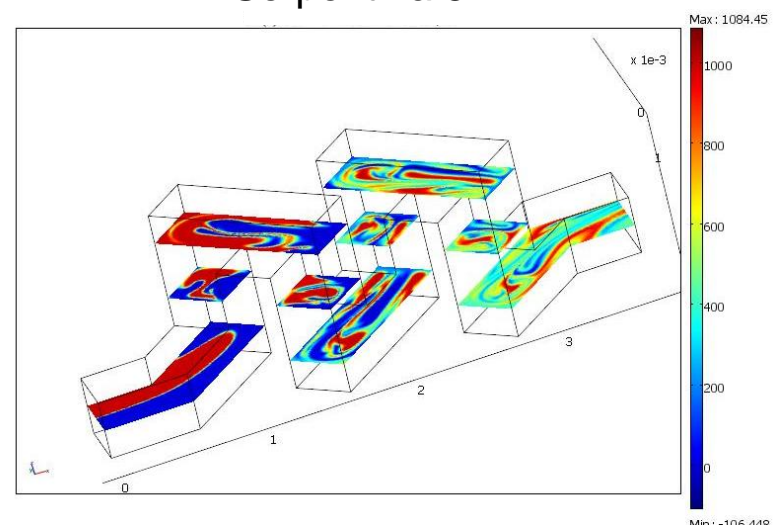

Zigzag 3D 2

Figura 38. Mapas de concentração: cortes no plano xy. 
Para detalhar melhor a questão da interface foram preparadas três figuras que mostram cortes nos planos $x y, x z$ e yz, onde é possível observar como é a evolução da interface entre os fluidos ao longo do eixo do escoamento.

A figura 38 mostra os mapas de concentração para as geometrias baseadas em sucessivos cotovelos para $R e=100$, em função dos cortes no plano xy. Observa-se para os melhores dispositivos 2D que a interface entre os fluidos é levemente distorcida no plano xy. Nos piores dispositivos 3D, observa-se que ao longo do eixo do escoamento a interface é intensamente aumentada e distorcida.

A figura 39 mostra os mapas de concentração para as geometrias baseadas em sucessivos cotovelos para $R e=100$, em função dos cortes no plano yz. Observa-se para os melhores dispositivos 2D que a interface entre os fluidos é aumentada e mais distorcida no plano yz em relação ao plano xy. Ainda assim, para os dispositivos 3D verifica-se que a interface é mais distorcida que para os dispositivos 2D.

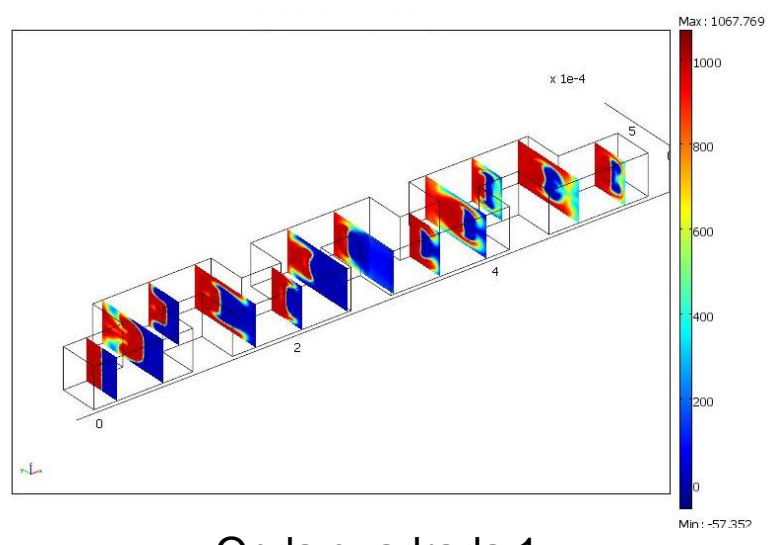

Onda quadrada 1

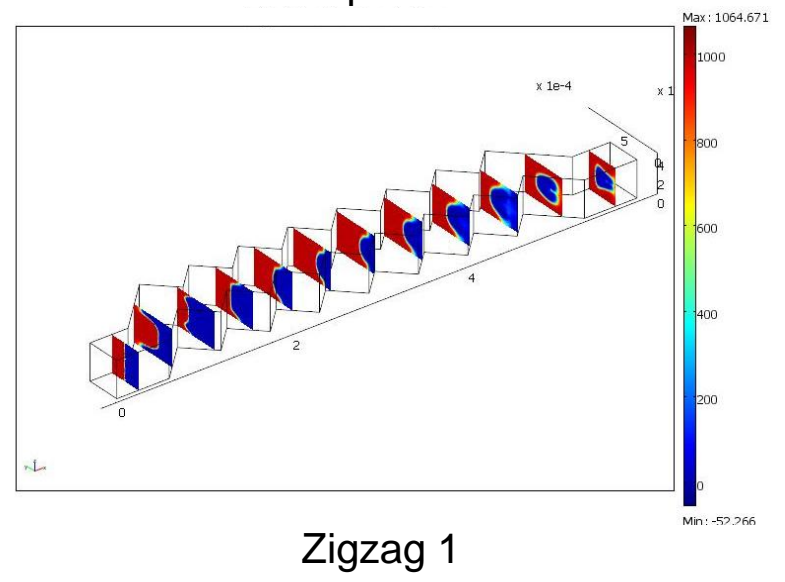

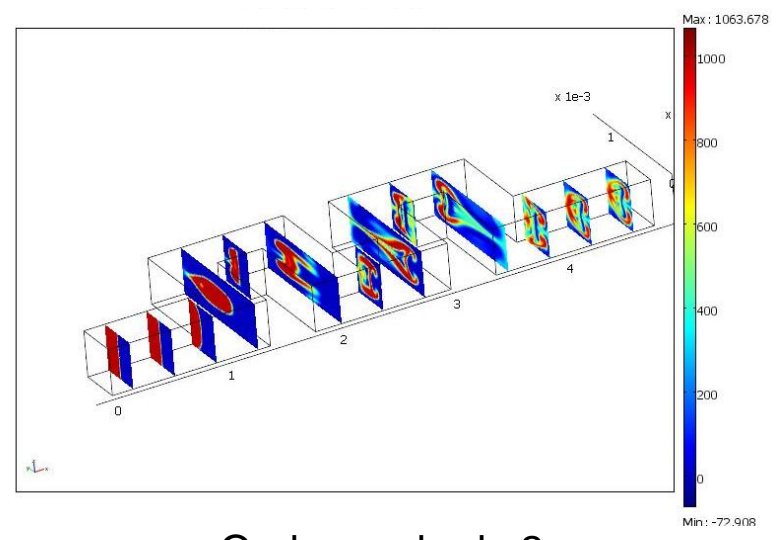

Onda quadrada 2

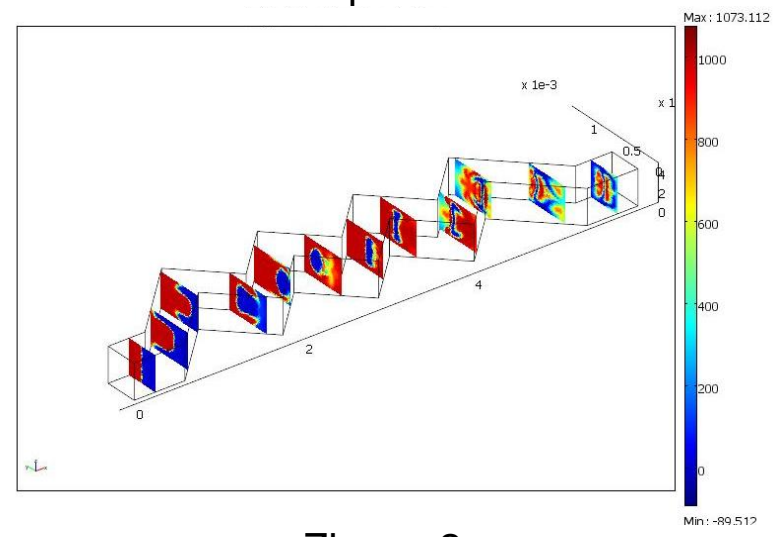

Zigzag 2 


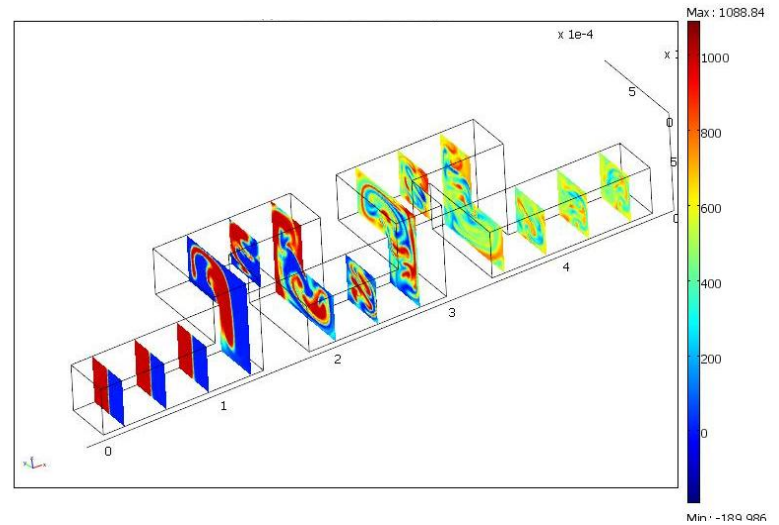

Serpentina 3D 1

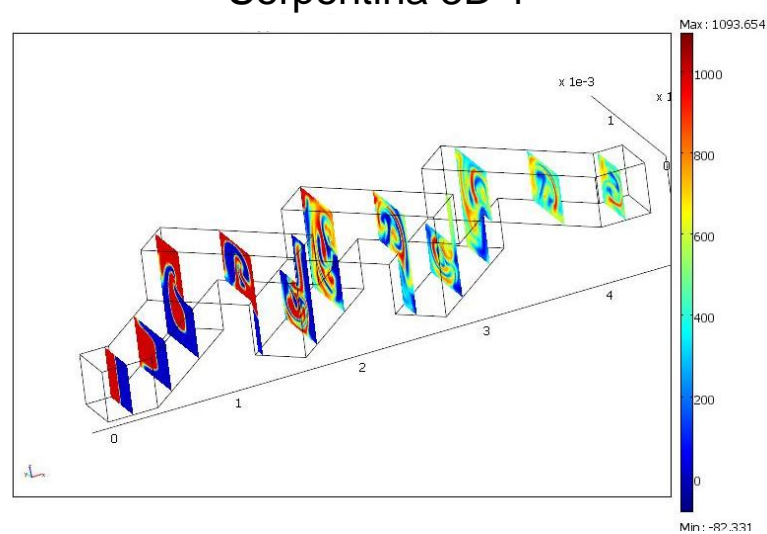

Zigzag 3D 1

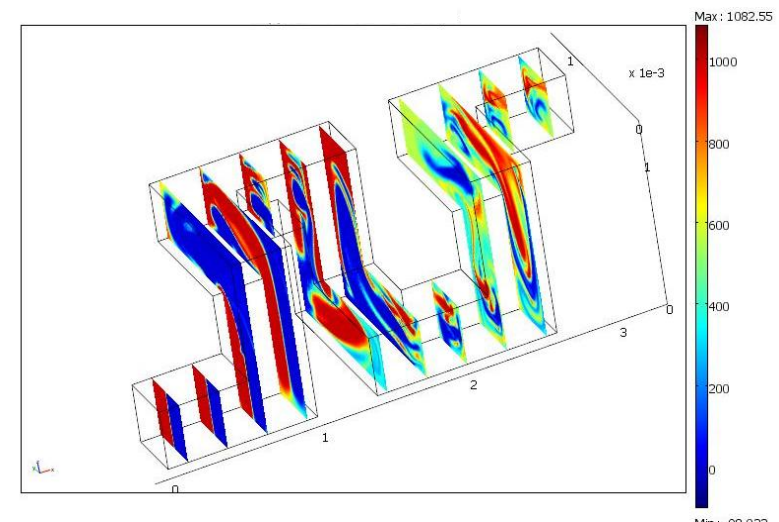

Serpentina 3D 2

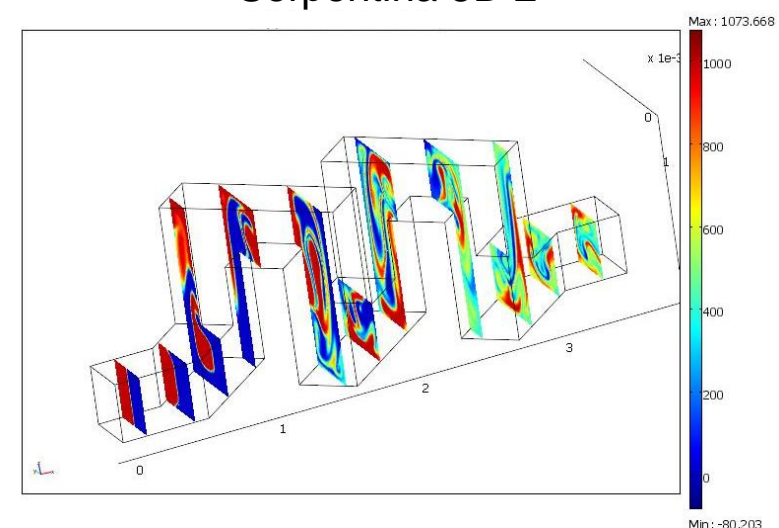

Zigzag 3D 2

Figura 39. Mapas de concentração: cortes no plano yz.

Portanto, a percepção inicial da figura 36 de que os dispositivos 3D apresentam uma melhor eficiência de mistura que os dispositivos $2 \mathrm{D}$ é visualmente consistentes analisando as figuras 37, 38 e 39. Percebe-se que os dispositivos 3D manipulam a interface entre os fluidos de forma mais efetiva para a mistura que os dispositivos 2D, tanto no plano xy como no plano yz. Adicionalmente, a mesma tendência é observada no plano $x z$, como mostrado na figura 40.

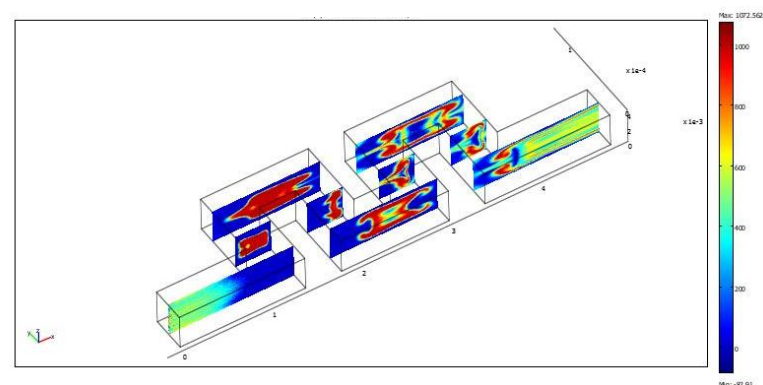

Onda quadrada 2

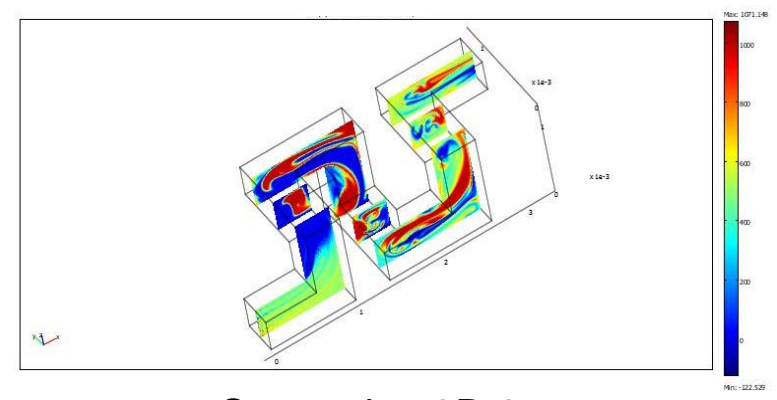

Serpentina 3D 2

Figura 40. Mapas de concentração: cortes no plano xz.

Após a visualização dos mapas de concentração foi realizada a obtenção dos parâmetros numéricos de interesse das nove geometrias estudadas. 
A eficiência de mistura é calculada pela comparação entre os perfis de concentração entrada e saída. A variância relativa do perfil de concentração é calculada nas faces entrada e na saída pela equação

$$
\sigma=\int(c-\bar{c})^{2} \cdot d A
$$

eq. 16,

onde c é a concentração em cada um dos elementos da face de entrada ou de saída, $\bar{c}$ é a concentração média na face de entrada e dA é o diferencial de área onde será feita a integração. Logo, a eficiência de mistura é dada pela equação

$$
\varepsilon=\frac{\sigma_{s}}{\sigma_{e}}
$$

eq. 17,

onde $\sigma_{\mathrm{e}}$ e $\sigma_{\mathrm{s}}$ são as variâncias relativas de entrada e saída, respectivamente. A eficiência de mistura é um parâmetro que varia de 0 a 1. Quanto mais próximo de 1, significa que não houve grandes alterações comparando-se entrada e saída. Quanto mais próximo de zero, significa que houve grandes alterações comparando-se entrada e saída.

O gráfico 17 mostra os dados calculados pela equação 17 de eficiência de mistura em função do número de Reynolds. Observa-se duas regiões no gráfico, a primeira localizada para Re entre 0,01 e 1, e a segunda localizada para Re entre 1 e 100.

Na primeira região, verifica-se uma boa eficiência de mistura para todas as geometrias, pois esse parâmetro aproxima-se de zero. Nessa região, comparandose as geometrias, fica claro que a melhor abordagem é a utilização do microcanal reto, pois apresenta mesmo resultado de eficiência que as demais geometrias, mas apresenta uma menor complexidade geométrica na fabricação deste microcanal.

$\mathrm{Na}$ segunda região, observa-se que a eficiência de mistura das geometrias estudadas é pior que na primeira região, pois os valores estão mais próximos de 1 . Nessa região, verifica-se que as geometrias microcanal reto, onda quadrada 1 e zigzag 1 apresentam uma pior eficiência em função do número de Reynolds. Enquanto que as outras geometrias apresentam uma pior eficiência até um ponto de máximo em $R e=10$, e a partir deste ponto até $R e=100$ a eficiência de mistura melhora novamente. 


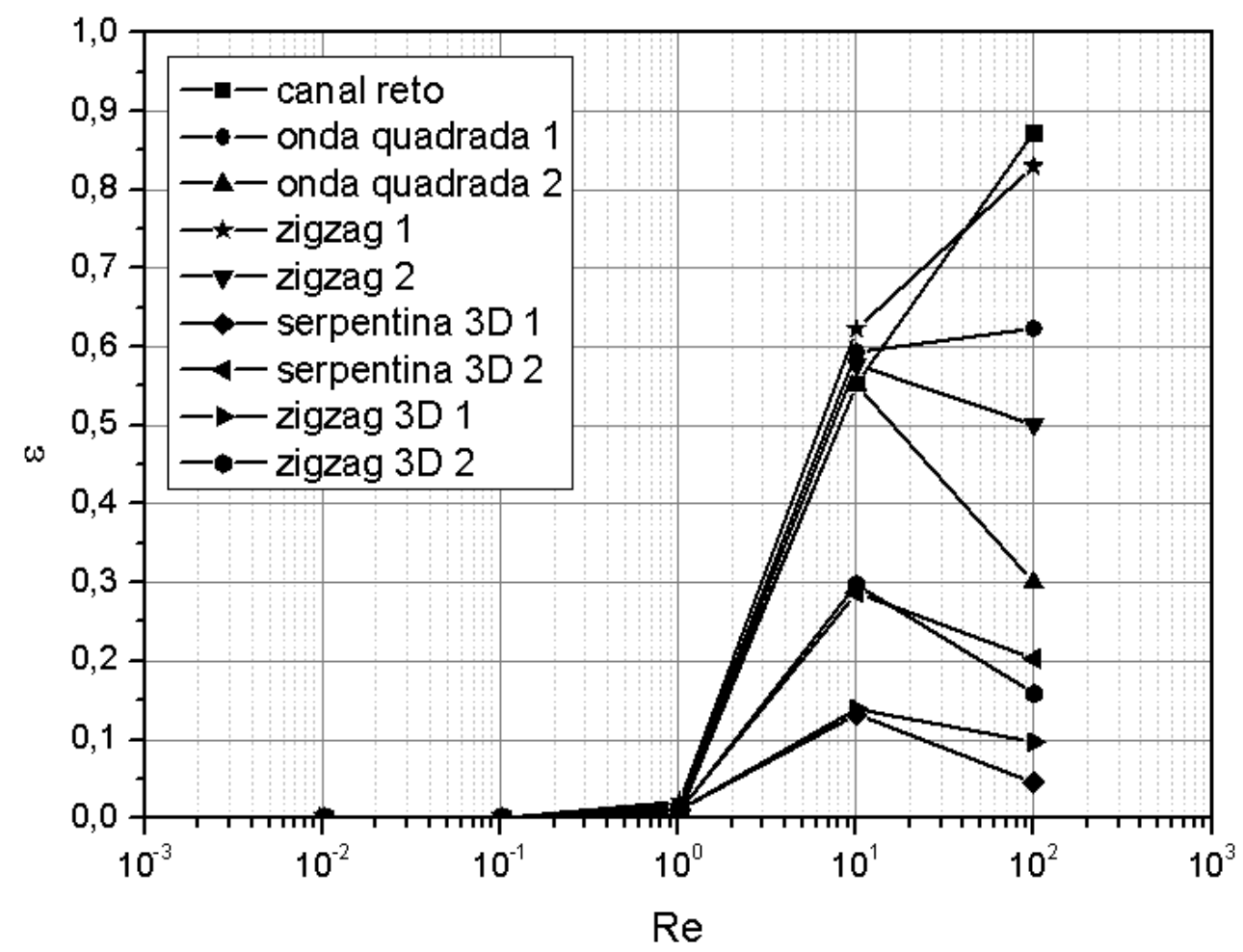

Gráfico 17. Eficiência de mistura em função do número de Reynolds.

A observação dos mapas de concentração confirma um pior desempenho das geometrias onda quadrada 1 e zigzag 1 , entre as geometrias baseadas em sucessivos cotovelos. Os dados numéricos de $\mathrm{K}$ e $\omega$, dos gráficos 12 e 13, respectivamente, indicam que ocorre transição de regime, mas com os mais baixos valores de $\omega$, gráfico 13. Portanto, as distâncias entre cotovelos escolhidas para o projeto dessas geometrias não foram adequadas.

Quanto às outras geometrias, a observação dos mapas de concentração confirma um bom desempenho delas, com destaque para a serpentina 3D 1 e a Zigzag 3D 1. A investigação das distâncias entre cotovelos foi efetiva, pois influenciou na qualidade de mistura. A investigação da transição de regime para Re entre 10 e 100, também influenciou na qualidade da mistura positivamente, pois mudou o comportamento encontrado da eficiência de mistura para Re entre $1 \mathrm{e}$ 10.

Para estabelecer a diferença de desempenho entre os dispositivos estudados, é mostrado na tabela 250 índice de comparação de desempenho das geometrias estudadas para $\operatorname{Re}=100$. 
Observando a tabela 25 confirma-se um melhor desempenho para as geometrias 3D. Destaque para as geometrias, serpentina 3D 1 e zigzag 3D 1. As geometrias onda quadrada 1 e zigzag 1 apresentam os piores índices de comparação de desempenhos entre as geometrias estudadas.

Tabela 25. Índice de comparação do desempenho das geometrias estudadas para $\mathrm{Re}=100$.

\begin{tabular}{|c|c|}
\hline Dispositivos & Índice de comparação \\
\hline microcanal reto & 1,00 \\
\hline onda quadrada 1 & 1,40 \\
\hline onda quadrada 2 & $\mathbf{2 , 9 1}$ \\
\hline zigzag 1 & 1,05 \\
\hline zigzag 2 & $\mathbf{1 , 7 4}$ \\
\hline serpentina 3D 1 & 19,23 \\
\hline serpentina 3D 2 & 4,30 \\
\hline zigzag 3D 1 & $\mathbf{9 , 0 2}$ \\
\hline zigzag 3D 2 & 5,50 \\
\hline
\end{tabular}

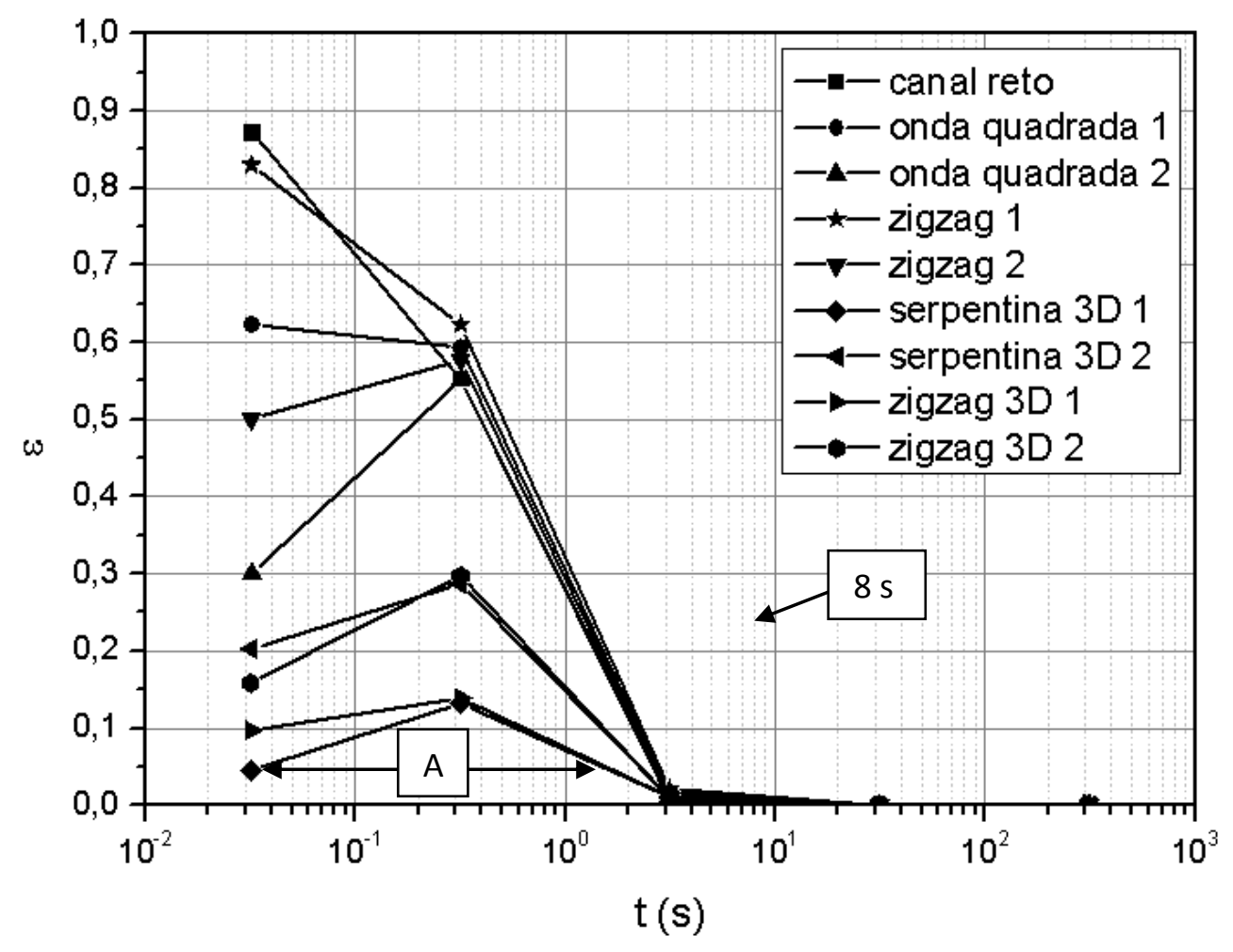

Gráfico 18. Eficiência de mistura em função do tempo de residência.

O gráfico 18 mostra a eficiência de mistura em função do tempo de residência. O tempo de residência teórico, calculado pela equação 15, é de $8 \mathrm{~s}$. Esse tempo 
divide o gráfico em duas regiões: (a) $t<8$ e (b) $t>8$. Observa-se na primeira região que para tempos menores que $8 \mathrm{~s}$ a mistura entre os fluidos não é efetiva.

Nessa região, observa-se também a linha $A$, que liga dois pontos com mesma eficiência de mistura, considerando a geometria serpentina 3D. O primeiro ponto para $t=0,03 \mathrm{~s}$ e o segundo ponto para $t=1,5 \mathrm{~s}$. $O$ tempo onde aproximadamente ocorre a transição de regime é $t=0,3 \mathrm{~s}$. Ou seja, os dois pontos ligados pela linha $A$, estão em dois regimes de escoamento diferentes. Portanto, a mudança de regime causou uma intensificação do tempo de mistura em aproximadamente duas ordens de grandeza, $10^{2}$.

O gráfico 19 mostra a eficiência de mistura em função da potência volumétrica. Verifica-se uma região de baixa potência onde a mistura foi efetivada. A região de alta potência apresenta uma qualidade de mistura pior que na região de baixa potência.

Portanto, apesar de terem sido obtidas geometrias otimizadas para realização de mistura, ainda é necessário estabelecer regras de projeto para a melhor geometria encontrada, onde se efetive a mistura de fluidos em alta potência, mas com tempo de residência muito curto.

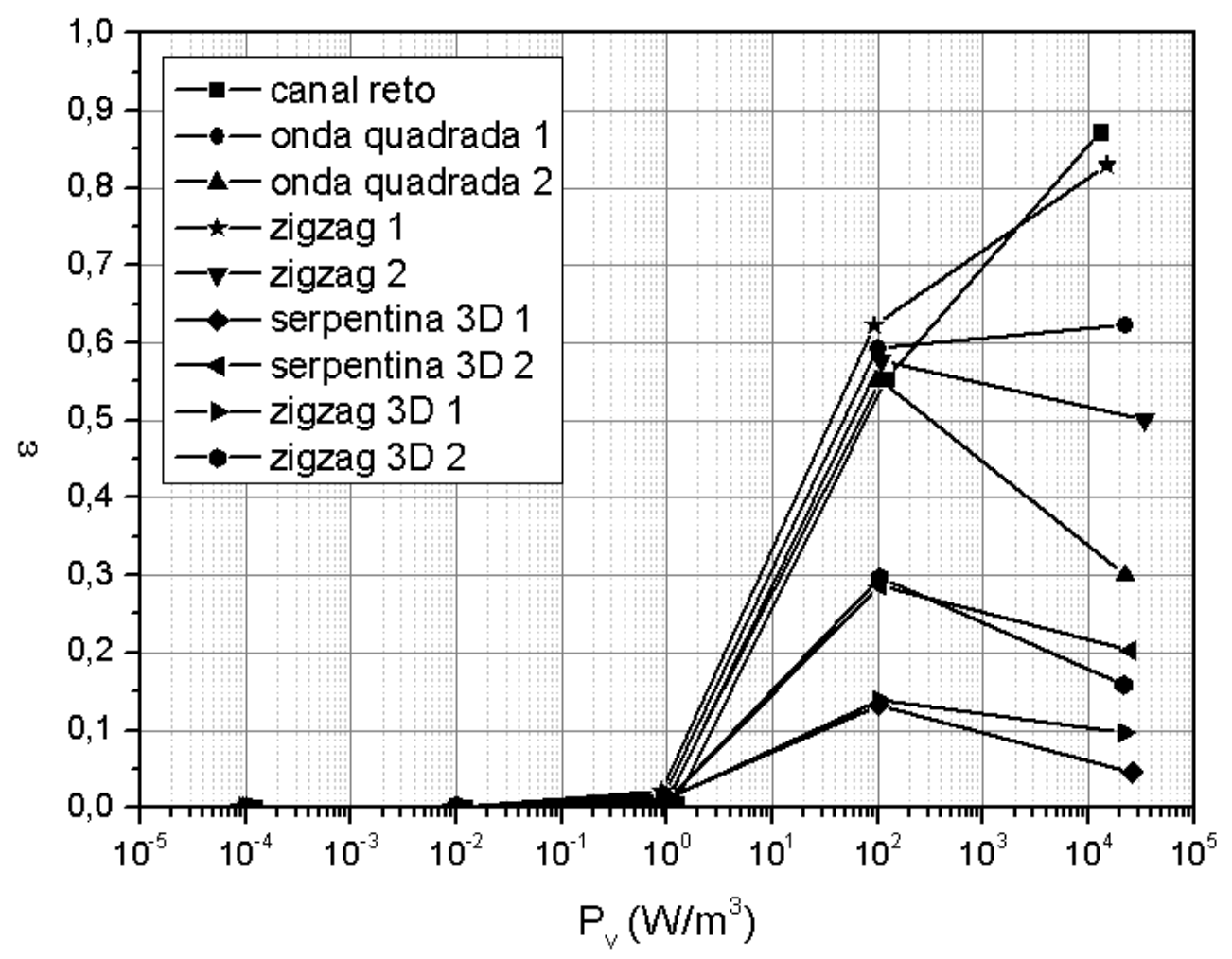

Gráfico 19. Eficiência de mistura em função da potência volumétrica. 


\subsubsection{Resumo}

Este estudo foi realizado com nove geometrias, um microcanal reto e oito geometrias baseadas em sucessivos cotovelos, para o intervalo de número de Reynolds entre 0,01 e 100. Para estabelecer a comparação entre as geometrias foi definido um diâmetro hidráulico comum entre elas de $400 \mu \mathrm{m}$ e um comprimento comum de $L=20$. Dh, resultando assim em volumes iguais para todas as geometrias estudas.

A visualização dos mapas de velocidade permitiu identificar dois regimes de escoamento, regime laminar, para Re entre 0,01 e 10, e regime intermediário, para Re entre 10 e 100. A obtenção dos parâmetros numéricos permitiu identificar que a transição de regime ocorre a partir de $\mathrm{Re}=10 . \mathrm{Em} R e=100$, o regime já é intermediário com presença de advecção caótica.

Verificou-se que a advecção caótica não ocorre em regime laminar e começa a ser apreciada em regime intermediário.

A eficiência de mistura também foi estudada. A visualização dos mapas de concentração permitiu identificar a influência das distâncias entre os cotovelos, utilizadas do estudo anterior para o projeto das geometrias deste estudo, na qualidade da mistura. Bem como, a influência do regime de escoamento na qualidade da mistura. Portanto, verificou- se as seguintes melhores eficiências de mistura

- Onda quadrada 2 melhor que onda quadrada 1;

- Zigzag 2 melhor que zigzag 1;

- Serpentina 3D 1 melhor que serpentina 3D 2;

- Zigzag 3D 1 melhor que zigzag 3D 2; e

- Geometrias 3D melhores que geometrias 2D.

Logo, as distâncias entre cotovelos mais efetivas foram:

- Estrutura 1: $\mathrm{dec}=2$,

- Estrutura 2: dec $=2$, e

- Estrutura 3: dec $=1$. 
Com a obtenção dos dados numéricos de eficiência de mistura confirmou-se as conclusões visualizadas nos mapas de concentração e permitiu estabelecer um índice de comparação de desempenho entre as geometrias estudadas para $\mathrm{Re}=$ 100. Destaque dado para a geometria zigzag 3D 1 que apresenta desempenho 09 vezes melhor que o microcanal reto, e para geometria serpentina 3D 1 que apresenta desempenho 19 vezes melhor que o microcanal reto.

A geometria zigzag 3D 1 é fruto da investigação realizada no estudo 2. Este estudo identificou os possíveis arranjos espaciais entre cotovelos, bem como, as melhores distâncias entre os cotovelos para os arranjos identificados, permitindo a proposição e investigação dessa geometria. Apesar da geometria zigzag 3D 1 não apresentar a mesma performance da geometria serpentina $3 D$ 1, ela também é uma geometria de alta performance em comparação ao encontrado no estado da arte. Portanto, a geometria zigzag 3D 1 é uma contribuição original ao estado da arte dos micromisturadores.

A mudança de regime permitiu identificar para a geometria serpentina 3D 1 pontos de mesma eficiência de mistura para tempos de residência diferentes em duas ordem de grandeza. Ou seja, uma intensificação do tempo de processo em $10^{2}$.

Para finalizar, considerando as distâncias entre os cotovelos mais efetivas, restam apenas 04 geometrias baseadas em sucessivos cotovelos, como mostradas na tabela 26. Observando a tabela, verifica-se que o pior caso é a geometria zigzag 2, enquanto, o melhor caso é a serpentina 3D 1. Com estas duas geometrias serão conduzidos os próximos estudos.

A geometria zigzag 2 é uma geometria aplicada com sucesso a produção de biodiesel (Wen, 2009). Suas características serão investigadas e comparadas com a geometria serpentina 3D 1, a escolhida para o processo de produção do biodiesel.

Tabela 26. Índice de comparação do desempenho das geometrias estudadas para $R \mathbf{R}=100$.

\begin{tabular}{|c|c|}
\hline Dispositivos & İndice de comparação \\
\hline onda quadrada 2 & $\mathbf{2 , 9 1}$ \\
\hline zigzag 2 & $\mathbf{1 , 7 4}$ \\
\hline serpentina 3D 1 & 19,23 \\
\hline zigzag 3D 1 & $\mathbf{9 , 0 2}$ \\
\hline
\end{tabular}




\subsection{Estudo 4: Estudo do pior caso, zigzag 2}

O objetivo deste estudo é verificar as características fluidodinâmicas do escoamento e avaliar sua eficiência de mistura. Além disso, é importante ressaltar que este tipo de dispositivo já foi utilizado com sucesso para a produção de biodiesel como mostrado no trabalho de Wen (2009).

O estudo consistirá em fixar um diâmetro hidráulico e um comprimento e variar o número de seções para a formação dos microcanais. A tabela 27 mostra a definição das geometrias com microcanais de seção transversal quadrada com diâmetro hidráulico de $400 \mu \mathrm{m}$, comprimento de $L=43,75 \cdot D_{h}$, com a variação do número de seções entre 1 a 10.

Tabela 27. Estudo 4: Definição das geometrias.

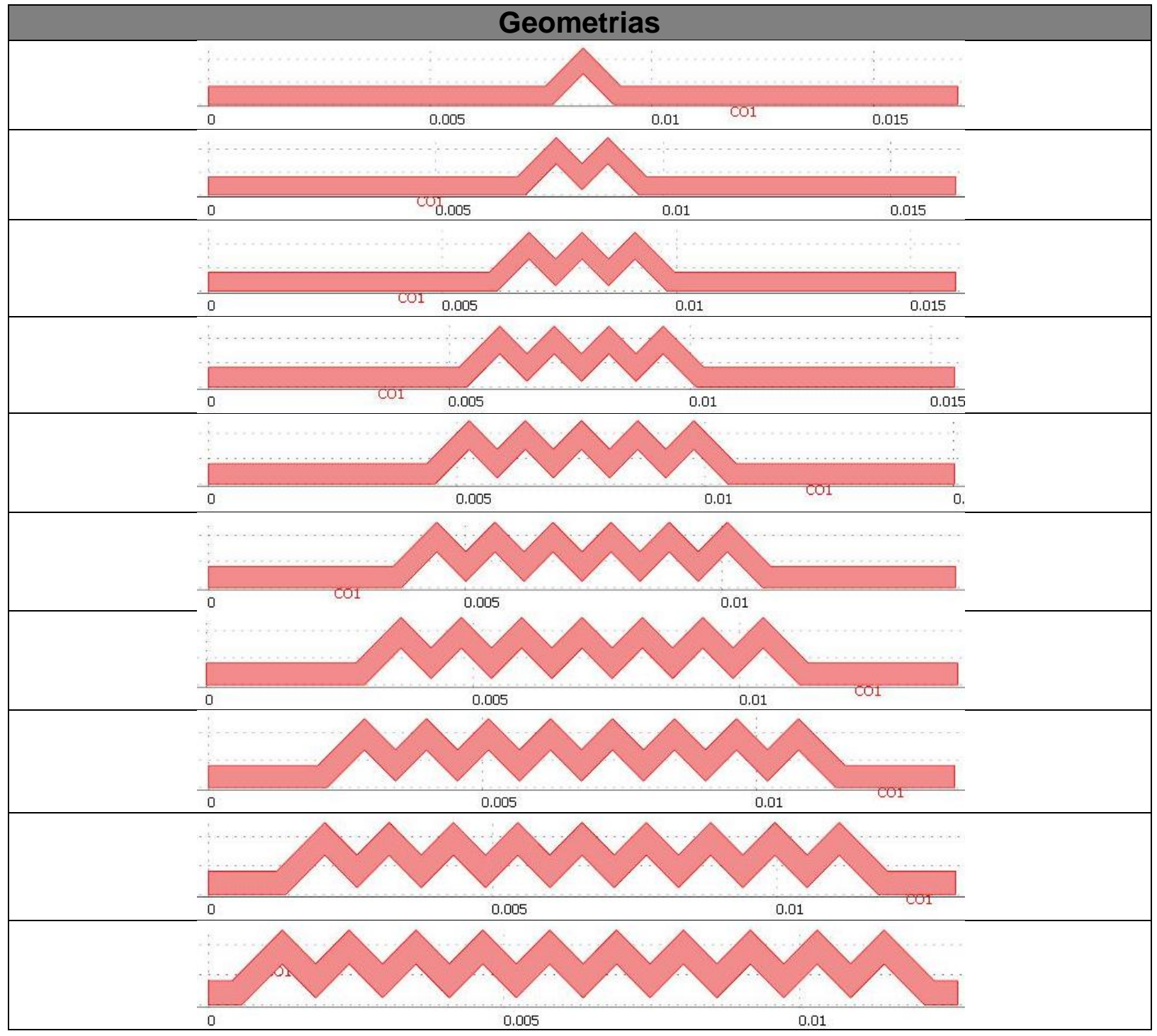




\begin{tabular}{|c|c|}
\hline \multicolumn{2}{|c|}{ Parâmetros } \\
\hline Seção transversal quadrada & $1,6 \cdot 10^{-7} \mathrm{~m}^{2}$ \\
\hline Diâmetro hidráulico $\left(\mathrm{D}_{\mathrm{h}}\right)$ & $4 \cdot 10^{-4} \mathrm{~m}$ \\
\hline Comprimento $(\mathrm{L})$ & $\mathrm{L}=43,75 \cdot \mathrm{D}_{\mathrm{h}} \mathrm{m}$ \\
& $17,5 \cdot 10^{-3} \mathrm{~m}$ \\
\hline Volume & $2,80 \cdot 10^{-9} \mathrm{~m}^{3}$ \\
\hline
\end{tabular}

Tabela 28. Estudo 4: Condições de contorno.

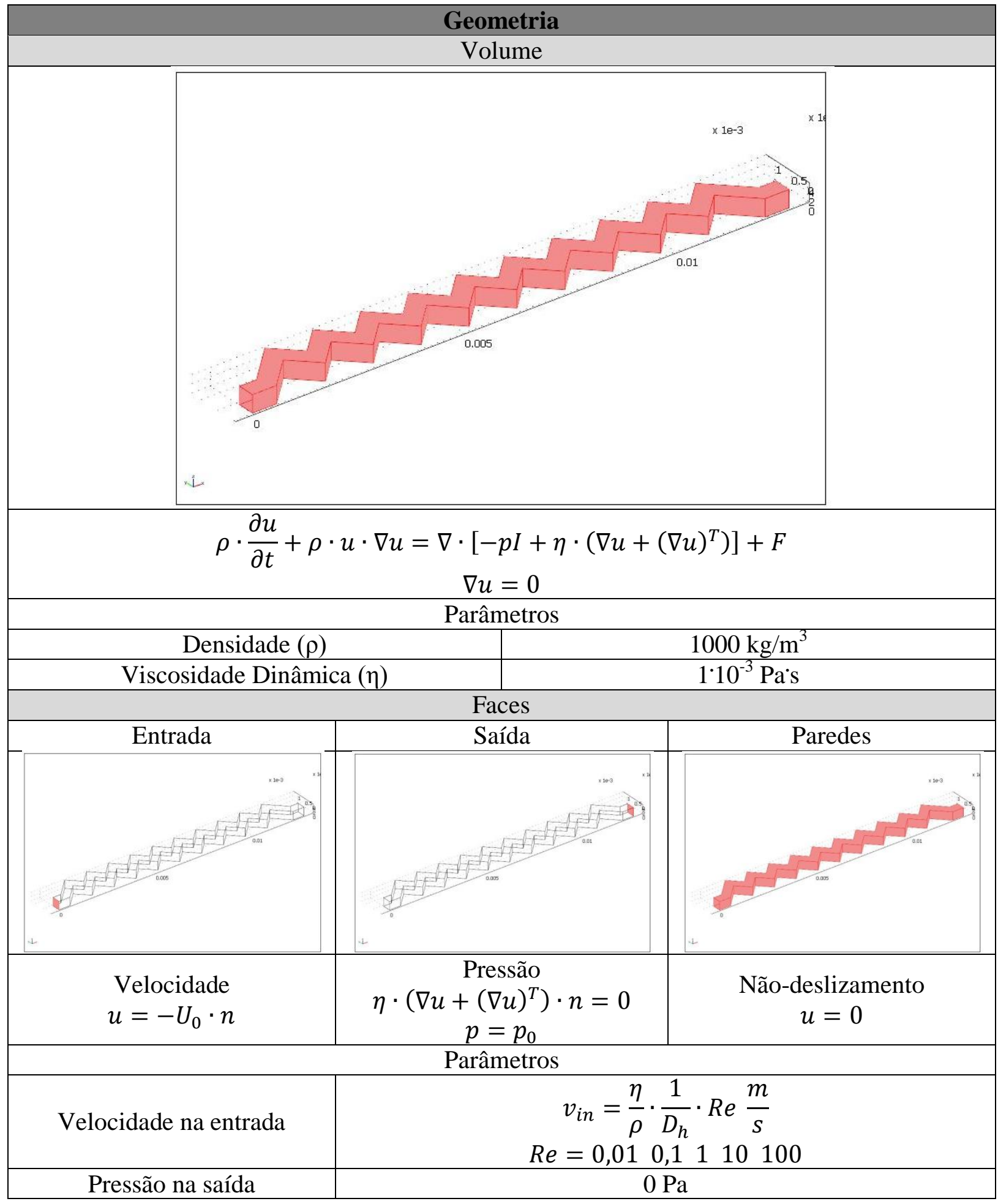


A tabela 28 mostra as condições de contorno aplicadas nas geometrias. No volume é resolvida a equação de Navier-Stokes na forma diferencial com difusão artificial Streamline diffusion - Galerkin Least-Squares (GLS). O fluido de trabalho é a água. Nas faces são aplicadas as seguintes condições de contorno: (a) perfil de velocidade constante na face de entrada, (b) pressão nula na face de saída e (c) velocidade nula nas paredes. O perfil de velocidades na entrada é parametrizado em função de cinco pontos de número de Reynolds no intervalo entre 0,01 a 100. Portanto, são cinco pontos por cada uma das 10 geometrias, totalizando 50 simulações.

A tabela 29 mostra a discretização da geometria. Foi utilizado o elemento tetraedro com tamanho global de $50 \mu \mathrm{m}$ e tamanho local de $16 \mu \mathrm{m}$. Foram aplicadas as mesmas condições de malha às 10 geometrias estudadas.

Tabela 29. Estudo 4: Discretização da geometria.

\begin{tabular}{|c|c|c|}
\hline \multicolumn{3}{|c|}{ Geometria } \\
\hline Global & \multicolumn{2}{|c|}{ Local } \\
\hline \multicolumn{3}{|c|}{$\mid$} \\
\hline
\end{tabular}


Após o processamento do modelo com solver GMRES e pré-condicionador Geometric multigrid, foram extraídos os mapas de velocidade e pressão para análise visual.
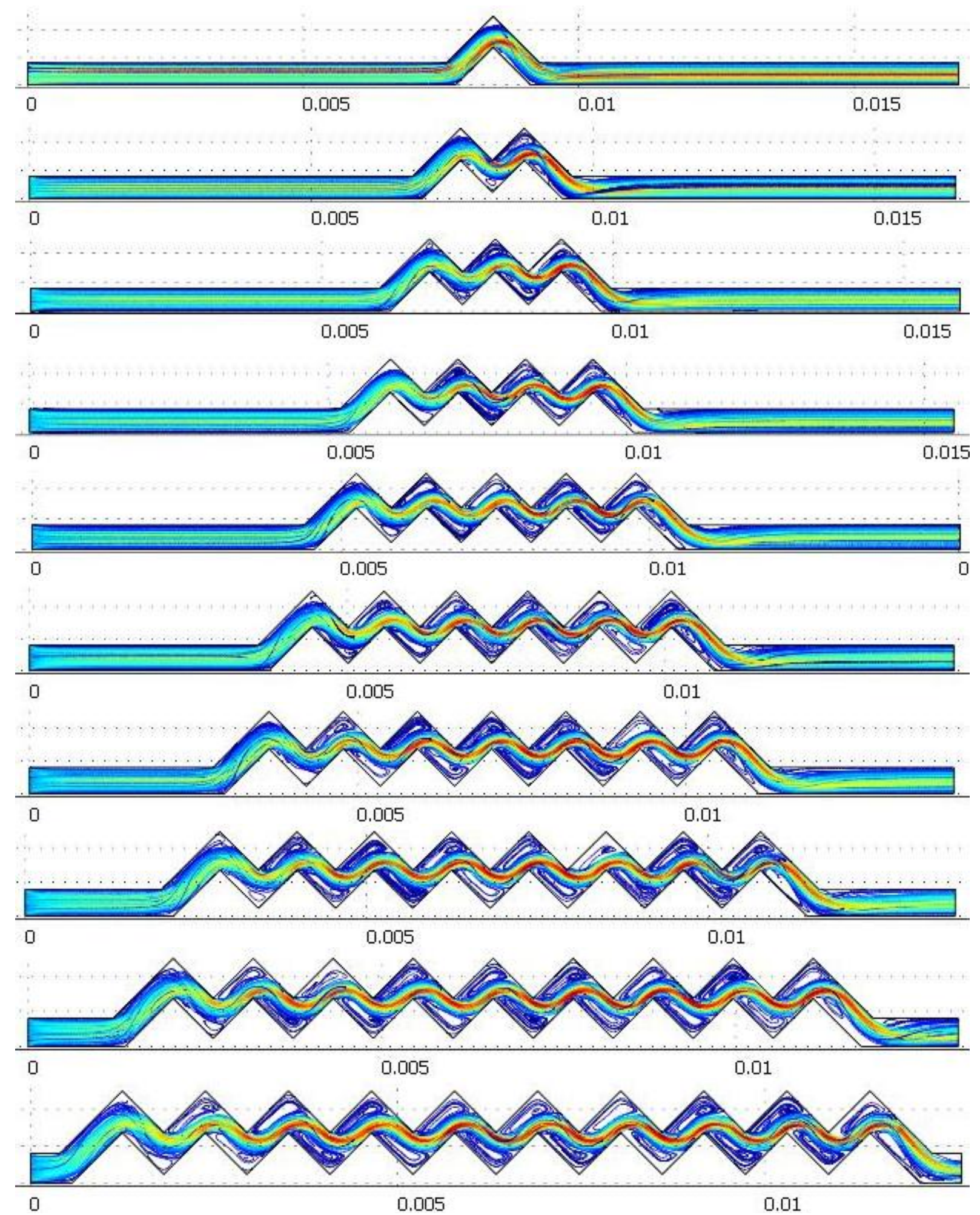

Figura 41. Mapas de velocidade em função do número de seções para $R e=$ 100. 
A figura 41 mostra os mapas de velocidade em função do número de seções para $R e=100$. Observa-se que o incremento do número de seções induz uma maior instabilidade nas linhas do campo de velocidades, com o aparecimento de diversas regiões de recirculação.

A princípio esta é uma boa característica para realizar a mistura de fluidos. No entanto, verificou-se no estudo anterior que esta geometria apresentou um desempenho pior que outras geometrias estudadas.

Portanto, com a posterior avaliação da eficiência em função do incremento de seções será possível inferir se o desempenho deste dispositivo pode ser incrementado de maneira satisfatória.

A figura 42 mostra cortes no plano xy dos mapas de velocidades em função do número de seções para $R e=100$. Se por um lado, observa-se na figura 41 a indução de instabilidades nas linhas do campo de velocidades em função do incremento do número de seções, por outro lado, verifica-se na figura 42 o aumento de grandes regiões de baixa velocidade (pontos de estagnação).

O aumento dessas regiões aumenta o volume morto do dispositivo de mistura, provocando um aumento na distribuição do tempo de residência.

A figura 43 mostra o mapa de pressão para a geometria com 10 seções para $R e=100$. A diferença de pressão nesta geometria é da ordem de $3 \mathrm{kPa}$. 

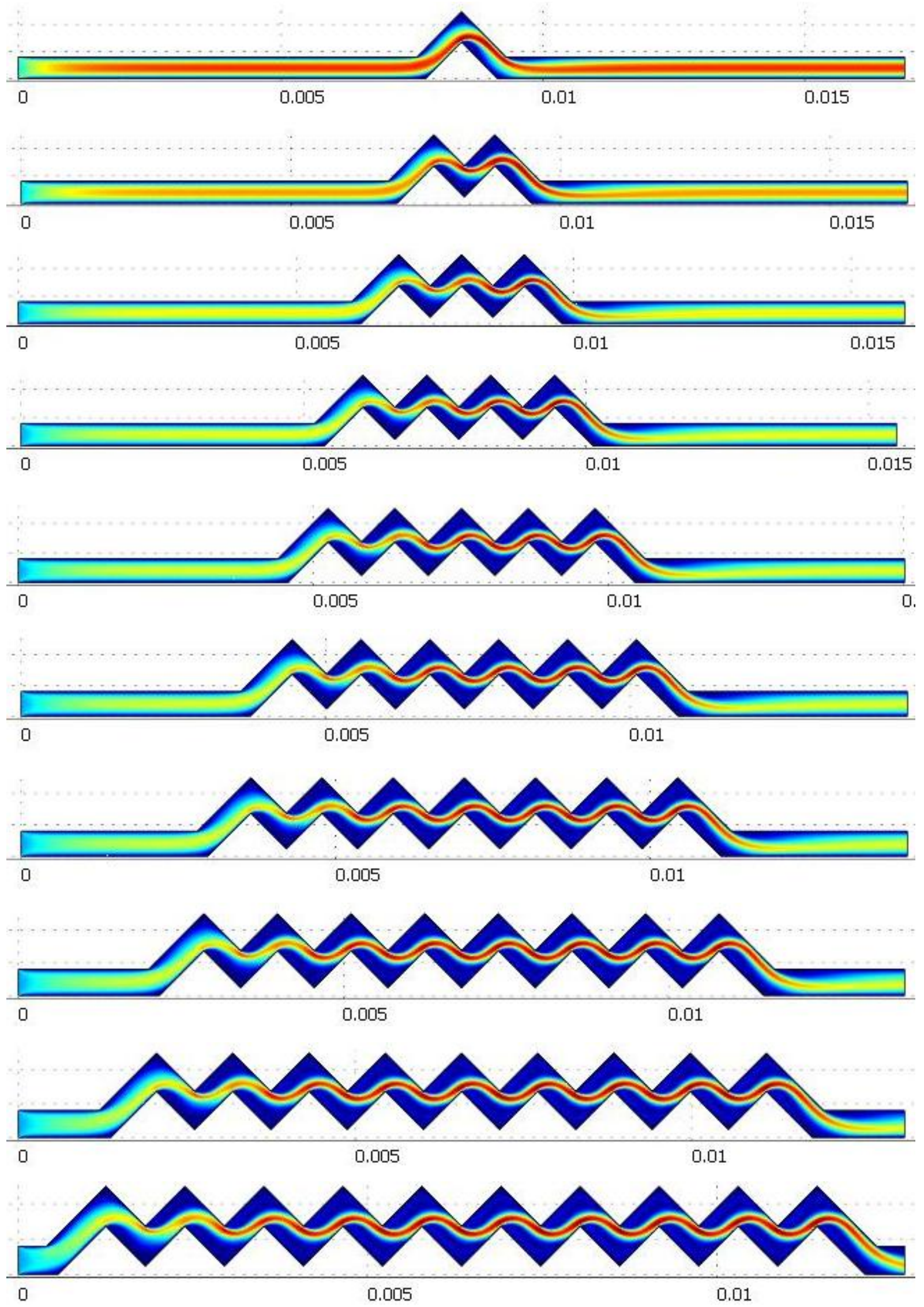

Figura 42. Mapas de velocidade em função do número de seções para $R e=$ 100: cortes no plano $x y$. 


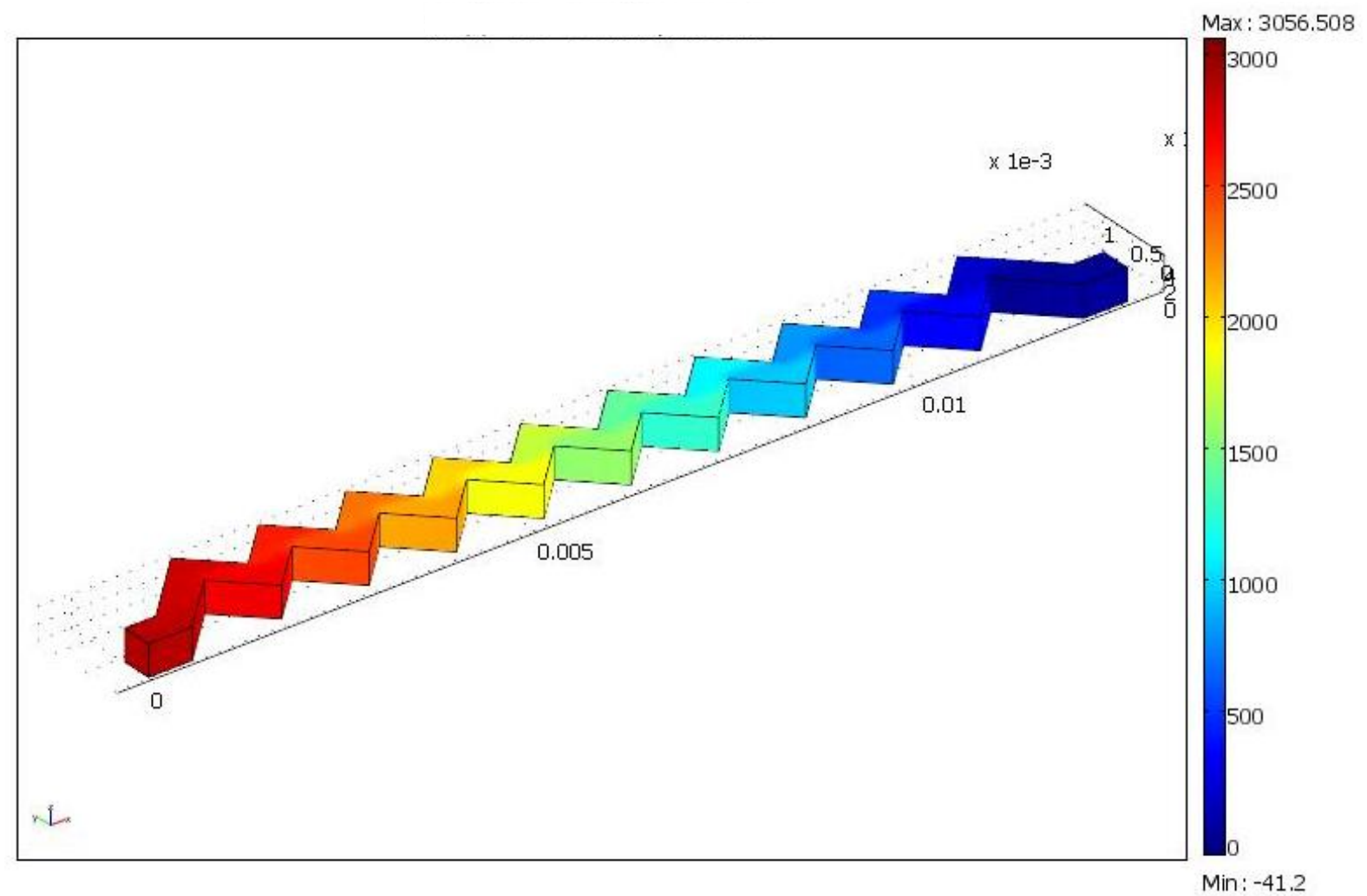

Figura 43. Mapa de pressão para zigzag com 10 seções para $R \mathbf{R}=100$.

Após a visualização dos mapas mais relevantes, foram extraídos os parâmetros numéricos de interesse: coeficiente de perda de carga, vorticidade e tempo de residência.

O gráfico 20 mostra as curvas do coeficiente de perda de carga em função do número de Reynolds para (a) valores absolutos e (b) valores relativos. Observa-se que a transição de regime ocorre aproximadamente em $R e=10$. O aumento do número de seções incrementou o valor do coeficiente de perda de carga, ou seja, a transição para o regime intermediário foi mais forte.

Nos valores relativos, observa-se também que o coeficiente de perda de carga diminui em função do aumento do número de seções para o intervalo de Re entre 0,01 e 10, indicando um aumento do volume morto em função do aumento do número de seções no regime de escoamento laminar. Para Re entre 10 e 100, observa-se o incremento do coeficiente de perda de carga em função do aumento do número de seções, não se verificando o efeito do volume como no intervalo anterior, apesar de observado nos mapas de velocidade. 


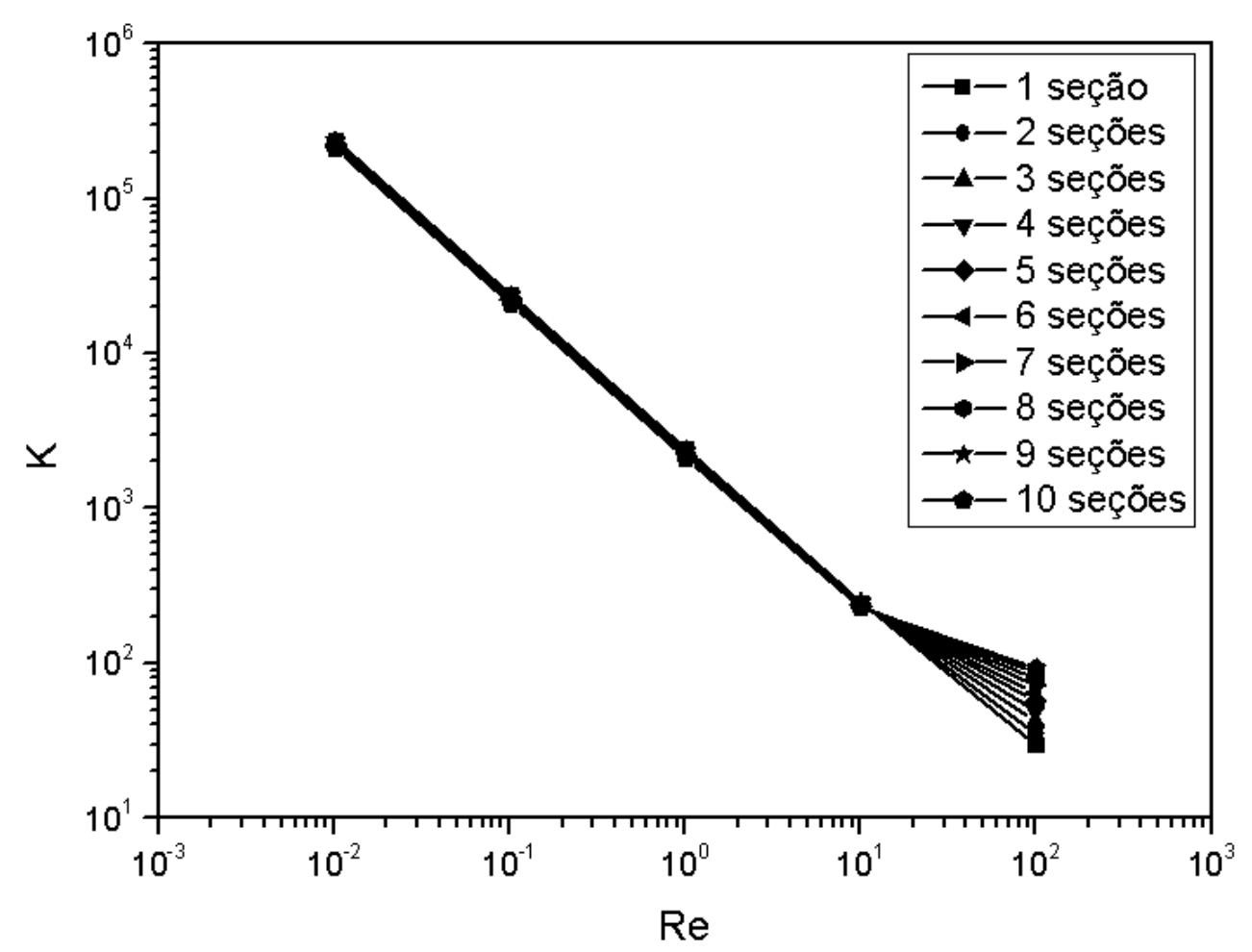

(a)

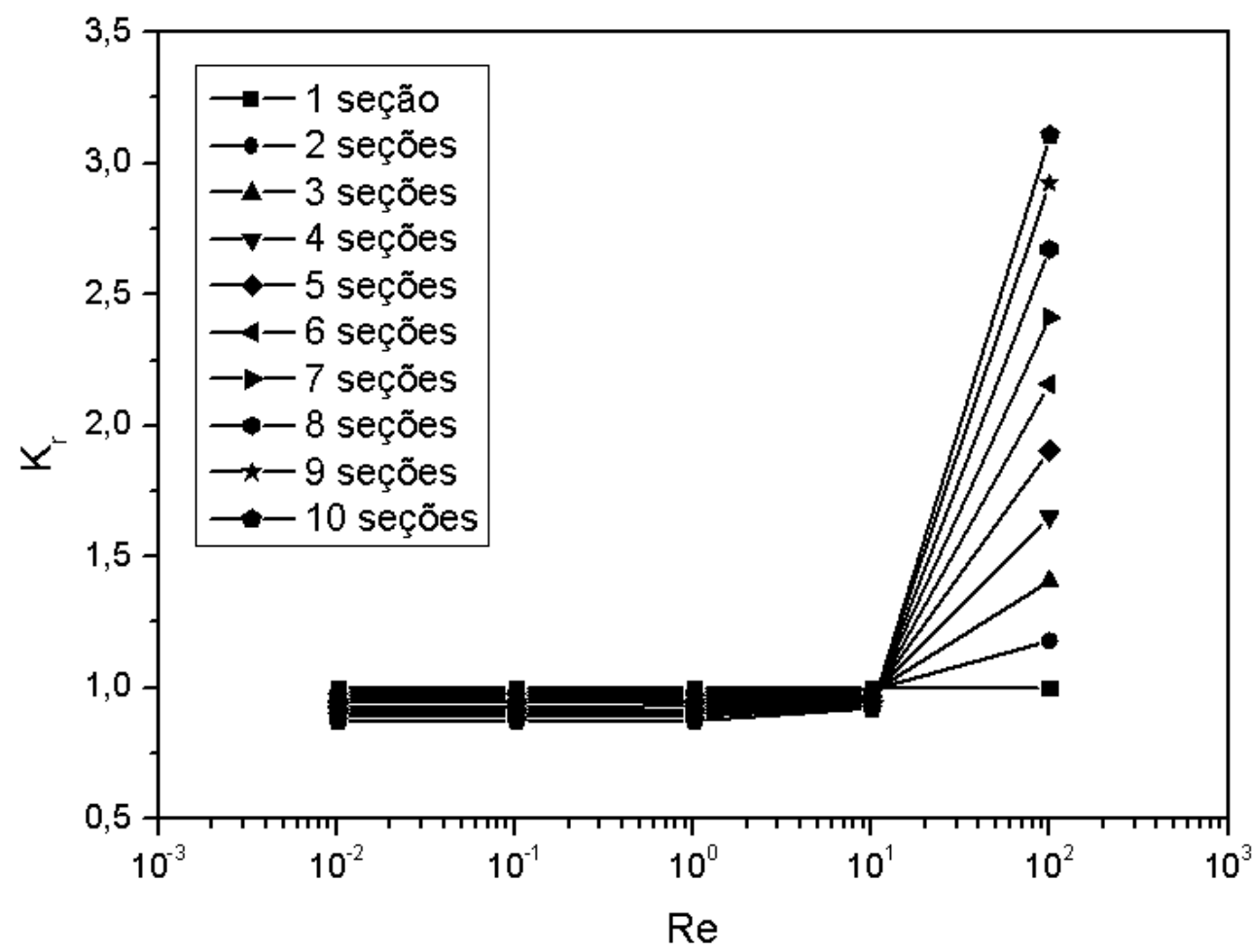

(b)

Gráfico 20. Coeficiente de perda de carga em função do número de Reynolds: (a) valores absolutos e (b) valores relativos. 


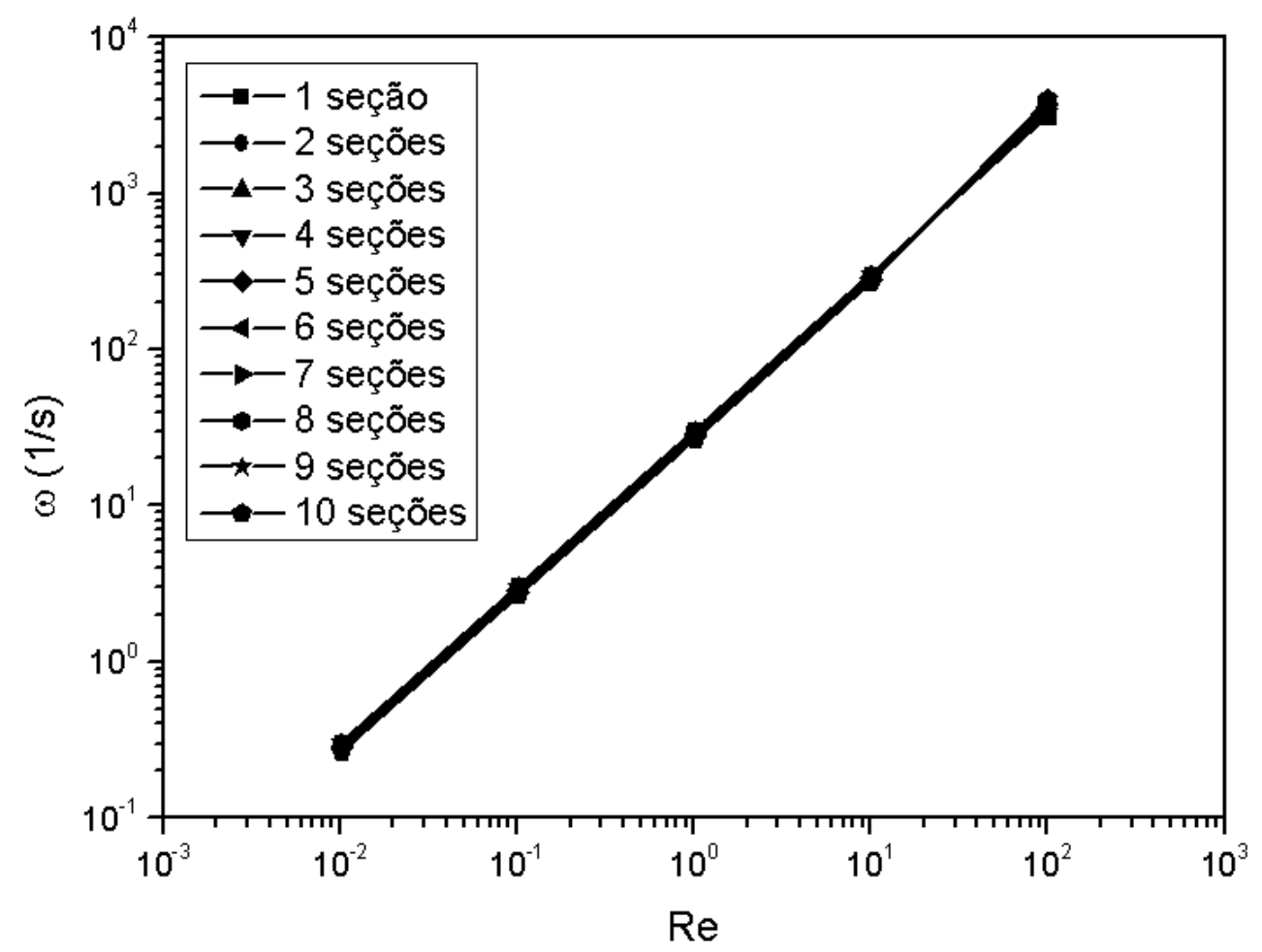

(a)

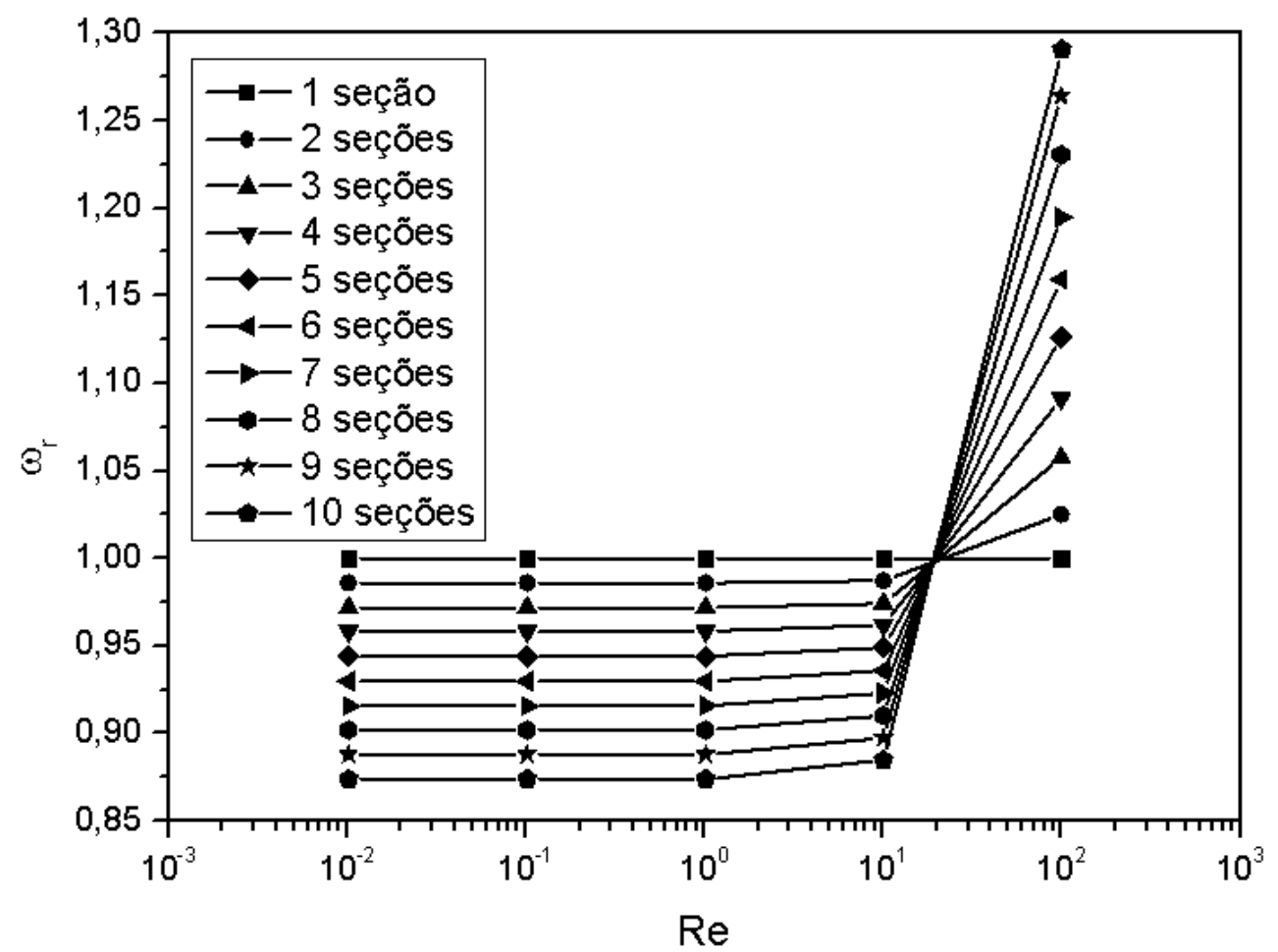

(b)

Gráfico 21. Vorticidade em função do número de Reynolds: (a) valores absolutos e (b) valores relativos.

O gráfico 21 mostra as curvas de vorticidade em função do número de Reynolds para (a) valores absolutos e (b) valores relativos. Observa-se nos valores 
absolutos que a vorticidade é diretamente proporcional ao número de Reynolds e apresenta valores na mesma ordem grandeza variando-se o número de seções.

Observando os valores relativos de vorticidade, verifica-se para Re entre 0,01 e 10 a perda de vorticidade em função do aumento do número de seções. Este fato comprova que em regime de escoamento laminar, os parâmetros fluidodinâmicos são influenciados pelo aumento do volume morto. Ressalta-se que as 10 geometrias estudadas têm volume interno fixo e a variação entre elas é exatamente o número de seções, que está provocando o aumento do volume morto.

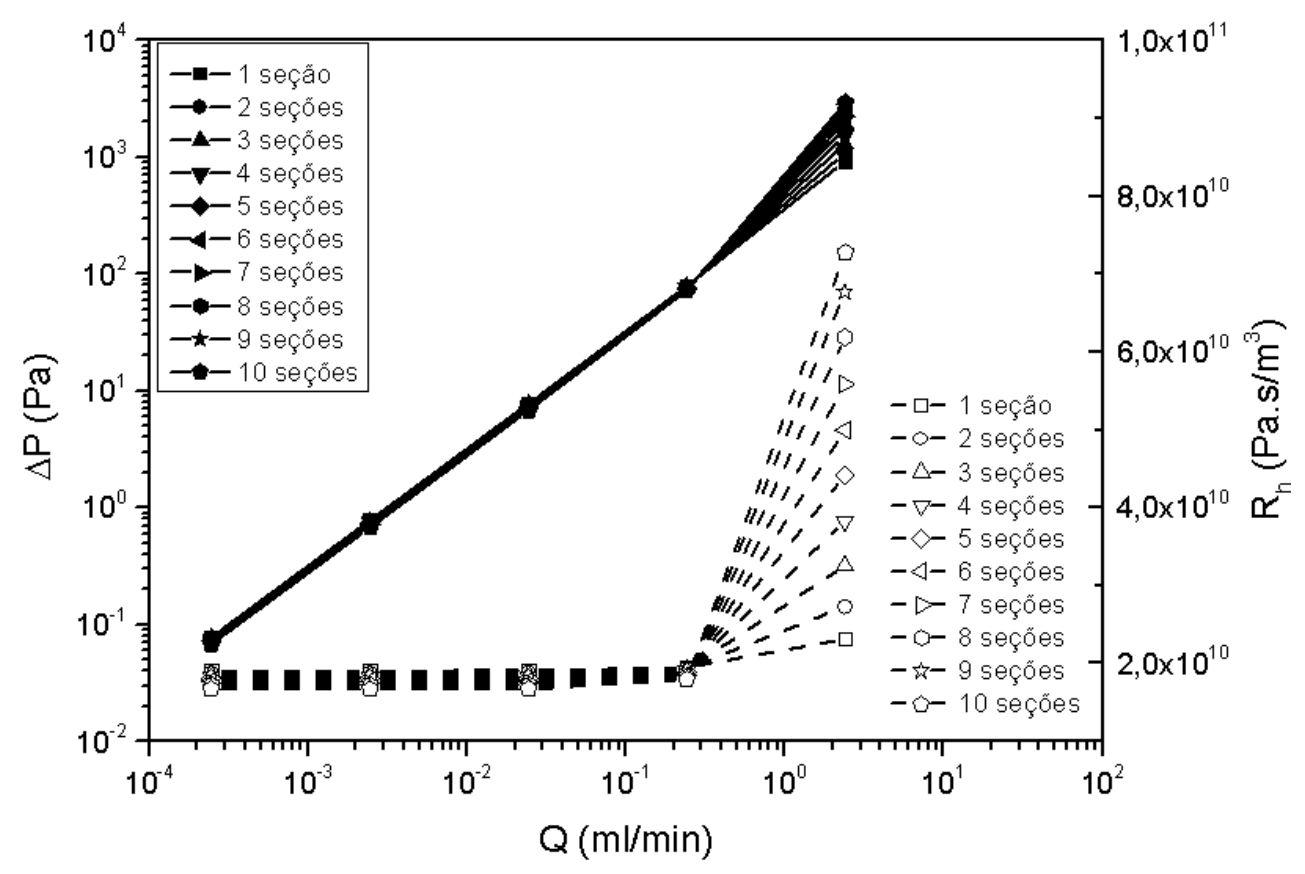

Gráfico 22. Diferença de pressão e resistência hidráulica em função da vazão.

O gráfico 22 mostra as curvas de diferença de pressão (linhas sólidas) e resistência hidráulica (linhas tracejadas) em função da vazão. Nas curvas de diferença de pressão, observa-se uma região linear em função da vazão, com os pontos de maior vazão apresentando um desvio de linearidade. Este desvio indica outra descrição de regime de escoamento.

Nas curvas de resistência hidráulica, observa-se uma região constante em função da vazão, com os pontos de maior vazão apresentando um desvio do comportamento constante. Portanto, fica bem caracterizada a transição de regime no intervalo estudado, tendo um intervalo em regime de escoamento laminar e outro em regime de escoamento intermediário. 


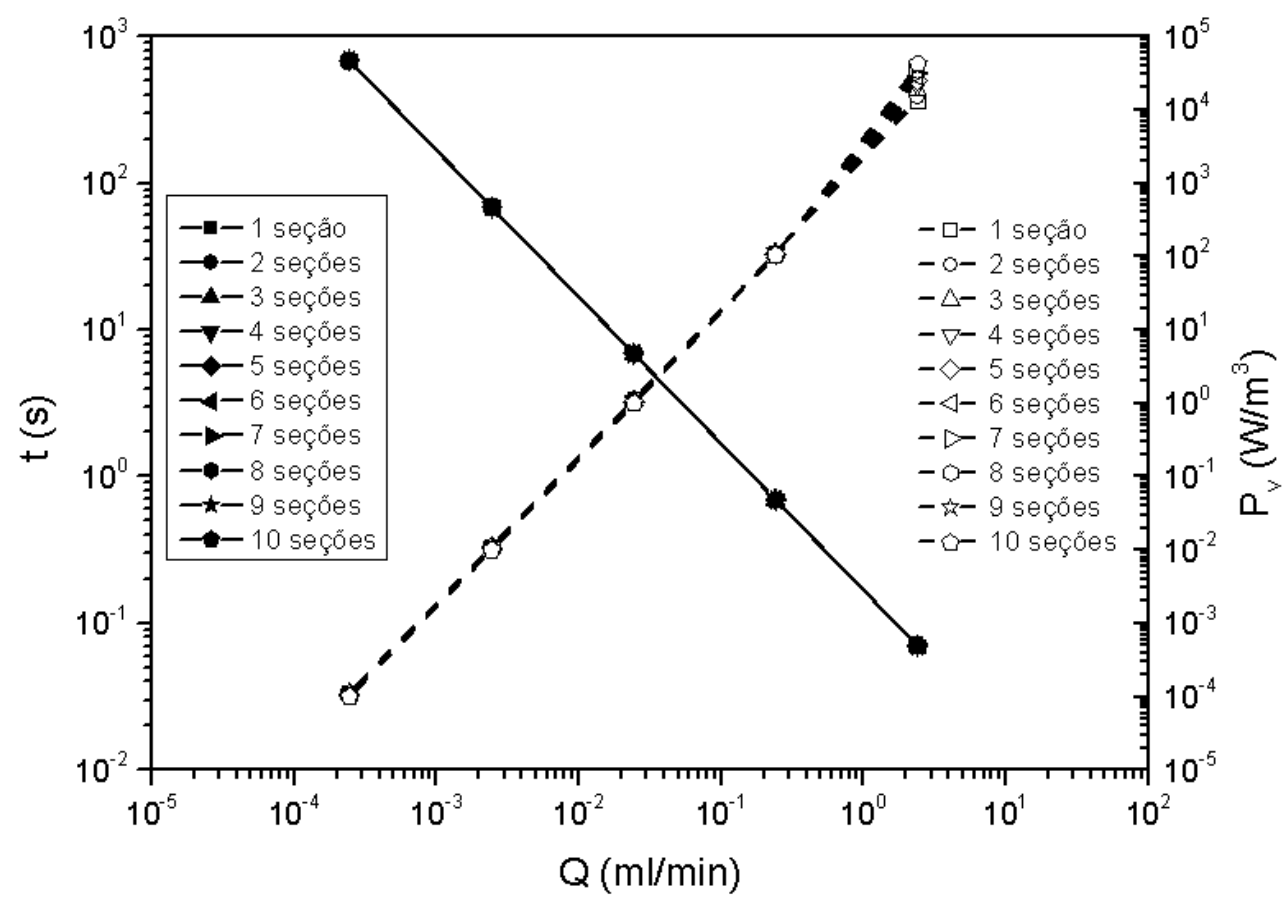

Gráfico 23. Tempo de residência e potência volumétrica em função da vazão.

O gráfico 23 mostra as curvas de tempo de residência (linhas sólidas) e potência volumétrica (linhas tracejadas) em função da vazão. $O$ tempo de residência é inversamente proporcional a vazão, enquanto a potência volumétrica é diretamente proporcional a vazão.

Portanto, foram mapeados os regimes de escoamento e os parâmetros fluidodinâmicos das 10 geometrias estudadas.

\subsubsection{Estudo 4.1: Eficiência de mistura}

Para definir o desempenho da geometria zigzag 2 em função da variação do número de seções, a eficiência de mistura será avaliada. As geometrias são as mesmas definidas na tabela 27.

As condições de contorno são as mostradas na tabela 30. A equação de convecção-difusão é resolvida numericamente no volume com difusão artificial Streamline diffusion - Petrov-Galerkin / Compensated. O fluido de trabalho é água a $25^{\circ} \mathrm{C}$. Foi definido o coeficiente de difusão fictício de $1 \cdot 10^{-8} \mathrm{~m}^{2} / \mathrm{s}$. Portanto, o tempo de residência teórico é 8s, calculado pela equação 15 . 
Nas faces foram aplicadas as seguintes condições de contorno: (a) na entrada um perfil de concentração, (b) na saída condição de fluxo convectivo e (c) nas paredes condição de isolamento/simetria.

Foram simuladas 10 geometrias em $\mathrm{Re}=100$, totalizando 10 simulações.

Tabela 30. Estudo 4.1: Condições de contorno.

\begin{tabular}{|c|c|c|}
\hline \multicolumn{3}{|c|}{ Geometria } \\
\hline \multicolumn{3}{|c|}{ Volume } \\
\hline \multicolumn{3}{|c|}{ 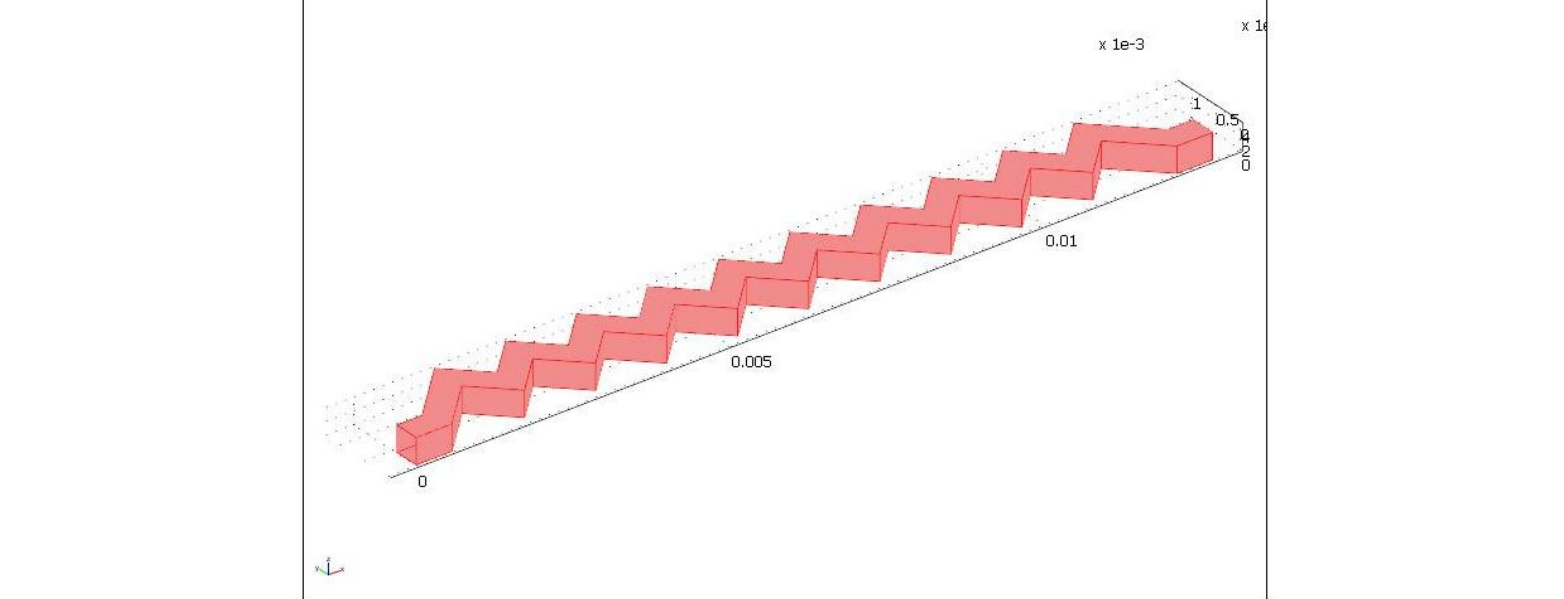 } \\
\hline \multicolumn{3}{|c|}{$\nabla \cdot(-\mathrm{D} \nabla \mathrm{c})=R-u \cdot \nabla \mathrm{c}$} \\
\hline \multicolumn{3}{|c|}{ Parâmetros } \\
\hline Coeficiente de dift & (D) & $1 \cdot 10^{-8} \mathrm{~m}^{2} / \mathrm{s}$ \\
\hline \multicolumn{3}{|c|}{ Faces } \\
\hline Entrada & Saída & Paredes \\
\hline$\sqrt{4^{4}+\sqrt{1+4}}$ & $\sqrt{4 \sqrt{4}+\sqrt{4}} \sqrt{4 \sqrt{4}+\sqrt{4}}$ & in \\
\hline $\begin{array}{l}\text { Perfil de concentração } \\
\qquad c=c_{0}\end{array}$ & $\begin{array}{l}\text { Fluxo Convectivo } \\
n \cdot(-\mathrm{D} \nabla \mathrm{c})=0\end{array}$ & $\begin{array}{l}\text { Isolamento/Simetria } \\
\begin{array}{l}n \cdot N=0 \\
N=-D \nabla c+c \cdot u\end{array}\end{array}$ \\
\hline \multicolumn{3}{|c|}{ Parâmetros } \\
\hline $\begin{array}{l}\text { Perfil de concentração na } \\
\text { entrada }\end{array}$ & $c_{0}=1000 \cdot(y>200 \cdot$ & $\begin{array}{l}+0 \cdot\left(y \leq 200 \cdot 10^{-6}\right) \frac{\mathrm{mol}}{\mathrm{m}^{3}} \\
100\end{array}$ \\
\hline
\end{tabular}


Tabela 31. Estudo 4.1: Discretização das geometrias.

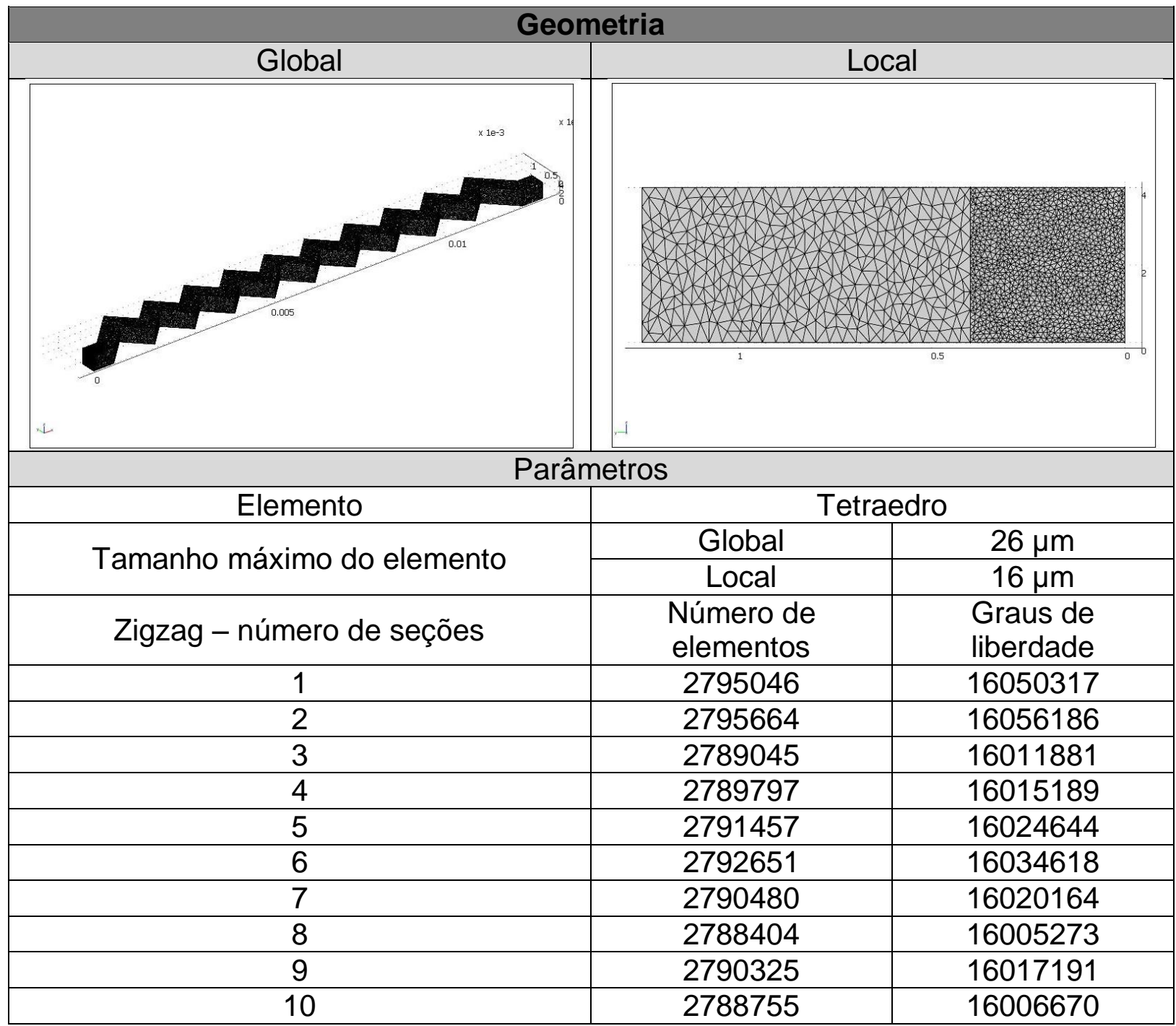

A tabela 31 mostra a discretização da malha para as dez geometrias estudadas. O elemento utilizado foi o tetraedro com tamanho máximo local de $16 \mu \mathrm{m}$ e global de $26 \mu \mathrm{m}$.

Após o processamento dos modelos com solver GMRES e pré-condicionador Geometric multigrid, foram obtidos os mapas de concentração para análise visual.

A figura 44 mostra os mapas de concentração das saídas das 10 geometrias estudadas, para $\operatorname{Re}=100$. Observando a figura, verifica-se que o aumento do número de seções provoca o aumento da superfície de contato entre os fluidos. 

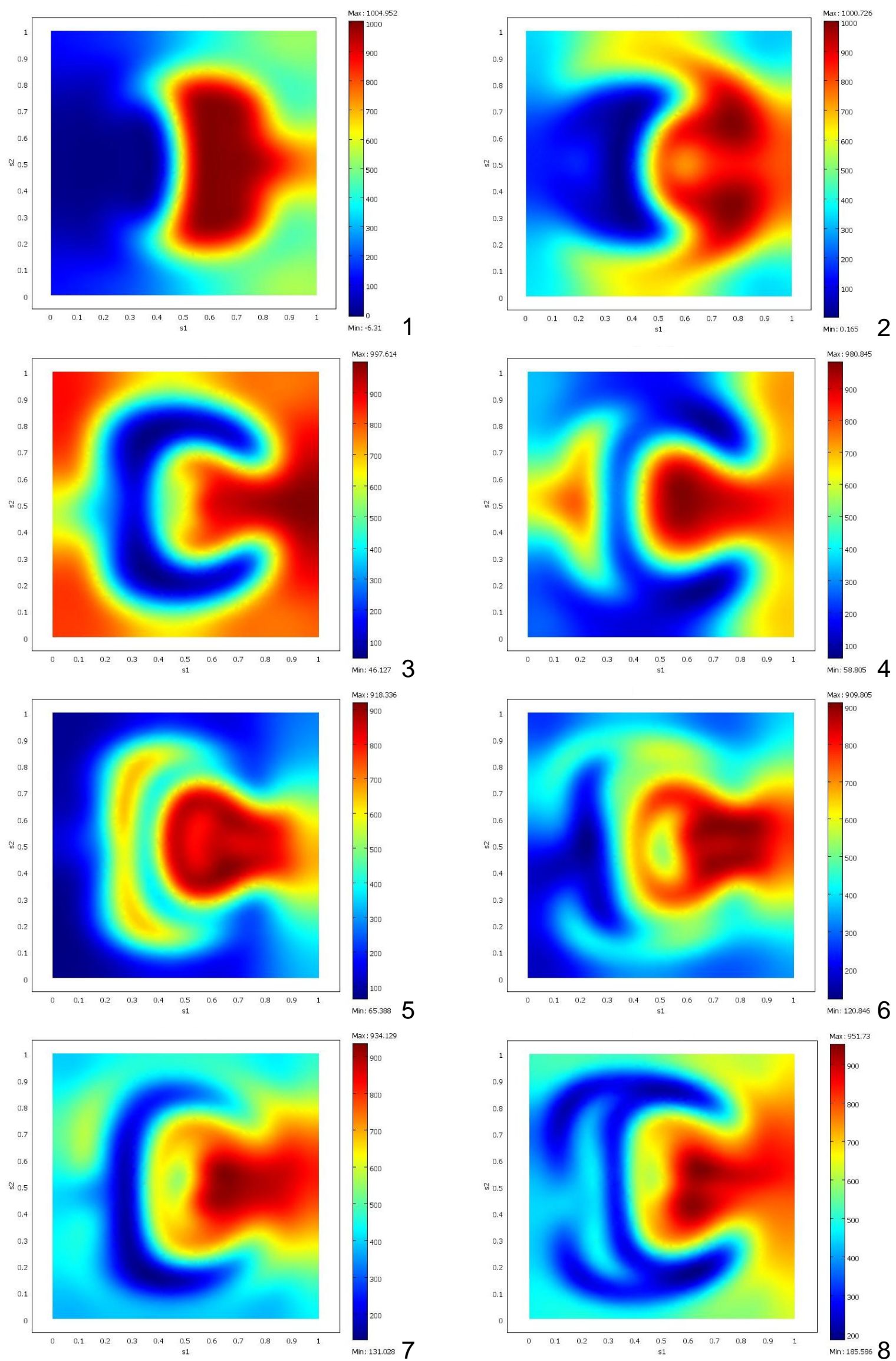

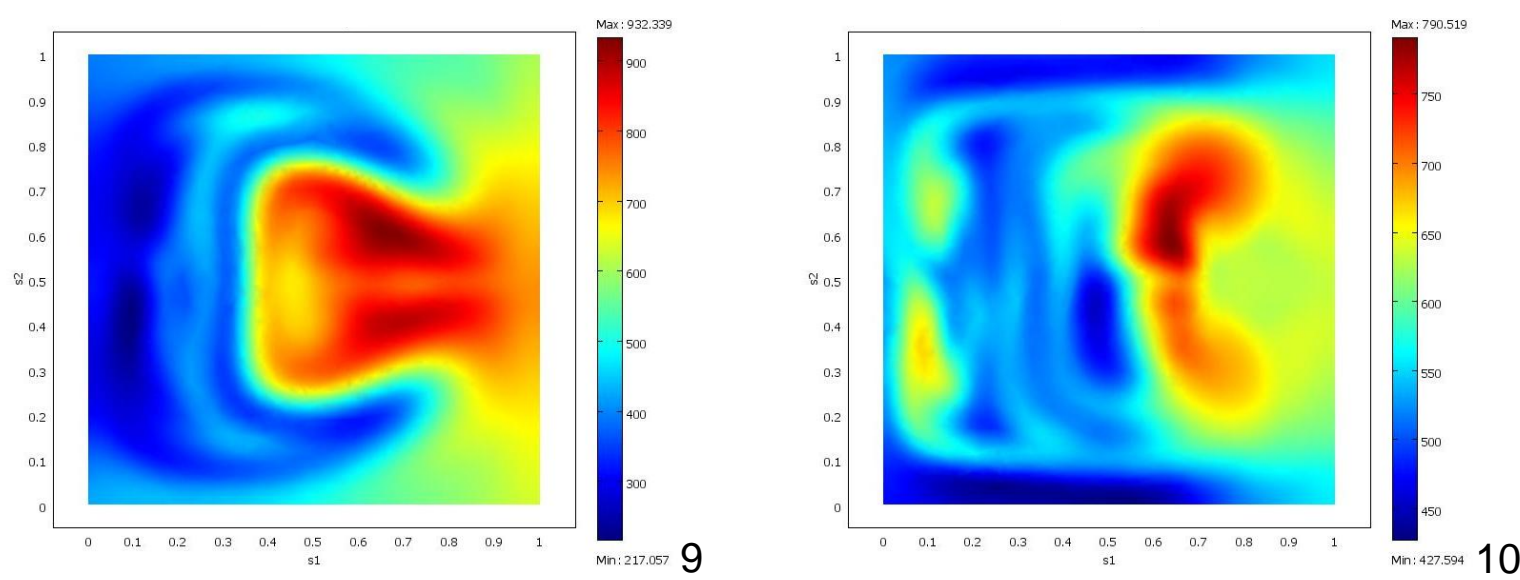

Figura 44. Mapas de concentração: saídas em função do número de seções.

Esse aumento na superfície de contato influencia diretamente a eficiência de mistura das 10 geometrias estudadas, como mostrado no gráfico 24. Para $R e=100$ ou $\mathrm{t}=0,07 \mathrm{~s}$, observa-se que a eficiência de mistura é melhorada uma ordem de grandeza, de $\sim 4,6 \cdot 10^{-1}$ para $\sim 4,5^{\cdot} 10^{-2}$, em função da variação do número de seções. No entanto, é difícil traçar uma curva de tendência em cima dos pontos obtidos devido ao comportamento irregular dos pontos.

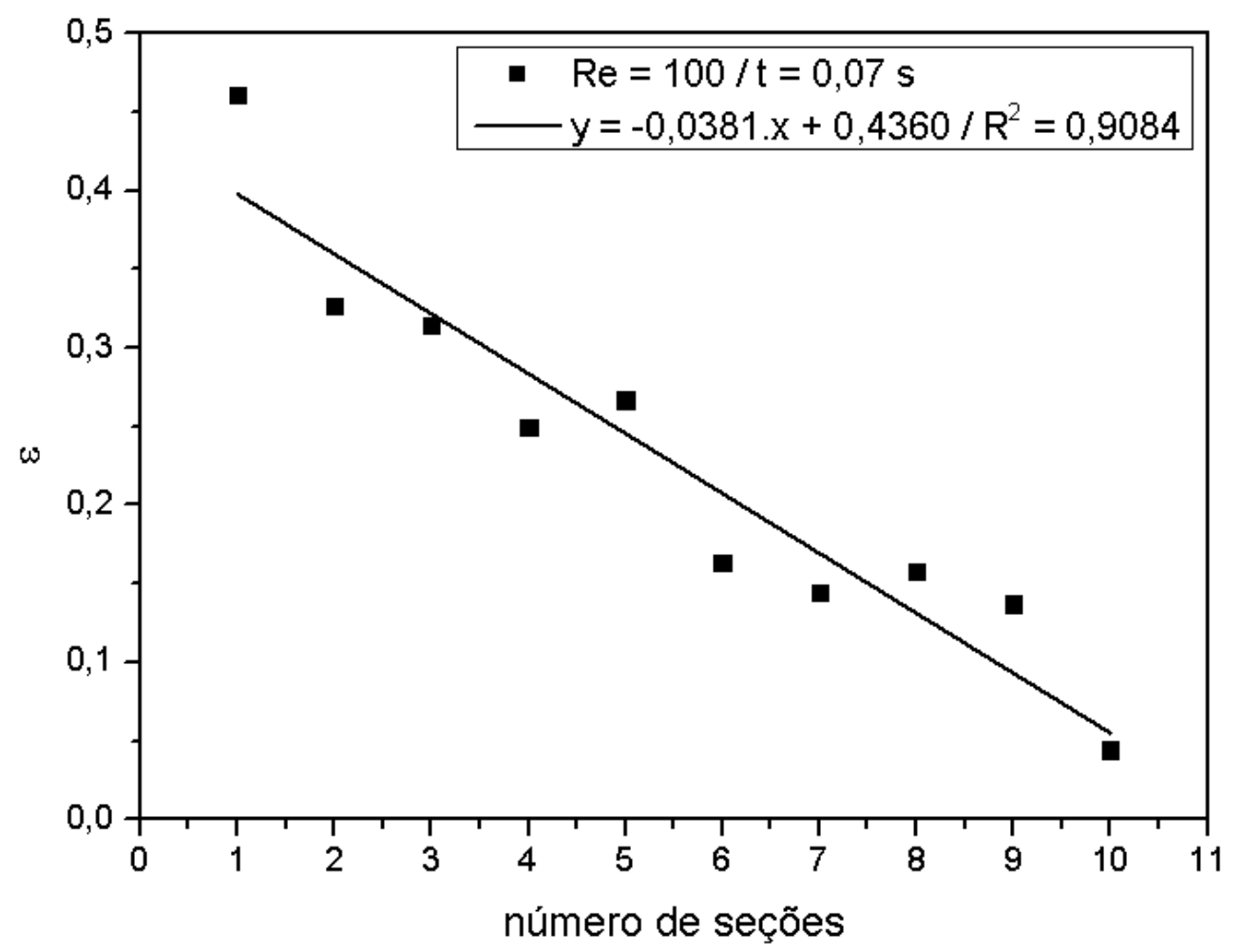

Gráfico 24. Eficiência de mistura em função do número de seções. 
Portanto, no tempo de $t=0,07 \mathrm{~s}$ foi possível melhorar a eficiência de mistura em função da modulação do número de seções. Considerando uma mistura efetivada para tempos de residência maiores que $8 \mathrm{~s}$ e as geometrias estudadas neste trabalho, a eficiência de mistura tem sido menor que $1 \cdot 10^{-3}$, sempre em regime laminar. Então, aproximando um comportamento linear, tem-se

- $\mathrm{t}=0,07 \mathrm{~s}-10$ seções - eficiência de mistura de $\sim 4,5 \cdot 10^{-2}$,

dobrando o número de seções

- $\mathrm{t}=0,14 \mathrm{~s}-20$ seções - eficiência de mistura provavelmente menor que $1 \cdot 10^{-3}$

ou seja, mistura efetivada num tempo muito menor que os $8 \mathrm{~s}$ calculado.

\subsubsection{Resumo}

O estudo foi realizado com 10 geometrias baseadas em zigzag, com dimensões fixas, volume, diâmetro hidráulico e comprimento. Foi modulado número de seções que compõe a geometria zigzag de 1 a 10.

Foi possível identificar os regimes de escoamento que as geometrias trabalharam no intervalo de Re estudado, de 0,01 a 100, em função da visualização dos mapas de velocidade e dos parâmetros fluidodinâmicos obtidos numericamente:

- regime de escoamento laminar para Re entre 0,01 e 10, e

- regime de escoamento intermediário para Re entre 10 e 100.

A eficiência de mistura foi melhorada em uma ordem de grandeza em função da modulação do número de seções. A tabela 32 mostra a comparação da eficiência de mistura relativamente a uma seção. 
Tabela 32. Comparação da eficiência de mistura relativamente a uma seção

\begin{tabular}{|c|c|}
\hline Número de seções & Eficiência relativa $(\mathrm{Re}=100 / \mathrm{t}=0,07 \mathrm{~s})$ \\
\hline 1 & 1,00 \\
\hline 2 & 1,41 \\
\hline 3 & 1,47 \\
\hline 4 & 1,85 \\
\hline 5 & 1,73 \\
\hline 6 & 2,82 \\
\hline 7 & 3,20 \\
\hline 8 & 2,93 \\
\hline 9 & 3,36 \\
\hline 10 & 10,47 \\
\hline
\end{tabular}


4.8. Estudo 5: Estudo do melhor caso, serpentina 3D 1

O objetivo deste estudo é explorar a quantidade de seções e o diâmetro hidráulico da geometria serpentina 3D e avaliar seu desempenho em função desses parâmetros.

A tabela 33 mostra a geometria usada como base neste estudo, com diâmetro hidráulico de $600 \mu \mathrm{m}$ e 4 seções. O diâmetro hidráulico será variado em cinco pontos, $150 \mu \mathrm{m}\left(1 D_{h}\right), 300 \mu \mathrm{m}\left(2 D_{h}\right), 600 \mu \mathrm{m}\left(4 D_{h}\right), 1200 \mu \mathrm{m}\left(8 D_{h}\right)$ e $2400 \mu \mathrm{m}(16$ $\left.D_{h}\right)$, mantendo fixo o número de 4 seções.

A quantidade de seções também será variada em cinco pontos, 1 seção, 2 seções, 4 seções, 8 seções e 16 seções, mantendo fixo diâmetro hidráulico de 600 $\mu \mathrm{m}$. Totalizando nove geometrias.

Tabela 33. Estudo 5: Definição das geometrias.

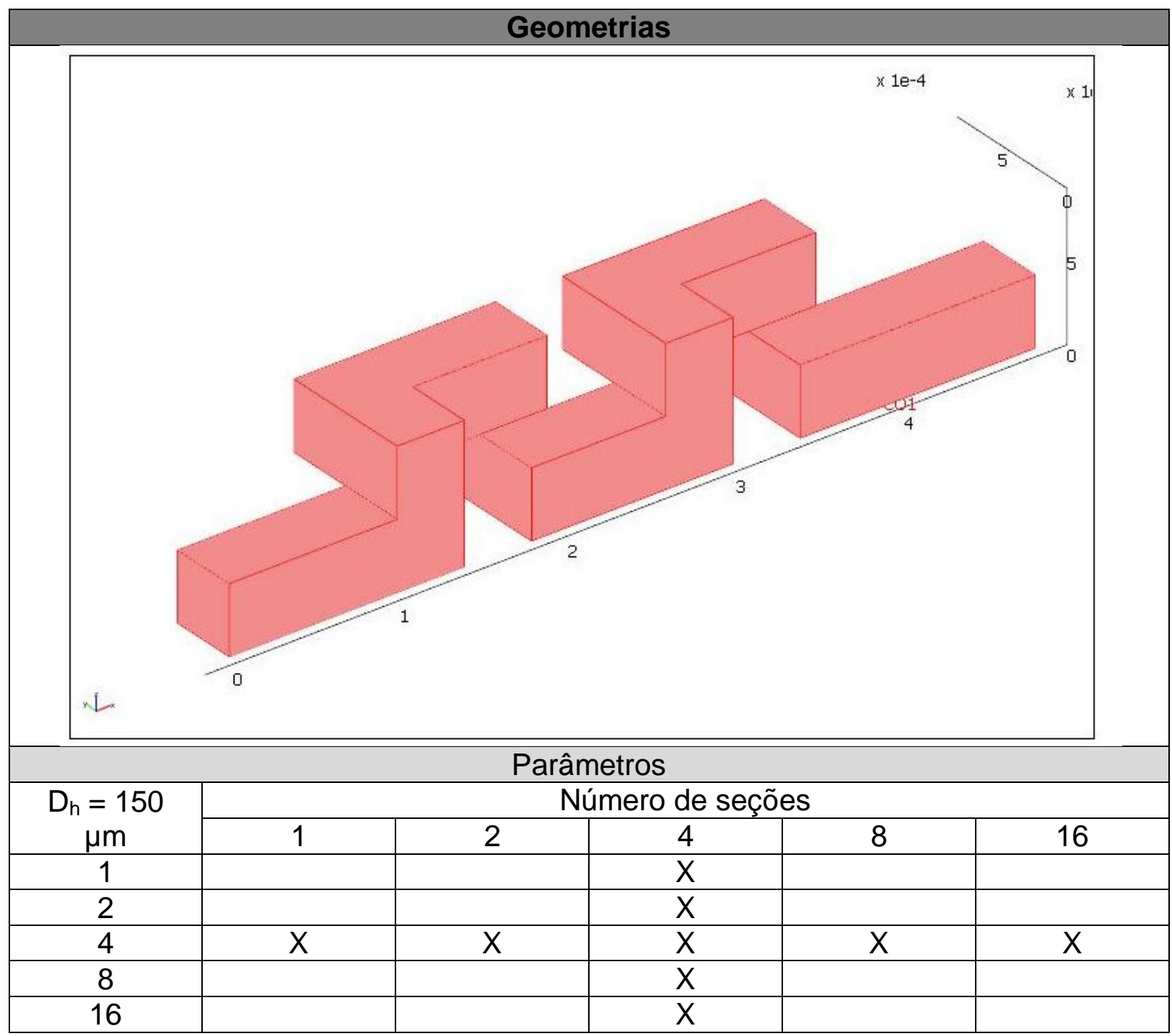


Tabela 34. Estudo 5: Condições de contorno.

\begin{tabular}{|c|c|}
\hline & Geometria \\
\hline \multicolumn{2}{|c|}{ Volume } \\
\hline \multicolumn{2}{|c|}{$|c|$} \\
\hline \\
\hline
\end{tabular}


A tabela 34 mostra as condições de contorno aplicadas nas geometrias deste estudo. No volume é resolvida a equação de Navier-Stokes na forma diferencial com difusão artificial Streamline diffusion - Galerkin Least-Squares (GLS). O fluido de trabalho é água a $25{ }^{\circ} \mathrm{C}$. Nas faces são aplicadas as seguintes condições: (a) na entrada perfil de velocidade uniforme parametrizado em função do número de Reynolds, (b) na saída pressão nula e (c) nas paredes velocidade nula (condição de não-deslizamento). São aplicadas cinco condições diferentes nas faces de entrada das nove geometrias propostas, totalizando 45 simulações.

A tabela 35 mostra a discretização da malha. O elemento utilizado foi o tetraedro com tamanho máximo local de $D_{h} / 25$ e tamanho máximo global de $D_{h} / 8$. Essa parametrização da malha é devido ao estudo de diversos $D_{h}$.

Tabela 35. Estudo 5: Discretização da geometria.

\begin{tabular}{|c|c|c|}
\hline \multicolumn{2}{|c|}{ Geometria } \\
\hline
\end{tabular}


Após o processamento dos modelos com o solver GMRES e pré-condicionador Geometric multigrid foram obtidos os mapas das propriedades de interesse.

A figura 45 mostra os mapas de velocidade e de pressão para a geometria serpentina 3D com $D_{h}=600 \mu m$ e 16 seções em $R e=100$. Observa-se que as linhas de campo do mapa de velocidade sofrem torção e também cruzam entre si, comportamento distinto do encontrado em regime de escoamento laminar. A velocidade máxima atinge o valor de $0,429 \mathrm{~m} / \mathrm{s}$. No mapa de pressão, observa-se que a diferença de pressão é de 1,4 kPa.

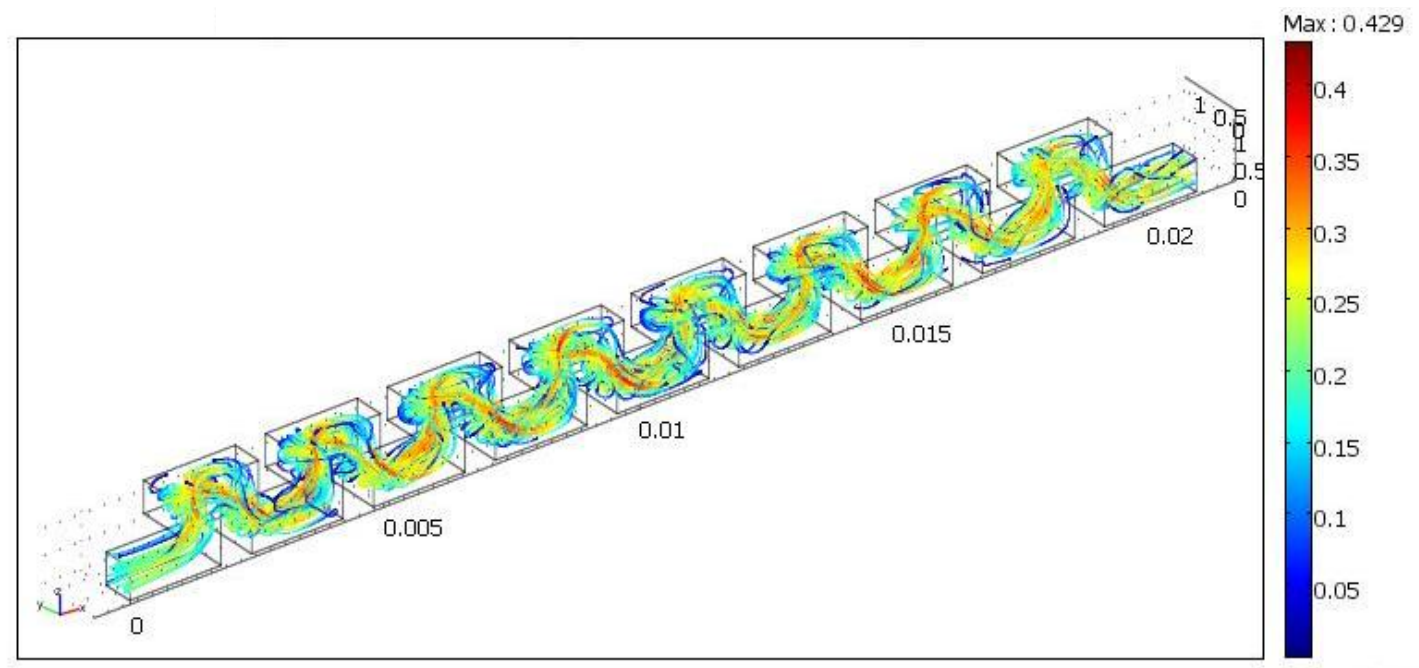

Min : $2.87 e-9$

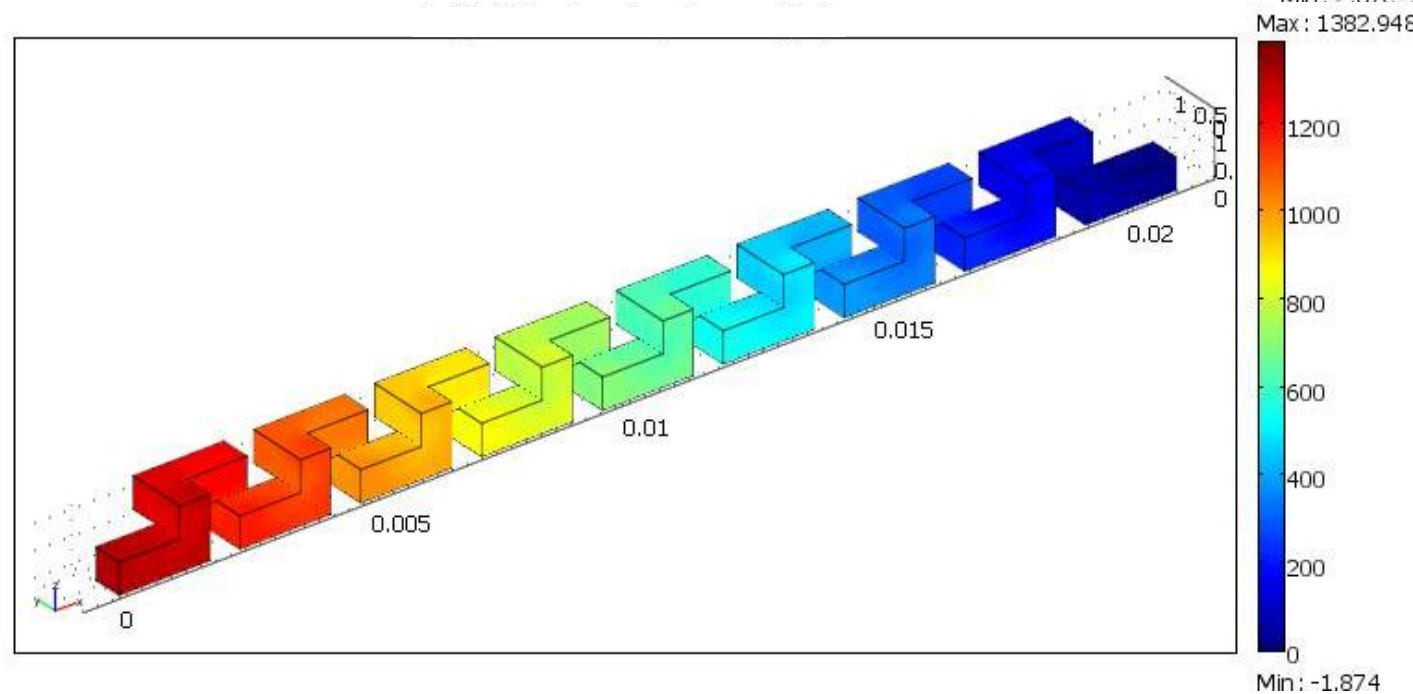

Figura 45. Mapas de velocidade e pressão para a geometria serpentina 3D de $600 \mu \mathrm{m}$ e 16 seções em $\operatorname{Re}=100$.

Após a apresentação dos mapas, foram obtidos os parâmetros numéricos de interesse para caracterização do(s) regime(s) de escoamento: coeficiente de perda de carga, vorticidade e diferença de pressão.

O gráfico 25 mostra o K em função do Re para (a) as seções e (b) para os $D_{h}$ trabalhados. Observam-se nas curvas dois comportamentos distintos: (a) para $\mathrm{Re}$ 
entre 0,01 e 10 regime laminar, e (b) para Re entre 10 e 100 regime intermediário. Este comportamento é válido tanto para variação em função do número de seções quanto para o valor do $D_{h}$ das nove geometrias estudadas.

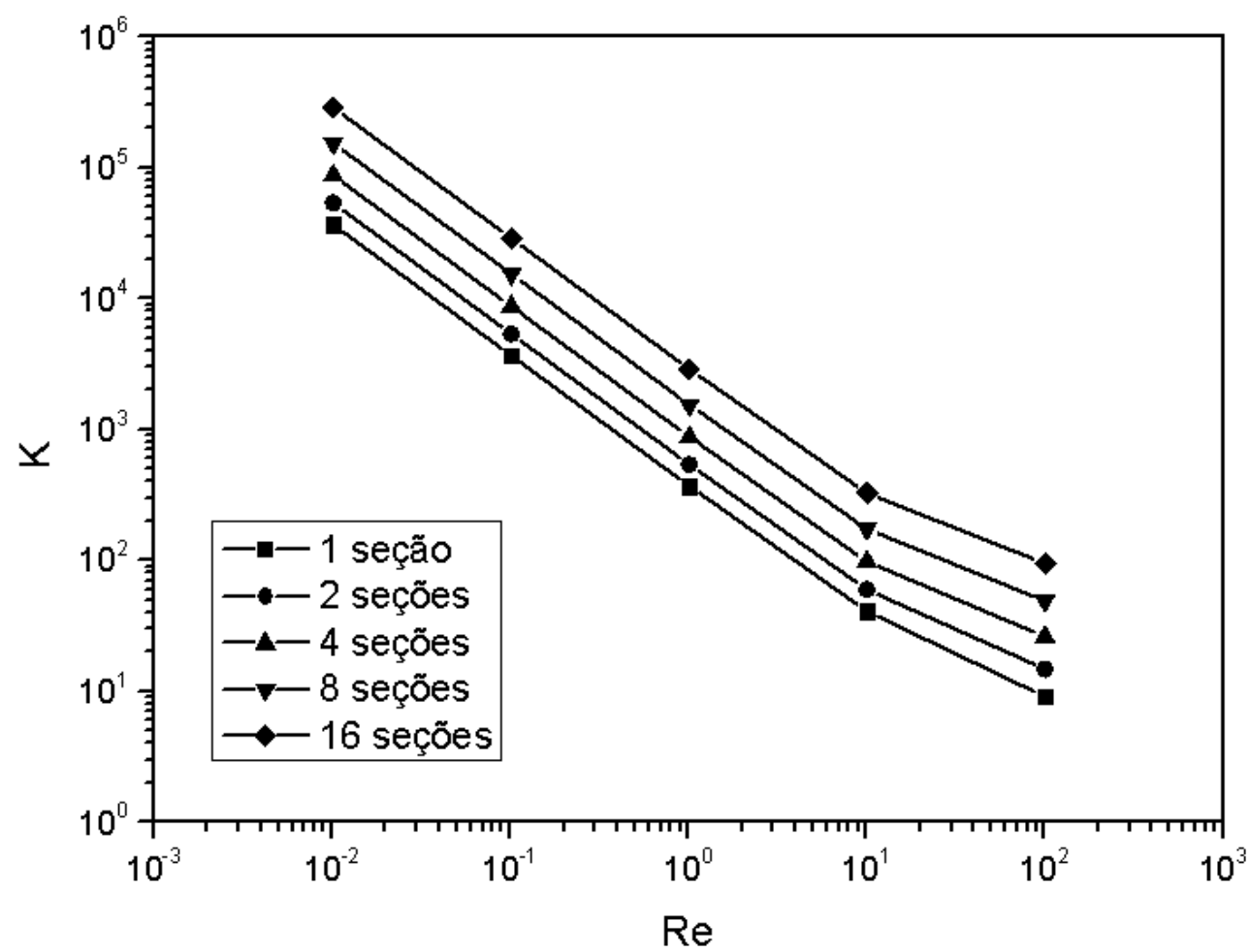

(a)

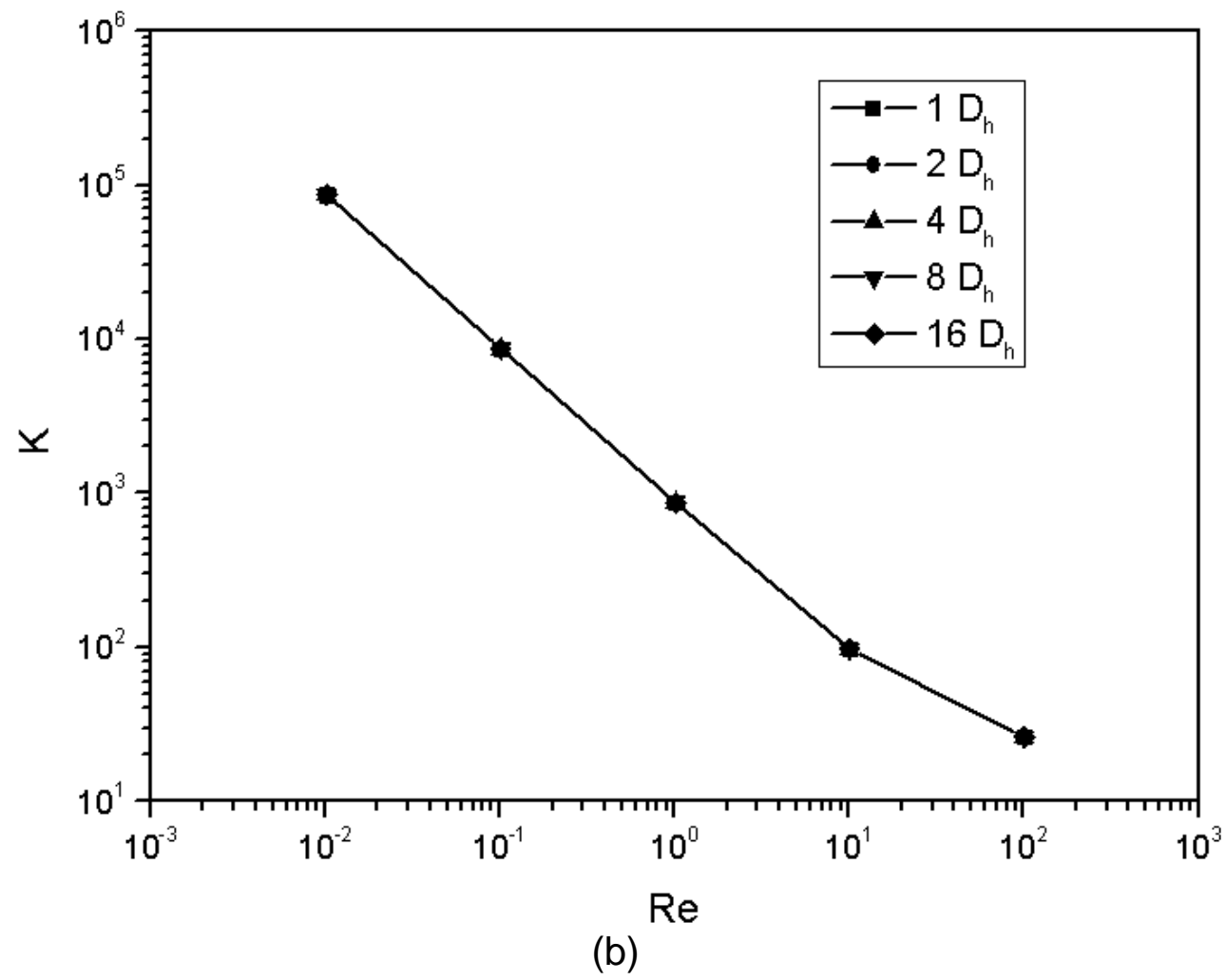

Gráfico 25. K em função de Re para variação do (a) número de seções e do (b) $D_{h}$. 


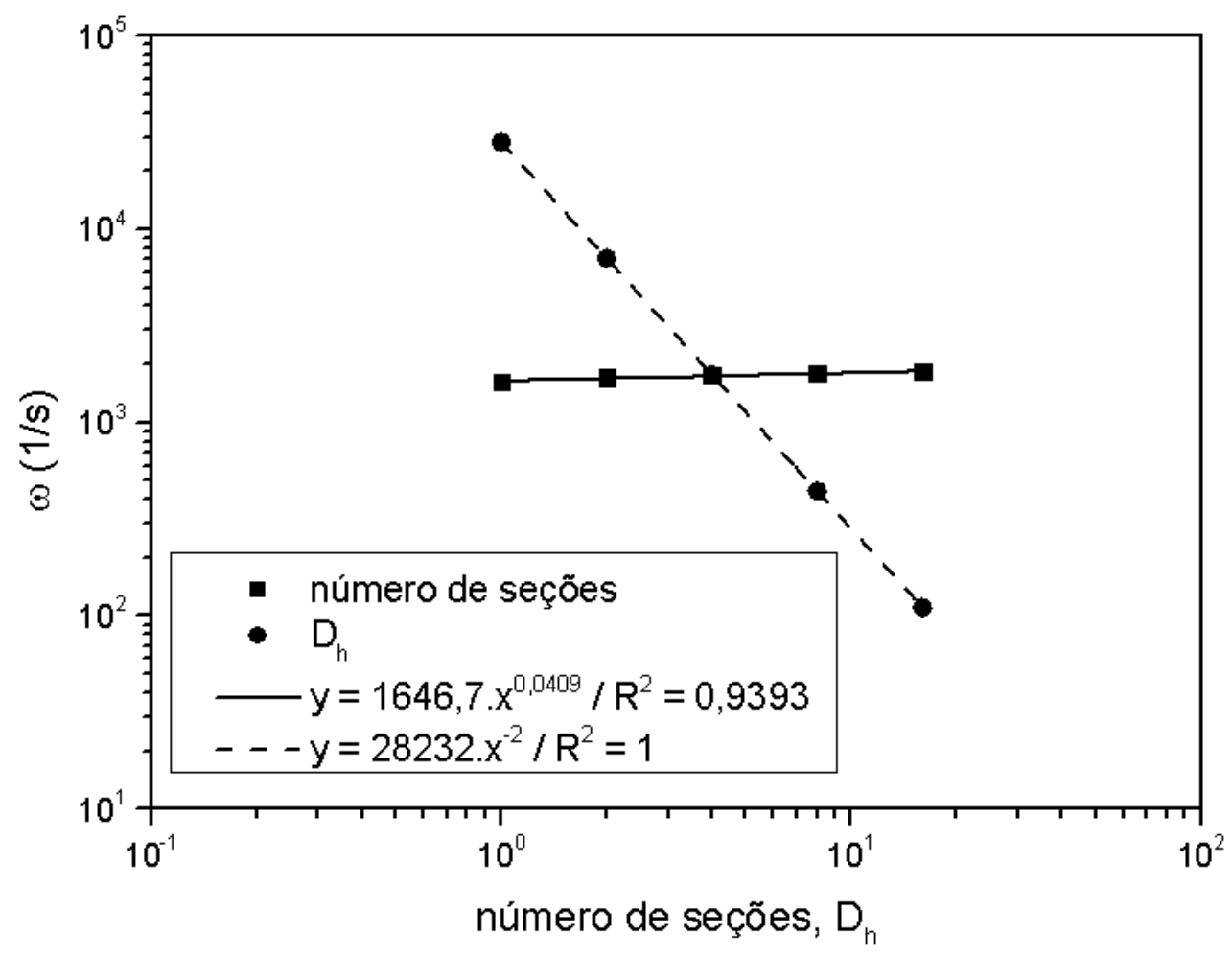

(a)

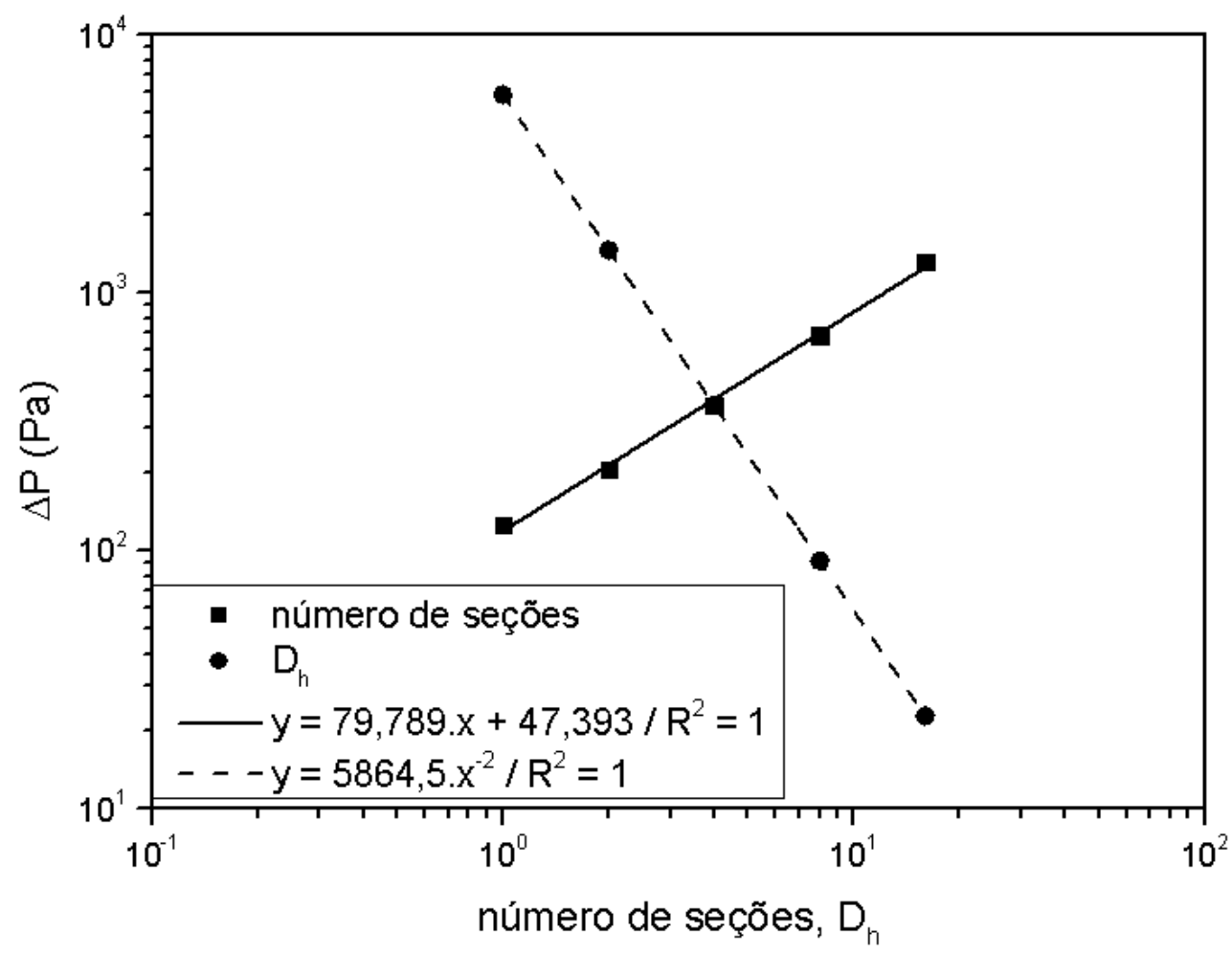

(b)

Gráfico 26. Parâmetros numéricos: (a) vorticidade em função do número de seções e do $D_{h}$ e (b) diferença de pressão em função do número de seções e do $D_{h}$. 
O gráfico 26 mostra a vorticidade e a diferença de pressão em função do número de seções e dos diâmetros hidráulicos, para $R e=100$. Observa-se que a vorticidade diminui em função do aumento do diâmetro hidráulico do microcanal, proporcional a um fator $x^{-2}$. Enquanto que a vorticidade permanece aproximadamente constante com o aumento do número de seções. A composição de diâmetro hidráulico e número de seções para otimizar a vorticidade é importante, pois a vorticidade é um parâmetro que provoca instabilidades nas linhas de fluxo, melhorando o processo de transferência de massa.

A diferença de pressão diminui em função do aumento do diâmetro hidráulico, proporcional a um fator $x^{-2}$. Enquanto que em função do número de seções, a diferença de pressão aumenta linearmente. A composição entre diâmetro e número de seções para otimizar a diferença de pressão também é importante, pois o dimensionamento do sistema de bombeamento dependerá desses fatores.

\subsubsection{Estudo 5.1: Eficiência de mistura}

Terminada a análise dos parâmetros fluidodinâmicos, o último parâmetro de interesse é a eficiência de mistura. Esse parâmetro será avaliado considerando a geometria definida na tabela 33, considerando as variações de diâmetro hidráulico e do número de seções.

A tabela 36 mostra as condições de contorno aplicadas nas nove geometrias. No volume é resolvida numericamente a equação de convecção-difusão com difusão artificial Streamline diffusion - Petrov-Galerkin / Compensated. O fluido de trabalho é a água a $25^{\circ} \mathrm{C}$. O coeficiente de difusão adotado foi de $1110^{-8} \mathrm{~m}^{2} / \mathrm{s}$.

Nas faces foram aplicadas as seguintes condições de contorno: (a) na face de entrada um perfil de concentração em cinco condições parametrizadas em função do Re, (b) na face saída a condição de fluxo convectivo e (c) nas paredes a condição de isolamento/simetria. Considerando nove geometrias e cinco condições para cada uma, totaliza-se 45 simulações.

A tabela 37 mostra a discretização da malha utilizada nas nove geometrias. $\mathrm{O}$ elemento utilizado foi o tetraedro irregular. O tamanho global da malha foi parametrizado em função do diâmetro hidráulico, Dh / 8. E o tamanho local Dh / 25. 
Tabela 36. Estudo 5.1: Condições de contorno.

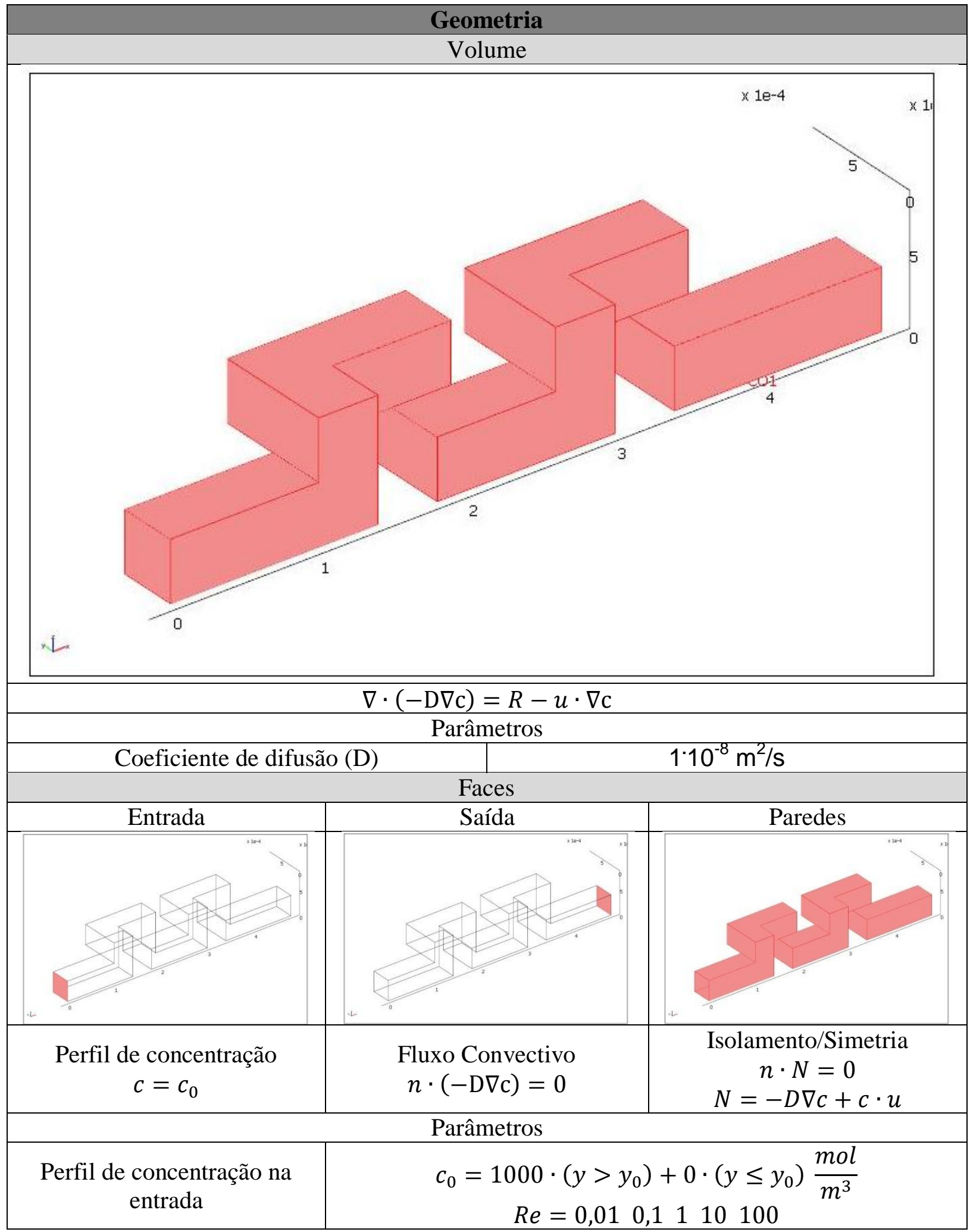


Tabela 37. Estudo 5.1: Discretização das geometrias.

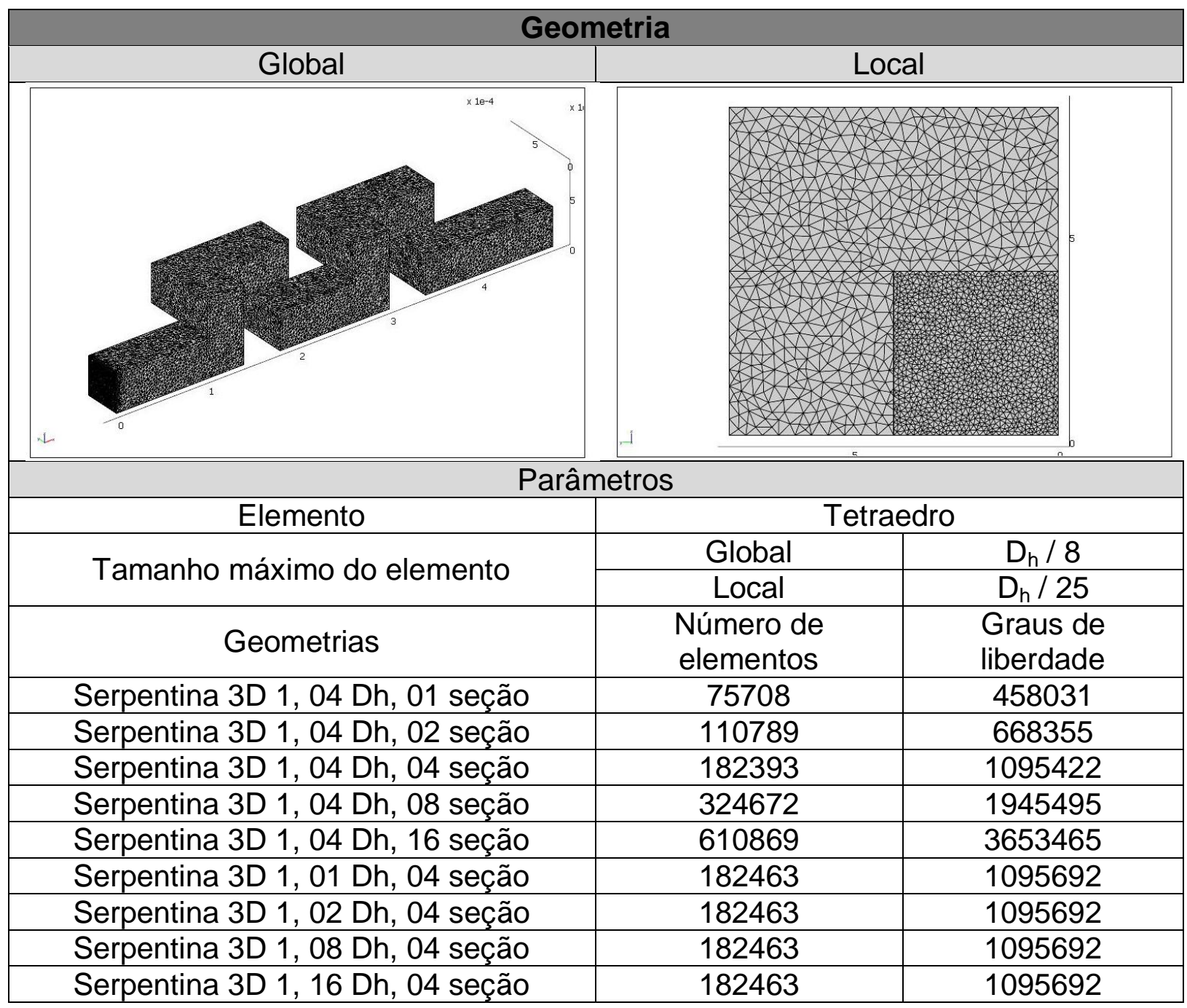

Após o processamento dos modelos com o solver GMRES e o précondicionador Geometric multigrid, os mapas de concentração foram obtidos.

A figura 46 mostra os mapas de concentração da saída em função do número de seções, para $R e=100$ e diâmetro hidráulico de $600 \mu \mathrm{m}$. Observa-se na figura que a qualidade da mistura é incrementada em função do aumento do número de seções.

Também é possível observar a evolução da interface de contato entre os fluidos para geometria com 08 seções, verificando a capacidade desta geometria em otimizar o processo de difusão. 

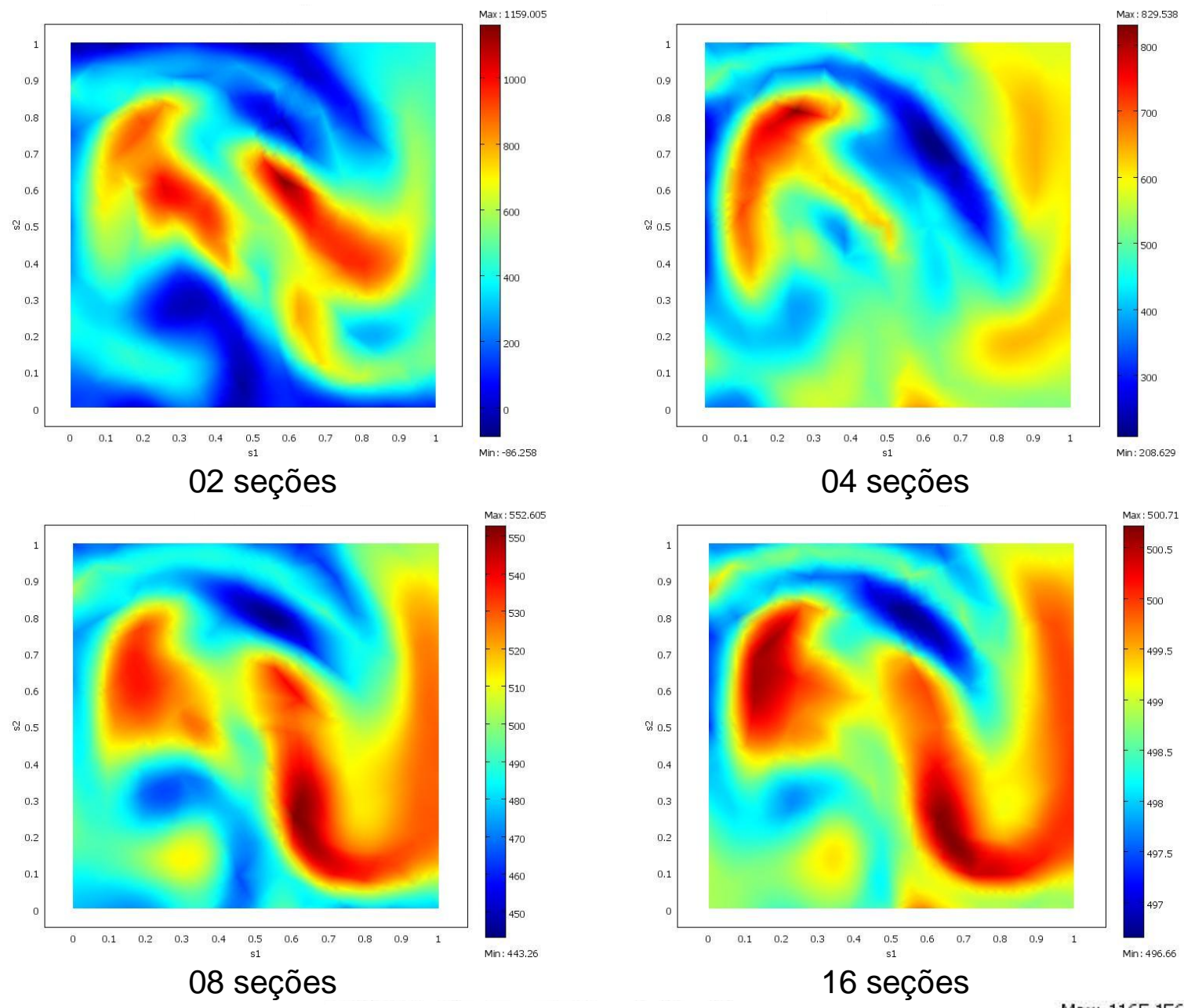

16 seções

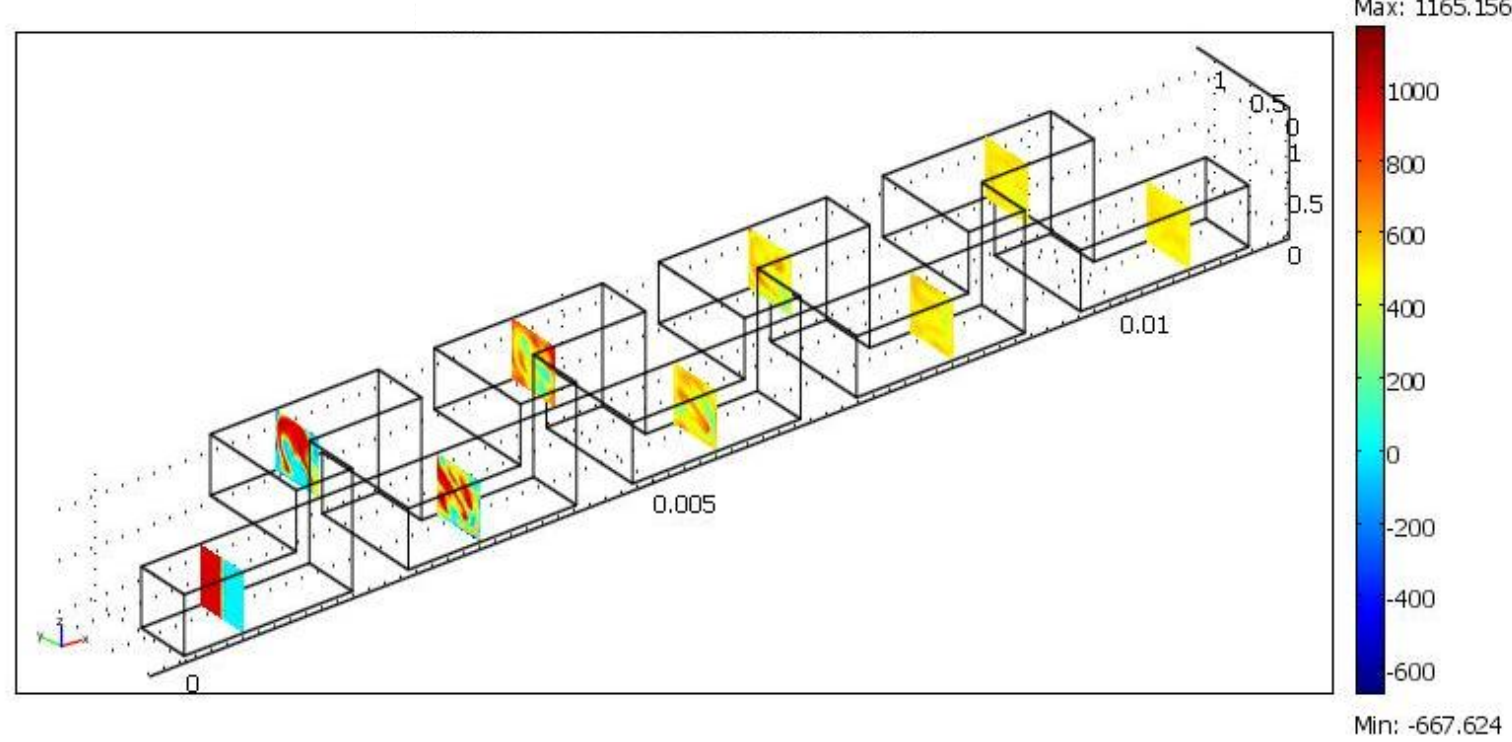

Geometria com 08 seções

Figura 46. Mapas de concentração da saída em função do número de seções, para $R e=100$ e $D_{h}=600 \mu \mathrm{m}$.

Após a visualização dos mapas de concentração mais significativos, foi obtida a eficiência de mistura em função do número de seções e do diâmetro hidráulico. 


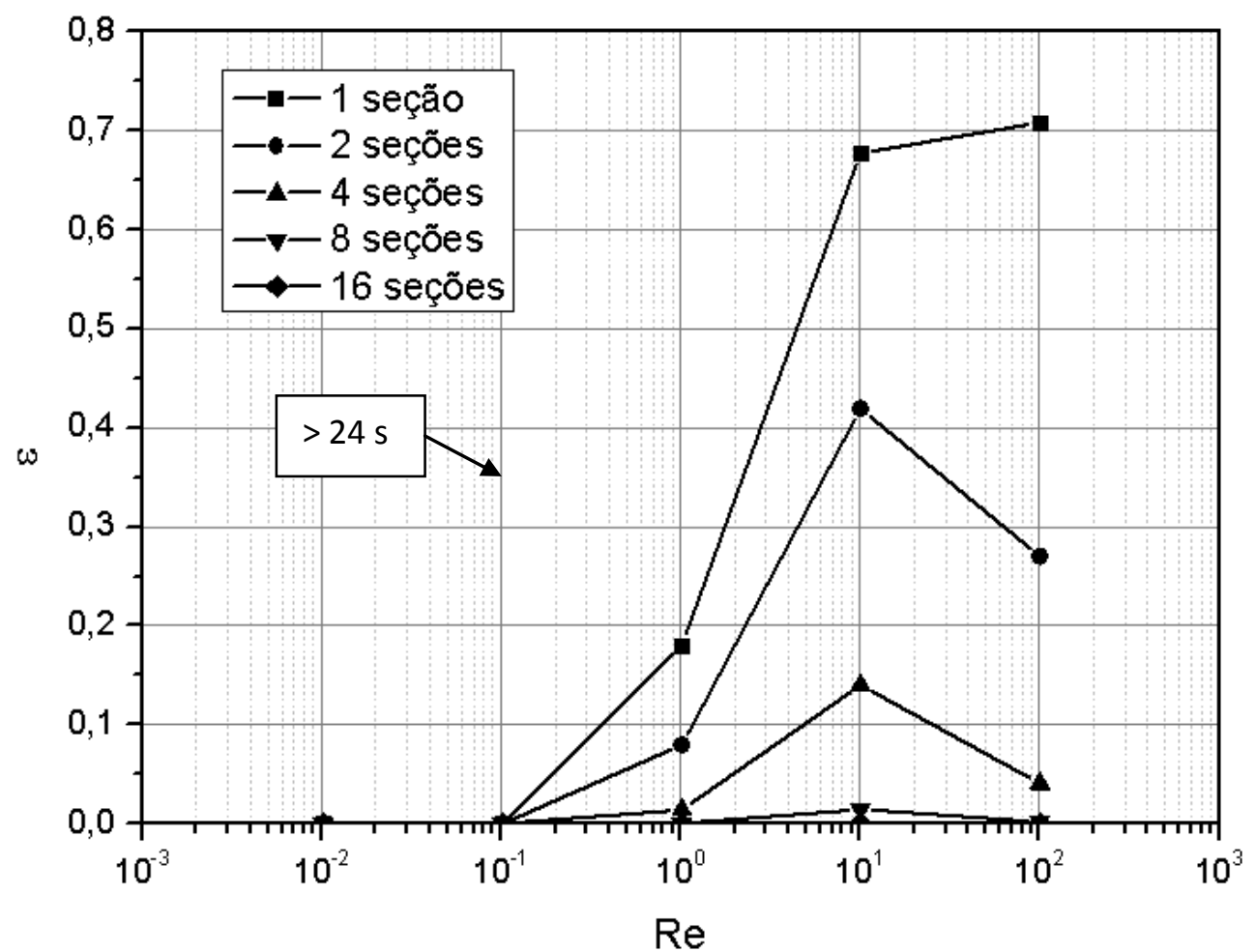

(a)

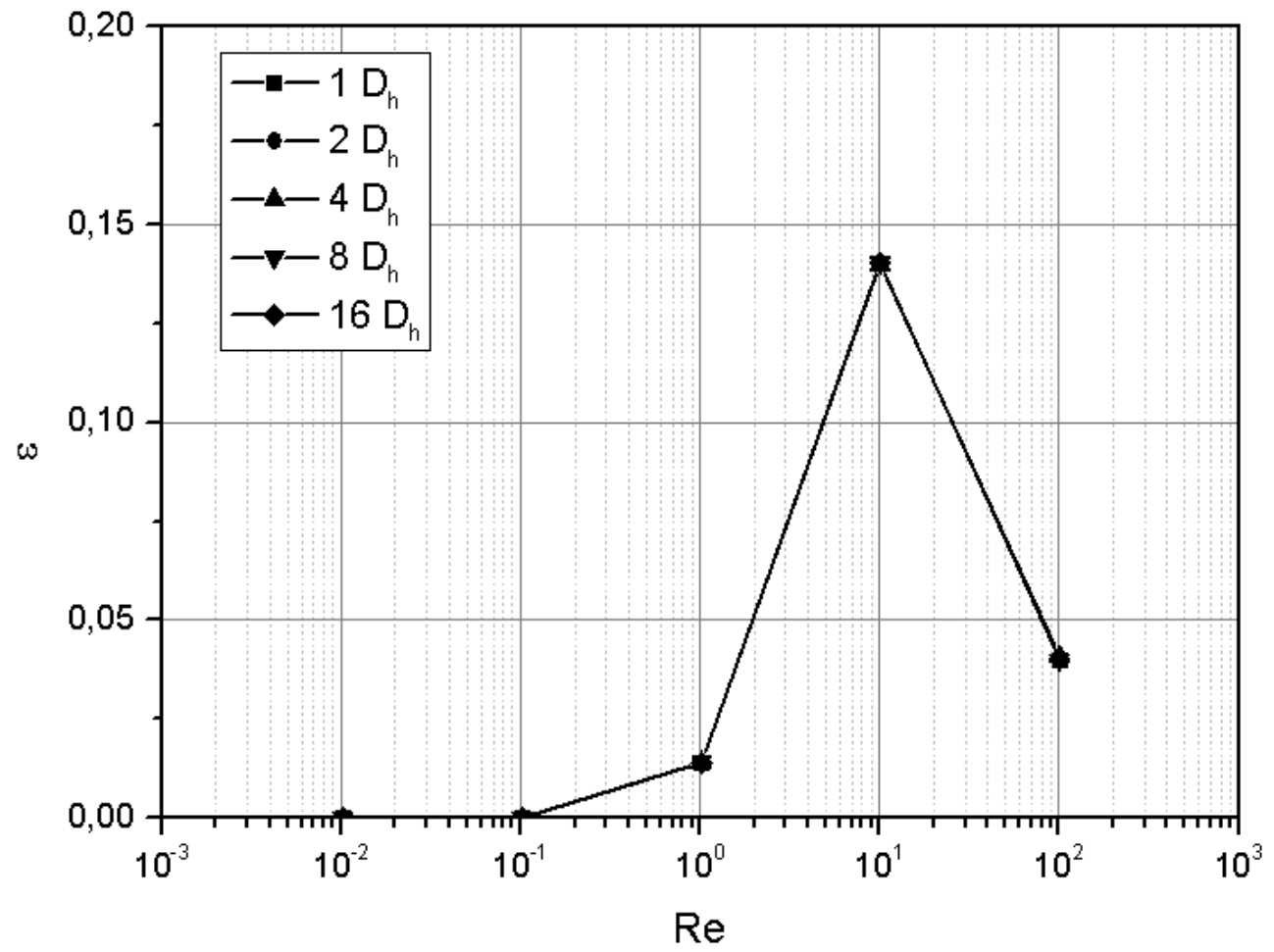

(b)

Gráfico 27. Eficiência de mistura em função do (a) número de seções e do (b) do $D_{h}$.

O gráfico 27 mostra a eficiência de mistura em função do número de Reynolds para variação (a) do número de seções e (b) do diâmetro hidráulico. Para variação do número de seções, observa-se que para Re entre 0,01 e 0,1 não há diferença 
significativa na eficiência de mistura em função da variação do número de seções. Nesse intervalo os tempos de residência praticados para as diversas geometrias são maiores que $24 \mathrm{~s}$. Em função do coeficiente de difusão adotado, o tempo de residência teórico para efetivação da mistura é de $18 \mathrm{~s}$. Ou seja, no intervalo em questão, a mistura está completa para as 05 cinco geometrias estudadas em função do número de seções.

Para o intervalo de Re entre 0,1 e 100, a mistura ainda não está completa e as diferenças de desempenho entre as geometrias ficam evidentes. Verifica-se que a eficiência de mistura é melhorada em função do aumento do número de seções. A tabela 38 mostra um índice comparativo em função do aumento de seções.

Tabela 38. Índice comparativo em função do número de seções.

\begin{tabular}{|c|c|c|}
\hline Número de seções & $\begin{array}{c}\text { Eficiência relativa } \\
\mathrm{Re}=10\end{array}$ & $\begin{array}{c}\text { Eficiência relativa } \\
\mathrm{Re}=100\end{array}$ \\
\hline 1 & 1 & 1 \\
\hline 2 & 1,62 & 2,62 \\
\hline 4 & 4,84 & 17,30 \\
\hline 8 & 46,25 & 375,51 \\
\hline 16 & 660,19 & 104395,80 \\
\hline
\end{tabular}

Para variação do diâmetro hidráulico, verifica-se no gráfico $27(\mathrm{~b})$ que a eficiência de mistura permanece a mesma no intervalo estudado de Re entre 0,01 a 100. A princípio este resultado induz a conclusão que a variação do número de seções influencia fortemente na melhora da qualidade de mistura, enquanto que a qualidade de mistura permanece constante com a variação do diâmetro hidráulico.

Para elucidar a influência do diâmetro hidráulico e do número de seções foi feito o gráfico 28 , que mostra a eficiência de mistura em função desses parâmetros para $R e=100$. Verifica-se claramente no gráfico $28(a)$ a influência do aumento do número de seções na melhora da eficiência de mistura. Enquanto a qualidade de mistura permanece constante em função da variação do diâmetro hidráulico.

No entanto, a variação do diâmetro hidráulico também significa variação no tempo de residência. O gráfico 28(b) mostra a eficiência de mistura em função do tempo. Verifica-se que a diminuição do diâmetro hidráulico reduz o tempo de residência deixando constante a qualidade de mistura. Portanto, tem-se a mesma qualidade de mistura em tempos menores com a redução do diâmetro hidráulico. 


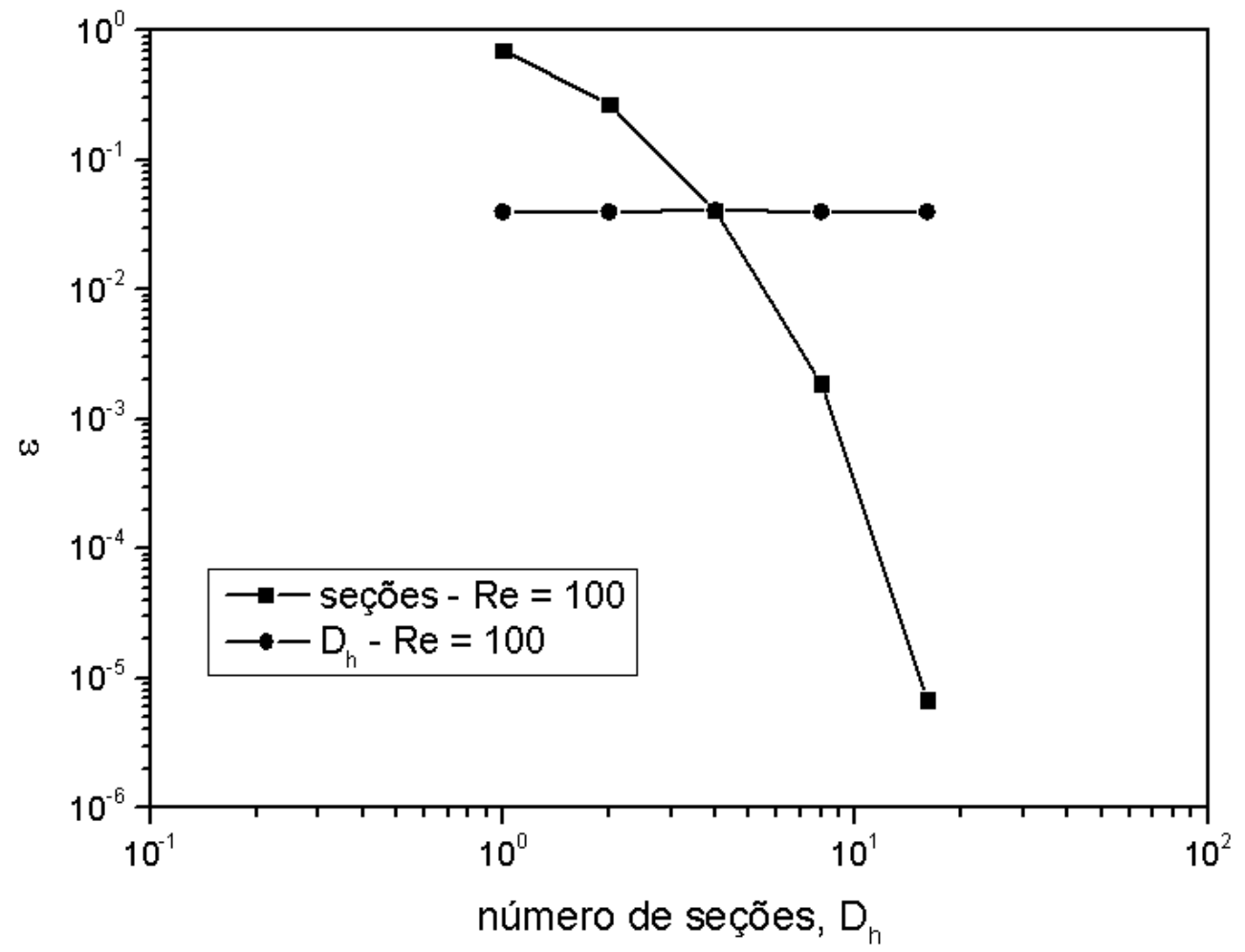

(a)

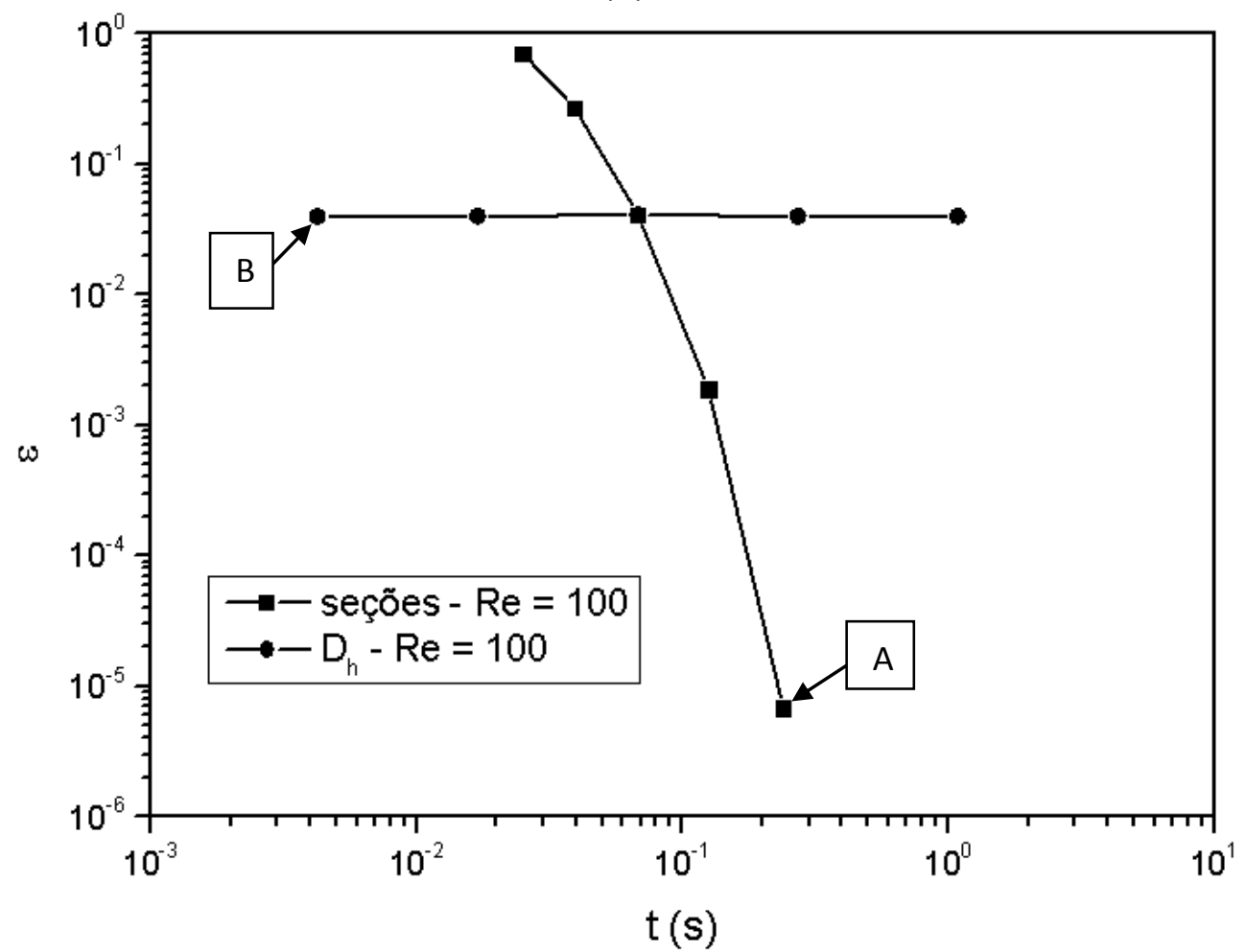

(b)

Gráfico 28. Eficiência de mistura em função do (a) número de seções e do Dh, e em função do (b) tempo de residência.

Portanto, a composição do número de seções com o diâmetro hidráulico $\left(D_{h}\right)$ é o ideal para avaliar a qualidade de mistura de determinado dispositivo. Enquanto a 
redução de $D_{h}$ reduz o tempo de residência, o aumento do número de seções melhora a qualidade de mistura.

A análise do gráfico abre diversas possibilidades para a otimização dimensional de dispositivos baseados na geometria serpentina $3 D$ 1. O ponto $A$ destacado no gráfico 28 (b) representa a uma boa eficiência de mistura obtida com a geometria com 16 seções e $D_{h}=600 \mu \mathrm{m}$. Dois parâmetros importantes no ajuste do processo são o tempo de residência e a perda de carga. Se o desejo for por um processo com menor perda de carga, a partir do ponto $A \circ D_{h}$ pode ser modulado a direita para satisfazer esse desejo, mantendo a eficiência constante. Mas, com o prejuízo de um processo mais lento. Por outro lado, se o desejo é um processo mais rápido, a partir do ponto $A \circ D_{h}$ pode ser modulado a esquerda.

$O$ ponto $B$ representa a eficiência de mistura obtida com a geometria com 4 seções e $D_{h}=150 \mu \mathrm{m}$. A eficiência de mistura pode ser incrementada modulando o número de seções.

Portanto, a escolha do $D_{h}$ define um tempo inicial a partir do qual a eficiência de mistura será modulada em função do número de seções do microcanal serpentina 3D 1. Essa modulação pode ser realizada ajustando uma curva de tendência aos pontos de eficiência de mistura em função do número de seções.

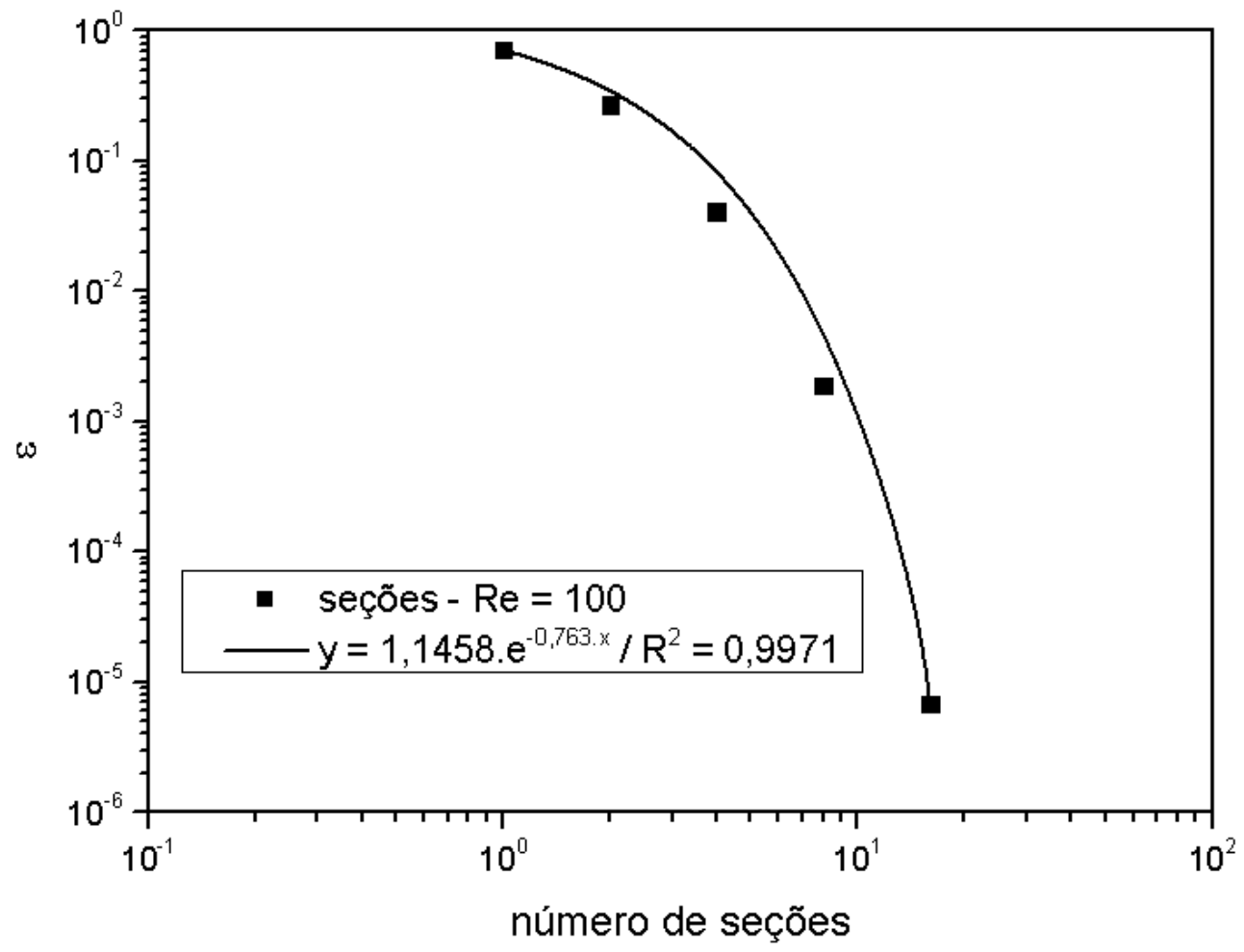

Gráfico 29. Comportamento da geometria serpentina 3D 1 em função do número de seções. 
O gráfico 29 mostra o comportamento da geometria serpentina 3D 1 em função do número de seções. Observa-se um comportamento exponencial da eficiência de mistura em função do número de seções dado pela equação ajustada no gráfico.

Logo, para o processo com água e coeficiente de difusão $D=1 \cdot 10^{-8} \mathrm{~m}^{2} / \mathrm{s}$, podese projetar a geometria serpentina 3D 1, modulando o número de seções para a eficiência desejada através de uma equação analítica.

Generalizando, o comportamento da geometria serpentina 3D 1 pode ser dado em função da equação

$$
y=A \cdot e^{-B \cdot x}
$$

eq. 18 ,

onde y é a eficiência de mistura, $x$ é o número de seções $e, A$ e $B$, são constantes características do processo. A constante $A$ é o valor inicial de eficiência de mistura.

Quanto a constante $B$, analisando o comportamento matemático da função em relação a esta constante, verifica-se que

- se B aumenta a eficiência de mistura aumenta mais rapidamente com o número de seções, e

- se B tende a zero a eficiência de mistura aumenta mais lentamente.

Portanto, a constante B está diretamente ligada ao coeficiente de transferência de massa do processo, pois um aumento de $B$ corresponde a uma menor resistência a mistura. Ou seja, quanto maior o coeficiente B mais eficiente é cada seção no processo. Logo, com o ajuste de B em função do coeficiente de difusão, pode-se projetar a geometria serpentina 3D 1 usando uma função analítica para qualquer processo envolvendo fases líquidas controlado por este coeficiente de transferência de massa.

\subsubsection{Resumo}

O estudo foi realizado para extrair as características da geometria serpentina 3D 1 para mistura de fluidos. Para alcançar este objetivo foi estudada a influência do $D_{h}$ e do número de seção na eficiência de mistura.

Primeiro definiu-se o intervalo de trabalho com a análise dos mapas e parâmetros fluidodinâmicos. O regime intermediário de interesse foi encontrado para Re entre 10 e 100, pois nessa região com a geometria serpentina 3D 1 efetiva-se mistura com parâmetros de processo desejáveis. 
Trabalhando a eficiência de mistura conseguiu-se isolar e entender a influência da variação do diâmetro hidráulico e o do número de seções no desempenho desta geometria. A diminuição do diâmetro hidráulico conduz a processos mais rápidos mantendo a qualidade de mistura constante. $O$ aumento do número de seções conduz a processos mais eficientes. A tabela 39 mostra a eficiência de mistura relativa a geometria com 1 seção, para $R e=10$ e $R e=100$. Observa-se que 0 aumento do número de seções intensifica fortemente a qualidade de mistura.

Tabela 39. Índice comparativo em função do número de seções.

\begin{tabular}{|c|c|c|}
\hline Número de seções & $\begin{array}{c}\text { Eficiência relativa } \\
\mathrm{Re}=10\end{array}$ & $\begin{array}{c}\text { Eficiência relativa } \\
\mathrm{Re}=100\end{array}$ \\
\hline 1 & 1 & 1 \\
\hline 2 & 1,62 & 2,62 \\
\hline 4 & 4,84 & 17,30 \\
\hline 8 & 46,25 & 375,51 \\
\hline 16 & 660,19 & 104395,80 \\
\hline
\end{tabular}

Para quantificar essa intensificação da qualidade de mistura foi traçada a curva de eficiência de mistura em função do número de seções, conforme mostrado no gráfico 30.

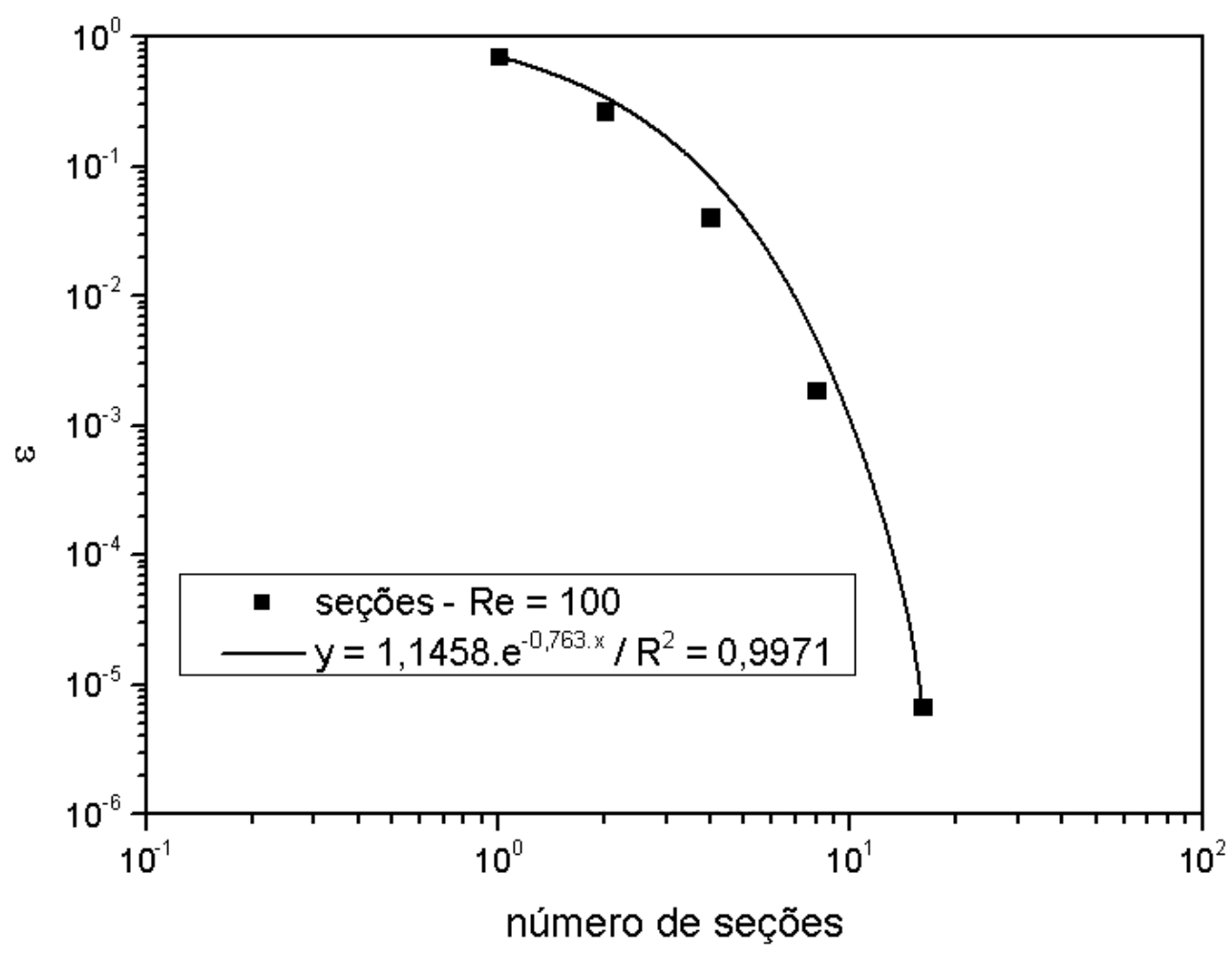

Gráfico 30. Comportamento da geometria serpentina 3D em função do número de seções. 
Com este gráfico consegui-se determinar uma curva característica do processo realizado com a geometria serpentina 3D 1, mostrando um comportamento exponencial entre o aumento do número de seções e a intensificação da qualidade da mistura.

A determinação do comportamento exponencial da geometria serpentina $3 D$ 1 para intensificação do processo de mistura, respeitando as condições de processo estabelecidas neste estudo, representa uma contribuição original ao estado da arte. 
4.9. Estudo 6: Serpentina 3D 1, nas condições de processo

O objetivo deste estudo é extrair os parâmetros fluidodinâmicos e o comportamento em relação a mistura de fluidos para a geometria escolhida, serpentina 3D 1. Para tal, dois parâmetros do processo de produção do biodiesel serão adotados para o estudo do escoamento, viscosidade dinâmica e densidade do óleo a $60 \stackrel{\circ}{\mathrm{C}}$.

A tabela 40 mostra a geometria escolhida, serpentina 3D 1, com 16 seções, diâmetro hidráulico de $600 \mu \mathrm{m}$ e comprimento de $4,02 \cdot 10^{-2} \mathrm{~m}$.

Tabela 40. Estudo 6: Definição da geometria.

\begin{tabular}{|c|c|}
\hline \multicolumn{2}{|c|}{ Geometrias } \\
\hline \\
\hline \\
\hline
\end{tabular}

A tabela 41 mostra as condições de contorno aplicadas na geometria. No volume, a equação de Navier-Stokes na forma diferencial é resolvida com difusão artificial Streamline diffusion - Galerkin Least-Squares (GLS). O fluido de trabalho é o óleo a $60 \stackrel{\circ}{\circ}$. Nas faces são aplicadas as seguintes condições de contorno: (a) na face de entrada - perfil de velocidade uniforme parametrizado em função do número de Reynolds, (b) na face de saída - pressão nula e (c) nas faces 
das paredes - velocidade nula (condição de não-deslizamento). Neste estudo uma geometria é estudada em 04 pontos de Re, totalizando 04 simulações.

Tabela 41. Estudo 6: Condições de contorno.

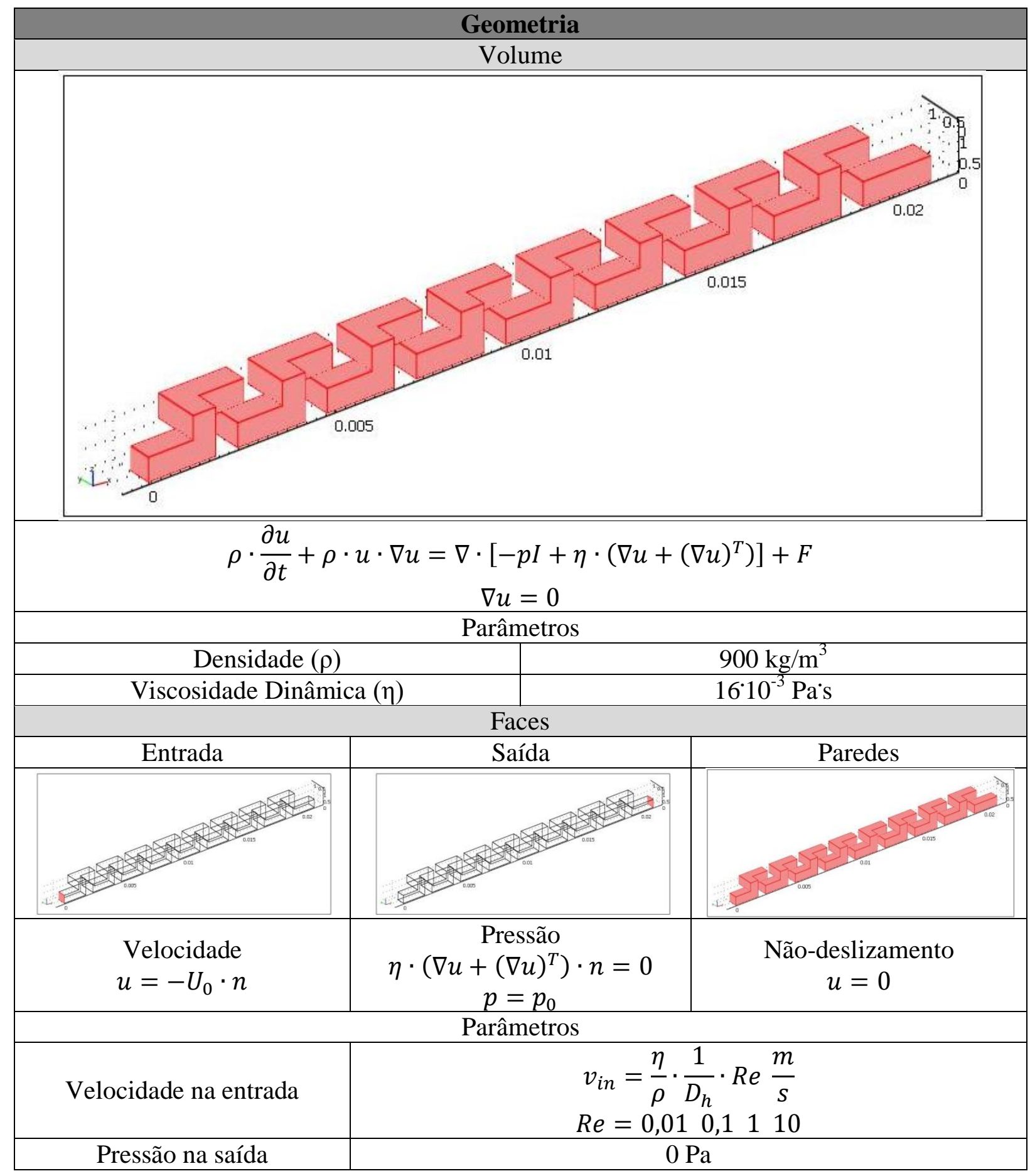

A tabela 42 mostra a discretização da geometria utilizando uma malha com refinamento global e local. O elemento utilizado é o tetraedro, com tamanho global de $150 \mu \mathrm{m}$. O refinamento local na face de entrada tem o elemento com tamanho de $24 \mu \mathrm{m}$. 
Tabela 42. Estudo 6: Discretização da geometria.

\begin{tabular}{|c|c|c|c|}
\hline \multicolumn{4}{|c|}{ Geometria } \\
\hline Global & \multicolumn{2}{|c|}{ Local } \\
\hline & & \\
\hline
\end{tabular}

Após o processamento do modelo com solver GMRES e pré-condicionador Geometric multigrid, os mapas de velocidade e de pressão foram extraídos para análise visual.
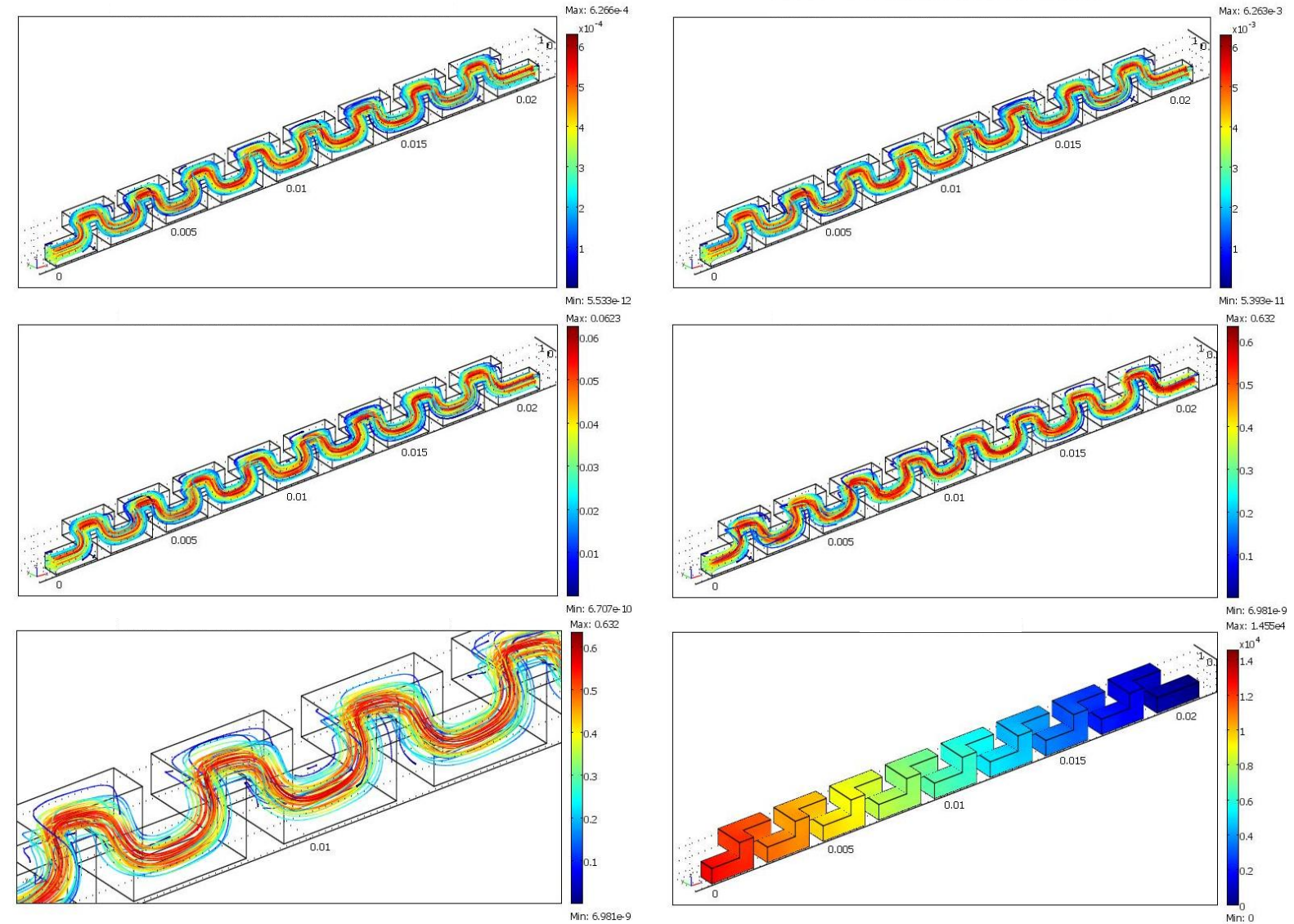

Figura 47. Mapas de velocidade em função do número de Reynolds e mapa de pressão para $\operatorname{Re}=10$. 
A figura 47 mostra os mapas de velocidade em função do número de Reynolds, de 0,01 a 10, mais o mapa de diferença de pressão. Observam-se escoamentos bem comportados para $\operatorname{Re}$ entre 0,01 e 1. Para $R e=10$, o detalhe do escoamento mostra que uma leve instabilidade começa a ser observada. No mapa de pressão para $R e=10$, observa-se um $\Delta \mathrm{P}=14 \mathrm{kPa}$.

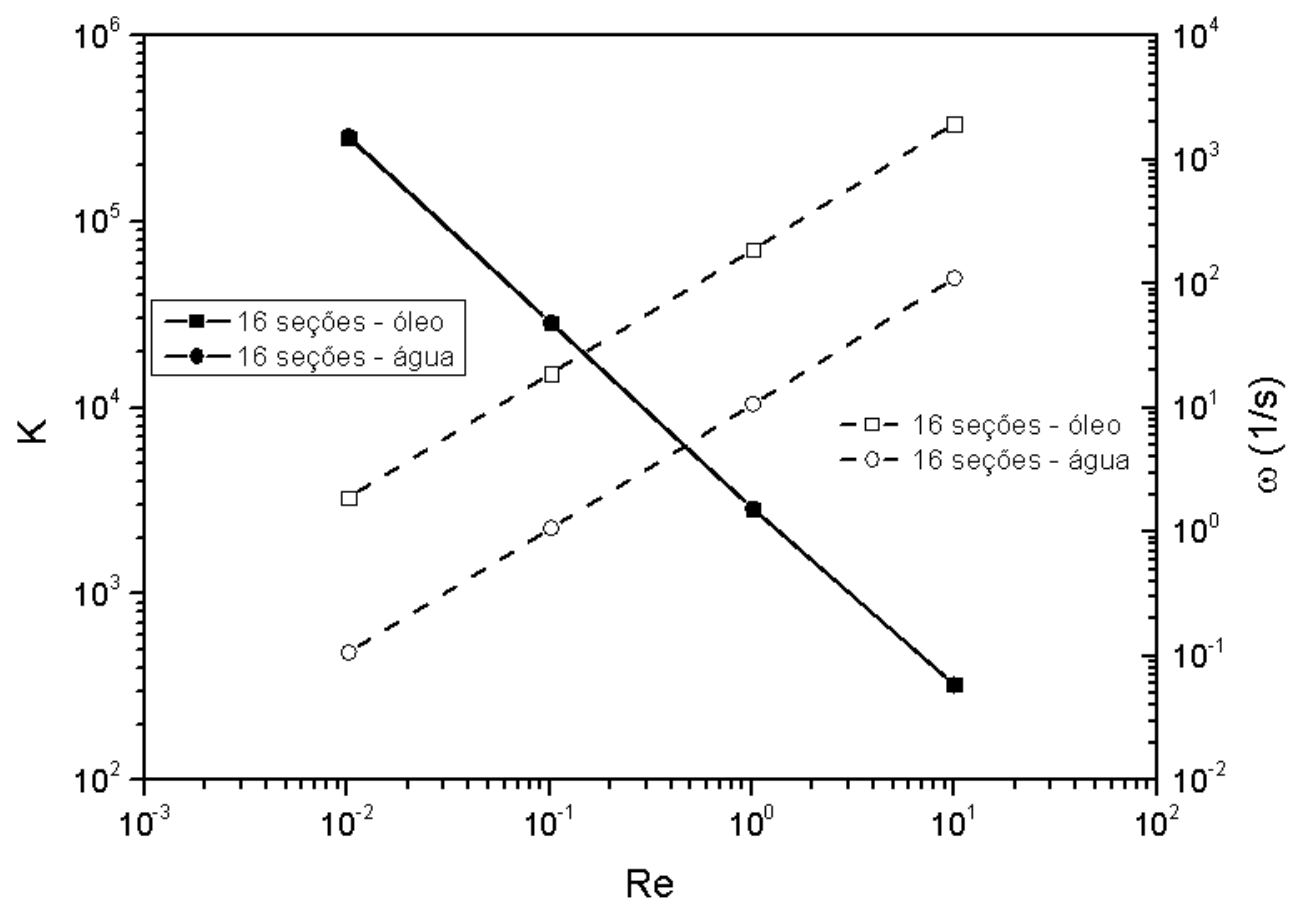

(a)

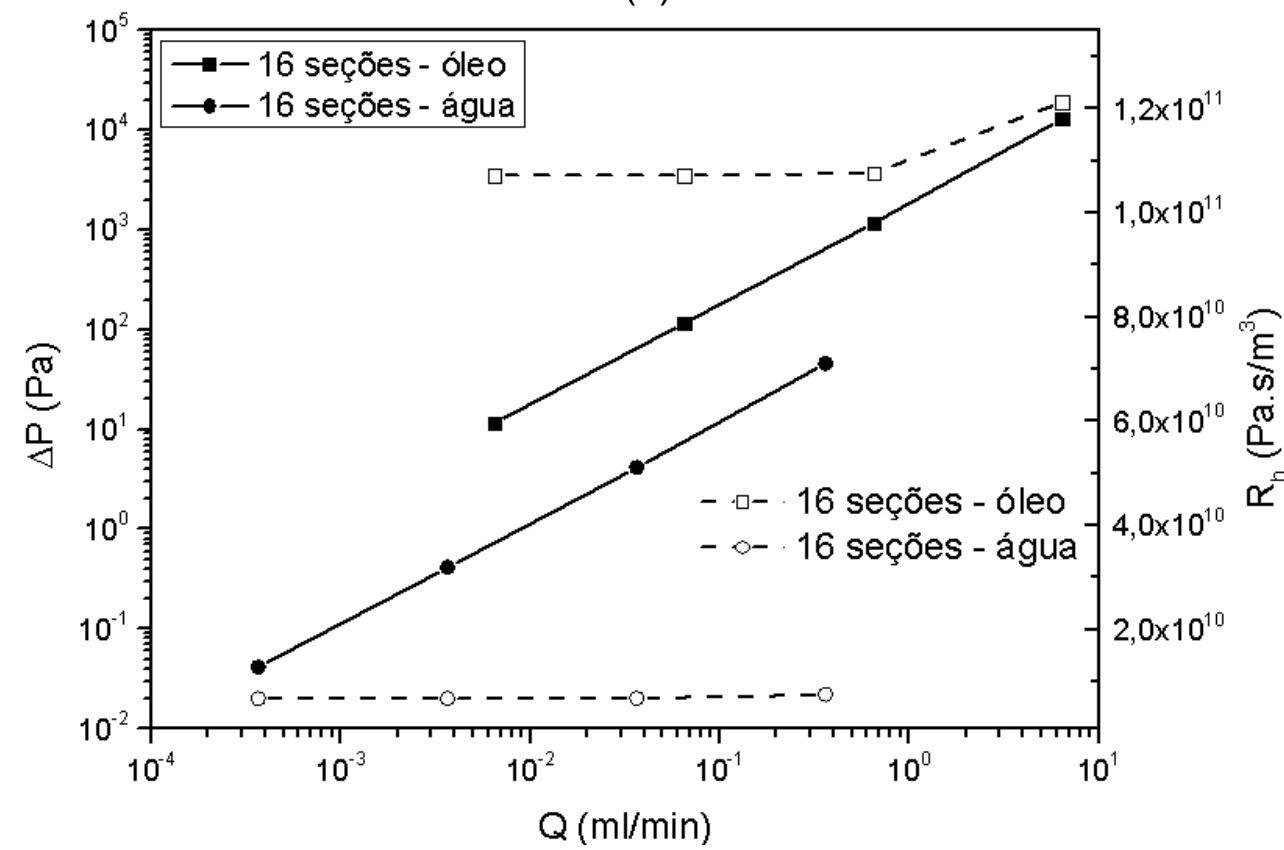

(b)

Gráfico 31. Parâmetros fluidodinâmicos: (a) $\mathrm{K}$ e vorticidade em função de Re e (b) diferença de pressão e resistência hidráulica em função da vazão. 
Após a visualização dos mapas de interesse, os parâmetros numéricos foram obtidos para caracterização do escoamento: $\mathrm{K}$, vorticidade, $\Delta \mathrm{P}, \mathrm{R}_{\mathrm{h}}$, tempo de residência e potência volumétrica.

O gráfico 31 mostra as curvas de (a) $\mathrm{K}$ e vorticidade em função de Re, e de (b) $\Delta P$ e $R_{h}$ em função da vazão. Observa-se no gráfico 31(a) que o $K$ é inversamente proporcional para todo o intervalo de Re estudado, enquanto que, a vorticidade é diretamente proporcional ao Re no mesmo intervalo estudado. Os comportamentos observados indicam um único regime de escoamento. Os dados para água a $25{ }^{\circ} \mathrm{C}$ foram traçados para servir de referência.

No entanto, no gráfico 31 (b) observa-se que a resistência hidráulica desvia-se do comportamento constante esperado para o regime laminar. Portanto, esse será o ponto de trabalho para avaliar a qualidade de mistura, $R e=10$.

No geral, observa-se que o escoamento de óleo em função das propriedades físicas, densidade e viscosidade dinâmica, apresentam para o intervalo de $\mathrm{Re}$ estudado valores maiores de diferença de pressão, vorticidade, resistência hidráulica, vazão, bem como, de potência volumétrica, como mostrado no gráfico 32.

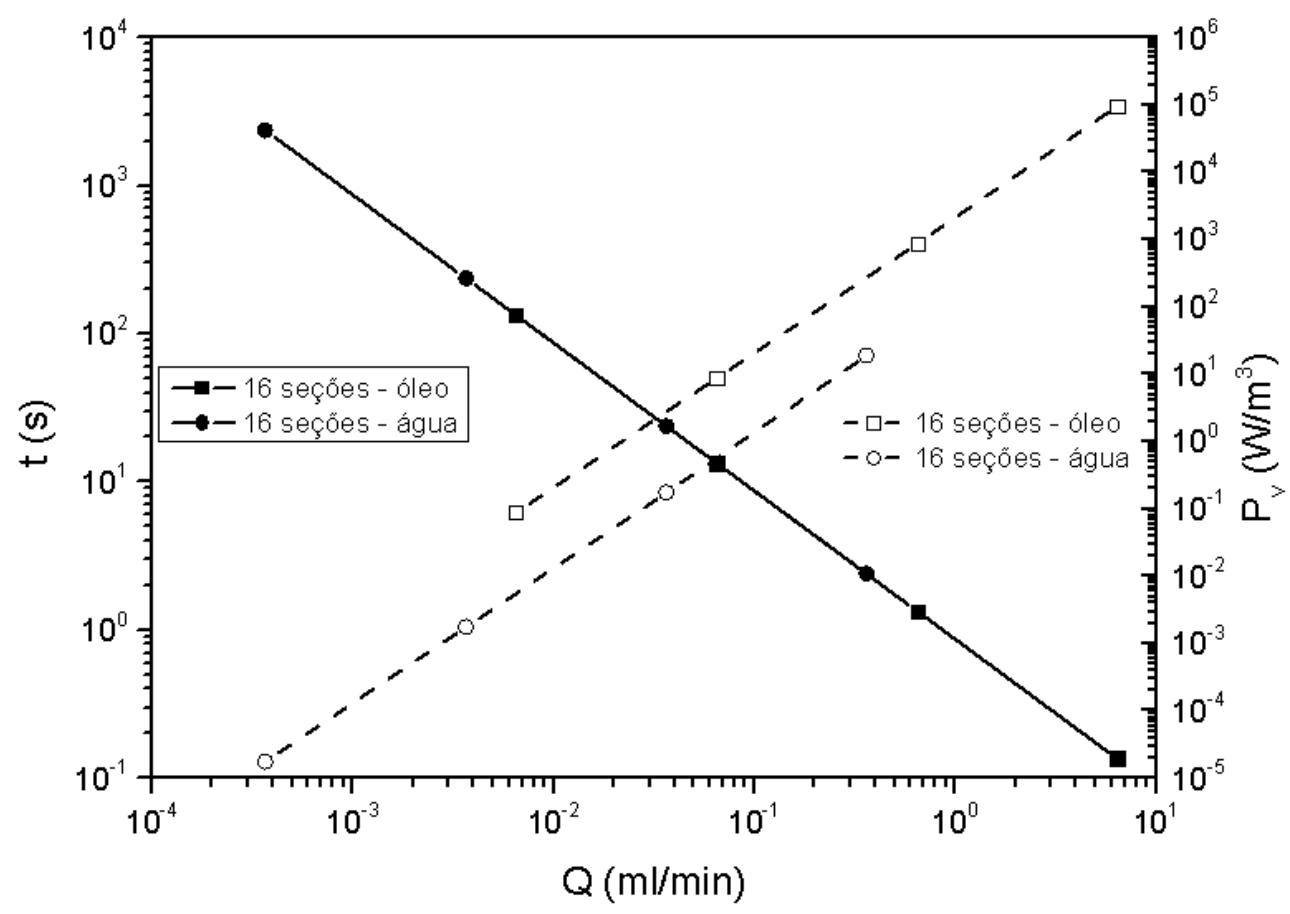

Gráfico 32. Tempo de residência e potência volumétrica em função da vazão. 


\subsubsection{Estudo 6.1: Eficiência de mistura}

O objetivo deste estudo é caracterizar a qualidade de mistura da geometria escolhida, definindo assim uma eficiência de mistura para o ponto de trabalho encontrado com a análise dos parâmetros fluidodinâmicos. A geometria é a mesma definida na tabela 40 .

Tabela 43. Estudo 6.1: Condições de contorno.

\begin{tabular}{|c|c|c|}
\hline \multicolumn{3}{|c|}{ Geometria } \\
\hline \multicolumn{2}{|c|}{ Volume } \\
\hline \multicolumn{2}{|c|}{$|c|$} \\
\hline
\end{tabular}

A tabela 43 mostra as condições de contorno aplicadas na geometria para obtenção da eficiência de mistura. No volume é resolvida numericamente a equação 
de difusão-convecção com difusão artificial Streamline diffusion - Petrov-Galerkin / Compensated. O coeficiente de difusão adotado foi de $1 \cdot 10^{-8} \mathrm{~m}^{2} / \mathrm{s}$. Nas faces são aplicadas as seguintes condições: (a) na entrada um perfil de concentração, (b) na saída condição de fluxo convectivo e (c) nas paredes condição de isolamento/simetria. A eficiência de mistura será calculada em função dos 04 campos de velocidades obtidos anteriormente para Re entre 0,01 e 10, totalizando 04 simulações.

A tabela 44 mostra a discretização da geometria utilizando o elemento tetraedro, com tamanho global de $65 \mu \mathrm{m}$ e tamanho local de $24 \mu \mathrm{m}$.

Tabela 44. Estudo 6.1: Discretização da geometria.

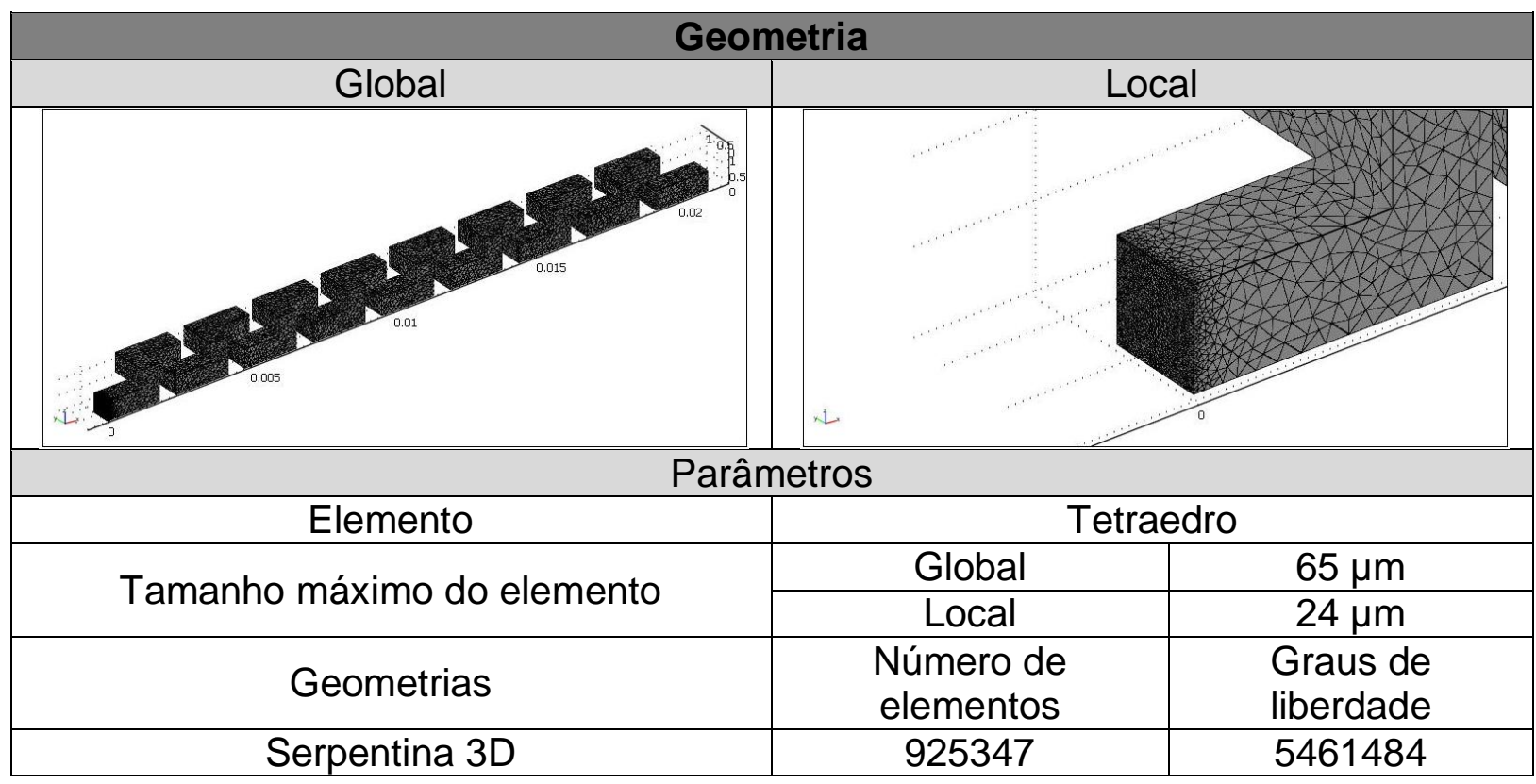

Após o processamento dos modelos com o solver GMRES e pré-condicionador Geometric multigrid, os mapas de concentração foram obtidos para análise visual.

A figura 48 mostra os mapas de concentração em função do número de Reynolds. Na coluna esquerda é mostrada a evolução da mistura ao longo da geometria. Na coluna direita são mostrados os mapas de concentração na saída dos dispositivos.

Observa-se que a qualidade da mistura diminui conforme o número de Reynolds aumenta, entre 0,01 e 1. Para $R e=10$ (escolhido como ponto de trabalho), a qualidade da mistura muda de comportamento, com a geometria apresentando um bom desempenho em função da transição de regime. 

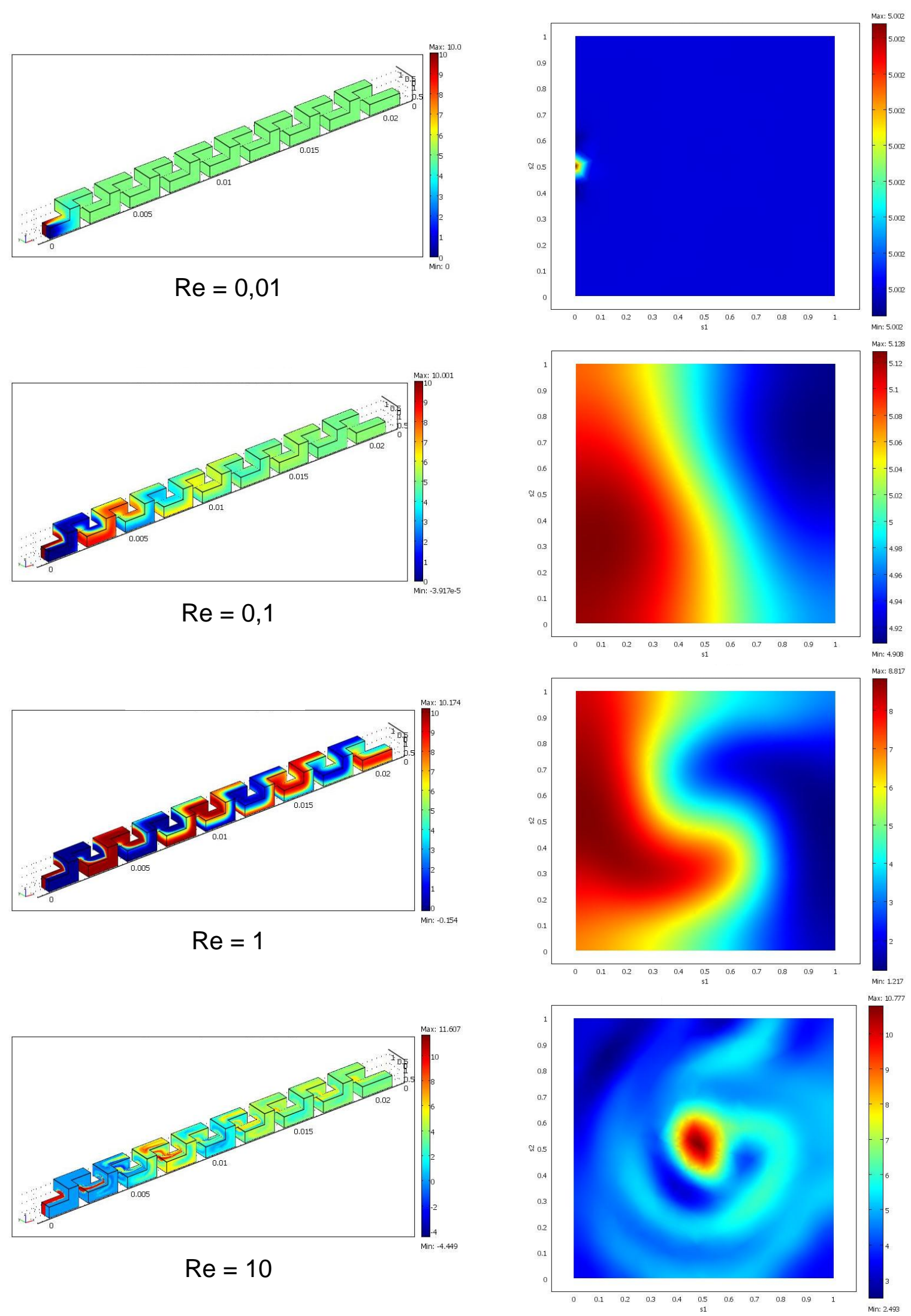

Figura 48. Mapas de concentração em função do número de Reynolds. 
É interessante comentar que conforme é feita a escolha do ponto de trabalho, a interface de contato onde ocorre a transferência de massa é intensificada, conforme pode ser observado nas saídas em função do Re da figura 48.

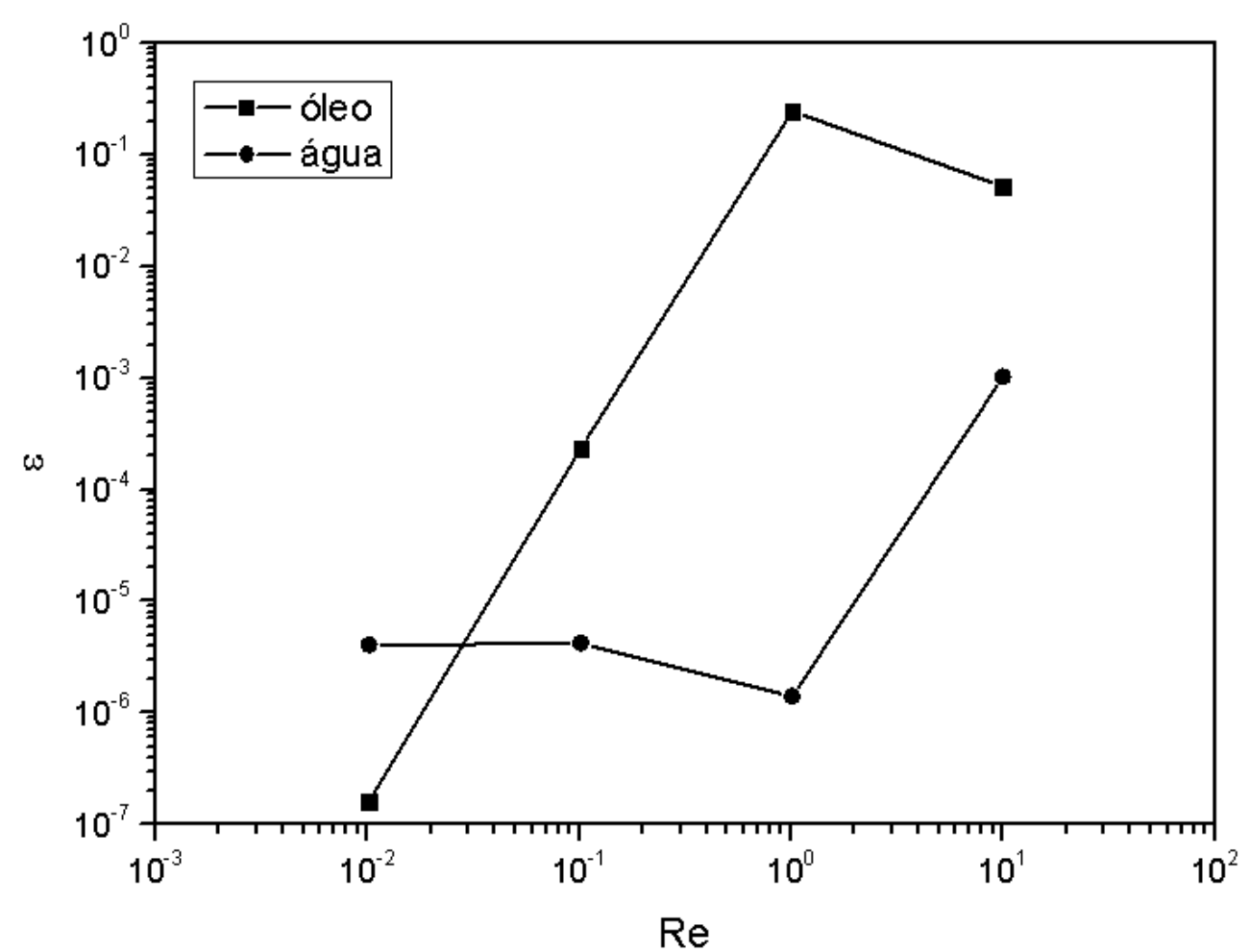

(a)

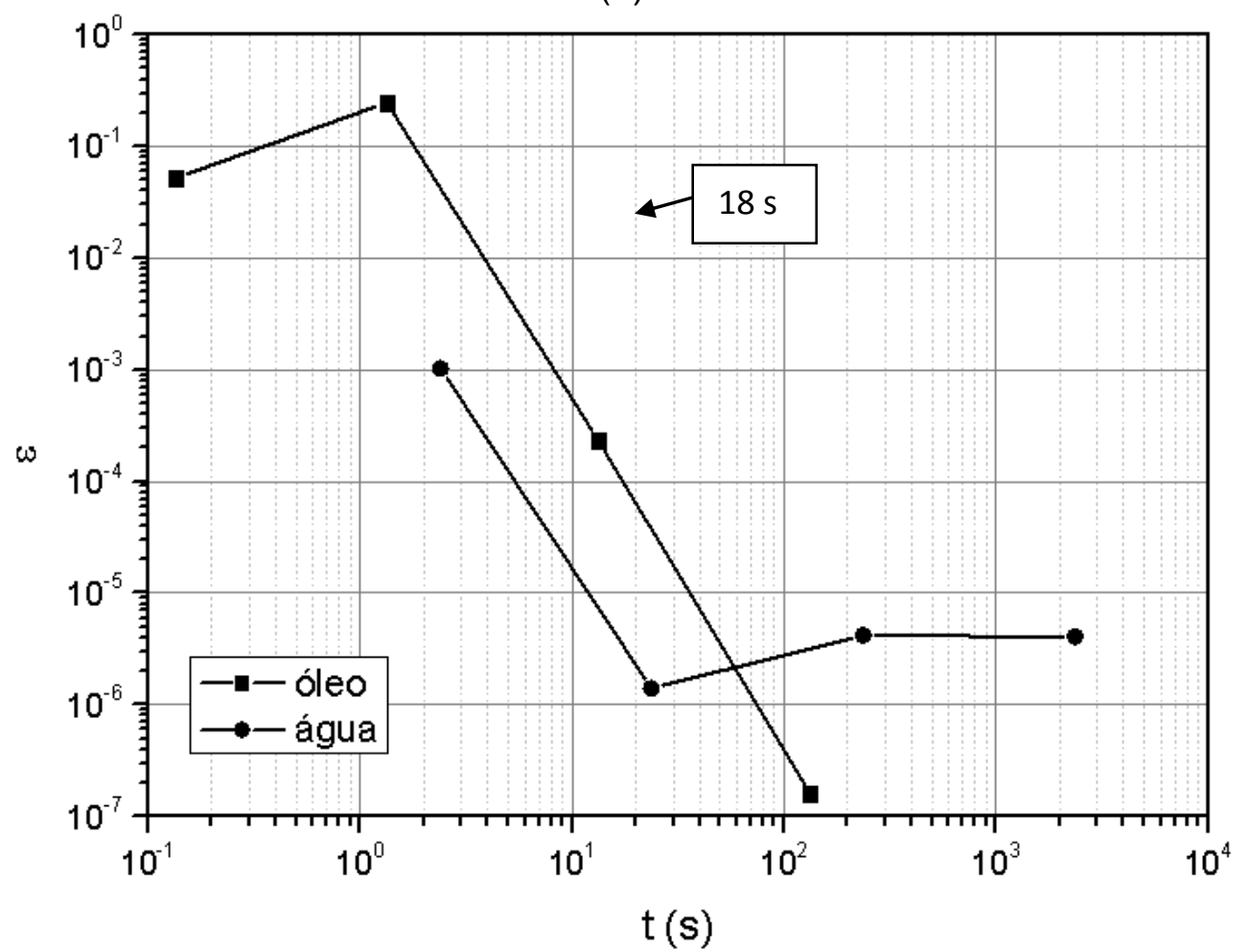

(b)

Gráfico 33. Eficiência de mistura em função do (a) número de Reynolds e (b) do tempo de residência. 
Após a visualização dos mapas de concentração, a eficiência de mistura foi obtida. O gráfico 33 mostra a eficiência de mistura em função do (a) número de Reynolds e do (b) tempo de residência. Observa-se no gráfico 33(a) que o pico representando a pior eficiência de mistura fica em $R e=1$. Após esse pico a mistura é melhorada em função da transição de regime de escoamento. Portanto, justificando a escolha do ponto de trabalho em $\mathrm{Re}=10$.

Comparando com os dados para água, o pico de pior eficiência fica em $R e=1$ para óleo, enquanto que, em $R e=10$ para água. $O$ ponto de trabalho analisado para água era em $R e=100$, enquanto que, para óleo é em $R e=10$. Essas alterações foram provocadas pela mudança das propriedades físicas do fluido de trabalho. Indicando que para cada fluido diferente sempre deve ser determinada a transição de regime para otimização da geometria.

O interessante do trabalho após a transição de regime é conseguir modular uma boa qualidade de mistura para o ponto de trabalho escolhido, $R e=10$. Por um lado, não tendo processos lentos para $R e \ll 10$. E por outro lado, não tendo processos com altas perdas de carga e alto consumo de energia para $R e>>10$.

O gráfico $33(b)$ mostra a eficiência de mistura em função do tempo de residência. Comparando a curva para óleo com o tempo de residência teórico de 18 $\mathrm{s}$, a mistura de fluidos usando a serpentina 3D 1 é efetivada com uma eficiência de mistura de aproximadamente $8 \cdot 10^{-5}$.

Esse valor será usado como referência para modular o número de seções da geometria serpentina $3 \mathrm{D} 1$, em $R e=10$, obtendo a mesma eficiência. No próximo capítulo será realizada a modulação do número de seções do micromisturador para realizar a composição com o módulo de tempo de residência.

\subsubsection{Resumo}

O estudo foi realizado com a geometria escolhida serpentina 3D 1, com 16 seções e diâmetro hidráulico de $600 \mu \mathrm{m}$. O fluido de trabalho foi o óleo a $60 \stackrel{\circ}{\circ}$, usando para o cálculo do escoamento os seguintes parâmetros: densidade de 900 $\mathrm{kg} / \mathrm{m}^{3}$ e viscosidade dinâmica de $16 \cdot 10^{-3}$ Pa's. O uso desse fluido de trabalho, relaciona diretamente este estudo ao processo de produção do biodiesel. 
Este estudo permitiu a obtenção de dois parâmetros de referência para a composição do micromisturador com o módulo de tempo de residência, que será realizado no próximo capítulo:

- Ponto de trabalho: $R e=10$;

- Eficiência de mistura: 8*10 ${ }^{-5}$.

Este ponto é referente ao regime intermediário. Portanto, o melhor ponto para o trabalho é após a transição de regime. 
4.10. Otimização de micromisturadores baseados em sucessivos cotovelos

O processo de escolha de uma geometria baseada em cotovelos sucessivos para aplicação em um processo químico usando simulações numéricas pode ser resumida com seguintes os passos:

- Estabelecer um padrão de comparação identificando os regimes de escoamento num determinado intervalo do número de Reynolds. O padrão adotado neste trabalho foi o microcanal e a investigação computacional identificou o intervalo de trabalho de Re entre 0,01 e 100 (regime de escoamento);

- Dentro do intervalo de Re estabelecido, investigaram-se os possíveis arranjos espaciais entre dois cotovelos sucessivos, bem como, as distâncias entre cotovelos mais adequadas para o projeto das geometrias;

- Determinação da transição de regime de escoamento, de laminar para intermediário, das diversas geometrias baseadas em sucessivos cotovelos, propostas em função da investigação da etapa anterior, comparando com o microcanal reto;

- Definição do parâmetro eficiência de mistura, que permitiu a escolha da geometria com melhor desempenho, serpentina 3D 1, além de estabelecer um índice de comparação entre as diversas geometrias estudadas numa determinada condição ótima escolhida em função da transição de regime de escoamento.

O processo de otimização da geometria escolhida, serpentina 3D 1, foi determinado em função dos seguintes passos:

- Determinação da transição do regime de escoamento para determinar um ponto de trabalho após a transição de regime;

- Modulação do diâmetro hidráulico para definir o tempo mínimo de processo;

- Modulação do número de seções para obter a eficiência de mistura desejada. Nesta etapa de investigação obteve-se uma importante contribuição para o estado da arte, a determinação do comportamento exponencial da eficiência de mistura em função do número de seções para a geometria serpentina 3D 1. 


\subsection{Metodologia experimental}

Paralelamente ao estudo computacional foram realizados dois estudos experimentais para verificar as características dos micromisturadores em relação ao processo de produção do biodiesel:

- Estudo 1: Produção de biodiesel - com o objetivo de verificar a viabilidade de produção e identificar as limitações do processo de produção com micromisturadores;

- Estudo 2: Produção de emulsões - com o objetivo de verificar a qualidade da emulsão gerada e estabelecer uma comparação entre as geometrias zigzag e a serpentina 3D.

\subsection{Estudo 1: Produção de Biodiesel}

Para demonstrar a viabilidade de produção de biodiesel em dispositivos microfluídicos foram realizados ensaios com uma família de dispositivos fabricados em tecnologia LTCC. As geometrias são mostradas na figura 49. Em função de problemas operacionais, apenas a geometria identificada como BIOD3, foi testada com sucesso.
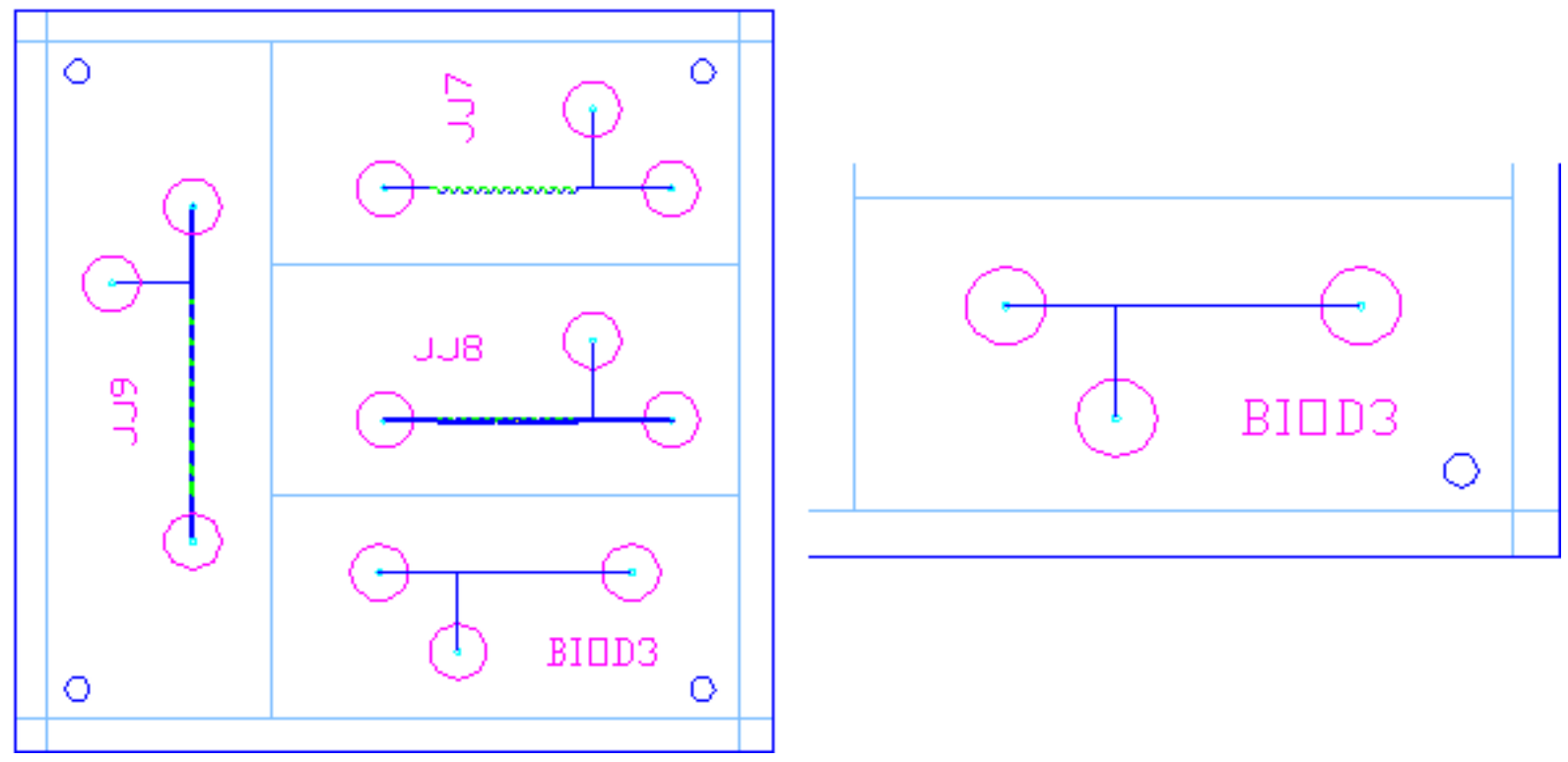

Figura 49. Geometria dos micromisturadores aplicados a produção de biodiesel. 
A geometria testada (BIOD3) é um microcanal reto com diâmetro hidráulico de $300 \mu \mathrm{m}$. O aparato experimental foi composto por duas bombas de alimentação (01 bomba de seringa e 01 bomba HPLC), um banho térmico e acoplado ao micromisturador um módulo de tempo de residência de mangueira plástica com 1,27 $\mathrm{mm}$ de diâmetro hidráulico e $2 \mathrm{~m}$ de comprimento. A figura 50 mostra a configuração do aparato experimental.
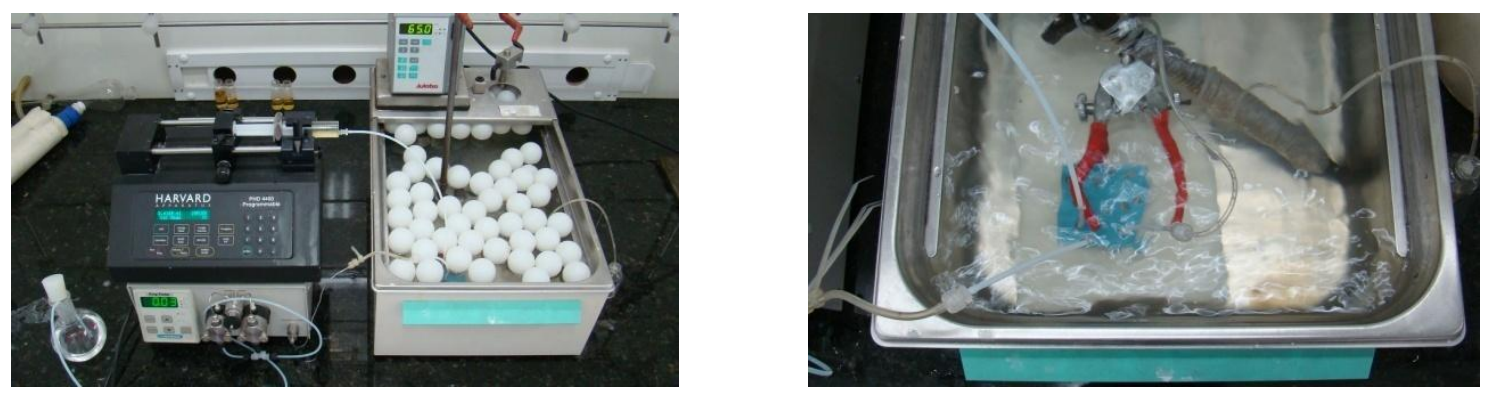

Figura 50. Aparato experimental.

Os ensaios foram realizados a temperatura de $60^{\circ} \mathrm{C}$, gerando cinco amostras conforme os parâmetros mostrados na tabela 45. O tempo de residência foi de $810 \mathrm{~s}$ a $50 \mathrm{~s}$, dependendo das vazões praticadas para cada amostra. A razão molar entre as fases (óleo:álcool) foi de 9:1. Usando álcool metanol e óleo de soja.

Tabela 45. Parâmetros dos ensaios de produção do biodiesel.

\begin{tabular}{|c|c|c|c|c|c|c|}
\hline \multirow{2}{*}{ Parâmetros } & \multicolumn{7}{|c|}{ Amostras (ml/min) } \\
\cline { 2 - 7 } & $\mathrm{A}$ & $\mathrm{B}$ & $\mathrm{C}$ & $\mathrm{D} 1$ & $\mathrm{D} 2^{\star *}$ & $\mathrm{E}$ \\
\hline $\begin{array}{c}\text { Fase } 1 \\
\text { (óleo) }^{*}\end{array}$ & 0,125 & 0,25 & 0,5 & 1 & 0,25 & 2 \\
\hline $\begin{array}{c}\text { Fase 2 } \\
\text { (álcool }^{*} \text { ) }\end{array}$ & 0,0625 & 0,125 & 0,25 & 0,5 & 0,125 & 1 \\
\hline
\end{tabular}

As amostras geradas são mostradas na figura 51. Observa-se no fundo de cada recipiente uma fase com coloração mais escura. Esta fase é a glicerina gerada no processo que tem peso molecular maior que os ésteres (biodiesel).

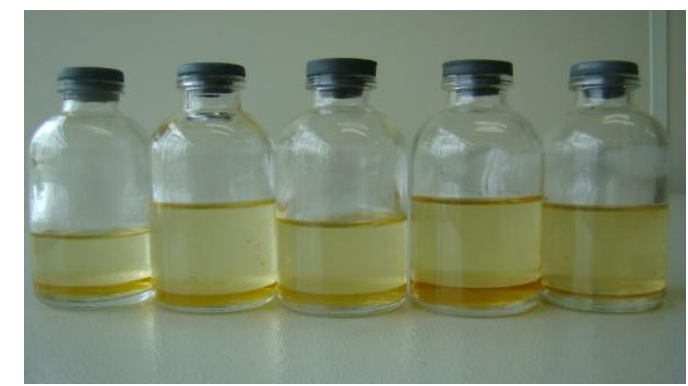

Figura 51. Amostras geradas nos ensaios de produção do biodiesel. 
A tabela 46 mostra os resultados obtidos por cromatografia gasosa para seis amostras geradas nesses ensaios (A, B, C, D1, D2 e E).

Tabela 46. Resultados obtidos por cromatografia gasosa.

\begin{tabular}{|c|c|c|c|c|c|c|c|c|}
\hline & REF & A & B & C & D1 & D2 & E & Especificação ANP \\
\hline Monoglicerídeos & 0,77 & 0,38 & 0,83 & 0,77 & 0,68 & 3,35 & 4,62 & anotar \\
\hline Diglicerídeos & 0,58 & 6,33 & 9,91 & 9,75 & 4,88 & 1,63 & 4,87 & anotar \\
\hline Triglicerídeos & 0,47 & 85,57 & 99,91 & 57,37 & 17,70 & 25,45 & 51,83 & anotar \\
\hline & \multicolumn{7}{|c|}{} \\
\hline Glicerol $(\% \mathrm{~m} / \mathrm{m})$ & 0,0014 & 0,14 & 0,24 & 0,24 & 0,09 & 10,64 & 2,14 & $0,02 \% \mathrm{~m} / \mathrm{m}$ \\
\hline Glicerina total $(\% \mathrm{~m} / \mathrm{m})$ & 0,33 & 10,12 & 12,36 & 7,88 & 2,84 & 14,40 & 9,47 & $0,25 \% \mathrm{~m} / \mathrm{m}$ \\
\hline
\end{tabular}

Os resultados mostram a formação de biodiesel e glicerina. Comparando com uma amostra de referência (REF) pode-se concluir que os resultados são pobres, pois cada amostra gerada apresentou diferenças significativas em relação a REF. Apenas a amostra D1 apresentou 03 dos 05 parâmetros analisados próximos da REF.

Estes resultados mostram a necessidade de se estabelecer uma metodologia de escolha e otimização de geometrias para micromisturadores para aplicação no processo de produção do biodiesel.

\subsection{Estudo 2: Produção de emulsões}

Este estudo tem por objetivo estabelecer uma comparação entre as geometrias zigzag 2 (Estudo 4) e a serpentina 3D 1 (Estudo 5) e verificar a qualidade da emulsão gerada por estes dispositivos, para viabilizar a produção de emulsão como uma etapa do processo de produção do biodiesel.

Com base nos resultados numéricos foram escolhidas duas geometrias para serem fabricadas: zigzag 2 e serpentina 3D 1. Foram fabricados em tecnologia LTCC os dispositivos com dois diâmetros diferentes $(600 \mu \mathrm{m}$ e $400 \mu \mathrm{m})$ e três números de seções diferentes (20, 40 e 80), totalizando 12 dispositivos. A figura 52 mostra o projeto em CAD de alguns dispositivos e a foto dos fabricados. 

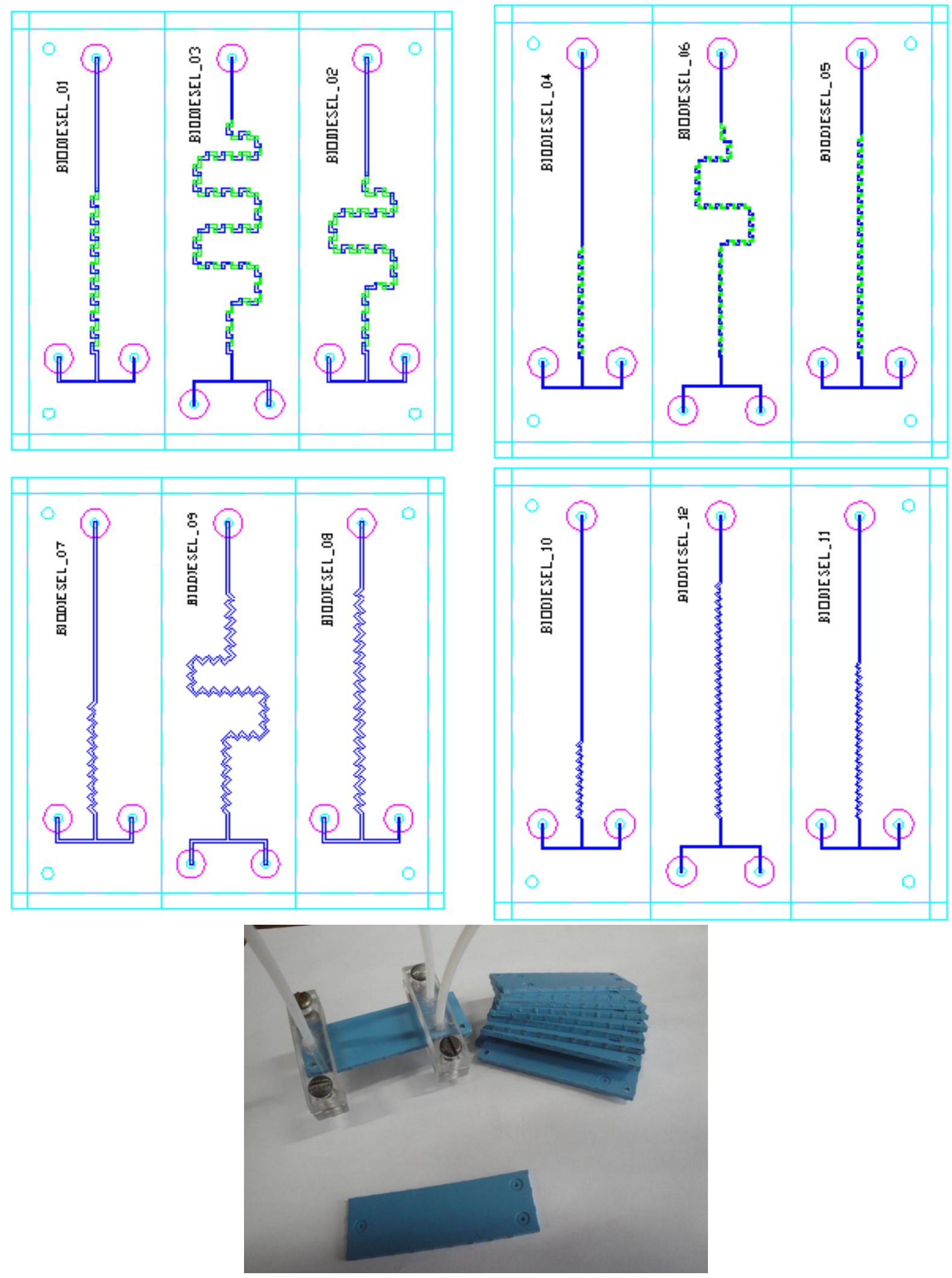

Figura 52. Projeto em CAD e dispositivos fabricados.

Os dispositivos foram caracterizados para determinação da perda de carga. As emulsões foram produzidas usando óleo de soja/álcool metanol. E caracterizadas 
por (1) espalhamento de luz para obter o tamanho da gota e por (2) turbidimetria (Turbiscan - CTPP/IPT) para medir a estabilidade da emulsão.

As medidas de perda de carga foram realizadas com um sensor de pressão absoluto de 1000 mbar de fundo de escala. Foram realizadas medidas em triplicatas para cada ponto. As curvas médias são mostradas no gráfico 34.

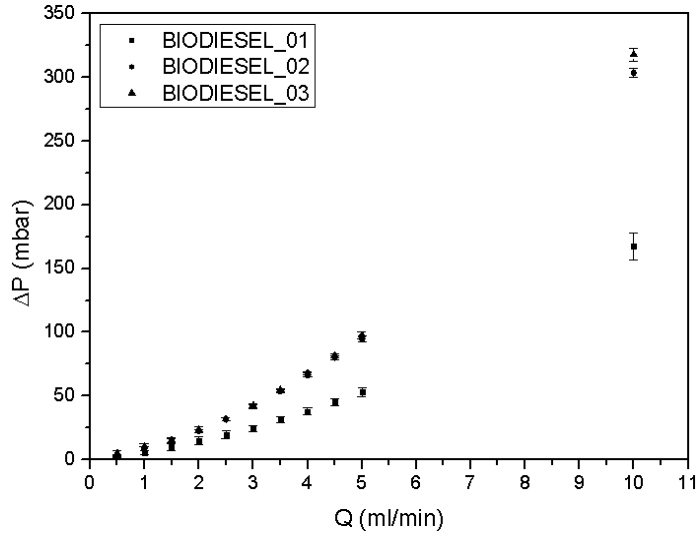

(a)

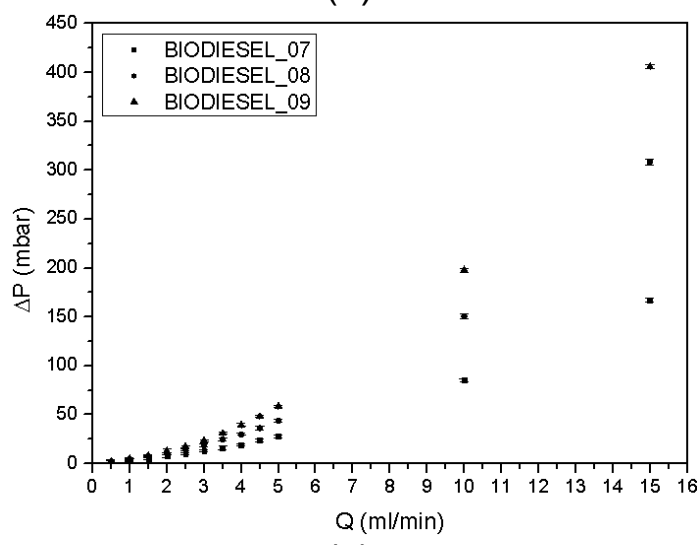

(c)

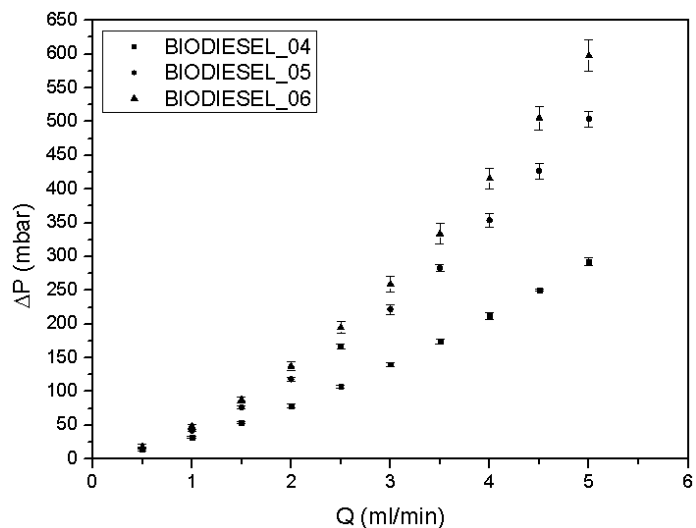

(b)

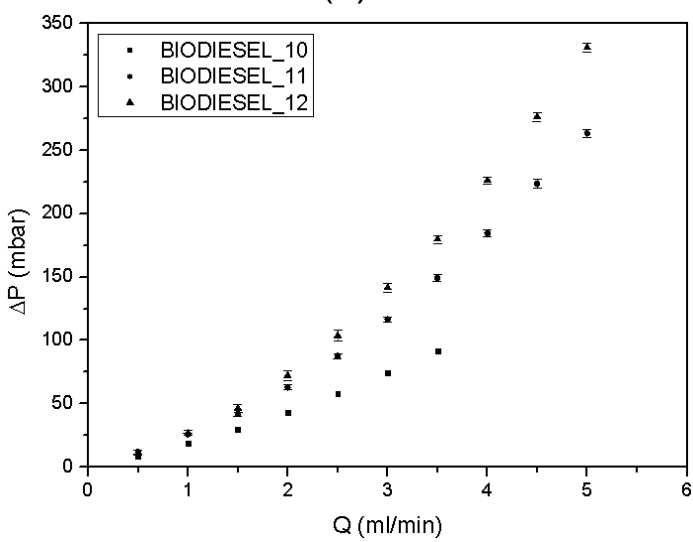

(d)

Gráfico 34, medidas de perda de carga: (a) BIODIESEL_01, 02 e 03, (b) BIODIESEL_04, 05 e 06, (c) BIODIESEL_07, 08 e 09 e (d) BIODIESEL_10, 11 e 12.

Observa-se que as curvas apresentadas no gráfico 34, para os diversos dispositivos estudados, são não-lineares. Este resultado conduz a um comportamento de regime de escoamento diferente do regime laminar, onde se tem a relação linear para diferença de pressão dada pela equação

$$
\Delta P=R_{h} \cdot Q
$$

onde $\Delta \mathrm{P}$ é a diferença de pressão, $\mathrm{R}_{\mathrm{h}}$ é a resistência hidraúlica e $\mathrm{Q}$ é a vazão.

Após caracterização fluidodinâmica, com a obtenção dos dados de perda de carga, foram realizados os ensaios para obtenção da emulsões. 
As emulsões foram produzidas utilizando a razão em volume de 1:4 (álcool/óleo), com $2 \%$ (v/v) de tensoativo SPAN 80 no óleo, vazão total de $30 \mathrm{ml} / \mathrm{min}$ e temperatura de $50 \stackrel{\circ}{ }$, para os dispositivos BIODIESEL_03 (serpentina 3D 1 - 80 seções, $D_{h}=600 \mu \mathrm{m}$ ) e BIODIESEL_09 (zigzag $2-80$ seções, $D_{h}=600 \mu \mathrm{m}$ ).

O gráfico 35 mostra as distribuições de tamanho de partículas para (a) BIODIESEL_03 e (b) BIODIESEL_09. Os resultados indicam que o dispositivo BIODIESEL_03, baseado na geometria serpentina3D 1 mostrou um melhor desempenho em relação ao BIODIESEL_09, baseado na geometria zigzag 2.

Os ensaios com a geometria 3D 1 geraram uma emulsão com diâmetro médio de gota de 11,96 $\mu \mathrm{m}$, enquanto que, os ensaios com a geometria zigzag 2 geraram uma emulsão com diâmetro médio de gota de 241,8 $\mu \mathrm{m}$.

Estes resultados comprovam os obtidos numericamente, que a geometria serpentina 3D apresenta uma intensificação da superfície de contato entre as fases, superior ao obtido com a geometria zigzag 2.

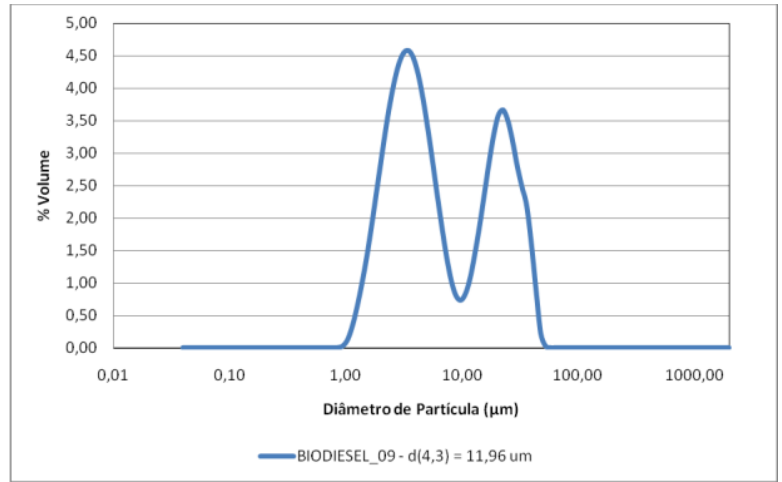

(a)

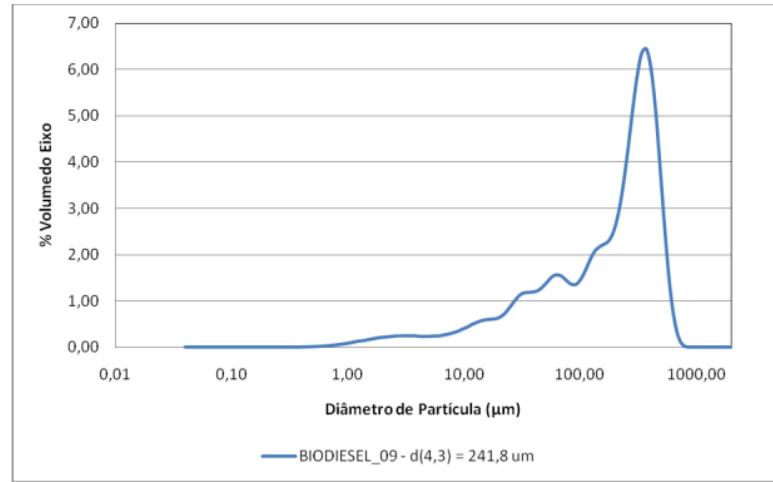

(b)

Gráfico 35. Distribuição de tamanho de partícula: (a) BIODIESEL_03 e (b) BIODIESEL_09.

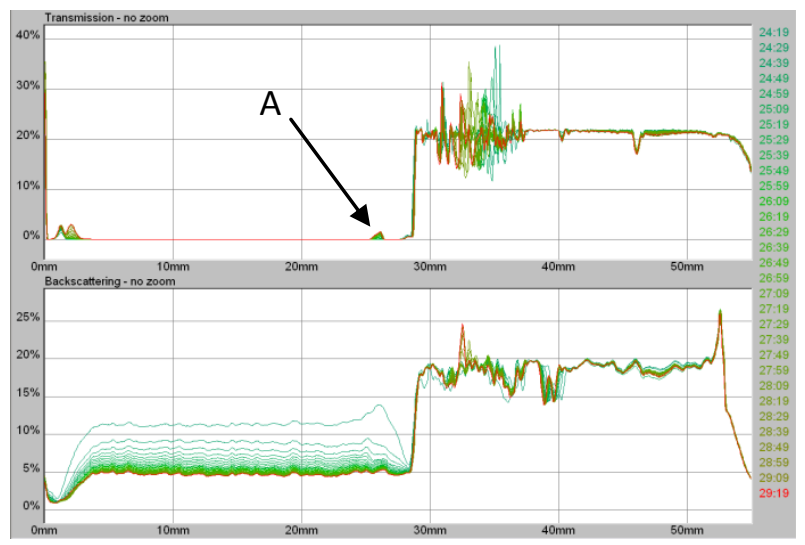

(a)

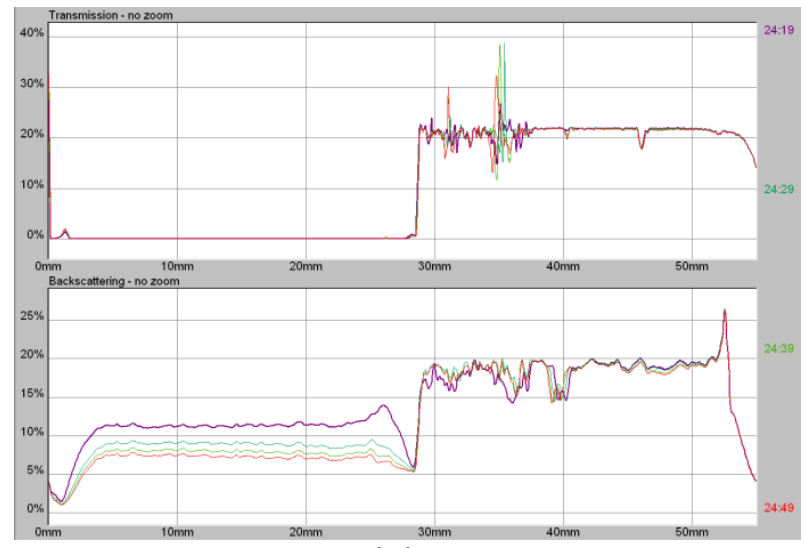

(b)

Gráfico 36. Estabilidade da emulsão produzida com BIODIESEL_03 para 5 horas e $30 \mathrm{~min}$. 
O gráfico 36 mostra a medida de estabilidade para emulsão preparada com o dispositivo BIODIESEL_03. O gráfico indica a separação de fase $(A)$ entre o óleo e álcool durante o período de medição de 05 cinco horas. Observa-se também que na primeira meia-hora não houve separação de fase, sendo assim possível efetivar a reação de biodiesel conforme os tempos de residência encontrados na literatura.

Os resultados apresentados indicam que a produção de uma emulsão como uma etapa para produção de BIODIESEL é viável. Logo, a composição de um micromisturador para produção de biodiesel com módulo de tempo de residência será explorada no próximo capítulo.

\subsection{Conclusões preliminares}

Neste capítulo foram desenvolvidos estudos computacionais e experimentais para investigar os micromisturadores com foco no problema de intensificação da superfície de contato entre dois fluidos. A seguir apresenta-se a síntese desses estudos com as principais observações.

O estudo computacional 1 foi realizado com três microcanais retos com diâmetros hidráulicos diferentes ( $1 \mathrm{~mm}, 100 \mu \mathrm{m}$ e $10 \mu \mathrm{m}$ ), no intervalo do número de Reynolds entre 0,01 e 2000.

A visualização dos mapas de velocidade permitiu identificar dois regimes de escoamento. Com a obtenção dos parâmetros numéricos foi possível identificar o regime de escoamento laminar no intervalo do número de Reynolds entre 0,01 e 100. No intervalo do número de Reynolds entre 100 e 2000, o regime de escoamento é intermediário entre o laminar e o turbulento. Essa transição de regime para canais em macro-escala é registrada na literatura para número de Reynolds entre 1000 e 2000.

A obtenção dos parâmetros numéricos permitiu verificar alguns comportamentos no intervalo do regime laminar:

- O fator de atrito é inversamente proporcional ao número de Reynolds,

- O coeficiente de perda de carga é inversamente proporcional ao número de Reynolds,

- A vorticidade é diretamente proporcional ao número de Reynolds, 
- A diferença de pressão é diretamente proporcional a vazão e relacionados por uma constante de proporcionalidade chamada resistência hidráulica,

- O tempo de residência é inversamente proporcional a vazão,

- O tempo de residência é inversamente proporcional a diferença de pressão,

- O tempo de residência é inversamente proporcional a potência volumétrica, e

- A potência volumétrica é diretamente proporcional a vazão.

Os próximos estudos foram conduzidos no intervalo do número de Reynolds entre 0,01 e 100, que é o intervalo conhecido de regime laminar em microcanais retos. Esse procedimento será adotado para comparação com os microcanais baseados em sucessivos cotovelos.

O estudo computacional 2 foi realizado com três estruturas com diferentes configurações espaciais entre dois cotovelos sucessivos, no intervalo do número de Reynolds entre 0,01 e 100 .

A visualização dos mapas do campo de velocidades permitiu identificar uma distinta descrição das linhas de campo, para $R e=100$, quando comparada com a descrição encontrada em outros valores de Re, no intervalo estudado.

Com a obtenção dos parâmetros numéricos foi possível identificar a combinação de uma vorticidade constante e uma perda de carga reduzida em função da diminuição da distância entre cotovelos.

Além disso, a redução da distância entre os cotovelos induz a geração de pontos com alta velocidade no escoamento, permitindo a escolha de distâncias entre os cotovelos para serem investigadas no próximo estudo:

- Estrutura $1-\mathrm{dec}=2$,

- Estrutura 2- dec $=1$ e 2, e

- Estrura 3- dec $=1$ e 2 .

O estudo computacional 3 foi realizado com nove geometrias, um microcanal reto e oito geometrias baseadas em sucessivos cotovelos, para o intervalo de número de Reynolds entre 0,01 e 100. Para estabelecer a comparação entre as geometrias foi definido um diâmetro hidráulico comum entre elas de $400 \mu \mathrm{m}$ e um comprimento comum de $L=20 \cdot D_{h}$, resultando assim em volumes iguais para todas as geometrias estudas. 
A visualização dos mapas de velocidade permitiu identificar dois regimes de escoamento, regime laminar, para Re entre 0,01 e 10, e regime intermediário, para Re entre 10 e 100. A obtenção dos parâmetros numéricos permitiu identificar que a transição de regime ocorre a partir de $\operatorname{Re}=10$. $E m \operatorname{Re}=100$, o regime já é intermediário com presença de advecção caótica.

Verificou-se que a advecção caótica não ocorre em regime laminar e começa a ser apreciada em regime intermediário.

A eficiência de mistura também foi estudada. A visualização dos mapas de concentração permitiu identificar a influência das distâncias entre os cotovelos, identificadas no estudo 2 para o projeto das geometrias deste estudo, na qualidade da mistura. Bem como, a influência do regime de escoamento na qualidade da mistura. Portanto, verificou- se as seguintes melhores eficiências de mistura

- Onda quadrada 2 melhor que onda quadrada 1;

- Zigzag 2 melhor que zigzag 1;

- Serpentina 3D 1 melhor que serpentina 3D 2;

- Zigzag 3D 1 melhor que zigzag 3D 2; e

- Geometrias 3D melhores que geometrias 2D.

Logo, as melhores distâncias entre cotovelos foram:

- Estrutura 1: dec = 2,

- Estrutura 2: dec $=2$, e

- Estrutura 3: $\mathrm{dec}=1$.

Com a obtenção dos dados numéricos de eficiência de mistura confirmou-se as conclusões visualizadas nos mapas de concentração e permitiu estabelecer um índice de comparação de desempenho entre as geometrias estudadas para $\mathrm{Re}=$ 100. Destaque dado para a geometria zigzag 3D 1 que apresenta desempenho 09 vezes melhor que o microcanal reto, e para geometria serpentina 3D 1 que apresenta desempenho 19 vezes melhor que o microcanal reto.

A geometria zigzag 3D 1 foi fruto da investigação realizada no estudo 2. Este estudo identificou os possíveis arranjos espaciais entre cotovelos, bem como, as melhores distâncias entre os cotovelos para os arranjos identificados, permitindo a proposição e investigação dessa geometria. Apesar da geometria zigzag 3D 1 não apresentar a mesma performance da geometria serpentina 3D 1, ela também é uma geometria de alta performance em comparação ao encontrado no estado da 
arte. Portanto, a geometria zigzag 3D 1 é uma contribuição original ao estado da arte dos micromisturadores.

A mudança de regime permitiu identificar para a geometria serpentina $3 D 1$ pontos de mesma eficiência de mistura para tempos de residência diferentes em duas ordem de grandeza. Ou seja, uma otimização do tempo de processo em $10^{2}$.

Para finalizar, considerando as distâncias entre os cotovelos mais efetivas, restaram apenas 04 geometrias baseadas em sucessivos cotovelos, como mostradas na tabela 47. Observando a tabela, verifica-se que o pior caso foi a geometria zigzag 2, enquanto, o melhor caso foi a serpentina 3D 1. Com estas duas geometrias foram conduzidos os próximos estudos.

A geometria zigzag 2 é uma geometria aplicada com sucesso a produção de biodiesel (Wen, 2009). Suas características foram investigadas e comparadas com a geometria serpentina 3D 1, a escolhida para o processo de produção do biodiesel.

Tabela 47. Índice de comparação do desempenho das geometrias estudadas para $\operatorname{Re}=100$.

\begin{tabular}{|c|c|}
\hline Dispositivos & Índice de comparação \\
\hline onda quadrada 2 & $\mathbf{2 , 9 1}$ \\
\hline zigzag 2 & $\mathbf{1 , 7 4}$ \\
\hline serpentina 3D 1 & 19,23 \\
\hline zigzag 3D 1 & $\mathbf{9 , 0 2}$ \\
\hline
\end{tabular}

O estudo computacional 4 foi realizado com 10 geometrias baseadas em zigzag, com dimensões fixas, volume, diâmetro hidráulico e comprimento. Foi modulado número de seções que compõe a geometria zigzag de 1 a 10.

Foi possível identificar os regimes de escoamento que as geometrias trabalharam no intervalo de Re estudado, de 0,01 a 100, em função da visualização dos mapas de velocidade e dos parâmetros fluidodinâmicos obtidos numericamente:

- regime de escoamento laminar para Re entre 0,01 e 10, e

- regime de escoamento intermediário para Re entre 10 e 100.

A eficiência de mistura foi melhorada em uma ordem de grandeza em função da modulação do número de seções. A tabela 48 mostra a comparação da eficiência de mistura relativamente a uma seção. 
Tabela 48. Comparação da eficiência de mistura relativamente a uma seção

\begin{tabular}{|c|c|}
\hline Número de seções & Eficiência relativa $(\mathrm{Re}=100 / \mathrm{t}=0,07 \mathrm{~s})$ \\
\hline 1 & 1,00 \\
\hline 2 & 1,41 \\
\hline 3 & 1,47 \\
\hline 4 & 1,85 \\
\hline 5 & 1,73 \\
\hline 6 & 2,82 \\
\hline 7 & 3,20 \\
\hline 8 & 2,93 \\
\hline 9 & 3,36 \\
\hline 10 & 10,47 \\
\hline
\end{tabular}

O estudo computacional 5 foi realizado para extrair as características da geometria serpentina 3D 1 para mistura de fluidos. Para alcançar este objetivo foi estudada a influência do $D_{h}$ e do número de seção na eficiência de mistura.

Primeiro definiu-se $\mathrm{o}$ intervalo de trabalho com a análise dos mapas $\mathrm{e}$ parâmetros fluidodinâmicos. O regime intermediário de interesse foi encontrado para Re entre 10 e 100, pois nessa região com a geometria serpentina 3D 1 efetiva-se mistura com parâmetros de processo desejáveis.

Trabalhando a eficiência de mistura conseguiu-se isolar e entender a influência da variação do diâmetro hidráulico e o do número de seções no desempenho desta geometria. A diminuição do diâmetro hidráulico conduz a processos mais rápidos mantendo a qualidade de mistura constante. $O$ aumento do número de seções conduz a processos mais eficientes. A tabela 49 mostra a eficiência de mistura relativa a geometria com 1 seção, para $R e=10$ e $R e=100$. Observa-se que 0 aumento do número de seções intensifica fortemente a qualidade de mistura.

Tabela 49. Índice comparativo em função do número de seções.

\begin{tabular}{|c|c|c|}
\hline Número de seções & $\begin{array}{c}\text { Eficiência relativa } \\
\mathrm{Re}=10\end{array}$ & $\begin{array}{c}\text { Eficiência relativa } \\
\mathrm{Re}=100\end{array}$ \\
\hline 1 & 1 & 1 \\
\hline 2 & 1,62 & 2,62 \\
\hline 4 & 4,84 & 17,30 \\
\hline 8 & 46,25 & 375,51 \\
\hline 16 & 660,19 & 104395,80 \\
\hline
\end{tabular}

Para quantificar essa intensificação da qualidade de mistura foi traçada a curva de eficiência de mistura em função do número de seções, conforme mostrado no gráfico 37. 


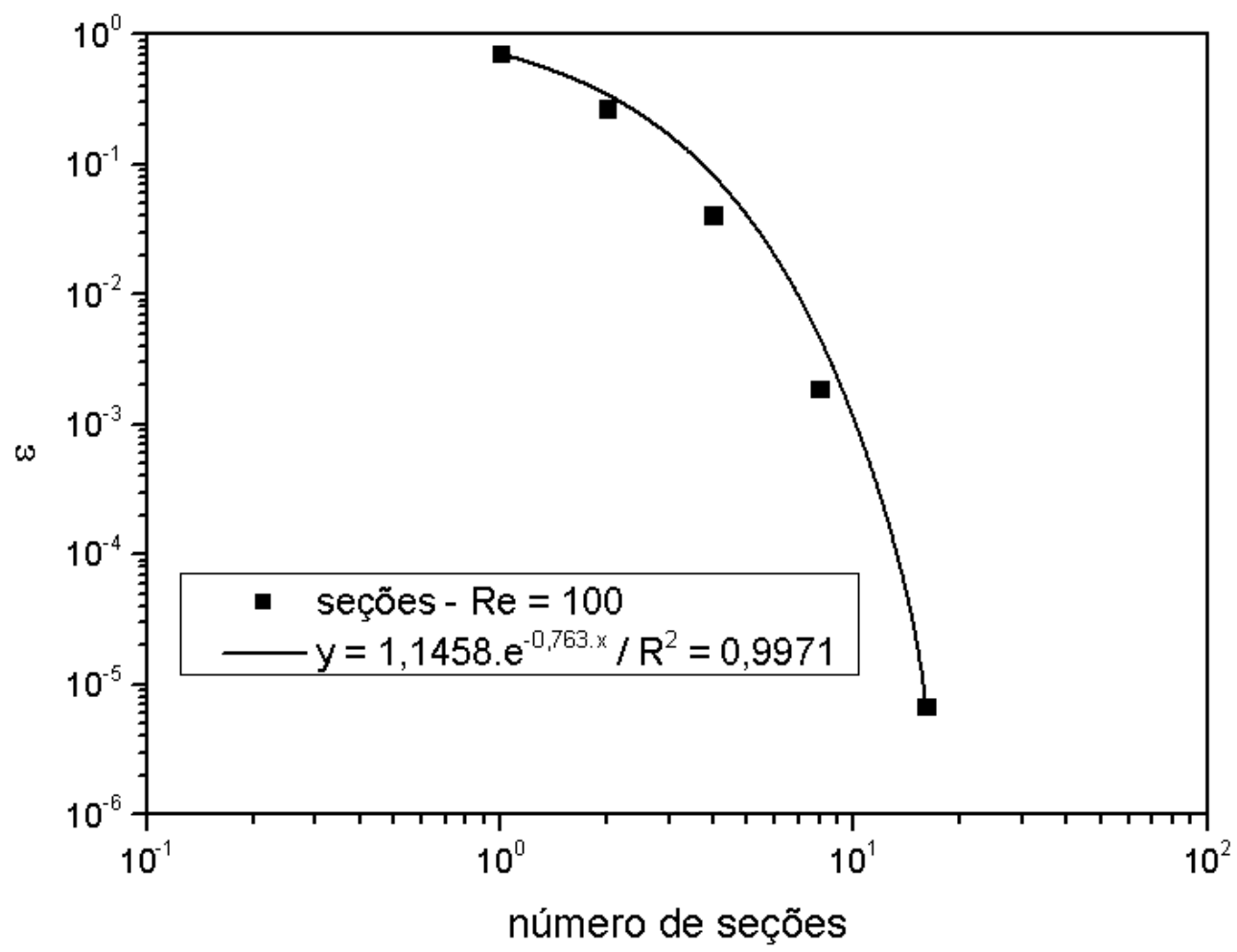

Gráfico 37. Comportamento da geometria serpentina 3D em função do número de seções.

Com este gráfico conseguiu-se determinar uma curva característica do processo realizado com a geometria serpentina $3 \mathrm{D}$ 1, mostrando um comportamento exponencial entre o aumento do número de seções e a otimização da eficiência de mistura.

A determinação do comportamento exponencial da geometria serpentina $3 D$ 1 para intensificação do processo de mistura, respeitando as condições de processo estabelecidas neste estudo, representa uma contribuição original ao estado da arte.

O estudo computacional 6 foi realizado com a geometria escolhida serpentina 3D 1, com 16 seções e diâmetro hidráulico de $600 \mu \mathrm{m}$. O fluido de trabalho foi o óleo a $60{ }^{\circ} \mathrm{C}$, usando para o cálculo do escoamento os seguintes parâmetros: densidade de $900 \mathrm{~kg} / \mathrm{m}^{3}$ e viscosidade dinâmica de $16 \cdot 10^{-3} \mathrm{~Pa}$. $\mathrm{S}$. uso desse fluido de trabalho, relaciona diretamente este estudo ao processo de produção do biodiesel.

Este estudo permitiu a obtenção de dois parâmetros de referência para a composição do micromisturador com o módulo de tempo de residência, que será realizado no capítulo 5:

- Ponto de trabalho: $\operatorname{Re}=10$; 
- Eficiência de mistura: $8 \cdot 10^{-5}$.

Em função de todos esses estudos computacionais é possível sintetizar o processo de escolha e otimização de uma geometria de micromisturador para aplicação em processos químicos, como é feito a seguir.

O processo de escolha de uma geometria baseada em cotovelos sucessivos para aplicação em um processo químico usando simulações numéricas pode ser resumida com seguintes os passos:

- Estabelecer um padrão de comparação identificando os regimes de escoamento num determinado intervalo do número de Reynolds. O padrão adotado neste trabalho foi o microcanal e a investigação computacional identificou o intervalo de trabalho de Re entre 0,01 e 100 (regime de escoamento);

- Dentro do intervalo de Re estabelecido, investigaram-se os possíveis arranjos espaciais entre dois cotovelos sucessivos, bem como, as distâncias entre cotovelos mais adequadas para o projeto das geometrias;

- Determinação da transição de regime de escoamento, de laminar para intermediário, das diversas geometrias baseadas em sucessivos cotovelos, propostas em função da investigação da etapa anterior, comparando com o microcanal reto;

- Definição do parâmetro eficiência de mistura, que permitiu a escolha da geometria com melhor desempenho, serpentina 3D 1, além de estabelecer um índice de comparação entre as diversas geometrias estudadas numa determinada condição ótima escolhida em função da transição de regime de escoamento.

O processo de otimização da geometria escolhida, serpentina 3D 1, foi determinado em função dos seguintes passos:

- Determinação da transição do regime de escoamento para determinar um ponto de trabalho após a transição de regime;

- Modulação do diâmetro hidráulico para definir o tempo mínimo de processo;

- Modulação do número de seções para obter a eficiência de mistura desejada. Nesta etapa de investigação obteve-se uma importante contribuição para o estado da arte, a determinação do comportamento exponencial da eficiência de mistura em função do número de seções para a geometria serpentina 3D 1. 
Finalizando, os estudos experimentais levaram as seguintes conclusões:

Produção de biodiesel. Os resultados mostraram a formação de biodiesel e glicerina. Comparando-se com uma amostra de referência (REF) pode-se concluir que os resultados são pobres, pois as amostras geradas apresentaram diferenças significativas em relação a uma amostra de referência. Apenas uma das amostras (D1) apresentou 03 dos 05 parâmetros analisados próximos da amostra de referência. Os resultados mostram a necessidade de se estabelecer uma metodologia de escolha e otimização de geometrias para micromisturadores para aplicação no processo de produção do biodiesel.

Produção de emulsões. Os resultados indicaram que a produção de uma emulsão como uma etapa para produção de BIODIESEL é viável. Logo, a composição de um micromisturador para produção de emulsão com módulo de tempo de residência para efetivação da reação química do processo de produção do biodiesel, será explorada no próximo capítulo.

\subsection{Referências}

Bau, Haim H., Zhong, Jihua, e Yi, Mingqiang, "A minute magneto hydro dynamic (MHD) mixer", Sensors and Actuators B, Vol. 79, 2001, pp. 207-215.

Beebe, David J.; Adrian, Ronald J.; Olsen, Michael G.; Stremler, Mark A.; Aref, Hassan e Jo, Byung-Ho, "Passive mixing in microchannels: Fabrication and flow experiments", Mec. Ind., Vol. 2, 2001, pp. 343-348.

Bengtsson, Martin e Laurell, Thomas, "Ultrasonic agitation in microchannels", Anal Bioanal Chem, Vol. 378, 2004, pp. 1716-1721.

Böhm, S.; Greiner, K.; Schlautmann, S.; de Vries, S. e van den Berg, A., "A Rapid Vortex Micromixer for Studying High-Speed Chemical Reactions", Proceedings of the HTAS 2001 Symposium, 2001, pp. 25-27.

Bottausci, Frédéric; Cardonne, Caroline; Mezić, Igor e Meinhart, Carl, "AN ACTIVELY CONTROLLED MICROMIXER: 3-D ASPECT", 0000. 
Branebjerg, Jens; Gravesen, Peter; Krog, Jens Peter e Nielsen, Claus Rye, "Fast mixing by lamination", IEEE, 1996.

Fox, R. W., e McDonald, A. T., "Introdução à Mecânica dos Fluidos", GuanabaraKoogan, $3^{\underline{a}}$ edição, 1988.

Freitas, S., Walz, A., Merkle, H. P. and Gander, B., "Solvent extraction employing a static micromixer: a simple, robust and versatile technology for the microencapsulation of proteins," Journal of microencapsulation, 2003, Vol. 20, No. 1, pp. $67-85$.

Gray, B. L., Jaeggi, D., Mourlas N. J., van Drieenhuizen, B. P., Williams, K. R., Maluf, N. I., and Kovacs G. T. A., "Novel interconnection technologies for integrated microfluidic systems," Sensors and Actuators A: Physical, Vol. 77, 1999, pp. 57-65.

Haverkamp, V., Ehrfeld, W., Gebauer, K., Hessel, V., Löwe, H., Richter, T., and Wille, C., "The potential of micromixers for contacting of disperse liquid phases", Fresenius' Journal of Analytical Chemistry, Vol. 364, 1999, pp. 617-624.

Judy, J., Maynes, D., and Webb, B. W., "Characterization of frictional pressure drop for liquid flows through microchannels", International Journal of Heat and Mass Transfer, Vol. 45, 2002, pp. 3477-3489.

Kang, Tae Gon e Kwon, Tai Hun, "Colored particle tracking method for mixing analysis of chaotic micromixers", J. Micromech. Microeng., Vol. 14, 2004, pp. 891899.

Lee, Yi-Kuen; Deval, Joanne; Tabeling, Patrick e Ho, Chih-Ming, "Chaotic Mixing in Electrokinetically and Pressure Driven Micro Flows", The $14^{\text {th }}$ IEEE Workshop on MEMS Interlaken, Switzerland, Janeiro, 2001.

$\boldsymbol{L i}$, H., and Olsen, M. G., "MicroPIV measurements of turbulent flow in square microchannels with hydraulic diameters from $200 \mu \mathrm{m}$ to $640 \mu \mathrm{m}$ ", International Journal of Heat and Fluid Flow, Vol. 27, 2006, pp. 123-134. 
Liu, R. H., Stremler, M. A., Sharp, K. V., Olsen, M. G., Santiago, J. G., Adrian, R. J., Aref, H. and Beebe, D. J., "Passive Mixing in a Three-Dimensional Serpentine Microchannel," Journal of Microelectromechanical Systems, Vol. 9, No. 2, 2000, pp. 190-197.

Mae, K., Maki, T., Hasegawa, I., Eto, U., Mizutani, Y. and Honda, N., "Development of a new micromixer based on split/recombination for mass production and its application to soap free emulsifier," Chemical Engineering Journal, 2004, Vol. 101, pp. 31-38.

Mala, G. M., and Li, D., "Flow characteristics of water in microtubes", International Journal of Heat and Fluid Flow, Vol. 20, 1999, pp. 142-148.

Mengeaud, Virginie; Josserand, Jacques e Girault, Hubert H., "Mixing Processes in a Zigzag Microchannel: Finite Element Simulations and Optical Study", Anal. Chem., Vol. 74, 2002, pp. 4279-4286.

Niu, Xize e Lee, Yi-Kuen, "Efficient spatial-temporal chaotic mixing in microchannels", J. Micromech. Microeng. Vol. 13, 2003, pp. 454-462.

Oddy, M. H.; Santiago, J. G. e Mikkelsen, J. C., "Electrokinetic Instability Micromixing", Anal. Chem., Vol. 73, 2001, pp. 5822-5832.

Park, Sung-Jin; Kim, Jung Kyung; Park, Junha; Chung, Seok; Chung, Chanil e Chang, Jun Keun, "Rapid three-dimensional passive rotation micromixer using the breakup process", J. Micromech. Microeng., Vol. 14, 2004, pp. 6-14.

Stroock, A D, Dertinger, S K, Ajdari, A, Mezic, I, Stone, H A, Whitesides, G M, Chaotic mixer for microchannels, Science, 295, 2002, pp. 647-51.

Stroock, Abraham D.; Dertinger, Stephan K.; Whitesides, George M. e Ajdari, Armand, "Patterning Flows Using Grooved Surfaces", Anal. Chem., Vol. 74, 2002, pp. 5306-5312.

Suzuki, Hiroaki e Ho, Chih-Ming, "A Magnetic Force Driven Chaotic Micro-Mixer", IEEE, 2002. 
Valencia, Alvaro e Sen, Mihir, "Unsteady flow and heat transfer in plane channels with spatially periodic vortex generators", 2002.

Vijayendran, Ravi A.; Motsegood, Kathleen M.; Beebe, David J., e Leckband, Deborah E., "Evaluation of a Three-Dimensional Micromixer in a Surface-Based Biosensor", Langmuir, Vol. 19, 2003, pp. 1824-1828.

Wang, Hengzi; lovenitti, Pio; Harvey, Erol e Masood, Syed, "Numerical investigation of mixing in microchannels with patterned grooves", J. Micromech. Microeng., Vol. 13, 2003, pp. 801-808.

Wischke, C., Lorenzen, D., Zimmermann, J., and Borchert, H. H., "Preparation of protein loaded poly $(\mathrm{D}, \mathrm{L}$-lactide-co-glycolide) microparticles for the antigen delivery to dendritic cells using a static micromixer", European Journal of Pharmaceutics and Biopharmaceutics, Vol. 62, No. 3, 2006, pp. 247-253.

Yang, Zhen; Matsumoto, Sohei; Goto, Hiroshi; Matsumoto, Mikio e Maeda, Ryutaro, "Ultrasonic micromixer for microfluidic systems", Sensors and Actuators A, Vol. 93, 2001, pp. 266-272. 


\section{MÓDULO DE TEMPO DE RESIDÊNCIA}

\subsection{Introdução}

O objetivo do módulo de tempo de residência (MTR) é compor juntamente com o micromisturador o sistema para realizar a reação química. A idéia é que o micromisturador realize uma mistura fina das fases envolvidas, enquanto o módulo de tempo de residência realize a reação química em função dos parâmetros cinéticos.

No caso da reação de produção do biodiesel sabe-se que a mistura fina entre óleo e álcool gera uma emulsão, intensificando a superfície de contato entre fases. Esse papel será realizado pelo micromisturador escolhido no capítulo anterior. Enquanto que a reação química começaria a ser processada pelo módulo de tempo de residência, na interface de contato otimizada pelo micromisturador.

Portanto, a primeira aproximação do sistema reacional é de:

- um dispositivo para a primeira etapa, geração de emulsão, com tempo $t_{1}$ de processamento, e

- um dispositivo para a segunda etapa, reação química, com tempo t $t_{2}$ de processamento.

A composição dos tempos ( $t_{1}$ e $\left.t_{2}\right)$ gerados nos dois dispositivos dará o tempo total de processamento.

$\mathrm{Na}$ prática, as duas etapas identificadas ocorrem paralelamente, com a reação controlada por uma das duas etapas. Mas serão considerados os dois dispositivos para obtenção de um tempo máximo de processo, comparando esse tempo com o que tem sido praticado na literatura, para concluir a relevância e a contribuição deste trabalho.

\subsection{Estado da arte}

O tempo de residência de um processo difusivo é dado pela equação

$$
\tau=\frac{d^{2}}{2 \cdot D} \text { (Nguyen, 2002) }
$$

eq. 20, 
onde d é uma dimensão característica do sistema de mistura e $D$ é o coeficiente de difusão. O tempo de residência de uma reação química depende de muitos parâmetros, temperatura de processo, tipo e concentração de catalisador, razão molar entre as fases. Em processos reacionais heterogêneos em que as fases envolvidas apresentam coeficientes de difusão muito baixos, normalmente fases imiscíveis, a reação química é controlada por difusão (Cussler, 2009).

Mendonça (2005) estudou em sua tese microemulsões de óleo/água, obtendo coeficientes de difusão da ordem de $10^{-12} \mathrm{~m}^{2} / \mathrm{s}$. O sistema óleo/álcool apresenta uma similaridade ao sistema estudado por Mendonça (2005) em função das fases imiscíveis que compõem estes sistemas.

Portanto, em função destas características pode-se inferir que a reação química do processo de produção do biodiesel é controlada por difusão. Ou seja, na composição de tempos de residência do micromisturador e do módulo de tempo de residência, $t_{1}>t_{2}$.

Outro fato que corrobora esta observação é a escala de tempos de residência apresentados em processos convencionais, que é da ordem de alguns minutos a algumas horas. Enquanto, processos usando a rota microtecnológica, que são mais eficientes em função (dentre outros fatores) da otimização da superfície de contato, apresentam a maioria dos resultados na escala de segundos. A tabela 50 mostra alguns resultados microtecnológicos em comparação com um processo convencional em reator batelada.

Tabela 50. Produção de biodiesel por via microtecnológica.

\begin{tabular}{|c|c|c|c|c|c|c|}
\hline Trabalhos & $\begin{array}{c}\text { Tipo de } \\
\text { misturador }\end{array}$ & $D_{h}$ & Seções & Comprimento & $\begin{array}{c}\text { Módulo de } \\
\text { tempo de } \\
\text { residência }\end{array}$ & $\begin{array}{c}\text { Tempo de } \\
\text { residência }\end{array}$ \\
\hline $\begin{array}{c}{ }^{*} \text { Nouredini } \\
(1997)\end{array}$ & $\begin{array}{c}\text { Reator } \\
\text { batelada }\end{array}$ & - & - & - & - & $\sim 90 \mathrm{~min}$ \\
\hline $\begin{array}{c}\text { Carlisle } \\
(2005)\end{array}$ & $\begin{array}{c}\text { Microcanal } \\
\text { reto }\end{array}$ & $\begin{array}{c}100 \\
\mu \mathrm{m}\end{array}$ & - & $7 \mathrm{~cm}$ & - & $45 \mathrm{~s}$ \\
\hline $\begin{array}{c}\text { Sun } \\
(2008)\end{array}$ & $\begin{array}{c}\text { Microcanal } \\
\text { reto }\end{array}$ & $\begin{array}{c}250 \\
\mu \mathrm{m}\end{array}$ & - & $30 \mathrm{~m}$ & - & $5,8 \mathrm{~min}$ \\
\hline $\begin{array}{c}\text { Wen } \\
(2009)\end{array}$ & $\begin{array}{c}\text { Microcanal } \\
\text { zigzag }\end{array}$ & $\begin{array}{c}240 \\
\mu \mathrm{m}\end{array}$ & 350 & $\sim 1 \mathrm{~m}$ & - & $28 \mathrm{~s}$ \\
\hline $\begin{array}{c}\text { Sun } \\
(2010)\end{array}$ & Diversos & $\begin{array}{c}250 \\
\mu \mathrm{m}\end{array}$ & - & - & $40 \mathrm{~cm}$ & $17 \mathrm{~s}$ \\
\hline
\end{tabular}

*processo convencional 
O trabalho de Wen (2009) é muito significativo dentro do contexto dessa tese, pois já foram apresentadas diversas comparações entre

- o microcanal zigzag aplicado a produção de biodiesel por Wen (2009), e

- o microcanal serpentina 3D, escolhido neste trabalho por apresentar as características mais favoráveis para a mistura de fluidos, dentro da família de microcanais baseados em sucessivos cotovelos.

O tempo de residência obtido por Wen (2009) é de $28 \mathrm{~s}$, com conversão de $\sim 99 \%$. Considerando a dimensão característica do microcanal zigzag utilizado podese calcular um coeficiente de difusão equivalente de

$$
D=\frac{d^{2}}{2 * \tau}=\frac{\left(240 * 10^{-6}\right)^{2}}{2 * 28}=1,0286 * 10^{-9} \mathrm{~m}^{2} / \mathrm{s},
$$

que servirá de referência para o projeto do micromisturador e do módulo de tempo de residência.

Outra referência importante é o trabalho de Sun (2010), que faz a composição de um micromisturador e um módulo de tempo de residência, mesma idéia implementada e apresentada neste trabalho (Estudo 2: Produção de Biodiesel), publicada no exame de qualificação desta tese em dezembro de 2009.

\subsection{Metodologia Computacional}

A metodologia computacional também será usada neste capítulo para resolver dois problemas:

- projetar o comprimento do microcanal serpentina 3D escolhido no capítulo sobre micromisturadores, e

- projetar um microcanal para o módulo de tempo de residência.

Com esses dois projetos será possível saber um tempo teórico para produção de biodiesel baseado em microcanais serpentina 3D.

A geometria inicial a ser trabalhada no comprimento, para obter a eficiência de mistura, é a serpentina 3D 1 de 16 seções e $600 \mu \mathrm{m}$ de diâmetro hidráulico, como mostrado na tabela 51. A idéia inicial é aumentar o número de seções a partir da geometria inicial, escolhida do estudo desenvolvido sobre micromisturadores do capítulo anterior. 
No entanto, o trabalho no comprimento tem um esforço computacional inviável, pois conforme o número de seções variarem a partir de 16, o número de elementos também começará a crescer além da capacidade da estação de trabalho disponível.

Tabela 51. Definição da geometria.

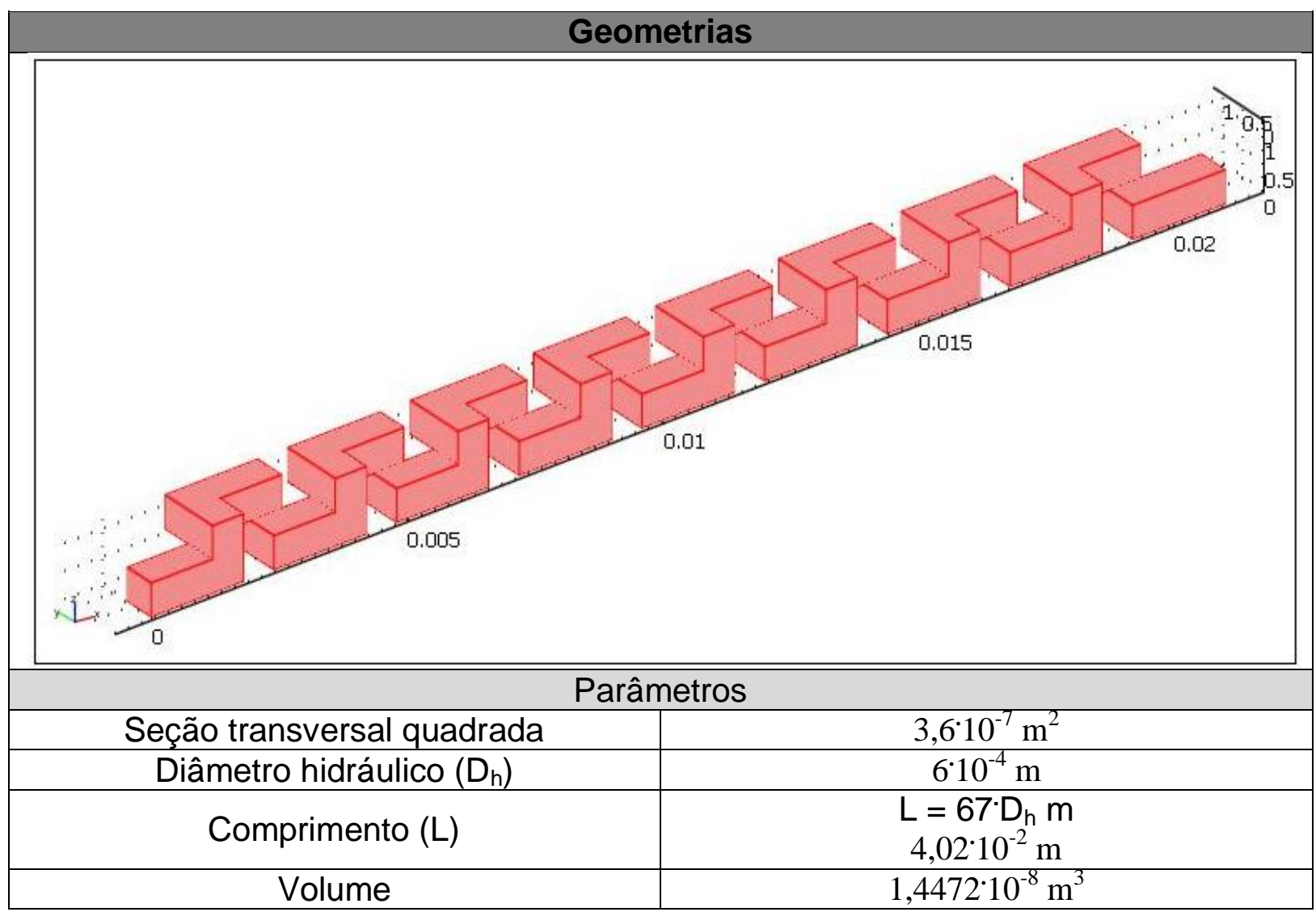

A proposta é desenvolver um método iterativo para resolver o problema. A geometria contará com 16 seções. No final de cada iteração o resultado do perfil da saída é ajustado na entrada da próxima iteração. Esse ajuste é feito obtendo-se o valor médio da saída de uma iteração e ajustando-se um perfil de concentração degrau na entrada da próxima interação. A figura 53 mostra esquematicamente o processo proposto. 


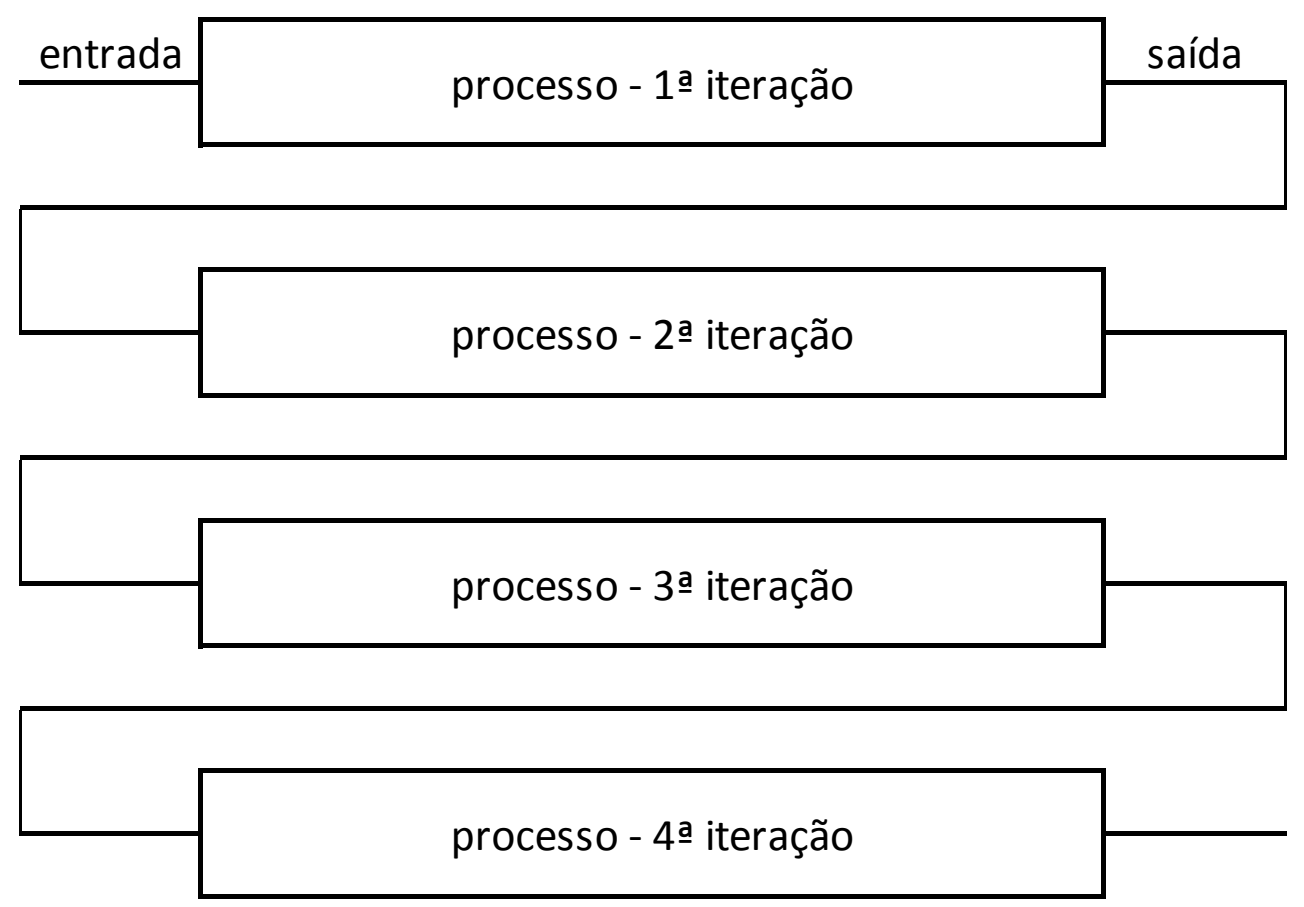

Figura 53. Desenho esquemático do processo iterativo para resolução do problema de eficiência de mistura.

As condições de contorno são mostradas na tabela 52, onde o problema é resolvido em duas etapas:

- A primeira é a resolução da equação de Navier-Stokes na forma diferencial no volume, para obter os mapas e os parâmetros fluidodinâmicos. Nas faces são aplicadas as seguintes condições: (a) perfil de velocidades uniformes parametrizados em função do número de Reynolds na entrada, (b) pressão nula na saída e (c) velocidade nula nas paredes. Foram 04 condições de Re, totalizando 04 simulações.

- A segunda é a resolução da equação de Convecção/Difusão no volume, para obter os mapas de concentração. Nas faces são aplicadas as seguintes condições: (a) perfil degrau de concentração na entrada, (b) fluxo convectivo na saída e (c) isolamento/simetria nas paredes. Foi realizado um total de 24 iterações, totalizando 24 simulações. 
Tabela 52. Condições de contorno.

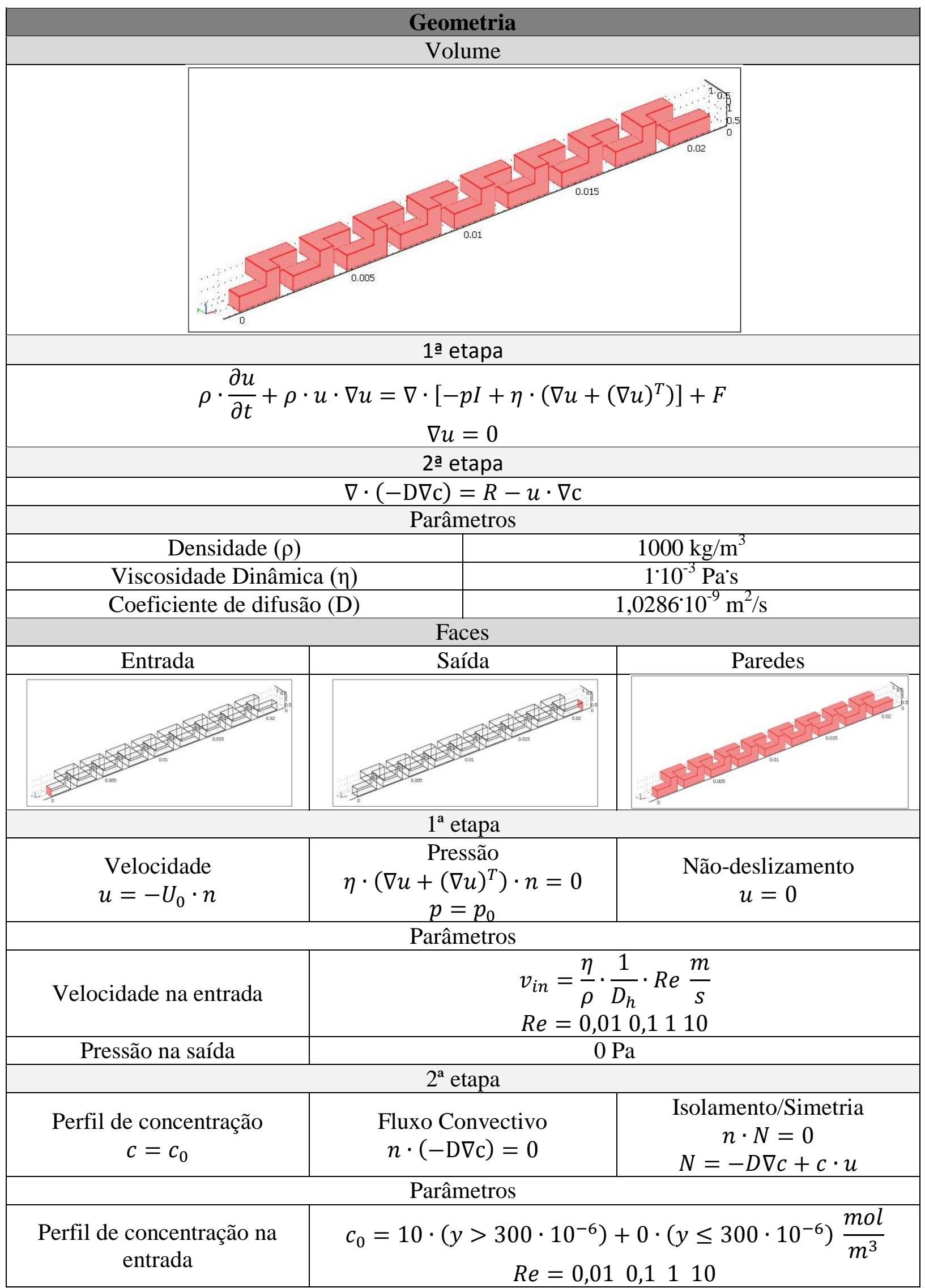


Tabela 53. Discretização.

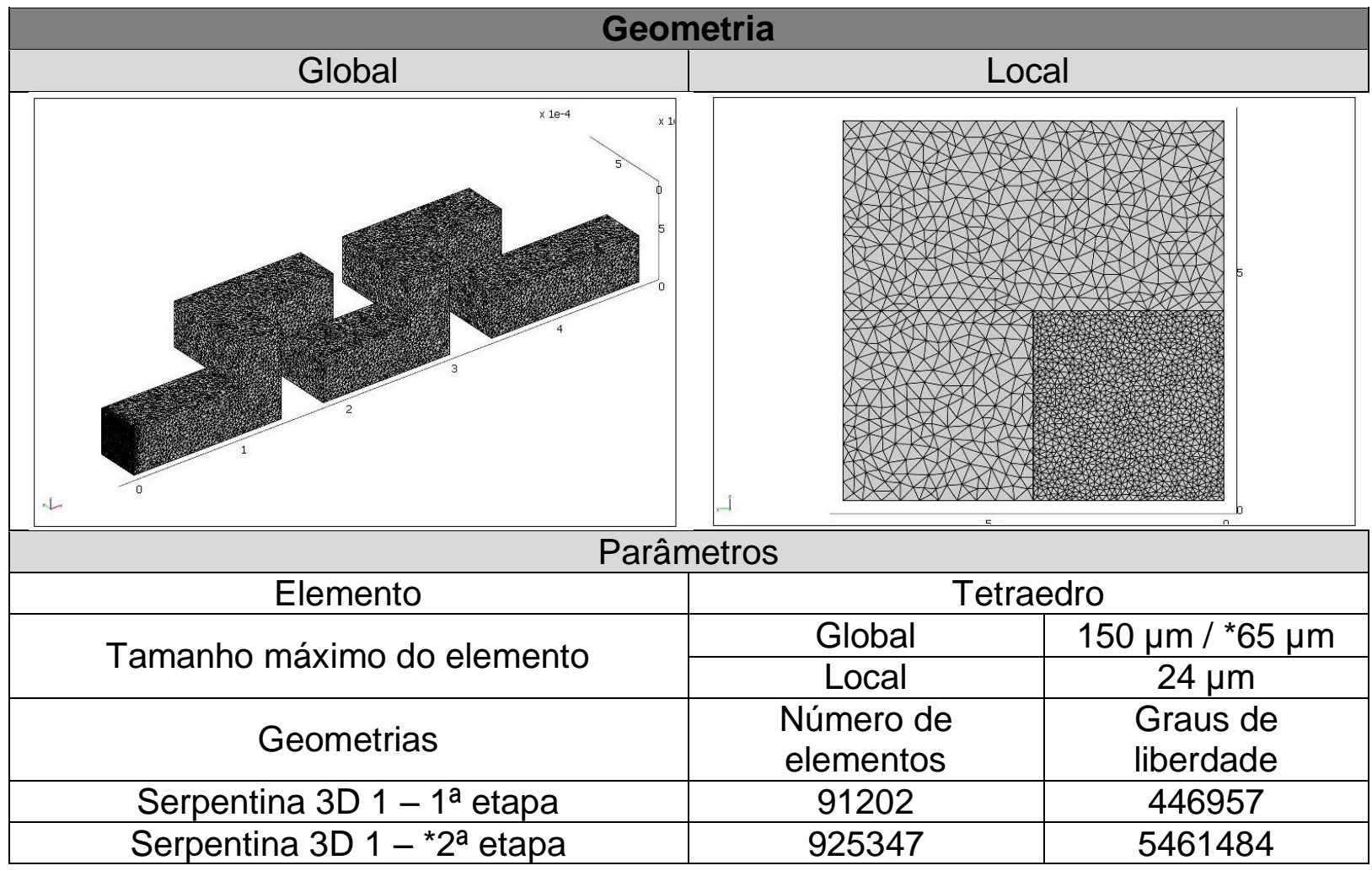

A tabela 53 mostra a discretização da malha, utilizando como elemento um tetraedro com tamanho local de malha de $24 \mu \mathrm{m}$ e tamanho global de malha de 150 $\mu \mathrm{m}$, para resolução da equação de Navier-Stokes. Para resolução da equação de convecção/difusão o tamanho da malha global foi ajustado para $65 \mu \mathrm{m}$.

\subsection{Resultados}

Foram obtidos os mapas de concentração em função das iterações para cada número de Reynolds trabalhado $(0,01 ; 0,1 ; 1$ e 10$)$. Com esses mapas foi possível avaliar a eficiência de mistura em função do número de seções para cada $R e$ trabalhado.

A figura 54 mostra a evolução dos mapas de concentração em função do número de iterações, onde entrada e saída são coluna esquerda e direita, respectivamente. Observa-se nos mapas de concentração a convergência das cores para uma coloração uniforme. Indicando que a cada iteração a qualidade de mistura foi sendo incrementada. 

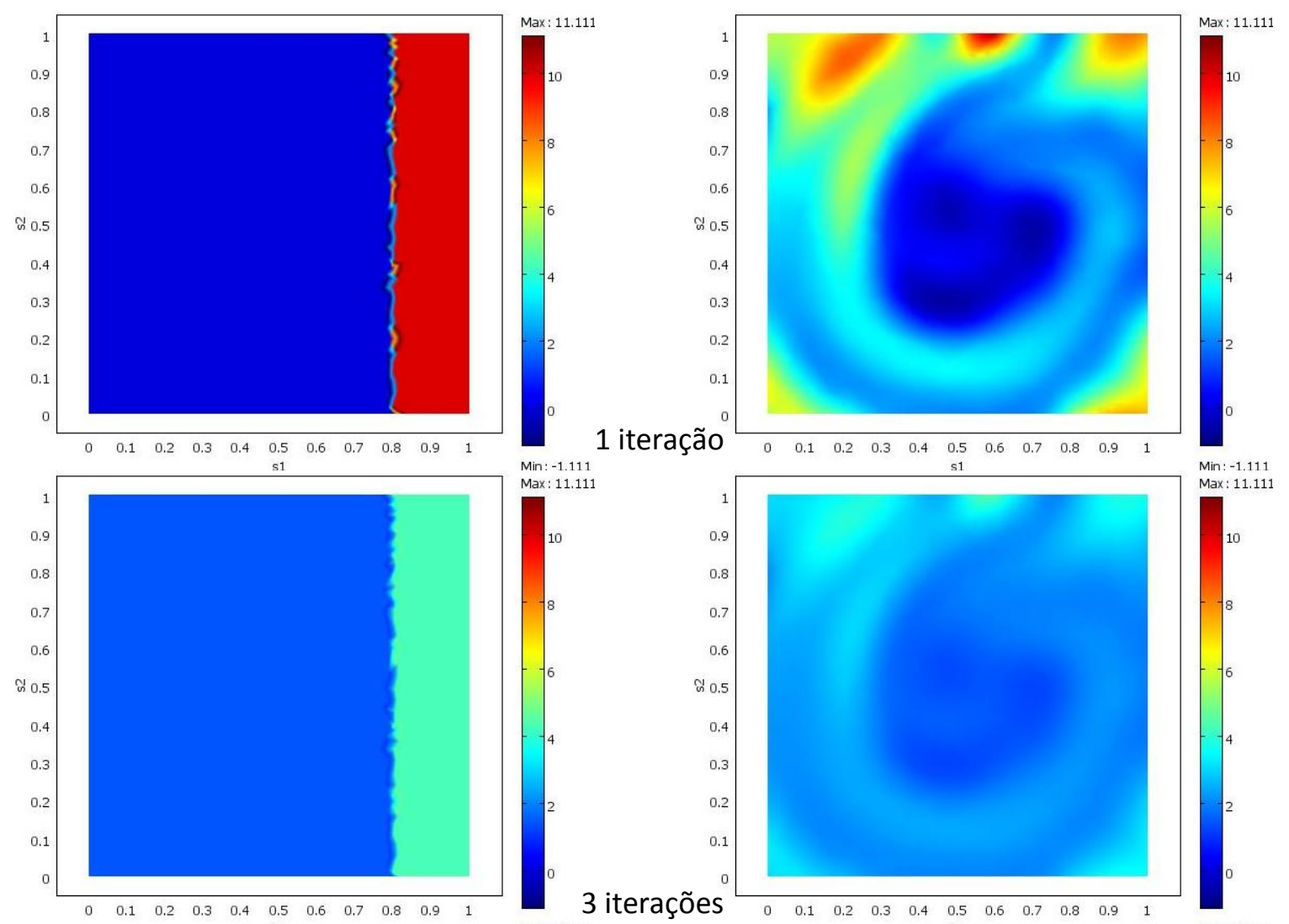
Min: $:-1.111$
Max: 11.111

1 iteração
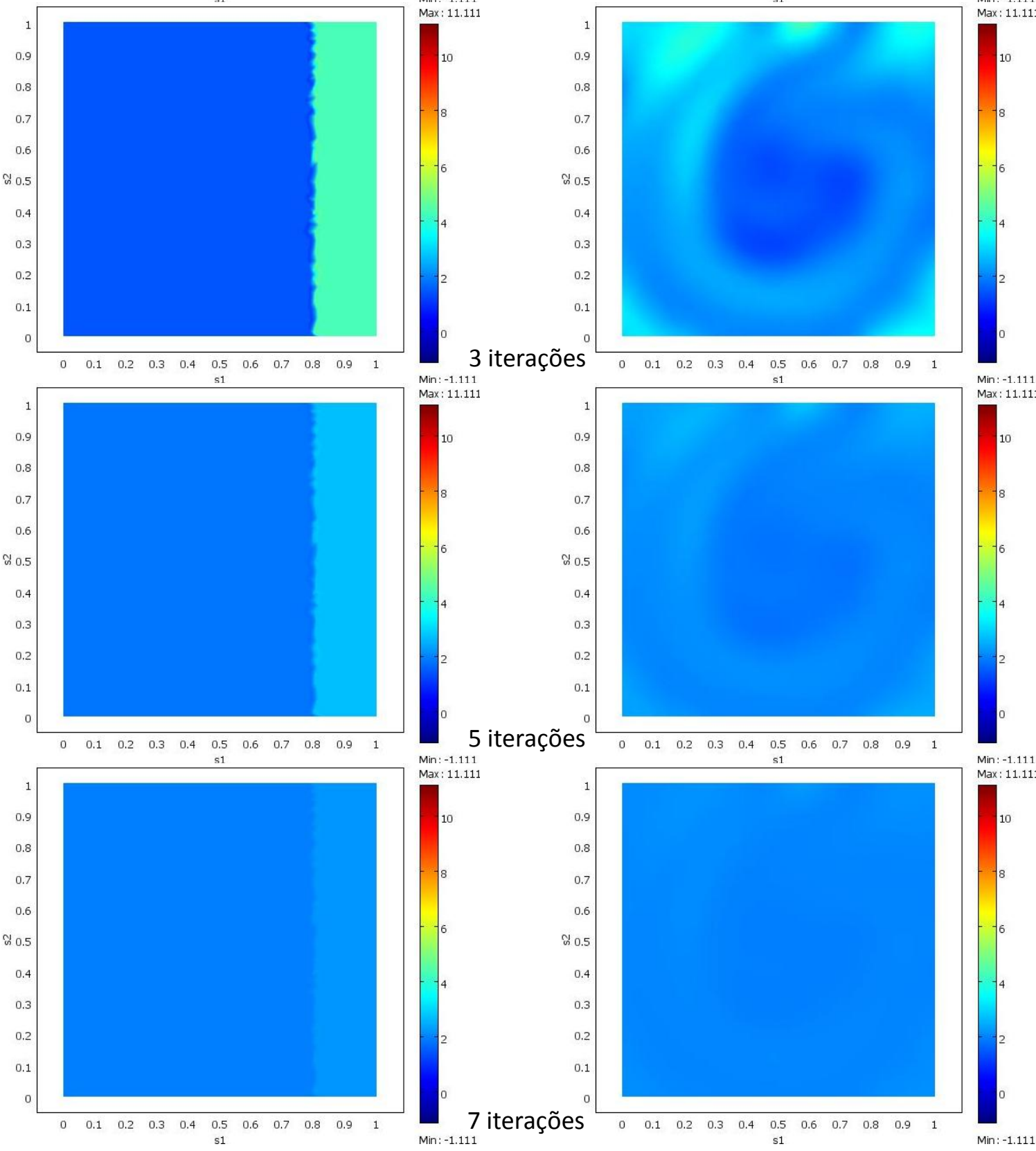

Min: :-1.111
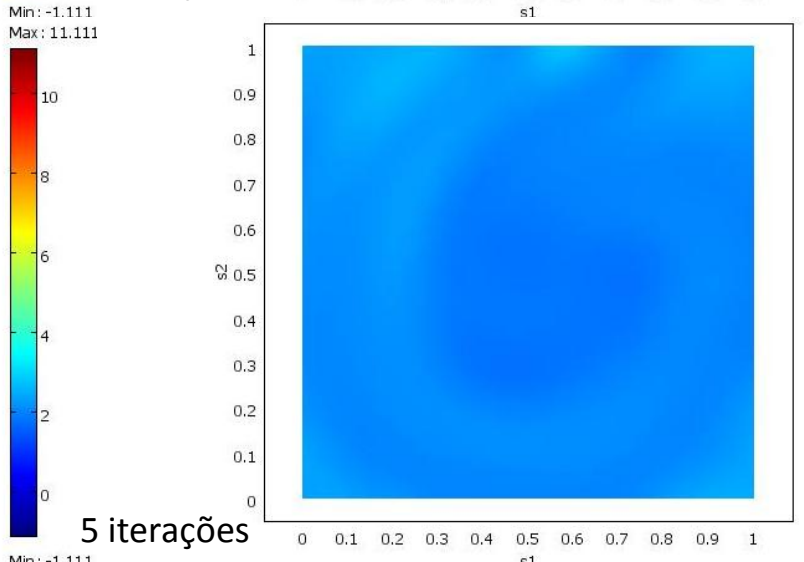

Min: - 1.111

Min: - 1.111
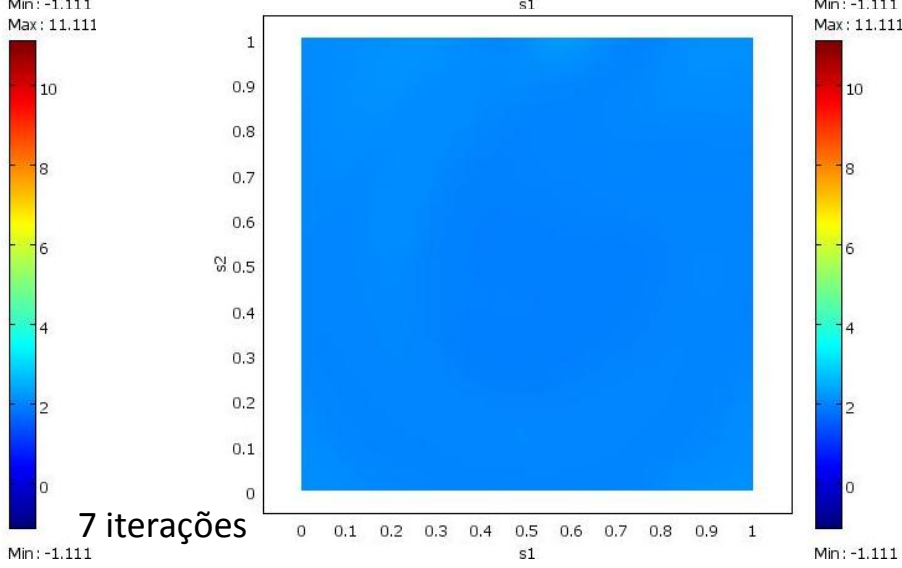

Min : - 1.11 


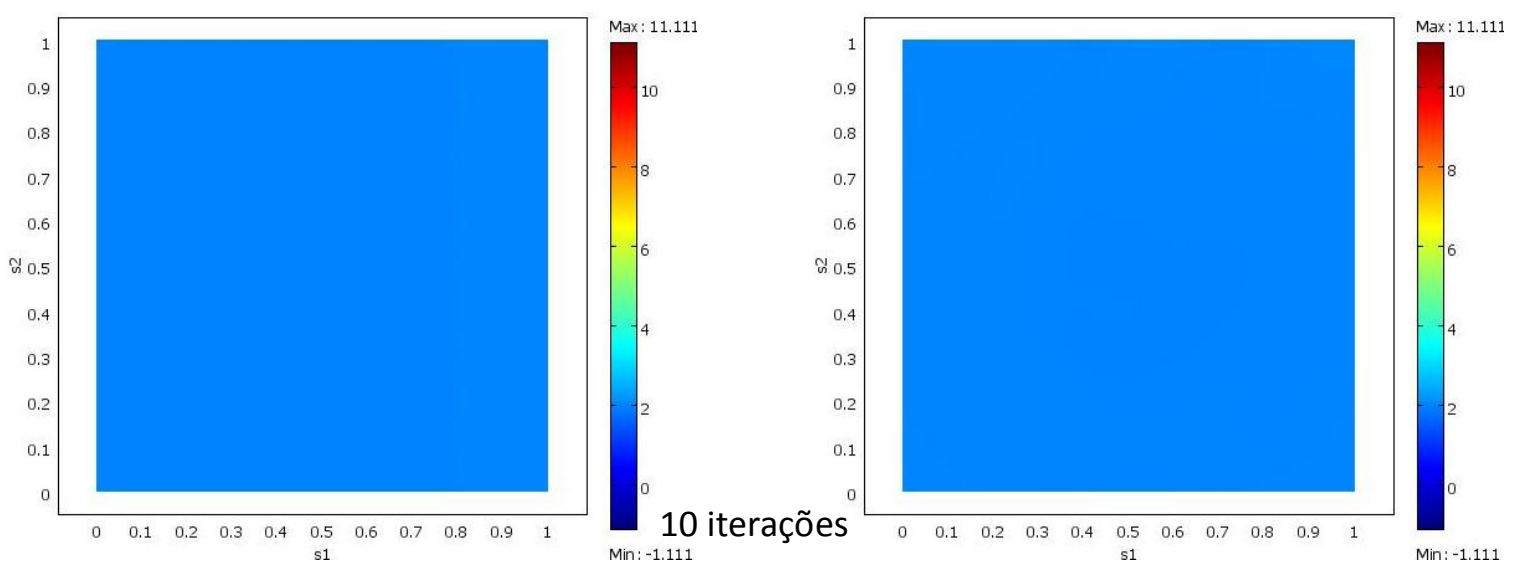

Figura 54. Evolução dos mapas de concentração em função do número de iterações.

Uma clara limitação desse processo é que a cada iteração, perde-se o efeito de deformação da interface de contato entre as fases em função do ajuste de um perfil degrau de concentração para a próxima iteração. Logo, esse processo resulta numa eficiência de mistura pior do que a situação em que se simulasse a geometria com o comprimento total.

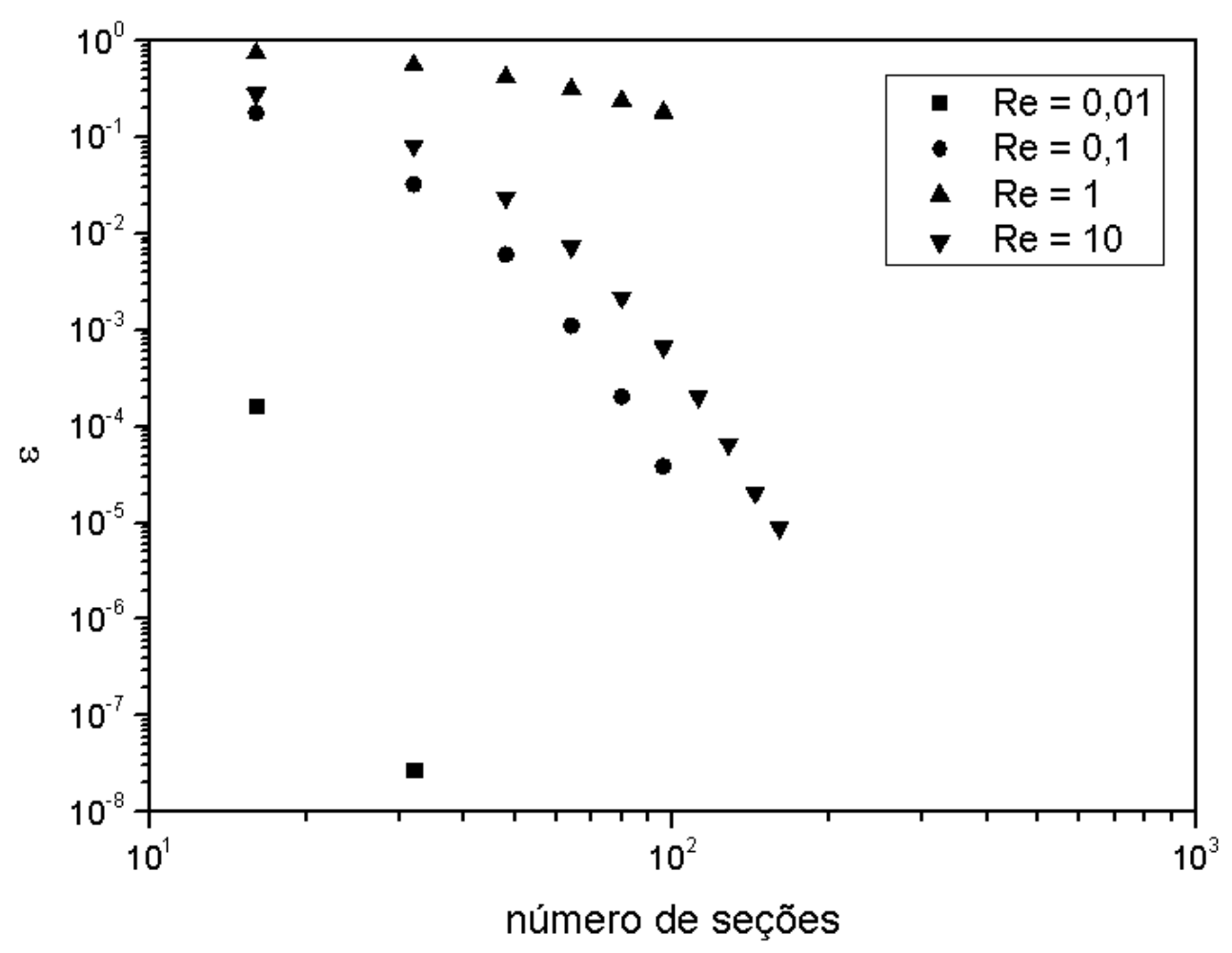

Gráfico 38. Eficiência de mistura em função do número de seções.

O gráfico 38 mostra a eficiência de mistura em função do número de seções para cada $R e$ trabalhado. Para $R e=0,01$, obteve-se uma geometria com 32 seções 
com uma excelente qualidade de mistura. O processo nesse ponto é realizado em regime laminar com duração de $273 \mathrm{~s}$. Considerando o coeficiente de difusão adotado, $D=1,0286 \cdot 10^{-9} \mathrm{~m}^{2} / \mathrm{s}$, a dimensão característica do microcanal, obtêm-se um tempo de residência teórico de

$$
\tau=\frac{d^{2}}{2 * D}=\frac{\left(600 * 10^{-6}\right)^{2}}{2 * 1,0286 * 10^{-9}}=175 s,
$$

justificando assim a excelente qualidade de mistura.

Para $R e=0,1$, obteve-se uma geometria com 96 seções com uma boa qualidade de mistura. $O$ processo nesse ponto é realizado em regime laminar com duração de $81 \mathrm{~s}$.

Para $R e=1$, obteve-se uma geometria com 96 seções com a pior qualidade de mistura entre os pontos simulados. $O$ processo nesse ponto é realizado em regime laminar com duração de $8,1 \mathrm{~s}$.

Portanto, em regime laminar conforme o tempo de residência no dispositivo diminui a qualidade de mistura piora, pois o processo é dominado por difusão, tendo como referência o tempo de residência teórico de $175 \mathrm{~s}$, para esse processo estudado.

Para $R e=10$, obteve-se uma geometria com 160 seções com uma boa qualidade de mistura, $8,9 \cdot 10^{-6}$, abaixo do valor referência definido no estudo 6 . 0 processo nesse ponto é realizado em regime intermediário com duração de 1,4 $\mathrm{s}$. Observa-se que a transição de regime influencia significativamente na qualidade de mistura, podendo realizar o processo em um tempo de residência muito curto.

\subsubsection{Especificação do módulo de tempo de residência}

No início deste capítulo foi discutido que a reação química do processo de produção do biodiesel é controlada por difusão, em função disto o tempo de mistura fina seria maior que o tempo de reação, $\mathrm{t} 1>\mathrm{t}$ 2. Como aproximação, o MTR será especificado com tempo de residência igual ao do micromisturador, $\mathrm{t} 2=\mathrm{t} 1, \mathrm{t} 2=1,4 \mathrm{~s}$ e t $1=1,4 \mathrm{~s}$.

Nesta etapa, o objetivo é completar o tempo para a efetivação da reação química. Portanto, não há a necessidade de uma geometria complexa. Então, a primeira especificação é a geometria do MTR: microcanal reto. 
O diâmetro hidráulico do micromisturador é de $600 \mu \mathrm{m}$. Para o MTR, para dar um alívio na diferença de pressão do sistema, o diâmetro hidráulico é especificado como $\mathrm{Dh}=800 \mu \mathrm{m}$.

Quanto ao comprimento, como foram definidos tempos iguais para o micromisturador e para o MTR, o volume dos dois dispositivos são iguais. Assim, dividindo o volume do micromisturador pela seção $800 \mu \mathrm{m} \times \mu \mathrm{m}$ do MTR, obtém-se um comprimento de 22, $6 \mathrm{~cm}$.

Portanto, o ponto crítico do projeto é o micromisturador. Otimizando os parâmetros de trabalho deste dispositivo, a especificação do MTR é realizada em função do micromisturador.

\subsection{Discussão}

Em função dos resultados obtidos, a tabela 54 sintetiza as características do micromisturador baseado na geometria serpentina 3D 1, bem como do módulo de tempo de residência.

Tabela 54. Sistema reacional.

\begin{tabular}{|l|c|}
\hline \multicolumn{2}{|c|}{ Micromisturador Serpentina 3D } \\
\hline \multicolumn{1}{|c|}{ Parâmetros } & Valor \\
\hline Diâmetro hidráulico & $600 \mu \mathrm{m}$ \\
\hline Número de seções & 160 \\
\hline Comprimento & $40,2 \mathrm{~cm}$ \\
\hline Tempo de residência & $1,4 \mathrm{~s}$ \\
\hline$\Delta \mathrm{P}$ & $126 \mathrm{kPa}$ \\
\hline \multicolumn{1}{|c|}{ Parâmetros } & \multicolumn{1}{c|}{ Valor } \\
\hline \multicolumn{1}{|c|}{ Parâmetros } & $800 \mu \mathrm{m}$ \\
\hline Diâmetro hidráulico & $22,6 \mathrm{~cm}$ \\
\hline Comprimento & $1,4 \mathrm{~s}$ \\
\hline Tempo de residência & $36 \mathrm{kPa}$ \\
\hline$\Delta \mathrm{P}$ & \\
\hline \multicolumn{2}{|c|}{ Sistema reacional } \\
\hline \multicolumn{1}{|c|}{} & $\mathrm{Valor}$ \\
\hline Vazão de trabalho & $6,4 \mathrm{ml} / \mathrm{min}$ \\
\hline$\Delta \mathrm{P}$ & $162 \mathrm{kPa}$ \\
\hline Tempo de residência total & $2,8 \mathrm{~s}$ \\
\hline
\end{tabular}


O modelo teórico desenvolvido para o sistema reacional é uma aproximação do que pode ser praticado experimentalmente. Essa aproximação é bem significativa, pois não considera diversos fatores que catalisam a qualidade de mistura:

- as paredes dos modelos foram consideradas planas e sem nenhuma rugosidade. A tecnologia de fabricação em LTCC gera uma rugosidade significativa nos microcanais. Essa rugosidade influencia diretamente na instabilidade do escoamento.

- a viscosidade do escoamento estudado foi considerada constante, da entrada do sistema reacional até a saída. Foi adotada a viscosidade do óleo. Ellis (2007) reporta a viscosidade durante o processo de produção do biodiesel, conforme mostrado na figura 55. Na prática, a viscosidade tem uma significativa queda em função da ocorrência da reação química. Com a diminuição da viscosidade ao longo do microcanal, a eficiência do dispositivo aumenta, pois para manter a conservação de massa e quantidade de movimento, a velocidade média do escoamento aumenta, aumentando também as instabilidades do escoamento.

- o modelo iterativo desenvolvido neste capítulo, como já citado, fornece uma qualidade de mistura pior do que realmente é, em função das aproximações entre as iterações.

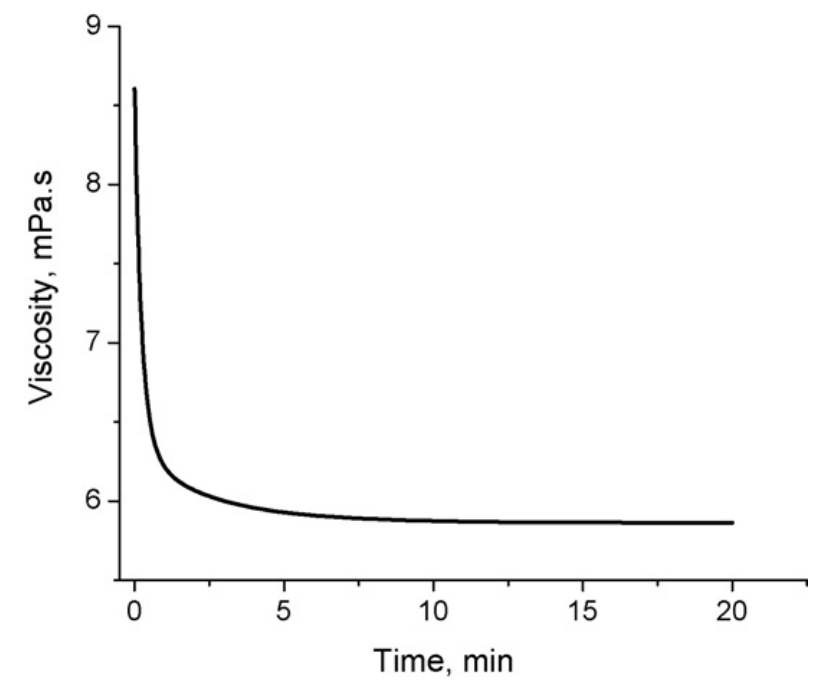

Figura 55. Variação da viscosidade ao longo do tempo no processo de produção do biodiesel.

Comparando o resultado teórico obtido, com a prática experimental encontrada na literatura, esse modelo teórico representa uma contribuição original ao estado da 
arte. A tabela 55 mostra essa comparação em relação a dois resultados experimentais significativos, Wen (2009) e Sun (2010).

Tabela 55. Comparação do modelo teórico com a prática experimental encontrada na literatura.

\begin{tabular}{|c|c|c|c|}
\hline \multicolumn{4}{|c|}{ Micromisturador Serpentina 3D } \\
\hline Parâmetros & Tese & Wen (2009) & Sun (2010) \\
\hline Diâmetro hidráulico & $600 \mu \mathrm{m}$ & $240 \mu \mathrm{m}$ & $250 \mu \mathrm{m}$ \\
\hline Número de seções & 160 & 350 & - \\
\hline Comprimento & $40,2 \mathrm{~cm}$ & $\sim 1 \mathrm{~m}$ & - \\
\hline Tempo de residência & $1,4 \mathrm{~s}$ & $28 \mathrm{~s}$ & - \\
\hline$\Delta \mathrm{P}$ & $126 \mathrm{kPa}$ & $1,7 \mathrm{MPa}$ & - \\
\hline \multicolumn{4}{|c|}{ MTR - Microcanal reto } \\
\hline Parâmetros & Tese & Wen (2009) & ${ }^{\star}$ Sun $(2010)$ \\
\hline Diâmetro hidráulico & $800 \mu \mathrm{m}$ & - & $2 \mathrm{~mm}$ \\
\hline Comprimento & $22,6 \mathrm{~cm}$ & - & $40 \mathrm{~cm}$ \\
\hline Tempo de residência & $1,4 \mathrm{~s}$ & - & $\sim 17 \mathrm{~s}$ \\
\hline$\Delta \mathrm{P}$ & $36 \mathrm{kPa}$ & - & $800 \mathrm{kPa}$ \\
\hline \multicolumn{4}{|c|}{ Sistema reacional } \\
\hline Parâmetros & Tese & Wen (2009) & Sun (2010) \\
\hline Vazão de trabalho & $6,4 \mathrm{ml} / \mathrm{min}$ & $\sim 1 \mathrm{ml} / \mathrm{min}$ & $7 \mathrm{ml} / \mathrm{min}$ \\
\hline$\Delta \mathrm{P}$ & $162 \mathrm{kPa}$ & $1,7 \mathrm{MPa}$ & $800 \mathrm{kPa}$ \\
\hline Comprimento & $62,8 \mathrm{~cm}$ & $\sim 1 \mathrm{~m}$ & $\sim 40 \mathrm{~cm}$ \\
\hline Tempo de residência total & $2,8 \mathrm{~s}$ & $28 \mathrm{~s}$ & $\sim 17 \mathrm{~s}$ \\
\hline
\end{tabular}

*MTR baseado em anéis de Dixon.

A primeira observação é em função do número de seções usadas por Wen (2009), 350 seções para geometria zigzag, enquanto que neste trabalho obteve-se um total de 160 seções para geometria serpentina 3D. Ao longo deste trabalho diversas comparações foram realizadas entre essas geometrias, evidenciando a maior eficiência da serpentina 3D.

O comprimento do sistema reacional (micromisturador + MTR) proposto aqui é de 62,8 cm, situado intermediariamente entre Sun (2010) e Wen (2009), $40 \mathrm{~cm}$ e $1 \mathrm{~m}$, respectivamente.

Quanto ao tempo, este trabalho obteve um tempo de residência mais curto em relação aos outros trabalhos. O conhecimento das características fluidodinâmicas das diversas geometrias estudadas neste trabalho, por exemplo, a determinação da transição de regime de escoamento, resultando na escolha e no projeto de uma geometria ótima, permitiu esta proposição. 
Portanto, ainda há muito espaço experimental para o estudo da cinética de reação do processo de produção do biodiesel em micro-escala. O conhecimento da descrição do regime de escoamento é fundamental para o planejamento experimental, ganhando a mesma importância que parâmetros cinéticos, como a razão molar entre as fases, o tipo de catalisador, a concentração de catalisador e a temperatura de processo.

\subsection{Conclusões preliminares}

A metodologia computacional usada neste trabalho permitiu otimizar um micromisturador para o processo de produção do biodiesel e conseqüentemente projetar o sistema reacional composto pelo micromisturador e um módulo de tempo de residência.

O projeto do sistema reacional baseado em simulações numéricas prevê um tempo de processo de $2,8 \mathrm{~s}$, considerando a geometria serpentina 3D 1, com 160 seções e $D_{h}=600 \mu \mathrm{m}$, combinando com um trecho de microcanal reto (MTR) com comprimento de $22,6 \mathrm{~cm}$ e $D_{\mathrm{h}}=800 \mu \mathrm{m}$.

Este resultado é relevante e original para o estado da arte, pois os resultados experimentais encontrados na literatura apontam tempos de processo de $17 \mathrm{~s}$ a 6 min, usando a rota microtecnológica.

O diálogo entre a modelagem computacional e a investigação experimental conduzirá brevemente a um processo de produção de biodiesel, usando a rota microtecnológica, mais rápido, eficiente e robusto. 


\subsection{Referências}

Cussler, E. L., Diffusion: Mass Transfer in Fluid Systems. 3aㅡ edição. Cambridge University Press, 2009, pg. 455-473.

Ellis, Naoko; Guan, Feng; Chen, Tim; Poon, Conrad. "Monitoring biodiesel production (transesterification) using in situ viscometer", Chemical Engineering Journal, 2008, Vol. 138, pp. $200-206$.

Mendonça, C. R. B., Desenvolvimento de metodologias para análise direta de óleos vegetais empregando microemulsões de água em óleo e meios não aquosos. Tese de doutorado, Porto Alegre, 2005, pg. 142. 


\section{MICRORREATOR}

\subsection{Introdução}

O processo de produção de biodiesel é governado pela reação química global descrita na equação 21, composta de $1 \mathrm{~mol}$ de triglicerídeo (TG) reagindo 3 mols de álcool (A), metanol ou etanol, produzindo 3 mols de ésteres $(E)$ e 1 mol de glicerina (G).

$$
\mathrm{TG}+3 \mathrm{CH}_{3} \mathrm{OH} \Leftrightarrow 3 E+G
$$

Esta reação química global é composta por três reações intermediárias, equações 22, 23 e 24, onde se forma o diglicerídeo (DG) e o monoglicerídeo (MG).

$$
\begin{array}{lc}
T G+\mathrm{CH}_{3} \mathrm{OH} \Leftrightarrow E+D G & \text { eq. } 22 . \\
D G+\mathrm{CH}_{3} \mathrm{OH} \Leftrightarrow E+M G & \text { eq. } 23 . \\
M G+\mathrm{CH}_{3} \mathrm{OH} \Leftrightarrow E+G & \text { eq. } 24 .
\end{array}
$$

As equações de governo (Noureddini, 1997; Marchetti, 2007), 25, 26 e 27, regem o processo de produção do biodiesel, definindo as concentrações de TG, DG, MG, G e E em função do tempo de processo. Define-se $\mathrm{k}_{1}$ e $\mathrm{k}_{2}$, como constantes de velocidade das reações direta e reversa, respectivamente, da equação 21 , e assim sucessivamente de $k_{3}$ a $k_{8}$ para as equações 22, 23 e 24.

$$
\begin{aligned}
& \frac{d[T G]}{d t}=-k_{1}[T G][A]^{3}+k_{2}[G][E]^{3}-k_{3}[T G][A]+k_{4}[D G][E] \\
& \frac{d[D G]}{d t}=k_{3}[T G][A]-k_{4}[D G][E]-k_{5}[D G][A]+k_{6}[M G][E] \\
& \frac{d[M G]}{d t}=k_{5}[D G][A]-k_{6}[M G][E]-k_{7}[M G][A]+k_{8}[G][E] \\
& \frac{d[E]}{d t}=k_{1}[T G][A]^{3}-k_{2}[G][E]^{3}+k_{3}[T G][A]-k_{4}[D G][E]+k_{5}[D G][A]-k_{6}[M G][E] \\
& +k_{7}[M G][A]-k_{8}[G][E]
\end{aligned}
$$




$$
\frac{d[G]}{d t}=k_{1}[T G][A]^{3}-k_{2}[G][E]^{3}+k_{7}[M G][A]-k_{8}[G][E]
$$

A motivação e a justificativa deste trabalho é o processo de produção do biodiesel, descrito pelas reações químicas e equações de governo acima. $O$ objetivo deste trabalho é desenvolver um microrreator para intensificar este processo.

\subsection{Estado da arte}

Diversas tecnologias de produção de biodiesel têm sido exploradas na literatura (Andrade, 2011), como o craqueamento, a esterificação, a transesterificação e o processo supercrítico. $O$ objetivo da investigação usando estas diversas tecnologias é conseguir intensificar as constantes k\#, equações de 25 a 29, no sentido direto de reação, para alcançar um processo de produção mais rápido e eficiente. A tabela 56 mostra todo o esforço investigativo, onde é observada a exploração de diversos parâmetros de processo obtendo-se vários conjuntos de constantes $\mathrm{k}$.

\section{Tabela 56. Investigação das constantes de velocidade de reação (Fonseca, 2010).}

Casos de estudo - condições experimentais

\begin{tabular}{lccccccc}
\hline Caso & $\mathrm{I}^{\mathrm{a}}$ & $\mathrm{II}^{\mathrm{b}}$ & $\mathrm{III}^{\mathrm{c}}$ & $\mathrm{IV}^{\mathrm{c}}$ & $\mathrm{V}^{\mathrm{e}}$ & $\mathrm{VI}^{\mathrm{d}}$ & $\mathrm{VII}^{\mathrm{e}}$ \\
\hline Óleo & $\mathrm{Soja}$ & Palma & Girassol & Girassol & Girassol & Brassica Carinata & Pongamia \\
Temperatura ( ${ }^{\circ} \mathrm{C}$ ) & 50 & 50 & 65 & 65 & 65 & 65 & 60 \\
Razão molar (metanol:óleo) & $6: 1$ & $6: 1$ & $6: 1$ & $6: 1$ & $6: 1$ & $6: 1$ & $10: 1$ \\
Catalizador & $\mathrm{NaOH}$ & $\mathrm{NaOH}$ & $\mathrm{KOH}$ & $\mathrm{KOH}$ & $\mathrm{KOH}$ & $\mathrm{KOH}$ & $\mathrm{KOH}$ \\
concentração de catalizador (wt. \%) & 0,2 & 0,2 & 0,5 & 1,0 & 1,5 & 1,5 & 1,0 \\
velocidade de rotação (rpm) & 300 & 400 & 600 & 600 & 600 & 600 & não avaliado \\
\hline Constantes usadas nas simulações & & & & & & & \\
\hline & $\mathrm{I}^{\mathrm{a}}$ & $\mathrm{II}^{\mathrm{b}}$ & $\mathrm{III} \mathrm{I}^{\mathrm{c}}$ & $\mathrm{IV}^{\mathrm{c}}$ & $\mathrm{V}$ & $\mathrm{VI}$ & $\mathrm{VII}$ \\
\hline $\mathrm{k}_{1}$ (L/mol.min) & 0,050 & 0,049 & 1,50 & 3,06 & 4,00 & 4,128 & 0,0286 \\
$\mathrm{k}_{2}$ (L/mol.min) & 0,110 & 0,112 & 13,7 & 23,9 & 27,0 & 28,2 & 0,0144 \\
$\mathrm{k}_{3}$ (L/mol.min) & 0,215 & 0,226 & 23,0 & 32,5 & 55,0 & 55,5 & 0,0058 \\
$\mathrm{k}_{4}$ (L/mol.min) & 1,228 & 0,133 & 41,4 & 57,5 & 65,5 & 63,9 & 0,0213 \\
$\mathrm{k}_{5}$ (L/mol.min) & 0,242 & 0,122 & 0,40 & 0,54 & 0,91 & 0,918 & 0,0111 \\
$\mathrm{k}_{6}$ (L/mol.min) & 0,007 & 0,016 & 0,0026 & 0,0009 & 0,0001 & 0,00012 & 0,000511 \\
\hline
\end{tabular}

A figura 56 mostra a simulação dos perfis de concentração das espécies envolvidas no processo de produção do biodiesel em função do tempo. 


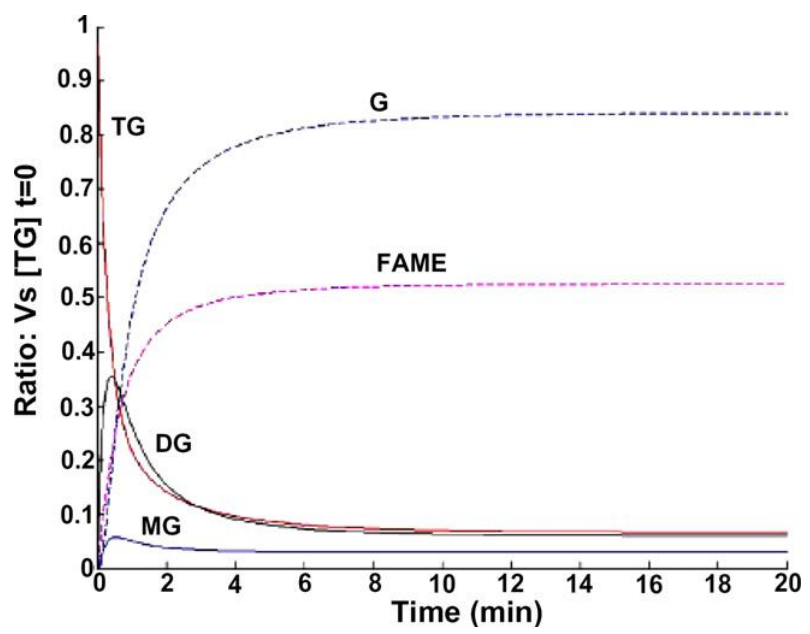

Figura 56. Perfis de concentração em função do tempo Sharma (2008).

As tecnologias de produção do biodiesel citadas acima apresentam diversas limitações, como a geração de produtos indesejáveis, a saponificação, uso de temperaturas e pressões excessivas, etc. Para superar essas limitações uma nova rota tecnológica tem sido explorada. A tabela 57 mostra os principais trabalhos encontrados na literatura usando dispositivos microtecnológicos.

Tabela 57. Produção de biodiesel por via microtecnológica.

\begin{tabular}{|c|c|c|c|c|c|c|}
\hline Trabalhos & $\begin{array}{c}\text { Tipo de } \\
\text { misturador }\end{array}$ & $D_{h}$ & Seções & Comprimento & $\begin{array}{c}\text { Módulo de } \\
\text { tempo de } \\
\text { residência }\end{array}$ & $\begin{array}{c}\text { Tempo de } \\
\text { residência }\end{array}$ \\
\hline $\begin{array}{c}\text { Carlisle } \\
(2005)\end{array}$ & $\begin{array}{c}\text { Microcanal } \\
\text { reto }\end{array}$ & $\begin{array}{c}100 \\
\mu \mathrm{m}\end{array}$ & - & $7 \mathrm{~cm}$ & - & $45 \mathrm{~s}$ \\
\hline $\begin{array}{c}\text { Sun } \\
(2008)\end{array}$ & $\begin{array}{c}\text { Microcanal } \\
\text { reto }\end{array}$ & $\begin{array}{c}250 \\
\mu \mathrm{m}\end{array}$ & - & $30 \mathrm{~m}$ & - & $5,8 \mathrm{~min}$ \\
\hline $\begin{array}{c}\text { Wen } \\
(2009)\end{array}$ & $\begin{array}{c}\text { Microcanal } \\
\text { zigzag }\end{array}$ & $\begin{array}{c}240 \\
\mu \mathrm{m}\end{array}$ & 350 & $\sim 1 \mathrm{~m}$ & - & $28 \mathrm{~s}$ \\
\hline $\begin{array}{c}\text { Sun } \\
(2010)\end{array}$ & Diversos & $\begin{array}{c}250 \\
\mu \mathrm{m}\end{array}$ & - & - & $40 \mathrm{~cm}$ & $17 \mathrm{~s}$ \\
\hline
\end{tabular}

Dentro deste contexto o objetivo do trabalho foi desenvolver um microrreator fabricado em tecnologia LTCC (tecnologia no apêndice $C$ ) para produção de biodiesel, composto por um micromisturador (capítulo 4) e um módulo de tempo de residência (capítulo 5). Indo além do proposto foram feitos estudos preliminares para acoplar ou integrar no protótipo proposto dois sensores de vazão (apêndice A), um aquecedor (apêndice B) e um sensor de temperatura (apêndice B).

Este desenvolvimento prevê a integração ou acoplamento destes diversos elementos, com foco na otimização computacional do micromisturador (capítulo 4), identificado como ponto crítico do sistema. 


\subsection{Metodologia}

A reação química que governa o processo de produção do biodiesel é uma reação heterogênea realizada com dois líquidos imiscíveis. Segundo Cussler (2009) este é um típico processo controlado por difusão, com duas etapas:

- o processo de transferência de massa, neste caso a geração de uma emulsão, e

- o processo reacional.

Cada uma dessas etapas é controlada por tempo de processo. A reação química do processo de produção do biodiesel é controlada por difusão, com o tempo do processo de transferência de massa maior que o tempo reacional. A figura 57 mostra esse modelo, com tempo 11 referente ao processo de transferência de massa e o tempo $\mathrm{t} 2$ referente ao processo reacional.

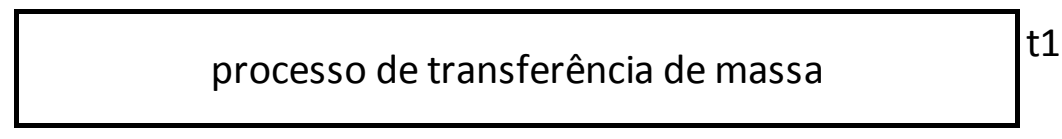

$\mathrm{t} 1>\mathrm{t} 2$

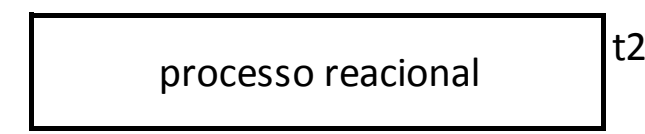

\section{Figura 57. Modelo do processo de reação do biodiesel.}

A aproximação usada neste trabalho para desenvolver a metodologia de projeto do microrreator é descrita na figura 58 , onde o processo de transferência de massa e o processo reacional ocorrem em série com $\mathrm{t} 1 \mathrm{t} \mathrm{t} 2$.

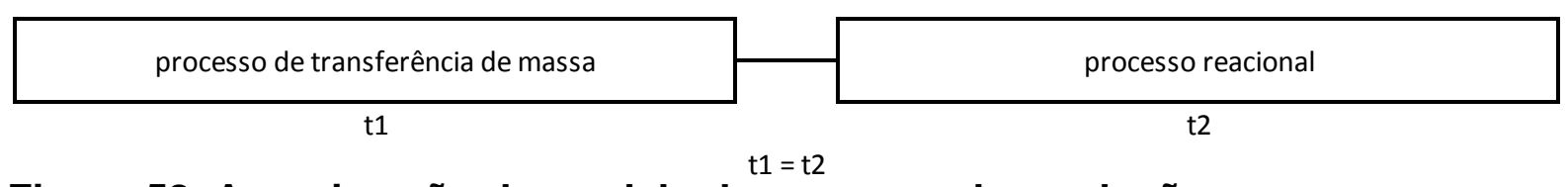

Figura 58. Aproximação do modelo de processo de produção.

Neste modelo, o processo referente ao tempo t1 é realizado pelo micromisturador (capítulo 4), enquanto, o módulo de tempo de residência (capítulo 5) é responsável por realizar o processo referente ao tempo t2.

O módulo para produção de biodiesel, além do desenvolvimento do micromisturador e do MTR seguindo o modelo da figura 58, foi desenvolvido conforme as seguintes especificações:

- Fabricação em tecnologia LTCC; 
- Sensor de vazão baseado no princípio de medição por diferença de pressão;

- Sensor de temperatura integrado no módulo baseado numa resistência do tipo PT-100;

- Aquecedor baseado no efeito Peltier.

\subsection{Resultados}

Paralelamente ao estudo computacional, 04 tentativas de fabricação do microrreator foram realizadas. A figura 59 identifica essas 04 tentativas em A, B, C e D. Todas essas tentativas foram feitas com aproximações dos resultados computacionais realizados paralelamente.

$\mathrm{Na}$ tentativa $\mathrm{A}$, projetou-se um micromisturador com um módulo de tempo de residência (MTR) acoplado. Nessa tentativa o objetivo era conseguir o maior comprimento possível do MTR em função da área de substrato disponível. Logo, o MTR foi projetado em duas camadas com os microcanais intercalados. Essa abordagem não foi interessante, pois em função do grande volume vazio no substrato, na etapa de fabricação chamada laminação (apêndice $C$ ) os microcanais colapsaram e conseqüentemente foram obstruídos.

$\mathrm{Na}$ tentativa B, o MTR foi projetado em duas camadas, mas sem intercalar os microcanais nos dois níveis. O resultado obtido foi o mesmo da tentativa $A$, microcanais obstruídos.

Na tentativa C, o MTR foi projetado com microcanais retos em dois níveis para obter o maior comprimento possível. Portanto, a abordagem nessa tentativa foi uma geometria mais simples que as tentativas anteriores. Nessa tentativa também foi contemplada a integração do micromisturador, das resistências hidráulicas para medida de vazão por diferença de pressão e do alojamento para a resistência PT100, responsável pela medida de temperatura. O resultado foi microcanais obstruídos. 

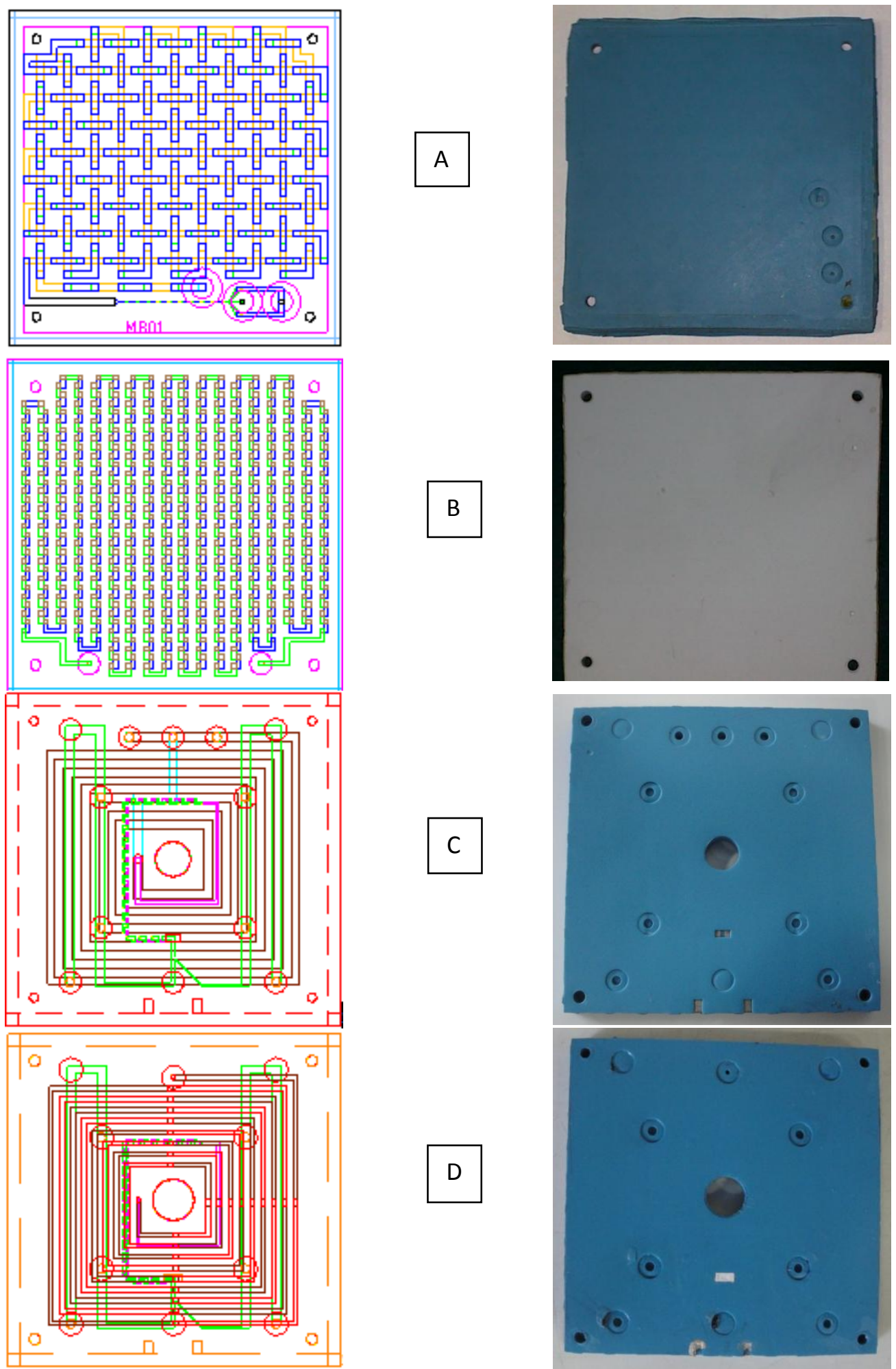

Figura 59. Tentativas de fabricação.

Na tentativa D, o MTR foi projetado com um comprimento final menor que em outras tentativas, em dois níveis com um maior espaçamento entre os microcanais em cada nível. Nessa tentativa também foi contemplada a integração do micromisturador, das resistências hidráulicas para medida de vazão por diferença de 
pressão e do alojamento para a resistência PT-100, responsável pela medida de temperatura. Nessa tentativa, conseguiu-se estabelecer 0 escoamento nos microcanais e sem vazamentos.

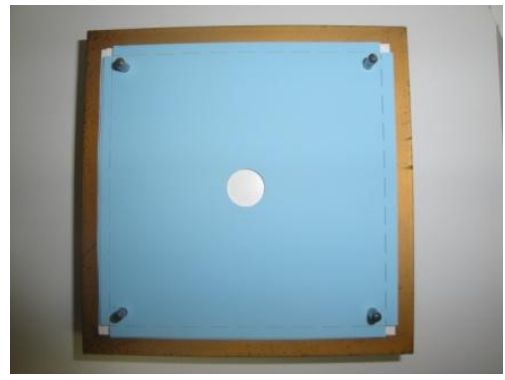

(a)

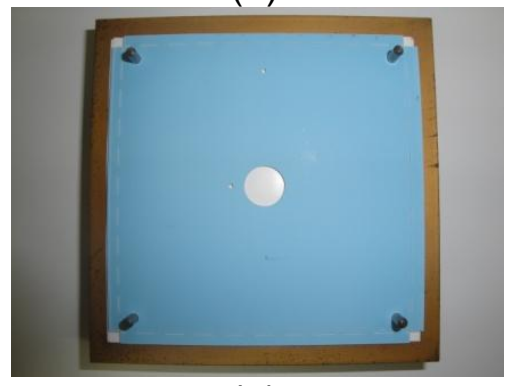

(d)

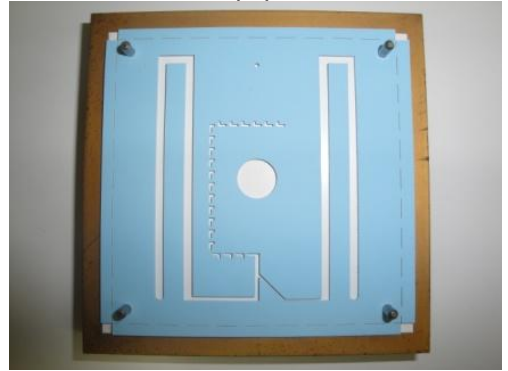

(g)

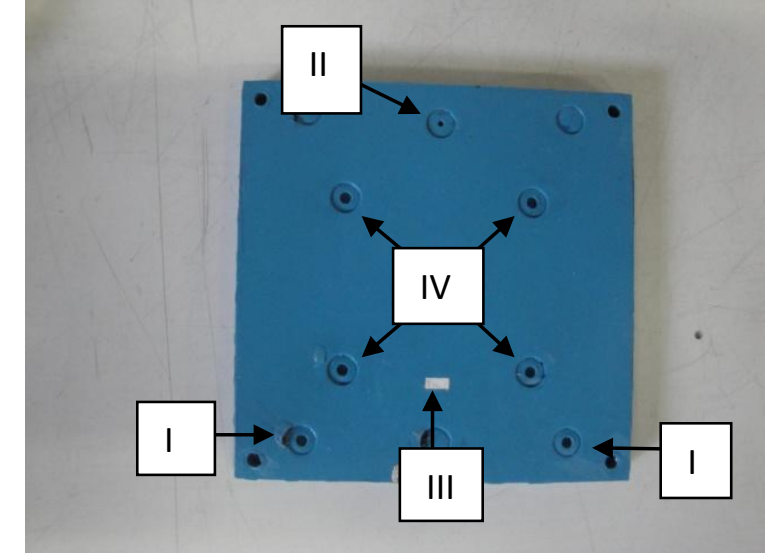

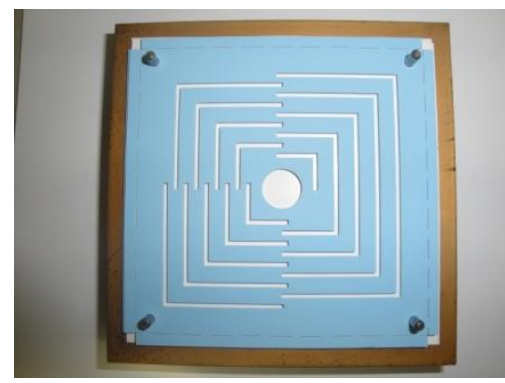

(b)

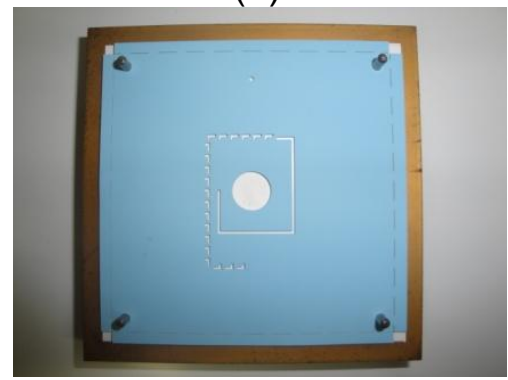

(e)

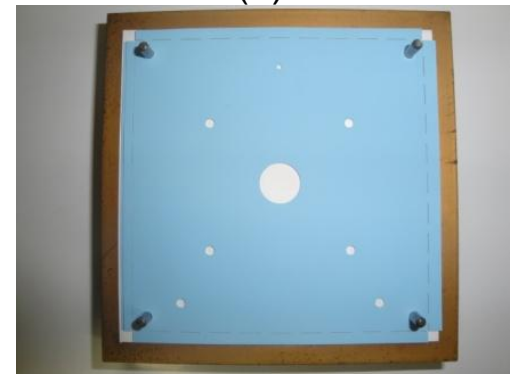

(h)

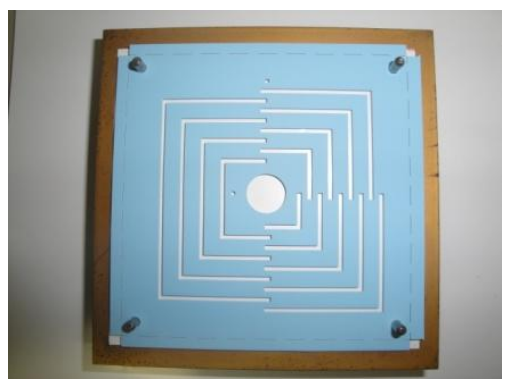

(c)

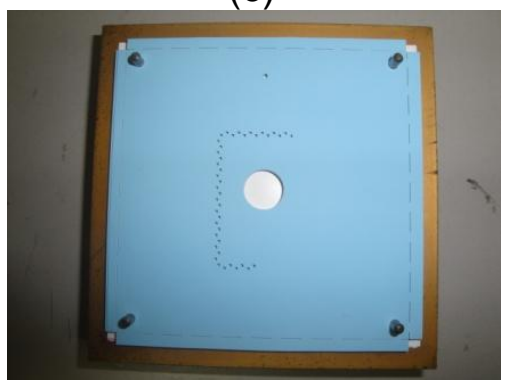

(f)

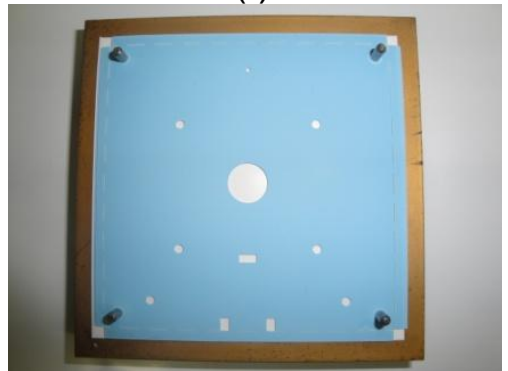

(i)

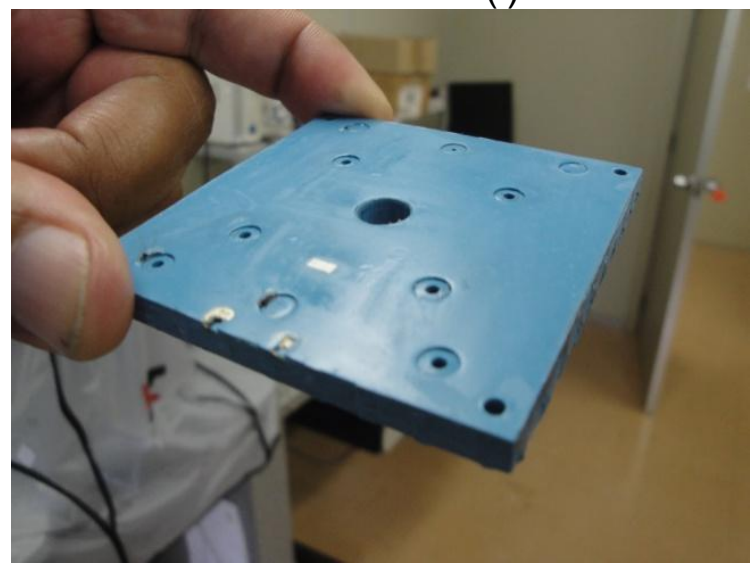

Figura 60. Camadas cerâmicas usinadas e microrreator pronto.

A figura 60 mostra as camadas cerâmicas que compõe o microrreator. 0 empilhamento na ordem de (a) a (i) gera o dispositivo desejado, seguindo as etapas de fabricação conforme apêndice $C$. 
Na figura 60 também são identificadas as partes constituintes do sistema final: (I) entradas dos reagentes, (II) saída dos produtos, (III) alojamento com resistência PT-100 para medição de temperatura e (IV) tomadas de pressão para medição de vazão pelo método de pressão diferencial.

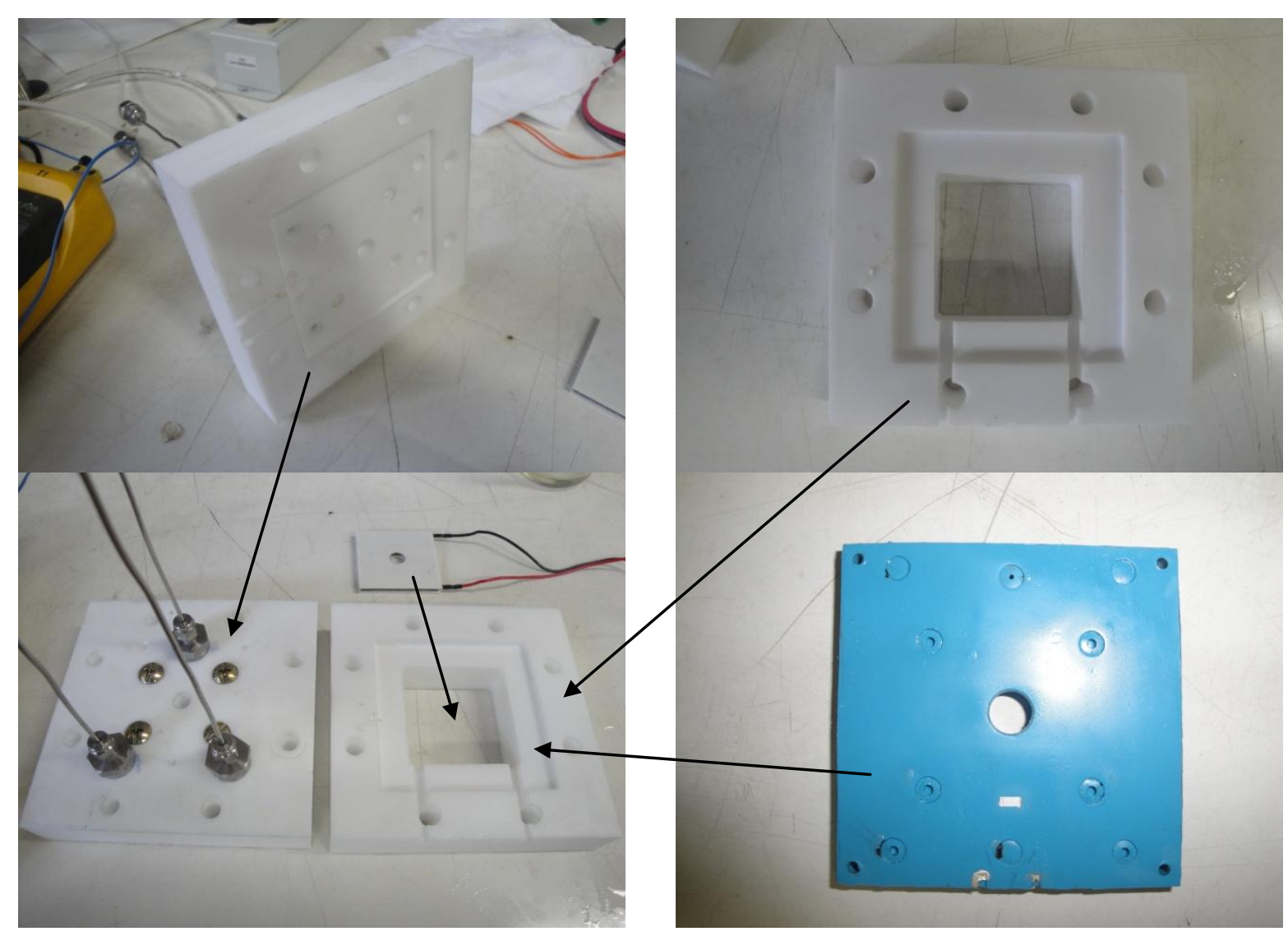

Figura 61. Encapsulamento do microrreator.

A figura 61 mostra os suportes fabricados em teflon para o encapsulamento do microrreator e o acoplamento do elemento Peltier (aquecedor). Nesse sistema o microrreator é intercalado pelos dois suportes fabricados. A vedação é realizada pela deformação de anéis órings intercalados entre o microrreator e um dos suportes. O elemento Peltier é acoplado ao sistema por um parafuso passando pelos furos centrais presentes em todas as peças. 

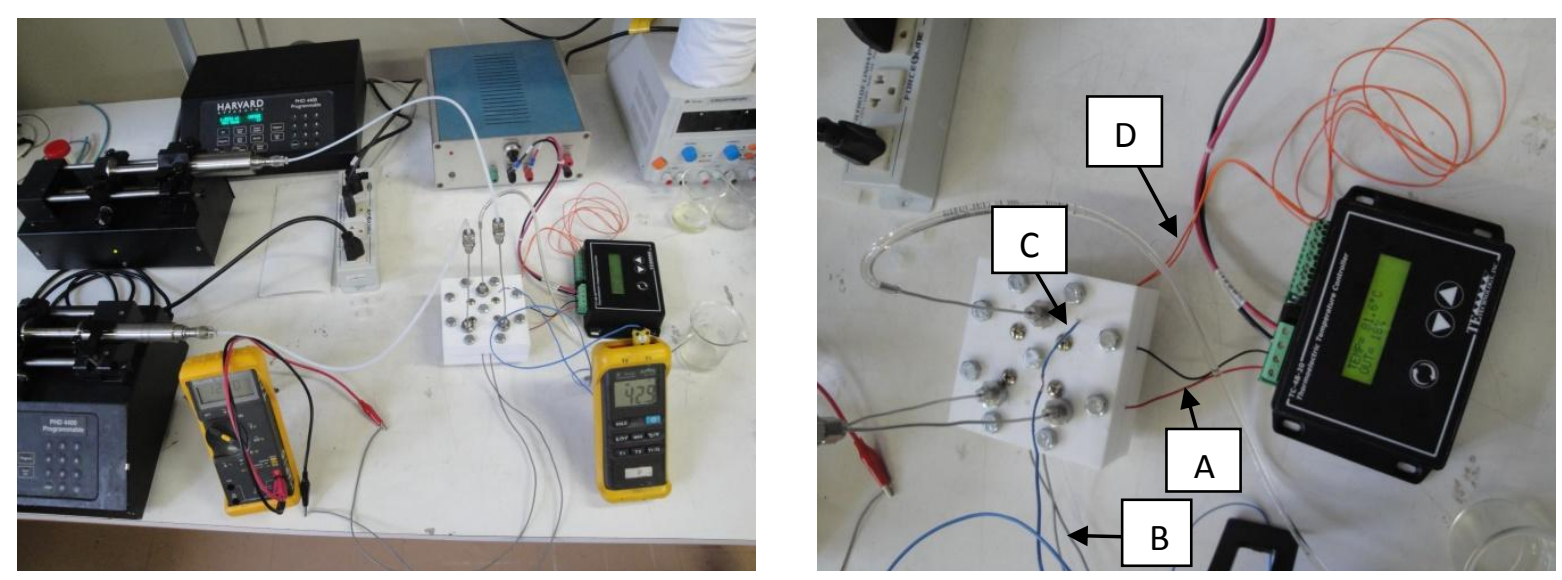

Figura 62. Módulo para produção de biodiesel.

A figura 62 mostra o módulo para produção de biodiesel em laboratório composto pelas bombas de seringas, pelo sistema de controle de temperatura e pelo microrreator. O sistema de controle de temperatura é identificado da seguinte forma: A - fios do elemento Peltier (aquecedor) acoplado no sistema, B - fios da resistência PT-100 para medição de temperatura no encontro dos fluidos, $C$ - medição da temperatura do teflon e $\mathrm{D}$ - fios da medição de temperatura da fase fria do elemento Peltier para o controle de temperatura.

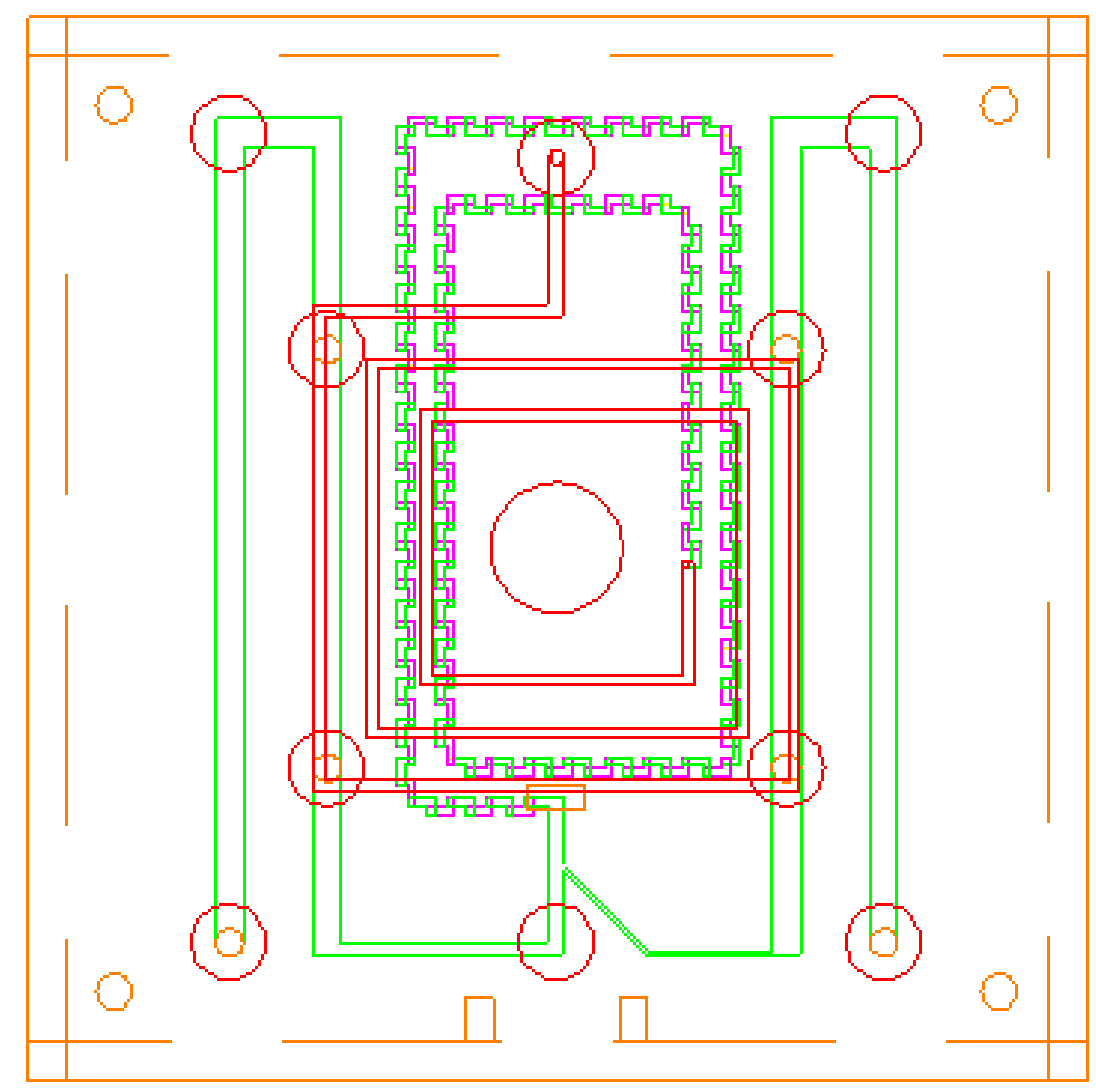

Figura 63. Projeto do microrreator otimizado.

A figura 63 mostra o projeto do microrreator com as dimensões otimizadas. 


\subsection{Discussão}

O principal problema enfrentado para obtenção do microrreator foi ajustar o processo de fabricação para o objetivo proposto, diversos dispositivos integrados num mesmo substrato em vários níveis diferentes, micromisturador, MTR, resistências hidráulicas para medição de vazão e o alojamento com a trilha de contato para a resistência PT-100 (medição de temperatura).

Outro fator importante, relacionado à operação do sistema, é a detecção de vazamento. Durante a operação do sistema alguns pontos de vazamento foram surgindo. O alinhamento entre suporte, anéis o'rings e microrreator, foi um ponto crítico na montagem do sistema. Os suportes precisam de um ajuste fino para que o alinhamento seja realizado de forma confiável.

\subsection{Conclusões preliminares}

O objetivo principal do trabalho foi alcançado, desenvolver o protótipo de um microrreator (micromisturador + MTR) fabricado em LTCC para produção de biodiesel. As dificuldades para fabricação em LTCC do protótipo foram superadas.

A metodologia computacional aliada a algumas investigações experimentais (Estudo 1: Produção de biodiesel e Estudo 2: Produção de emulsões) permitiu escolher e otimizar o micromisturador e o módulo de tempo de residência, para o desenvolvimento do microrreator com parâmetros ótimos.

O microrreator projetado conforme o modelo desenvolvido indica um tempo de processo de 2,8 s, proporcionando então a intensificação de processo.

Portanto, este trabalho contribui de forma relevante para o processo de desenvolvimento de microrreatores para aplicação no processo de produção do biodiesel, e conseqüentemente de outros processos similares.

\subsection{Referências}

Andrade, J.E., Pérez, A., Sebastian, P.J., e Eapen, D., "A review of bio-diesel production processes", Biomass and bioenergy, Vol. 35, 2011, pp. 1008 e 1020. 
Carlisle, Trevor, Kurt Spies, Sara York. Production of Biodiesel using a Microreactor. Technical Notes, Oregon University, 2005.

Cussler, E. L., Diffusion: Mass Transfer in Fluid Systems. 3aㅡ edição. Cambridge University Press, 2009, pg. 455-473.

Fonseca, Felipe A.S., Vidal-Vieira, José A., Ravagnani Sergio P., Transesterification of vegetable oils: Simulating the replacement of batch reactors with continuous reactors, Bioresource Technology, 101, 2010, pp. 8151-8157.

Marchetti, J.M.; Miguel, V.U.; Errazu, A.F. "Possible methods for biodiesel production", Renewable and Sustainable Energy Reviews, 2007, Vol. 11, pp. 1300 1311.

Noureddini, H., Zhu, D., Kinetics of transesterification of soybean oil. JAOCS 1997;74(11):1457-63.

Sharma, Y.C., Singh, B., Upadhyay, S.N., "Advancements in development and characterization of biodiesel: A review", Fuel, Vol. 87, 2008, pp. 2355-2373.

Sun, Juan, Jingxi Ju, Lei Ji, Lixiong Zhang, Nanping Xu. Synthesis of Biodiesel in Capillary Microreactors. Ind. Eng. Chem. Res. 2008, 47, 1398-1403.

Sun, Peiyong, Bin Wang, Jianfeng Yao, Lixiong Zhang, and Nanping Xu. Fast Synthesis of Biodiesel at High Throughput in Microstructured Reactors. Ind. Eng. Chem. Res. 2010, 49, 1259-1264.

Wen, Zhenzhong, Xinhai Yu, Shan-Tung Tu, Jinyue Yan, Erik Dahlquist. Intensification of biodiesel synthesis using zigzag micro-channel reactors. Bioresource Technology, Vol. 100, 2009, 3054-3060. 


\section{REVISÃO DOS RESULTADOS}

O objetivo deste capítulo é elencar todos os resultados obtidos ao longo do trabalho para poder realizar a conclusão no próximo capítulo. Portanto, foram elencados os resultados dos capítulos 4, 5 e 6, respectivamente.

No capítulo 4 foram desenvolvidos estudos computacionais e experimentais para investigar os micromisturadores com foco no problema de intensificação da superfície de contato entre dois fluidos. A seguir apresenta-se a síntese desses estudos com as principais observações.

O estudo computacional 1 foi realizado com três microcanais retos com diâmetros hidráulicos diferentes ( $1 \mathrm{~mm}, 100 \mu \mathrm{m}$ e $10 \mu \mathrm{m}$ ), no intervalo do número de Reynolds entre 0,01 e 2000.

A visualização dos mapas de velocidade permitiu identificar dois regimes de escoamento. Com a obtenção dos parâmetros numéricos foi possível identificar o regime de escoamento laminar no intervalo do número de Reynolds entre 0,01 e 100. No intervalo do número de Reynolds entre 100 e 2000, o regime de escoamento é o intermediário entre o laminar e o turbulento. Essa transição de regime para canais em macro-escala é registrada na literatura para número de Reynolds entre 1000 e 2000.

A obtenção dos parâmetros numéricos permitiu verificar alguns comportamentos no intervalo do regime laminar:

- O fator de atrito é inversamente proporcional ao número de Reynolds,

- O coeficiente de perda de carga é inversamente proporcional ao número de Reynolds,

- A vorticidade é diretamente proporcional ao número de Reynolds,

- A diferença de pressão é diretamente proporcional a vazão e relacionados por uma constante de proporcionalidade chamada resistência hidráulica,

- O tempo de residência é inversamente proporcional a vazão,

- O tempo de residência é inversamente proporcional a diferença de pressão,

- O tempo de residência é inversamente proporcional a potência volumétrica, e 
- A potência volumétrica é diretamente proporcional a vazão.

Os próximos estudos foram conduzidos no intervalo do número de Reynolds entre 0,01 e 100, que é o intervalo conhecido de regime laminar em microcanais retos. Esse procedimento foi adotado para comparação com os microcanais baseados em sucessivos cotovelos.

O estudo computacional 2 foi realizado com três estruturas com diferentes configurações espaciais entre dois cotovelos sucessivos, no intervalo do número de Reynolds entre 0,01 e 100.

A visualização dos mapas do campo de velocidades permitiu identificar um comportamento distinto das linhas de campo, para $R e=100$, quando comparado com o comportamento encontrado em outros valores de $\mathrm{Re}$, no intervalo estudado.

Com a obtenção dos parâmetros numéricos foi possível identificar a combinação de uma vorticidade constante e a diminuição de perda de carga em função da diminuição da distância entre cotovelos.

Além disso, a redução da distância entre os cotovelos induz a geração de pontos com alta velocidade no escoamento, permitindo a escolha de distâncias entre os cotovelos para serem investigadas no estudo computacional 3 :

- Estrutura 1- dec $=2$,

- Estrutura $2-\operatorname{dec}=1$ e 2, e

- Estrura 3- dec $=1$ e 2 .

O estudo computacional 3 foi realizado com nove geometrias, um microcanal reto e oito geometrias baseadas em sucessivos cotovelos, para o intervalo de número de Reynolds entre 0,01 e 100. Para estabelecer a comparação entre as geometrias foi definido um diâmetro hidráulico comum entre elas de $400 \mu \mathrm{m}$ e um comprimento comum de $L=20 \cdot D_{h}$, resultando assim em volumes iguais para todas as geometrias estudas.

A visualização dos mapas de velocidade permitiu identificar dois regimes de escoamento, regime laminar, para Re entre 0,01 e 10, e regime intermediário, para Re entre 10 e 100. A obtenção dos parâmetros numéricos permitiu identificar que a transição de regime ocorre a partir de $R e=10$. $E m ~ R e=100$, o regime já é intermediário com presença de advecção caótica. 
Verificou-se que a advecção caótica não ocorre em regime laminar e começa a ser apreciada em regime intermediário.

A eficiência de mistura também foi estudada. A visualização dos mapas de concentração permitiu identificar a influência das distâncias entre os cotovelos, identificadas do estudo 2 para o projeto das geometrias deste estudo, na qualidade da mistura. Bem como, a influência do regime de escoamento na qualidade da mistura. Portanto, verificou- se as seguintes melhores eficiências de mistura:

- Onda quadrada 2 melhor que onda quadrada 1;

- Zigzag 2 melhor que zigzag 1;

- Serpentina 3D 1 melhor que serpentina 3D 2;

- Zigzag 3D 1 melhor que zigzag 3D 2; e

- Geometrias 3D melhores que geometrias 2D.

Logo, as melhores distâncias entre cotovelos foram:

- Estrutura 1: dec = 2,

- Estrutura 2: dec = 2, e

- Estrutura 3: dec = 1 .

Com a obtenção dos dados numéricos de eficiência de mistura confirmou-se as conclusões visualizadas nos mapas de concentração e permitiu estabelecer um índice de comparação de desempenho entre as geometrias estudadas para $\mathrm{Re}=$ 100. Destaque dado para a geometria zigzag 3D 1 que apresenta desempenho 09 vezes melhor que o microcanal reto, e para geometria serpentina $3 D 1$ que apresenta desempenho 19 vezes melhor que o microcanal reto.

A geometria zigzag 3D 1 é fruto da investigação realizada no estudo 2. Este estudo identificou os possíveis arranjos espaciais entre cotovelos, bem como, as melhores distâncias entre os cotovelos para os arranjos identificados, permitindo a proposição e investigação dessa geometria. Apesar da geometria zigzag 3D 1 não apresentar a mesma performance da geometria serpentina $3 D$ 1, ela também é uma geometria de alta performance em comparação ao encontrado no estado da arte. Portanto, a geometria zigzag 3D 1 é uma contribuição original ao estado da arte dos micromisturadores.

A mudança de regime permitiu identificar para a geometria serpentina 3D 1 pontos de mesma eficiência de mistura para tempos de residência diferentes em duas ordem de grandeza. Ou seja, uma otimização do tempo de processo em $10^{2}$. 
Para finalizar, considerando as distâncias entre os cotovelos mais efetivas, restaram apenas 04 geometrias baseadas em sucessivos cotovelos, como mostradas na tabela 58. Observando a tabela, verifica-se que o pior caso é a geometria zigzag 2, enquanto, o melhor caso é a serpentina 3D 1. Com estas duas geometrias foram conduzidos os próximos estudos.

A geometria zigzag 2 é uma geometria aplicada com sucesso a produção de biodiesel (Wen, 2009). Suas características serão investigadas e comparadas com a geometria serpentina 3D 1, a escolhida para o processo de produção do biodiesel.

Tabela 58. Índice de comparação do desempenho das geometrias estudadas para $R e=100$.

\begin{tabular}{|c|c|}
\hline Dispositivos & Indice de comparação \\
\hline onda quadrada 2 & $\mathbf{2 , 9 1}$ \\
\hline zigzag 2 & $\mathbf{1 , 7 4}$ \\
\hline serpentina 3D 1 & 19,23 \\
\hline zigzag 3D 1 & $\mathbf{9 , 0 2}$ \\
\hline
\end{tabular}

O estudo computacional 4 foi realizado com 10 geometrias baseadas em zigzag, com dimensões fixas, volume, diâmetro hidráulico e comprimento. Foi modulado número de seções que compõe a geometria zigzag de 1 a 10.

Foi possível identificar os regimes de escoamento que as geometrias trabalharam no intervalo de Re estudado, de 0,01 a 100, em função da visualização dos mapas de velocidade e dos parâmetros fluidodinâmicos obtidos numericamente:

- regime de escoamento laminar para Re entre 0,01 e 10, e

- regime de escoamento intermediário para Re entre 10 e 100.

A eficiência de mistura foi melhorada em uma ordem de grandeza em função da modulação do número de seções. A tabela 59 mostra a comparação da eficiência de mistura relativamente a uma seção. 
Tabela 59. Comparação da eficiência de mistura relativamente a uma seção

\begin{tabular}{|c|c|}
\hline Número de seções & Eficiência relativa $(\mathrm{Re}=100 / \mathrm{t}=0,07 \mathrm{~s})$ \\
\hline 1 & 1,00 \\
\hline 2 & 1,41 \\
\hline 3 & 1,47 \\
\hline 4 & 1,85 \\
\hline 5 & 1,73 \\
\hline 6 & 2,82 \\
\hline 7 & 3,20 \\
\hline 8 & 2,93 \\
\hline 9 & 3,36 \\
\hline 10 & 10,47 \\
\hline
\end{tabular}

O estudo computacional 5 foi realizado para extrair as características da geometria serpentina 3D 1 para mistura de fluidos. Para alcançar este objetivo foi estudada a influência do $D_{h}$ e do número de seção na eficiência de mistura.

Primeiro definiu-se o intervalo de trabalho com a análise dos mapas e parâmetros fluidodinâmicos. O regime intermediário de interesse foi encontrado para Re entre 10 e 100, pois nessa região com a geometria serpentina 3D 1 efetiva-se mistura com parâmetros de processo desejáveis.

Trabalhando a eficiência de mistura conseguiu-se isolar e entender a influência da variação do diâmetro hidráulico e o do número de seções no desempenho desta geometria. A diminuição do diâmetro hidráulico conduz a processos mais rápidos mantendo a qualidade de mistura constante. $O$ aumento do número de seções conduz a processos mais eficientes. A tabela 60 mostra a eficiência de mistura relativa a geometria com 1 seção, para $R e=10$ e $R e=100$. Observa-se que 0 aumento do número de seções melhora fortemente a qualidade de mistura.

Tabela 60. Índice comparativo em função do número de seções.

\begin{tabular}{|c|c|c|}
\hline Número de seções & $\begin{array}{c}\text { Eficiência relativa } \\
\mathrm{Re}=10\end{array}$ & $\begin{array}{c}\text { Eficiência relativa } \\
\mathrm{Re}=100\end{array}$ \\
\hline 1 & 1 & 1 \\
\hline 2 & 1,62 & 2,62 \\
\hline 4 & 4,84 & 17,30 \\
\hline 8 & 46,25 & 375,51 \\
\hline 16 & 660,19 & 104395,80 \\
\hline
\end{tabular}

Para quantificar essa melhora na qualidade de mistura foi traçada a curva de eficiência de mistura em função do número de seções, conforme mostrado no gráfico 39. 


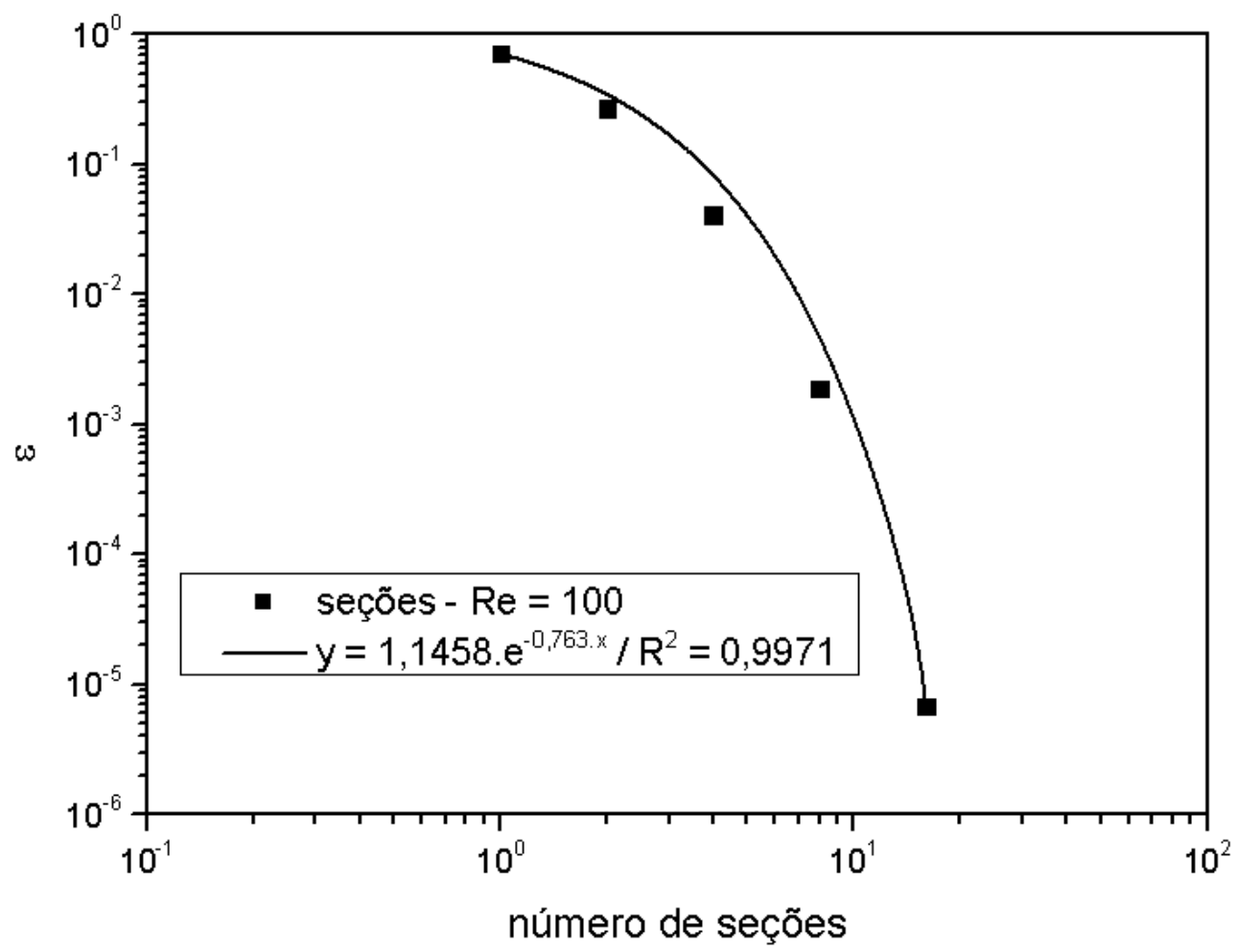

Gráfico 39. Comportamento da geometria serpentina 3D em função do número de seções.

Com este gráfico conseguiu-se determinar uma curva característica do processo realizado com a geometria serpentina $3 \mathrm{D} 1$, mostrando um comportamento exponencial entre o aumento do número de seções e a melhor eficiência de mistura.

A determinação do comportamento exponencial da geometria serpentina $3 D$ 1 para intensificação do processo de mistura, respeitando as condições de processo estabelecidas neste estudo, representa uma contribuição original ao estado da arte.

O estudo computacional 6 foi realizado com a geometria escolhida serpentina 3D 1, com 16 seções e diâmetro hidráulico de $600 \mu \mathrm{m}$. O fluido de trabalho foi o óleo a $60 \stackrel{\circ}{\circ}$, usando para o cálculo do escoamento os seguintes parâmetros: densidade de $900 \mathrm{~kg} / \mathrm{m}^{3}$ e viscosidade dinâmica de $16 \cdot 10^{-3} \mathrm{~Pa}$. $\mathrm{O}$. uso desse fluido de trabalho, relaciona diretamente este estudo ao processo de produção do biodiesel.

Este estudo permitiu a obtenção de dois parâmetros de referência para a composição do micromisturador com o módulo de tempo de residência, que foi realizado no capítulo 5:

- Ponto de trabalho: $\mathrm{Re}=10$;

- Eficiência de mistura: $8 \cdot 10^{-5}$. 
Em função de todos esses estudos computacionais é possível sintetizar o processo de escolha e otimização de uma geometria de micromisturador para aplicação em processos químicos, como é feito a seguir.

O processo de escolha de uma geometria baseada em cotovelos sucessivos para aplicação em um processo químico usando simulações numéricas pode ser resumida com seguintes os passos:

- Estabelecer um padrão de comparação identificando os regimes de escoamento num determinado intervalo do número de Reynolds. O padrão adotado neste trabalho foi o microcanal e a investigação computacional identificou o intervalo de trabalho de Re entre 0,01 e 100 (regime de escoamento);

- Dentro do intervalo de Re estabelecido, investigaram-se os possíveis arranjos espaciais entre dois cotovelos sucessivos, bem como, as distâncias entre cotovelos mais adequadas para o projeto das geometrias;

- Determinação da transição de regime de escoamento, de laminar para intermediário, das diversas geometrias baseadas em sucessivos cotovelos, propostas em função da investigação da etapa anterior, comparando com o microcanal reto;

- Definição do parâmetro eficiência de mistura, que permitiu a escolha da geometria com melhor desempenho, serpentina 3D 1, além de estabelecer um índice de comparação entre as diversas geometrias estudadas numa determinada condição ótima escolhida em função da transição de regime de escoamento.

O processo de otimização da geometria escolhida, serpentina $3 D$ 1, foi determinado em função dos seguintes passos:

- Determinação da transição do regime de escoamento para determinar um ponto de trabalho após a transição de regime;

- Modulação do diâmetro hidráulico para definir o tempo mínimo de processo;

- Modulação do número de seções para obter a eficiência de mistura desejada. Nesta etapa de investigação obteve-se uma importante contribuição para o estado da arte, a determinação do comportamento exponencial da eficiência de mistura em função do número de seções para a geometria serpentina 3D 1.

Finalizando, os estudos experimentais levaram as seguintes conclusões: 
Produção de biodiesel. Os resultados mostraram a formação de biodiesel e glicerina. Comparando-se com uma amostra de referência (REF) pode-se concluir que os resultados são pobres, pois as amostras geradas apresentaram diferenças significativas em relação a uma amostra de referência. Apenas uma das amostras (D1) apresentou 03 dos 05 parâmetros analisados próximos da amostra de referência. Os resultados mostram a necessidade de se estabelecer uma metodologia de escolha e otimização de geometrias para micromisturadores para aplicação no processo de produção do biodiesel.

Produção de emulsões. Os resultados indicaram que a produção de uma emulsão como uma etapa para produção de BIODIESEL é viável. Logo, a composição de um micromisturador para produção de emulsão com módulo de tempo de residência para efetivação da reação química do processo de produção do biodiesel, foi explorada no capítulo 5 .

No capítulo 5, foi desenvolvida uma metodologia computacional para otimização do tempo de residência do micromisturador e MTR.

A metodologia computacional usada neste trabalho permitiu otimizar um micromisturador para o processo de produção do biodiesel e conseqüentemente projetar o sistema reacional composto pelo micromisturador e um módulo de tempo de residência.

O projeto do sistema reacional baseado em simulações numéricas prevê um tempo de processo de 2,8 s, considerando a geometria serpentina 3D 1, com 160 seções e $D_{h}=600 \mu \mathrm{m}$, combinando com um trecho de microcanal reto (MTR) com comprimento de 22,6 $\mathrm{cm}$ e $D_{\mathrm{h}}=800 \mu \mathrm{m}$.

Este resultado é relevante e original para o estado da arte, pois os resultados experimentais encontrados na literatura apontam tempos de processo de $17 \mathrm{~s}$ a 6 min, usando a rota microtecnológica.

Portanto, este trabalho contribui de forma relevante para o processo de desenvolvimento de microrreatores para aplicação no processo de produção do biodiesel, e conseqüentemente de outros processos similares.

O diálogo entre a modelagem computacional e a investigação experimental conduzirá brevemente a um processo de produção de biodiesel, usando a rota microtecnológica, mais rápido, eficiente e robusto. 
No capítulo 6 foi mostrado o resultado final, onde o objetivo principal do trabalho foi alcançado, disponibilizar o protótipo de um microrreator fabricado em LTCC para produção de biodiesel. As dificuldades para fabricação em LTCC do protótipo foram superadas.

A metodologia computacional aliada a algumas investigações experimentais (Estudo 1: Produção de biodiesel e Estudo 2: Produção de emulsões) permitiu escolher e otimizar o micromisturador e o módulo de tempo de residência, para o desenvolvimento do microrreator com parâmetros ótimos. 


\section{CONCLUSÃO}

Com base nos principais resultados do trabalho, elencados no capítulo anterior, conclui-se que os principais objetivos foram alcançados:

- Desenvolvimento de um protótipo de um microrreator em tecnologia LTCC para aplicação no processo de produção do biodiesel;

- Otimização de uma geometria de micromisturador para integração no protótipo, que é o ponto crítico do sistema proposto.

Alcançados os objetivos propostos, listam-se as contribuições deste trabalho:

- Determinação da transição de regime de escoamento de laminar para intermediário, importante para a otimização das geometrias;

- Relacionamento entre regime intermediário e advecção caótica;

- Determinação do comportamento exponencial da geometria serpentina 3D em função do número de seções;

- Otimização do sistema reacional (micromisturador + MTR) obtendo-se um tempo de processo de 2,8 $\mathrm{s}$, respeitando as características de projeto determinadas ao longo do trabalho;

- Disponibilização de um protótipo para aplicação no processo de produção do biodiesel;

- Disponibilização de metodologias computacionais para otimização de processos usando a via microtecnológica, podendo ser adaptadas e aplicadas em diversos processos químicos.

No início do trabalho, o tema foi contextualizado dentro de três áreas do conhecimento: microtecnologia, intensificação de processo e biocombustíveis. Portanto, o resultado final do trabalho dessas três articulações: foi fabricado um microrreator baseado em conceitos microtecnológicos, onde o modelo teórico indica que é possível intensificar o processo de produção de biodiesel até $2,8 \mathrm{~s}$.

A ferramenta computacional utilizada foi fundamental para obtenção dos resultados e cumprimento dos principais objetivos. 


\section{TRABALHOS FUTUROS}

Apesar do foco dedicado a proposta de otimização de uma geometria do micromisturador, do $\mathbf{M T R}$ e a superação das dificuldades de fabricação para conceber o protótipo do microrreator, alguns estudos preliminares foram começados e não terminados, ficando como proposta para trabalhos futuros:

- Sistema de medição e controle de vazão: (1) o circuito controlador do sistema não foi desenvolvido, (2) os sensores de vazão não foram caracterizados;

- Sistema de medição e controle de temperatura: (1) a realimentação da temperatura medida pela resistência do tipo PT-100 no controle não foi realizada, (2) uma caracterização mais ampla não foi realizada;

- Medidas de conversão de biodiesel com a ferramenta disponibilizada não foram realizados.

Portanto, estes itens elencados ficam como proposta para trabalhos futuros. Em particular, o terceiro item, onde parâmetros como tipo e concentração de catalisador, temperatura de processo, razão molar entre óleo/álcool, podem ser explorados.

Além da exploração desses parâmetros, conforme sugestão do Dr. João Guilherme Rocha Poço (LPP - CTPP), a adição de querosene ou biodiesel no óleo para melhorar a viscosidade e deslocar o equilíbrio da reação no sentido direto, também é uma proposta de trabalhos futuros.

Além disso, em função da determinação, específica para as condições tratadas no trabalho, do comportamento exponencial da geometria serpentina 3D, uma importante proposta de trabalho futuro é a generalização desse comportamento exponencial em função de um coeficiente de transferência de massa, servindo assim de regra prática para aplicação em uma larga gama de processos químicos. 


\section{APÊNDICE A - SISTEMA DE MEDIÇÃO E CONTROLE DE VAZÃO}

O objetivo do sistema de medição e controle de vazão será manter a vazão total do sistema, bem como manter a proporção entre as vazões das duas fases envolvidas na produção de biodiesel, álcool e óleo. O sistema será constituído por duas bombas de e por dois sensores de vazão.

A medição de vazão em microcanais pode ser realizada seguindo diversos princípios dos mais variados campos da física. A figura A1, adaptada de Nguyen (2002), elenca diversos princípios englobando os seguintes campos da física: Acústica, Mecânica, Física Nuclear, Ótica, Estocástica, Termodinâmica, Eletrodinâmica e Fluidodinâmica.

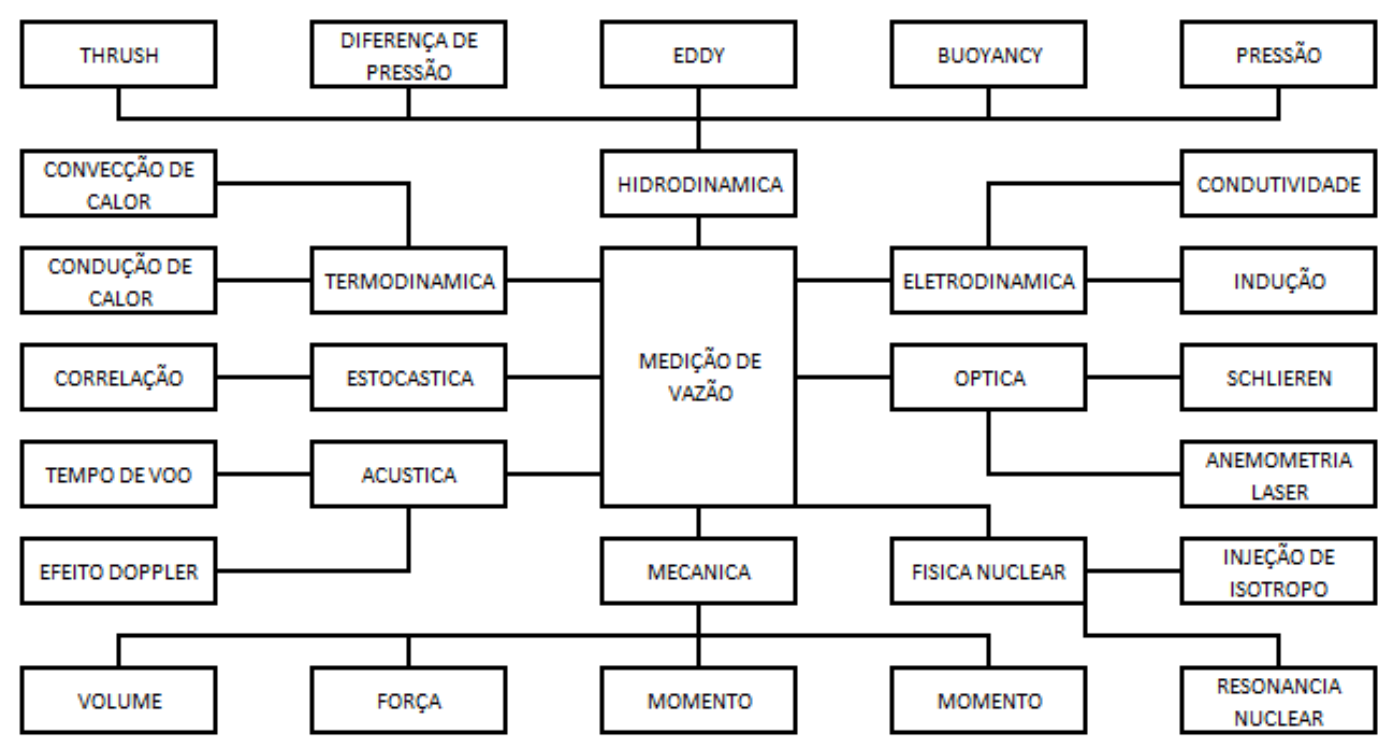

Figura A1. Princípios físicos de medição de vazão.

Basicamente, este trabalho foca no desenvolvimento de um microssistema aplicado à uma reação química por meio de um escoamento contínuo. A medição de vazão estará integrada neste microssistema e a escolha do princípio de medição é importante para especificação do projeto.

Aproveitando toda a discussão em relação ao escoamento em microcanais desenvolvida no capítulo 4, pode-se identificar o princípio de diferença de pressão, um dos citados na figura A1, como o mais compatível para ser especificado neste microssistema. 
Em regime de escoamento laminar em microcanais, a diferença de pressão é caracterizada pela seguinte equação

$$
\Delta P=R_{h} * Q
$$

onde $\Delta P$ é a diferença de pressão, $Q$ é a vazão e $R_{h}$ é a resistência hidráulica, ou seja, o fator proporcionalidade entre diferença de pressão e vazão.

Considerando que os microcanais característicos deste trabalho são de seção transversal retangular, a resistência hidráulica é calculada pela seguinte equação

$$
R_{h}=\frac{12 * \eta * L}{h * w^{3}} * \frac{1}{\left(1-\left(\frac{192}{\pi^{5}} * \frac{w}{h} * \sum_{i=1,3,5, \cdots}^{\infty} \frac{\tanh \left(\frac{i * \pi * h}{2 * w}\right)}{i^{5}}\right)\right)}
$$

onde $\eta$ é a viscosidade dinâmica, $L$ é o comprimento do microcanal, $h$ é o lado menor e w é o lado maior da seção transversal retangular.

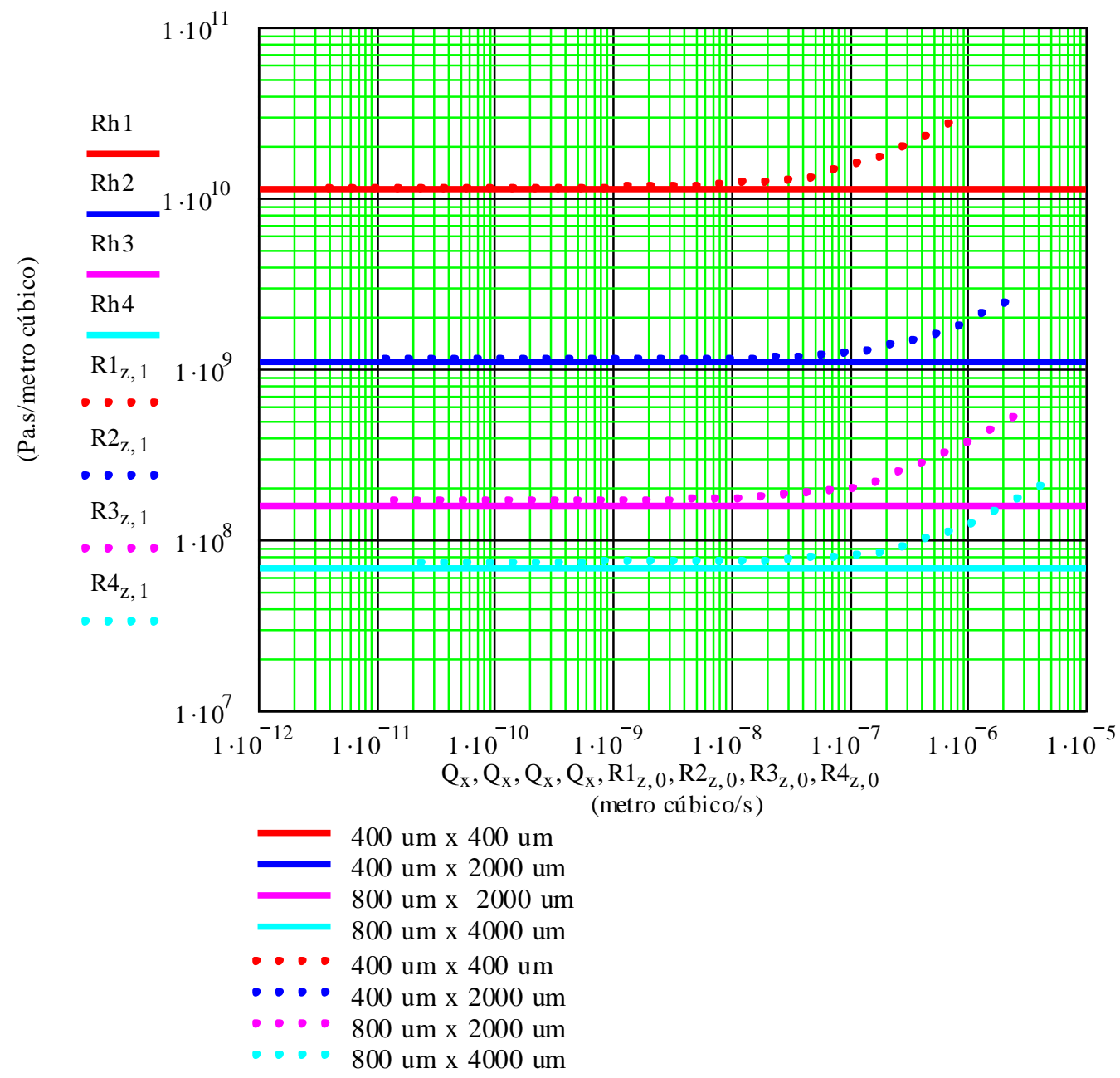

Figura A2. Comparação entre dados calculados analiticamente (linhas sólidas) e simulados numericamente (linhas pontilhadas). 
A figura A2 mostra a comparação entre dados calculados analiticamente e simulados numericamente. Observa-se que os dados calculados analiticamente aceitam qualquer valor de vazão. No entanto, nas simulações numéricas é possível determinar a transição de regime.

O interesse é pelo intervalo onde a resistência hidráulica é constante (regime laminar), pois de forma imediata relaciona-se a medida de diferença de pressão com a vazão do sistema.

Considerando o ponto de trabalho do micromisturador, projetou-se duas resistências hidráulicas com seção transversal de $2 \mathrm{~mm} \times 0,8 \mathrm{~mm}$ e comprimento de $30 \mathrm{~mm}$.

Apesar de o micromisturador estar trabalhando em regime intermediário, como as resistências hidráulicas para medição de vazão são baseadas em canais retos, não existe incompatibilidade, pois o intervalo de Re para regime laminar é maior em canais retos do que em canais com sucessivos cotovelos.

Logo, pode-se trabalhar com os dois dispositivos, em uma determinada vazão, onde o micromisturador esteja em regime intermediário e a resistência hidráulica da medição de vazão esteja em regime laminar. A figura A3 mostra os sensores de pressão especificados neste trabalho.
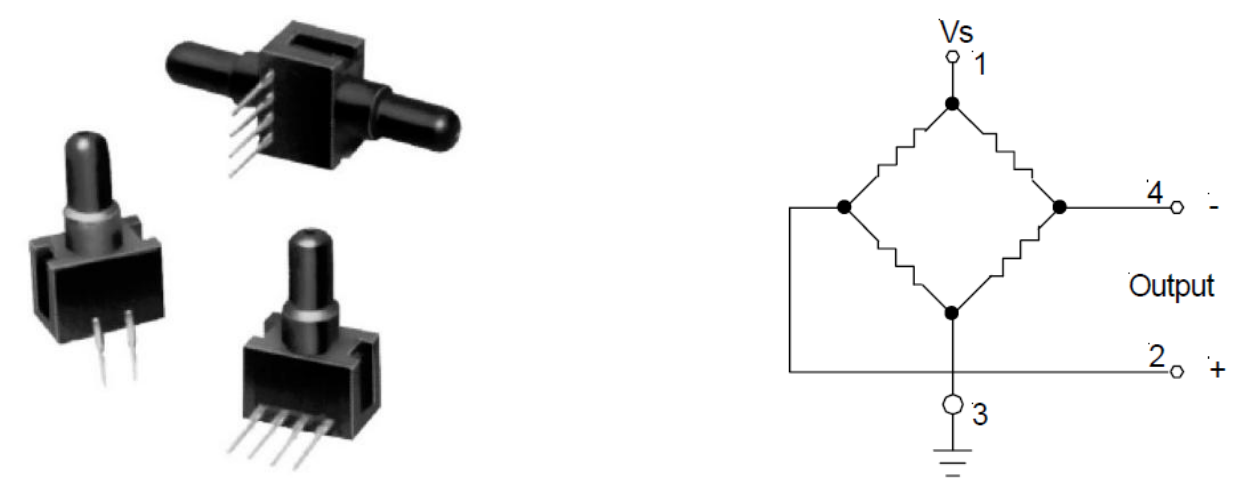

Figura A3. Sensores de pressão da Sensortechnics (www.sensortechnics.com) e o circuito de polarização.

Referências

Nguyen, N.-T., and Wereley, S. T., "Fundamentals and Applications of Microfluidics," Artech House, 2002, p. 1-10. 


\section{APÊNDICE B - SISTEMA DE MEDIÇÃO E CONTROLE DE TEMPERATURA}

O principio de medição de temperatura escolhido foi o baseado na variação de resistência elétrica em função da variação da temperatura. Um dispositivo comercial escolhido foi o PT-100, amplamente usado em ensaios acadêmicos e industriais. A figura B1 mostra o PT-100 adquirido da empresa Enercorp (www.enercorp.com), com suas principais dimensões.

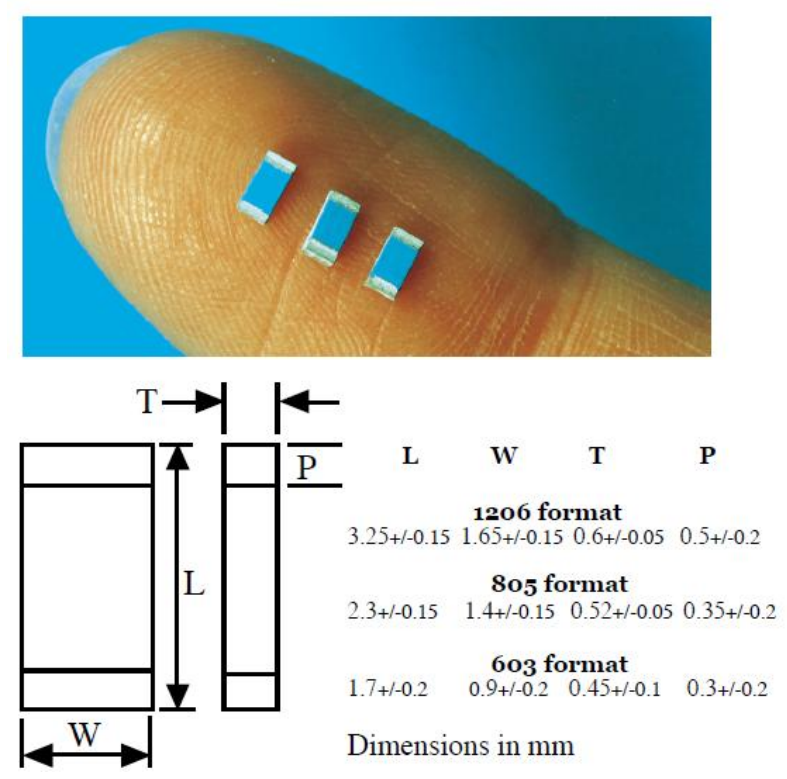

Figura B1. PT-100 da empresa Enercorp (www.enercorp.com).

A vantagem de se trabalhar com este tipo de dispositivo é que ele apresenta variação de resistência linear em função da temperatura e seus dados podem ser encontrados tabelados nas mais diversas fontes, como mostrado na tabela B1. 
Tabela B1. PT-100: Resistência em função da temperatura.

\begin{tabular}{|c|c|c|c|c|c|c|c|c|c|c|}
\hline $\mathrm{T}$ & \multicolumn{2}{|c|}{$\begin{array}{c}\text { PT100 } \\
\alpha=0.00395\end{array}$} & \multicolumn{2}{|c|}{$\begin{array}{c}\text { PT } 100 \\
g=0.003926\end{array}$} & \multicolumn{2}{|c|}{$\begin{array}{c}\text { PT25 } \\
\alpha=0.003926\end{array}$} & \multicolumn{2}{|c|}{$\begin{array}{c}\text { PT10 } \\
\alpha=0.003926\end{array}$} & \multicolumn{2}{|c|}{$\begin{array}{c}\text { ITS-90 } \\
\text { Reference Punction }\end{array}$} \\
\hline-200 & 18.52 & 0.43 & $16.9 \mathrm{~B}$ & 0.43 & 4.24 & 0.11 & & & 0.16975189 & 0.00430 \\
\hline-160 & 35.54 & 0.42 & 34.26 & 0.43 & 8.57 & 0.11 & & & 0.24263938 & $0.0042 \mathrm{~B}$ \\
\hline-140 & $43.8 \mathrm{Bg}$ & 0.41 & 42.76 & 0.42 & 10.69 & 0.11 & & & 0.42764904 & 0.00422 \\
\hline-120 & 52.11 & 0.41 & 51.15 & 0.42 & 12.79 & 0.10 & & & 0.51154679 & 0.00417 \\
\hline-90 & 68.33 & 0.40 & $67.6 \mathrm{~B}$ & 0.41 & 16.92 & 0.10 & & & 0.67679040 & 0.00410 \\
\hline-60 & 76.33 & 0.40 & 75.84 & 0.41 & 18.96 & 0.10 & & & 0.75938970 & 0.00407 \\
\hline-40 & 84.27 & 0.40 & B3.94 & 0.40 & 20.99 & 0.10 & & & 0.83943592 & 0.00404 \\
\hline-20 & 92.16 & 0.29 & 91.99 & 0.40 & 23.00 & 0.10 & & & $0.9199458 \mathrm{~B}$ & 0.00401 \\
\hline 0 & 100,00 & 0.39 & 100.00 & 0.40 & 25.00 & 0.10 & 10.00 & 0.040 & 0.99996011 & 0.00399 \\
\hline 20 & 107.79 & 0.39 & 107.95 & 0.40 & 26.99 & 0.10 & 10.79 & 0.040 & 1.07948751 & 0.00396 \\
\hline 100 & 139.51 & 0.39 & 139.28 & 0.29 & 34.82 & 0.10 & 13.93 & 0.039 & 1.29277281 & 0.00387 \\
\hline 120 & 146.07 & 0.39 & 146.99 & 0.38 & 36.75 & 0.10 & 14.70 & 0.039 & 1.46989789 & 0.00384 \\
\hline 140 & $153.5 B$ & 0.37 & 154.65 & 0.38 & $3 B .66$ & 0.10 & 15.47 & 0.039 & 1.54654781 & 0.00392 \\
\hline 160 & 161.05 & 0.37 & 162.27 & 0.39 & 40.57 & 0.09 & 16.23 & 0.039 & 1.62272420 & 0.00390 \\
\hline 180 & $168.4 B$ & 0.37 & 169.84 & 0.39 & 42.46 & 0.09 & 16.99 & 0.039 & 1.69942990 & 0.00377 \\
\hline 200 & 17586 & 0.37 & 177.37 & 0.37 & 44.34 & 0.09 & 17.74 & 0.037 & $1 . T 7366331$ & 0.00375 \\
\hline 220 & 183.19 & 0.37 & 184.94 & 0.37 & 46.21 & 0.09 & 18.48 & 0.037 & 1. B4942945 & 0.00373 \\
\hline 240 & 180.47 & 0.36 & 192.27 & 0.37 & 48.07 & 0.09 & 19.23 & 0.037 & 1.92272984 & 0.00370 \\
\hline 280 & 197.71 & 0.36 & 199.66 & 0.37 & 49.91 & 0.09 & 19.97 & 0.037 & 1. $9965629 \mathrm{~B}$ & 0.00368 \\
\hline 290 & 20490 & 0.36 & 206.99 & 0.37 & 51.75 & 0.09 & 20.70 & 0.037 & 2.08993313 & 0.00366 \\
\hline 300 & 212.05 & 0.36 & 214.28 & 0.36 & 53.57 & 0.09 & 21.43 & 0.036 & 2.14284029 & 0.00363 \\
\hline 460 & 267.56 & 0.34 & 270.94 & 0.34 & 67.74 & 0.09 & 27.09 & 0.034 & 2.70942664 & 0.00345 \\
\hline 490 & 27429 & 0.34 & 277.81 & 0.34 & 69.45 & 0.09 & 27.78 & 0.034 & 2.77914985 & 0.00342 \\
\hline 500 & $2 \mathrm{BO} 9 \mathrm{~B}$ & 0.33 & 284.64 & 0.34 & 71.16 & 0.08 & 28.46 & 0.034 & 2.B4639697 & 0.00340 \\
\hline 520 & & & 291.42 & 0.34 & 72.95 & 0.08 & 29.14 & 0.034 & 2.91416913 & $0.0033 B$ \\
\hline 540 & & & 298.15 & 0.34 & 74.54 & 0.08 & 29.81 & 0.034 & 2.99145939 & 0.00335 \\
\hline $5 B O$ & & & 304.93 & 0.33 & 76.21 & 0.08 & 30.48 & 0.033 & 3.04826779 & 0.00333 \\
\hline 590 & & & 311.46 & 0.33 & 77.96 & 0.08 & 31.15 & 0.033 & 3.11459044 & 0.00330 \\
\hline 600 & & & 318.04 & 0.33 & 79.51 & 0.08 & 31.90 & 0.083 & 3.18042462 & $0.0032 \mathrm{~B}$ \\
\hline 700 & & & & & & & 35.02 & 0.032 & 3.50219482 & 0.00316 \\
\hline $\mathrm{BOO}$ & & & & & & & $3 B .12$ & 0.030 & 3.81156573 & 0.00303 \\
\hline 900 & & & & & & & 41.09 & 0.029 & 4.10972717 & 0.00291 \\
\hline 1000 & & & & & & & 43.94 & 0.029 & 4.39418009 & 0.00290 \\
\hline
\end{tabular}

Para realizar aquecimento foi escolhido um dispositivo baseado no efeito Peltier, onde o dispositivo é polarizado e apresenta uma fase fria e uma fase quente. Portanto, o aquecimento ou resfriamento é feito por uma diferença de temperatura. A figura B2 mostra o elemento Peltier utilizado no trabalho.

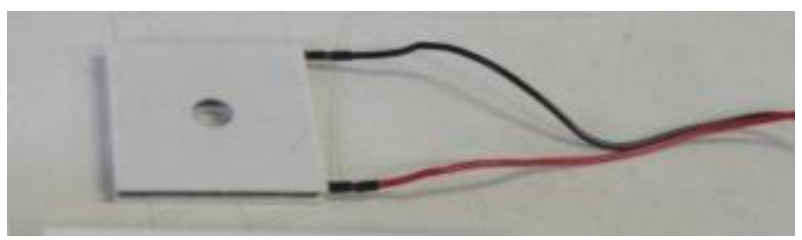

Figura B2. Elemento Peltier. 
Os elementos Peltier usados neste trabalho foram adquiridos na TE Technology, Inc, juntamente com o controlador.

O maior tamanho do elemento Peltier encontrado foi de $40 \mathrm{~mm} \times 40 \mathrm{~mm}$, o que se tornou em um problema para o trabalho com o microrreator, que tem corpo cerâmico após a sinterização de $60 \mathrm{~mm}$ x 60 mm, conforme mostra a figura B3.

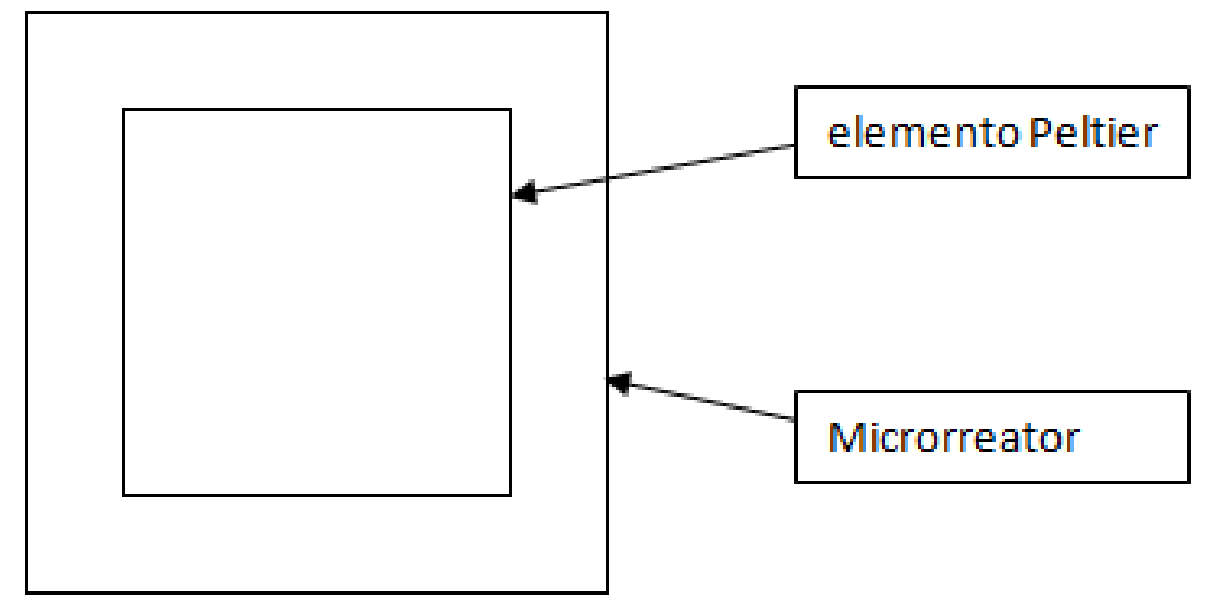

Figura B3. Tamanho do microrreator em relação ao tamanho do elemento Peltier.

Na montagem do módulo para produção de biodiesel, verificou que o elemento Peltier escolhido fornecia ao sistema a temperatura adequada, gerando uma diferença de temperatura $80^{\circ} \mathrm{C}$, entre a fase quente e a fase fria.

A principal preocupação nessa configuração da figura B3 é função da uniformidade de temperatura na borda do microrreator.

Para entender melhor o fenômeno simulações numéricas preliminares, foram desenvolvidas para verificar a uniformidade da temperatura.

O estudo foi conduzido em seis etapas, considerando o acréscimo de camadas condutoras e camadas refratárias:

1. Sistema: substrato + aquecedor (SA)

2. Sistema: substrato + aquecedor + condutor (SAC)

3. Sistema: substrato + aquecedor + refratario1F (SAR1F)

4. Sistema: substrato + aquecedor + refratario2F1C (SAR2F1C)

5. Sistema: substrato + aquecedor + refratario2F2C (SAR2F2C)

6. Sistema: substrato + aquecedor + condutor + refratario2F1C (SACR2F1C)

O estudo indica preliminarmente, que a etapa 6 (SACR2F1C), mostrou o melhor desempenho, conforme pode ser observado na figura B4. Na etapa, foi utilizada uma camada de material condutor e duas camadas de material refratário. 


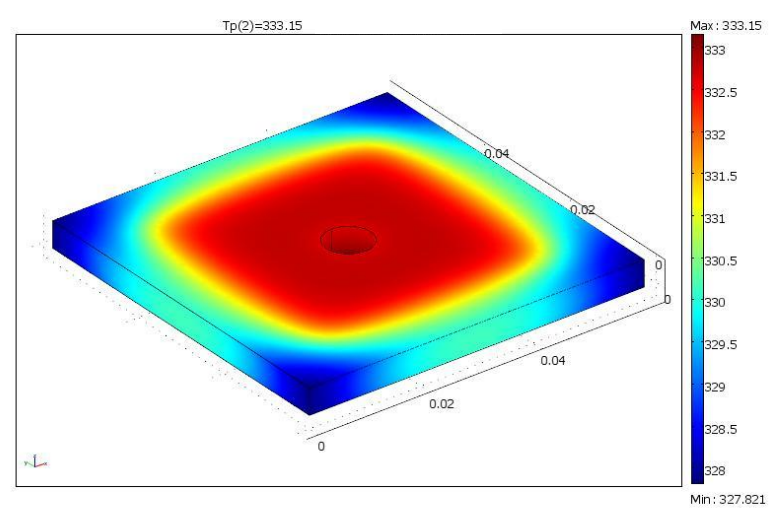

1

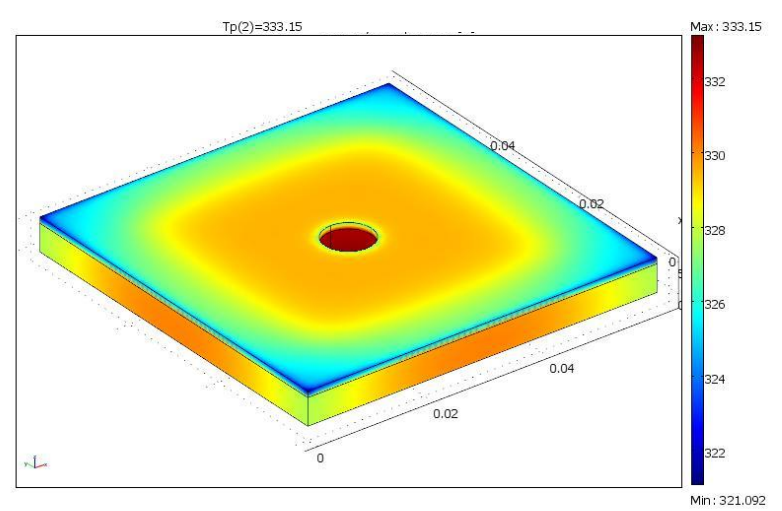

3

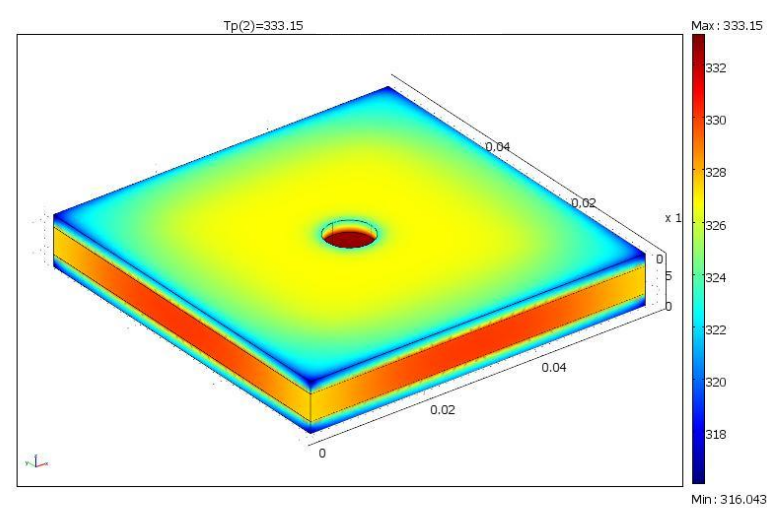

5

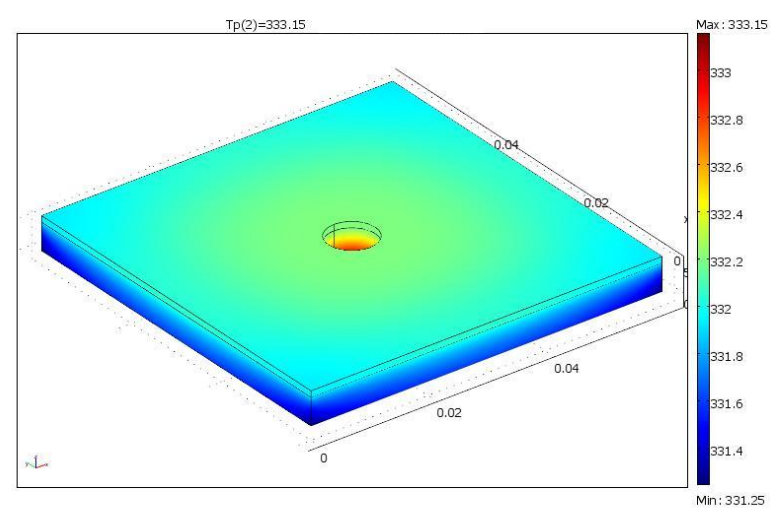

2

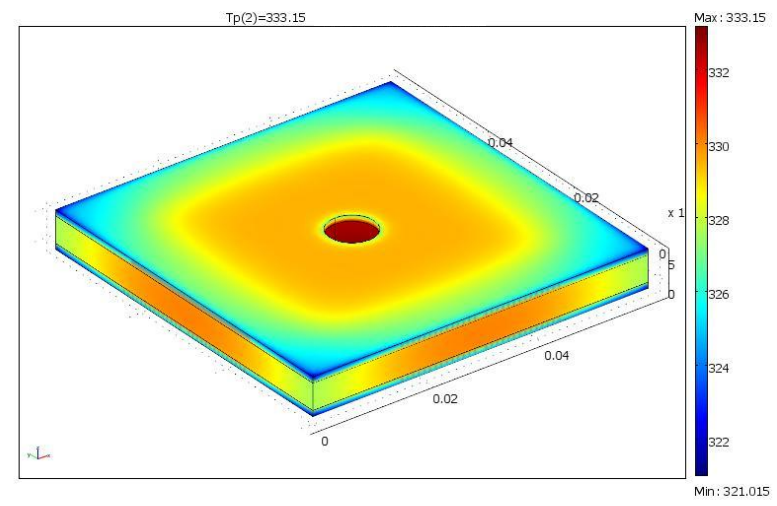

4

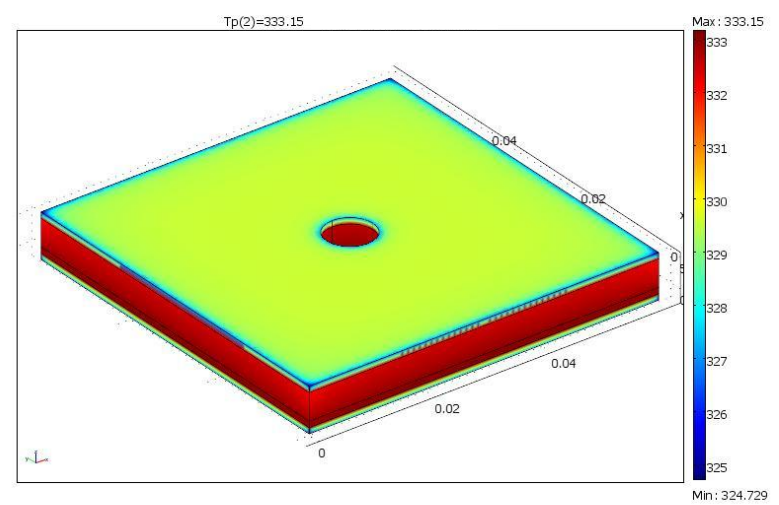

6

Figura B4. Estudo de uniformidade de temperatura. 


\section{APÊNDICE C - FABRICAÇÃO EM TECNOLOGIA LTCC}

A fabricação do microrreator foi realizada em tecnologia LTCC, que é um material comumente usado em MCM ("MultiChip Module"). A tecnologia LTCC para fabricação de dispositivos microfluídicos apresenta vantagens como: fabricação de dispositivos 3D; fabricação de módulos com dispositivos com funcionamento em vários domínios de energia (como exemplo um misturador de funcionamento mecânico e sensor de funcionamento elétrico), e auto-encapsulamento. A figura C1, mostra alguns produtos fabricados em LTCC.

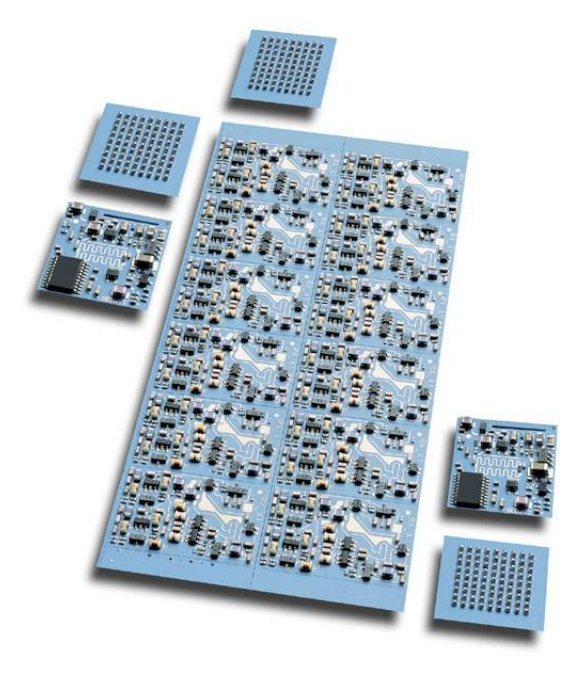

(a)

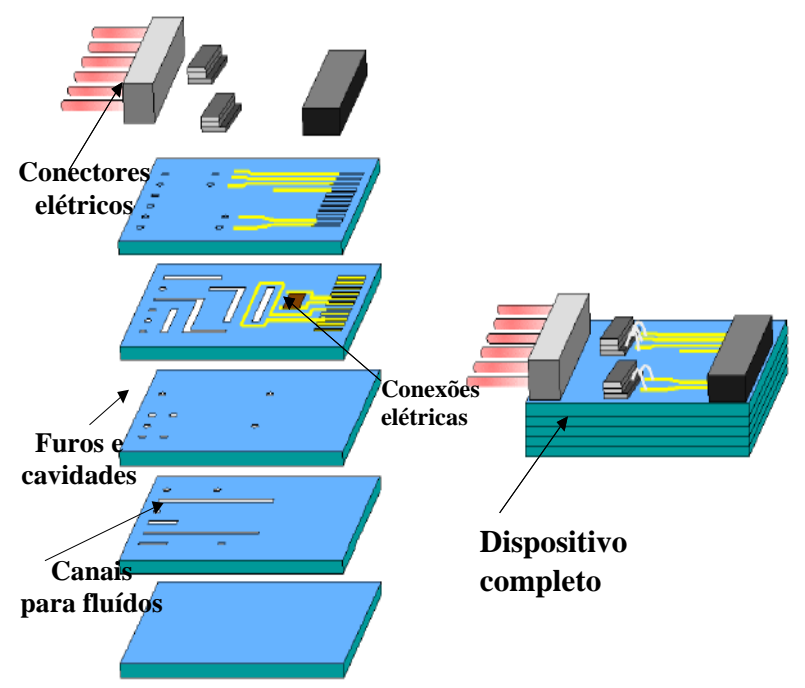

(b)

Figura C1. Tecnologia LTCC: (a) módulos eletrônicos e (b) módulo híbrido.

Enquanto, como desvantagens, pode-se citar: material cerâmico opaco que impossibilita a visualização do fluxo, sendo que o problema pode ser resolvido com a colocação de janelas de vidro ao longo da estrutura; e dimensão mínima, que em tecnologias como a do silício consegue-se estruturas abaixo de $1 \mu \mathrm{m}$, em LTCC (com o equipamento disponível para usinagem a laser) os limites são canais da ordem de $150 \mu \mathrm{m}$ no plano XY, que é o spot do laser. No eixo $Z$ o limite é 200 ou $100 \mu \mathrm{m}$, espessura da camada cerâmica.

Nesta tecnologia, depois da definição do projeto, a fabricação do dispositivo realiza-se basicamente com três etapas de processo: usinagem da cerâmica verde (LTCC), laminação e sinterização. O desenho ou o projeto dos dispositivos é 
realizado numa ferramenta de CAD comercial, onde cada camada do dispositivo a ser fabricado é desenhada individualmente.

Os dispositivos são dispostos em uma área de 3" x 3", que é a dimensão do molde usado para alinhamento e laminação das camadas. No desenho também são definidos furos nas extremidades que servirão de alinhamento entre as várias camadas e no caso de ter-se mais de um dispositivo na área mencionada é desenhada uma camada adicional, para servir de corte para separação dos dispositivos.

Na figura C2(a), mostra-se o desenho das camadas de dispositivos fabricados para teste, onde a camada na cor vermelha é a tampa inferior dos dispositivos, a camada na cor verde os canais inferiores, a camada na cor azul os canais superiores, a camada na cor ciano as entradas do dispositivo e na cor rosa cavidades para assentar as conexões de entrada.

$\mathrm{Na}$ figura $\mathrm{C} 3(\mathrm{~b})$ observe-se que as linhas na cor azul claro que delimitam os três dispositivos é apenas uma camada imaginária para o corte de separação dos dispositivos, não representando uma camada de cerâmica verde. Nota-se também os furos nas extremidades para alinhamento das camadas.

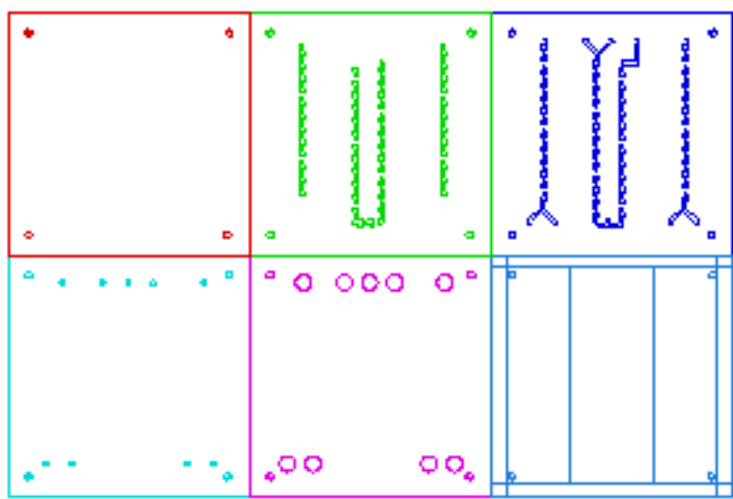

(a)

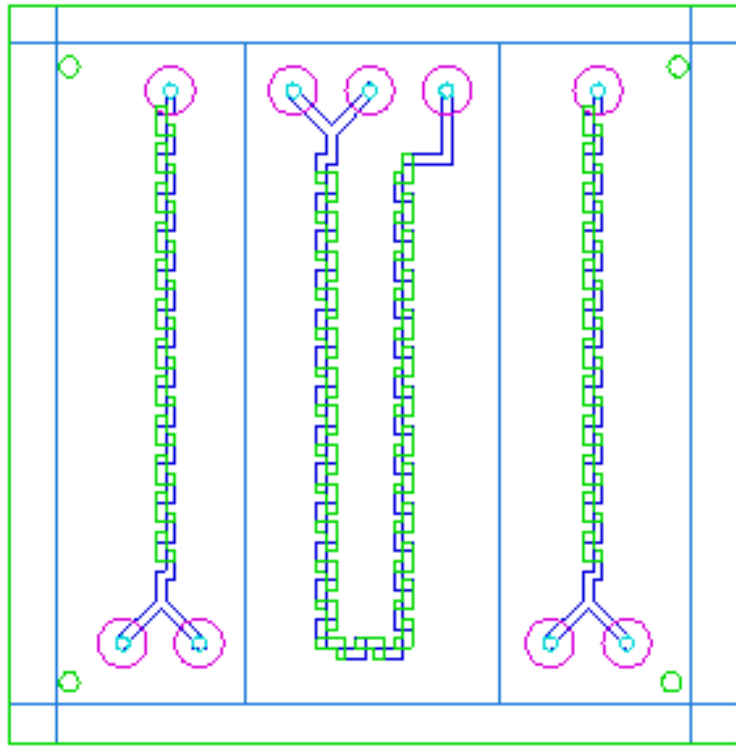

(b)

Figura C2. Projeto CAD.

Depois de desenhadas as camadas, elas são exportadas para o aplicativo que controla o laser, onde se definem parâmetros como velocidade de avanço e potência do laser. Portanto, com o uso deste aplicativo como interface inicia-se a etapa de usinagem. 
A usinagem é a etapa de processo onde são realizados os cortes e furos das várias camadas que formarão os dispositivos, segundo as formas definidas em desenho. A figura $\mathrm{C} 3(\mathrm{a})$ mostra esquematicamente como ficam as várias camadas depois da usinagem e na figura $\mathrm{C} 3(\mathrm{~b})$ mostra-se a foto de uma camada usinada.

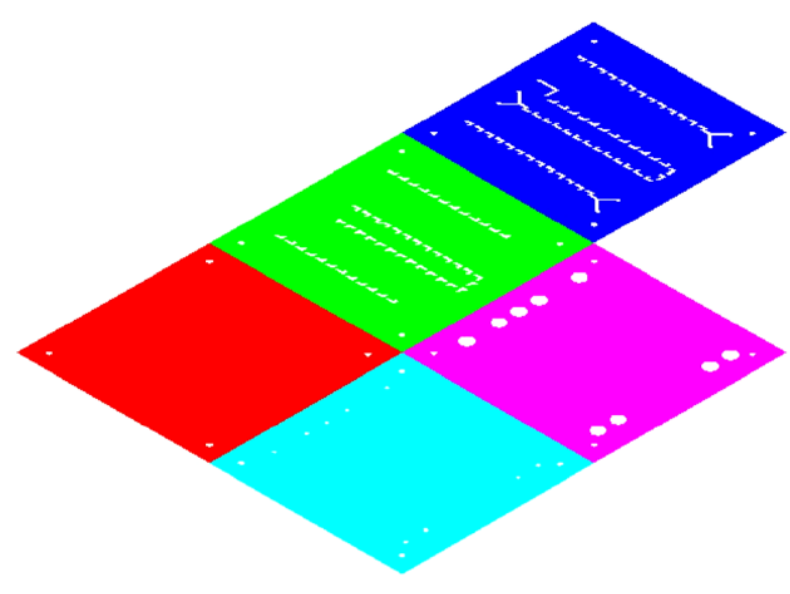

(a)

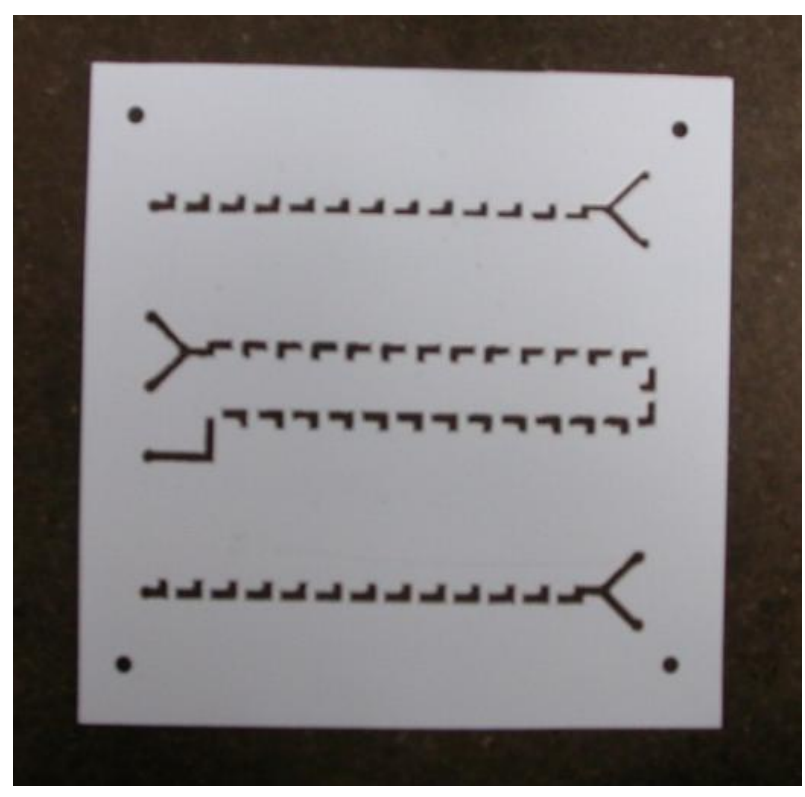

(b)

Figura C3. Usinagem: (a) esquema das camadas usinadas e (b) foto de uma camada usinada.

$\mathrm{Na}$ etapa de usinagem algumas situações características do processo devem ser apreciadas, pois influenciam na forma e dimensões do canal, por exemplo, a rugosidade das paredes do canal. A figura C4 mostra a foto de uma cerâmica usinada, exemplificando o arredondamento dos cantos, a inclinação e rugosidade das paredes.

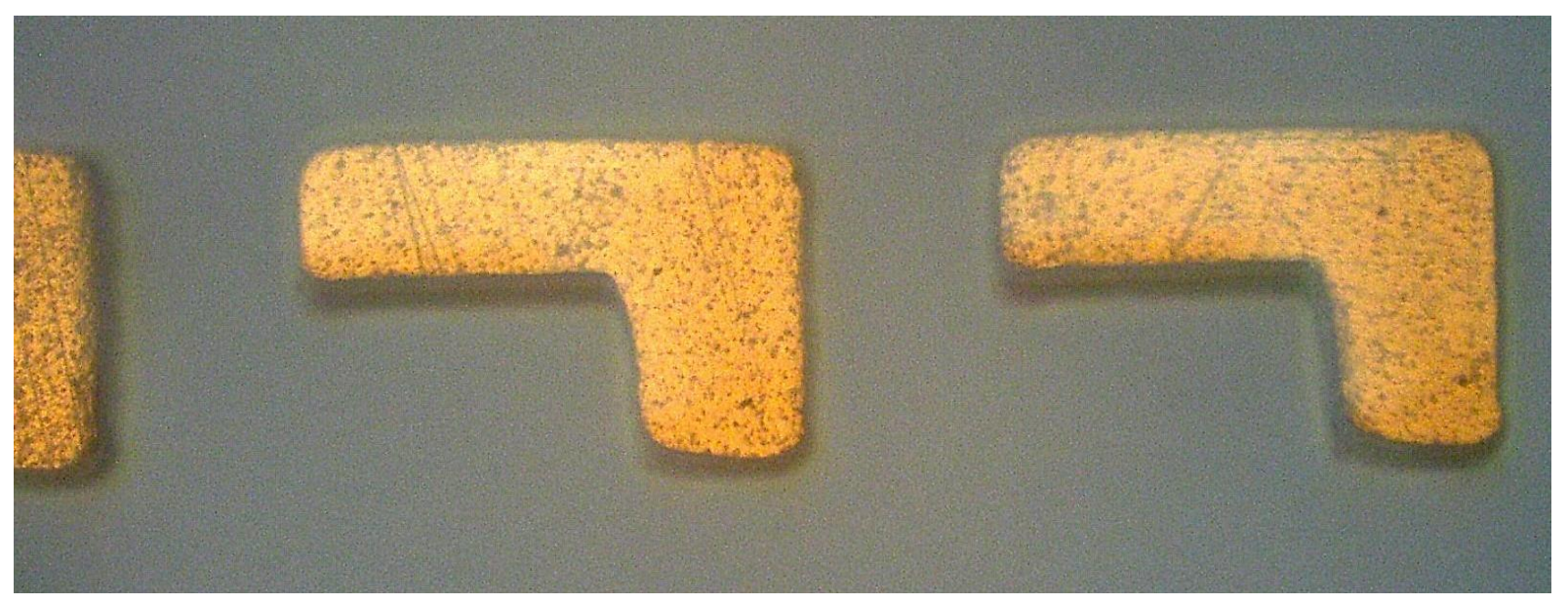

Figura C4. Detalhe da forma do canal após etapa de usinagem. 
A laminação é a etapa em que as camadas usinadas são alinhadas e coladas através de uma compressão com determinada carga e temperatura. As camadas usinadas são alinhadas numa placa (molde de alinhamento) com quatro pinos coincidindo os furos de alinhamento usinados em todas as camadas de cerâmica verde. Este molde com as camadas alinhadas é fechado por outra placa com quatros furos, formando o conjunto a ser submetido à compressão. A figura C5 mostra as duas placas do conjunto com as camadas usinadas de cerâmica verde.

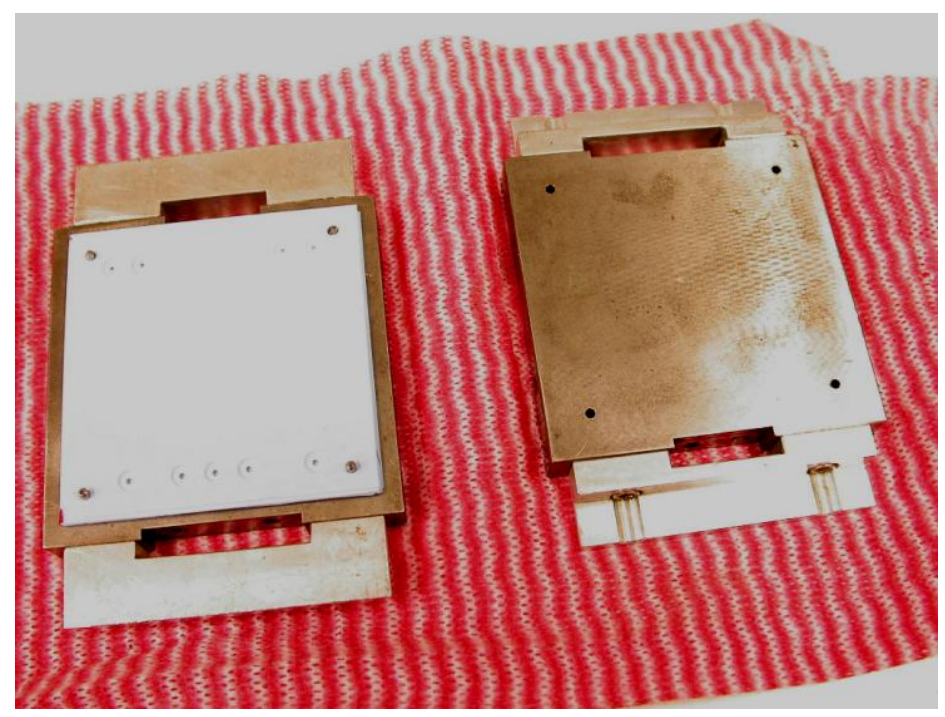

Figura C5. Molde para laminação.

Na laminação, a fase de alinhamento das camadas é o ponto na fabricação dos dispositivos, pois podem gerar formato de canal diferente do projetado.

A etapa de sinterização é realizada para dar rigidez mecânica a vitro-cerâmica utilizada na fabricação dos dispositivos. Nesta etapa o laminado cerâmico é colocado no forno em ambiente atmosférico e submetido ao perfil de temperatura, mostrado na figura $\mathrm{C} 6$.

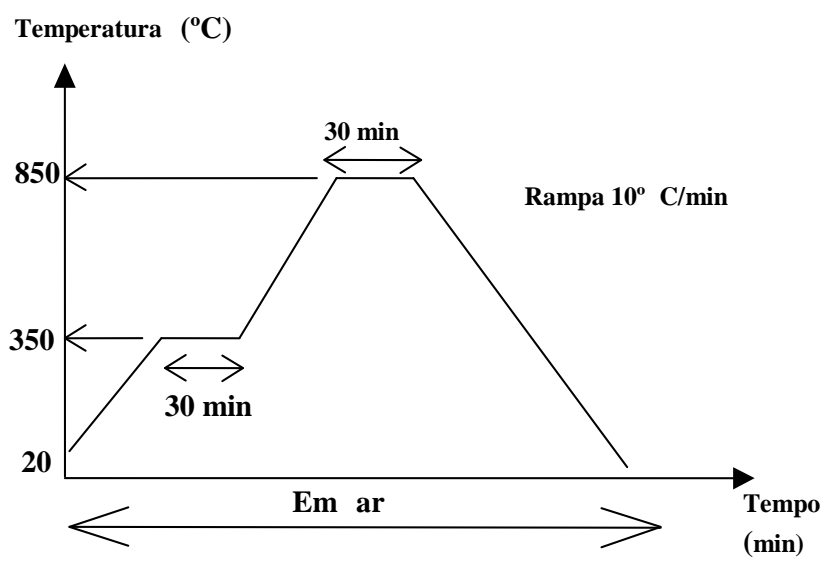

Figura C6. Perfil de temperatura da etapa de sinterização. 
Neste perfil de temperatura destacam-se algumas características importantes para a etapa de sinterização da cerâmica utilizada. Primeiramente, o patamar de temperatura a $350{ }^{\circ} \mathrm{C}$ por 30 minutos, realizado para eliminação dos compostos orgânicos presentes na cerâmica usada, restando apenas grãos de alumina e de vidro.

Com a temperatura em aproximadamente $650{ }^{\circ} \mathrm{C}$ acontece a transição vítrea. Neste fenômeno os grãos de vidro tornam-se líquidos e envolvem os grãos de alumina, sendo que estes estão no estado sólido.

No patamar de $850{ }^{\circ} \mathrm{C}$ por 30 minutos garante-se que todos os grãos de alumina sejam envoltos por vidro. Posteriormente a este patamar o forno é desligado e a temperatura começa a diminuir, começando assim a vitrificação da cerâmica, conferindo-Ihe rigidez mecânica. Na figura $\mathrm{C} 7$ é ilustrado o processo em que os grãos de vidro envolvem os grãos de alumina.

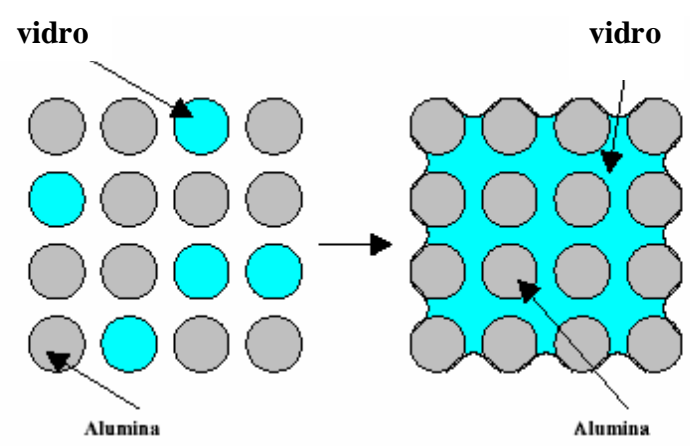

Figura C7. Etapa de sinterização da cerâmica LTCC.

Uma característica importante desta etapa é o encolhimento da cerâmica, que ocorre devido aos grãos de vidro passarem para o estado líquido, envolverem os grãos de alumina, vitrificando posteriormente, assim encapsulando e compactando o material cerâmico.

Este encolhimento segundo o fabricante é aproximadamente 15\% no plano $X Y$ e $20 \%$ no eixo Z (DUPONT) e deve ser levado em conta no projeto. 